Studien

zu Staat, Recht und Verwaltung

Ramin Nikkho

\title{
Der Ausschluss aus der staatlichen Parteienfinanzierung
}

Legalität, Legitimität und Folgen 
Studien zu Staat, Recht und Verwaltung

Herausgegeben von

Prof. Dr. Gabriele Britz

Prof. Dr. Wolfgang Hoffmann-Riem

Prof. Dr. Jens-Peter Schneider

Band 34 
Ramin Nikkho

\section{Der Ausschluss aus der staatlichen Parteienfinanzierung}

Legalität, Legitimität und Folgen 
Die Open-Access-Veröffentlichung der elektronischen Ausgabe dieses Werkes wurde ermöglicht mit Unterstützung durch die Universitätsbibliothek Passau.

Die Deutsche Nationalbibliothek verzeichnet diese Publikation in der Deutschen Nationalbibliografie; detaillierte bibliografische Daten sind im Internet über http://dnb.d-nb.de abrufbar.

Zugl.: Passau, Univ., Diss., 2020

\section{Auflage 2021}

(c) Ramin Nikkho

Publiziert von

Nomos Verlagsgesellschaft mbH \& Co. KG

Waldseestraße 3-5 | 76530 Baden-Baden

www.nomos.de

Gesamtherstellung:

Nomos Verlagsgesellschaft $\mathrm{mbH} \& \mathrm{Co}$. KG

Waldseestraße 3-5 | 76530 Baden-Baden

ISBN (Print): 978-3-8487-7747-1

ISBN (ePDF): 978-3-7489-2143-1

DOI: https://doi.org/10.5771/9783748921431

\section{(9) $(1) \Theta \Theta$}

Dieses Werk ist lizenziert unter einer Creative Commons Namensnennung

- Nicht kommerziell - Keine Bearbeitungen 4.0 International Lizenz. 
Meinen Eltern, in Liebe und Dankbarkeit 


\section{Vorwort}

Die vorliegende Arbeit entstand während meiner Tätigkeit als Wissenschaftlicher Mitarbeiter am Lehrstuhl für Öffentliches Recht, Europarecht und Informationstechnologierecht an der Universität Passau und wurde im August 2020 von der Juristischen Fakultät der Universität Passau als Dissertation angenommen. Sie befasst sich mit dem Ausschluss verfassungsfeindlicher Parteien aus der staatlichen Parteienfinanzierung nach Art. 21 Abs. 3 GG und seinen Folgen.

Mein besonderer Dank gilt zunächst meinem Doktorvater, Herrn Prof. Dr. Meinhard Schröder, unter dessen Betreuung und an dessen Lehrstuhl diese Arbeit angefertigt wurde. Unter Gewährung großzügiger Freiheiten zur Erstellung meiner Dissertation stand er mir stets als Mentor mit wertvollen Ratschlägen, Hinweisen und Anregungen zur Seite. Die Zeit an seinem Lehrstuhl prägte nicht nur diese Arbeit, sondern auch mich selbst, sodass ich gerne an sie zurückdenke.

Sehr herzlich danke ich ferner Herrn Prof. Dr. Rainer Wernsmann für die zügige Erstellung des Zweitgutachtens und für seine wertvolle Kritik an der Arbeit. Den Austausch über das Thema, der bereits im Vorfeld der eigentlichen Erstellung der Arbeit begann, habe ich stets als sehr bereichernd empfunden.

Mein herzlicher Dank gilt zudem all meinen guten Freunden und Kollegen am Lehrstuhl, insbesondere Frau Laura Wexler, Herrn Dr. Richard Rotermund und Herrn Dr. Florian Berger. Die freundschaftliche Zusammenarbeit hat mir stets große Freude bereitet.

Schließlich möchte ich meinen Eltern, Herrn Mehdi Nikkho und Frau Dr. Sylvia Nikkho sowie meiner langjährigen Lebenspartnerin Frau Lisa Sophie Brachmann für ihre andauernde und vielschichtige Unterstützung vom ganzen Herzen danken. Ihr liebevoller Beistand hat entscheidend zu meinem Werdegang beigetragen. 


\section{Inhaltsverzeichnis}

$\begin{array}{ll}\text { Einleitung } & 15\end{array}$

$\mathbb{} 1$ Historische Betrachtung des staatlichen Umgangs mit Parteien $\quad 21$

A. Deutsches Kaiserreich von 1871 bis 1918

I. Rechtsstellung der Parteien 22

II. Das Sozialistengesetz vom 21. Oktober $1878 \quad 27$

III. Kaiserliches Beamtenrecht und Parteien 31

B. Verfassungsfeindliche Parteien in der Weimarer Republik 33

I. Rechtliche Stellung der Parteien 33

II. Der Staatsschutz der Weimarer Republik 37

1. Staatsfeindliche Beamte 38

2. Verordnungen zum "Schutz der Republik“ 39

3. Das Gesetz zum Schutze der Republik 44

\$2 Die Parteien im Verfassungsgefüge des Grundgesetzes 49

A. Die Parteien und ihre Funktionen im demokratischen Verfassungsstaat

I. Verortung der Parteien im demokratischen Verfassungsstaat

II. Die Aufgabe und Funktion von Parteien 51

B. Allgemeine Rechtsstellung von Parteien 51

I. Der Freiheitsstatus $\quad 52$

II. Der Gleichheitsstatus 55

1. Dogmatische Herleitung 55

2. Die Wettbewerbsbezogenheit der Gleichheitsgarantie $\quad 57$

a) Ansatz des Bundesverfassungsgerichtes 58

b) Ansatz in der Literatur $\quad 59$

c) Stellungnahme $\quad 60$

III. Öffentlichkeitsstatus 61

1. Innenwirkung 62

2. Außenwirkung 63 
\$3 Institution der Parteienfinanzierung 65

A. Arten der staatlichen Parteienfinanzierung 66

I. Staatliche Teilfinanzierung nach den $\$ \$ 18$ ff. PartG 67

II. Steuerliche Privilegierungen als mittelbare staatliche $\begin{array}{ll}\text { Parteienfinanzierung } & 67\end{array}$

III. Abgeordnetenentschädigung und Fraktionsfinanzierung $\quad 68$

1. Inhalt und Funktion der Abgeordnetenentschädigung und Fraktionsfinanzierung 69

a) Abgeordnetenentschädigung 69

b) Fraktionsfinanzierung $\quad 70$

2. Abgeordnetenentschädigung als ,staatliche Parteienfinanzierung"?

3. Fraktionsfinanzierung als ,staatliche Parteienfinanzierung“? $\quad 73$

IV. Staatliche Zuschüsse an politische Stiftungen 74

V. Finanzierung der politischen Jugendorganisationen $\quad 75$

B. Entwicklung der unmittelbaren und mittelbaren staatlichen Parteienfinanzierung 78

I. Anfänge der Parteienfinanzierung 78

II. Erste gesetzgeberische Versuche der steuerrechtlichen Privilegierung $\quad 79$

III. Globalzuschüsse als unmittelbare Parteienfinanzierung $\quad 80$

IV. Wahlkampfkostenerstattung als unmittelbare Parteienfinanzierung $\quad 82$

V. Teilfinanzierung als unmittelbare Parteienfinanzierung $\quad 84$

VI. Verbot steuerlicher Begünstigungen von Zuwendungen juristischer Personen an Parteien

VII. Parteienfinanzierung nach der Empfehlung der unabhängigen Sachverständigenkommission $\quad 88$

VIII. Moderne Parteienfinanzierung $\quad 89$

IX. Erhöhung der absoluten Obergrenze $\quad 90$

X. Parteienfinanzierung als Waffe einer wehrhaften Demokratie 91

1. Inhalt der Änderung 92

2. Neue Ratio der Parteienfinanzierung 93

3. Parteienfinanzierung als verfassungsrechtliches Institut? 94

C. Anspruchsvoraussetzungen und ihre verfassungsrechtliche

Problematik 99

I. Parteieneigenschaft 99

1. Die parteibildenden „Elemente“ 101 
2. Annex: Parteienregistrierung 104

II. Zweckgebundenheit 106

III. Mindestquorum und Verteilungsgrundsätze 107

1. Mindestquorum als Sperrklausel 107

2. Wahlerfolgsbezogene Mittelgewährung 113

\4 Das Finanzierungsausschlussverfahren nach Art. 21 Abs. 3 GG 116

A. Entwicklung des Ausschlussverfahrens 116

I. Urteil des Bundesverfassungsgerichts vom 17.01.2017 116

II. EGMR-Rechtsprechung zu Parteiverboten 118

III. Einfluss auf die verfassungsgerichtliche Rechtsprechung 121

IV. Einfluss auf die Gesetzgebung 121

B. Verfassungsrechtliche Pflichtenkollision 123

C. Inhalt des Finanzierungsausschlusses 125

I. Tatbestand 125

1. Auslegung der Tatbestandsmerkmale 125

2. Bestand der Bundesrepublik und die freiheitliche demokratische Grundordnung als Schutzgüter $\quad 127$

3. Zielsetzung und Anhängerschaft der Partei 132

4. Ausgerichtet-sein 133

II. Rechtsfolgen 141

1. Ausschluss von staatlicher Finanzierung 141

a) Finanzielle Konsequenzen 141

b) Konsequenzen im gesellschaftlichen Ansehen $\quad 143$

2. Erstreckungwirkung 145

a) Ersatzparteien 145

b) Politische Jugendorganisationen 147

(1) Unmittelbare Erstreckung des

Finanzierungsausschlussverfahrens $\quad 148$

(2) Mittelbare Erstreckung des

Finanzierungsausschlussverfahrens $\quad 152$

(a) Statuszurechnung 152

(b) Zurechnungsfolgen 154

(3) Zusammenfassung 155

3. Dauer des Ausschlusses 156

4. Anwendbarkeit des Grundsatzes der
Verhältnismäßigkeit

$\begin{array}{ll}\text { III. Verfahren } & 167\end{array}$

1. Anwendungsbereich 167 
2. Antragstellung

a) Legalitäts- oder Opportunitätsprinzip $\quad 171$

b) Umfang des Ermessens 175

D. Art. 79 Abs. 3 GG als Maßstab der Verfassungsänderung 178

I. Notwendigkeit der Verfassungsänderung 178

1. Staatliche Garantenstellung als Rechtfertigung einer Ungleichbehandlung

2. Parteienprivileg als verfassungsrechtliches Prinzip $\quad 180$

a) Inhalt und Bedeutung des Parteienprivilegs 181

b) Parteienprivileg als Einschränkung staatlicher Handlungsmöglichkeiten

3. Einfachgesetzliche Rechtsfolgenmodifikation des Art. 21 Abs. 2 GG

II. Legalität der Verfassungsänderung 186

1. Maßstab des Art. 79 Abs. 3 GG 186

a) Verfassungsidentität als Schutzgut 187

b) Klassifikation der unberührbaren Grundsätze $\quad 188$

c) Materielle Schranken des Art. 79 Abs. 3 GG bei leitprinzipiellen Konkretisierungen

2. Chancengleichheit als unberührbarer Verfassungsgrundsatz

a) Menschenwürde, Art. 1 Abs. 1 GG 195

b) Demokratieprinzip, Art. 20 Abs. 1 GG 197

(1) Parteiengleichheit als Teil des offenen politischen Willensbildungsprozesses

(2) Wehrhaftigkeit als Bestandteil und Schranke des Demokratieprinzips

3. Vereinbarkeit mit Art. 79 Abs. 3 GG 203

a) Gestörtes Konkurrenzverhältnis 204

b) Bewertung der Intensität der Ungleichbehandlung 207

c) Argumentum a maiore ad minus 209

(1) Streitstand zur Qualifizierung als „Minus“ oder "Aliud“

(2) Stellungnahme

4. Annex: Finanzierungsausschluss unter der Geltung der EMRK

a) Anzuwendende Konventionsrechte 216

b) Vereinbarkeit von Art. 21 Abs. 3 GG mit der EMRK 219

E. Rechtspolitische Bewertung

I. Modifizierte Wettbewerbslage 
II. Entscheidungszuständigkeit 224

III. Geringeres Einsatzhemmnis 228

IV. Ende der Parteiverbote? 230

V. Anspruch auf Feststellung der Verfassungskonformität de lege ferenda

\5 Der Status der Verfassungsfeindlichkeit

A. Begriff der Verfassungsfeindlichkeit

B. Auswirkung des Finanzierungsausschlusses auf die Rechtsstellung der Parteien

I. Ausschluss aus der staatlichen Parteienfinanzierung als Anknüpfungsgrundlage weiterer staatlicher Maßnahmen

II. Verfassungsfeindlichkeit im politischen Wettbewerb 238

1. Die Figur der faktischen Nachteile 239

a) Problemstellung 239

b) Faktische Beeinträchtigung der Wettbewerbslage 241

c) Dogmatik 241

(1) Ansatz des Bundesverfassungsgerichtes 241

(2) Ansätze in der Literatur 243

(3) Faktische Nachteile als Eingriffsäquivalent 244

2. Paradigmatische Darstellung der Rechtsstellung verfassungsfeindlicher Parteien

a) Staatliche Teilnahme am politischen

Meinungskampf

(1) Neutralitätsgebot 249

(2) Herleitung von Äußerungsbefugnissen 250

(a) Bundespräsident 251

(b) Bundesregierung 252

(c) (Ober-)Bürgermeister 252

(3) Grenzen amtlicher Beteiligung am politischen Diskurs

(a) Aufgaben- und Zuständigkeitszuweisung 254

(b) Verhältnismäßigkeit 254

(4) Modifizierung durch Art.21 Abs. 3 GG 256

(a) Ausschließlichkeit 257

(b) Schrankenmodifizierung 258

b) Öffentlicher Dienst 259

(1) Bisherige Praxis 260

(2) Parteizugehörigkeit als Ablehnungsgrund 261 
(3) Mitgliedschaft in verfassungsfeindlichen Parteien iSd. Art. 21 Abs. 3 GG und das Beamtenverhältnis

c) Nachrichtendienstliche Überwachung 264

(1) Aufgabeneröffnung 265

(2) Befugnisse 266

(a) Auswertung öffentlich zugänglicher Informationen 266

(b) Öffentliche Berichterstattung durch den Verfassungsschutz

(c) Observation durch den Einsatz nachrichtendienstlicher Befugnisse

(d) Auswirkungen des Finanzierungsausschlussverfahrens auf nachrichtendienstliches Handeln

d) Nutzung öffentlicher Einrichtungen 271

(1) Grundsätze

(2) Privatrechtliche Ausgestaltung kommunaler Nutzungsverhältnisse

(3) Ausgestaltungsregelungen

(a) Untersuchungsbeispiel 1: Nachweis einer Haftpflichtversicherung

(b) Untersuchungsbeispiel 2: Übertragung verschuldensunabhängiger Haftungsregime

e) Verfassungsfeindlichkeit als Gefahr

3. Rehabilitierung durch Zeitablauf

4. Rechtsstellung der verfassungsfeindlichen Partei

A. Parteiengleichheit und der Parteienwettbewerb 287

B. Parteienfinanzierung als Wettbewerbsmodifikator 288

C. Verfassungsmäßigkeit des Finanzierungsausschlussverfahrens 290

D. Rechtsstellung der verfassungsfeindlichen Partei 293

$\begin{array}{ll}\text { Literaturverzeichnis } & 297\end{array}$ 


\section{Einleitung}

Revolutionen, Systemstürze und gesellschaftspolitische Veränderungen prägen seit dem 19. Jahrhundert die deutsche Geschichte. Eine zentrale Rolle nahmen dabei Parteien ein, die auf gewaltsamem oder friedlichem Wege die bestehenden Herrschaftsverhältnisse bekämpften und nach einer radikalen Veränderung der Staatsordnung strebten. Seit der Etablierung und Integration von Parteien in die deutsche Staatsordnung wurden diese sowohl als notwendige Institution der Verfassungssysteme als auch als mit Misstrauen behandelte Gefährder der bestehenden Herrschaftsordnung angesehen. Aufgrund dessen wurde die Rechtsstellung im Kaiserreich von 1871 - 1919 bewusst so schwach gehalten, dass sich aus ihr keine nennenswerten subjektiven Schutzrechte haben ableiten lassen. Maßnahmen gegen die von Parteien ausgehende Gefährdung waren überwiegend auf die politische Kommunikation gerichtet und umfassten, neben dem auch in der Bundesrepublik etablierten Parteiverbot, vor allem Druck- und Versammlungsverbote. Die staatliche Repression galt allerdings nicht allen Parteien gleichermaßen, sondern betraf anfänglich insbesondere die SPD. Durch den Erlass des Sozialistengesetzes 1878 brandmarkte der Staat erstmalig eine Partei als „verfassungsfeindlich“ und begann, sie über die Einräumung von Exekutivbefugnissen aktiv zu bekämpfen. Die Maßnahmen sollten zwar die politische Kommunikation der Sozialdemokraten beschränken, die Wählbarkeit sozialdemokratischer Politiker in öffentliche Ämter war indessen nicht beeinträchtigt. So wurde die Partei zwar staatlich bekämpft, ihre Teilnahme am politischen Wettbewerb allerdings weiterhin geduldet. Hieraus folgte eine Kategorisierung in "staatlich-erwünschte“ und „staatlich-unerwünschte“ Parteien. Diese Form des Staatsschutzes setzte sich in der Weimarer Republik fort, wobei die Maßnahmen des Staatsschutzes dort zwar überwiegend politisch rechtsextremen Parteien galten, allerdings bewusst überparteilich formuliert waren und keine politische Strömung mehr pauschal pönalisierten. ${ }^{1}$

Doch auch in der neuen deutschen Geschichte gingen Gefahren für die bestehende demokratische Ordnung von Parteien aus. Seit der Gründung der Bundesrepublik konnte der Staat nur über das Parteiverbot nach Art. 21 Abs. 2 GG gegen verfassungswidrige Parteien vorgehen und sich

1 Siehe $\$ 1$. B. II. 


\section{Einleitung}

und seine Verfassungsordnung somit vor extremistischen Kräften schützen. Die Entscheidung des Bundesverfassungsgerichts über das Verbot der Nationaldemokratischen Partei Deutschlands (NPD) vom 17.01.2017² leitete einen historisch bedeutsamen Kausalverlauf ein, der zu einer Umgestaltung der verfassungsrechtlichen Stellung von politischen Parteien führte. Obwohl der Antrag des Bundesrates, die Verfassungswidrigkeit der NPD nach Art. 21 Abs. 2 GG feststellen zu lassen, abgelehnt wurde, bekräftigte das Bundesverfassungsgericht in der Urteilsbegründung, dass es der festen Überzeugung sei, dass die NPD eine verfassungsfeindliche Zielsetzung verfolgen würde. Aufgrund der Ermangelung einer hinreichenden Potentialität zur Realisierung ihrer Parteiziele sei aber das Tatbestandsmerkmal des „Darauf-Ausgehens“ nicht erfüllt ${ }^{3}$, womit trotz des Vorliegens einer verfassungsfeindlichen Zielsetzung die Verfassungswidrigkeit der Partei nicht festgestellt werden könne. Die neue verfassungsgerichtliche Rechtsprechung zu Parteiverboten stellt einen Bruch der bisherigen Verbotspraxis dar und verschärft die Verbotsvoraussetzungen erheblich: zu den sonst in der Zielsetzung und der Betätigung der Partei wurzelnden Anforderungen tritt nun eine objektive Gefahrenprognose hinzu. ${ }^{4}$

Da das Parteiverbot zum Zeitpunkt der Urteilsverkündung das einzige staatliche Mittel war, um gegen verfassungsfeindliche Parteien vorzugehen, sah sich der Gesetzgeber angesichts der verfassungsgerichtlichen Rechtsprechung mit dem Problem konfrontiert, nur noch gegen solche Parteien vorgehen zu können, die über eine ausreichende „Realisierungspotentialität“ verfügen, und damit verfassungsfeindliche und radikale Kleinstparteien dulden zu müssen. Die NPD, gegen die bereits 2003 ein Verbotsantrag der Bundesregierung scheiterte ${ }^{5}$, war somit - zumindest rechtlich - unantastbar geworden, und der Staat gezwungen, sie trotz ihrer staatsfeindlichen Eigenschaft weiterhin im politischen Wettbewerb zu dulden und gleich der anderen Parteien zu behandeln. Das Bundesverfassungsgericht stellte in der Urteilsbegründung - wohl als Hinweis an den Gesetzgeber - fest, dass „die Schaffung von Möglichkeiten gesonderter Sanktionierung im Fall der Erfüllung einzelner Tatbestandsmerkmale des Art. 21 Abs. 2 GG unterhalb der Schwelle des Parteiverbots, dem verfassungsändernden Gesetzgeber vorbehalten ist. " ${ }^{6}$ Der verfassungsändernde

2 BVerfGE 144, $20 \mathrm{ff}$.

3 BVerfGE 144, 20 (225).

4 Siehe hierzu Näheres bei $\$ 4$. A.

5 BVerfGE 107, $339 \mathrm{ff}$.

6 BVerfGE 144, 20 (202). 
Gesetzgeber reagierte kurz darauf mit einer Verfassungsänderung, die zu einer Kategorisierung von Parteien führte und eine Systemmodifizierung des Parteienrechts zur Folge hatte. Deutlich ist, dass Anlass dieser Verfassungsänderung das gescheiterte Verbotsverfahren war, da in der Generaldebatte über den Gesetzesentwurf des verfassungsändernden Gesetzes Abgeordnete aller Fraktionen stets die NPD als mahnendes Beispiel für die rechtspolitische Gebotenheit dieses Vorgehens anführten. ${ }^{7}$ Weil das Parteiverbot die „schärfste Waffe“ ${ }^{8}$ des Staates im Umgang mit verfassungswidrigen Parteien darstellt, konnte der verfassungsändernde Gesetzgeber lediglich weniger einschneidende Mittel schaffen, um gegen verfassungsfeindliche Parteien vorzugehen. Da die Rechtsfolge des neuen Mittels des „Verfassungsschutzes" allerdings milder war als die des Parteiverbots, konnten gleichwohl auch geringere Anforderungen an dessen Anordnung gestellt werden.

Ansatzpunkt für die „neue“ Handlungsalternative im Umgang mit verfassungsfeindlichen Parteien bildet die staatliche Parteienfinanzierung, deren Entstehen, Zweck und Gewährungsvoraussetzungen im Rahmen dieser Arbeit auch näher untersucht werden. Die staatliche Parteienfinanzierung wurde in den Anfangsjahren der Bundesrepublik etabliert und über die Jahrzehnte zu einem unverzichtbaren Teil des Parteienwesens ausgestaltet. Durch die staatliche Parteienfinanzierung wurde der politische Wettbewerb auf ein neues Niveau gehoben, indem die Finanzkraft von Parteien sowohl mittelbar über steuerliche Privilegierungen als auch unmittelbar über staatliche Zahlungen verbessert wurde. Um die gesellschaftlich bedingten Wettbewerbsdivergenzen nicht zu nivellieren, bestimmt sich die Höhe der staatlichen Leistungen der unmittelbaren Teilfinanzierung anhand des gesellschaftlichen Rückhaltes der Partei, der über den Erfolg bei Wahlen sowie über finanzielle Zuwendungen bemessen wird. Neben einer Niveausteigerung des gesamten politischen Wettbewerbs hat die staatliche Parteienfinanzierung allerdings auch den staatlichen Abhängigkeitsgrad der Parteien verstärkt. Da aufgrund der Parteiengleichheit eine Ungleichbehandlung von Parteien aufgrund ihrer inhaltlichen Ausrichtung unzulässig war, solange sie vom Bundesverfassungsgericht nicht als „verfassungswidrig“ qualifiziert wurden, mussten bei der Mittelvergabe auch Parteien berücksichtigt werden, deren Zielsetzung sich gegen die freiheitliche demokratische Grundordnung richtete. Beispielsweise erhielt die NPD auch im Jahr 2019 noch staatliche Mittel in Höhe von 407.038,23 €

7 BT-Protokoll, 22.06.2017, S. $24551 \mathrm{ff}$.

8 So BVerfGE 144, 20 (159). 
als unmittelbare Zuwendung9, obwohl das Bundesverfassungsgericht zwei Jahre zuvor in seiner Urteilsbegründung ${ }^{10}$ keine Zweifel an der Verfassungsfeindlichkeit ihrer Zielsetzung aufkommen ließ. Um keine Parteien mehr fördern zu müssen, die sich einer Bekämpfung der freiheitlichen demokratischen Grundordnung verschrieben haben, wurde der Art. 21 GG dahingehend geändert, dass nun als Alternative zum Parteiverbot der Ausschluss aus der staatlichen Parteienfinanzierung festgestellt werden kann. Demnach stellt gemäß Art. 21 Abs. 3, Abs. 4 GG das Bundesverfassungsgericht fest, ob eine Partei aufgrund ihrer verfassungsfeindlichen Ausrichtung von der Begünstigung durch die staatliche Parteienfinanzierung auszuschließen ist. Indem der Staat nun zwischen Parteien bei der Gewährung der staatlichen Parteienfinanzierung differenziert, erfolgt eine Kategorisierung in „staatlich-erwünschte" und „verfassungsfeindliche“ Parteien. Zwar sind die qualifizierenden Unterscheidungsmerkmale verhältnismäßig gering ausgeprägt, dennoch sind Parallelen zum Kaiserreich erkennbar. ${ }^{11}$

Ob das über Art. 79 Abs. 3 GG unberührbare Demokratieprinzip zulässt, durch die Möglichkeit des Ausschlusses aus der staatlichen Parteienfinanzierung einen Parteienwettbewerb zu etablieren, innerhalb dessen die Erfolgschancen der Teilnehmer unter engen Voraussetzungen einer staatlichen Lenkungswirkung ausgesetzt sind, soll einen Untersuchungsgegenstand bilden. ${ }^{12}$ Das Demokratieprinzip setzt voraus, dass sich die Willensbildung innerhalb einer handlungsfähigen Institution von „unten nach oben" vollzieht und der konkrete Willensbildungsprozess deshalb offen gestaltet sein muss. Je freier der politische Wettbewerb die Staatsgewalt beeinflusst, umso höher ist die Legitimität des demokratischen Systemes. Indem der Staat einzelne Parteien aus der staatlichen Parteienfinanzierung ausschließt, während alle anderen weiterhin begünstigt werden, wird der politische Wettbewerb durch staatliches Handeln verzerrt und die Offenheit des Willensbildungsprozesses beeinträchtigt. Der Staat nutzt das von ihm selbst etablierte Instrument der staatlichen Parteienfinanzierung, um den politischen Wettbewerb zulasten einer verfassungsfeindlichen Partei

9 Einsehbar unter https://www.bundestag.de/blob/503226/eb02070236090c98b3ca2 4ce9dfc57fa/finanz_16-data.pdf, zul. aufgerufen am 18.02.2020.

10 Siehe BVerfGE 144, 20 (246 ff.), wo das Bundesverfassungsgericht feststellt, dass die Ziele und das Verhalten der Parteianhänger gegen die Menschenwürde und den Kern des Demokratieprinzips verstößen und zudem eine Wesensverwandtschaft zum historischen Nationalsozialismus aufwiesen.

11 Siehe hierzu $\$ 1 \mathrm{~A}$.

12 Siehe hierzu $\mathbb{4} 4 \mathrm{D}$. II 3. 
zu verändern. Eine solche Beeinflussung des offenen Willensbildungsprozesses könnte aufgrund des Prinzips der „wehrhaften Demokratie“ gerechtfertigt sein, sodass ein Verstoß gegen Art. 79 Abs. 3 GG nicht vorläge und die Verfassungsänderung damit zulässig wäre.

Abgesehen von der Verfassungsmäßigkeit der Verfassungsänderung ${ }^{13}$ ist auch problematisch, ob Parteien weitergehende Nachteile zu befürchten haben, wenn sie durch das Feststellungsurteil des Bundesverfassungsgerichtes aus der Parteienfinanzierung ausgeschlossen wurden. Der Ausschluss aus der staatlichen Parteienfinanzierung erfolgt aufgrund einer verfassungsfeindlichen Ausrichtung, die insofern durch das verfassungsgerichtliche Urteil auch verbindlich festgestellt wird. Zwar kann neben dem Parteiverbot als einzige Handlungsalternative nur der Ausschluss aus der staatlichen Parteienfinanzierung festgestellt werden ${ }^{14}$, allerdings wird bei einem Ausschluss anders als beim Parteiverbot die Existenz der betroffenen Partei im politischen Wettbewerb weiterhin geduldet. Die Faktizität des Ausschlusses aus der staatlichen Parteienfinanzierung könnte einen Paradigmenwechsel im staatlichen Umgang mit Parteien hervorrufen, sodass die einzuhaltenden Voraussetzungen zur Durchführung bestimmter Maßnahmen verändert werden. So wird beispielsweise zu untersuchen sein, ob Amtsträger bei der Teilnahme am politischen Diskurs die verfassungsgerichtlich festgestellte Verfassungsfeindlichkeit verwenden dürfen, um die Partei offen als extremistisch zu bezeichnen. Auch ist fraglich, wie sich ein Ausschluss aus der staatlichen Parteienfinanzierung auf eine Beobachtung durch die Verfassungsschutzbehörden oder einer Gewährung anderer staatlicher Leistungen, wie beispielsweise der Gebrauchsüberlassung von öffentlichen Einrichtungen, auswirkt. ${ }^{15}$

Das Mittel zur Bekämpfung verfassungsfeindlicher Parteien, die aufgrund einer mangelnden Realisierungspotentialität nicht die Voraussetzungen eines Verbotes nach Art. 21 Abs. 2 GG erfüllen, ist deutlich subtiler als die aus der Vergangenheit bekannten und angewendeten Mittel. Dennoch ist seit der Gründung der Bundesrepublik neu, dass der Staat nun in rechtserheblicher Weise zwischen Parteien derart differenziert, dass diese (staatlich bedingt) unter unterschiedlichen Voraussetzungen und Anforderungen am politischen Wettbewerb teilnehmen. Während die eine Art von Parteien auf meist regelmäßige Leistungen vom Staat vertrauen kann und eine weitgehende steuerliche Privilegierung genießt, müssen die aus der

13 BGBl. 2017, I, S. 2346.

14 Siehe Streinz, in: Huber/Voßkuhle (Hrsg.), Grundgesetz, ${ }^{7} 2018$, Art. 21, Rn. 252d.

15 Siehe hierzu $\$ 5$ B. II. 2. 


\section{Einleitung}

staatlichen Parteienfinanzierung ausgeschlossenen Parteien ohne die $\mathrm{Zu}$ wendung staatlicher Mittel und einer steuerlichen Privilegierung untereinander und mit Parteien aus der ersten Kategorie konkurrieren.

Zweck dieser Arbeit ist es, die Verfassungsänderung vom 18.07.2017 16 und ihre Auswirkungen auf den politischen Wettbewerb zu untersuchen. Berücksichtigt wird in diesem Rahmen auch insbesondere die Rechtsstellung einer aufgrund des Ausschlusses aus der staatlichen Parteienfinanzierung ausgeschlossenen Partei und welche rechtlichen wie tatsächlichen Folgen diese zu befürchten hat.

16 BGBl. 2017, I, S. 2346. 


\section{$\$ 1$ Historische Betrachtung des staatlichen Umgangs mit Parteien}

Bereits im Kaiserreich von 1871 bis 1918 waren Parteien im politischen Wettbewerb fest etabliert und bestimmten maßgeblich die Zusammensetzung der Volksvertretung mit. Trotz ihrer staatstragenden Funktion wurden Parteien von staatlicher Seite mit großem Misstrauen behandelt und waren bis zur Gründung der Bundesrepublik Deutschland auch rechtlich kaum geschützt.

Dieses Kapitel soll einen Überblick über mögliche Handlungsalternativen gegen Parteien bieten, der sich an der historischen Vergangenheit Deutschlands orientiert. Es soll insbesondere ein Vergleich der damaligen Rechtsstellung von Parteien und des staatlichen Umgangs mit Parteien mit der aktuell geltenden Rechtslage ermöglicht und hierdurch zur Verständlichkeit der Hintergründe des besonderen Schutzes von Parteien in der Bundesrepublik beitragen werden. Denn während der Bundesrepublik lediglich ein überschaubarer Maßnahmenkatalog - namentlich dem Parteiverbot und dem Finanzierungsausschlussverfahren - zum Zwecke der unmittelbaren Bekämpfung staatsfeindlicher Parteien zur Verfügung steht, so griffen ihre historischen Vorgänger zu einer wesentlich breiteren Anzahl an Maßnahmen, um die Gefährdung der jeweils geltenden Staatsform durch Parteien zu minimieren.

\section{A. Deutsches Kaiserreich von 1871 bis 1918}

Durch die Verfassung des deutschen Kaiserreiches - und auch zuvor zur Zeit des Norddeutschen Bundes ${ }^{17}$ - wurde eine Volksvertretung als Teil der Legislative institutionalisiert. Parteien haben damit erstmals Einfluss auf die Staatsgewalt nehmen können und wurden deshalb auch von der stark monarchisch geprägten Herrschaftsordnung geduldet. Das Misstrauen des Staates gegenüber den Parteien war dennoch so hoch, dass unter Verwendung hoheitlicher Gewalt gegen unliebsame politische Strömun-

17 Die Verfassung des Norddeutschen Bundes war mit der des Deutschen Kaiserreichs bis auf wenige Ausnahmen identisch; so Fenske, Deutsche Parteiengeschichte, 1994, S. 104. 
gen vorgegangen wurde. Die Staatsordnung zwischen 1871 und 1918 fällt in eine Epoche, in der durch das „Gesetz gegen die gemeingefährlichen Bestrebungen der Sozialdemokratie“ - auch bekannt als "Sozialistengesetz ${ }^{18 “}$ - die politischen Wirkmöglichkeiten einer Partei staatlich verringert werden sollten und der Staat selbst versuchte, den Parteienwettbewerb durch ein solches Unternehmen in seinem Sinne zu formen.

\section{Rechtsstellung der Parteien}

Durch die Konstituierung des Reichstages nach der Gründung des Norddeutschen Bundes 1866 und des Deutschen Reiches 1871 wurde das Repräsentativsystem eingeführt. ${ }^{19}$ Demnach waren die Abgeordneten des Reichstags gemäß Art. 29 RV die Vertreter des gesamten Deutschen Volkes und übten nach Art. 5 RV gemeinsam mit dem Bundesrat die Gesetzgebung aus. Dem Volk wurde dadurch die Möglichkeit eingeräumt, über den Reichstag repräsentativ an der Gesetzgebung des Reiches teil zu haben. Die Parteien waren im Kaiserreich faktisch existent und hatten für die Reichstagswahlen eine konstitutive Bedeutung. ${ }^{20}$ Eine konkrete Erwähnung der Parteien in der Reichsverfassung sucht man dennoch vergeblich, weswegen ihnen keine verfassungsrechtlich gewährleisteten Freiheiten zustanden.

Die sedes materiae des Parteienwesens im Kaiserreich lag im (privaten) Vereinsrecht. ${ }^{21}$ Das damalige Vereinsrecht hob sog. "Wahlvereine“ als besonders qualifizierte Vereinigungen hervor und privilegierte sie rechtlich. Während politische Vereine sowohl auf landes-22 als auch bundesrechtli-

18 RGBl. 1878, Nr. 34, S. $351-358$.

19 Hierzu Shirvani, MIP 2006, 77 (77).

20 Huber, Deutsche Verfassungsgeschichte seit 1789 - Bismarck und das Reich, Bd. III, ${ }^{3} 1988$, S. 868.

21 Nipperdey, Die Organisation der deutschen Parteien vor 1918, 1961, S. 13.

22 Siehe z.B. die Verordnung vom 27. Januar 1851 des Großherzogtums Mecklenburg - Schwerin (Registrierungsblatt Nr. 7):

Die Abhaltung von öffentlichen Versammlungen zu politischen Zwecken oder die Bildung von Vereinen zu politischen Zwecken darf nur mit Genehmigung des Ministeriums des Innern geschehen.

Dasselbe ist ermächtigt, diejenigen jetzt vorhandenen politischen Vereine, von deren Wirksamkeit ein nachteiliger Einfluß auf die Ruhe und den inneren Frieden des Landes zu besorgen ist, sofort zu verbieten und alle zu deren Auflösung erforderlichen Maßregeln zu treffen. 
cher ${ }^{23}$ Ebene bedenklichen Restriktionen unterworfen waren ${ }^{24}$, wurde den Wahlvereine eine großzügigere Freiheitssphäre gewährt. Die Wahlvereine waren lokale Organisationen, die sich ausschließlich für die Vorbereitung einer konkreten Wahl bildeten ${ }^{25}$ und sich die Unterstützung eines bestimmten Kandidaten zum Ziel machten, indem sie diesen auf ihrer Wahlliste führten und im Wahlkampf für ihn warben. Die Aktivität des Wahlvereins war mit Abschluss des konkreten Wahlaktes beendet und somit zeitlich limitiert. Die Wahlvereine erschöpften sich in ihrer Funktion und ihrem Bestand in der konkret anstehenden Reichstagswahl. Im Unterschied zu den Wahlvereinen waren die politischen Vereine auf Dauer angelegte Ortsvereine, die charakteristisch eine andauernde Gesinnungs- und Aktionsgemeinschaft bildeten. ${ }^{26}$ Aus den zunächst ad hoc gebildeten Wahlvereinen bildeten sich die dauerhaften Ortskomitees, die dann als ,erste institutionalisierte Träger einer permanenten politischen Funktion der Parteien" fungierten. ${ }^{27}$

$\mathrm{Ob}$ und in welchem Maße Parteien im Deutschen Kaiserreich überhaupt neben den Vereinen eigenständig rechtlich anerkannt waren, ist umstritten.

So sieht Ernst Rudolf Huber die Reichsverfassung in einem Gesamtzusammenhang ${ }^{28}$ und geht trotz der fehlenden Erwähnung in der Verfassungsurkunde des Deutschen Reiches von einer materiellrechtlichen Verfassungsimmanenz der Parteien aus. ${ }^{29}$ Die verfassungsrechtliche Stellung der Parteien werde demnach aus den in Art. 20 RV festgelegten Wahlgrundsätzen hergeleitet, wonach der Reichstag aus allgemeinen, direkten

23 So das Bundesvereinsgesetz vom 13. Juli 1854. Dieses ordnete die Länder an, die notwenigen Maßnahmen zur Restriktion politischer Vereine zu treffen, insbesondere sich rechtliche Grundlagen dafür zu schaffen.

24 Dazu ausführlich Schmidt, Die Freiheit verfassungswidriger Parteien und Vereinigungen, 1983, S. 29.

25 Delius, Das preußische Vereins- und Versammlungsrecht, 1891; Huber, Deutsche Verfassungsgeschichte seit 1789 - Ausbau, Schutz und Untergang der Weimarer Republik, Bd. III, ${ }^{3} 1988$, S. 867.

26 Huber, Deutsche Verfassungsgeschichte seit 1789 - Struktur und Krisen des Kaiserreichs, Bd. IV, ${ }^{2} 1994$, S. 7.

27 Ders., Deutsche Verfassungsgeschichte seit 1789 - Struktur und Krisen des Kaiserreichs, Bd. IV, ${ }^{2} 1994$, S. 7.

28 Ders., Deutsche Verfassungsgeschichte seit 1789 - Struktur und Krisen des Kaiserreichs, Bd. IV, ${ }^{2}$ 1994, S. 5; auch Zirn, Das Parteiverbot nach Art. 21 Abs. 2 GG im Rahmen der streitbaren Demokratie des Grundgesetzes, 1988, S. 17.

29 Folgend: Huber, Deutsche Verfassungsgeschichte seit 1789 - Ausbau, Schutz und Untergang der Weimarer Republik, Bd. III, ${ }^{3} 1988$, S. 867 ff. 
und geheimen Wahlen hervorgehe. Da die Wahlen ohne die Mitwirkung von Parteien nicht durchführbar wären, habe der Gesetzgeber die Parteien somit als konstitutiv für die Durchführbarkeit der Reichstagswahlen erachtet und durch die Einführung des Repräsentativsystems auch verfassungsrechtlich anerkannt. Die Schaffung des $\$ 7 \mathrm{RWG}^{30}$ würde die Intention des Gesetzgebers, die Parteien in ihrer Funktion durch sogenannte „Wahlvereine“ zu stärken, verdeutlichen. So seien die Wahlvereine „Hilfsorgane der politischen Parteien “31 und hätten die Betätigung der Parteien in Bezug zu den Reichstagswahlen rechtlich abgesichert. Die hinter den Wahlvereinen stehenden Parteien haben diese aktiv für den Wahlkampf und für die aktive Agitation genutzt und sie damit zu ihrem Werkzeug gemacht. Durch die in $₫ 17$ RWG festgeschriebene Garantie der Wahlvereine wollte der Gesetzgeber den dahinterstehenden Parteien einen öffentlich-rechtlichen Status einräumen. Ernst Rudolf Huber zieht daraus den Schluss, dass aus der Gesamtheit der Normen aus dem bürgerlich-rechtlichen Vereinsrecht, dem öffentlichen Vereins- und Versammlungsrecht und dem Presserecht des Reichspreßgesetzes vom 7. Mai $1874^{32}$ eine „institutionelle Garantie des freien Parteiwesens" abgeleitet werden könne. ${ }^{33}$

Eine gegenläufige Auffassung vertritt Thomas Schmidt. Da das damalige Vereinsrecht zwar politische Vereine kannte, jedoch ihre besondere staatsmitwirkende Bedeutung nicht ausreichend berücksichtige, seien diese rechtlich nicht existent gewesen. ${ }^{34}$ Nur die Wahlvereine seien rechtlich anerkannt und dienten ausschließlich der Gewährleistung der Reichstagswahl. Allerdings sei es nicht die Intention des Gesetzgebers gewesen, mit $\$ 17$ RWG die Parteien rechtlich anzuerkennen, sondern ausschließlich die Durchführung der Wahl zu sichern. $\$ 17$ RWG sei deshalb keineswegs dem Parteien- oder Vereinsrecht, sondern dem Wahlrecht zuzuordnen. Die Wahlvereine stellten somit keine rechtliche Garantie für das Parteiwe-

30 So lautete $\$ 17$ RWG:

„Die Wahlberechtigten haben das Recht, zum Betrieb der den Reichstag betreffenden Wahlangelegenheiten Vereine zu bilden und in geschlossenen Räumen unbewaffnet öffentliche Versammlungen zu veranstalten.“

31 Huber, Deutsche Verfassungsgeschichte seit 1789 - Ausbau, Schutz und Untergang der Weimarer Republik, Bd. III, ${ }^{3} 1988$, S. 867.

32 RGBl. 1874, Nr. 16, S. 65.

33 Huber, Deutsche Verfassungsgeschichte seit 1789 - Struktur und Krisen des Kaiserreichs, Bd. IV, ${ }^{2} 1994$, S. 9.

34 Im Folgenden Schmidt, Die Freiheit verfassungswidriger Parteien und Vereinigungen, 1983, S. $361 \mathrm{ff}$;; dem folgend Hettich, Die Zulässigkeit verschiedener Handlungsalternativen des Staates im Vorgehen gegen extremistische Parteien unter Berücksichtigung des Parteienprivilegs, 2015, S. 26. 
sen dar, sondern erschöpften ihren Zweck und ihre Existenzberechtigung einzig in der Gewährleistung der Reichstagswahlen. Während ausschließlich die Betätigung der Parteien an den Wahlen durch die Wahlvereine rechtlich geschützt gewesen sei, sei jedwede parteiliche Tätigkeit außerhalb des Wahlkampfes den weitreichenden Exekutivbefugnissen aus dem öffentlichen Vereins- und Versammlungsrecht ausgesetzt und vor bundesund landesrechtlichen Restriktionen weitestgehend ungeschützt. Bildlich trägt Thomas Schmidt vor, dass die für die Wahlagitation und die Organisation des konkreten Wahlkampfes zuständigen Wahlvereine durch $\$ 17$ RWG geschützt seien; der parteipolitische „Rumpf“, der sich in politischen Vereinen organisierte und hinter dem Wahlverein stand, jedoch uneingeschränkt den vereins- und versammlungsrechtlichen Restriktionen ausgesetzt sei. Weiter wird angeführt ${ }^{35}$, dass nach Art. 4 Nr. 16 RV das Reich die Kompetenz für das Vereinswesen habe. Hätte das Reich Parteien verfassungsrechtlich anerkennen wollen, hätte es jederzeit von dieser Kompetenz Gebrauch machen können. Dies blieb jedoch aus. Stattdessen wurde durch das 1878 verkündete Sozialistengesetz ${ }^{36}$ die Kompetenz zur Schwächung sozialdemokratischer Politik genutzt. Auch waren die vereinsrechtlichen Restriktionen auf Bundesebene weitaus strenger als manche landesrechtliche Einschränkung.

Beide Ansichten vermögen nur zum Teil zu überzeugen. Ernst Rudolf Huber ist insoweit zuzustimmen, dass den Parteien durch die Einführung des Repräsentativsystems in der Reichsverfassung eine gewisse verfassungsrechtliche Systemimmanenz zuerkannt wurde. ${ }^{37}$ Auch wenn die Parteien in der Verfassungsurkunde nicht explizit erwähnt wurden, so ist es durchaus überzeugend, auf die materiellen Voraussetzungen abzustellen, die für die Durchführbarkeit eines in der Verfassung verankerten Prinzips notwendig sind. Ohne die Parteien, dies war dem Gesetzgeber auch bewusst, wäre die Einführung des Repräsentativsystems unmöglich gewesen, sodass zumindest eine objektive Bestandsgarantie der Verfassung entnommen werden kann.

Die Ausführungen von Thomas Schmidt in Bezug zur absoluten rechtlichen Nichtexistenz von Parteien überzeugen in dieser Hinsicht nicht. Der Begriff der Partei wird dabei zu eng definiert. Gerade hier ist es wichtig,

35 Schmidt, Die Freiheit verfassungswidriger Parteien und Vereinigungen, 1983, S. 34 .

36 RGB1. 1878, Nr. 34, S. $351-358$.

37 Huber, Deutsche Verfassungsgeschichte seit 1789 - Struktur und Krisen des Kaiserreichs, Bd. IV, ${ }^{2}$ 1994, S. 4 f.; so auch Shirvani, MIP 2006, 77 (87). 
die von der Reichsverfassung etablierte Rolle der Parteien zu berücksichtigen. Thomas Schmidt ist insoweit zuzustimmen, dass das Schutzgut des $\$ 17$ RWG das Repräsentativsystem und eben nicht die Parteien waren. Der Zweck des $\$ 17$ RWG erschöpfte sich jedoch entgegen seiner Auffassung nicht allein im Wahlrecht. ${ }^{38}$ Durch die Wahlvereine, die die Einflussnahme von Parteien auf das Verfassungssystem ermöglichten, wollte der Gesetzgeber die Voraussetzungen für eine aktive Teilnahme der Parteien am Repräsentativsystem schaffen. Hierin sah die Verfassung auch den alleinigen Zweck der Parteien. Die Reichstagswahl als Merkmal des Repräsentativsystems darf nicht darüber hinwegtäuschen, dass es sich bei dem damaligen System um eine konstitutionelle Monarchie gehandelt hat. ${ }^{39}$ Auch wenn über den Reichstag der Einfluss des Volkes auf die Reichsgesetzgebung in erheblicher Weise gestärkt wurde, so war der Einfluss über die Reichsregierung auf die öffentlichkeitswirksame Diskussion und Ausgabenbewilligung beschränkt. ${ }^{40}$ Die herrschende Staatsordnung hatte kein Interesse, den Parteien eine über die Ermöglichung der Reichstagswahlen hinausgehende rechtliche Bedeutung einzuräumen und ihnen insbesondere subjektive Abwehrrechte gegen den Staat selbst zu gewähren. Bestimmte Parteien mit revolutionären Gesinnungen sollten schnellstmöglich beseitigt werden können, um die konstitutionelle Monarchie nicht zu gefährden. Dies erklärt auch, weshalb der Reichsgesetzgeber nicht von seiner Kompetenz nach Art. 4 Nr. 16 RV Gebrauch gemacht hat, um Parteien final eine gesonderte Stellung einzuräumen. Die damalige rechtliche Privilegierung von Wahlvereinen gegenüber politischen Vereinen sorgte dafür, wie Thomas Schmidt zutreffend ausführt, dass die Wahlvereine vor administrativer Willkür geschützt wurden und damit ein weitgehend störungsfreier Ablauf der Reichstagswahlen gewährleistet war. ${ }^{41}$ Hierin lag jedoch auch, wie bereits erwähnt, der alleinige Zweck der Parteien nach der Vorstellung der Reichsverfassung. Die Betätigung in ihrem verfassungsrechtlich festgelegten Bereich der Reichstagswahl sollten die Parteien ungestört wahrnehmen können. Der Organisation in den politischen Vereinen stand der Gesetzgeber jedoch gerade kritisch gegenüber. ${ }^{42}$ Somit sollte durch die

38 So Schmidt, Die Freiheit verfassungswidriger Parteien und Vereinigungen, 1983, S. 34 .

$39 \mathrm{Zu}$ dem Begriff der konstitutionellen Monarchie: Kimminich, Deutsche Verfassungsgeschichte, ${ }^{2} 1987$, S. 327.

40 Ders., Deutsche Verfassungsgeschichte, ${ }^{2} 1987$, S. 431.

41 Schmidt, Die Freiheit verfassungswidriger Parteien und Vereinigungen, 1983, S. 34 .

42 Shirvani, MIP 2006, 77 (77). 
Wahlvereine nur der eigentliche Sinn der Parteien geschützt werden. Eine darüberhinausgehende Organisation sah der Gesetzgeber als Gefahr an und schaffte die Bedingungen für ein schnelles und möglichst effizientes Eingreifen. Dies erklärt auch, weshalb das Sozialistengesetz das Mandat sowie das aktive und passive Wahlrecht der sozialdemokratischen Abgeordneten nicht tangierte.

Der Gesetzgeber erkannte durch die Einführung des Repräsentativsystems die Parteien als verfassungsimmanente Institution an. So wie Ernst Rudolf Huber von einer „institutionellen Garantie des freien Parteiwesens“ zu sprechen ${ }^{43}$, geht jedoch angesichts der Restriktionsmöglichkeiten auf Reichs- und Landesebene eindeutig zu weit. ${ }^{44}$ Der Gesetzgeber räumte den Parteien aufgrund des revolutionären Gedankenguts und der von ihnen ausgehenden abstrakten Gefahr bewusst eine schwache, allerdings dennoch objektivrechtlich existente rechtliche Stellung ein. Nach der Reichsverfassung musste es zwar Parteien geben, eine besondere subjektiv-rechtliche Position der einzelnen Parteien gegen den Staat kannte die Verfassung allerdings nicht. Ohne subjektive Abwehrrechte gegenüber dem Staat kann es kein freies Parteiwesen geben, da staatlichen Eingriffen in die Betätigungssphäre der Partei keine subjektive Rechtsposition entgegengehalten werden könnte. Man kann somit eine objektiv-rechtliche Institutsgarantie der Parteien annehmen, eine institutionelle Garantie des freien Parteiwesens angesichts der fehlenden subjektiven Rechtspositionen hingegen nicht.

\section{Das Sozialistengesetz vom 21. Oktober 1878}

Nach zwei erfolglosen Attentaten auf Kaiser Wilhelm I. ${ }^{45} \mathrm{kam}$ es am 21. Oktober 1878 zum Erlass des Gesetzes gegen die gemeingefährlichen Bestrebungen der Sozialdemokratie, welches allgemein als „Sozialistengesetz" bezeichnet wurde. Die Sozialdemokratie wurde gesellschaftlich als staatsgefährdende politische Strömung angesehen, welche durch das als Einzelfallgesetz erlassene Sozialistengesetz eingedämmt werden sollte. Es

43 Huber, Deutsche Verfassungsgeschichte seit 1789 - Struktur und Krisen des Kaiserreichs, Bd. IV, ${ }^{2} 1994$, S. 9.

44 So auch Shirvani, MIP 2006, 77 (87).

45 Das Erste war das sog. Hödelsche Attentat am 11. Mai 1878, das Zweite das Nobilingsche Attentat am 2. Juni 1878. Das erste Attentat überlebte der Kaiser unverletzt, beim Zweiten wurde er so schwer verletzt, dass er für mehrere Monate seiner Arbeit als Staatsoberhaupt nicht nachgehen konnte. 
handelte sich hierbei schlechthin um eine Maßnahme des Verfassungsschutzes durch den Gesetzgeber. ${ }^{46}$

Der formelle Gesetzgeber entschied über die Pönalisierung politischer Strömungen und war in seiner Entscheidungsgewalt nicht begrenzt, sodass die parlamentarische Mehrheit über die Kategorisierung von „unerwünschten " Parteien und politischen Strömungen willkürlich entscheiden konnte. Die entscheidende Instanz war somit stark politisch geprägt und ließ insoweit Neutralität missen. Doch nicht nur die Entscheidung über die staatliche Bekämpfung einer bestimmten politischen Richtung, sondern auch die Art und Weise des Vorgehens sind mit dem neuzeitigen Demokratieverständnis unvereinbar. Das Sozialistengesetz sah eine Reihe von Befugnissen für die Behörden vor, um gegen die - aus Sicht des Gesetzgebers existenten - Bedrohung durch sozialdemokratische, sozialistische und kommunistische gesellschaftliche Strömungen vorzugehen.

Dabei setzte das Sozialistengesetz zwei Tatbestandsmerkmale voraus, die für eine Maßnahmenergreifung notwendig waren. Zum einen mussten die Vereinigungen, Versammlungen oder Druckschriften im Dienste der sozialdemokratischen, sozialistischen oder kommunistischen Bestrebung stehen und zum anderen den Umsturz der bestehenden Staats- und Gesellschaftsordnung bezwecken. ${ }^{47}$ Das Gesetz stellte somit auf die Gesinnung und die Gefährlichkeit für die Staats- und Gesellschaftsordnung ab und war damit auch im weiten Sinne dem materiellen „Verfassungsschutz“ zuzuordnen.

Nach dem Sozialistengesetz wurde der zuständigen Behörde bei der Entscheidung über die Durchführung der Maßnahmen (bis auf die Anordnung des „kleinen Belagerungszustandes“ nach $\mathbb{} \$ 28$ SozG) kein Ermessen eingeräumt. Die Behörden waren mithin verpflichtet, bei Erfüllung des Tatbestandes die konkreten Maßnahmen auszuführen, womit die Rechtsfolgen gebundene Entscheidungen der Verwaltung darstellten ${ }^{48}$ und der gesetzgeberische Wille zur entschlossenen Bekämpfung der Sozialdemokratie besonders zum Ausdruck kam. Allerdings stand ihnen bei der Auslegung der normativen Voraussetzungen ein gewisser Einschätzungsspiel-

46 Huber, Deutsche Verfassungsgeschichte seit 1789 - Struktur und Krisen des Kaiserreichs, Bd. IV, ${ }^{2} 1994$, S. 1158.

47 Ders., Deutsche Verfassungsgeschichte seit 1789 - Struktur und Krisen des Kaiserreichs, Bd. IV, ${ }^{2} 1994$, S. 1160.

48 Siehe $\mathbb{S} \mathbb{1}$ 1, 9, 11, 16 SozG. Die Formulierung „sind“ schließt ein behördliches Ermessen aus. 
raum zu. ${ }^{49}$ Das Sozialistengesetz sah präventive und repressive Befugnisse zur Bekämpfung „verfassungsfeindlicher“ Bestrebungen vor. $\mathrm{Zu}$ den präventiven Maßnahmen gehörten unter anderem nach $\$ 1$ SozG ein Vereinsverbot, nach $₫ 9$ SozG ein Versammlungsverbot, nach $₫ 11$ SozG das Verbot von Druckschriften, nach $\$ 16$ SozG das Verbot von Beitragssammlungen und nach $\mathbb{2} 28$ SozG die Verhängung eines „kleinen Belagerungszustands" 50 . Obwohl eine staatliche Parteienfinanzierung zu diesem Zeitpunkt nicht existent ${ }^{51}$ und aufgrund des staatlichen Misstrauens gegenüber Parteien wohl auch politisch undenkbar war, verstand der Gesetzgeber durch das Verbot der Beitragssammlung den politischen Wettbewerb zum Nachteil sozialdemokratischer Strömungen zu verändern. Angesichts der Existenz weiterer Maßnahmen mit weitaus höherer Intensität wird allerdings deutlich, dass die Beeinträchtigung der wirtschaftlichen Aktivität nur einen kleinen Bestandteil des gegen die Sozialdemokratie gerichteten Gesamtkonzeptes darstellt und zu dieser Zeit als eine der „milderen“ Maßnahmen eine eher untergeordnete Bedeutung einnahm.

Als repressive Maßnahmen sah das Sozialistengesetz Geld- und Freiheits-

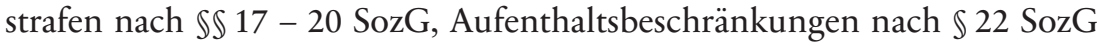
und die Untersagung eines Gewerbebetriebs nach $\$ \mathbb{S} 23$, 24 SozG vor. Während der Adressat der präventiven Maßnahmen die sozialdemokratische Vereinigung als juristische Person war, richtete sich der repressive Befugniskatalog gegen deren Anhänger. Die politische Aktivität des Einzelnen wurde sanktioniert und somit zusätzlich durch staatliches Handeln unattraktiv gestaltet.

Rechtsbehelfe gegen Maßnahmen des Sozialistengesetzes waren zwar vorgesehen, vermochten einen effektiven Rechtsschutz allerdings nur unzureichend zu gewährleisten. Das Sozialistengesetz schloss in seinem gesamten Regelungswerk den Zugang zur Verwaltungsgerichtsbarkeit aus

49 Huber, Deutsche Verfassungsgeschichte seit 1789 - Struktur und Krisen des Kaiserreichs, Bd. IV, ${ }^{2} 1994$, S. 1161.

50 Ders., Deutsche Verfassungsgeschichte seit 1789 - Struktur und Krisen des Kaiserreichs, Bd. IV, ${ }^{2}$ 1994, S. 1163, Fn. 29: Umgangssprachlich wurde die Maßnahme nach $₫ 28$ SozG „kleiner Belagerungszustand“ genannt. Diese Maßnahme ermöglichte die Verhängung eines Ausnahmezustandes über einen bestimmten Bezirk. In diesem konnten dann Versammlungen unter einen Genehmigungsvorbehalt gestellt, das öffentliche Verbreiten von Druckschriften und der Aufenthalt von Personen im Bezirk untersagt und der Besitz und die Einführung von Waffen verboten oder beschränkt werden. $\$ 28$ SozG war die einzige Maßnahme, bei der der zuständigen Behörde ein Ermessen eingeräumt wurde.

51 Siehe zu den Anfängen der staatlichen Parteienfinanzierung $\$ 3$ A. I. 
und setzte speziell für das Vereinsverbot $(\mathbb{8} 8 \mathrm{SozG})$ und dem Verbot der Druckschriften ( $\$ 13$ SozG) nach $\$ 26$ SozG als erste und ausschließliche Rechtsbehelfsinstanz eine besondere Kommission ein, die aus insgesamt neun Mitgliedern, wovon vier aus der Mitte des Bundesrats gewählt wurden und die fünf weiteren Mitglieder Richter der obersten Reichsgerichte waren, bestand. Auch lagen nach $\mathbb{8}$ Abs. 2 SozG und nach $\mathbb{1} 13$ Abs. 3 SozG die Beschwerdefristen zur Kommission bei lediglich einer Woche. Die Beschwerde hatte auch keine aufschiebende Wirkung und die Kommission konnte gem. $\$ 27$ Abs. 1 S. 5 SozG nach freiem Ermessen endgültig über die Rechtmäßigkeit der Maßnahme entscheiden. Nach Ablauf der Frist oder endgültigen Entscheidung der Kommission war die Maßnahme insgesamt bestandskräftig und unanfechtbar. An die Bestandskraft der Maßnahme konnten dann weitere belastende Maßnahmen, die mangels geeigneten Rechtsbehelfs ab dem Zeitpunkt ihrer Anordnung unanfechtbar waren, geknüpft werden, wie beispielsweise die „Unbrauchbarmachung" von Druckschriften nach $\mathbb{1} 14$ Abs. 1 S. 3 SozG. Gegen die außer den in $\mathbb{S} 8$ und 13 SozG vorgesehenen Maßnahmen präventiven Charakters war nur die Beschwerde zur Aufsichtsbehörde statthaft, welche insoweit auch ausschließlich über die Rechtmäßigkeit der Maßnahme zu entscheiden hatte. ${ }^{52}$ Repressive Maßnahmen gegen Anhänger der Sozialdemokratie konnten mit den Rechtsbehelfen der damals geltenden Strafprozessordnung angefochten werden. ${ }^{53}$

Vor Maßnahmen auf Grund des Sozialistengesetzes waren die Abgeordneten des Reichstages geschützt. Diese wurden in ihrem aktiven und passiven Wahlrecht sowie ihrer parlamentarischen Tätigkeit nicht eingeschränkt. Die Immunität der Abgeordneten nach Art. 31 RV blieb von den Maßnahmen des Sozialistengesetzes unangetastet. Eine Entziehung der Mandate von sozialdemokratischen Abgeordneten konnte über das Sozialistengesetz nicht erreicht werden. ${ }^{54}$ Durch die Unterdrückung sozialdemokratischer Organisationen unter Wahrung der parlamentarischen Rechte der sozialdemokratischen Abgeordneten ging, entgegen dem Zweck des Sozialistengesetzes, die Sozialdemokratie gestärkt aus dieser Zeit der Unterdrückung hervor. So gewannen die Sozialdemokraten in der Phase der gezielten staatlichen Repression fortlaufend Anhänger und Wählerstim-

52 Siehe z.B. $\$ 7$ Abs. 6 SozG.

53 Huber, Deutsche Verfassungsgeschichte seit 1789 - Struktur und Krisen des Kaiserreichs, Bd. IV, ${ }^{2} 1994$, S. 1163.

54 Ders., Deutsche Verfassungsgeschichte seit 1789 - Struktur und Krisen des Kaiserreichs, Bd. IV, ${ }^{2} 1994$, S. 1160. 
men. Als 1890 das Sozialistengesetz zeitlich auslief und nicht verlängert wurde, konnten die Sozialdemokraten bei den Reichstagswahlen fast 1,5 Millionen Stimmen für sich gewinnen. ${ }^{55}$

Das Sozialistengesetz deklarierte eine gesamte politische Strömung als staatsfeindlich und verlieh der Exekutive aus diesem Grund weitreichende Befugnisse zur „Abwehr“ dieser Gefahr, gegen die es einen nur überschaubaren Rahmen an Rechtsschutzmöglichkeiten eröffnete. Vergleichbar mit der heutigen Rechtslage ${ }^{56}$ setzte das Sozialistengesetz zwar auch ein konkretes Streben nach einem Umsturz der bestehenden Gesellschafts- und Verfassungsordnung voraus, weshalb es materiell auch eine Maßnahme des Staatsschutzes darstellte. Dennoch setzte eine solche Maßnahme tatbestandlich zusätzlich voraus, dass die Umsturzbestrebungen von einer sozialdemokratischen Organisation ausgingen. Das Sozialistengesetz stellte nicht nur auf ein staatsgefährdendes Handeln, sondern darüber hinaus auch auf die politische Gesinnung des „Gefährders“ ab. Die Maßnahmen nach dem Sozialistengesetz waren zwar für die betroffenen Parteien einschneidend und auch Rechtsschutzmöglichkeiten waren kaum vorhanden, im Ergebnis verfehlte das Sozialistengesetz jedoch seinen Zweck. Obwohl eine ganze politische Strömung von Staatswegen als „staatsfeindlich“ und dadurch zum Adressaten einer repressiven Politik erklärt wurde, gingen die Sozialdemokraten gestärkt und als Sieger des politischen Machtkampfes hervor.

\section{Kaiserliches Beamtenrecht und Parteien}

Das Kaiserreich ergriff nicht nur Maßnahmen nach dem Sozialistengesetz, um die unliebsame sozialdemokratische Strömung im Reich zu bekämpfen, sondern sah darüber hinaus auch dienstrechtliche Konsequenzen vor, sofern ein Staatsbediensteter sich in einer unliebsamen Partei betätigte. Diese dienstrechtlichen Folgen wurden maßgeblich durch die Rechtsprechung der Verwaltungsgerichte geformt. Bereits in den 1880er und 1890er mussten sich die Verwaltungsgerichte mit der Vereinbarkeit der beamten-

55 Lösche, Kleine Geschichte der deutschen Parteien, 1993, S. 57.

56 Vgl. maßgeblich die freiheitliche demokratische Grundordnung als Schutzgut des Parteiverbots in Ipsen, in: Sachs (Hrsg.), Grundgesetz, ${ }^{8} 2018$, Art. 21 Rn. 160 ff.; Streinz, in: Huber/Voßkuhle (Hrsg.), Grundgesetz, ${ }^{72018, ~ A r t . ~ 21, ~}$ Rn. 224 ff.; Klein, in: Maunz/Dürig (Hrsg.), Grundgesetz, 2018, Art. 21, Rn. 519. 
rechtlichen Dienstpflichten und einer parteipolitischen Betätigung befassen. ${ }^{57}$

Die Betätigung in einer als „staatsfeindlich“ geltenden Partei, insbesondere der SPD, war mit der Beamtentätigkeit unvereinbar und stellte insoweit ein Dienstvergehen dar, welches disziplinarrechtliche Maßnahmen zur Folge haben konnte. Ob eine politische Betätigung in einer Partei als Dienstvergehen gewertet wurde, hing maßgeblich davon ab, ob die Partei, in der sich der Beamte außerdienstlich betätigte, auf dem „Boden der bestehenden Rechts- und Staatsordnung stand“ oder gegen die „Grundlagen der Rechts- und Staatsordnung ankämpfte“58. Insofern fand bereits im Kaiserreich eine staatliche Kategorisierung von Parteien statt, die jeweils Vorwie auch Nachteile für einzelne Parteimitglieder und damit mittelbar auch für die Partei selbst begründen konnten. Der Disziplinarsenat des Preußischen Oberverwaltungsgerichtes urteilte, dass ein Beamter in seiner außerdienstlichen politischen Tätigkeit grundsätzlich befugt sei, die Auffassung der Regierung zu bekämpfen, solange die Grenzen des achtungswürdigen Verhaltens gewahrt blieben, deren Befolgung zu den beamtenrechtlichen Dienstpflichten gehörte. ${ }^{59}$ Eine Betätigung in der SPD sei allerdings grundsätzlich als beamtenrechtliche Pflichtverletzung zu werten, da die SPD eine Partei sei, „die notorisch die Grundlagen der bestehenden Rechts- und Staatsordnung bekämpft und, sofern sie die Macht zur Verwirklichung ihrer Ziele hätte, bis zu deren Erreichung auf gesetzmäßigem Wege schwerlich warten würde ${ }^{\text {600 }}$. Der SPD wurde somit die Zielsetzung eines gewaltsamen Umsturzes unterstellt, weshalb eine geringere staatliche Toleranzschwelle als bei anderen Parteien zur Anwendung kam. Obwohl nicht ausdrücklich durch die Rechtsprechung festgestellt, lässt sich aus der Gänze der Gerichtsentscheidungen schließen, dass bei einer Betätigung in der SPD der Beamte zwingend aus dem Amt zu entlassen war und dem Dienstherren insoweit kein Ermessen zustand. ${ }^{61}$ Das Sozialistengesetz delegitimierte die Teilnahme der Sozialdemokraten am politischen Meinungskampf, indem

57 Siehe dazu Ule, in: Külz/Naumann (Hrsg.), Staatsbürger und Staatsgewalt, 1963, S. $113,125 \mathrm{f}$.

58 Ders., in: Külz/Naumann (Hrsg.), Staatsbürger und Staatsgewalt, 1963, S.113, 125.

59 Preußisches OVG, Urt. v. 25.06.1887, Reger Bd. 8, S. 312 f.; siehe auch Ule, in: Külz/Naumann (Hrsg.), Staatsbürger und Staatsgewalt, 1963, S. 113, 125.

60 Preußisches OVG, Urt. v. 29.01.1897, Reger Bd. 17, S. 348.

61 Ule, in: Külz/Naumann (Hrsg.), Staatsbürger und Staatsgewalt, 1963, S. 113, 125 f.; PrOVGE, 56, 229 ff.; PrOVGE 58, 447 f.; PrOVGE 63, 468 ff.; PrOVGE 66, 437 (439 ff.). 
es sich insbesondere gegen die politische Kommunikation und den Bestand sozialdemokratischer Organisationen richtete. Darüber hinaus erstreckte sich der "Staatsschutz" des Kaiserreiches auch auf das Beamtenrecht und gewährte den Staatsbediensteten zwar die Freiheit der kontroversen Gedanken und deren Äußerung, allerdings keine Betätigung in einer als „staatsfeindlich“ wahrgenommenen Partei - namentlich der SPD.

\section{B. Verfassungsfeindliche Parteien in der Weimarer Republik}

Nachdem das Deutsche Kaiserreich im Ersten Weltkrieg im Jahr 1918 am Rande der Kapitulation stand, entwickelte sich aus der Kriegsmüdigkeit der deutschen Bevölkerung ein Drängen nach einer Demokratisierung des Deutschen Reiches. ${ }^{62}$ Nach revolutionären Bewegungen im ganzen Staatsgebiet wurde schließlich am 14. August 1919 die Weimarer Reichsverfassung ${ }^{63}$ verkündet. Die Weimarer Republik ging zeitlich der durch den Nationalsozialismus bedingten Katastrophe des Zweiten Weltkriegs vor. $\mathrm{Zu}$ ihrer Zeit musste sich die junge Republik gegen Umsturzbestrebungen aus verschiedensten politischen Richtungen erwehren und hatte sich insoweit auf eine Umgangsart mit staatsfeindlichen Parteien und deren Anhängern festzulegen. Im Folgenden wird die Rechtsstellung der Parteien in der Weimarer Republik dargestellt und die Maßnahmen des Staates zur Abwehr der von den Parteien ausgehenden Gefahren für die bestehende Staatsordnung untersucht werden. Der Staatsschutz während der Weimarer Republik - insbesondere in der Form des Gesetzes zum Schutze der Republik $^{64}$ - konnte letzten Endes die seit 1919 geltende Staatsform nicht schützen.

\section{Rechtliche Stellung der Parteien}

Durch das Inkrafttreten der Weimarer Reichsverfassung wurde die „normative Enthaltsamkeit ${ }^{“ 65}$ der Verfassungsurkunde des Deutschen Reiches zu Parteien aufgehoben. In Art. 130 Abs. 1 WRV wurden die Parteien erst-

62 So Kimminich, Deutsche Verfassungsgeschichte, ${ }^{2} 1987$, S. 478.

63 RGBl. 1919, S. $1383 \mathrm{ff}$.

64 RGBl. I, 1922, S. 585-590.

65 Siehe zum Begriff im Bezug zur Parteienfinanzierung Klein, in: Maunz/Dürig (Hrsg.), Grundgesetz, 2018, Art. 21, Rn. 406. 
malig im Wortlaut einer Verfassungsnorm berücksichtigt. ${ }^{66}$ Durch die Vorschrift sollte deutlich zum Ausdruck gebracht werden, dass die durch das Parlament (und damit mittelbar durch die Parteien) eingesetzten Beamten nicht deren politischen Einfluss unterliegen sollten. ${ }^{67}$ Adressaten waren gleichwohl alle Beamte, unabhängig von der Art ihrer Berufung. ${ }^{68}$ Rechte und Pflichten oder eine sonstige subjektive Rechtsposition der Parteien konnten aus Art.130 WRV indessen nicht abgeleitet werden. Aus Art.130 WRV erfolgt lediglich eine formelle Erwähnung in der Verfassungsurkunde, was den Schluss zulässt, dass der Gesetzgeber die Parteien als Institutionen erkannte und sich ihrer Existenz bewusst war.

Ähnlich wie zur Zeit des Deutschen Kaiserreichs wurde aus dem in Art. 1, 20, 22 WRV verankerten Repräsentativsystem eine objektive Bestandsgarantie für Parteien hergeleitet. ${ }^{69}$ Die Existenz von Parteien - wie schon im Kaiserreich ${ }^{70}$ - wurde durch die Staatsformwahl vorausgesetzt, damit die Erstellung von Wahllisten als indisponibler Beitrag zur Durchführung der Reichstagswahl sichergestellt werden konnte. Durch die „Demokratisierung" der Staatsordnung und die damit zusammenhängende Stärkung der parlamentarischen Rechte im Wege der Novemberrevolution haben die Parteien zumindest mittelbar eine gewisse Kontrolle über und Einflussmöglichkeit auf die Reichsregierung erhalten und somit gegenüber ihren „Vorgängern“ aus der Kaiserzeit ihre Macht ausbauen können. So war die Regierung auf den Rückhalt des Parlamentes angewiesen und musste nach Art.54 WRV zurücktreten, wenn der Reichstag ihr durch einen Beschluss das Vertrauen entzog. ${ }^{71}$

Eine weitere Besonderheit der Weimarer Reichsverfassung gegenüber der Bismarck'schen war die Gewährleistung von Grundrechten. Subjektive Abwehrrechte, die der Einzelne dem Staat entgegenhalten konnte, fanden somit erstmals Einzug in die Verfassungsordnung des Deutschen Reiches.

66 So heißt es in Art. 130 I WRV: Die Beamten sind Diener der Gesamtheit, nicht einer Partei.

67 Vgl. Anschütz, in: ders. (Hrsg.), Die Verfassung des Deutschen Reiches vom 11. August 1919, ${ }^{14} 1933$, Art. 130 Nr. 1; Radbruch, in: Anschütz/Thoma (Hrsg.), Handbuch des deutschen Staatsrechts, 1930, Bd. 1, S. 285, 289.

68 Anschütz, in: ders. (Hrsg.), Die Verfassung des Deutschen Reiches vom 11. August $1919,{ }^{14} 1933$, Art. 130 Nr. 1.

69 Radbruch, in: Anschütz/Thoma (Hrsg.), Handbuch des deutschen Staatsrechts, 1930, Bd. 1, S. 285, 290 f.; ähnlich bezüglich des Kaiserreichs Huber, Deutsche Verfassungsgeschichte seit 1789 - Ausbau, Schutz und Untergang der Weimarer Republik, Bd. III, ${ }^{3} 1988$, S. 867 ff.

70 Siehe $\mathbb{1}$ A.

71 Ähnlich wie das Misstrauensvotum nach Art. 67 GG. 
Der Gewährleistungsbereich der Grundrechte erstreckte sich auch auf das politische Vereinswesen, und räumte dem Einzelnen auch in diesem Rahmen notwendige Rechtspositionen ein. So waren insbesondere die Bildung von, der Beitritt zu und das Verbleiben in Vereinen - nicht jedoch die Teilnahme an der vereinsspezifischen Betätigung 72 - durch Art. $124 \mathrm{WRV}^{73}$ verfassungsrechtlich geschützt. Die damals herrschende Staatsrechtslehre hielt Art. 124 WRV für ein Individualrecht ${ }^{74}$ und verstand Parteien auch als „Vereine oder Gesellschaften“ im Sinne des Grundrechts, weshalb erstmalig parteibezogene Rechte etabliert wurden ${ }^{75}$. Nur die Personen, die hinter den Vereinen standen, konnten sich auf das Grundrecht berufen, mangels einer Regelung wie Art. 19 Abs. 3 GG jedoch nicht die Vereine selbst. Art. 124 WRV gewährte allen Mitgliedern einer Partei - und somit faktisch der Partei an sich - einen umfassenden Schutz vor Maßnahmen der Exekutive; speziell vor polizeilichen Maßnahmen $^{76}$, im weiteren Sinne auch vor sämtlichen Akte der öffentlichen Gewalt. ${ }^{77}$

Trotz des Freiheitsbereiches des Art. 124 WRV waren die Parteien nicht umfassend vor Maßnahmen der Legislative geschützt. So war es dem Gesetzgeber nach Art. 76 WRV durch den Erlass sogenannter „verfassungs-

72 Kiesow/Zweigert, in: dies. (Hrsg.), Gesetz zum Schutze der Republik, 1923, $\mathbb{} 7$ Nr. 4 I.

73 Art. 124 WRV:

(1) Alle Deutschen haben das Recht, zu Zwecken, die den Strafgesetzen nicht zuwiderlaufen, Vereine und Gesellschaften zu bilden. Dies Recht kann nicht durch Vorbeugungsmaßregeln beschränkt werden. Für religiöse Vereine und Gesellschaften gelten dieselben Bestimmungen.

(2) Der Erwerb der Rechtsfähigkeit steht jedem Verein gemäß den Vorschriften des bürgerlichen Rechts frei. Er darf einem Verein nicht aus dem Grunde versagt werden, daß er einen politischen, sozialpolitischen oder religiösen Zweck verfolgt.

74 Schmidt, Die Freiheit verfassungswidriger Parteien und Vereinigungen, 1983, S. 36; Waldecker, in: Anschütz/Thoma (Hrsg.), Handbuch des deutschen Staatsrechts, 1930, Bd. 2, S. 637, 643, mit der Ablehnung der Existenz von „Doppelgrundrechten“.

75 Anschütz, in: ders. (Hrsg.), Die Verfassung des Deutschen Reiches vom 11. August $1919,{ }^{14} 1933$, Art. 124 Nr. 3.

76 So Schmidt, Die Freiheit verfassungswidriger Parteien und Vereinigungen, 1983, S. 37; Anschütz, in: ders. (Hrsg.), Die Verfassung des Deutschen Reiches vom 11. August 1919, ${ }^{14} 1933$, Art. 124 Nr. 2, 3.

77 Waldecker, in: Anschütz/Thoma (Hrsg.), Handbuch des deutschen Staatsrechts, 1930, Bd. 2, S. 637, 644. 
transzendierender"78 Gesetze möglich, ohne Änderung des Verfassungswortlautes mit der Reichsverfassung im Widerspruch stehende, allerdings dennoch wirksame Gesetze zu erlassen. ${ }^{79}$ Der Gesetzgeber unterlag bei Verfassungsänderungen keiner rechtlichen Einschränkung, solange die nach Art. 76 Abs. 1 WRV erforderliche Zweidrittel-Mehrheit gewahrt wurde. ${ }^{80}$ Auch wäre im Vergleich zur Bundesrepublik eine stillschweigende Änderung des Grundgesetzes aufgrund von Art. 79 Abs. 1 GG nicht möglich. ${ }^{81}$ Dies ging sogar so weit, dass der Reichstag unbewusst, d.h. ohne den konkreten Willen die Verfassung zu ändern, ein verfassungstranszendierendes Gesetz erlassen konnte, solange bei der Abstimmung die nötige Zweidrittel-Mehrheit erreicht wurde. ${ }^{82}$ Das Reich verfügte in diesem Sinne über eine plenitudo potestatis, die nur in formeller Hinsicht durch das Erfordernis einer qualifizierten Mehrheit eingeschränkt wurde. ${ }^{83}$ Materielle Grenzen von Verfassungsänderungen, wie heutzutage Art. 79 Abs. 3 GG vorsieht, existierten nicht. ${ }^{84}$

Durch die gesetzgeberische Befugnis, nach Art.76 WRV sogenannte „verfassungstranszendierende Gesetze“ zu erlassen, gewährte Art. 124 WRV den Parteien einen nur eingeschränkten Schutzbereich, der sein größtes „Schutzpotential“ vor Maßnahmen der Exekutive entfaltete. Darüber hinaus war der Reichspräsident nach Art. 48 Abs. 2 S. 2 WRV befugt, das Grundrecht aus Art. 124 WRV vorübergehend außer Kraft zu setzen und damit einhergehend auch die Exekutivgewalt gegenüber Parteien auszuweiten. Wie sich zeigte, nutzte der Reichspräsident seine durch Art. 48 Abs. 2 WRV konstituierten Befugnisse, um von radikalen Parteien ausgehenden Gefahren entgegentreten zu können. In den 1920ern wurden eine Reihe von Rechtsverordnungen und Gesetzen erlassen, die den Behör-

78 Zum Begriff siehe Thoma, in: Anschütz/Thoma (Hrsg.), Handbuch des deutschen Staatsrechts, 1930, Bd. 2, S. 137, 153.

79 Jellinek, in: Anschütz/Thoma (Hrsg.), Handbuch des deutschen Staatsrechts, 1930, Bd. 2, S. 182, 187.

80 Thoma, in: Anschütz/Thoma (Hrsg.), Handbuch des deutschen Staatsrechts, 1930, Bd. 1, S. 186, 193-194; a.A. Schmitt, Verfassungslehre, ${ }^{10} 2010$, S. 103.

81 Anschütz, in: ders. (Hrsg.), Die Verfassung des Deutschen Reiches vom 11. August 1919, ${ }^{14} 1933$, Art. 76 Nr. 3; Stern, Staatsrecht I, ${ }^{2} 1984$, S. 159; Dreier, in: Dreier/Bauer (Hrsg.), Grundgesetz, ${ }^{3} 2015$, Art. 79 Abs. 1 Rn. 19 m.w.N.

82 Jellinek, in: Anschütz/Thoma (Hrsg.), Handbuch des deutschen Staatsrechts, 1930, Bd. 2, S. 182, 188.

83 Thoma, in: Anschütz/Thoma (Hrsg.), Handbuch des deutschen Staatsrechts, 1930, Bd. 2, S. 137, 154.

84 A.A. Schmitt., Verfassungslehre, ${ }^{10} 2010$, S. 103, der Grundentscheidungen der Verfassung von der Dispositionsgewalt des Gesetzgebers als entzogen ansieht. 
den Befugnisse zur Bekämpfung extremistischer Parteien einräumten und den „Staatsschutz“ zum gesetzlichen Schutzgut erhoben.

\section{Der Staatsschutz der Weimarer Republik}

Die junge Republik versuchte sich gegen die radikalen politischen Kräfte im Land zu verteidigen, gewährte ihnen gleichzeitig allerdings auch weitgehende Freiheiten. So erließ der Reichspräsident Friedrich Ebert nach einer Reihe von tödlichen Anschlägen auf namhafte Politiker der Weimarer Republik Verordnungen, die dem Zwecke des Staats- und Verfassungsschutzes dienten, wobei sich insbesondere das Notverordnungsrecht des Reichspräsidenten nach Art. 48 Abs. 2 WRV als ein durchaus geläufiges Mittel des Staatsschutzes erwies. ${ }^{85}$ Nach der Ermordung von Karl Gareis ${ }^{86}$ und Matthias Erzberger ${ }^{87}$ wurde die "Verordnung des Reichspräsidenten auf Grund des Art. 48 WRV vom 29. August 1921“ („Erzberger-Verordnung ") ${ }^{88}$ und nach der Ermordung von Walther Rathenau ${ }^{89}$ am 24.06.1922 die "Verordnung zum Schutz der Republik“ („Rathenau-Verordnung“)90 erlassen. Am 23.07.1922 trat sodann das „Gesetz zum Schutz der Republik" "91 in Kraft, welches den Regelungsgehalt der zuvor erlassenen Verordnungen nun gesetzlich einkleiden sollte, um den von ihnen ausgehenden Anschein einer diktatorischen Gewaltmaßnahme des Reichspräsidenten durch eine demokratische Legitimierung zu mindern. ${ }^{92}$

In Bezug zur eigenen Staatsverwaltung, insbesondere dem Berufsbeamtentum, gewährte die WRV allerdings auch extremistischen Beamten weitgehende Gesinnungs- und Vereinigungsfreiheiten, womit die Mitglied-

85 Huber, Deutsche Verfassungsgeschichte seit 1789 - Die Weimarer Reichsverfassung, Bd. VI, 1993, S. 688.

86 Karl Gareis war USPD-Führer und ein bayrischer Landtagsabgeordneter. Er wurde am 09. Juni 1921 ermordet.

87 Matthias Erzberger war Reichsfinanzminister und wurde am 26. August 1921 ermordet.

88 RGBl. 1921, I, S. 1239.

89 Zum Zeitpunkt seiner Ermordung am 24. Juni 1922 war er Reichsaußenminister.

90 RGBl. 1922, I, S. 521.

91 RGBl. 1922, I, S. 585.

92 Hierzu Graf zu Dohna, in: Anschütz/Thoma (Hrsg.), Handbuch des deutschen Staatsrechts, 1930, Bd. 1, S. 200, 204; Kiesow/Zweigert, in: dies. (Hrsg.), Gesetz zum Schutze der Republik, 1923, Einleitung S. XV; es sollte der Öffentlichkeit vermittelt werden, dass die Notstandsmaßnahmen des Reichspräsidenten nun durch ein parlamentarisches Verfahren demokratisch bestätigt worden seien. 
schaft in einer radikalen Partei mit einer Beschäftigung im öffentlichen Dienst vereinbar sein konnte. Wie weit diese Freiheiten reichten, wird nachfolgend dargestellt werden, bevor auf die Notstandsverordnungen und das „Gesetz zum Schutz der Republik“ im Einzelnen eingegangen wird.

\section{Staatsfeindliche Beamte}

Eine Problemstellung, die auch noch heute zu Diskussionen anregt, stellte der staatliche Umgang mit politisch radikal eingestellten Beamten und Angestellten des öffentlichen Dienstes dar. Die Weimarer Reichsverfassung garantierte in Art. 130 Abs. 2 WRV den Beamten eine Gesinnungs- und Vereinigungsfreiheit. Dies führte dazu, dass die damalige Rechtsprechung das Bekenntnis eines Beamten zu einer „staatsfeindlichen“ Partei für zulässig erachtete, eine Betätigung für dieselbe allerdings als Verstoß gegen die beamtenrechtlichen Pflichten qualifizierte, der zu einer disziplinarrechtlichen Entfernung aus dem öffentlichen Dienst führen konnte. ${ }^{93}$ Staatsfeindliche Ideologien konnten Beamte somit vertreten, solange sich diese nicht durch ein aktives Tätigwerden niederschlugen. Ob die bloße Mitgliedschaft in einer „revolutionären“ Partei als Pflichtverletzung anzusehen war, blieb in der Rechtsprechung ungeklärt. Die wohl herrschende Auffassung in der Literatur negierte die Annahme einer Pflichtverletzung aufgrund der einfachen Zugehörigkeit zu einer radikalen Partei. ${ }^{94}$

$\mathrm{Da}$ in der Weimarer Reichsverfassung keine Regelung wie Art. 21 Abs. 4 GG vorgesehen war, waren staatliche Stellen nicht gehindert, eine inhaltliche Bewertung der Parteiziele vorzunehmen und bestimmte Parteien als staatsfeindlich oder „revolutionär“ zu charakterisieren. Dies führte zu unterschiedlichen Entscheidungen hinsichtlich der Vereinbarkeit der Parteiziele mit der bestehenden Staatsordnung der Weimarer Republik. Aufgrund des Fehlens einer einheitlichen Instanz, die über die Frage der „Staatsfeindlichkeit“ entschied, konnten die Entscheidungen der Verwaltung und der Gerichte materiell auseinanderfallen. Durch die Freiheit der politischen Gesinnung war auch nicht gefordert, dass die Beamten eine

93 Anschütz, in: ders. (Hrsg.), Die Verfassung des Deutschen Reiches vom 11. August 1919, ${ }^{14} 1933$, Art. 130, S. 64 f. Nr. 2; Maurer, NJW 1972, 601 (601).

94 Anschütz, in: ders. (Hrsg.), Die Verfassung des Deutschen Reiches vom 11. August 1919, ${ }^{14} 1933$, Art. 124 S. 576 Nr. 3, Art. 130, S. 605 f. Nr. 3; Maurer, NJW 1972, 601 (601f.). 
Gewähr für ein jederzeitiges Eintreten für die bestehende Staatsordnung bieten mussten. ${ }^{95}$ Die Weimarer Reichsverfassung enthielt - im Gegensatz zum Grundgesetz - keine Bestimmungen über einen materiellen Verfassungsschutz oder einen staatlichen Auftrag, die Grundwerte der Weimarer Reichsverfassung zu schützen. ${ }^{96}$ Die Unterscheidung zwischen einem zulässigen Bekenntnis zu den Zielen einer staatsfeindlichen Partei und der unzulässigen Betätigung für eine staatsfeindliche Partei führte zu einer Duldungspflicht des Staates für politisch radikal eingestellte Beamte. Insoweit wurden auch im eigenen Staats- und Verwaltungsapperat Personen geduldet, die aus eigener Überzeugung die Grundordnung der Republik ablehnten. Nur wenn die Schwelle zur aktiven Betätigung überschritten war, konnten disziplinarrechtliche Maßnahmen eingeleitet werden.

\section{Verordnungen zum „Schutz der Republik“}

Art. 48 Abs. 2 WRV ermächtigte den Reichspräsidenten, die „nötigen Maßnahmen zur Wiederherstellung der öffentlichen Sicherheit und Ordnung“ zu treffen. Die öffentliche Sicherheit und Ordnung wurden als „Grundlage des staatlichen und gesellschaftlichen Lebens, wie es sich im Rahmen der sozialen Gegebenheiten und der Naturgewalten abspielt" ${ }^{\text {(97 }}$ verstanden. Schutzgut des Art. 48 Abs. 2 WRV war damit unter anderem auch die Sicherheit und der Bestand des Reiches sowie seine Verfassungsordnung. ${ }^{98}$ $\mathrm{Zu}$ den in Art. 48 Abs. 2 WRV vorgesehenen „Maßnahmen“ gehörte auch der Erlass von Verordnungen mit Gesetzeskraft, die formelle Gesetze durchbrechen, abändern oder aufheben konnten. ${ }^{99}$ Durch diese sogenann-

95 Anders in der Bundesrepublik, wo eine solche Verpflichtung in $\$ \$ 7$ Abs. 1 Nr. 2 BBG, 7 Abs. 1 Nr. 2 BeamtStG festgeschrieben wurde und über Art. 33 Abs. 5 GG als „hergebrachter Grundsatz des Berufsbeamtentums“ verfassungsrechtlich anerkannt ist, siehe dazu Battis, in: Sachs (Hrsg.), Grundgesetz, ${ }^{8}$ 2018, Art. 33, Rn. 71.

96 Vgl. Maurer, NJW 1972, 601 (602).

97 So Grau, in: Anschütz/Thoma (Hrsg.), Handbuch des deutschen Staatsrechts, 1930, Bd. 2, S. 274, 278; siehe auch Huber, Deutsche Verfassungsgeschichte seit 1789 - Die Weimarer Reichsverfassung, Bd. VI, 1993, S. 699.

98 Poetzsch-Heffter, in: ders. (Hrsg.), Handkommentar der Reichsverfassung vom 11. August 1919, ${ }^{3} 1928$, Art. 48 WRV, Nr. 9 b).

99 Vgl. Anschütz, in: ders. (Hrsg.), Die Verfassung des Deutschen Reiches vom 11. August 1919, ${ }^{14} 1933$, Art. 48, Nr. 13 b). 
te „Diktaturgewalt" ${ }^{“ 100}$ nach Art. 48 Abs. 2 WRV war der Reichspräsident weiter ermächtigt, die in der Norm abschließend aufgezählten Grundrechte vorübergehend ganz oder teilweise außer Kraft zu setzen. ${ }^{101}$ Durch die Befugnis, die Art. 118, 123 und 124 WRV außer Kraft zu setzen, verfügte der Reichspräsident über ein Mittel, die in einer Demokratie notwendigen Kommunikationsgrundrechte ${ }^{102}$ wirkungslos zu gestalten. Die Dikaturgewalt konnte auf diese Weise zur unmittelbaren staatlichen Einwirkung auf den politischen Wettbewerb verwendet werden. In dem Amt des Reichspräsidenten konzentrierten sich somit die Exekutivgewalt und die Befugnis der materiellen Rechtssetzung, was eine Besonderheit in der sonst rechtsstaatlich organisierten Staatsordnung darstellte. ${ }^{103}$ Die Weimarer Republik konnte sich den Einflüssen der Kaiserzeit nicht vollständig entziehen.

Die Erzberger-Verordnung wurde zwar überparteilich formuliert, diente taktisch jedoch überwiegend dem Kampf gegen die rechte politische Strömung. ${ }^{104}$ Sie erhob in ihrem $\mathbb{} 4$ u.A. die „Verfassung und die verfassungsmäßigen Einrichtungen des Reiches und seiner Länder“ zum Schutzgut. Allerdings nur insoweit, als die Gefährdung der Schutzgüter auf gewaltsame Art und Weise erfolgen sollte. Eine Beeinträchtigung oder Abschaffung der Verfassung und der verfassungsmäßigen Einrichtungen des Reiches waren auf friedlichem Wege nach wie vor geduldet und nicht Ziel staatlicher Präventionsmaßnahmen. Somit richtete sich der „Staatsschutz“ der Verordnung nur gegen gewaltsame Umsturzbestrebungen und diente nicht der Präservierung der Staatsordnung an sich. Aufgrund der nur durch qualifizierte Mehrheitserfordernisse eingeschränkten Verfügungsgewalt des verfassungsändernden Gesetzgebers war aufgrund der Weimarer Reichsverfassung selbst die Beseitigung der bestehenden Staatsordnung auf „legalem Wege“ möglich.

100 Als „Diktaturgewalt“ wurde nach der allgemeinen Staatslehre die Befugnis des Reichspräsidenten nach Art. 48 WRV bezeichnet; vgl. Pobl, in: Anschütz/Thoma (Hrsg.), Handbuch des deutschen Staatsrechts, 1930, Bd. I, S. 482, 498; Grau, in: Anschütz/Thoma (Hrsg.), Handbuch des deutschen Staatsrechts, 1930, Bd. II, S. 274.

101 Anschütz, in: ders. (Hrsg.), Die Verfassung des Deutschen Reiches vom 11. August 1919, ${ }^{14} 1933$, Art. 48, S. 288 f. Nr. 15.

102 Vgl. BVerfGE 27, 71 (81); BVerfGE 69, 315 (345 ff.); Grzeszick, in: Maunz/Dürig (Hrsg.), Grundgesetz, 2018, Art. 20, Rn. 17.

103 Grau, in: Anschütz/Thoma (Hrsg.), Handbuch des deutschen Staatsrechts, 1930, Bd. 2, S. 274, 275.

104 Jasper, Der Schutz der Republik, 1963, S.36; Huber, Deutsche Verfassungsgeschichte seit 1789 - Die Weimarer Reichsverfassung, Bd. VI, 1993, S. 660. 
Die Verordnung sah als Präventivmaßnahme vor allem die Einschränkung von Kommunikationsgrundrechten, wie der Presse-, Versammlungsund Vereinigungsfreiheit aus Art. 118, 123 und 124 WRV $^{105}$ vor. Hierdurch sollte keine subtile Beeinflussung des politischen Wettbewers vollzogen, sondern die Legitimität der Teilnahme an dem politischen Meinungskampf unmittelbar abgesprochen werden. So konnten nach $\mathbb{1} 1$ ErzVO Druckschriften durch die zuständige Behörde verboten werden. $\$ 2$ Erz-VO ermächtigte zur Beschlagnahmung von Druckschriften, $\$ 3$ ErzVO stellte das Herausgeben, Verlegen, Drucken und Verbreiten der nach $\$ 1$ Erz-VO verbotenen Druckschriften unter Strafe. $\$ 4$ Erz-VO regelte das Verbot von Versammlungen und Vereinigungen während $₫ 5$ Erz-VO auf repressiver Ebene das Veranstalten einer nach $₫ 4$ Erz-VO verbotenen Veranstaltung und das Auftreten in dieser als Redner unter Strafe stellte. Hierdurch konnte das Verbreiten einer staatsfeindlichen Meinung nicht nur durch die Polizeibehörden verhindert, sondern darüber hinaus auch zur Abschreckung bestraft werden. Der Staat wollte eine ihm feindlich gesinnte politische Strömung insgesamt aus dem politischen Wettbewerb verbannen.

Der Rechtsschutz gegen Maßnahmen der Erz-VO wurde in $\$ 6$ Erz-VO geregelt und enthielt deutliche Parallelen zum Sozialistengesetz. Demnach wurde als Rechtsbehelfsinstanz ein Ausschuss eingerichtet, dessen sieben Mitglieder vom Reichsrat aus dessen Mitte gewählt wurden. Betroffene konnten im Wege der Beschwerde gegen eine nach der Erzberger-Verordnung erlassene Maßnahme rechtlich vorgehen, wobei der Rechtsbehelf keine aufschiebende Wirkung hatte.

Nach $₫ 1$ Abs. 4 Erz-VO iVm. ihrer Ausführungsverordnung ${ }^{106}$ waren neben dem Reichsinnenminister auch die örtlichen Polizeibehörden für die Anordnung der Maßnahmen zuständig. Die Ansiedelung der Zuständigkeit bei einem Reichsminister löste einen föderalen Konflikt aus, der im weiteren Verlauf erhebliche Auswirkungen auf die Zuständigkeitsverteilung hatte und dazu führte, dass das Reich Kompetenzen an die Länder abtreten musste. Die bayerische Landesregierung sah die Verordnung als einen Eingriff in ihre Eigenstaatlichkeit an, kam aus diesem Grund Anordnungen des Reichsinnenministers nicht nach und ignorierte diese gezielt. ${ }^{107}$ Nach Verhandlungen des Reiches mit dem Freistaat erging als

105 Diese Grundrechte konnte der Reichspräsident nach Art. 48 Abs. 2 S. 2 WRV zeitweise ganz oder teilweise außer Kraft setzen.

106 RGBl. 1921, I, S. 1250.

107 Ausführlich hierzu Jasper, Der Schutz der Republik, 1963, S. 43 ff. m.w.N. 
Kompromiss eine neue Verordnung ${ }^{108}$, nach deren $\ 4$ die Zuständigkeit für den Erlass von Maßnahmen nach der Erzberger-Verordnung bei den Landeszentralbehörden angesiedelt wurde. Diese Verordnung trat nach deren $₫ 10$ an die Stelle der Verordnung vom 29. August 1921. Der Einfluss des Reiches auf die Landeszentralbehörden wurde insoweit begrenzt, dass der Reichsinnenminister lediglich ein Ersuchen stellen konnte, eine bestimmte Maßnahme zu erlassen. Bei einem Dissenz zwischen dem Reichsinnenministerium und der Landeszentralbehörde sah $\$ 7$ Erz-VO einen eigens einzurichtenden Ausschuss vor, welcher um eine Entscheidung anzurufen war. Dadurch sollten die föderale Struktur des Reiches und die traditionelle Länderkompetenz des Polizeirechts gewahrt bleiben. Die Erzberger-Verordnung in ihrer zuletzt geänderten Fassung ${ }^{109}$ wurde durch die Verordnung vom 23. Dezember $1921^{110}$ aufgehoben. Bis zur Ermordung von Walther Rathenau wurde vom Erlass einer ähnlich lautenden Verordnung abgesehen.

Nach der Ermordung Walther Rathenaus trat am 24. Juni 1922 die Verordnung zum Schutz der Republik ${ }^{111}$ in Kraft, die sich ebenfalls gegen die rechte politische Strömung im Reich richtete. Der damalige Reichskanzler Joseph Wirth äußerte anlässlich der Ermordung Rathenaus die bis heute bekannten Worte: „Da steht der Feind, der sein Gift in die Wunden eines Volkes träufelt. - Da steht der Feind - und darüber ist kein Zweifel: dieser Feind steht rechts!". 112

Die sogenannte Rathenau-Verordnung wies einen ähnlichen Regelungsgehalt wie die vorangegangenen Verordnungen auf und sah erneut weitgehende Einschränkungen der Kommunikationsgrundrechte vor. Die Verordnung richtete sich nun gegen die „gesetzeswidrige Beseitigung der republikanischen Staatsform" und "Gewalttaten gegen Mitglieder der früheren oder jetzigen Regierung des Reiches oder seiner Länder“. Die Änderung der Formulierung des Schutzzweckes von der „gewaltsamen Beseitigung der Verfassung und der verfassungsmäßigen Einrichtungen des Reiches und seiner Länder“ zu der "gesetzwidrigen Beseitigung der republikanischen Staatsform" hatte zur Folge, dass ein gewaltsames Vorgehen somit nicht mehr zwingend notwendig war.

108 RGBl. 1921, I, S. 1271.

109 RGBl. 1921, I, S. 1271.

110 RGBl. 1921, I, S. 1664.

111 RGBl. 1922, I, S. 521.

112 Wirth, RT-Protokoll, 25.06.1922, S. 8058. 
Auf der Grundlage der „Rathenau-Verordnung“ konnten in konsequenter Fortführung der Regelungen der „Erzberger-Verordnung“ Versammlungen und Vereinigungen verboten, Druckschriften beschlagnahmt und damit zusammenhängende repressive Maßnahmen getroffen werden. Neu war nach $\$ 6$ Rath-VO allerdings die Errichtung eines Sondergerichtes. Als Rechtsbehelfsinstanz für Maßnahmen nach der Rathenau-Verordnung war nun der „Staatsgerichtshof zum Schutze der Republik“ allein zuständig. Dieser wies eine Ähnlichkeit zu dem durch die Erzberger-Verordnung eingesetzten Ausschuss auf und sollte sowohl als Strafgericht für Straftaten nach $₫ 5$ Rath-VO als auch für die Entscheidung über die Rechtmäßigkeit der nach der Verordnung erlassenen Maßnahmen zuständig sein. Der bayerische Widerstand gegen die Erzberger-Verordnung wirkte beim Erlass der Rathenau-Verordnung nach. Demnach wurde für die Maßnahmen der Verordnung die Zuständigkeit bei den Landeszentralbehörden angesiedelt. Der Reichsinnenminister konnte - so wie vorher auch - die Landeszentralbehörden lediglich um ein Tätigwerden ersuchen. Bei Uneinigkeiten zwischen dem Reichsinnenminister und der Landeszentralbehörde war in konsequenter Fortführung der Staatsgerichtshof zum Schutze der Republik für eine Entscheidung anzurufen, der insoweit den durch die Erzberger-Verordnung eingesetzten Ausschuss ersetzte und dessen Funktion übernahm. Anders als zuvor wurde das entscheidende Gremium nicht mehr vom Reichsrat, sondern durch den Reichspräsidenten besetzt, wodurch sich die Entscheidungsgewalt wieder etwas mehr zum Reich verlagerte. ${ }^{113}$ Am 29. Juni 1922 folgte eine weitere Verordnung ${ }^{114}$, die die Teilnahme an einer Vereinigung, deren Ziel die Ermordung von amtierenden und ehemaligen Regierungsmitgliedern war, unter Strafe stellte und die Strafbestimmungen der Rathenau-Verordnung in weiteren Teilen ergänzte.

Die Verordnungen vom 26. Juni 1922 und vom 29. Juni 1922 wurden durch Verordnung vom 23. Juli $1922^{115}$ aufgehoben. Grund war das Inkrafttreten des Gesetzes zum Schutz der Republik. ${ }^{116}$

113 Jasper, Der Schutz der Republik, 1963, S. 59.

114 RGBl. 1922, I, S. 532.

115 RGBl. 1922, I, S. 630.

116 RGBl. 1922, I, S. 585. 


\section{Das Gesetz zum Schutze der Republik}

Die Reichsregierung wollte, um den Eindruck einer Diktatur durch den Reichspräsidenten zu vermeiden, den Regelungsinhalt der Verordnungen in ein formelles Gesetz einkleiden. ${ }^{117}$ Aus diesem Grund wurde am 23. Juli 1922 das „Gesetz zum Schutze der Republik“ (RSG) erlassen. Das RSG enthielt ähnliche Regelungen wie die vorangegangenen Verordnungen. Auch der Staatsgerichtshof zum Schutze der Republik blieb erhalten und war für die Verurteilung von Straftaten nach dem RSG und der Entscheidung über die Rechtmäßigkeit von Maßnahmen nach dem RSG zuständig. ${ }^{118}$ Unverkennbaren Einfluss auf das RSG hatten die zahlreichen und teilweise erfolgreichen Attentate auf namenhafte Politiker der Weimarer Republik. So wurde nach $₫ 1$ Abs. 2 RSG allein die Beteiligung an einer Vereinigung mit lebenslanger Haft oder dem Tode bestraft, sofern die Bestrebungen der Vereinigung in der Tötung eines Mitglieds der Reichsregierung lagen, der Täter von diesen Bestrebungen Kenntnis hatte und eine Tötung begangen oder versucht worden war; dies stellte eine - auch für die damalige Zeit besonders schwere Strafe dar. ${ }^{119}$ Eine Mittäterschaft oder Teilnahme an dem Tötungsvorhaben wurde nicht vorausgesetzt.

Die $\int S 14$ Abs. 2, 7 Nr. 4 RSG sahen Vereins- und Vereinigungsverbote vor, wenn deren Zielsetzung sich auf die Untergrabung der „verfassungsmäßig festgestellten republikanischen Staatsform“ richtete. Der Vereinsbegriff war öffentlich-rechtlicher Natur und bezeichnete „einen freiwilligen, auf Dauer berechneten Zusammenschluss mehrerer Personen zur Verfolgung eines gemeinsamen Zwecks mittels Unterordnung unter eine organisierte Willensmacht“. ${ }^{120}$ Politische Parteien unterfielen nach der allgemei-

117 Graf zu Dohna, in: Anschütz/Thoma (Hrsg.), Handbuch des deutschen Staatsrechts, 1930, Bd. I, S. 200, 204; Kiesow/Zweigert, in: dies. (Hrsg.), Gesetz zum Schutze der Republik, 1923, Einleitung S. XV.

118 Am 31. März 1926 wurde durch Gesetz (Reichsgesetzblatt 1926, I, S. 190) die Zuständigkeit des Staatsgerichtshofs in Strafsachen auf die ordentlichen Gerichte übertragen. Am 2. Juni 1927 wurden die verbliebenen Zuständigkeiten auf das Reichsgericht übertragen und der Staatsgerichtshof zum Schutze der Republik ganz aufgelöst.

119 Graf zu Dohna, in: Anschütz/Thoma (Hrsg.), Handbuch des deutschen Staatsrechts, 1930, Bd. I, S. 200, 204.

120 Kiesow/Zweigert, in: dies. (Hrsg.), Gesetz zum Schutze der Republik, 1923, $\$ 14$ VI; vgl. auch die Rechtsprechung zum preußischen Vereinsgesetz RGSt 18, 169 (172); RGSt 21, 71 (73); RGSt 28, 66 (67 f.). 
nen Staatslehre dem öffentlich-rechtlichen Vereinsbegriff. ${ }^{121}$ Das RSG unterschied nicht zwischen Parteien und Vereinen, obwohl die staatsmitwirkungsbezogene Funktion der Parteien eine gesonderte Stellung zu den sonstigen Vereinen gebieten würde. Das Verbot einer Partei hatte, ähnlich wie bei der Geltung des Sozialistengesetzes, keine Auswirkung auf das Mandat der gewählten Abgeordneten und der Zusammensetzung der Fraktionen im Reichstag. ${ }^{122}$ Von der Verbotsmöglichkeit waren nach $\$ 15$ RSG Wahlversammlungen ausgenommen. Wie zur Zeit der Geltung des Sozialistengesetzes sollte auch hier der Wahlvorgang vor staatlichen Eingriffen geschützt werden. ${ }^{123}$

Schutzgut der $\mathbb{S} 4$ Abs. 2, 7 Nr. 4 RSG war die „verfassungsmäßig festgestellte republikanische Staatsform“. Der Begriff ist das Ergebnis einer langen parlamentarischen Diskussion. So war im ersten Gesetzesentwurf der Reichsregierung ${ }^{124}$ in Anlehnung an die Formulierung der Rathenau-Verordnung noch in $\$ 15$ von der "republikanischen Staatsform“ die Rede. Aus Sorge, dass das Gesetz keinen Schutz vor der Schaffung einer Räterepublik bieten würde, wurde der Wortlaut von „republikanische Staatsform“ zu „verfassungsmäßig festgestellte republikanische Staatsform“ geändert. ${ }^{125}$ Die „verfassungsmäßig festgestellte republikanische Staatsform“ wurde von Johannes Bell während der zweiten Beratung über das „Gesetz zum Schutze der Republik“ in der 247. Sitzung des Reichstags vom 10. Juli 1922 wie folgt definiert:

„Unter verfassungsmäßiger republikanischer Staatsform ist der Inbegriff derjenigen Einrichtungen der Reichsverfassung zu verstehen, in denen der republikanische Gedanke seinen Ausdruck findet. Es gehören also zur verfassungsmäßigen republikanischen Staatsform nicht nur die Programmsätze in Art. 1 Abs. 1 und in Art. 17 Abs. 1 der Reichsverfassung, sondern auch alle Verfassungsvorschriften, in denen diese Programmsätze im Einzelnen durchgeführt werden. Die republikanische Staatsform der Länder ist nach Art. 17

121 Huber, Deutsche Verfassungsgeschichte seit 1789 - Die Weimarer Reichsverfassung, Bd. VI, 1993, S. 677; Kiesow/Zweigert, in: dies. (Hrsg.), Gesetz zum Schutze der Republik, 1923, $\$ 14$ - VI; Häntzschel/Schönner, in: dies. (Hrsg.), Gesetz zum Schutze der Republik, 1930, $\mathbb{} 129$ Nr. 4.

122 Huber, Deutsche Verfassungsgeschichte seit 1789 - Die Weimarer Reichsverfassung, Bd. VI, 1993, S. 677 m.w.N.

123 Schmidt, Die Freiheit verfassungswidriger Parteien und Vereinigungen, 1983, S. 40.

124 Drucksache des Reichsrats Nr. 172.

125 Jasper, Der Schutz der Republik, 1963, S. 71; Kiesow/Zweigert, in: dies. (Hrsg.), Gesetz zum Schutze der Republik, 1923, $\$ 7$ Nr. 4 - IV Nr. 2. 
Abs. 1 der Reichsverfassung ein untrennbarer Teil der republikanischen Staatsform des Reichs. "126

Der Begriff der „verfassungsmäßig festgestellten republikanischen Staatsform" war somit weit gefasst und sollte die republikanische Staatsform als einheitliches verfassungsrechtliches Konzept, mit allen dazugehörigen Grundsätzen, schützen. Die „verfassungsmäßig festgestellte republikanische Staatsform“ beschrieb den Ideen- und Gedankenkreis, der sich in der Verfassungsurkunde rechtlich niedergeschlagen hatte. ${ }^{127}$ So ist in diesem Zusammenhang insbesondere Art. 1 Abs. 2 WRV erwähnenswert. Gerade im Bezug zur „verfassungsmäßig festgestellten Republik“ ist das in Art. 1 Abs. 2 WRV verankerte Demokratieprinzip von besonderer Bedeutung. Denn geschützt werden sollte nicht eine allgemein republikanische, sondern gerade die demokratisch-republikanische Staatsform. ${ }^{128}$

Die $\int S 14$ Abs. 2, 7 Nr. 4 RSG setzen ferner ein „Untergraben“ der „verfassungsmäßig festgestellten republikanischen Staatsform“ voraus. Mit „Untergraben“ war jede auf die Beseitigung, Änderung oder Erschütterung der verfassungsmäßigen republikanischen Staatsform gerichtete Tätigkeit gemeint. ${ }^{129}$ Diese musste nicht unbedingt einen gewaltsamen oder rechtswidrigen Charakter aufweisen. ${ }^{130}$ Damit konnte ein „Untergraben“ auch schon in einer legalen Handlung liegen, solange sie sich gegen die Abschaffung der republikanischen Staatsform richtete. Die Verwerflichkeit des Handelns und die daraus resultierende Sanktionierung ergab sich bereits aus der geheimen oder staatsfeindlichen Natur der Vereinigung. ${ }^{131}$ Seit Erlass der Erzberger-Verordnung sollte der Schutzzweck der gesetzlichen Maßnahmen mehr zu einem allgemeinen Republikschutz ausgedehnt werden und war damit nicht mehr nur auf gewaltsame Umsturzversuche beschränkt.

Für den Ausspruch eines Verbots der Vereinigungen waren nach $\$ 17$ RSG - wie bei den vorangegangenen Verordnungen - die Landeszentralbehörden zuständig. Auch hier konnte der Reichsinnenminister diese

126 Bell, RT-Protokoll, 10.07.1922, S. 8398.

127 RG, Urt. v. 23.03.1923, Rs. - IV 885/22 -., RGSt 57, 209 (211).

128 Kiesow/Zweigert, in: dies. (Hrsg.), Gesetz zum Schutze der Republik, 1923, $\mathbb{} 7$ Nr. 4 - IV Nr. 2.

129 Dies., in: dies. (Hrsg.), Gesetz zum Schutze der Republik, 1923, $\$ 7$ Nr. 4 - IV Nr. 3.

130 Dies., in: dies. (Hrsg.), Gesetz zum Schutze der Republik, 1923, $\mathbb{7}$ Nr. 4 - IV Nr. 3.

131 Vgl. die Gesetzgebungsmaterialien Bell, RT-Protokoll, 10.07.1922, S. 8398. 
um ein Tätigwerden ersuchen. Den Landeszentralbehörden wurde bei der Entscheidung über das Verbot und die Auflösung einer Partei ein Ermessen eingeräumt; es galt das Opportunitätsprinzip. ${ }^{132}$ Durch die Zuständigkeit der Landeszentralbehörden konnten Parteiverbote nur auf Landesebene ausgesprochen werden, was in Verbindung mit dem Opportunitätsprinzip zu einer uneinheitlichen Anwendung des RSG führte. ${ }^{133}$

Das auf fünf Jahre befristete RSG wurde 1927 noch einmal um zwei weitere Jahre verlängert. Als es 1929 zeitlich auslief, gelang es der Regierung nicht, eine nach Art. 76 WRV notwendige Zweidrittel-Mehrheit des Parlaments für eine Verlängerung des Gesetzes zu gewinnen. So kam es zum sogenannten „Zweiten Republikschutzgesetz"134, welches bis auf für diese Arbeit unerhebliche Veränderungen dem vorangegangen entsprach.

$\mathrm{Zu}$ den wohl namhaftesten Parteien, die von Verbotsmaßnahmen nach dem "Gesetz zum Schutze der Republik“ betroffen waren, gehörte die NSDAP. ${ }^{135}$ Obwohl der Staat die Partei bekämpfte, konnte die Machtübernahme der Nationalsozialisten nicht verhindert werden. Die Partei konnte trotz der aufgeführten Staatsschutz-Maßnahmen die republikanische Staatsform abschaffen und eine Diktatur unter Adolf Hitler etablieren. Die Weimarer Reichsverfassung und der in ihr wohnende Gedanke von Demokratie und Rechtstaatlichkeit fanden mit der Machtübergabe an Adolf Hitler ihr Ende. ${ }^{136}$ Die errungene Staatsgewalt nutzte die NSDAP, um die mit ihr konkurrierenden Parteien zu bekämpfen und den demokratischen Wettbewerb vollständig zu beseitigen. Am 28. Februar 1933 erging die „Verordnung des Reichspräsidenten zum Schutz von Volk und Staat"137, welche zunächst die KPD traf. In der Folgezeit wurden alle anderen Parteien aufgelöst oder verboten, sodass die gesamte Staatsgewalt einzig der Kontrolle der NSDAP unterlag. Durch das „Gesetz zur Behebung der Not von Volk und Reich“ (sog. Ermächtigungsgesetz) ${ }^{138}$ vom 24. März 1933

132 Huber, Deutsche Verfassungsgeschichte seit 1789 - Die Weimarer Reichsverfassung, Bd. VI, 1993, S. 681.

133 Eine Übersicht über ergangene Verbote in: Jasper, Der Schutz der Republik, 1963, S. $316 \mathrm{ff}$.

134 RGBl. 1930, I, S. 91.

135 Diese war auf Grundlage des RSG in Preußen, Sachsen, Baden, Thüringen, Hessen, Hamburg, Braunschweig, Oldenburg, Bremen, Lippe-Detmold und LippeSchaumburg verboten. Die Verbote wurden 1924 wieder aufgehoben, vgl. Jasper, Der Schutz der Republik, 1963, S. 316 ff.

136 Huber, Deutsche Verfassungsgeschichte seit 1789 - Ausbau, Schutz und Untergang der Weimarer Republik, Bd. VII, 1984, S. 1266.

137 RGBl 1933, I, S. 83.

138 RGBl. 1933, I, S. 141. 
wurde die Reichsregierung zum Erlass von Gesetzen ermächtigt. Nach dem Tod von Reichspräsidenten Paul von Hindenburg trat am 02. August 1934 das "Gesetz über das Staatsoberhaupt des Deutschen Reiches“ in Kraft, wonach das Amt des Reichskanzlers mit dem des Reichspräsidenten vereinigt wurde. In der Folgezeit wurde die Machtstellung Adolf Hitlers weiter gefestigt, sodass zwar die Weimarer Reichsverfassung formell noch in Kraft war, rein faktisch jedoch keinerlei Bedeutung mehr hatte. ${ }^{139}$ Dies führte zu einer der größten humanitären Katastrophen der Weltgeschichte.

139 Vgl. Schneider, in: Isensee/Badura/Achterberg u.a. (Hrsg.), Handbuch des Staatsrechts der Bundesrepublik Deutschland I, ${ }^{3} 2003$, $\mathbb{5}$, Rn. 85; Huber, Deutsche Verfassungsgeschichte seit 1789 - Ausbau, Schutz und Untergang der Weimarer Republik, Bd. VII, 1984, S. 1266. 


\section{$\$ 2$ Die Parteien im Verfassungsgefüge des Grundgesetzes}

\section{A. Die Parteien und ihre Funktionen im demokratischen Verfassungsstaat}

Nachdem die Parteien in der deutschen Vergangenheit erheblichen Restriktionen ausgesetzt waren, wurden sie innerhalb der Rechtsordnung des Grundgesetztes zu verfassungsrechtlichen Institutionen erhoben. ${ }^{140} \mathrm{Im}$ Vergleich zum Kaiserreich und der Weimarer Republik wurde ihre Rechtstellung entsprechend ihrer staatstragenden Funktion angepasst, was die Parteien vor einer unzulässigen staatlichen Einflussnahme schützen und somit auch den freien und gleichen Parteienwettbewerb sicherstellen soll. Dies gilt nicht nur für eine staatliche Einflussnahme durch Maßnahmen der Eingriffsverwaltung, sondern auch vor einer unzulässigen Einflussnahme oder Benachteiligung innerhalb der Leistungsverwaltung. Gerade im Hinblick auf die staatliche Parteienfinanzierung darf keine unzulässige staatliche Steuerungswirkung auf den Parteienwettbewerb ausgeübt werden. Die Ausgestaltung der Parteienfinanzierung muss sich an der Funktion und der hiermit verbundenen Rechtsstellung messen lassen.

Aus diesem Grund werden im Rahmen dieses Kapitels zunächst die verfassungsrechtliche Bedeutung und die Rechtsstellung der Parteien erläutert. Dies soll zur Verständlichkeit der verfassungsrechtlichen Probleme im Zusammenhang mit der staatlichen Parteienfinanzierung, welche im Rahmen des nächsten Kapitels untersucht werden, beitragen.

I. Verortung der Parteien im demokratischen Verfassungsstaat

Die Bundesrepublik Deutschland ist nach Art. 21 Abs. 1 i.V.m. Art. 20 Abs. 1, 2 GG eine Parteiendemokratie. ${ }^{141}$ Diese besondere Demokratieform spricht den Parteien zu, als notwendige Elemente des Verfassungssystems eine besondere Rolle im Verfassungsstaat einzunehmen. ${ }^{142}$ Durch

140 BVerfGE 1, 208 (225); BVerfGE 2, 1 (73); siehe auch BVerfGE 20, 56 (100); BVerfGE 73, 40 (85);-Vchtsprechung.

141 Vgl. BVerfGE 4, 144 (149); Sommermann, in: Huber/Voßkuhle (Hrsg.), Grundgesetz, ${ }^{7} 2018$, Art. 20, Rn. 69, 73 m.w.N.

142 Morlok, in: Dreier/Bauer (Hrsg.), Grundgesetz, ${ }^{3} 2015$, Art. 21, Rn. 19. 
Art. 21 GG wurden die Parteien im Staatsgefüge der Bundesrepublik nach der Ansicht des Bundesverfassungsgerichts zu einer verfassungsrechtlichen Institution erhoben ${ }^{143}$, sie gehören jedoch nicht $\mathrm{zu}$ den obersten Staatsorganen, sondern sind vielmehr „frei gebildete, im gesellschaftlich-politisch Raum verwurzelte Gruppen“. ${ }^{144}$ Diese Verortung der Parteien zwischen Staat und Gesellschaft nahm das Bundesverfassungsgericht auch zum Anlass, eine staatliche Pflicht zur Parteienfinanzierung abzulehnen. ${ }^{145}$

Ausgangspunkt für die genaue Bestimmung des verfassungsrechtlichen Standorts der Parteien und ihrer Funktion ist die Normierung der Parteien und ihrer Aufgaben in Art. 21 Abs. 1 GG sowie eine Betrachtung der Rolle von Parteien in der Verfassungswirklichkeit. ${ }^{146}$ Durch die eigentliche Funktion der Partei wird ihre spezifische verfassungsrechtliche Stellung vorausgesetzt. ${ }^{147}$ Den Parteien kommt durch das Zusammentreffen von gesellschaftlichen und staatlichen Wirkungsbedingungen eine verfassungsrechtliche Doppelstellung zu. ${ }^{148}$ Aus dieser verfassungsrechtlichen Doppelstellung leitet sich ihre Funktion, rechtliche Stellung und auch der konkrete Begriff der Partei ab. Diese Doppelstellung - die sich aus der staatlichen Institutionsstellung und gesellschaftlichen „Verwurzelung“ ergibt - folgt aus der „Verzahnung“ von der Willensbildung des Volkes mit der Willensbildung des Staates. ${ }^{149}$ Michael Stolleis zieht in diesem Zusammenhang einen die Funktion von Parteien gut beschreibenden bildlichen Vergleich, wonach die Parteien „mit ihren Wurzeln in der Gesellschaft gründeten, mit ihren Wipfeln aber bereits Verfassungsorgane wurden"150.

143 Vgl. BVerfGE 1, 208 (225); BVerfGE 2, 1 (73); BVerfGE 20, 56 (100); BVerfGE 73, 40 (85); BVerfGE 107, 33 (358), BVerfGE 121, 30 (54); BVerfGE 144, 20 (194) - ständige Rechtsprechung.

144 BVerfGE 20, 56 (101); vgl. auch BVerfGE 1, 208 (224); BVerfGE 3, 383 (393); BVerfGE 121, 30 (53); BVerfGE 144, 20 (231).

145 BVerfGE 20, 56 (102); BVerfGE 52, 63 (86); BVerfGE 73, 40 (86); BVerfGE 104, 287 (300); BVerfGE 111, 54 (98f.) - ständige Rechtsprechung; zurückhaltender BVerfGE 85, 264 (288).

146 Hesse in: VVDStRL 17 (1967), S. 1, 15.

147 Hesse in: VVDStRL 17 (1967), S. 1, 27.

148 Schröder, in: Merten/Papier (Hrsg.), Handbuch der Grundrechte V, 2013, $\$ 119$, Rn. 13.

149 Vgl. BVerfGE 20, 56 (98 ff.); Klein, in: Maunz/Dürig (Hrsg.), Grundgesetz, 2018, Art. 21, Rn. 153 m.w.N.

150 Stolleis, in: VVDStRL 44 (1986), S. 8, 11. 


\section{Die Aufgabe und Funktion von Parteien}

Als Gebilde zwischen Staat und Gesellschaft nehmen die Parteien eine Art „Brückenfunktion“ wahr. Ihre Funktion liegt darin, das gesamte Volk als Handlungseinheit zusammenzufassen, hierdurch die Ausgestaltung der Staatsgewalt durch das Volk nach Art. 20 Abs. 2 S. 1 und S. 2 GG erst zu ermöglichen und dadurch konkret an der politischen Willensbildung des Volkes mitzuwirken. ${ }^{151}$ Näher sind die Aufgaben der Parteien in $\mathbb{1} 1$ Abs. 2 PartG festgesetzt. So obliegt es den Parteien unter anderem, die von ihnen erarbeiteten politischen Ziele in den Prozess der staatlichen Willensbildung einzuführen und für eine ständige lebendige Verbindung zwischen dem Volk und den Staatsorganen zu sorgen. Interessen und Auffassungen in der Bevölkerung sollen durch die Parteien zu politischen Zielen kanalisiert und dadurch in die staatlichen entscheidungstragenden Gremien eingebracht werden. ${ }^{152}$ Diese Aufgabe erfüllen die Parteien vornehmlich durch die Teilnahme an Wahlen. ${ }^{153}$ Ihrer durch das Grundgesetz zugewiesenen Funktion können die Parteien nur dann gerecht werden, wenn ihnen eine besondere Rechtstellung zuteil wird, die die effiziente Erfüllung ihrer Aufgaben verfassungsrechtlich gewährleistet. Die Funktion der Parteien im Verfassungsleben setzt dadurch eine gewisse verfassungsrechtliche Stellung voraus. ${ }^{154}$

\section{B. Allgemeine Rechtsstellung von Parteien}

Durch ihre besondere Funktion innerhalb der Parteiendemokratie setzt das Grundgesetz eine gewisse parteiliche Rechtsstellung voraus, die gewährleistet, dass die Parteien ihre verfassungsspezifische Funktion unbeeinträchtigt erfüllen können. ${ }^{155}$ In diesem Sinne wegweisend war die Statuslehre von Konrad Hesse, der aus der Aufgabe bzw. Funktion der Parteien

151 BVerfGE 85, 264 (284f.); BVerfGE 91, 262 (267 f.); vgl. auch BVerfGE 20, 56 (10 0 f.); BVerfGE 44, 125 (139f.); BVerfGE 73, 40 (85); Klein, in: Maunz/Dürig (Hrsg.), Grundgesetz, 2018, Art. 21, Rn. 216.

152 Vgl. Morlok, in: Dreier/Bauer (Hrsg.), Grundgesetz, ${ }^{3} 2015$, Art. 21, Rn. 21.

153 Vgl. Streinz, in: Huber/Voßkuhle (Hrsg.), Grundgesetz, ${ }^{7} 2018$, Art. 21, Rn. 13 ff.; Ipsen, in: Sachs (Hrsg.), Grundgesetz, ${ }^{8} 2018$, Art. 21, Rn. 23; Klein, in: Maunz/ Dürig (Hrsg.), Grundgesetz, 2018, Art. 21, Rn. 231.

154 Hesse in: VVDStRL 17 (1967), S. 1, 27.

155 Ders. in: VVDStRL 17 (1967), S. 1, 27; siehe auch Klein, in: Maunz/Dürig (Hrsg.), Grundgesetz, 2018, Art. 21, Rn. 248. 
drei Status ableitete, die insgesamt in der verfassungsrechtlichen Rechtsstellung der Parteien enthalten sind; nämlich den Status der Freiheit, den Status der Gleichheit und den der Öffentlichkeit. ${ }^{156}$ Die Aufteilung der verfassungsrechtlichen Rechtsstellung bedeutet keineswegs, dass diese drei Status unabhängige „Teile“ der Rechtsstellung sind. Vielmehr befinden sie sich in einem unauflösbaren Zusammenhang. ${ }^{157}$

Die staatliche Parteienfinanzierung und deren gesetzgeberische Ausund Umgestaltung wirkt sich auf alle drei verfassungsrechtliche Status der Parteien in unterschiedlicher Art und Weise aus. ${ }^{158}$ Der Maßstab, an dem sich der Ausschluss aus der Parteienfinanzierung letztendlich messen lassen muss, ergibt sich also aus der Rechtsstellung der Parteien. Damit eine Untersuchung der Frage, ob ein Ausschluss von der staatlichen Parteienfinanzierung verfassungsrechtlich zulässig ist, durchgeführt werden kann, muss daher zunächst kurz auf die drei Status im Allgemeinen - losgelöst von der staatlichen Parteienfinanzierung - eingegangen werden.

\section{Der Freiheitsstatus}

Der Status der Parteienfreiheit kann allgemein als „Bündel derjenigen Rechte, die das Grundgesetz den Parteien einräumt“, bezeichnet werden. ${ }^{159}$ Auszugehen ist zunächst von dem anfänglich simplen und in Art. 21 Abs. 1 S. 2 GG wörtlich zum Ausdruck kommenden Gedanken, dass zunächst die Parteiengründung frei sein muss, denn wie sonst sollten Parteien ihre verfassungsrechtliche Funktion wahrnehmen können, wenn ihre eigentliche Gründung und der damit einhergehende Beginn ihrer Existenz nicht gewährleistet werden würde. ${ }^{160}$ Der Status der Parteienfreiheit resultiert an sich nicht allein aus Art. 21 Abs. 1 S. 2 GG. Wie oben bereits ausgeführt, handelt es sich bei der „Parteienfreiheit“ um eine Bezeichnung aller Rechte, die durch das Grundgesetz den Parteien zugewiesen wurden. Art. 21 Abs. 1 S. 2 GG ist auch nach zutreffender Ansicht kein Grundrecht, wie die systematische Einordnung der Norm unter „Bund und Länder" und die fehlende Erwähnung in Art. 93 Abs. 1 Nr. 4a GG

156 Hesse in: VVDStRL 17 (1967), S. 1, 27.

157 Klein, in: Maunz/Dürig (Hrsg.), Grundgesetz, 2018, Art. 21, Rn. 252.

158 Steinberger, in: Bitburger Gespräche, 1993, Bd. 2, S. 25, 27.

159 Klein, in: Maunz/Dürig (Hrsg.), Grundgesetz, 2018, Art. 21, Rn. 262.

160 Vgl. Shirvani, AöR 134 (2009), 572 (577). 
zeigt $^{161}$, sondern weist den Rechtscharakter einer objektiv-rechtlichen Institutions- oder auch „Einrichtungsgarantie“ 162 auf, die zur Sicherstellung ihrer Funktion mit einem „subjektiv-rechtlichen Element“ angereichert ist. ${ }^{163}$ Die Parteienfreiheit wird geschützt „durch die einschlägigen Grundrechte in der von Art. 21 GG bewirkten besonderen Ausprägung“. ${ }^{164}$ Die Wahl der Organisationsform, sowie die Gründung, Auflösung oder Fusion der Parteien fallen unter den Schutzbereich von Art. 9 Abs. 1 GG, der in diesem Zusammenhang durch Art. 21 Abs. 1 S. 2 GG inhaltlich geprägt wird. ${ }^{165} \mathrm{Im}$ Übrigen ist, so wie das Bundesverfassungsgericht feststellte, für den Parteibereich Art. 21 Abs. 1 GG die maßgebliche Verfassungsnorm ${ }^{166}$, weshalb Art. 21 Abs. 2 GG auch gegenüber Art. 9 Abs. 2 GG vorrangig ist. ${ }^{167}$ Gemeint ist damit der verfassungsrechtliche Wirkbereich des Art. 21 GG gegenüber Art.9 GG, denn die Feststellung des Bundesverfassungsgerichts wurde im sachlichen Zusammenhang mit der Verbotsmöglichkeit des Art. 21 Abs. 2 GG getroffen; die weitergehende Deutung, der Art. 21 GG wäre lex specialis im Verhältnis zu Art. 9 GG, kann daraus nicht folgen. ${ }^{168}$

Neben der Gründungsfreiheit von Parteien muss auch die parteispezifische Betätigung als subjektives Recht verfassungsrechtlich gewährleistet werden. Der Betätigungsschutz von Parteien ist, so wie die Gründungsfreiheit auch, eine Absicherung der Funktionalität des Parteiwesens und dient wieder als „Sammelbegriff“ aller Recht, die einer Partei zur effektiven Erfüllung ihrer verfassungsrechtlichen Aufgabe zustehen müssen. ${ }^{169}$ Die Betätigungsfreiheit folgt nicht allein aus Art. 21 Abs. 1 S. 2 GG, sondern setzt

161 Morlok, in: Dreier/Bauer (Hrsg.), Grundgesetz, ${ }^{3} 2015$, Art. 21, Rn. 49; Klein, in: Maunz/Dürig (Hrsg.), Grundgesetz, 2018, Art. 21, Rn. 256; Streinz, in: Huber/ Voßkuhle (Hrsg.), Grundgesetz, ${ }^{72018}$, Art. 21, Rn. 99; Hettich, Die Zulässigkeit verschiedener Handlungsalternativen des Staates im Vorgehen gegen extremistische Parteien unter Berücksichtigung des Parteienprivilegs, 2015, S. 64; Mauersberger, Die Freiheit der Parteien, 1994, S. 30; a.A. Seifert, Die politischen Parteien im Recht der Bundesrepublik Deutschland, 1975, S. 111; Ipsen, in: Sachs (Hrsg.), Grundgesetz, ${ }^{8}$ 2018, Art. 21, Rn. 29; Wietschel, Der Parteibegriff, 1996, S. 196; Tsatsos/Morlok, Parteienrecht, 1982, S. 75.

162 Mauersberger, Die Freiheit der Parteien, 1994, S. 30, $70 \mathrm{ff}$.

163 Morlok, in: Dreier/Bauer (Hrsg.), Grundgesetz, ${ }^{3} 2015$, Art. 21, Rn. 50.

164 Ders., in: Dreier/Bauer (Hrsg.), Grundgesetz, ${ }^{3} 2015$, Art. 21, Rn. 55.

165 Ders., in: Dreier/Bauer (Hrsg.), Grundgesetz, ${ }^{3} 2015$, Art. 21, Rn. 55.

166 BVerfGE 25, 69 (77).

167 BVerfGE 2, 1 (13); BVerfGE 12, 296 (304); BVerfGE 13, 174 (177); BVerfGE 17, 155 (166).

168 Klein, in: Maunz/Dürig (Hrsg.), Grundgesetz, 2018, Art. 21, Rn. 257.

169 Ders., in: Maunz/Dürig (Hrsg.), Grundgesetz, 2018, Art. 21, Rn. 280. 
sich aus der Gesamtheit aller Grundrechte zusammen, deren Schutzbereich durch die konkrete parteispezifische Betätigung eröffnet ist. ${ }^{170}$ Dafür spricht, dass bei einer extensiven Auslegung des Art. 21 Abs. 1 S. 2 GG als allumfassendes Sonderrecht und der alleinigen Verortung der Betätigungsfreiheit der Parteien eine Bestimmung der Schranken äußerst problematisch wäre, da Art. 21 Abs. 1 S. 3 und S. 4 GG als Schranken für sämtliche parteispezifischen Tätigkeiten, wie zum Beispiel dem Plakatieren, Wahlwerbespots oder andere wahlkampfbezogene Werbung, nicht tauglich sind. ${ }^{171}$ Auch hier werden die speziellen Grundrechte, deren Schutzbereich eine konkrete parteibezogene Betätigung umfasst, durch Art. 21 Abs. 1 S. 2 GG in gewichtiger Weise inhaltlich aufgeladen; die Norm modifiziert den Schutzbereich und die Schranken des jeweils einschlägigen Grundrechts. ${ }^{172}$

Aus dem Status der Parteienfreiheit leiten sich nicht nur eine objektive Institutsgarantie sowie subjektive Rechte der Parteien ab, sondern auch ein objektiv-rechtliches Verbot jeder „staatlich-institutionellen Verfestigung der Parteien“173. Insbesondere dürfen demnach Parteien „kein Bestandteil der organisierten Staatlichkeit werden“. Das Bundesverfassungsgericht hat dieses Verbot, den Ausführungen Konrad Hesses folgend ${ }^{174}$, in seinem zweiten Urteil zu der verfassungsrechtlichen Zulässigkeit der staatlichen Parteienfinanzierung anerkannt. ${ }^{175}$ Parteien seien demnach freie, gesellschaftliche Gebilde, die aufgrund ihrer bedeutsamen Funktion für die im Grundgesetz verankerte Parteiendemokratie nicht in die staatliche Organisationsstruktur eingefügt werden und auch nicht von einer "staatlichen Vorsorge“ abhängig gemacht werden dürfen. Die Mitwirkung an einer freien politischen Willensbildung und das Einfügen in die organisierte Staatlichkeit sind miteinander nicht zu vereinbaren. ${ }^{176}$

170 Schmidt, Die Freiheit verfassungswidriger Parteien und Vereinigungen, 1983, S. $107 \mathrm{ff}$.

171 Überzeugend ders., Die Freiheit verfassungswidriger Parteien und Vereinigungen, 1983, S. $108 \mathrm{f}$.

172 Pieroth, in: Jarass/Pieroth (Hrsg.), Grundgesetz für die Bundesrepublik Deutschland, ${ }^{14}$ 2016, Art. 21, Rn. 15; Morlok, in: Dreier/Bauer (Hrsg.), Grundgesetz, ${ }^{3}$ 2015, Art. 21, Rn. 50; wohl auch Bethge, ZUM 2003, 253 (260).

173 Hesse in: VVDStRL 17 (1967), S. 1, 33; BVerfGE 20, 56 (101 f.).

174 Ders. in: VVDStRL 17 (1967), S. 1, 33.

175 BVerfGE 20, 56 (102).

176 Hesse in: VVDStRL 17 (1967), S. 1, 34. 


\section{Der Gleichheitsstatus}

Die Freiheit der Parteien und die Gleichheit der Parteien bedingen sich gegenseitig. ${ }^{177}$ Aus der Freiheit, auf die politische Willensbildung des Volkes Einfluss zu nehmen, folgt gleichzeitig auch die Gleichheit im Wettbewerb. Der freie Wettbewerb, den die Parteien innerhalb der ihnen zustehenden Parteienfreiheit ausgestalten, kann jedoch nur dann gewährleistet werden, wenn allen Parteien dieselbe Möglichkeit eingeräumt wird, Einfluss auf die politische Willensbildung des Volkes zu nehmen. ${ }^{178}$ Die Parteien müssen, die Gefahr des „Abrutschens“ in die Bedeutungslosigkeit stets gegenwärtig, um den Zuspruch der Bürger streiten und auf Unterstützung ihrer politischen Inhalte hoffen. Die subjektiven Gleichheitsrechte der Parteien führen zu einem objektiven Institut des politischen Wettbewerbs. Eine Verzerrung des Wettbewerbs durch Ungleichbehandlungen führt gleichzeitig zu einer Beeinträchtigung des subjektiven Gleichheitsrechtes einer Partei und muss deshalb zur Wahrung der demokratischen Staatsordnung in der Regel untersagt sein. Insoweit ist von einer wettbewerbsbezogenen Chancengleichheit der Parteien zu sprechen. ${ }^{179}$

\section{Dogmatische Herleitung}

Die dogmatische Herleitung der Chancengleichheit ist umstritten und wird auch vom Bundesverfassungsgericht nicht konsequent beibehalten. In der Rechtsprechung des Bundesverfassungsgerichts wird die Chancengleichheit der Parteien sowohl aus Art. 21 Abs. 1 S. 2 GG $^{180}$ als auch aus Art. 3 Abs. 1 i.V.m. Art. 21 Abs. 1 GG $^{181}$ hergeleitet, wobei das Bundesverfassungsgericht auch einen engen Zusammenhang zu dem Grundsatz der

177 Klein, in: Maunz/Dürig (Hrsg.), Grundgesetz, 2018, Art. 21, Rn. 296.

178 Kersten, in: Kersten/Rixen/Augsberg (Hrsg.), Parteiengesetz (PartG) und europäisches Parteienrecht, 2009, $\mathbb{1}$ 1, Rn. 62; siehe auch Morlok, NVwZ 2005, 157 (157f.).

179 Siehe dazu u.A. BVerfGE 1, 208 (242); BVerfGE 20, 56 (118); Augsberg, in: Kersten/Rixen/Augsberg (Hrsg.), Parteiengesetz (PartG) und europäisches Parteienrecht, 2009, $\mathbb{5}$ 5, Rn. 5; Morlok, in: Dreier/Bauer (Hrsg.), Grundgesetz, ${ }^{3} 2015$, Art. 21, Rn. 78; Seifert, Die politischen Parteien im Recht der Bundesrepublik Deutschland, 1975, S. 131; Tsatsos/Morlok, Parteienrecht, S. 86; Morlok/Jürgensen, JZ 2018, 695 (698 f.).

180 BVerfGE 1, 208 (255); BVerfGE 6, 273 (280); BVerfGE 47, 198 (225); BVerfGE 52, 63 (88); BVerfGE 73, 1 (19).

181 BVerfGE 111, 54 (106). 
Allgemeinheit und der Gleichheit der Wahl in Art. 38 Abs. 1 S. 1 GG herstellt, sofern im Einzelfall ein konkreter Wahlbezug (wie beispielsweise bei der Wahlkampfkostenpauschale) besteht. ${ }^{182}$

Der Status der Chancengleichheit kann nicht nur in einer bestimmten Norm oder Normverbindung verortet werden. Vielmehr umfasst die Chancengleichheit der Parteien auf der einen Seite eine objektive Institutsgarantie, die den freien Wettbewerb der Parteien verfassungsrechtlich gewährleistet, indem sie einen objektiv-rechtlichen, vor staatlicher Einflussnahme geschützten Bereich des freien und gleichen Parteienwettbewerbs schafft und auf der anderen Seite einen subjektiven Rechtsanspruch auf Wahrung der Chancengleichheit, die zum Zwecke der Durchsetzbarkeit der Chancengleichheit den einzelnen Parteien eingeräumt wird und deren Schutz diese auch prozessual geltend machen können müssen. ${ }^{183}$

Die objektiv-rechtliche Institution des freien und gleichen Parteienwettbewerbs ist richtigerweise in Art. 21 Abs. 1 S. 1 und S. 2 GG i.V.m. dem in Art. 20 Abs. 1, Abs. 2 und Art. 28 Abs. 1 S. 1 GG verfassungsrechtlich verankertem Demokratieprinzip zu verorten. ${ }^{184}$ In einer Mehrparteiendemokratie muss die Willensbildung des Volkes frei sein, um die sich durch Wahlen zusammensetzenden Staatsorganen zu legitimieren; um also eine funktionierende Demokratie zu gewährleisten. Die Parteien, deren Aufgabe die Kanalisierung der politischen Meinungen und Interessen des Volkes ist, müssen deshalb alle grundlegend dieselbe Möglichkeit der Mitwirkung an der politischen Willensbildung des Volkes erhalten. Ohne den von staatlichen Einflüssen weitestgehend befreiten politischen Wettbewerb kann sich keine offene und freie und vom Grundgesetz vorgesehene Willensbildung des Volkes zu den Staatsorganen vollziehen. Aus diesem Grund spricht Art. 21 Abs. 1 S. 1 GG auch von Parteien im Plural und sieht in

182 BVerfGE 24, 300 (340); BVerfGE 111, 382 (398).

183 Ähnlich Tsatsos/Morlok, Parteienrecht, 1982, S. 89; Seifert, Die politischen Parteien im Recht der Bundesrepublik Deutschland, 1975, S. 132; Morlok, in: Dreier/ Bauer (Hrsg.), Grundgesetz, ${ }^{32015}$, Art. 21, Rn. 81; wohl auch Hettich, Die Zulässigkeit verschiedener Handlungsalternativen des Staates im Vorgehen gegen extremistische Parteien unter Berücksichtigung des Parteienprivilegs, 2015, S. 68.

184 Tsatsos/Morlok, Parteienrecht, 1982, S. 88; Kunig, in: Arnauld (Hrsg.), Grundgesetz-Kommentar, 2012, Art. 21, Rn. 33, 34; Morlok, in: Dreier/Bauer (Hrsg.), Grundgesetz, ${ }^{3} 2015$, Art. 21, Rn. 78; siehe auch Ipsen, in: Sachs (Hrsg.), Grundgesetz, ${ }^{8} 2018$, Art. 21, Rn. 33; Lipphardt, Die Gleichheit der politischen Parteien vor der öffentlichen Gewalt, 1975, S. 690 ff.; Volkmann, Politische Parteien und öffentliche Leistungen, 1993, S. 151 ff.; Kißlinger, Das Recht auf politische Chancengleichheit, 1998, S. 17 ff., $27 \mathrm{ff}$. 
Art. 21 Abs. 1 S. 2 GG eine freie Gründung derselben vor. ${ }^{185}$ Der freie Wettbewerb unter den Parteien wird durch die von der Verfassung gewählten Form der Parteiendemokratie vorausgesetzt. Die subjektive Rechtsposition der Parteien auf Wahrung der Chancengleichheit im Wettbewerb ergibt sich aus Art. 3 Abs. 1 GG und dem Demokratieprinzip aus Art. 20 Abs. 1 und Abs. 2, 28 Abs. 1 i.V.m. Art. 21 Abs. 1 S. 1 und S. 2 GG. ${ }^{186}$

\section{Die Wettbewerbsbezogenheit der Gleichheitsgarantie}

Durch den engen und gewichtigen Zusammenhang der Chancengleichheit der Parteien mit der Mehrparteiendemokratie ist der Gleichheitssatz streng und formal. ${ }^{187}$ Ungleichbehandlungen von Parteien, unabhängig von ihrer politischen Gesinnung und ihrem Programm, können nur unter sehr hohen Anforderungen gerechtfertigt werden. ${ }^{188}$ Das Bundesverfassungsgericht verwendet den Begriff der „zwingenden Gründe“ oder ähnlich lautende Synonyme, um die Anforderungen an die Rechtfertigung einer parteienbezogenen Ungleichbehandlung zu umschreiben. ${ }^{189}$

Trotz weitgehender Einigkeit über die Existenz der Parteiengleichheit als objektives wie subjektives Rechtgut ist dessen konkreter Inhalt umstritten. Während Stimmen der Literatur aus dem Gleichheitsgrundsatz ein „Gebot der staatlichen Nichtidentifikation“ herleiten ${ }^{190}$ bzw. dem Gleich-

185 Volkmann, Politische Parteien und öffentliche Leistungen, 1993, S. 156; Seifert, Die politischen Parteien im Recht der Bundesrepublik Deutschland, 1975, S. $107 \mathrm{ff}$.

186 Morlok, in: Dreier/Bauer (Hrsg.), Grundgesetz, ${ }^{3} 2015$, Art. 21, Rn. 78; wohl auch Klein, in: Maunz/Dürig (Hrsg.), Grundgesetz, 2018, Art. 21, Rn. 304.

187 BVerfGE 8, 51 (68); BVerfGE 14, 121 (132); BVerfGE 20, 56 (116) - ständige Rechtsprechung; in der Literatur Arnim, DÖV 1984, 85 ff.; Lipphardt, Die Gleichheit der politischen Parteien vor der öffentlichen Gewalt, 1975, S. 694 f.; Kißlinger, Das Recht auf politische Chancengleichheit, 1998, S. $80 \mathrm{ff}$.

188 Statt aller Morlok, in: Dreier/Bauer (Hrsg.), Grundgesetz, ${ }^{32} 2015$, Art. 21, Rn. 82 m.w.N.

189 BVerfGE 20, 56 (117); BVerfGE 24, 300 (339ff.); BVerfGE 111, 382 (398); siehe auch BVerfGE 6, 273 (280) - „verfassungsrechtliche Gründe“ oder BVerfGE 12, 10 (28) - „besondere Gründe“.

190 So Volkmann, in: Friauf/Höfling (Hrsg.), Berliner Kommentar zum Grundgesetz, 2000, Art. 21, Rn. 60. 
heitsgrundsatz ein absolutes Verständis zugrundelegen ${ }^{191}$, stellt das Bundesverfassungsgericht auf eine wettbewerbsbezogene Sichtweise ${ }^{192}$ ab. Hierzu im Einzelnen:

\section{a) Ansatz des Bundesverfassungsgerichtes}

Das Bundesverfassungsgericht stützt seine Rechtsprechung auf der Erwägung, dass der Staat aufgrund des Neutralitätsgebotes die vorgefundene Wettbewerbslage grundsätzlich nicht verfälschen darf. ${ }^{193}$ Der politische Wettbewerb sorge für ein unausgeglichenes Kräfteverhältnis und auch für ein verschiedenartiges politisches Gewicht unter den Parteien. Der Staat dürfe durch den freien politischen Wettbewerb hervorgerufene Ungleichheiten nicht in der Art ausgleichen, dass er allen Parteien die gleichen finanziellen Mittel gewährt. ${ }^{194}$ Die politische Ungleichheit zwischen den Parteien sei somit gerade durch den gesellschaftlich-politischen Wettbewerb geprägt und ist dadurch dessen fester Bestandteil. Sollte sich der Staat demnach beispielsweise für die Teilfinanzierung von Parteien entscheiden, so müsse das dafür vorgesehene Verfahren bei der konkreten Verteilung der Mittel die faktischen Ungleichheiten der Parteien und die vorgefundene Wettbewerbslage insoweit als normatives Leitbild berücksichtigen. ${ }^{195}$

Welche gesellschaftliche Bedeutung einer Partei zukommt, ist nur schwer bestimmbar. Im Hinblick auf die staatliche Parteienfinanzierung hat das Bundesverfassungsgericht den Wahlerfolg in Form des für eine Parteiliste abgegebenen Stimmanteils und den Betrag, den eine Partei als $\mathrm{Zu}-$ wendungen aus dem gesellschaftlichen Bereich erlangt, als zulässige Deter-

191 Volkmann, in: Friauf/Höfling (Hrsg.), Berliner Kommentar zum Grundgesetz, 2000, Art. 21, Rn. 60; Seifert, Die politischen Parteien im Recht der Bundesrepublik Deutschland, 1975, S. 308 ff.; Lipphardt, Die Gleichheit der politischen Parteien vor der öffentlichen Gewalt, 1975, S. 633 ff.; Volkmann, KJ 1995, 203 (206f.).

192 BVerfGE 20, 56 (118); BVerfGE 41, 399 (414); BVerfGE 52, 63 (89); BVerfGE 69, 92 (109); BVerfGE 73, 40 (89); BVerfGE 85, 264 (297); BVerfGE 104, 287 (300) ständige Rechtsprechung.

193 BVerfGE 20, 56 (118); BVerfGE 41, 399 (414); BVerfGE 52, 63 (89); BVerfGE 69, 92 (109); BVerfGE 73, 40 (89); BVerfGE 85, 264 (297); BVerfGE 104, 287 (300) ständige Rechtsprechung.

194 BVerfGE 20, 56 (118); vgl. auch BVerfGE 14, 121 (134ff.); ebenfalls vertretend Koch, in: Ipsen (Hrsg.), Parteiengesetz, 2008, $\$ 18$, Rn. 55.

195 Vgl. insoweit zum Begriff des „normativen Leitbildes“ Morlok/Jürgensen, JZ 2018, 695 (698). 
minanten für die Feststellung der gesellschaftlichen Bedeutsamkeit erachtet. ${ }^{196}$

b) Ansatz in der Literatur

Maßgeblicher dogmatischer Ansatz ist hier, wie auch in der Rechtsprechung des Bundesverfassungsgerichtes, das Neutralitätsgebot des Staates. Demnach sei es dem Staat untersagt, bei der Gewährung von Vorteilen zwischen den Parteien in irgendeiner Weise zu differenzieren; er sei vielmehr gehalten, die Leistungen sowohl in Qualität als auch Quantität allen Parteien in gleicher Weise zukommen zu lassen. So sehen Stimmen in der Literatur beispielsweise ausschließlich eine absolut gleiche staatliche Teilfinanzierung als mit dem Neutralitätsgebot vereinbar an. ${ }^{197}$

Uwe Volkmann versteht das Neutralitätsgebot als staatliches Gebot der „Nichtidentifikation“. ${ }^{198}$ Es solle gerade Parteien vor einer staatlichen Beurteilung ihrer gesellschaftlichen Stellung und hieran anknüpfender rechtlicher wie wirtschaftlicher Folgen schützen. ${ }^{199}$ Zwingende Folge dieser Überlegung sei die Schaffung und Aufrechterhaltung eines offenen politischen Prozesses, der eine regelmäßige Neuverteilung der politischen Kräfteverhältnisse ohne größere Hürden ermögliche. Eine ähnliche Auffassung wird von Karl-Heinz Seifert und Hanns-Rudolf Lipphardt vertreten, die in der Verschärfung der wettbewerbsbedingten Ungleichheit eine Versteinerung des Parteiwesens sehen und damit im Ergebnis auch die staatliche Wettbewerbsneutralität als ein Gebot der Aufrechterhaltung eines offenen politischen Prozesses anerkennen. ${ }^{200}$

Der Staat würde mit der Proporzverteilung der staatlichen Mittel die durch den politischen Wettbewerb faktisch geschaffene Ungleichheit ver-

196 BVerfGE 20, 56 (118 f.); BVerfGE 24, 300 (344 ff.).

197 Volkmann, in: Friauf/Höfling (Hrsg.), Berliner Kommentar zum Grundgesetz, 2000, Art. 21, Rn. 60; Seifert, Die politischen Parteien im Recht der Bundesrepublik Deutschland, 1975, S. 308 ff.; Lipphardt, Die Gleichheit der politischen Parteien vor der öffentlichen Gewalt, 1975, S. 633 ff.; Volkmann, KJ 1995, 203 (206f.).

198 Volkmann, in: Friauf/Höfling (Hrsg.), Berliner Kommentar zum Grundgesetz, 2000, Art. 21, Rn. 60.

199 Ders., in: Friauf/Höfling (Hrsg.), Berliner Kommentar zum Grundgesetz, 2000, Art. 21, Rn. 60.

200 Seifert, Die politischen Parteien im Recht der Bundesrepublik Deutschland, 1975, S. 308 ff.; Lipphardt, Die Gleichheit der politischen Parteien vor der öffentlichen Gewalt, 1975, S. $641 \mathrm{ff}$. 
schärfen und so seine Neutralitätspflicht gegenüber den Parteien verletzen. ${ }^{201}$

c) Stellungnahme

Die Ansicht des Bundesverfassungsgerichts überzeugt. ${ }^{202}$ Ausgangspunkt muss der freie politische Wettbewerb sein, indem die streitenden Parteien um Vertrauen und Rückhalt in der Bevölkerung werben. Die unverfälschte und vom Staat vorgefundene Wettbewerbslage gibt ihm insoweit ein normatives Leitbild ${ }^{203}$ vor, dass zur Bewertung staatlicher Ungleichbehandlungen im Parteienwesen als Maßstab heranzuziehen ist. Der Status der Chancengleichheit gewährleistet einen freien politischen Wettbewerb ${ }^{204}$, der bereits aufgrund seiner Natur zu Ungleichheiten zwischen den Parteien führt. ${ }^{205}$ Die gesellschaftlichen Kräfteverhältnisse und zeitbezogenen Wettbewerbsphasen führen zu einer divergierenden Größe der Anhängerschaft, Mitgliederzahl und finanziellen Kräfteverhältnisse. Dies ist auch grundsätzlich hinzunehmen, denn es liegt im Wesen eines freien Wettbewerbs, dass dessen Teilnehmer ihre Vorteile nutzen, um sich gegenüber ihrer Konkurrenz durchzusetzen und ihre Erfolgschancen positiv, auch zulasten ihrer Kontrahenten, zu beeinflussen. Die Wettbewerbsbezogenheit der Chancengleichheit garantiert insoweit ausschließlich eine „Startgleichheit“206 im politischen Wettbewerb und keine Gleichheit „am Ziel“207. Der Staat ist gegenüber den Parteien und ihren Anhängern zur Neutralität ver-

201 Seifert, Die politischen Parteien im Recht der Bundesrepublik Deutschland, 1975, S. 309, der auf die Widersprüchlichkeit der Rechtsprechung des Bundesverfassungsgerichts (BVerfGE 8, 67) hinweist und in der Proporzverteilung der staatlichen Mittel eine Verschärfung der faktischen Ungleichheit sieht.

202 BVerfGE 20, 56 (118); BVerfGE 41, 399 (414); BVerfGE 52, 63 (89); BVerfGE 69, 92 (109); BVerfGE 73, 40 (89); BVerfGE 85, 264 (297); BVerfGE 104, 287 (300) ständige Rechtsprechung.

203 Siehe zum Begriff Morlok/Jürgensen, JZ 2018, 695 (698).

204 Morlok/Jürgensen, JZ 2018, 695 (698).

205 Siehe Morlok/Jürgensen, JZ 2018, 695 (698), die insoweit von einem durch das Bundesverfassungsgericht etablierten „normativen Leitbild der vorgefundenen Wettbewerbslage" sprechen.

206 Schoch, DVBI 1988, 863 (880); Schwerdtner, DÖV 1990, 14 (16); Kißlinger, Das Recht auf politische Chancengleichheit, 1998, S. $14 \mathrm{ff}$.

207 Westerwelle, Das Parteienrecht und die politischen Jugendorganisationen, 1994, S. 64. 
pflichtet und darf die vorgefundene Wettbewerbslage nicht verfälschen. ${ }^{208}$ Der Wettbewerb muss grundsätzlich frei von staatlicher Einflussnahme sein; eine Steuerungswirkung staatlicher Maßnahmen ist durch das Grundgesetz grundsätzlich untersagt. Sollte sich der Staat dennoch dafür entscheiden, den Parteien für ihre Bemühungen bestimmte Vorteile (welcher Art auch immer) zukommen zu lassen, so darf der durch den freien Wettbewerb bedingte status quo der politischen Kräfteverhältnisse grundsätzlich in seiner weiteren Entwicklung nicht durch die öffentliche Hand beeinflusst werden. Dass der Staat bestehende Unterschiede nicht ausgleichen oder verschärfen darf, ist zwingende Folge des politischen Neutralitätsgebotes. ${ }^{209}$

Der Staat ist ohne das Vorliegen eines zwingenden Grundes lediglich gehindert, die bereits bestehenden wettbewerbsbedingten Ungleichheiten weiter zu verschärfen. ${ }^{210}$ Austragungsort politischer Machtkämpfe ist die Gesellschaft. Die nach den Regeln des freien Wettbewerbs entstehenden Ungleichheiten sind damit nicht als verbesserungswürdiger Umstand, sondern als gesunde und natürliche Entwicklung gesellschaftspolitisch ausgetragener Konkurrenzen zu verstehen. Insbesondere dürfen gesellschaftlich wurzelnde Ungleichheiten nicht zum Anlass staatlichen Handelns erhoben werden.

\section{III. Öffentlichkeitsstatus}

Die Parteien sind, um einer ungewollten privaten Einflussnahme vorzubeugen, nach Art. 21 Abs. 1 S. 4 GG dazu verpflichtet, über die Herkunft und Verwendung ihrer Mittel sowie über ihr Vermögen öffentlich Rechenschaft abzulegen. Diese Pflicht wird in den $\$ \$ 23 \mathrm{ff}$. PartG näher gesetzlich konkretisiert. Diese und andere Pflichten fallen unter den Status der Öffentlichkeit der Parteien.

Durch die besondere Rechtstellung der Parteien wird ihnen zugleich eine verfassungsrechtlich verankerte Macht zugewiesen. Die Parteien nehmen an den demokratischen Legitimitätsprinzipien teil und gestalten im Rahmen ihrer Funktion die höchsten staatlichen Organe mit. Die Len-

208 BVerfGE 8, 51 (67); BVerfGE 20, 56 (118); in der Literatur siehe u.A. Kißlinger, Das Recht auf politische Chancengleichheit, 1998, 16 f.; Morlok, DVBl 2017, 995 (998); Morlok/Jürgensen, JZ 2018, 695 (698f.).

209 BVerfGE 8, 51 (67); BVerfGE 14, 121 (134); BVerfGE 20, 56 (118).

210 BVerfGE 8, 51 (66f.). 
kungs- und Kontrollfunktion des Volkes in einer Demokratie verlangt eine Öffentlichkeit des staatlichen Handelns ${ }^{211}$ und durch die besondere Rolle der Parteien im staatlichen Willensbildungsprozess auch eine Öffentlichkeit der Parteien selbst. ${ }^{212}$ Das Grundgesetz kennt keine „Macht ohne Verantwortlichkeit" 213 und verleiht den Parteien nicht nur Rechte, sondern legt ihnen auch einen „Pflichtenstatus“214 auf. Dieser Pflichtenstatus hat sowohl eine Innen- als auch Außenwirkung auf die Parteien.

\section{Innenwirkung}

Nach Art. 21 Abs. 1 S. 3 GG muss die „innere Ordnung“ der Parteien demokratischen Grundsätzen entsprechen. Auch dieser Umstand wird durch das verfassungsrechtliche Mandat der Parteien vorausgesetzt und dient der Gewährleistung der Funktionalität. ${ }^{215}$ Denn nur durch eine demokratische Organisations- und Handlungsstruktur wird innerhalb der Partei eine reelle Mitbestimmungsmöglichkeit der Mitglieder geschaffen, ohne die es der Partei nicht möglich wäre, die Interessen und Meinungen innerhalb der Bevölkerung zu kanalisieren. Die Pflicht zur Organisation nach demokratischen Grundsätzen ist deshalb dem Öffentlichkeitsstatus zuzurechnen, da die Parteien als Teilnehmer an den Legitimitätsprinzipien des Staates der Allgemeinheit Einsicht in die Vorgänge ermöglichen sollen und dies nur dann sichergestellt ist, wenn die interne Willensbildung auch innerhalb der Partei von „unten nach oben“ vollzogen wird. ${ }^{216}$ Der „demokratische Grundsatz“ der inneren Ordnung setzt als Rahmenbedingung voraus, dass die Willensbildung innerhalb der Partei von „unten nach oben“ zu erfolgen habe, alle Mitglieder gleichwertig und die Freiheit des Ein- und Austritts gewährleistet sein muss. ${ }^{217}$ Art. 21 Abs. 1 S. 3 GG weist ferner einen

211 Vgl. Kloepfer, in: Böckenförde/Isensee/Kirchhof (Hrsg.), Handbuch des Staatsrechts der Bundesrepublik Deutschland III, ${ }^{3} 2005$, $\$ 42$, Rn. 19.

212 Klein, in: Maunz/Dürig (Hrsg.), Grundgesetz, 2018, Art. 21, Rn. 316.

213 So Hesse in: VVDStRL 17 (1967), S. 1, 42; siehe auch Roellecke, in: Umbach/ Clemens (Hrsg.), GG, 2002, Art. 21, Rn. 30.

214 Klein, in: Maunz/Dürig (Hrsg.), Grundgesetz, 2018, Art. 21, Rn. 317.

215 Morlok, in: Dreier/Bauer (Hrsg.), Grundgesetz, ${ }^{3} 2015$, Art. 21, Rn. 123.; vgl. auch Ipsen, in: Sachs (Hrsg.), Grundgesetz, ${ }^{8} 2018$, Art. 21, Rn. 53.

216 Vgl. Hesse in: VVDStRL 17 (1967), S. 1, 44.

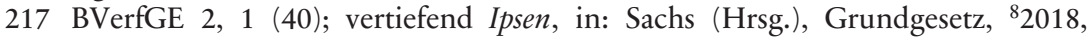
Art. 21, Rn. 54 ff. 
subjektiv-rechtlichen Gehalt auf, der sich durch die aus dem zivilrechtlichen Mitgliedschaftsverhältnis ergebenden Recht äußert. ${ }^{218}$

\section{Außenwirkung}

Der Status der Öffentlichkeit verlangt hinsichtlich der Finanzquellen der Parteien nach außen hin eine gewisse Transparenz. Regelmäßig erlangen Spenden von größeren Unternehmen an Parteien mediale Aufmerksamkeit und können, wenn sie in den gängigen Massenmedien verbreitet werden, Auswirkungen auf die Zustimmung und den Rückhalt in der Bevölkerung haben. ${ }^{219}$ Durch die Offenlegung ihrer Finanzmittel sollen sich die Parteien der öffentlichen Kontrolle unterwerfen und politische Einflussnahme durch das Bereitstellen finanzieller Mittel aufzeigen. ${ }^{220}$ Den Bürgern wird die Möglichkeit eröffnet, die Herkunft und Größenordnung der Zuwendungen an die Parteien in Erfahrung zu bringen und daraus ihre politischen Konsequenzen zu ziehen. Das Transparenzgebot in Art. 21 Abs. 1 S. 4 GG ist unmittelbar anwendbares Recht ${ }^{221}$, und muss über den Ausgestaltungsauftrag nach Art. 21 Abs. 5 GG einfachgesetzlich geformt werden.

Der Gesetzgeber hat das Transparenzgebot im Rahmen seines Ausgestaltungauftrags nach Art. 21 Abs. 5 GG in den $\$ \$ 23$ ff. PartG konkretisiert. ${ }^{222}$ Demnach ist der Vorstand einer Partei nach $\$ 23$ Abs. 1 S. 1 PartG verpflichtet, über die Herkunft und Verwendung ihrer Mittel sowie über das Vermögen der Partei jährlich wahrheitsgemäß und nach bestem Wissen und Gewissen öffentlich Rechenschaft mittels eines Rechenschaftsberichts abzulegen. Art. 21 Abs. 1 S. 4 GG sowie die $\$ \mathbb{S} 23$ ff. PartG verlangen einen vollständigen und materiell richtigen Rechenschaftsbericht. ${ }^{223}$ Die Kon-

218 Morlok, in: Dreier/Bauer (Hrsg.), Grundgesetz, ${ }^{32} 2015$, Art. 21, Rn. 132 m.w.N.

219 Siehe beispielsweise Preuss, FAZ 21.04.2017, http:/www.faz.net/aktuell/wirtscha $\mathrm{ft} /$ unternehmen/spenden-daimler-oeffnet-die-geldboerse-fuer-parteien-14980215. html zul. aufgerufen am 18.02.2020.

220 BVerfGE 24, 300 (356); BVerfGE 111, 54 (83); vgl. auch BVerfGE 20, 56 (106); BVerfGE 52, 63 (86f.); BVerfGE 85, 264 (319).

221 BVerfGE 111, 54 (85); auch Klein, in: Maunz/Dürig (Hrsg.), Grundgesetz, 2018, Art. 21, Rn. 469; Ipsen, in: Sachs (Hrsg.), Grundgesetz, ${ }^{8} 2018$, Art. 21, Rn. 110; anders noch BVerfGE 2, 1 (13).

222 Huber, DÖV 2000, 745 (746).

223 BVerfGE 111, 54 (88 f.); Morlok, in: Dreier/Bauer (Hrsg.), Grundgesetz, ${ }^{32} 2015$, Art. 21, Rn. 114. 
trolle über die Rechenschaftsablegung obliegt nach $\$ \mathbb{S} 19 \mathrm{f}$. PartG dem Bundestagspräsidenten, der die Auszahlung von staatlichen Mitteln nach $\mathbb{S} \mathbb{1 8}, 19$ PartG von dem Vorliegen eines nach den $\mathbb{S} \$ 23 \mathrm{ff}$. PartG ordnungsgemäß erstellten Rechenschaftsberichts abhängig machen muss.

Ein fehlender oder inhaltlich falscher Rechenschaftsbericht kann nach $\$$ 19a Abs. 3 S. 3 und S. 4 PartG den vollständigen und endgültigen Verlust des Anspruchs auf staatliche Zuwendungen für das Anspruchsjahr zur Folge haben. Die Verletzung der Rechenschaftspflicht wird ähnlich wie die Feststellung der Verfassungsfeindlichkeit einer Partei nach Art. 21 Abs. 3 GG mit dem Wegfall staatlicher Mittel geahndet. Eine Unterscheidung wird lediglich in der Dauer und dem Erhalt steuerlicher Begünstigungen getroffen. 224 Überdies sind, um die Einhaltung des Transparenzgebots strafrechtlich zu sichern, in Gestalt des $₫ 31$ d PartG Straftatbestände eingeführt worden. ${ }^{225}$

Der Status der Öffentlichkeit erschöpft sich nach außen hin nicht allein in der Publizität der Parteifinanzen. Das allgemeine demokratische Öffentlichkeitsprinzip ${ }^{226}$ hat auch Einfluss auf das Parteienrecht und fordert, dass die Parteien Informationen über ihre wesentlichen politischen Ziele, ihre organisatorische Struktur und die Zusammensetzung der Leitgremien für jedermann öffentlich zugänglich machen. ${ }^{227}$ Einfachgesetzlich ist diese Verpflichtung in $\$ 6$ Abs. 3 PartG festgeschrieben, wonach die Satzung, das Programm und die Namen sowie die Funktion der Vorstandsmitglieder der Partei und ihrer Landesverbände dem Bundeswahlleiter mitzuteilen sind und nach $\$ 6$ Abs. 3 S. 3 PartG von jedermann eingesehen werden können. Nach $\$ 6$ Abs. 3 S. 4 PartG ist auf Anforderung auch eine Abschrift der hinterlegten Unterlagen auszuhändigen.

224 Bei der Feststellung der Verfassungsfeindlichkeit einer Partei ist diese nach $₫ 46 a$ Abs. 1 S. 1 BVerfGG für die Dauer von sechs Jahren aus der staatlichen Parteienfinanzierung ausgeschlossen. Bei einem verfristeten Rechenschaftsbericht entfällt lediglich der Anspruch für ein Jahr. Siehe grundlegend zur Thematik Shirvani, NVwZ 2017, $1321 \mathrm{ff}$.

225 Grundlegend dazu Saliger, Parteiengesetz und Strafrecht, 2005, S. 605 ff.

226 Dreier, in: Dreier/Bauer (Hrsg.), Grundgesetz, ${ }^{3} 2015$, Art. 20 (Demokratie), Rn. $76 \mathrm{ff}$.

227 Morlok, in: Dreier/Bauer (Hrsg.), Grundgesetz, ${ }^{3} 2015$, Art. 21, Rn. 120. 


\section{$\$ 3$ Institution der Parteienfinanzierung}

Der rechtliche Anknüpfungspunkt des Art. 21 Abs. 3 GG ist die staatliche Parteienfinanzierung, weshalb im Folgenden näher auf sie eingegangen wird. Zur Gründung der Bundesrepublik war eine staatliche Finanzierung des Parteiwesens noch weitestgehend unbekannt und deren Handhabe verfassungsrechtlich unsicher. Erst durch eine Vielzahl verfassungsgerichtlicher Entscheidungen konnten dem Staat bei der Finanzierung von Parteien wichtige rechtliche Leitlinien an die Hand gegeben werden. Für das Verständnis der heutigen Gestaltung der staatlichen Parteienfinanzierung und deren Bedeutung für den politischen Wettbewerb ist ein Blick auf ihre historische Entwicklung unerlässlich, da signifikante Stellen maßgeblich durch die sich ändernde Rechtsprechung des Bundesverfassungsgerichtes vorgegeben wurden und sich insoweit das "normative Leitbild“ eines politischen Wettbewerbs in erheblicher Weise in den Gewährungsvoraussetzungen niederschlug.

Mittlerweile nimmt der „staatliche Anteil“ an den Gesamtfinanzen der Parteien einen wesentlichen Umfang ein. Im Jahr 2019 erhielten die nachfolgenden Parteien hohe Summen, die mindestens 1/4 ihrer Gesamtfinanzen bildeten ${ }^{228}$ :

\begin{tabular}{|c|c|c|c|c|c|c|}
\hline \multirow[t]{2}{*}{ Partei } & \multicolumn{3}{|c|}{ Festsetzung der staatlichen Parteienfinanzierung } & \multicolumn{2}{|c|}{ Obergrenzen } & \multirow{2}{*}{$\begin{array}{l}\text { Staats- } \\
\text { anteil } \\
\text { an Fi- } \\
\text { nan- } \\
\text { zen } \\
\text { in } \%\end{array}$} \\
\hline & $\begin{array}{l}\text { Wähleranteil } \\
\text { in } € \\
\text { \ } 18 \text { Abs. } 3 \\
\text { S. } 1 \text { Nr. } 1 \text { u. } \\
\text { S. } 2 \text { PartG }\end{array}$ & $\begin{array}{c}\text { Zuwendungsan- } \\
\text { teil in } € \\
\mathbb{S} 18 \text { Abs. } 3 \mathrm{~S} .1 \\
\text { Nr. } 3 \text { PartG }\end{array}$ & $\begin{array}{l}\text { Summe } \\
\text { in } €\end{array}$ & $\begin{array}{c}\text { Relative Ober- } \\
\text { grenze in } € \\
\text { (Selbst erwirt- } \\
\text { schaftete Ein- } \\
\text { nahmen) }\end{array}$ & $\begin{array}{c}\text { Absolute } \\
\text { Obergrenze in } \\
€ \\
\text { (Endbetrag) }\end{array}$ & \\
\hline CDU & $26.781 .486,37$ & $28.617 .085,73$ & $55.398 .572,10$ & $90.514 .845,81$ & $54.018 .918,68$ & 37,375 \\
\hline SPD & $21.510 .127,73$ & $35.627 .163,84$ & $57.137 .291,57$ & $114.255 .647,38$ & $55.714 .336,85$ & 32,779 \\
\hline GRÜNE & $15.414 .201,43$ & $9.187 .381,60$ & $24.601 .583,60$ & $27.719 .914,29$ & $23.988 .901,93$ & 46,392 \\
\hline LINKE & $8.396 .305,35$ & $6.365 .578,76$ & $14.760 .884,11$ & $17.765 .174,50$ & $14.393 .277,09$ & 44,757 \\
\hline CSU & $7.305 .626,18$ & $7.765 .040,10$ & $15.070 .666,28$ & $31.404 .027,92$ & $14.695 .344,40$ & 31,876 \\
\hline AfD & $13.471 .177,59$ & $3.789 .600,40$ & $17.260 .777,99$ & $10.460 .454,98$ & $10.203 .583,65$ & 49,378 \\
\hline FDP & $9.364 .366,47$ & $6.448 .422,15$ & $15.812 .788,62$ & $20.624 .164,07$ & $15.418 .984,82$ & 42,779 \\
\hline NPD & $46.918,56$ & $370.515,50$ & $417.434,06$ & $1.149 .343,22$ & $407.038,23$ & 26,153 \\
\hline
\end{tabular}

228 Einsehbar unter www.bundestag.de/resource/blob/694474/b12215becf05c5eac1 3772a0377f10ce/finanz_19-data.pdf, zul. aufgerufen am 21.09.2020. 


\section{A. Arten der staatlichen Parteienfinanzierung}

Die durch den Staat erfolgende Teilfinanzierung der gesamten politischen Tätigkeit der Parteien prägt das Parteiwesen und die Gestaltung der Politik in der Bundesrepublik Deutschland in einem wesentlichen Maße. Die historische Entwicklung sowie die durch die $\$ \$ 18 \mathrm{ff}$. PartG normierten Voraussetzungen der Gewährung der staatlichen Parteienfinanzierung vermögen - wie bereits erwähnt - Aufschluss über den Inhalt und die Funktion der Institution an sich und deren Einfluss auf die Parteiengleichheit und den Parteienwettbewerb zu geben.

Eine „staatliche“ Finanzierung von Parteien kann in ihrer Art und Weise eine vielfältige Gestalt annehmen. So erhalten die Parteien einerseits unmittelbar staatliche Mittel nach den $\mathbb{S} 18 \mathrm{ff}$. PartG, sowie mittelbar durch die steuerliche Begünstigung und den damit einhergehenden staatlichen Steuerverzicht. ${ }^{229}$ Von der staatlichen Finanzierung der Abgeordneten nach Art. 48 Abs. 3 S. 1 GG, $\mathbb{S} 11$ ff. AbgG sowie der Fraktionen nach $\$ 50 \mathrm{AbgG}$ und "parteinahen" Stiftungen profitieren durch die personelle wie organisatorische Verflechtung auch die Parteien. ${ }^{230}$ So könnten die Abgeordnetenalimentierung ${ }^{231}$, Fraktionsfinanzierung ${ }^{232}$ oder auch die finanzielle Unterstützung „parteinaher“ Stiftungen ${ }^{233}$ aus einer gesamtwirtschaftlichen Betrachtung unter den Begriff der „staatlichen Finanzierung“ fallen. ${ }^{234}$ Auch die Jugendorganisationen der Parteien erhalten Mittel aus dem Staatshaushalt ${ }^{235}$ und stellen, je nach der Zugrundelegung eines engen oder weiten Verständnisses, eine staatliche Finanzierung der Parteien dar.

Im Folgenden wird untersucht, welche Arten der staatlichen Leistungsgewährung als „staatliche Parteienfinanzierung“ im weiteren Sinne verstanden werden können. Welche der hier angesprochenen „Finanzierungsarten“ als „staatliche Parteienfinanzierung“ iSd. Art. 21 Abs. 3 GG zu ver-

229 BVerfGE 8, 51 (62); vgl. auch BVerfGE 24, 300 (359 ff.); Streinz, in: Huber/ Voßkuhle (Hrsg.), Grundgesetz, ${ }^{72018}$, Art. 21, Rn. 195.; Morlok, in: Dreier/ Bauer (Hrsg.), Grundgesetz, ${ }^{3} 2015$, Art. 21, Rn. 44; Tsatsos/Morlok, Parteienrecht, 1982, S. 140.

230 Grundlegend Arnim, NVwZ 2003, 1076 ff.

231 Vgl. BVerfGE 29, 56 (103 f.).

232 Vgl. BVerfGE 20, 56 (104).

233 Vgl. BVerfGE 73, 1 (31 f.).

234 Siehe hierzu Landfried, Parteifinanzen und politische Macht, 1990, S. $961 \mathrm{ff}$.

235 Näheres $\$ 3$ B. IV. 
stehen ist, wird im Rahmen der Untersuchung der Rechtsfolgen des Finanzierungsausschlussverfahrens näher behandelt. ${ }^{236}$

\section{Staatliche Teilfinanzierung nach den $\$ \mathbb{S} 18 \mathrm{ff}$. PartG}

Parteien erhalten aufgrund ihrer „Parteieneigenschaft“ und ihres Erfolges bei Landtags-, Bundestags- und Europawahlen nach den $\mathbb{S} \$ 18 \mathrm{ff}$. PartG eine staatliche Teilfinanzierung. Es handelt sich dabei um eine unmittelbare, vornehmlich aus finanziellen Gütern bestehende Zuwendung des Staates an die Parteien zum Zwecke der Finanzierung ihrer allgemeinen politischen Tätigkeit; also der Erfüllung des ihnen nach Art. 21 Abs. 1 S. 1 GG obliegenden verfassungsrechtlichen Mandats. ${ }^{237}$

Unabhängig davon, ob man den Begriff der „staatlichen Finanzierung“ eng oder weit versteht, bleibt festzuhalten, dass die staatliche Finanzierung nach den $\mathbb{S} 18$ ff. PartG den Parteien allein schon dann zusteht, wenn sie die Begriffsmerkmale des Parteienbegriffs nach Art. 21 Abs. 1 S. 1 GG, $\$ 2$ PartG erfüllen ${ }^{238}$, und sie damit eindeutig schon allein ihrer Natur nach eine „staatliche Finanzierung von Parteien“ darstellt.

Es ist naheliegend, eine staatliche "Parteienfinanzierung" schon dann anzunehmen, wenn der Staat den Parteien finanzielle Unterstützung für die Erfüllung ihres verfassungsrechtlichen Mandats zuwendet. Denn dann erschöpft sich der Zweck der Leistung gerade in der Förderung des Parteiwesens und stellt damit eine „staatliche Parteienfinanzierung“ dar.

II. Steuerliche Privilegierungen als mittelbare staatliche Parteienfinanzierung

Nach allgemeiner Auffassung handelt es sich bei der steuerlichen Begünstigung von Parteien und von Zuwendungen an Parteien um eine mittelbare staatliche Parteienfinanzierung. ${ }^{239}$ Der Gesetzgeber hat unter anderem in $\$ 5$ Abs. 1 Nr. 7 KStG die politischen Parteien von der Entrichtung der

236 Siehe $\$ 4$. C. II. 1. a).

237 Koch, in: Ipsen (Hrsg.), Parteiengesetz, 2008, $\mathbb{1} 18$, Rn. 5.

238 Stricker, Der Parteienfinanzierungsstaat, 1998, S. 25; grundlegend zum Parteienbegriff Wietschel, Der Parteibegriff, 1996.

239 Morlok, in: Dreier/Bauer (Hrsg.), Grundgesetz, ${ }^{3} 2015$, Art. 21, Rn. 44.; Streinz, in: Huber/Voßkuhle (Hrsg.), Grundgesetz, ${ }^{72018}$, Art. 21, Rn. 195; Ipsen, JZ 2017, 933 (934). 


\section{$\$ 3$ Institution der Parteienfinanzierung}

Körperschaftssteuer befreit und auch steuerliche Privilegierungen von $\mathrm{Zu}$ wendungen in $\$ \$ 10 \mathrm{~b}$ Abs. 2, 34g EStG vorgesehen. Demnach können $\mathrm{Zu}$ wendungen an Parteien nach $\$ 4$ Abs. 6 EStG zwar nicht als Betriebsausgaben von der Einkommenssteuer abgezogen, allerdings nach $\$ 34 \mathrm{~g}$ EStG zunächst als Steuerermäßigung berücksichtigt und im Übrigen als Sonderausgaben nach $\mathbb{1} 10 \mathrm{~b}$ Abs. 2 EStG in Abzug gebracht werden. Durch die steuerrechtliche Privilegierung von Parteien und von Zuwendungen an Parteien „verzichtet“ der Staat auf Steuereinnahmen, die ihm bei einer nicht differenzierenden Steuerrechtslage zustehen würden. ${ }^{240}$

\section{Abgeordnetenentschädigung und Fraktionsfinanzierung}

Problematischer als die unmittelbare Teilfinanzierung der Parteien nach den $\mathbb{S} \mathbb{S} 18 \mathrm{ff}$. PartG ist die Frage, ob auch die Abgeordnetenentschädigung nach Art. 48 Abs. 3 GG und die Fraktionsfinanzierung nach $\$ 50$ AbgG als „staatliche Parteienfinanzierung" verstanden werden können. Die Parteien profitieren zumindest mittelbar von der staatlichen Alimentierung ,ihrer ${ }^{\text {“ }}$ Parlamentarier. Dieser Umstand wurde im Rahmen der unmittelbaren staatlichen Teilfinanzierung der Parteien bereits in $₫ 24$ Abs. 4 Nr. 2 PartG berücksichtigt und damit gesetzlich anerkannt. Ein ähnliches Problem ergibt sich aus der staatlichen Finanzierung von Fraktionen im Parlament. Schwierig gestaltet sich dabei insbesondere eine Differenzierung zwischen denjenigen Mitteln, die die Fraktionen für ihre Tätigkeit verwendet, und den Mitteln, die für die politische Tätigkeit der Parteien eingesetzt werden. Eine inhaltliche Auseinandersetzung mit Art. 48 Abs. 3 GG, $\mathbb{5} 50$ AbgG und Art. 21 GG gibt Aufschluss über den Inhalt und die Grenzen des Begriffs der „staatlichen Finanzierung“ und vermag hinsichtlich der unterschiedlichen staatlichen Leistungen an verfassungsrechtliche Institutionen oder staatliche Organe eine klarere Kontur des Begriffs zu zeichnen.

240 BVerfGE 8, 51 (62); vgl. auch BVerfGE 24, 300 (359 ff.); siehe auch Wernsmann, Verhaltenslenkung in einem rationalen Steuersystem, 2005, S. 134 f.; Streinz, in: Huber/Voßkuhle (Hrsg.), Grundgesetz, ${ }^{72018}$, Art. 21, Rn. 195.; Morlok, in: Dreier/Bauer (Hrsg.), Grundgesetz, ${ }^{3} 2015$, Art. 21, Rn. 44; Tsatsos/Morlok, Parteienrecht, 1982, S. 140. 
1. Inhalt und Funktion der Abgeordnetenentschädigung und Fraktionsfinanzierung

\section{a) Abgeordnetenentschädigung}

Ein Anspruch auf eine angemessene Entschädigung der Abgeordneten ist in Art. 48 Abs. 3 S. 1 GG verfassungsrechtlich vorgesehen und durch Art. 48 Abs. 3 S. $3 \mathrm{GG}^{241}$ in den $\mathbb{S} 11 \mathrm{ff}$. AbgG ausgestaltet worden. Durch den subjektiv-rechtlichen Anspruch auf eine angemessene Entschädigung soll die Unabhängigkeit der Abgeordneten gewährleistet und in diesem Zusammenhang ihre Entschließungsfreiheit sowie die von ihrer Funktion vorausgesetzten Rechte und Pflichten geschützt werden. ${ }^{242}$ In diesem $\mathrm{Zu}$ sammenhang sollte die Abgeordnetenentschädigung auch sicherstellen, dass sich angesichts der durch das Amt eingeschränkten beruflichen sowie anderweitigen wirtschaftlichen Perspektive nicht nur finanziell gut situierte Bürger um ein solches Amt bemühen. ${ }^{243}$ Sie sollte, zumindest in ihrer ursprünglichen Form, eine „Aufwandsentschädigung“ für die Ausübung des „Ehrenamtes“ des Bundestagsabgeordneten darstellen.244 Durch einen grundlegenden Wandel dieses Amtes hat sich die Entschädigung zu einer Alimentation des Lebensunterhalts der Bundestagsabgeordneten und ihrer Familien entwickelt. ${ }^{245}$ Das Bundesverfassungsgericht betonte, dass die Abgeordnetenentschädigung alleinig dem Zweck der Gestattung einer dem Amt eines Bundestagsabgeordneten angemessenen Lebensführung dienen darf und stufte in diesem Rahmen explizit den Zweck der Abgeordnetenentschädigung als eine staatliche Mitfinanzierung der hinter dem Abgeordneten stehenden Partei als unzulässig ein. ${ }^{246}$ Allerdings wird in nahezu jeder Partei erwartet, dass die Mandatsträger bestimmte Beträge an die Partei abführen. ${ }^{247}$ Die Zuwendungen an die Parteien durch die durch den

241 Schulze-Fielitz, in: Dreier/Bauer (Hrsg.), Grundgesetz, ${ }^{3} 2015$, Art. 48, Rn. 34.

242 BVerfGE 20, 56 (103 f.); BVerfGE 80, 188 (217f.); siehe auch grundlegend Roth, AöR 129 (2004), 219 ff.

243 Vgl. Schulze-Fielitz, in: Dreier/Bauer (Hrsg.), Grundgesetz, ${ }^{3} 2015$, Art. 48, Rn. 20; Storr, in: Huber/Voßkuhle (Hrsg.), Grundgesetz, ${ }^{7} 2018$, Art. 48, Rn. 50.; Magiera, in: Sachs (Hrsg.), Grundgesetz, ${ }^{8} 2018$, Art. 48, Rn. 17.

244 Schulze-Fielitz, in: Dreier/Bauer (Hrsg.), Grundgesetz, ${ }^{32015}$, Art. 48, Rn. 19.

245 BVerfGE 40, 296 (314, 316); Arnim, in: Bitburger Gespräche, 1993, S. 169.

246 BVerfGE 40, 296 (315 f.).

247 Z.B. sind nach $\$ 6$ Abs. 3 der Bundessatzung der Partei „Bündnis90/Die Grünen“ Mandatsträger verpflichtet, sogenannte „MandatsträgerInnenbeiträge“ an den Bundesverband zu zahlen oder auch $\$ 2$ Abs. 1 der Finanzordnung der SPD; einzige Ausnahme bildet die FDP, die in ihrer Satzung keine Sonderbeiträge für 


\section{\3 Institution der Parteienfinanzierung}

Staat alimentierten Abgeordneten sind dann wiederum steuerlich privilegiert. ${ }^{248}$

\section{b) Fraktionsfinanzierung}

Der Begriff „Fraktion“249 umschreibt üblicherweise einen Zusammenschluss mehrerer Abgeordneter ${ }^{250}$ zu einer parlamentarischen Handlungseinheit. Der Begriff wird im Grundgesetz nicht ausgefüllt oder näher beschrieben, sondern lediglich in Art. 53a Abs. 1 S. 2 GG im Zusammenhang mit der Besetzung des Gemeinsamen Ausschusses erwähnt. Das Bundesverfassungsgericht spricht auch von „notwendigen Einrichtungen des Verfassungslebens “251 oder einer „ständigen Gliederung des Bundestages“ “252, wodurch Parlamentsfraktionen in die „organisierte Staatlichkeit“ eingefügt sind. ${ }^{253}$ Die Fraktionen dienen der Effizienzsteigerung der parlamentarischen Arbeit der einzelnen Abgeordneten. Sie organisieren, rationalisieren und gestalten inhaltlich die Arbeit der Abgeordneten im Parlament. ${ }^{254}$ Durch die soziale und wirtschaftliche Komplexität der Gesellschaft und den informationstechnologischen Fortschritt ${ }^{255}$ ist der Zusammenschluss der Abgeordneten zu Fraktionen zwecks der Aufbereitung und Kanalisierung der verschiedenen Meinungen und Interessen und der anschließen-

Mandatsträger festschreibt. Ob solche Beiträge verfassungsrechtlich zulässig sind ist problematisch, wird jedoch wohl als noch vereinbar mit dem Grundgesetz angesehen, siehe Kühr, Legalität und Legitimität von Mandatsträgerbeiträgen, 2014.

248 Kritisch, im Ergebnis jedoch als zulässig erachtend Wietschel, Der Parteibegriff, 1996, S. 106, Fn. 311.

249 Grundlegen zur Begrifflichkeit der „Fraktion“ siehe Kretschmer, Fraktionen, 1984, S. 9 ff.

250 Schneider, Die Finanzierung der Parlamentsfraktionen als staatliche Aufgabe, 1997, S. 17.

251 BVerfGE 2, 143 (160); BVerfGE 20, 56 (104); BVerfGE 43, 142 (147); BVerfGE 70, 324 (350); BVerfGE 84, 304 (322).

252 BVerfGE 2, 143 (160); BVerfGE 43, 142 (147); BVerfGE 80, 188 (231).

253 BVerfGE 20, 56 (104); BVerfGE 62, 194 (202); BVerfGE 70, 324 (350f.); BVerfGE 80, 188 (231).

254 Schmidt-Jortzig/Hansen, NVwZ 1994, 1145 (1146); grundlegend zur Funktion von Fraktionen siehe Bäcker, Der Ausschluss aus der Bundestagsfraktion, 2011; Hölscheidt, Das Recht der Parlamentsfraktionen, 2001; Schneider, Die Finanzierung der Parlamentsfraktionen als staatliche Aufgabe, 1997, S. $21 \mathrm{ff}$.

255 Vgl. ders, Die Finanzierung der Parlamentsfraktionen als staatliche Aufgabe, 1997, S. 22. 
den tauglichen Einbringung in das Parlament zu einer Notwendigkeit geworden. Sie nehmen innerhalb der parlamentarischen Demokratie nach den Vorstellungen des Grundgesetzes eine zentrale Rolle ein.

Die Fraktionen erhalten nach $₫ 50$ AbgG zur Erfüllung ihrer Aufgaben Geld- und Sachleistungen aus dem Bundeshaushalt. Gerechtfertigt wird die Zuwendung von staatlichen Mitteln an die Fraktionen durch deren Mitwirkung und Arbeit im Bundestag. ${ }^{256}$ Aus diesem Grund dürfen die Mittel, die den Fraktionen im Rahmen des $₫ 50$ Abs. 1 AbgG zufließen, nach $₫ 50$ Abs. 4 S. 2 AbgG nicht für die den Parteien obliegenden Aufgaben verwendet werden. ${ }^{257}$

2. Abgeordnetenentschädigung als „staatliche Parteienfinanzierung“?

Die Abgeordneten verpflichten sich regelmäßig gegenüber ihrer Partei, einen bestimmten Anteil ihrer Abgeordnetenentschädigung an sie abzuführen. Die Parteien profitieren regelmäßig mittelbar von der Abgeordnetenentschädigung. Allein daraus kann allerdings nicht geschlossen werden, dass die Abgeordnetenentschädigung eine „staatliche Parteienfinanzierung" darstellt.

Trotz ihrer personellen wie ideologischen Verbundenheit differenziert das Staatsrecht streng zwischen Parteien und den ihnen zuzuordnenden Abgeordneten. ${ }^{258}$ Die Verschiedenartigkeit der Partei und des Abgeordneten in ihrer Funktion und ihrer systematischen Stellung im Grundgesetz zeichnet den Begriff der „staatlichen Finanzierung“ von Parteien maßgeblich mit und grenzt ihn gewissermaßen auch ein. Das Grundgesetz ordnet den jeweiligen Institutionen eigene Rechtstellungen zu, die die Funktionalität des Verfassungsstaates und dessen Zweckbindung an das Gemeinwohl ${ }^{259}$ in seiner durch das Grundgesetz vorausgesetzten Form gewährleisten sollen. Dementsprechend ist eine Finanzierung der Abgeordneten, Fraktionen, oder Parteien, in welcher Form auch immer, stets an den mit dem Tätigkeits- und Aufgabenbereich anfallenden Aufwand auszurich-

256 Ders., Die Finanzierung der Parlamentsfraktionen als staatliche Aufgabe, 1997, S. $71 \mathrm{ff}$.

257 Morlok, in: Dreier/Bauer (Hrsg.), Grundgesetz, ${ }^{3} 2015$, Art. 21, Rn. 190.

258 Vgl. Arnim, NVwZ 2003, 1076 (1076).

259 Siehe hierzu Link/Ress/Ipsen $u$. a. (Hrsg.), Staatszwecke im Verfassungsstaat nach 40 Jahren Grundgesetz, 2013, S. 19. 
ten. ${ }^{260}$ Der Finanzierungszweck und der prognostizierte Bedarf an Finanzmitteln sind maßgeblich bei staatlichen Budgetentscheidungen zu berücksichtigen, weshalb eine in dieser Hinsicht strikte Differenzierung der Institutionen notwendig ist.

Eine formell-typisierende Betrachtung, die die in der Verfassungswirklichkeit existierende Verwachsung der Parteien und ihrer Abgeordneten unberücksichtigt lässt, führt zu dem Ergebnis, dass die Abgeordnetenalimentierung, unabhängig von einer unter Umständen damit zusammenhängenden mittelbaren Parteienfinanzierung, ein Aliud zur staatlichen Parteienfinanzierung darstellt. Das Bundesverfassungsgericht stellte in seiner Entscheidung im ersten Parteienfinanzierungsurteil in diesem Zusammenhang fest, dass die Abgeordnetenalimentierung in Art. 48 Abs.3 GG dem materiellen Parlamentsrecht zuzuordnen ist und allein aus diesem Grund keine Parallele zu der einfachgesetzlich geschaffenen Parteienfinanzierung i.S.d. $\$ \mathbb{S} 18 \mathrm{ff}$. PartG gezogen werden kann. ${ }^{261}$ Während die Abgeordnetenalimentierung bereits zur Zeit des Kaiserreichs und der Weimarer Republik ${ }^{262}$ die Unabhängigkeit des Abgeordneten wahren, das Amt nicht nur für finanziell gutsituierte Bürger attraktiv machen ${ }^{263}$ und gewährleisten sollte, dass er „die sich aus seinem repräsentativen verfassungsrechtlichen Status ergebenden Rechte und Pflichten in Freiheit ausüben“264 kann, ist die Parteienfinanzierung der Verfassungsordnung fremd gewesen und stellt im Vergleich zur Abgeordnetenalimentierung ein rechtliches Novum dar. Diese Erwägung kann auf die Auslegung des nun normativ verankerten Begriffs der „staatlichen Finanzierung“ übertragen werden.

Auch der auf einer zugegebenermaßen stark formelle und sich strikt am Wortlaut orientierende Gedanke, dass bei einer Mittelzuwendung von Abgeordneten an ihre Parteien ein Verhältnis begründet werde, welches den Staat formell nicht einbindet, kann bei der Auslegung des Begriffs zielführend sein. ${ }^{265}$ Denn die Zahlung eines Abgeordneten an seine Partei verlässt formell nicht das spezifische Verhältnis des Abgeordneten zu seiner Partei

260 Folgend Schneider, Die Finanzierung der Parlamentsfraktionen als staatliche Aufgabe, 1997, S.76f.

261 BVerfGE 20, 56 (103 f.).

262 Vgl. Poetzsch-Heffter, in: ders. (Hrsg.), Handkommentar der Reichsverfassung vom 11. August 1919, ${ }^{3} 1928$, Art. 40 WRV Nr. 1 ff., wonach die WRV bereits eine Abgeordnetenentschädigung vorsah; zur historischen Auslegung der Abgeordnetenentschädigung siehe auch Roth, AöR 129 (2004), 219 (224).

263 Arnim, ZRP 1989, 257 (262) m.w.N.

264 BVerfGE 20, 56 (103 f.).

265 Wietschel, Der Parteibegriff, 1996, S. 106, Fn. 311. 
und bindet, unabhängig von der ursprünglichen Herkunft der Mittel, den Staat nicht in dieses Verhältnis mit ein. Die spezifischen Mittel stammen damit nicht, zumindest unmittelbar, aus dem Staatshaushalt. Die Abgeordneten sind bei der Verwendung der ihnen zur Verfügung gestellten Mittel nicht zweckgebunden und haben eine umfangreiche Dispositionsbefugnis über die durch die Abgeordnetenalimentation erlangten Leistungen; sie sind hinsichtlich des Bezugs und der Verwendung ihrer Mittel auch nicht rechenschaftspflichtig. ${ }^{266}$ Die Zuwendungen der Abgeordneten an ihre Partei sind auch nicht in besonderer Art und Weise im Rechenschaftsbericht zu kennzeichnen.

Die Abgeordnetenentschädigung nach Art. 48 Abs. 3 S. 1 GG fällt demnach nicht unter den Begriff der "staatlichen Parteienfinanzierung".

\section{Fraktionsfinanzierung als „staatliche Parteienfinanzierung“?}

Die Fraktionsfinanzierung 267 ist im Gegensatz zur Abgeordnetenentschädigung nicht verfassungsrechtlich verankert und wurde durch den einfachen Gesetzgeber im Abgeordnetengesetz einfachgesetzlich konstituiert. Die Argumentation, weshalb die Fraktionsfinanzierung keine „staatliche Parteienfinanzierung" darstellen kann, folgt demselben Muster wie die im Rahmen der Abgeordnetenentschädigung durchgeführten Untersuchung und beschränkt sich auf die „Aliud-Eigenschaft“ der Fraktionsfinanzierung im Verhältnis zu der staatlichen Parteienfinanzierung.

So schreibt $\$ 50$ Abs. 4 S. 2 AbgG ausdrücklich vor, dass die der Fraktion zugewendeten Mittel keine Verwendung bei den parteispezifischen Aufgaben finden dürfen. Der Anspruch wurde mit einem speziellen Verwendungsverbot verknüpft und kennzeichnet dadurch deutlich, unabhängig von einer faktisch vorliegenden Verwobenheit der Fraktionen mit ihren Parteien, dass das Institut der Fraktionsfinanzierung nicht nur keine staatliche Parteienfinanzierung darstellen kann, sondern darüber hinaus auch nicht darstellen darf. Fraktionen sind nach der zutreffenden Ansicht des Bundesverfassungsgerichts als eine „ständige Gliederung des Bundestages“

266 Dies., Der Parteibegriff, 1996, S. 106, Fn. 311.

$267 \mathrm{Zu}$ Abgaben von Abgeordneten an ihre Fraktion oder Partei siehe vertiefend Mardini, Die Finanzierung der Parlamentsfraktionen durch staatliche Mittel und Beiträge der Abgeordneten, 1990; Lontzek, Die Sonderbeiträge von Abgeordneten an Partei und Fraktion, 2012. 


\section{\3 Institution der Parteienfinanzierung}

in den staatlichen Bereich eingefügt worden ${ }^{268}$, was nach der allgemeinen Staatslehre gerade für die gesellschaftlich-wurzelnden Parteien nicht gilt. ${ }^{269}$ Die Zulässigkeit der Fraktionsfinanzierung basiert auf einer strikten Trennung der Fraktionsfinanzen von den Finanzen ihrer Partei. ${ }^{270}$ Die Parteienfinanzierung darf aus diesem Grund schon von Verfassungs wegen keine rechtliche oder tatsächliche Einheit mit der Fraktionsfinanzierung bilden. Die Fraktionsfinanzierung stellt damit ebenfalls ein Aliud im Verhältnis zur staatlichen Parteienfinanzierung dar. ${ }^{271}$

\section{Staatliche Zuschüsse an politische Stiftungen}

Für fast jede parteipolitische Strömung, die im Bundestag vertreten ist, existiert eine parteinahe Stiftung. Die Stiftungen betreiben politische Bildungsarbeit als gemeinnützigen Zweck und erhalten hierfür auch Mittel aus dem Staatshaushalt. Sie werden als Nebenorganisationen ${ }^{272}$, Sonderorganisationen ${ }^{273}$ oder "parteinahe“ Organisationen ${ }^{274}$ der ihnen nahestehenden Partei eingestuft. Dem Gesetzgeber sind „parteinahe“ Stiftungen auch bekannt, wie beispielsweise $\$ 11$ Abs. 2 S. 3 PartG zeigt. Durch Globalzuschüsse des Staates an die parteinahen Stiftungen wird ihre Tätigkeit im Bereich der politischen Bildungsarbeit, Studien- und Forschungsförderung, des Publikationswesens und der internationalen Zusammenarbeit

268 BVerfGE 20, 56 (104); BVerfGE 62, 194 (202); BVerfGE 70, 324 (350f.); BVerfGE 80, 188 (231).

269 BVerfGE 20, 56 (101 f.); Hesse in: VVDStRL 17 (1967), S. 1, 33.

270 Arnim, in: Wewer (Hrsg.), Parteienfinanzierung und politischer Wettbewerb, 1990, S. 134, 136.

271 Zur Differenzierung von Fraktion und Partei siehe Seifert, Die politischen Parteien im Recht der Bundesrepublik Deutschland, 1975, S. 345 ff.; siehe auch auf die Fraktionsfinanzierung auf kommunaler Ebene bezogen VGH Kassel, Urt. v. 05.04.2017 - 8C 459/17.N -, juris und die Urteilsanmerkung von Meyer, NVwZ $2017,886 \mathrm{ff}$.

272 Oerter, Rechtsfragen des Verhältnisses zwischen politischen Parteien und ihren Sonder- und Nebenorganisationen, 1971, S. 157, 164, 170, 183.

273 In Bezug zu Parteiunternehmen Seifert, Die politischen Parteien im Recht der Bundesrepublik Deutschland, 1975, S. 22.

274 BVerfGE 73, 1 (31 f.), das voraussetzt, dass die Stiftungen rechtlich und tatsächlich unabhängig von den ihnen nahestehenden Parteien sind. $\mathrm{Zu}$ dem aus dem Urteil abgeleiteten Begriff der „parteinahen“ Organisation Westerwelle, Das Parteienrecht und die politischen Jugendorganisationen, 1994, S. 126. 
staatlich gefördert. ${ }^{275}$ Das Bundesverfassungsgericht urteilte, dass eine staatliche Finanzierung parteinaher Stiftungen nur dann zulässig sei, wenn die Stiftungen „rechtlich und tatsächlich unabhängige Institutionen“ seien. ${ }^{276}$ Dabei berief es sich auf seine frühere Rechtsprechung zu der verfassungsrechtlichen Zulässigkeit einer staatlichen Parteienfinanzierung ${ }^{277}$, die das Bundesverfassungsgericht 1966 noch für unzulässig hielt und lediglich eine reine Wahlkampfkostenerstattung mit den Bestimmungen des Grundgesetzes für vereinbar erklärte. Unabhängig von der Frage nach der verfassungsrechtlichen Zulässigkeit einer staatlichen Parteienfinanzierung hat sich hinsichtlich der rechtlich und tatsächlich von der Partei unabhängigen Stiftung nichts geändert. ${ }^{278}$ Als selbstständige Organisationen mit einem eigenen und von den Parteien klar abzugrenzenden Aufgaben- und Tätigkeitsbereich ${ }^{279}$ sind die Zuschüsse aus dem Staatshaushalt nicht als staatliche Parteienfinanzierung, sondern als eine staatliche Finanzierung von Stiftungen zu qualifizieren; sie stellen auch in diesem Fall ein Aliud zu der staatlichen Parteienfinanzierung dar.

\section{Finanzierung der politischen Jugendorganisationen}

Fast jeder Partei steht eine politische Jugendorganisation nahe, die eine weitgehende ideologische Nähe aufweist und für sie - ohne selbst bei Wahlen anzutreten - im Wahlkampf wirbt. Sie sind regelmäßig rechtlich verselbstständigt und somit als sogenannte „Nebenorganisatonen“ zu qualifizieren. ${ }^{280}$ Jugendorganisationen, denen eine rechtliche Verselbstständigung fehlt und lediglich eine Untergruppierung innerhalb der Partei dar-

$275 \mathrm{Zu}$ den Aufgabenfeldern einer politischen Stiftung siehe Vieregge, in: Wewer (Hrsg.), Parteienfinanzierung und politischer Wettbewerb, 1990, S. 164.

276 BVerfGE 73, 1 (31 f.).

277 BVerfGE 20, 56 (112).

278 Zweifelnd Stricker, Der Parteienfinanzierungsstaat, 1998, S. 37 f.; die Selbstständigkeit und Unabhängigkeit der „parteinahen“ Stiftungen von den Parteien hat das Bundesverfassungsgericht auch nach Änderung der Rechtsprechung bzgl. der Zulässigkeit der staatlichen Parteienfinanzierung bestätigt, BVerfGE 85, 264 (289).

279 In diesem Zusammenhang problematisch ist insbesondere das Merkmal der „Nähe“ der Stiftung zu einer Partei, siehe Günther/Vesper, ZRP 1994, 289 (289).

280 Als „Nebenorganisationen“ gelten vor allem die „Junge Union“ und die „Jungen Liberalen e.V“. Abzustellen ist auf deren rechtliche Verselbstständigung von der „Mutterpartei“. Siehe dazu Höfling, NJW 1985, 1943 (1944); Westerwelle, Das Parteienrecht und die politischen Jugendorganisationen, 1994, S. 52; Seifert, 
stellen, sind bereits nach ihrer Organisationsform ihrer „Mutterpartei“ zugehörig. Auf sie wird im weiteren Verlauf deshalb nicht mehr eingegangen werden.

Dass öffentliche Zuschüsse an die politischen Jugendorganisationen fließen, hat auch Berücksichtigung in den Regelungen der unmittelbaren staatlichen Parteienfinanzierung gefunden. $\$ 24$ Abs. 12 PartG geht davon aus, dass zumindest ein Institut der „öffentlichen Bezuschussung von politischen Jugendorganisationen" existiert. Der Gesetzgeber hat durch die Schaffung des $₫ 83$ Abs. 1 S. 2 SGB VIII zudem die Möglichkeit der staatlichen Förderung von politischen Jugendorganisationen auf Bundesebene gesetzlich vorgesehen. Die Norm teilt die Geschichte vieler Vorschriften des Parteienrechts und findet ihren Ursprung in einer gerichtlichen Entscheidung (in diesem Falle des OVG Berlin-Brandenburg) ${ }^{281}$. In der Norm ist geregelt, dass die fachlich zuständige oberste Bundesbehörde die Tätigkeit der Jugendhilfe anregen und fördern solle, soweit diese von überregionaler Bedeutung ist und ihrer Art nach nicht durch ein Land allein wirksam gefördert werden kann. Nach Art. 83 Abs. 1 S. 2 SGB VIII gehören die Tätigkeiten der politischen Jugendorganisationen auch zur "Jugendhilfe" und können demnach durch die fachlich zuständige oberste Bundesbehörde gefördert werden. Die Voraussetzungen, das Verfahren sowie die Art und Weise der Förderung der Jugendhilfe legt das Bundesministerium für Familie, Senioren, Frauen und Jugend als fachlich zuständige oberste Bundesbehörde ${ }^{282}$ in einer Richtlinie ${ }^{283}$ fest. Eine gesetzliche Regelung mit einem weitergehenden Inhalt sucht man vergebens. Die Richtlinie sieht vor, dass auf Antrag einer Jugendorganisation Fördermittel durch das Bundesministerium gewährt werden können.

Die politischen Parteien im Recht der Bundesrepublik Deutschland, 1975, S. 21; ders., DÖV 1956, 1 (5).

281 Die heutige Fassung des $₫ 83$ Abs. 1 SGB VIII wurde an das Urteil des OVG Berlin-Brandenburg, Urt. v. 14.03.2012, Rs. OVG 6 B 19.11. = NVwZ 2012, 1265 ff. angelehnt. Siehe zu dem Urteil Merten, NVwZ 2012, $1228 \mathrm{ff}$.

282 Kern, in: Fischer/Mann/Schellhorn u.a. (Hrsg.), SGB VIII, ${ }^{5} 2017, \mathbb{8} 83$, Rn. 3.

283 Bundesministerium für Familie, Senioren, Frauen und Jugend, Richtlinie über die Gewährung von Zuschüssen und Leistungen zur Förderung der Kinder- und Jugendhilfe durch den Kinder- und Jugendplan des Bundes (KJP), 29.09.2016, https://www.bmfsfj.de/blob/111964/2f7ae557daa0d2d8fe78f8a3f956 9f21/richtlinien-kjp-2017-data.pdf, zul. aufgerufen am 18.02.2020. 
Ferner sollen nach $\$ 74$ Abs. 1 S. 1 SGB VIII die Träger der öffentlichen Jugendhilfe ${ }^{284}$ die Tätigkeit im Bereich der freiwilligen Tätigkeit der Jugendhilfe anregen. Vorschriften zur Förderung politischer Jugendorganisationen sind in verschiedenen landesrechtlichen Ausführungsgesetzen zum SGB VIII enthalten und legen neben der bundesgesetzlichen Norm, anlehnend an die Voraussetzungen des $\$ 74$ Abs. 1 S. 1 SGB VIII, teilweise die Voraussetzungen zur Gewährung finanzieller Mittel fest. ${ }^{285}$

Der Tätigkeitsbereich der politischen Jugendorganisationen lässt sich funktional in drei Teile aufteilen.286 Dies sind die Vertretung der Partei und ihrer Ziele bei jungen Menschen, die Vertretung der spezifischen Jugendinteressen in der Partei und in der Gesellschaft sowie ihre Funktion als Nachwuchsorganisation der Partei. ${ }^{287}$ Guido Westerwelle bezeichnet die politischen Jugendorganisationen in diesem Zusammenhang als „Mittler“ zwischen ihrer Zielgruppe und ihrer Partei. ${ }^{288}$ Sie wirken insoweit im selben Maße auf die politische Willensbildung ein wie ihre Mutterpartei. ${ }^{289}$ Die Betätigung der Jugendorganisationen in einen „parteipolitischen“ und „überparteilich-gemeinnützigen“ Bereich aufzuteilen, ist nicht ohne Weiteres möglich. ${ }^{290}$ Da $\ 83$ Abs. 1 S. 2 SGB VIII insoweit die Arbeit der politischen Jugendorganisationen ausdrücklich der „Tätigkeit der Jugendhilfe“

284 Die Träger der öffentlichen Jugendhilfe werden durch landesrechtliche Ausführungsgesetze festgelegt. So sind z.B. Träger der öffentlichen Jugendhilfe im Freistaat Bayern nach Art. 15 Abs. 1 S. 1 AGSG die Landkreise und kreisfreien Gemeinden, die wiederum nach Art. 16 Abs. 1 AGSG Jugendämter einzurichten haben, die die Aufgaben der örtlichen Träger der Jugendhilfe wahrnehmen.

285 So z.B. das Hamburgische Gesetz zur Ausführung des Achten Sozialgesetzbuches (SGB VIII), das in $₫ 31$ a eine Regelung zur Förderung der politischen Jugendorganisationen getroffen hat. Auch nach dieser Vorschrift muss die Jugendorganisation eine Gewähr für die den Zielen des Grundgesetzes förderliche Arbeit bieten.

286 OVG Berlin-Brandenburg, Urt. v. 14.03.2012, Rs. OVG 6 B 19.11., NVwZ 2012, 1265 ff. (1267) unter Bezugnahme von Westerwelle, Das Parteienrecht und die politischen Jugendorganisationen, 1994, S. 33.

287 Westerwelle, Das Parteienrecht und die politischen Jugendorganisationen, 1994, S. 33; auch OVG Berlin-Brandenburg, Urt. v. 14.03.2012, Rs. OVG 6 B 19.11., NVwZ 2012, 1265 ff. (1267).

288 Westerwelle, Das Parteienrecht und die politischen Jugendorganisationen, 1994, S. 34 .

289 OVG Berlin-Brandenburg, Urt. v. 14.03.2012, Rs. OVG 6 B 19.11., NVwZ 2012, 1265 ff. (1267).

290 So insbesondere Klein, NJW 2000, 1441 (1444); zweifelnd, allerdings offenlassend OVG Berlin-Brandenburg, Urt. v. 14.03.2012, Rs. OVG 6 B 19.11., NVwZ 2012, 1265 ff. (1268) m.w.N. 


\section{$\$ 3$ Institution der Parteienfinanzierung}

zuordnet, wird hinreichend deutlich, dass der Gesetzgeber trotz Vorliegen einer parteipolitischen Bindung eine institutionelle Förderung der Jugendorganisationen beibehalten wollte und nicht eine ausschließliche Förderung „überparteilicher, gemeinnütziger“ Jugendarbeit im Blick hatte. Bei der staatlichen Förderung der jugendpolitischen Organisationen handelt es sich mithin um eine „staatliche Parteienfinanzierung“ im weiteren Sinne, da die Tätigkeit der Jugendorganisationen ganz überwiegend parteigebunden ist und in erheblicher Weise den Parteiinteressen entspricht. $\mathrm{Ob}$ die Förderung politischer Jugendorganisationen unter den Begriff der „staatlichen Finanzierung“ iSd. Art. 21 Abs. 3 S. 1 GG fällt, wird erst im Rahmen der Untersuchung der Rechtsfolgen des Finanzierungsausschlussverfahrens behandelt. ${ }^{291}$

\section{B. Entwicklung der unmittelbaren und mittelbaren staatlichen Parteienfinanzierung}

\section{Anfänge der Parteienfinanzierung}

Vor der Gründung der Bundesrepublik war eine staatliche Förderung von Parteien weitestgehend unbekannt und rechtlich nicht existent. ${ }^{292}$ Die Parteien waren in der Weimarer Republik für ihre Finanzierung und wirtschaftliche Erhaltung ausschließlich selbst verantwortlich und in diesem Sinne vollständig auf den Rückhalt in der Bevölkerung angewiesen. ${ }^{293}$ Zwar wurde 1928 auf Initiative Gustav Stresemanns ${ }^{294}$ über eine Wahlkampfkostenerstattung beraten, diese konnte sich allerdings nicht durchsetzen. ${ }^{295}$ Ein in Grundzügen in die Richtung einer Parteienfinanzierung verweisender Wahlkostenzuschuss in Höhe von 1, 8 Milliarden Reichsmark wurde 1932 vom Reich an die Paul von Hindenburg als Reichspräsidenten unterstützenden Parteien ausbezahlt. Allerdings war kein eigener

291 Siehe insoweit $\$ 4$ A. C. II. 2. b).

292 Vgl.Jülich, Chancengleichheit der Parteien, 1966, S. 34.

293 Eschenburg, Probleme der modernen Parteifinanzierung, 1961, S. 44; demnach gerieten gerade die liberalen Parteien der Weimarer Republik in eine starke Abhängigkeit zu ihren Spendern, da diese eine weitere Gewährung von Spenden von im eigenen Interesse liegenden Bedingungen abhängig gemacht haben, ders., Probleme der modernen Parteifinanzierung, 1961, S. 11.

294 Gustav Stresemann war zur Zeit der Weimarer Republik ein deutscher Politiker der DVP, ehemaliger Reichskanzler und Minister für Auswärtiges.

295 Eschenburg, Probleme der modernen Parteifinanzierung, 1961, S. 11. 
Haushaltsposten für diesen „Wahlkostenzuschuss“ vorgesehen. Kurz nach der Wahl hat das Reich dem Land Preußen den Betrag des Wahlkostenzuschusses von dem Polizeikostenzuschuss abgezogen. ${ }^{296}$

Im Geburtsjahr der Bundesrepublik Deutschland 1949 haben die Länder anlässlich der im Sommer 1948 durchgeführten Währungsreform und den daraus für die Parteien entstandenen finanziellen Schwierigkeiten für die erste bevorstehende Bundestagswahl sogenannte „Wählerkredite“ bewilligt. ${ }^{297}$ Die Wählerkredite sahen eine Zahlung von fünf Pfennig pro erhaltene Wählerstimme bei den letzten Landtagswahlen vor. Auf eine Rückforderung der Wählerkredite wurde von staatlicher Seite aus weitestgehend verzichtet. Dadurch erfolgte zum ersten Mal in der Geschichte der Bundesrepublik Deutschland eine öffentliche Förderung von Parteien zur Wahrnehmung ihres verfassungsrechtlichen Mandats.

\section{Erste gesetzgeberische Versuche der steuerrechtlichen Privilegierung}

Die ersten gesetzgeberischen Versuche, die mittelbare Parteienfinanzierung rechtlich zu institutionalisieren, scheiterten am Richterspruch des Bundesverfassungsgerichts. Dieser Umstand trug erheblich dazu bei, dass die weitere Entwicklung bis zu diesem Tage maßgeblich durch die verfassungsgerichtliche Rechtsprechung mitgestaltet wurde. Durch das im Jahr 1954 erlassene „Gesetz zur Neuregelung von Steuern“298 sollten nunmehr Ausgaben zur Förderung staatspolitischer Zwecke nach $\$ 49$ EStDVO als Sonderausgaben abzugsfähig sein. Unter den Begriff der „Förderung staatspolitischer Zwecke" vielen insbesondere auch Spenden und andere Leistungen an Parteien. ${ }^{299}$ Durch die Entscheidung für eine steuerliche Begünstigung von Parteien entstand zu diesem Zeitpunkt erstmalig die Institution der mittelbaren staatlichen Parteienfinanzierung. Das Gesetz trat am 16.12.1954 in Kraft, wurde jedoch 1957 durch das Bundesverfassungsgericht für verfassungswidrig und damit für nichtig erklärt. ${ }^{300}$ Das Bundesverfassungsgericht stützte seine Entscheidung auf den Umstand, dass eine steuerliche Begünstigung nur für Parteien in Betracht kam, die im Bundes-

296 Dübber, Parteifinanzierung in Deutschland, 1962, S. 79.

297 Rabus, AöR 78 (1952), 163 (191).

298 BGBl. 1954, I, S. 373 ff.

299 Vgl. Kulitz, Unternehmerspenden an politische Parteien, 1983; Stricker, Der Parteienfinanzierungsstaat, 1998, S. 42.

300 BVerfGE 6, $273 \mathrm{ff}$. 
tag oder in einem Landtag vertreten waren. Diese Diskriminierung von nicht parlamentarisch vertretenen Parteien war im Hinblick auf die Gleichheit der Parteien nicht zu rechtfertigen und führte letztlich zum Scheitern dieser Initiative. ${ }^{301}$

Ein weiterer Versuch, Parteispenden steuerrechtlich abzugsfähig zu machen, scheiterte 1958. Von dieser Regelung betroffen waren die Lohn- und Körperschaftssteuer. So sollten Parteispenden bis zu 10\% des einkommenssteuerlich und 5\% des körperschaftssteuerlich veranlagten Einkommens abzugsfähig sein. Das Bundesverfassungsgericht hat auch diese Regelung für verfassungswidrig erklärt. ${ }^{302}$ Es stellte in seinem Urteil zwar fest, dass eine staatliche Förderung von Parteien grundsätzlich zulässig sei ${ }^{303}$, im konkreten Fall verstieße die Ausgestaltung der steuerlichen Begünstigung jedoch gegen den Status der Chancengleichheit. Demnach ginge vom Wortlaut der einschlägigen steuerrechtlichen Normen keine unmittelbare Ungleichbehandlung aus, allerdings würden durch diese Regelung faktisch die Parteien bevorzugt werden, die „kapitalkräftige“ Kreise ansprächen. ${ }^{304}$ Ohne eine Begrenzung der Abzugsmöglichkeit hätten diejenigen Parteien einen ungerechtfertigten Vorteil, die aufgrund ihrer Zielsetzung und politischen Ausrichtung von finanzstarken Wählern bevorzugt würden und aus diesem Grund mit hohen Spendenbeträgen rechnen könnten. ${ }^{305}$

\section{Globalzuschüsse als unmittelbare Parteienfinanzierung}

Nach Feststellung der Verfassungswidrigkeit der steuerlichen Begünstigungen in ihrer durch den Gesetzgeber geschaffenen Form suchte dieser nach Alternativen, um den finanziellen Erhalt eines Großteils der Parteien sicher zu stellen. ${ }^{306}$ So sah ein Jahr nach dem 1958 ergangenem Urteil des Bundesverfassungsgerichts ${ }^{307}$ der Bundestag in seinem Haushalt Globalzu-

301 BVerfGE 6, 273 (279).

302 BVerfGE 8, $51 \mathrm{ff}$.

303 BVerfGE 8, 51 (63).

304 BVerfGE 8, 51 (66f.).

305 BVerfGE 8, 51 (67).

306 Stricker, Der Parteienfinanzierungsstaat, 1998, S.43, der zusätzlich auf eine schwierige wirtschaftliche Lage mitgliedsschwacher Parteien hinweist und das vorangegangene Urteil des Bundesverfassungsgerichtes (BVerfGE 8, 51 [63]) als Ideenanstoß für die Gewährung von Globalzuschüssen bezeichnet.

307 BVerfGE 8, $51 \mathrm{ff}$. 
schüsse an die im Bundestag vertretenen Parteien vor. Für die genaue Bemessung der Gewährung der Finanzmittel war dabei die Fraktionsstärke maßgeblich. In den folgenden Jahren steigerte der Bundestag diesen Betrag kontinuierlich. So erhöhten sich die 1959 vorgesehenen 5 Millionen DM bis zum Jahr 1964 auf 38 Millionen DM. Durch die Gewährung von Globalzuschüssen unter Aufgabe der Zweckgebundenheit der für die Parteien vorgesehenen Finanzmittel wurde erstmalig in der Geschichte der Bundesrepublik die Institution der unmittelbaren, öffentlichen Parteienfinanzierung geschaffen. ${ }^{308}$ Die verfassungsgerichtliche Rechtsprechung übte dabei einen wesentlichen, wenn nicht gar den maßgeblichen, Einfluss auf die Entwicklung und die heutige Gestaltung der Parteienfinanzierung aus. Hinsichtlich der Gewährung der Globalzuschüsse an die im Bundestag vertretenen Parteien urteilte das Bundesverfassungsgericht 1966 besonders streng und erklärte in einer die unmittelbare staatliche Parteienfinanzierung betreffenden Grundsatzentscheidung die öffentliche Finanzierung der allgemeinen Parteientätigkeit für verfassungswidrig. ${ }^{309}$ Diesen rechtlichen Schluss zog das Bundesverfassungsgericht, den wegweisenden Ausführungen Konrad Hesses folgend ${ }^{310}$, aus dem Verbot der „staatlich-institutionellen Verfestigung des Parteiwesens“311. Durch eine unmittelbare, staatliche Parteienfinanzierung würden die Parteien zwar „nicht in die organschaftliche Staatlichkeit eingefügt“, jedoch mit dieser in unzulässiger Weise verschränkt und dadurch der staatlichen Vorsorge überantwortet werden. ${ }^{312}$ Das Bundesverfassungsgericht sah in der finanziellen Abhängigkeit vom Staat die Gefahr, dass eine nicht zu rechtfertigende staatliche Einflussnahme auf die politische Willens- und Meinungsbildung begründet würde. Eine staatliche Parteienfinanzierung dürfe ausschließlich in Form der Erstattung der notwendigen Kosten eines angemessenen Wahlkampfes erfolgen. ${ }^{313}$ Da durch die Vorschriften des Grundgesetzes eine unmittelbare Parteienfinanzierung per se unzulässig war, ließ das Bundesverfassungsgericht in diesem Urteil die Möglichkeit einer subjektiven Rechtsverletzung offen. ${ }^{314}$

308 Stricker, Der Parteienfinanzierungsstaat, 1998, S. 43 f.

309 BVerfGE 20, $56 \mathrm{ff}$.

310 Hesse in: VVDStRL 17 (1967), S. 1, 33.

311 BVerfGE 20, 56 (101 f.).

312 BVerfGE 20, 56 (102).

313 BVerfGE 20, 56 (113 ff.).

314 BVerfGE 20, 56 (102), allerdings stellte das Bundesverfassungsgericht in den Organstreitverfahren BVerfGE 20, 119 ff. und BVerfGE 20, $134 \mathrm{ff}$. fest, dass, da eine staatliche Parteienfinanzierung per se verfassungswidrig sei, kein Grund dafür 
IV. Wahlkampfkostenerstattung als unmittelbare Parteienfinanzierung

Das Bundesverfassungsgericht erklärte in seinem Urteil vom 24. Juni $1958^{315}$ die vom Gesetzgeber vorgesehene Form der steuerlichen Privilegierung von Parteien für verfassungswidrig. Allerdings betonte es im selbigem Urteil, dass „da die Abhaltung von Wahlen eine öffentliche Aufgabe ist und den Parteien bei der Durchführung dieser öffentlichen Aufgabe von Verfassungs wegen eine entscheidende Rolle zukommt, [es auch zulässig sein muss], nicht nur für die Wahlen selbst, sondern auch für die die Wahlen tragenden politischen Parteien finanzielle Mittel von Staats wegen zur Verfügung zu stellen“. 316

Diesen Hinweis setzte der Gesetzgeber nach dem Scheitern der Globalzuschüsse im „neuen“ Parteiengesetz vom 24. Juli 1967 um und führte durch die $\mathbb{S} 18 \mathrm{ff}$. PartG 1967 die Institution der Parteienfinanzierung in Form der Wahlkampfkostenerstattung ein. Das System der Wahlkampfkostenerstattung sah in $\$ 18$ Abs. 1 PartG 1967 eine Zahlung von 2,50 DM für jeden Wahlberechtigten vor. Das Geld wurde nach dem Verhältnis der auf die einzelnen Parteien entfallenden Zweitstimmen aufgeteilt. Um einen Missbrauch der Wahlkampfkostenerstattung durch Splittergruppen vorzubeugen, wurde als konstitutives Merkmal des Auszahlungsanspruches ein Mindestquorum von 2,5\% der im Wahlkreis abgegebenen Zweitstimmen gesetzlich festgesetzt. ${ }^{317}$ Die Auszahlung erfolgte nach \$20 I PartG 1967 durch Abschlagszahlungen, die je nach Fortschritt der Wahlperiode variierten. Durch die über die Wahlperiode erfolgenden Abschlagszahlungen wurde der Charakter der "Wahlkampfkostenerstattung“" im Kern hin zu einer kontinuierlich erfolgenden Parteienfinanzierung umgestaltet. ${ }^{318}$

Dass auch diese Form der staatlichen Finanzierung in Teilen nach Ansicht des Bundesverfassungsgerichts mit den Vorschriften des Grundgesetzes unvereinbar war, zeigte sich am 3. Dezember 1968. ${ }^{319}$ Das Auszahlungsverfahren nach $\$ 20$ Abs. 1 PartG 1967 und die Höhe der Wahlkampfkostenerstattung wurden vom Bundesverfassungsgericht gebilligt. Jedoch

bestehe, dass nur einige Parteien (die im Bundestag vertreten waren) diese verfassungswidrige Art der Mittelgewährung erhielten und deshalb auch der Status der Gleichheit der Parteien verletzt sei.

315 BVerfGE 8, $51 \mathrm{ff}$.

316 BVerfGE 8, 51 (63).

317 Stricker, Der Parteienfinanzierungsstaat, 1998, S. 47 m.w.N.

318 Kritisch ders., Der Parteienfinanzierungsstaat, 1998, S. 48.

319 BVerfGE 24, $300 \mathrm{ff}$. 
sah es in dem Mindestquorum von 2,5\% einen Verstoß gegen den Grundsatz der Chancengleichheit der Parteien. ${ }^{320}$ Es wies zugleich darauf hin, dass ein solches Mindestquorum „erheblich unter der 5\%-Grenze“ liegen müsse ${ }^{321}$ und zur Missbrauchskontrolle eine Hürde von 0,5\% des Wählerstimmenanteils bereits völlig ausreichend und wohl auch maximal zulässig sei. ${ }^{322}$ Den Hinweis des Bundesverfassungsgerichtes setzte der Gesetzgeber $1969^{323}$ um und senkte das Mindestquorum auf den verfassungsgerichtlichen Vorschlag von $0,5 \%$ des Wählerstimmenanteils ab.

Der Ausschluss unabhängiger Wahlbewerber aus der Parteienfinanzierung sah das Bundesverfassungsgericht 1976 aufgrund einer Verletzung der chancengleichen Teilnahme an der Bundestagswahl als verfassungswidrig $a^{324}$, und gab dem Gesetzgeber einen erneuten Anlass zur Änderung der Parteienfinanzierung. Durch den Ausschluss unabhängiger Wahlbewerber aus der Parteienfinanzierung sei ihre Chancengleichheit im politischen Wettbewerb verletzt, was eine Berücksichtigung solcher Bewerber für den Gesetzgeber als zwingend gestaltete. Durch eine Änderung des \18 PartG 1976 wurden nun auch solche unabhängigen Wahlbewerber bei der Wahlkampfkostenerstattung berücksichtigt, die in einem Wahlkreis mindestens 10\% des Erststimmenanteils auf sich vereinen konnten. Dieses Quorum erklärte das Bundesverfassungsgericht auch für zulässig. 325

Der politische Affront der sog. Flick-Affäre ${ }^{326}$ führte 1983 zu einer Novellierung der Parteienfinanzierung, die hinsichtlich des Chancenausgleichs und der Kappungsgrenze 1986 vom Bundesverfassungsgericht überprüft und, zumindest hinsichtlich der unmittelbaren Parteienfinanzierung, für verfassungsgemäß befunden wurde. ${ }^{327}$ Der Versuch, durch eine steuerliche Begünstigung von Parteien eine mittelbare Parteienfinanzierung einzuführen, scheiterte allerdings erneut am Richterspruch des Bundesverfassungsgerichtes. ${ }^{328}$ So waren die $\$ 10$ b Abs. 1 S. 1 EStG 1983 und

320 BVerfGE 24, 300 (339 ff.).

321 BVerfGE 24, 300 (340).

322 BVerfGE 24, 300 (342).

323 BGBl. 1969, I, S. 925.

324 BVerfGE 41, 399 (412 ff.).

325 BVerfGE 41, 399 (424f.).

326 Die Flick-Affäre zerstörte nachhaltig das Vertrauen der Bevölkerung in die Parteiendemokratie. Im Kern ging es um verdeckt erfolgte Parteispenden des FlickKonzerns an unterschiedliche Parteien. Siehe dazu im Allgemeinen Leyendecker/ Stiller/Prantl, Helmut Kohl, die Macht und das Geld, ${ }^{2} 2000$; Kilz, Flick: Die gekaufte Republik, ${ }^{81} 1984$.

327 BVerfGE 73, 40 (94 ff.).

328 BVerfGE 73, 40 (70 ff.). 
$\$ 9$ Nr. 3 S. 1 KStG 1983 mit dem Grundsatz der gleichen politischen Teilhabe aller Bürger unvereinbar. Die betroffenen Vorschriften sahen im Jahr 1983 vor, dass die steuerliche Abzugsfähigkeit von Ausgaben zur Förderung staatspolitischer Zwecke (wozu Parteispenden gehörten) nach einem bestimmen Prozentsatz der gesamten Einkünfte bzw. des gesamten Einkommens bemessen wird. Das Bundesverfassungsgericht stellte fest, dass Bürger mit höheren Einkommen durch diese Regelung bevorzugt würden und statuierte daraus eine Verletzung des Rechtes auf gleiche Teilhabe am politischen Willensbildungsprozess. ${ }^{329}$ Der Gesetzgeber korrigierte die verfassungsrechtlichen Mängel am 01.01.1989 durch eine entsprechende Änderung der Vorschriften durch das „Fünfte Gesetz zur Änderung des Parteiengesetzes und anderer Gesetze vom 22.12.1988“330. Demnach wurde für die steuerliche Abzugsmöglichkeit von Parteispenden nach dem EStG eine Höchstgrenze von 60.000 DM vorgesehen, bei der Zusammenlegung von Ehegatten lag diese Grenze bei 120.000 DM.

\section{Teilfinanzierung als unmittelbare Parteienfinanzierung}

Die verfassungsgerichtliche Überprüfung des „Fünften Gesetzes zur Änderung des Parteiengesetzes und anderer Gesetze vom 22.12.1988“ ließ nicht lange auf sich warten. Auf Antrag der Bundespartei Bündnis 90/DIE GRÜNEN sollte das Bundesverfassungsgericht über dessen Vereinbarkeit mit dem Grundgesetz entscheiden. ${ }^{331}$ Problematisch war nach der Ansicht der Antragstellerin die Verfassungsmäßigkeit der Einführung eines Sockelbetrages, die Änderung des Chancenausgleichs, die Schaffung einer Publizitätsgrenze für Spenden ab 40.000 DM sowie die aufgrund der zuvor ergangenen verfassungsgerichtlichen Entscheidung festgelegte Höchstgrenze der steuerlichen Abzugsfähigkeit von Parteispenden und Mitgliedsbeiträgen.

Das Bundesverfassungsgericht billigte in seinem Urteil im Jahr 1992 teilweise die kürzlich geänderte Fassung der unmittelbaren Parteienfinanzierung. Allerdings sah es in der Gewährung eines Sockelbetrages für die Parteien, die mindestens 2\% des Wählerstimmenanteils auf sich vereinigen konnten, einen Verstoß gegen das Verbot der staatlich-institutionellen Verfestigung des Parteiwesens und stellte - erneut - die Verfassungswidrigkeit

BVerfGE 73, 40 (71).

330 BGBl. 1988, I, S. 2615.

331 BVerfGE 85, $264 \mathrm{ff}$. 
der gesetzlich in dieser Form vorgesehenen Parteienfinanzierung fest. ${ }^{332}$ Demnach würde die Gewährung eines Sockelbetrages nicht die Bemühungen der Parteien „um eine finanzielle Unterstützung ihrer Politik durch Mitglieder und Spender sowie ihren Wahlerfolg berücksichtigen“"333. Das Bundesverfassungsgericht machte hier erneut deutlich, dass die Parteien zwingend auf einen Rückhalt in der Bevölkerung angewiesen seien und ihre Verwurzelung im gesellschaftlich-politischen Bereich nicht durch eine staatliche Finanzierung aufgehoben oder wesentlich beeinträchtigt werden dürfe. ${ }^{334}$ Ein Sockelbetrag, der den gesellschaftlichen Rückhalt einer Partei (in Form von Mitgliedsbeiträgen, Spenden oder den Wahlergebnissen) bei der Berechnung des Betrags unberücksichtigt lässt, begründe die Gefahr der staatlichen Einflussnahme auf die politische Willensbildung und sei aus diesem Grund mit Art. 21 Abs. 1 S. 1 GG nicht vereinbar.

Umso überraschender war es, dass der Senat im selben Urteil seine bisherige Rechtsprechung über die alleinige Zulässigkeit einer unmittelbaren Parteienfinanzierung in Form einer Wahlkampfkostenerstattung aufgab und nunmehr eine allgemeine, staatliche Parteienfinanzierung für verfassungsrechtlich zulässig befand. ${ }^{335}$ Für die aktuelle Ausgestaltung der unmittelbaren Parteienfinanzierung stellt dieses Urteil einen „Meilenstein“ dar, da es dem Gesetzgeber nunmehr freistünde, die staatliche Parteienfinanzierung, so wie anfänglich geplant, in Form von Globalzuschüssen zu gewähren. Die Ausrichtung der Zahlungen an den „Kosten eines angemessenen Wahlkampfes" wurde mit dem Hinweis aufgehoben, dass eine zeitliche Differenzierung zwischen dem Wahlkampf einer Partei und dessen sonstiger politischer Tätigkeit nicht möglich sei. ${ }^{336}$ Die politischen Tätigkeiten außerhalb und innerhalb des Wahlkampfes seien, so das Bundesverfassungsgericht in seiner Begründung, identisch und damit sei es auch nicht sinnvoll, eine Trennung der allgemeinen politischen Tätigkeiten in dieser Art vorzunehmen. Das verfassungsrechtliche Mandat aus Art. 21 Abs. 1 S. 1 GG beziehe sich nicht allein auf die „Vorbereitung einer Wahl“, sondern verlange gerade, dass die Parteien die Interessen, Meinungen und Bestrebungen innerhalb der Bevölkerung sammeln und diese so kanalisieren, dass diese in tauglicher Art und Weise die Bildung der obersten Staats-

332 BVerfGE 85, 264 (283).

333 BVerfGE 85, 264 (283f.).

334 BVerfGE 85, 264 (287).

335 BVerfGE 85, 264 (285); hierzu auch Hoffmann, DÖV 1994, 504 ff.; siehe auch die Konzeptvorschläge von Ipsen, JZ 1992, 753 (758 ff.).

336 BVerfGE 85, 264 (285 ff.). 
organe maßgeblich mitgestalten. ${ }^{337}$ Allerdings darf es sich weiterhin nicht um eine öffentliche Vollalimentierung der Parteien handeln. Der Grundsatz der Staatsfreiheit erlaube lediglich eine Teilfinanzierung der allgemeinen politischen Parteitätigkeit, da die Parteien als gesellschaftliche Gebilde zwingend, gerade in finanzieller Hinsicht, auf den Rückhalt der Gesellschaft angewiesen seien und notwendigerweise das Gros ihrer Einnahmen aus Mitgliedsbeiträgen und Spenden erwirtschaften müssten. ${ }^{338}$

Zusammen mit der Abweichung von der bisherigen verfassungsgerichtlichen Rechtsprechung setzte das Bundesverfassungsgericht damit einen rechtlichen Rahmen für eine allgemeine Parteienfinanzierung. Insbesondere hob es hinsichtlich der Höhe der zu gewährenden Zahlungen eine sogenannte relative und absolute Obergrenze hervor. ${ }^{339}$ Aufgrund des Gebotes der Staatsfreiheit darf der Betrag, der einer Partei aufgrund der staatlichen Teilfinanzierung zukommt, nicht höher sein als das Einkommen, welches sie aus privatwirtschaftlichen Einnahmequellen, wie Mitgliedsbeiträgen und Spenden, generiert (sog. relative Obergrenze). Um ferner zu verhindern, dass mit steigendem privatwirtschaftlich generiertem Einkommen auch die staatliche Teilfinanzierung ins Unermessliche steigt, verlangt das Bundesverfassungsgericht erneut unter Berufung auf das Gebot der Staatsfreiheit der Parteien die Festsetzung eines Höchstbetrages, der im Wege der staatlichen Parteienfinanzierung an alle Parteien insgesamt ausgezahlt werden darf (sog. absolute Obergrenze). ${ }^{340}$ Die verfassungsgerichtlich entworfene absolute und relative Obergrenze wurde vom Gesetzgeber durch die Schaffung von $\$ 18$ Abs. 2 und Abs. 5 PartG umgesetzt. Die Berechnung der absoluten Obergrenze erfolgt dabei nach $\$ 18$ Abs. 2 PartG und richtet sich maßgeblich nach $\$ 18$ Abs. 2 S. 2 PartG an dem Preisindex der für eine Partei typischen Ausgaben in dem dem Anspruchsjahr vorangegangenem Jahr.

337 BVerfGE 85, 264 (286); BVerfGE 44, 125 (145 f.).

338 BVerfGE 85, 264 (285 ff.).

339 BVerfGE 85, 264 (288ff.).

340 BVerfGE 85, 264 (290 ff.); siehe dazu auch Schwartmann, Verfassungsfragen der Allgemeinfinanzierung politischer Parteien, 1995, S. 223. 
VI. Verbot steuerlicher Begünstigungen von Zuwendungen juristischer Personen an Parteien

Das Bundesverfassungsgericht urteilte auch hinsichtlich der durch die steuerlichen Begünstigungen erfolgenden mittelbaren staatlichen Parteienfinanzierung, dass eine steuerrechtliche Begünstigung von Zuwendungen juristischer Personen mit dem verfassungsrechtlichen Grundsatz der gleichen Teilhabe aller Bürger an der politischen Willensbildung unvereinbar $^{341}$ und die Höchstgrenze des Abzugsbetrages vom Gesetzgeber auch (mit 60.000 DM bzw. 120.000 DM bei Zusammenlegung von Ehegatten) zu hoch angesetzt worden sei. ${ }^{342}$ Das Erreichen dieser Höchstbeträge sei für einen Großteil der Bürger weiterhin nicht möglich, sodass nur ein bestimmter Kreis an wohlsituierten Spendern die steuerlichen Vergünstigungen vollumfänglich ausschöpfen könne. Der Grundsatz der gleichen Teilhabe aller Bürger an der politischen Willensbildung sei durch die zu hoch bemessenen Höchstgrenzen der Abzugsfähigkeit verletzt worden.

Auch schloss sich das Bundesverfassungsgericht der in einem Sondervotum vertretenen Meinung des Bundesverfassungsrichters Ernst-Wolfgang Böckenförde im vorangegangenen Parteienfinanzierungsurteil an $^{343}$, und sah in der steuerlichen Privilegierung von Spenden juristischer Personen an Parteien, neben der hohen Abzugshöchstgrenze, ebenfalls einen Verstoß gegen den Grundsatz der gleichen Teilhabe aller Bürger am politischen Willensbildungsprozess. ${ }^{344}$ Die Personen, die hinter der Personengesellschaft oder Körperschaft stünden, erhielten durch die steuerliche Abzugsfähigkeit von Parteispenden im Rahmen der zu zahlenden Körperschaftssteuer im Vergleich zu anderen Bürgern eine zusätzliche Möglichkeit der politischen Einflussnahme. Dies geschehe insbesondere auf Kosten der übrigen Steuerzahler, wodurch die Ungleichbehandlung bei der Teilnahme an der politischen Willensbildung noch gravierender sei. Im Ergebnis wurde durch die verfassungsgerichtliche Rechtsprechung eine steuerliche Privilegierung von durch juristische Personen geleisteten Spenden für generell unzulässig erklärt und dem Gesetzgeber insoweit Grenzen bei den Bestimmungen der Begünstigten gesetzt. Allein Spenden von natürlichen

341 BVerfGE 85, 264 (314f.).

342 BVerfGE 85, 264 (312 ff.).

$343 \mathrm{Im}$ Folgenden: BVerfGE 85, 264 (314ff.), siehe das Sondervotum von Böckenförde in BVerfGE 73, 40 (103 ff.).

344 BVerfGE 85, 264 (314f.). 
Personen dürfen demnach durch den Gesetzgeber steuerrechtlich begünstigt werden.

\section{Parteienfinanzierung nach der Empfehlung der unabhängigen Sachverständigenkommission}

Durch den Wandel der verfassungsrechtlichen Rechtsprechung hinsichtlich der generellen Zulässigkeit einer allgemeinen Parteienfinanzierung wurde auf Initiative des ehemaligen Bundespräsidenten Richard von Weizsäcker eine Kommission unabhängiger Sachverständiger eingesetzt, die unter Berücksichtigung des verfassungsrechtlichen Mandats der Parteien und dem Urteil des Bundesverfassungsgerichts vom 09.04.1992 ${ }^{345}$ eine Empfehlung über die künftige Gestaltung der staatlichen Parteienfinanzierung abgeben sollte. ${ }^{346}$

In dem Bericht sah die Kommission die Ersetzung der bisherig gewährten Wahlkampfkostenerstattung durch eine die allgemeine politische Tätigkeit der Parteien finanzierende staatliche und unmittelbare Parteienfinanzierung vor. ${ }^{347}$ Zweck der neuen Parteienfinanzierung sollte nach den Vorstellungen der Kommission die Bekämpfung der Politikverdrossenheit und die Erweiterung der parteipolitischen Handlungsfähigkeit sein. ${ }^{348}$ Die Sachverständigenkommission sah in ihrer Empfehlung vor, dass die Bemessung der Höhe der staatlichen Zahlungen nach dem Grad des gesellschaftlichen Rückhaltes der Parteien innerhalb der Bevölkerung erfolgen müsse. Maßgebliche Kriterien, an denen sich der „gesellschaftliche Rückhalt" in tauglicher Art und Weise messen lassen könne, seien die Stimmanteile bei Landtags-, Bundestags- oder Europaparlamentswahlen, sowie die aus dem privatwirtschaftlichen Gesellschaftsbereich stammenden Spenden und Mitgliedsbeiträge. Als Wählerstimmenmindestquorum sah die Sachverständigenkommission in ihrer Empfehlung einen Anteil von 0,5\% der abgegebenen Wählerstimmen bei einer nicht näher qualifizierten Parla-

345 BVerfGE 85, $264 \mathrm{ff}$.

346 Kommission unabhängiger Sachverständiger, Empfehlung der Kommission unabhängiger Sachverständiger zur Parteienfinanzierung, 19.02.1993.

347 Dies., Empfehlung der Kommission unabhängiger Sachverständiger zur Parteienfinanzierung, 19.02.1993.

348 Dies., Empfehlung der Kommission unabhängiger Sachverständiger zur Parteienfinanzierung, 19.02.1993, S.21. 
mentswahl vor. ${ }^{349}$ Der individuell auszuzahlende Betrag solle, so wie das Bundesverfassungsgericht bereits im vorherigen Urteil feststellte, durch eine relative und der insgesamt zu gewährende Betrag durch eine absolute Obergrenze eingeschränkt werden. ${ }^{350}$

Auch der mittelbaren Parteienfinanzierung und der mit ihr zusammenhängenden verfassungsrechtlichen Problematik nahm sich die unabhängige Sachverständigenkommission an. So schlug sie vor, die in $\$ 34 \mathrm{~g}$ S. 2 EstG und $\ 10 \mathrm{~b}$ Abs. 2 EstG vorgesehene Grenze der Abzugsfähigkeit auf höchstens 2000 DM, bei Ehegatten 4000 DM, zu beschränken. ${ }^{351}$

\section{Moderne Parteienfinanzierung}

Auf Grundlage der Empfehlung der unabhängigen Sachverständigenkommission verabschiedete der Gesetzgeber 1994 das „Sechste Gesetz zur Änderung des Parteiengesetzes und anderer Gesetze“352. Durch dieses Gesetz erfolgte eine grundlegende Reformation des Parteienfinanzierungssystems. Nach $\mathbb{1 8}$ Abs. 1 PartG nahm die unmittelbare Parteienfinanzierung nun die Form einer durch Globalzuschüsse erfolgenden Teilfinanzierung der gesamten politischen Parteitätigkeit an.

Dem Vorschlag der unabhängigen Sachverständigenkommission folgend ersetze er die bis dahin gewährte Wahlkampfkostenerstattung durch ein die allgemeine politische Tätigkeit der Parteien förderndes System der unmittelbaren Parteienfinanzierung. Wie in der ständigen verfassungsgerichtlichen Rechtsprechung hervorgehoben und bereits im Rahmen der Regelung der Wahlkampfkostenerstattung auch vom Gesetzgeber vorgesehen, knüpft die Gewährung („Ob“) und die Höhe des staatlichen Zuschusses („Wie“) an den Rückhalt der Parteien in der Gesellschaft an. Der Gesetzgeber entschied, seine bereits bei der Regelung der Parteienfinanzierung in Form der Wahlkostenerstattung zum Ausdruck kommende Tendenz beizubehalten und die Gewährung der unmittelbaren staatlichen Parteienfinanzierung von dem Erreichen eines Mindeststimmenquorums abhängig zu machen. So müssen Parteien, um überhaupt in den Genuss der

349 Dies., Empfehlung der Kommission unabhängiger Sachverständiger zur Parteienfinanzierung, 19.02.1993, S. 25.

350 Dies., Empfehlung der Kommission unabhängiger Sachverständiger zur Parteienfinanzierung, 19.02.1993, S. $21 \mathrm{ff}$.

351 Dies., Empfehlung der Kommission unabhängiger Sachverständiger zur Parteienfinanzierung, 19.02.1993, S. $2131 \mathrm{f}$.

352 BGBl. 1994, I, S. $104 \mathrm{ff}$. 


\section{$\$ 3$ Institution der Parteienfinanzierung}

staatlichen Teilfinanzierung zu gelangen, bei Bundestags- und Europaparlamentswahlen nach $\mathbb{} 18$ Abs. 4 S. 1 PartG mindestens 0,5\% und bei Landtagswahlen mindestens $1 \%$ des Wählerstimmenanteils auf sich vereinen können.

Die Gesamthöhe des Betrages, der einer anspruchsberechtigten Partei zukommt, richtet sich dann nach der konkreten Anzahl der Wählerstimmen, die bei einer für die Parteienfinanzierung nach $\$ 18$ Abs. 1 S. 2, Abs. 4 S. 1 PartG maßgeblichen Wahl auf eine Partei entfallen und der an die Partei geleisteten Zuwendungen. So erhielten Parteien, wenn sie das Mindestquorum erreicht haben, für jede für sie abgegebene Stimme einen Betrag von einer Deutschen Mark (heute 0, 83 Cent). Ferner wurde jede Deutsche Mark, die einer Partei durch einen Mitgliedsbeitrag oder einer Spende zugutekam, mit der Gewährung von 0,50 DM (heute 0,45 Cent) durch die staatliche Teilfinanzierung honoriert. Allerdings wurde im Rahmen der an die Mitgliedsbeiträge und Spenden anknüpfenden Bezuschussung nur ein Betrag von höchstens 6000 DM (heute $3300 €$ ) pro Jahr berücksichtigt. Jeder darüberhinausgehende Betrag wurde nicht mehr durch staatliche Mittel honoriert. Ferner wurde durch die Schaffung des $\$ 25$ Abs. 3 PartG eine Publizitätsgrenze in Höhe von 20000 DM (heute $10000 €$ ) eingeführt.

Auch hinsichtlich der mittelbaren Parteienfinanzierung folgte der Gesetzgeber dem Richterspruch des Bundesverfassungsgerichts. Durch die Reformation der Parteienfinanzierung wurde, insbesondere im Körperschaftssteuergesetz, die steuerliche Anrechnungsfähigkeit von Spenden juristischer Personen i.S.d. $\ 1$ Abs. $1 \mathrm{KStG}$ an Parteien abgeschafft. Seit dem Inkrafttreten des „Sechsten Gesetzes zur Änderung des Parteiengesetzes und anderer Gesetze“ wird den Parteien ein System der staatlichen Finanzierung zur Verfügung gestellt, das nicht nur die Belastung der konkreten „Wahlkampfkosten“ verringert, sondern nun hauptsächlich die gesamte politische Tätigkeit der Parteien finanziell fördert.

\section{Erhöhung der absoluten Obergrenze}

Durch einen Beschluss des Deutschen Bundestages am 15. Juni 2018 wurde der Betrag der absoluten Obergrenze erhöht. ${ }^{353}$ Zwar sah die vorige Rechtslage bei der Bemessung der Höhe der absoluten Obergrenze einen Inflationsausgleich vor, doch sei dieser nach Auffassung der das Gesetz beschließenden Regierungsfraktionen aus CDU/CSU und SPD nicht mehr 
ausreichend, damit angesichts der „neuen Aufgaben oder sonstiger ein-

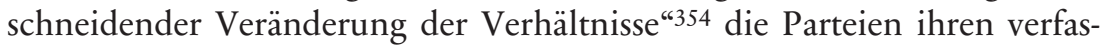
sungsrechtlichen Auftrag aus Art. 21 Abs.1. S. 1 GG, an der politischen Willensbildung des Volkes mitzuwirken, ordnungsgemäß wahrnehmen konnten. Insbesondere seien, so die Gesetzesbegründung, durch die fortschreitende Digitalisierung der Kommunikationswege und Medien eine Vielzahl neuer politischer Foren entstanden, auf denen sich Parteien zur Wahrnehmung ihres verfassungsrechtlichen Mandats betätigen müssten. ${ }^{355}$ Die erhöhten Einstiegs- und Betriebsinvestionen würden maßgeblich durch die Pflicht zur Erfüllung der Rahmenbedingungen zur Datensicherheit und die Sicherung eigener Auftritte und Kommunikationsbeiträge vor digitalen Angriffen entstehen. Weiter seien noch durch die „Veränderung der politisch-kulturellen und der rechtlichen Rahmenbedingungen neuer innerparteilicher Partizipationsinstrumente (Mitglieder- statt Delegiertenparteitage, Mitgliederentscheide und „erhöhten Transparenz- und Rechenschaftsanforderungen “356) erhebliche Kosten verursacht worden, zu deren Kompensation der durch die damalige Obergrenze eingeschränkte Betrag nicht mehr ausreichend sei.

$\mathrm{Ob}$ die Erhöhung der Obergrenze in dieser Form verfassungsmäßig war, wird das Bundesverfassungsgericht zu entscheiden haben. Am 05.07.2018 kündigten die Bundestagsfraktionen der FDP, Linken und Bündnis 90/Die Grünen an, das Änderungsgesetz ${ }^{357}$ im Rahmen eines abstrakten Normenkontrollverfahrens durch das Bundesverfassungsgericht auf seine Verfassungsmäßigkeit überprüfen zu lassen. Angesichts der dahinterstehenden Problematik der "Staatsfreiheit" der Parteien ${ }^{358}$ wird sich zeigen, ob eine zweckbezogene Erhöhung der absoluten Obergrenze durch den Gesetzgeber in dieser Form möglich ist.

\section{Parteienfinanzierung als Waffe einer wehrhaften Demokratie}

Das Finanzierungsmodell der allgemeinen Teilfinanzierung hat sich seit seiner Einführung bis zum Jahr 2017 im Grundsatz nicht wesentlich verändert. Am 17. Januar 2017 entschied das Bundesverfassungsgericht über

354 BT-Drucksache 19/2509, S. 6.

355 BT-Drucksache 19/2509, S. 6.

356 BT-Drucksache 19/2509, S. 6.

357 BGBl. 2018, I, S. 1116.

358 BVerfGE 20, 56 (101 f.); siehe auch Hesse, in: VVDStRL 17 (1967), S. 1, 33. 
einen Antrag des Bundesrates, die Verfassungswidrigkeit der Nationaldemokratischen Partei Deutschlands (NPD) festzustellen und sie als zwingende Folge hiervon zu verbieten. ${ }^{359}$ Das Gericht wies den Antrag des Bundesrates zurück, da der NPD kein für ein Verbot ausreichendes Gefahrenpotential und damit die Eigenschaft der „Verfassungswidrigkeit“, wie sie Art. 21 Abs. 2 GG vorsieht, nachgewiesen werden konnte. ${ }^{360}$ Es hob allerdings im Rahmen des Urteils hervor, dass „eine Modifizierung des Regelungskonzepts [des Art. 21 Abs. 2 GG], etwa hinsichtlich der Schaffung von Möglichkeiten gesonderter Sanktionierung im Fall der Erfüllung einzelner Tatbestandsmerkmale des Art. 21 Abs. 2 GG unterhalb der Schwelle des Parteiverbots, dem verfassungsändernden Gesetzgeber vorbehalten ist." 361 . Diese Feststellung, welche wohl eher einem verfassungsgerichtlichen Hinweis an die Legislative gleichkommt, veranlasste den Gesetzgeber am 13. Juli 2017 das Grundgesetz dahingehend zu ändern ${ }^{362}$, dass der Ausschluss verfassungsfeindlicher Parteien aus der staatlichen Parteienfinanzierung im Rahmen eines verfassungsrechtlichen Verfahrens nun möglich ist.

\section{Inhalt der Änderung}

Durch Änderung des Art. 21 Abs. 3 S. 1 GG entfällt die unmittelbare staatliche Parteienfinanzierung für diejenigen Parteien, die nach ihren Zielen oder dem Verhalten ihrer Anhänger darauf ausgerichtet sind, die freiheitliche demokratische Grundordnung zu beeinträchtigen oder zu beseitigen oder den Bestand der Bundesrepublik Deutschland zu gefährden. Zugleich entfällt nach Art. 21 Abs. 3 S. 2 GG jegliche steuerliche Begünstigung. Die Feststellung der Verfassungsfeindlichkeit obliegt nach Art. 21 Abs. 4 Alt. 2 GG dem Bundesverfassungsgericht.

Wenige Tage nach Inkrafttreten der Verfassungsänderung passte der Gesetzgeber die Parteienfinanzierung an den neuen Regelungsgehalt des Art. 21 GG an und änderte die zentralen Vorschriften im Parteiengesetz

359 BVerfGE 144, $20 \mathrm{ff}$.

360 Das Tatbestandsmerkmal „Darauf-Ausgehen“ setzt nach der neuen Rechtsprechung des Bundesverfassungsgerichts eine Gefahrenpotentialität hinsichtlich der Beseitigung der Beeinträchtigung der freiheitlichen demokratischen Grundordnung voraus. Diese „Potentialität“ konnte der NPD im laufenden Verfahren nicht nachgewiesen werden. Siehe BVerfGE 144, 20 (224f.).

361 BVerfGE 144, 20 (202).

362 BGBl. 2017, I, S. 2346. 
und den spezifischen Steuergesetzen. ${ }^{363}$ Wichtig ist dabei insbesondere die Änderung des $₫ 18$ Abs. 7 PartG. Demnach schied bisher eine Partei dann aus der Parteienfinanzierung aus, wenn sie sich aufgelöst hatte oder vom Bundesverfassungsgericht verboten wurde. Durch die Änderung wurde zusätzlich ein weiterer Satz an die Vorschrift angefügt, wonach eine Partei auch dann von der Finanzierung nach $\mathbb{S} \mathbb{S} 18 \mathrm{ff}$. PartG ausgeschlossen ist, wenn das Bundesverfassungsgericht im Rahmen des Finanzierungsausschlussverfahrens die Verfassungsfeindlichkeit der Partei feststellt. Daran anknüpfend sieht unter anderem $\$ 5$ Abs. $1 \mathrm{Nr} .7 \mathrm{KStG}$ vor, dass bei Entfallen der unmittelbaren staatlichen Parteienfinanzierung nach $₫ 18$ Abs. 7 S. 2 PartG auch eine Befreiung von der Körperschaftssteuer ipso iure entfällt.

\section{Neue Ratio der Parteienfinanzierung}

Die Änderung des Grundgesetzes modifiziert die Ratio der gesamten Institution der staatlichen Parteienfinanzierung. Während die ursprüngliche Intention eine formale staatliche Unterstützung der Parteien bei der Durchführung ihres politischen und verfassungsrechtlichen Mandats war, so ist sie heute zumindest auch zu einem Mittel des materiellen Verfassungsschutzes geworden. ${ }^{364}$ Der Staat hat durch die Etablierung eines staatlichen Parteienfinanzierungssystems die Finanzsituation des bundesdeutschen Parteienwesens in einem solchen Maße verändert, dass ein Ausschluss aus dem System einen nicht zu vernachlässigenden Wettbewerbsnachteil für eine betroffene Partei darstellt. Die der Rechtstellung der Parteien immanente Parteiengleichheit wird modifiziert. ${ }^{365}$ Eine verfassungskonforme Einstellung der Partei wird per constitutionem zum Wettbewerbsvorteil erhoben.

Ruft man sich ins Gedächtnis, dass die staatliche Parteienfinanzierung erst stückweise und unter strenger Korrektur der Judikative seit der Gründung der Bundesrepublik bis zum heutigen Tage entwickelt wurde, so hinterlässt das neue Finanzierungsausschlussverfahren einen bitteren Nachgeschmack. Denn der Staat sorgt seit der Einführung der staatlichen Partei-

363 BGBl. 2017, I, S. 2730.

364 Nikkho, DVBl 2018, 337 ff.; Ferreau, DÖV 2017, 494 (498); Kloepfer, NVwZ 2017, $913 \mathrm{ff}$.

365 Schwarz, NVwZ-Beilagenheft 2017, 39 (41), der in diesem Zusammenhang von einer „systemimmanenten Modifizierung der Chancengleichheit“ spricht. 
enfinanzierung dafür, dass Parteien fortschreitend von den öffentlichen Globalzuschüssen abhängig werden, um dann durch Umgestaltung des Finanzierungssystems das selbst etablierte Modell gegen unliebsame Parteien zu nutzen. Die Frage, ob die Modifikation der Parteienfinanzierung hin zum Werkzeug der „wehrhaften Demokratie“366 als solche zulässig ist, muss sich am Maßstab des Art. 79 Abs. 3 GG messen lassen. ${ }^{367}$

\section{Parteienfinanzierung als verfassungsrechtliches Institut?}

Neben der partiellen Zweckänderung der staatlichen Parteienfinanzierung wurde diese nun auch wörtlich im Verfassungstext, konkret in Art. 21 Abs. 3 S. 1 GG, verankert. Dadurch stellt sich langfristig und unter Vorbehalt der Verfassungsmäßigkeit der Verfassungsänderung die Frage, ob die Parteienfinanzierung zu einer verfassungsrechtlichen Institution erhoben wurde, die eine staatliche Pflicht zur Einrichtung und Aufrechterhaltung eines tauglichen staatlichen Parteienfinanzierungssystems begründet. Vor der Verfassungsänderung wurde eine durch das Grundgesetz begründete Finanzierungspflicht des Staates von der h.M. abgelehnt. ${ }^{368}$ In der Literatur wurde vereinzelnd eine staatliche Parteienfinanzierung als eine für die Parteiendemokratie konstitutive Institution erklärt und daraus ableitend eine objektive verfassungsrechtliche Pflicht des Staates konstruiert, ein staatliches Parteienfinanzierungssystem zu etablieren und aufrecht zu er-

366 BVerfGE 39, 334 (349); oder die Begrifflichkeit der „streitbaren Demokratie“ verwendend BVerfGE 5, 85 (139); BVerfGE 30, 1 (19).

367 Siehe hierzu $₫ 4 . D$.

368 BVerfGE 20, 56 (102); BVerfGE 52, 63 (86); BVerfGE 73, 40 (86); BVerfGE 104, 287 (300); BVerfGE 111, 54 (98f.) - ständige Rechtsprechung; zurückhaltender BVerfGE 85, 264 (288); Ipsen, in: Sachs (Hrsg.), Grundgesetz, ${ }^{8} 2018$, Art. 21, Rn. 96 ff.; Schröder, in: Merten/Papier (Hrsg.), Handbuch der Grundrechte V, 2013, $\mathbb{1} 119$, Rn. 51; Koch, in: Ipsen (Hrsg.), Parteiengesetz, 2008, Vorb. $\mathbb{S} 18$, Rn. 47; Küstermann, Das Transparenzgebot des Art. 21 Abs. 1 Satz 4 GG und seine Ausgestaltung durch das Parteiengesetz, 2003, S. 62; Kersten, in: Kersten/ Rixen/Augsberg (Hrsg.), Parteiengesetz (PartG) und europäisches Parteienrecht, 2009, \1, Rn.93; wohl auch Schwarz, NVwZ-Beilagenheft 2017, 39 (40), der nach Ablehnung eines Anspruchs der Parteien auf eine staatliche Finanzierung auf eine staatliche Schutzpflicht zur Funktionsgewährleistung des Parteiwesens hinweist. 
halten. ${ }^{369}$ Nach der ausschließlich in der Literatur vertretenen Ansicht soll aus der objektiv-rechtlichen Institutsgarantie im Einzelfall auch subjektivrechtliche Ansprüche der Parteien gegen den Staat auf die Gewährung von Finanzmitteln begründet werden können. ${ }^{370}$

$\mathrm{Ob}$ eine Parteiendemokratie ohne staatliche Parteienfinanzierung tatsächlich langfristig nicht aufrechtzuerhalten wäre, lässt sich stark bezweifeln. Wie Jörn Ipsen überzeugend darstellt, gab es vor der Änderung des Art. 21 Abs. 3 GG für eine solche verfassungsrechtliche Institution weder Anhaltspunkte im Wortlaut der Norm, noch spricht die Entstehungsgeschichte der Parteienfinanzierung dafür. ${ }^{371}$ Gregor Stricker kam zu dem Ergebnis, dass selbst bei hohen finanziellen Verlusten ein Ausgleich im Wege der Mitgliedsbeiträge erzielt werden könne. ${ }^{372}$

Das Bundesverfassungsgericht hat in seiner Rechtsprechung zu der $\mathrm{Zu}-$ lässigkeit der staatlichen Parteienfinanzierung auch deutlich hervorgehoben, dass das Grundgesetz „den Parteien das Risiko des Fehlschlagens eigener Bemühungen um ihre Finanzierung nicht abgenommen hat“. ${ }^{373}$ Die Verfassungsordnung nimmt damit in Kauf, dass sich Parteien aufgrund schlechter Finanzlage auflösen oder ihren politischen Wirkungskreis verkürzen müssen. Für die Annahme, dass eine Parteiendemokratie nicht ohne eine staatliche Parteienfinanzierung aufrechtzuerhalten wäre, gibt es keine Anhaltspunkte. Schon vor der Einführung der Steuervergünstigungen und der Wahlkampfkostenerstattung konnten stabile Regierungen und ein funktionierendes Parlament durch die damals schon vorhandenen Parteien gebildet werden. Inwieweit die Demokratie ohne eine staatliche

369 Morlok, in: Dreier/Bauer (Hrsg.), Grundgesetz, ${ }^{3} 2015$, Art. 21, Rn. 45; ders., in: Tsatsos/Fromont (Hrsg.), Politikfinanzierung in Deutschland und in Europa, 1997, S. 92; Klein, in: Maunz/Dürig (Hrsg.), Grundgesetz, 2018, Art. 21, Rn. 434; Morlok, in: Dreier/Bauer (Hrsg.), Grundgesetz, ${ }^{32015}$, Art. 21, Rn. 45; bejahend nur für den Fall, dass ohne Parteienfinanzierung die moderne Demokratie gefährdet wäre Pieroth, in: Jarass/Pieroth (Hrsg.), Grundgesetz für die Bundesrepublik Deutschland, ${ }^{14} 2016$, Art. 21, Rn. 14.

370 Morlok, in: Dreier/Bauer (Hrsg.), Grundgesetz, ${ }^{32015}$, Art. 21, Rn. 45; siehe auch Klein, in: Maunz/Dürig (Hrsg.), Grundgesetz, 2018, Art. 21, Rn. 434.

371 Ipsen, in: Sachs (Hrsg.), Grundgesetz, ${ }^{8} 2018$, Art. 21, Rn. 96.

372 Ausführlich und unter Darlegung von (zugegebenermaßen heutzutage veralteten, aber dennoch in diesem Fall aufschlussreichen) Zahlen Stricker, Der Parteienfinanzierungsstaat, 1998, S. 112-116.

373 BVerfGE 111, 54 (99). 
Parteienfinanzierung gefährdet sei, können auch die Stimmen der Literatur nicht überzeugend belegen. ${ }^{374}$

Die „normative Enthaltsamkeit“ 375 des Grundgesetzes hinsichtlich der staatlichen Parteienfinanzierung hat der verfassungsändernde Gesetzgeber durch die Einführung des Finanzierungsausschlussverfahrens für verfassungsfeindliche Parteien im Art. 21 Abs. 3 GG nun aufgehoben. Demnach entwickelt sich allerdings die Stellung der staatlichen Parteienfinanzierung als verfassungsrechtliche Institution nicht aus einer "Schutzpflicht" des Staates für die Parteiendemokratie, sondern aus der Modifizierung der Rechtsstellung der Parteien durch das neue Werkzeug der „wehrhaften Demokratie". 376

Zunächst verankerte der verfassungsändernde Gesetzgeber im Normtext des Art. 21 Abs. 3 S. 1 GG die staatliche Finanzierung von Parteien wörtlich. Das Grundgesetz geht nunmehr davon aus, dass es so etwas wie eine staatliche Förderung finanzieller Art für Parteien gibt. Der verfassungsändernde Gesetzgeber schuf anlässlich des verfassungsgerichtlichen Hinweises im Rahmen des zweiten NPD-Verbotsverfahrens ${ }^{377}$ eine Sanktion unterhalb der Schwelle des Parteiverbotsverfahrens nach Art. 21 Abs. 2 GG und modifizierte damit die Rechtsstellung der Parteien. Der dahinterstehende Gedanke, dass der Staat es lediglich unterlässt, Parteien weiterhin finanziell zu fördern ${ }^{378}$, die sich gegen die freiheitliche demokratische Grundordnung oder den Bestand der Bundesrepublik Deutschland rich-

374 So wird zwar stets angeführt, dass den Staat hinsichtlich der Aufrechterhaltung der von dem Grundgesetz vorgesehenen Parteiendemokratie eine „Schutzpflicht“ trifft, allerdings fehlt jedwede Erklärung oder Darlegung, weshalb die Parteiendemokratie ohne staatliche Parteienfinanzierung gefährdet sei. Vgl. in diesem Zusammenhang Morlok, in: Dreier/Bauer (Hrsg.), Grundgesetz, ${ }^{3} 2015$, Art. 21, Rn. 45; ders., in: Tsatsos/Fromont (Hrsg.), Politikfinanzierung in Deutschland und in Europa, 1997, S. 92; Klein, in: Maunz/Dürig (Hrsg.), Grundgesetz, 2018, Art. 21, Rn. 434; Morlok, in: Dreier/Bauer (Hrsg.), Grundgesetz, ${ }^{3}$ 2015, Art. 21, Rn. 45; am überzeugendsten noch Pieroth, in: Jarass/Pieroth (Hrsg.), Grundgesetz für die Bundesrepublik Deutschland, ${ }^{14} 2016$, Art. 21, Rn. 14, der das tatsächliche Vorliegen einer Gefährdung noch als konstitutives Merkmal der staatlichen Schutzpflicht ansieht, dabei jedoch keine Stellung zu der Frage nimmt, ob eine solche ohne staatliche Parteienfinanzierung tatsächlich gegeben sei.

375 Siehe zum Begriff Klein, in: Maunz/Dürig (Hrsg.), Grundgesetz, 2018, Art. 21, Rn. 406.

376 Siehe hierzu Nikkho, DVBl 2018, 337 ff.; a.A. Ipsen, in: Sachs (Hrsg.), Grundgesetz, ${ }^{8} 2018$, Art. 21, Rn. 98.

377 BVerfGE 144, $20 \mathrm{ff}$.

378 Grundlegend zu dieser Problematik Linck, DÖV 2006, 939 ff. 
ten, ist nicht ausreichend, um die Tragweite der Verfassungsänderung angemessen und vollumfänglich zu erfassen. Das von Jörn Ipsen vorgetragene Argument, der Verfassungsänderung käme nur eine mit der Praxis der Parteienfinanzierung verbundene affirmative Bedeutung $\mathrm{zu}^{379}$, übersieht die Abhängigkeit des Regelungsgehaltes des Art. 21 Abs. 3 GG von der Existenz der Parteienfinanzierung. Die Änderung bestätigt nicht nur die generelle Zulässigkeit der Parteienfinanzierung, sondern verlangt darüber hinaus auch über Absatz 5 eine bundesgesetzliche Ausgestaltung des Finanzierungsausschlussverfahrens. Dieses Verfahren nach Art. 21 Abs.3GG kann allerdings nur dann tauglich ausgestaltet werden, wenn eine Parteienfinanzierung existiert. Es ist nicht ausgeschlossen, dass der verfassungsändernde Gesetzgeber durch das Änderungsgesetz vom 18.07.2017380 die Rechtsprechung des Bundesverfassungsgerichtes bestätigen wollte. Allerdings lässt der Wortlaut des Absatz 3 i.V.m. Absatz 5 sowie der Zweck des Finanzierungsausschlussverfahrens keinen anderen Schluss zu, als dass der Gesetzgeber verpflichtet ist, ein für das Finanzierungsausschlussverfahren konstitutives Parteienfinanzierungssystem aufrechtzuerhalten und in tauglicher Weise auszugestalten. ${ }^{381}$

Der freie und gleiche Parteienwettbewerb wurde, auch wenn dies bis zum ersten Ausschluss einer Partei aus der staatlichen Parteienfinanzierung praktisch keine spürbare Wirkung entfalten mag, grundlegend umgestaltet. Während ein erfolgreiches Parteiverbotsverfahren nach Art. 21 Abs. 2 GG eine Partei vollständig aus dem Parteienwettbewerb entfernt, gestaltet das Finanzierungsausschlussverfahren nach Art. 21 Abs. 3 GG innerhalb des Parteienwettbewerbs ein „Zwei-Klassen-System“, indem durch den Staat missbilligte, jedoch geduldete ${ }^{382}$ Parteien gegen vom Staat geförderte und damit im Wettbewerb privilegierte Wahlkampfkonkurrenten antreten müssen. Die Entscheidung des verfassungsändernden Gesetzgebers, eine im Grundgesetz verankerte Sanktionsmöglichkeit unterhalb der Schwelle des Parteiverbotsverfahrens zu schaffen, hat zur Folge, dass eine Institution der staatlichen Parteienfinanzierung zwingend existieren muss. ${ }^{383}$ Das verfassungsrechtlich etablierte Werkzeug der „wehrhaften Demokratie" setzt somit voraus, dass der Staat ein System der Parteienfinan-

379 Ipsen, in: Sachs (Hrsg.), Grundgesetz, ${ }^{8} 2018$, Art. 21, Rn. 98.

380 BGBl. 2017 I, S. 24551 ff.

381 Nikkho, DVBl 2018, $337 \mathrm{ff}$.

382 Zum Konzept der ablehnenden Duldung im Zusammenhang mit dem Finanzierungsausschlussverfahren siehe Kloepfer, NVwZ 2017, $913 \mathrm{ff.}$

383 Vgl. Nikkho, DVBl 2018, 337 (339 ff.). 
zierung aufrechterhält, um verfassungsfeindlich ausgerichtete Parteien hiervon ausschließen zu können. Die staatliche Parteienfinanzierung wird zum Mittel des objektiven Verfassungsschutzes; der durch sie beeinflusste Parteienwettbewerb entwickelt sich für aus der staatlichen Finanzierung ausgeschlossene Parteien zu einer unmittelbaren Bedrohung ihrer Existenz. Das Institut der staatlichen Parteienfinanzierung ist deshalb Folge des „neuen“ objektiven Verfassungsschutzes in Art. 21 Abs 3 GG. Dies wirft die Frage auf, ob Parteien aus einem objektiv-rechtlichen Institut zum Schutze der freiheitlichen demokratischen Grundordnung eigene, subjektiv-rechtliche Ansprüche auf die Gewährung einer staatlichen Finanzierung ableiten können ${ }^{384}$ und mithin, ob ein eigenes, justiziables Recht der Parteien auf eine staatliche Finanzierung ihrer allgemeinen politischen Tätigkeit existiert.

Die Ratio des Art. 21 Abs. 3 GG steht einem subjektiv-rechtlichen Anspruch der Parteien auf die konkret-individuelle Gewährung von staatlichen Finanzmitteln entgegen. ${ }^{385}$ Vorausgesetzt wird allein ein Parteienfinanzierungssystem, welches den Ausschluss verfassungsfeindlicher Parteien aus der staatlichen Parteienfinanzierung ermöglicht. Vorrangig soll nicht nur die politische Willensbildung profitieren, sondern sich der Schutz der freiheitlichen demokratischen Grundordnung intensivieren. Zwar ist die öffentliche Mittelgewährung an Parteien ein konstitutives Merkmal der staatlichen Parteienfinanzierung, allerdings obliegt es nach dem Ausgestaltungsauftrag des Art. 21 Abs. 5 GG allein dem Bund, ein staatliches Parteienfinanzierungssystem einzurichten und die Voraussetzungen der Gewährung im Einklang mit dem Grundgesetz festzusetzen. ${ }^{386}$ Den Parteien kann aus diesem Grund kein verfassungsrechtlicher Anspruch auf Gewährung von öffentlichen Geldern in einer konkreten Höhe im Zusammenhang mit der staatlichen Parteienfinanzierung zustehen; ein solcher ist ihnen lediglich durch Bundesgesetz einzuräumen. ${ }^{387} \mathrm{Da}$ das Finanzierungsausschlussverfahren allerdings einen unmittelbaren Einfluss auf die Rechtsstellung der Parteien ausübt, und der Bund zumindest verpflichtet ist, ein solches Institut einzurichten und über Bundesgesetz den Parteien auch subjektive Ansprüche einzuräumen, wird man einen verfas-

384 Morlok, in: Dreier/Bauer (Hrsg.), Grundgesetz, ${ }^{3} 2015$, Art. 21 Rn. 45; ders., in: Tsatsos/Fromont (Hrsg.), Politikfinanzierung in Deutschland und in Europa, 1997, S. 92.

385 Nikkho, DVBl 2018, 337 (342).

386 Ders., DVB1 2018, 337 (341 f.).

387 Ders., DVB1 2018, 337 (342). 
sungsrechtlichen Anspruch der Parteien aus Art. 21 Abs. 1 S. 1, Abs. 3 GG gerichtet auf die Einrichtung und Aufrechterhaltung eines tauglichen staatlichen Parteienfinanzierungssystems annehmen können.

\section{Anspruchsvoraussetzungen und ibre verfassungsrechtliche Problematik}

Die Anspruchsvoraussetzungen bergen, wie bereits die historische Einleitung zur Parteienfinanzierung ansatzweise indizierte, eine Reihe wesentlicher Probleme, die maßgeblich mit der Chancengleichheit der Parteien zusammenhängen. Insbesondere können Parteien bereits über die Mindestquoren, die zwar nicht an die inhaltliche politische Ausrichtung, sondern an den „gesellschaften Rückhalt" anknüpfen, aus der staatlichen Parteienfinanzierung ausgeschlossen werden. Dies vor Augen geführt lohnt sich dahingehend eine tiefergehende Auseinandersetzung. In diesem Rahmen erfolgt zunächst eine Auseinandersetzung mit dem „Parteibegriff“, bevor sodann die übrigen Anspruchsvoraussetzungen untersucht werden.

\section{Parteieneigenschaft}

Der Parteienbegriff ist zur Qualifizierung einer Vereinigung als „Partei“ konkret zu bestimmen, da alle parteispezifischen Rechte und Pflichten erst durch ihn begründet werden. ${ }^{388}$ Die von der Definition geforderten Voraussetzungen einer Partei entfalten unmittelbare Rechtswirkung und legen Vereinigungen Pflichten auf, die diese erfüllen müssen, um als Partei anerkannt zu werden und auch als solche anerkannt zu bleiben. ${ }^{389}$ Der Begriff der „Partei“ richtet sich nach dem Inhalt des verfassungsrechtlichen Mandates des Art. 21 Abs. 1 GG und gibt ihm insoweit Leitlinien vor, die einzuhalten sind, um eine Vereinigung als „Partei“ zu qualifizieren.

Der Gesetzgeber hat durch die Schaffung des $\$ 2$ Abs. 1 PartG versucht, den grundgesetzlichen Parteienbegriff aus Art. 21 Abs. 1 GG einfachgesetzlich näher zu konkretisieren bzw. zu definieren. Nach dieser Norm sind Parteien Vereinigungen von Bürgern, die dauernd oder für längere Zeit für den Bereich des Bundes oder eines Landes auf die politische Willensbildung Einfluss nehmen und an der Vertretung des Volkes im Deutschen Bundestag oder einem Landtag mitwirken wollen, wenn sie nach dem Ge-

388 Henke, Das Recht der politischen Parteien, 1964, S. 13.

389 Ders., Das Recht der politischen Parteien, 1964, S. 13. 
samtbild der tatsächlichen Verhältnisse, insbesondere nach Umfang und Festigkeit ihrer Organisation, nach der Zahl ihrer Mitglieder und nach ihrem Hervortreten in der Öffentlichkeit eine ausreichende Gewähr für die Ernsthaftigkeit dieser Zielsetzung bieten. Nach $\$ 2$ Abs. 1 S. 2 PartG können nur natürliche Personen Mitglieder einer Partei sein.

Der Begriff in $\$ 2$ Abs. 1 PartG stellt keine authentische Interpretation des Verfassungsbegriffs dar. ${ }^{390}$ Art. 21 Abs. 1 GG enthält zwar keine Definition der „Partei“, setzt jedoch durch die Bezeichnung der grundgesetzlichen Aufgabe in Art. 21 Abs. 1 GG ein „konstituierendes Element“ des verfassungsrechtlichen Begriffs voraus. ${ }^{391}$ Der einfache Gesetzgeber ist deshalb nicht befugt, über Art. 21 Abs. 3 GG den Parteienbegriff authentisch $\mathrm{zu}$ interpretieren. ${ }^{392}$ Eine Konkretisierung des Begriffes ist nur solange möglich, wie das vom verfassungsrechtlichen Mandat in Art. 21 Abs. 1 S. 1 GG vorgegebene Leitbild gewahrt bleibt. Dem $\$ 2$ Abs. 1 PartG kommt in diesem Sinne lediglich eine Hilfsfunktion zu. ${ }^{393}$

Der Parteienbegriff kann in Anlehnung an die einfachgesetzliche Definition des $\mathbb{2}$ Abs. 1 PartG durch die Systematisierung der ihr innewohnenden Elemente näher gekenneichnet werden. So enthält der Begriff der „Partei“ ein Struktur-, Ziel-, und Ernsthaftigkeitselement. ${ }^{394}$ Diese Elemente leiten sich, wie die gesamte Definition, aus den verfassungsrechtlichen Aufgaben und dem Zweck und Bedeutung der Partei für ein demokratisches Herrschaftssystem ab.

390 Morlok, DVBl 1989, 393 (395); ders., in: Dreier/Bauer (Hrsg.), Grundgesetz, ${ }^{3}$ 2015, Art. 21 Rn. 363; Streinz, in: Huber/Voßkuhle (Hrsg.), Grundgesetz, ${ }^{7} 2018$, Art. 21, Rn. 46; Ipsen, in: ders. (Hrsg.), Parteiengesetz, 2008, $\mathbb{2}$ 2, Rn. 2; Henrichs, DVB1 1958, 227 (229).

391 Seifert, Die politischen Parteien im Recht der Bundesrepublik Deutschland, 1975, S. 159; Klein, in: Maunz/Dürig (Hrsg.), Grundgesetz, 2018, Art.21, Rn. 222.

392 Ipsen, in: Sachs (Hrsg.), Grundgesetz, ${ }^{8} 2018$, Art. 21, Rn. 16; Kunig, in: Böckenförde/Isensee/Kirchhof (Hrsg.), Handbuch des Staatsrechts der Bundesrepublik Deutschland III, ${ }^{3} 2005, \mathbb{}$ 40, Rn. 15.

393 Morlok, in: Dreier/Bauer (Hrsg.), Grundgesetz, ${ }^{3} 2015$, Art. 21, Rn. 34.

394 Ders., in: Dreier/Bauer (Hrsg.), Grundgesetz, ${ }^{3} 2015$, Art. 21, Rn. 35; Streinz, in: Huber/Voßkuhle (Hrsg.), Grundgesetz, ${ }^{72018}$, Art. 21, Rn. 52; Pieroth, in: Jarass/ Pieroth (Hrsg.), Grundgesetz für die Bundesrepublik Deutschland, ${ }^{14} 2016$, Art. 21, Rn. 5 - 10; Kunig, in: Böckenförde/Isensee/Kirchhof (Hrsg.), Handbuch des Staatsrechts der Bundesrepublik Deutschland III, ${ }^{3} 2005$, $\mathbb{S} 40$, Rn. 6 - 13; Hettich, Die Zulässigkeit verschiedener Handlungsalternativen des Staates im Vorgehen gegen extremistische Parteien unter Berücksichtigung des Parteienprivilegs, 2015, S. 52. 


\section{Die parteibildenden „Elemente“}

Das Strukturelement verlangt zunächst einen gefestigten Zusammenschluss von Personen zu einem bestimmten Zweck ${ }^{395}$ und setzt eine körperschaftliche Organisationsstruktur voraus, die gewährleistet, dass die wesentliche Bestimmungsmacht in der Partei bei den Mitgliedern liegt und dadurch überhaupt die verfassungsrechtliche Aufgabe wahrgenommen werden kann. ${ }^{396}$ Die demokratische Ordnungsstruktur wird durch Art. 21 Abs. 1 S. 3 GG vorausgesetzt und verlangt, dass die parteilichen Entscheidungen durch die einzelnen Mitglieder in Form der Parteibasis legitimiert werden müssen. Aus der demokratischen Organisationsstruktur folgt auch, dass die Chancengleichheit der Bürger bei der politischen Einflussnahme auf den parteilichen Entscheidungsprozess gewahrt werden muss und deshalb nur natürliche Personen als Mitglied in eine Partei eintreten und darin verbleiben können. ${ }^{397}$ Die Rechtsform der Vereinigung bestimmt sich nach dem bürgerlichen Recht, unabhängig von ihrer Rechtsfähigkeit. ${ }^{398}$

Nach dem einfachgesetzlichen Parteienbegriff des $\$ 2$ Abs. 3 PartG ist eine Vereinigung dann keine Partei, wenn die Mehrheit der Mitglieder der Vereinigung oder der Mitglieder des Vorstands der Vereinigung Ausländer sind. Die sich zu einem festen Zusammenschluss zusammenfindenden Personen müssen somit Deutsche im Sinne des Art. 116 Abs. 1 GG sein. Dieser Umstand ist dahingehend problematisch, dass $\$ 2$ Abs. 3 PartG durch den umfassenden Begriff „Ausländer“ auch Staatsangehörige der Mitgliedsstaaten der Europäischen Union ausschließt, weshalb ihre Verfassungsmäßigkeit bezweifelt wird. Angesichts der fehlenden Relevanz für die vorliegende Arbeit wird auf die einschlägige Literatur verwiesen. 399

395 Streinz, in: Huber/Voßkuhle (Hrsg.), Grundgesetz, ${ }^{7} 2018$, Art. 21, Rn. 53.

396 Vgl. Morlok, in: Dreier/Bauer (Hrsg.), Grundgesetz, ${ }^{3} 2015$, Art. 21, Rn. 36; Streinz, in: Huber/Voßkuhle (Hrsg.), Grundgesetz, ${ }^{72018, ~ A r t .21, ~ R n . ~} 53$ m.w.N.

397 Vgl. Kunig, in: Arnauld (Hrsg.), Grundgesetz-Kommentar, 2012, Art. 21, Rn. 14; Morlok, in: Dreier/Bauer (Hrsg.), Grundgesetz, ${ }^{3} 2015$, Art. 21, Rn. 36.

398 Vgl. Kunig, in: Böckenförde/Isensee/Kirchhof (Hrsg.), Handbuch des Staatsrechts der Bundesrepublik Deutschland III, ${ }^{3} 2005$, $\$ 40$, Rn. 6; so sind zum Beispiel die CDU und die SPD als nichtrechtsfähige Vereine organisiert, die FDP als eingetragener Verein nach $\$ 21 \mathrm{BGB}$.

399 Die Verfassungswidrigkeit der Norm vertretend Wietschel, Der Parteibegriff, 1996, S. 147, Fn. 436; Dolde, Die politischen Rechte der Ausländer in der Bundesrepublik, 1972, S.73; Zuleeg, DÖV 1973, 361 (370); a.A. Pieroth, in: Jarass/ Pieroth (Hrsg.), Grundgesetz für die Bundesrepublik Deutschland, ${ }^{14} 2016$, Art. 21, Rn. 5; Kunig, in: Arnauld (Hrsg.), Grundgesetz-Kommentar, 2012, 
Das Zielelement gibt, wie in der Bezeichnung bereits angedeutet, die Zweckrichtung der Vereinigung vor, damit diese als „Partei“ anerkannt werden kann. Eine Partei muss demnach durch die Mitwirkung an der Wahl der Volksvertretung auf die politische Willensbildung des Volkes Einfluss nehmen. ${ }^{400} \$ 2$ Abs. 1 S. 1 PartG konkretisiert die Zielvorgabe insoweit, dass eine Partei dauernd oder auf längere Zeit für den Bereich des Bundes oder eines Landes auf die politische Willensbildung Einfluss nehmen und an der Vertretung des Volkes im Deutschen Bundestag oder einem Landtag mitwirken muss. ${ }^{401}$ Die konkrete Beteiligung an Wahlen wird zwar in $\mathbb{} 2$ Abs. 1 S. 1 PartG nicht erwähnt, dieses Voraussetzung ergibt sich jedoch aus $\mathbb{2}$ Abs. 2 PartG $^{402}$, wonach Parteien dann nicht mehr als solche gelten, wenn sie sechs Jahre auf Bundes- oder Landesebene keine eigenen Wahlvorschläge eingereicht haben. Das Erreichen des Ziels ist nicht ausschlaggebend, ein voluntatives Streben danach reicht bereits aus. ${ }^{403}$

Durch $₫ 2$ Abs. 1 S. 1 PartG wird ferner eine „ernsthafte“ Verfolgung der parteispezifischen Zielsetzung vorausgesetzt. ${ }^{404}$ Demnach ist es notwendig, dass Parteien insbesondere nach Umfang und Festigkeit ihrer Organisation, nach der Zahl ihrer Mitglieder und nach ihrem Hervortreten in der Öffentlichkeit eine ausreichende Gewähr für die Ernsthaftigkeit dieser Zielsetzung bieten. Vornehmlich handelt es sich bei dem Element der Ernsthaftigkeit um eine gebotene Missbrauchskontrolle ${ }^{405}$, die verhindern

Art. 21, Rn.28; Isensee, in: VVDStRL 32 (1974), S. 98; Seifert, Die politischen Parteien im Recht der Bundesrepublik Deutschland, 1975, S. 169.

400 Klein, in: Maunz/Dürig (Hrsg.), Grundgesetz, 2018, Art. 21, Rn. 230; Morlok, in: Dreier/Bauer (Hrsg.), Grundgesetz, ${ }^{3} 2015$, Art. 21, Rn. 37.

401 Dass eine Partei neben der Vertretung des Volkes im Bundes- oder Landtag noch auf die politische Willensbildung Einfluss nehmen soll ist zwar richtig, jedoch in der gesetzlichen Begriffsdefinition überflüssig. Durch die Definition soll lediglich eine Abgrenzung zu anderen politischen Vereinen erfolgen, so Seifert, Die politischen Parteien im Recht der Bundesrepublik Deutschland, 1975, S. 162.

402 Ders., Die politischen Parteien im Recht der Bundesrepublik Deutschland, 1975, S. 163.

403 Wietschel, Der Parteibegriff, 1996, S. 158; Hettich, Die Zulässigkeit verschiedener Handlungsalternativen des Staates im Vorgehen gegen extremistische Parteien unter Berücksichtigung des Parteienprivilegs, 2015, S. 53.

404 Vgl. BVerfGE 91, 262 (271 f.); vgl. auch BVerfGE 91, 276 (289); Wißmann, in: Kersten/Rixen/Augsberg (Hrsg.), Parteiengesetz (PartG) und europäisches Parteienrecht, 2009, $\$ 2$, Rn. 40.

405 Vgl. Klein, in: Maunz/Dürig (Hrsg.), Grundgesetz, 2018, Art. 21, Rn. 229; Morlok, in: Dreier/Bauer (Hrsg.), Grundgesetz, ${ }^{3} 2015$, Art. 21, Rn. 40; Seifert, Die politischen Parteien im Recht der Bundesrepublik Deutschland, 1975, S. 165. 
soll, dass solche Vereinigungen in den Genuss der parteispezifischen Rechte und Pflichten kommen, ohne die im Grundgesetz vorgesehene Aufgaben und Verpflichtungen ernsthaft erfüllen zu wollen. Zwingend Voraussetzung, um als Vereinigung dem Parteienbegriff zu unterfallen, ist nach $\$ 2$ Abs. 2 PartG die Teilnahme an Wahlen. ${ }^{406}$ Das Verlangen nach einer ernsthaften Zielverfolgung ist durchaus berechtigt.

Ob die Voraussetzungen für die „Ernsthaftigkeit“ einer Partei vorliegen, bestimmt sich nach objektiven Kriterien. ${ }^{407}$ Nach der Rechtsprechung des Bundesverfassungsgerichts bestimmt sich die „Ernsthaftigkeit“ nach dem "Gesamtbild der tatsächlichen Verhältnisse“. ${ }^{408}$ Diese "tatsächlichen Verhältnisse" ergeben sich auch aus den in $\$ 2$ Abs. 1 S. 1 PartG genannten Voraussetzungen der „Ernsthaftigkeit“, sind dabei jedoch nicht abschließend, was sich aus dem Wort „insbesondere“ herleiten lässt. 409

Durch die Betrachtung des „Gesamtbilds der tatsächlichen Verhältnisse“ muss eine Vereinigung nach der Rechtsprechung des Bundesverfassungsgerichts nicht alle Voraussetzungen des $\$ 2$ Abs. 1 S. 1 PartG gleichermaßen erfüllen; die Vereinigungen sind nur dann nicht als Parteien anzuerkennen, wenn sie offensichtlich nicht imstande sind, auf die politische Willensbildung des Volkes Einfluss zu nehmen und die Verfolgung dieser Zielsetzung erkennbar unrealistisch und aussichtslos ist. ${ }^{410}$ An die Zahl der Mitglieder allein dürften keine allzu hohen Anforderungen gestellt werden $^{411}$, acht Mitglieder reichen nach der Rechtsprechung des Bundesverfassungsgerichts jedoch nicht aus. ${ }^{412}$ Auch müssen Parteien nach der Rechtsprechung des Bundesverfassungsgerichts ab dem Zeitpunkt ihrer Gründung „zunehmend in der Lage sein, die ihnen nach $\$ 2$ Abs. 1 PartG in Übereinstimmung mit dem Grundgesetz zugedachten Aufgaben wirksam zu erfüllen“. 413

In der Literatur wird das Element der „Ernsthaftigkeit“ zwar wohlwollend, die Rechtsprechung des Bundesverfassungsgerichts dazu jedoch nicht

406 Wietschel, ZRP 1996, 208 (209).

407 So treffend Morlok, in: Dreier/Bauer (Hrsg.), Grundgesetz, ${ }^{3} 2015$, Art. 21, Rn. 40; vgl. auch BVerfGE 91, 276 (288).

408 BVerfGE 47, 198 (222); BVerfGE 89, 291 (311); BVerfGE 91, 276 (288).

409 Vgl. BVerfGE 91, 276 (288).

410 BVerfGE 91, 276 (289).

411 Vgl. BVerfGE 24, 300 (332).

412 BVerfGE 134, 131 (134f.); kritisch Kunig, in: Böckenförde/Isensee/Kirchhof (Hrsg.), Handbuch des Staatsrechts der Bundesrepublik Deutschland III, ${ }^{3} 2005$, $\$ 40$, Rn. 79.

413 BVerfGE 91, 276 (287). 


\section{\3 Institution der Parteienfinanzierung}

unkritisch aufgenommen. Mangels einer hervorgehobenen Bedeutung des Streitstandes für die Arbeit wird auch hier auf die einschlägige Literatur verwiesen. ${ }^{414}$

\section{Annex: Parteienregistrierung}

In der Praxis erweist sich die Anerkennung von Vereinigungen als Parteien kompliziert. So kann das Infragestellen der Parteieneigenschaft einer Vereinigung zum Beispiel zu einer Nichtzulassung zu der Bundestagswahl nach $\$ 18$ Abs. 4 BWG oder dem Ausschluss von der staatlichen Parteienfinanzierung nach $\ 18 \mathrm{ff}$. PartG führen. Auch existiert keine zentrale Stelle, die über das Vorliegen der Parteieneigenschaft einer Vereinigung verbindlich für andere Behörden entscheidet. 415 Die Mitteilung an den Bundeswahlleiter nach $\$ 6$ Abs. 3 BWG sowie die Feststellung des Bundeswahlausschusses nach $\$ 18$ Abs. 4 BWG vermögen keine in diese Richtung führende rechtliche Bindungswirkung herzustellen. ${ }^{416}$ Konsequent gilt dies auch für die Entscheidung des Bundestagspräsidenten nach den $\$ \$ 19 \mathrm{ff}$. PartG über die Gewährung der staatlichen Teilfinanzierung. Um eine bestehende Rechtsschutzlücke bezüglich der Zulassung zur Bundestagswahl zu schließen, wurde die Nichtanerkennungsbeschwerde nach Art.93 Abs. 1 Nr. 4c GG, $\mathbb{S} \$ 13$ Nr. 3a, 96 ff. BVerfGG als Rechtsbehelf eingeführt ${ }^{417}$; vor Schaffung dieser Regelung war nur ein nachträglicher Rechtsschutz möglich. ${ }^{418}$

In Teilen der Literatur wird deshalb zugunsten der Sicherheit im Rechtsverkehr eine Parteienregistrierung gefordert. ${ }^{419}$ Durch die Registrierung einer Vereinigung als Partei soll der Rechtsunsicherheit bei der An-

414 Streinz, in: Huber/Voßkuhle (Hrsg.), Grundgesetz, ${ }^{72018}$, Art. 21, Rn. 68; Ipsen, in: Sachs (Hrsg.), Grundgesetz, ${ }^{8} 2018$, Art. 21, Rn. 21; ders., in: ders. (Hrsg.), Parteiengesetz, ${ }^{2} 2018, \mathbb{S}$ 2, Rn. 11; Wietschel, ZRP 1996, 208 (210 f.); dem Bundesverfassungsgericht zustimmend Klein, in: Maunz/Dürig (Hrsg.), Grundgesetz, 2018, Art. 21, Rn. 229.

415 Seifert, Die politischen Parteien im Recht der Bundesrepublik Deutschland, 1975, S. 171.

416 Streinz, in: Huber/Voßkuhle (Hrsg.), Grundgesetz, ${ }^{7} 2018$, Art. 21, Rn. 51.

417 Siehe hierzu Frau, DÖV 2018, 152 ff.

418 Detterbeck, in: Sachs (Hrsg.), Grundgesetz, ${ }^{8} 2018$, Art. 93, Rn. 104a.

419 Henrichs, DVBl 1958, 227 (231 ff.); Wietschel, Der Parteibegriff, 1996, S. 209; Morlok/Bäcker, NVwZ 2011, 1153 (1157); kritisch Henke, Das Recht der politischen Parteien, 1964, S.26; Klein, in: Maunz/Dürig (Hrsg.), Grundgesetz, 2018, Art. 21, Rn. 220. 
wendung des Parteienbegriffs abgeholfen werden. Wenn eine zentrale Behörde über die Anerkennung aller Parteien zu entscheiden hat, würde es zu einer einheitlichen Anwendung des Parteienrechts auf die einschlägigen Vereinigungen kommen. Die 1958 vom Bundesinnenministerium eingesetzte Kommission zur Klärung der genauen Umsetzung des Ausgestaltungsauftrags aus Art. 21 Abs. 3 GG hat sich bewusst gegen eine Parteienregistrierung entschieden. ${ }^{420}$

In der Literatur wird eine konstitutiv wirkende Registrierung, aufgrund der Unvereinbarkeit mit der Parteiengründungsfreiheit aus Art. 21 Abs. 1 S. 2 GG, geschlossen abgelehnt. ${ }^{421}$ Die Ansichten überzeugen, weshalb auch nicht weiter auf die Möglichkeit der Parteienregistrierung mit rechtsbegründender Wirkung eingegangen wird. Bei einer deklaratorischen Wirkung einer Registrierung gehen die Ansichten auseinander. Wiebke Wietschel sieht eine Parteienregistrierung mit deklaratorischer Wirkung nicht nur als rechtspolitisch wünschenswert, sondern - aufgrund der Verfahrensprägung des Art. 21 Abs. 1 S. 2 GG - als verfassungsrechtlich geboten an. ${ }^{422}$ Ohne ein Registrierungsverfahren mit deklaratorischer Wirkung würde durch das wiederholte Infragestellen der Parteieneigenschaft einer Vereinigung deren Betätigungsfreiheit in unzulässiger Weise beeinträchtigt werden. 423

Die Gegenstimmen halten eine Registrierung mit deklaratorischer Wirkung für verfassungsrechtlich zulässig, lehnen sie jedoch aus Praktikabilitätsgründen ab. ${ }^{424}$ Ausschlaggebend sei eine Abwägung zwischen Nutzen und Aufwand einer solchen Registrierung. Selbst wenn zugunsten einer Partei das Vorliegen der Parteieneigenschaft vermutet würde, so würde die Notwendigkeit einer Überprüfung, zum Beispiel im Fall des $\$ 27$ Abs. 1

420 Bundesministerium des Innern - Kommission, Rechtliche Ordnung des Parteiwesens - Problem eines Parteiengesetzes: Bericht, 1958, S. 153.

421 So schon dies., Rechtliche Ordnung des Parteiwesens - Problem eines Parteiengesetzes: Bericht, 1958, S. 142; Wietschel, Der Parteibegriff, 1996, S. 199; Henrichs, DVBl 1958, 227 (231); Klein, in: Maunz/Dürig (Hrsg.), Grundgesetz, 2018, Art. 21, Rn. 220; Streinz, in: Huber/Voßkuhle (Hrsg.), Grundgesetz, ${ }^{7} 2018$, Art. 21, Rn. 51; Seifert, Die politischen Parteien im Recht der Bundesrepublik Deutschland, 1975, S. 115.

422 Wietschel, Der Parteibegriff, 1996, S. 209.

423 Dies., Der Parteibegriff, 1996, S. 208.

424 Klein, in: Maunz/Dürig (Hrsg.), Grundgesetz, 2018, Art. 21, Rn. 220; Henke, Das Recht der politischen Parteien, 1964, S. 26; Wißmann, in: Kersten/Rixen/Augsberg (Hrsg.), Parteiengesetz (PartG) und europäisches Parteienrecht, 2009, $\mathbb{2}$, Rn. 53. 


\section{$\$ 3$ Institution der Parteienfinanzierung}

S. 1 BWG oder des Vereinsverbots nach \3 VereinsG, nicht entfallen. ${ }^{425}$ Eine gesetzliche Vermutung des Vorliegens der Parteieneigenschaft habe zwar innerhalb der Prüfung des Tatbestandes eine vereinfachende und für die Parteien durchaus angenehmere Wirkung, der Aufwand, eine solche Registrierung einzuführen und ein Register zu verwalten, stehe dazu jedoch in keinem Verhältnis.

\section{Zweckgebundenheit}

Nach $\int 18$ Abs. 1 S. 1 PartG erhalten die Parteien „Mittel als Teilfinanzierung der allgemein ihnen nach dem Grundgesetz obliegenden Tätigkeit“. Damit soll hervorgehoben werden, dass die staatliche Finanzierung der Parteien einen verfassungsrechtlichen Bezug bzw. ein durch das Grundgesetz legitimiertes oder gar gebotenes Ziel verfolgt. Unter Inbezugnahme der verfassungsgerichtlichen Rechtsprechung zur Zulässigkeit einer staatlichen Teilfinanzierung ${ }^{426}$ erschöpft sich der Zweck in der Förderung der Intensität der Mitwirkung der Parteien an der politischen Willensbildung des Volkes als verfassungsrechtliche Aufgabe.

Da ein Handeln im Sinne des Art. 21 Abs. 1 S. 1 GG allerdings ein konstitutives Merkmal einer als „Partei“ zu qualifizierenden Vereinigung ist $^{427}$, scheidet eine Zweckbindung der gewährten Mittel aus. Nur Vereinigungen, die an der politischen Willensbildung des Volkes im Sinne des Art. 21 Abs. 1 S. 1 GG mitwirken, sind als Parteien zu qualifizieren. Der Zweck erschöpft sich damit in der Parteieneigenschaft selbst und kann so kein eigenständiges Merkmal bilden. Die in $₫ 18$ Abs. 1 S. 1 PartG vorgenommene Beschreibung, dass Parteien „Mittel als Teilfinanzierung der allgemeinen ihnen nach dem Grundgesetz obliegenden Tätigkeit" erhalten, ist damit rein deklaratorischer Art und vermag keine Vorgaben bezüglich der Mittelverwendung festzuschreiben. Der Anwendungsbereich der $\int \mathbb{S} 18 \mathrm{ff}$. PartG ist bereits dann eröffnet, wenn eine Vereinigung als „Partei“ zu qualifizieren ist.

425 So formuliert von Klein, in: Maunz/Dürig (Hrsg.), Grundgesetz, 2018, Art. 21, Rn. 220.

426 BVerfGE 85, 264 (285).

427 Bereits oben $\$ 3$.C.I.1. 


\section{Mindestquorum und Verteilungsgrundsätze}

Bei der Gewährung von Mitteln im Rahmen der staatlichen Parteienfinanzierung werden nach $\$ 18$ Abs. 4 PartG solche Parteien nicht berücksichtigt, die bei vorangegangenen Wahlen ein bestimmtes Mindestquorum an Stimmen nicht erreichen konnten. Der Wahlerfolg einer Partei wirkt sich dabei allerdings nicht nur auf die Frage der Gewährung an sich („ob“), sondern auch auf die Höhe der im Einzelfall zu gewährenden Zahlungen („wie“) aus. Der Erfolg bei Landtags-, Bundestags- und Europaparlamentswahlen wird damit zur Determinante bei der Auswahl der durch die staatliche Parteienfinanzierung zu begünstigenden Parteien und die Höhe der einer Partei bereitzustellenden Finanzmittel. Es erfolgt damit eine ungleiche Verteilung staatlicher Gelder an verschiedene Parteien. Diese Differenzierung ist hinsichtlich des parteienrechtlichen Gleichheitssatzes problematisch. Es ist allgemein anerkannt, dass es sich bei der Wahlerfolgsbezogenheit der staatlichen Parteienfinanzierung um eine im Hinblick auf den verfassungsrechtlichen Gleichheitsstatus rechtfertigungsbedürftige Ungleichbehandlung handelt. Ob diese Ungleichbehandlung verfassungsrechtlich gerechtfertigt werden kann, ist allerdings umstritten.

\section{Mindestquorum als Sperrklausel}

Die wahlerfolgsbestimmte Sperrklausel des $₫ 18$ Abs. 4 PartG schließt solche Parteien vollständig aus dem System der unmittelbaren staatlichen Parteienfinanzierung aus, die bei den letzten Europaparlaments-, Bundestags-, und Landtagswahlen einen bestimmten Anteil der Wählerstimmen nicht auf sich vereinigen konnten. Die Sperrklausel verlangt insoweit von den Parteien, bei den Europa- und Bundestagswahlen einen Stimmanteil von mindestens $0,5 \%$ und bei Landtagswahlen einen Stimmanteil von mindestens 1\% auf sich zu vereinen. Der Staat schafft damit eine Hürde, die von allen Parteien überschritten werden muss, um sich als förderungswürdig zu erweisen. Die Fragen, ob eine solche Sperrklausel generell durch die Vorschriften des Grundgesetzes gebilligt werde und, falls dies der Fall sein sollte, wie hoch diese dann anzusetzen sei, wirft verfassungsrechtliche Probleme auf.

Das Bundesverfassungsgericht zieht aus dem strengen und formalen Gleichheitssatz den Schluss, dass eine Ungleichbehandlung im Rahmen der staatlichen Finanzierung zwar verfassungsrechtlich zulässig sein könne, dafür jedoch besonders gewichtige oder zwingende Gründe vorliegen 
müssen. ${ }^{428}$ Unter diesen Voraussetzungen erachtet das Gericht bei der Gewährung staatlicher Leistungen an Parteien eine Differenzierung nach der politischen Bedeutung für zulässig, soweit diese sachlich gerechtfertigt sei. ${ }^{429}$ In Bezug zu dem Stimmenquorum, welches zunächst nur über die generelle Berücksichtigung im Verteilungsverfahren entscheidet, zog das Bundesverfassungsgericht eine Parallele zu der Rechtfertigung der sog. 5\%Klausel in $\$ 6$ Abs. 3 BWG und sah in der Entgegenwirkung der „Gefahr einer übermäßigen Aufsplitterung der Stimmen und der Parteien“430 einen sachlichen Grund, der diese Ungleichbehandlung im verfassungsrechtlich sensiblen Bereich des Parteienrechts zu rechtfertigen mag. Konkret äußerte sich das Bundesverfassungsgericht wie folgt:

„Es läßt sich voraussehen, daß die Erstattung von Wablkampfkosten geeignet ist, künftig die Bildung neuer politischer Parteien anzuregen. Damit würde eine Entwicklung gefördert, der die vom Bundesverfassungsgericht anerkannte 5 v.H.-Klausel entgegengewirkt hat. “431

Das Bundesverfassungsgericht stellte damit zunächst fest, dass solche Sperrklauseln generell im Bereich der staatlichen Parteienfinanzierung zulässig seien, der Staat also zulässigerweise zwischen den einzelnen Parteien bei der Gewährung staatlicher Mittel differenzieren dürfe. Die hierfür angesetzte Grenze von 5\% des Wählerstimmenanteils sei, so das Bundesverfassungsgericht, allerdings zu hoch angesetzt und müsse deutlich unter dem in $\$ 6$ Abs. 3 BWG angegebenen Wert liegen. 432

Der Argumentation des Bundesverfassungsgerichtes liegt maßgeblich der Gedanke einer Missbrauchskontrolle zugrunde, die wiederum ihren Ursprung in der Funktionsfähigkeit des Parlamentarismus sucht. ${ }^{433}$ Falls der Staat sich für eine Subventionierung des Parteienwesens entscheide, von der auch die einzelnen Parteien profitieren sollen, so müssen nach dem Grundsatz der Parteiengleichheit zunächst alle Parteien gleichbehandelt werden und Zugang zu den finanziellen Leistungen erhalten. Sollte

428 BVerfGE 20, 56 (117); BVerfGE 24, 300 (339 ff.).

429 BVerfGE 7, 99 (108); BVerfGE 13, 204 (205); BVerfGE 14, 121 (134, 137 f.); BVerfGE 24, 300 (344f.); BVerfGE 69, 92 (108 f.).

430 BVerfGE 20, 56 (117); so iÜ auch EGMR, Urt. v. 10.5.2012, ÖDP v. Turkey, Nr. 7819/03, Rz. 37 ff.

431 BVerfGE 20, 56 (117).

432 BVerfGE 20, 56 (117).

433 Deutlich BVerfGE 24, 300 (342), wobei die Missbrauchskontrolle wohl als Bestandteil der parlamentarischen Funktionsgarantie angesehen wird. Siehe allerdings auch EGMR, Urt. v. 10.5.2012, ÖDP v. Turkey, Nr. 7819/03, Rz. 37 ff. 
allerdings die Förderung finanzielle Anreize zur Neugründung von Parteien schaffen und dadurch die Funktionsfähigkeit des parlamentarischen Herrschaftssystems beeinträchtigen, so dürfe der Gesetzgeber Kontrollmechanismen einführen, die einer derartigen Entwicklung entgegenwirken. Eine Überprüfung der Ernsthaftigkeit der Wahlkampfbemühungen sei nach diesem Ansatz ein geeignetes Mittel. Auch die Bestimmung einer ausreichend ernsthaften Wahlkampfbemühung durch das Überschreiten eines bestimmten Stimmergebnisses bei der Wahl sei nach der Ansicht des Bundesverfassungsgerichts zulässig.

In Teilen der Literatur wird eine wahlerfolgsbezogene Differenzierung der Parteien im Rahmen der Gewährung einer staatlichen Finanzierung als verfassungswidrig erachtet. Die Begründung erfolgt zunächst gleichlaufend mit der des Bundesverfassungsgerichtes. Die Diskriminierung von kleinen Parteien durch eine wahlerfolgsbezogene Sperrklausel stelle nach beiden Auffassungen eine rechtfertigungsbedürftige Ungleichbehandlung der Parteien dar. Während das Bundesverfassungsgericht allerdings eine Rechtfertigung dieses Eingriffs anerkennt, so negieren Teile der Literatur das Vorliegen rechtfertigender Gründe und zweifeln auch die generelle Rechtfertigungsfähigkeit einer solchen Ungleichbehandlung an. ${ }^{434}$ Besonders scharf kritisierte Karl-Heinz Seifert die Rechtsprechung des Bundesverfassungsgerichts: er sieht staatliche Differenzierungen und Diskriminierungen im Parteienwesen als für mit dem parteienrechtlichen Gleichheitsstatus unvereinbar an. ${ }^{435}$ Die Divergenz zwischen Rechtsprechung und diesem Teil der Literatur beruht maßgeblich auf einem unterschiedlichen Verständnis des Gleichbehandlungsgrundsatzes. Die Kritiker der Sperrklausel des $\mathbb{1} 18$ Abs. 4 PartG erkennen die Abwehr der „Gefahr einer übermäßigen Aufsplitterung der Stimmen und Parteien"436 durch eine solche wahlerfolgsbezogene Hürde nicht als rechtfertigenden Umstand an, da der Staat sich in diesem Falle anmaße, bei der Mittelvergabe die gesellschaftliche Bedeutsamkeit einer Partei als Determinanten zu wählen und den konkreten Grad der Bedeutsamkeit selbst durch ein gesetzlich geregeltes Ver-

434 Seifert, Die politischen Parteien im Recht der Bundesrepublik Deutschland, 1975, S. 308 ff.; Lipphardt, Die Gleichheit der politischen Parteien vor der öffentlichen Gewalt, 1975, S. 633 ff., Volkmann, KJ 1995, 203 (206f.).

435 Seifert, Die politischen Parteien im Recht der Bundesrepublik Deutschland, 1975 , S. $308 \mathrm{f}$.

436 BVerfGE 20, 56 (117). 
fahren zu beurteilen. ${ }^{437}$ Das Ergebnis sei eine durch die Abschaffung des status quo manifestierte Verfestigung des Parteienwesens, was unter den Gesichtspunkten des Demokratieprinzips und der ihm innewohnenden Parteiengleichheit nicht zu vereinbaren sei. ${ }^{438}$ Karl-Heinz Seifert bezeichnet diese Folge unter Inbezugnahme der (vom Bundesverfassungsgericht gleichfalls gebilligten ${ }^{439}$ ) abgestuften Sendezeitgewährung 440 und der 5\%Hürde des $\$ 6$ Abs. 3 BWG überspitzt als „Oligopoldemokratie der Großparteien". ${ }^{441}$ Die Zementierung des Parteienwesens als Folge der staatlichen Bewertung der gesellschaftlichen Bedeutsamkeit einer Partei und daran anknüpfender Gewährleistung staatlicher Leistungen schließe demnach ein System der abgestuften Leistungsgewährung, das durch Einführung von wahlerfolgsbezogenen Sperrklauseln das Profitieren von Kleinstparteien unterbindet, von Verfassung wegen aus. Der Staat müsse, um den verfassungsrechtlichen Anforderungen einer demokratischen Staatsstruktur gerecht zu werden, für unbedingte Chancengleichheit sorgen.

Dass gesetzliche Sperrklauseln bei der staatlichen Mittelvergabe an Parteien eine verfassungsrechtlich relevante Ungleichbehandlung darstellen, ist zutreffend. Der Staat unterscheidet zwischen Parteien, die bei der letzten, vom Gesetzgeber als relevant angesehenen Wahl einen Wählerstimmenanteil über dem von der Sperrklausel vorausgesetzten Wert erzielt haben und solchen, die keinen ausreichenden Anteil an Wählerstimmen auf sich vereinigen konnten. Die verfassungsrechtliche Zulässigkeit hängt maßgeblich von der Rechtfertigungsfähigkeit dieser Ungleichbehandlung ab.

Das Bundesverfassungsgericht verhält sich in seiner Entscheidung über die verfassungsrechtliche Zulässigkeit von Sperrklauseln innerhalb der Parteienfinanzierung misstrauisch gegenüber neugegründeten Kleinstparteien. Während es auf der einen Seite die Parteiengleichheit als für die Demo-

437 In Bezug zu der Verteilung von Wahlsendezeiten, allerdings gedanklich auf die Sperrklausel im Rahmen der Parteienfinanzierung übertragbar vgl. Seifert, Die politischen Parteien im Recht der Bundesrepublik Deutschland, 1975, S. 148 ff., 308 ff., vgl. auch Volkmann, KJ 1995, 203 (206 ff.).

438 Lipphardt, Die Gleichheit der politischen Parteien vor der öffentlichen Gewalt, 1975, S. 633 ff., Seifert, Die politischen Parteien im Recht der Bundesrepublik Deutschland, 1975, S. 308 f.

439 BVerfGE 7, 99 ff.; BVerfGE 14, $121 \mathrm{ff}$.

440 Seifert, Die politischen Parteien im Recht der Bundesrepublik Deutschland, 1975, S. 147 ff.

441 Ders., Die politischen Parteien im Recht der Bundesrepublik Deutschland, 1975, S. 311; Begrifflichkeit in einem ähnlichen Kontext verwendend Dübber, Parteifinanzierung in Deutschland, 1962, S. 80. 
kratie herausragendes Gut hervorhebt und eine staatliche Einschränkung nur aus „Zwingenden“ Gründen ${ }^{42}$ für zulässig erachtet, enttäuscht es die selbst erzeugten Erwartungen, indem es eine abstrakte Gefahr „einer übermäßigen Aufsplitterung der Stimmen und der Parteien"443 als rechtfertigenden Umstand anerkennt. Auch hegt das Bundesverfassungsgericht den Verdacht, dass sich die Gründung und Wahlbeteiligung von Kleinstparteien im unseriösen Bereich des Rechtsmissbrauches bewegen. ${ }^{444}$ Weiter führt das Bundesverfassungsgericht aus, dass aus diesem Grund bei der Kontrolle der Ernsthaftigkeit von Wahlkampfbemühungen vom Staat wesentlich höhere Anforderungen gestellt werden können als bei der Kontrolle der Ernsthaftigkeit der Wahlvorschläge. ${ }^{445}$

Auch wenn das Ergebnis des Bundesverfassungsgerichts, die Sperrklausel als zulässigen Missbrauchsmechanismus anzuerkennen, sympathisch ist, so vermag die Dogmatik hinter der Entscheidung nicht zu überzeugen. Die Argumentation des Bundesverfassungsgerichts überzeugt deshalb nicht, da die staatliche Förderung von Parteien zumindest im Bereich der politischen Willensbildung aufgrund der hohen Anforderungen an die Rechtfertigungsfähigkeit nicht von einer staatlichen Bewertung des Erfolges abhängig gemacht werden darf und darüber hinaus eine Missbrauchskontrolle in Form einer Sperrklausel nicht erforderlich ist.

In Art. 21 Abs. 1 S. 2 GG gewährleistet das Grundgesetz die freie Gründung von Parteien. Freilich tut das Grundgesetz dies nicht aus einem Selbstzweck heraus, sondern beabsichtigt gerade hinsichtlich der vom verfassungsgebenden Gesetzgeber gewählten Demokratieform eine möglichst vielfältige Parteienlandschaft sicherstellen. Die Parteiendemokratie setzt gerade einen Meinungspluralismus voraus. Auch Kleinstparteien wirken an der politischen Willensbildung des Volkes mit und tragen durch die Erweiterung des politischen Wettbewerbs somit zum Meinungspluralismus bei, weshalb sie zunächst nach dem Zweck der staatlichen Parteienfinanzierung ebenfalls wie ihre „erfolgreichere“ Konkurrenz bei der Vergabe

442 BVerfGE 20, 56 (117); BVerfGE 24, 300 (339 ff.); BVerfGE 111, 382 (398); siehe auch BVerfGE 6, 273 (280) - „verfassungsrechtliche Gründe“ oder BVerfGE 12, 10 (28) - „besondere Gründe“.

443 BVerfGE 20, 56 (117).

444 So auch Lipphardt, Die Gleichheit der politischen Parteien vor der öffentlichen Gewalt, 1975, S. 637; in BVerfGE 20, 56 (118) hebt das Bundesverfassungsgericht die Gefahr der Gründung von Kleinstparteien allein zum Zwecke des Missbrauchs der unmittelbaren staatlichen Parteienfinanzierung besonders hervor.

445 BVerfGE 24, 300 (341 f.). 
von Mittel berücksichtigt werden müssen. Im Vergleich zur 5\%-Klausel des $₫ 6$ Abs. 3 BWG steht als rechtfertigender Zweck der Sperrklausel des $\$ 18$ Abs. 4 PartG auch nicht die Bewahrung der Handlungs- und Funktionsfähigkeit des Parlamentes im Vordergrund, sondern die Bildung einer möglichst eingeschränkt-heterogenen Wählermasse bereits im Vorfeld der Wahl. Dies mag allerdings allenfalls einen sachlichen, jedoch keinesfalls einen „Zwingenden“ Grund darstellen.

Ferner ist die vom Bundesverfassungsgericht vorhergesagte Gefahr der unkontrollierten Gründung von Kleinstparteien zum alleinigen Zwecke der Vorteilsziehung aus der staatlichen Parteienfinanzierung und der damit zusammenhängenden „Zersplitterung des Parteiwesens“ nicht überzeugend. Da die „Parteieneigenschaft“ einer Vereinigung nach $\mathbb{\$} 18$ Abs. 1 S. 1 PartG eine konstitutive Anspruchsvoraussetzung darstellt und eine Vereinigung ohnehin erst dann als Partei zu qualifizieren ist, wenn sie beabsichtigt, „ernsthaft“ an der politischen Willensbildung des Volkes mitzuwirken und in diesem Zusammenhang nach Umfang und Festigkeit ihrer Organisation, nach der Zahl ihrer Mitglieder und nach ihrem Hervortreten in der Öffentlichkeit eine ausreichende Gewähr für die Ernsthaftigkeit dieser Zielsetzung bieten muss ${ }^{446}$, wird eine Vereinigung, die sich ausschließlich zum Zwecke des Missbrauchs der staatlichen Parteienfinanzierung an der Wahl beteiligt, schon in den meisten Fällen gar keine „Partei“ im Sinne des Art. 21 Abs. 1 S. 1 GG, $\mathbb{S} \mathbb{S}$ Abs. 1, 18 Abs. 1 PartG darstellen. Nach der Rechtsprechung des Bundesverfassungsgerichtes soll sogar die Teilnahme an Wahlen nicht in jedem Fall zur Realisierung der „Parteieneigenschaft" einer Vereinigung führen. ${ }^{447}$ Der Bereich des Rechtsmissbrauches wird bereits dann verlassen, wenn die Vereinigung eine ausreichende Gewähr für die Mitwirkung an der politischen Willensbildung des Volkes bieten kann, was wiederum eine gefestigte Organisationsstruktur, eine dementsprechend beachtliche Mitgliederzahl und einem mit der Zielsetzung zu vereinbarenden Hervortreten in der Öffentlichkeit voraussetzt. Die Bemühungen um ausreichende Mitgliederzahlen, Unterstützerquoren und einer gefestigten organisatorischen Struktur bleiben deutlich hinter den möglichen Vorteilen der staatlichen Parteienfinanzierung zurück. ${ }^{448}$

446 BVerfGE 91, 262 (271 f.); vgl. auch BVerfGE 91, 276 (289); Wißmann, in: Kersten/Rixen/Augsberg (Hrsg.), Parteiengesetz (PartG) und europäisches Parteienrecht, 2009, $\$ 2$, Rn. 40.

447 BVerfGE 91, 262 (271 f.); vgl. auch BVerfGE 91, 276 (289).

448 Ähnlich Lipphardt, Die Gleichheit der politischen Parteien vor der öffentlichen Gewalt, 1975, S. 637 f. 
Diese Erfordernisse begründen schon für sich einen ausreichenden Schutz vor einer „Aufsplitterung der Parteien und der Stimmen“, weshalb eine Ungleichbehandlung durch die Anwendung einer derartigen Sperrklausel nicht erforderlich ist.

Durch die Rechtsprechung des Bundesverfassungsgerichtes wurde demnach die gesetzgeberische Entscheidung für zulässig erachtet, dass Parteien durch das Erreichen bestimmter, vom Gesetzgeber festgelegter Wahlerfolge (mit der Obergrenze von $0,5 \%$ des Wählerstimmenanteils ${ }^{449}$ ) wiederholt die ernsthafte Verfolgung des ihnen durch Art. 21 GG zugewiesenen Zweckes unter Beweis zu stellen haben. Dies kann verfassungsrechtlich kein gewünschtes Ergebnis sein. Die Überprüfung der Parteieneigenschaft bei der Gewährung der staatlichen Teilfinanzierung durch den Bundestagspräsidenten ginge mit einem wohl höheren Bürokratie- und Arbeitsaufwand einher, der für sich genommen allerdings auch keinen Eingriff in den strengen und formalen Gleichheitssatz des Parteienwesens zu rechtfertigen mag.

\section{Wahlerfolgsbezogene Mittelgewährung}

Der Staat diskriminiert nicht nur, sondern differenziert auch bei der Gewährung der staatlichen Teilfinanzierung. Nach $₫ 18$ Abs. 3 S. 1 PartG bestimmt sich die vom Staat gewährte Summe maßgeblich am Erfolg bei den relevanten Wahlen und den Zuwendungen an die Parteien. So erhalten Parteien nach $\$ 18$ Abs. 3 S. 1 PartG für jede für ihre jeweilige Liste oder für sie in einem Wahl- und Stimmkreis abgegebene Stimme 0,83 Euro und für jeden Euro, den sie als Zuwendung erhalten haben, 0,45 Euro. Für die Bemessung des Finanzierungsbetrages nach $₫ 18$ Abs. 3 S. 1 Nr. 3 PartG sind nur rechtmäßige Spenden, Mandatsträgerbeiträge und Mitgliedsbeiträge relevant.

Es handelt sich mithin um eine erfolgsbezogene Verteilung der vom Staat gewährten Mittel. Parteien mit einem hohen Stimmen- oder Zuwendungsanteil bekommen wesentlich höhere Beträge ausgezahlt als vergleichsweise bei der Wahl nur bedingt erfolgreiche oder mitglieds- und spenderschwache Parteien. Dass der Staat bei der Höhe der zu verteilenden Mittel auch zwischen den Parteien differenziert und als Determinanten die Anzahl an Spenden und erlangten Stimmen wählte, ist nach dem bereits

449 BVerfGE 24, 300 (342 f.). 
oben erläuterten Verständnis einer wettbewerbsbezogenen Parteiengleichheit nur konsequent. ${ }^{450}$

Kritische Stimmen der Literatur sehen allerdings bei einer ungleichen Verteilung der über die staatliche Teilfinanzierung zu gewährenden Mittel einen Verstoß gegen den parteienrechtlichen Gleichheitssatz und bemängeln als Folge die Verfestigung des etablierten Parteiwesens. ${ }^{451}$ Das Bundesverfassungsgericht sieht die proportionale Verteilung der Mittel nicht nur als verfassungsrechtlich zulässig, sondern gar zwingend an. ${ }^{452}$ Diese Divergenz beruht maßgeblich auf einem unterschiedlichen Verständnis des Neutralitätsgebotes als Folge der Parteiengleichheit, welches bereits an anderer Stelle der Arbeit ausführlicher diskutiert wurde und sich somit eine tiefergehende Auseinandersetzung mit dem Meinungsstreit an dieser Stelle erübrigt. ${ }^{453}$

Durch eine staatliche Teilfinanzierung hat der Staat ein verfassungsrechtliches Dilemma geschaffen, welches er, sofern er am Konzept der Teilfinanzierung der Parteientätigkeit festhält, nur schwer lösen kann. Er steht vor der Entscheidung, allen Parteien die gleiche Höhe an Finanzmitteln zukommen zu lassen und damit durch den politischen Wettbewerb vorgegebene Unterschiede auszugleichen und diesen damit im Ergebnis zu verzerren oder eine proportionale Mittelvergabe, mit dem politischen Kräfteverhältnis als Determinanten, zu wählen. Kern der Problematik ist die Veränderung des politischen Wettbewerbes durch die öffentliche Steigerung der Finanzkraft einzelner, im Rahmen des Verteilungsverfahrens zu berücksichtigenden Parteien. Wenn demnach durch eine staatliche Maßnahme die Finanzkraft der sich am Wahlkampf beteiligenden Parteien erhöht wird, so muss sie sich an der durch den Wettbewerb geschaffenen Situation messen lassen. Der zu wählende Maßstab der Verteilung wird damit richtigerweise durch die vorgefundene Wettbewerbssituation vorgegeben. ${ }^{454}$ Der durch den Staat vorgefundene Wettbewerb darf nicht den Regelungsgegenstand, sondern muss den Regelungsmaßstab der staatlichen

450 Siehe hierzu bereits $₫ 2$. B. II. 2.

451 Seifert, Die politischen Parteien im Recht der Bundesrepublik Deutschland, 1975, S. 308 ff.; Lipphardt, Die Gleichheit der politischen Parteien vor der öffentlichen Gewalt, 1975, S. 633 ff.; Volkmann, in: Friauf/Höfling (Hrsg.), Berliner Kommentar zum Grundgesetz, 2000, Art. 21, Rn. 60; ders., KJ 1995, 203 (206 f.).

452 Wohl BVerfGE 20, 56 (118), dass die Auszahlung eines gleichen Betrages an alle Parteien für eine staatliche Verfälschung des politischen Wettbewerbes erachtet; siehe auch Koch, ZParl 2002, 694 (698 ff.).

453 Siehe hierzu bereits $\mathbb{2}$ 2. B. II. 2.

454 So bereits oben $\$ 2$. B. II. 2. 
Teilfinanzierung bilden. Eine gleiche Zuteilung an Mitteln würde die durch den Wettbewerb geschaffenen Unterschiede in der Tendenz nivellieren und den Maßstab, an dem sich die Verteilung zu richten hat, verfälschen. ${ }^{455}$ Die Gewährung eines Sockelbetrages für alle Parteien bei einer gleichzeitigen Honorierung des Wahlerfolges durch eine an Wählerstimmen orientierten Finanzierung stellt, auch nach der zutreffenden Rechtsprechung des Bundesverfassungsgerichts ${ }^{456}$, einen Verstoß gegen das Verbot der staatlich-institutionellen Verfestigung des Parteiwesens dar. Die Bemühungen der Parteien „um eine finanzielle Unterstützung ihrer Politik durch Mitglieder und Spender sowie ihren Wahlerfolg“ müssen im Rahmen des Verteilungsverfahrens berücksichtigt werden. ${ }^{457}$ Ein Sockelbetrag, der den gesellschaftlichen Rückhalt einer Partei (in Form von Mitgliedsbeiträgen, Spenden oder den Wahlergebnissen) bei der Berechnung des Betrags unberücksichtigt lässt, begründet die Gefahr der staatlichen Einflussnahme auf die politische Willensbildung und ist aus diesem Grund mit Art. 21 Abs. 1 S. 1 GG nicht vereinbar. ${ }^{458}$

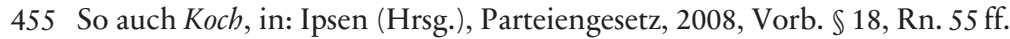

456 BVerfGE 85, 264 (283).

457 BVerfGE 85, 264 (283 f.).

458 Vgl. insoweit schon die historischen Ausführungen zur Rechtsprechung des BVerfG in der Sache, $\mathbb{} 3$ A. I. 5. 


\section{\4 Das Finanzierungsausschlussverfahren nach Art. 21 Abs. 3 GG}

\section{A. Entwicklung des Ausschlussverfabrens}

I. Urteil des Bundesverfassungsgerichts vom 17.01.2017

Mit Änderungsgesetz vom 19.07.2017 459 verankerte der verfassungsändernde Gesetzgeber die Möglichkeit des Ausschlusses verfassungsfeindlicher Parteien aus der Parteienfinanzierung. Anlass der Verfassungsänderung war ein im Rahmen des zum zweiten Mal gescheiterten NPD-Verbotsverfahrens erteilter Hinweis des Bundesverfassungsgerichts, dass „die Schaffung der Möglichkeit gesonderter Sanktionierung im Fall der Erfüllung einzelner Tatbestandsmerkmale des Art. 21 Abs. 2 GG unterhalb der Schwelle des Parteiverbots dem verfassungsändernden Gesetzgeber vorbehalten ist. " ${ }^{460}$ Mit Blick auf ein Parteiverbot stellte das Bundesverfassungsgericht zwar fest, dass die NPD die Grundprinzipien, die für den freiheitlichen demokratischen Verfassungsstaat unverzichtbar seien, missachte und die Parteiziele und das Verhalten der Anhänger gegen die Menschenwürde und den Kern des Demokratieprinzips verstößen sowie Elemente einer Wesensverwandtschaft mit dem historischen Nationalsozialismus aufwiesen und weitergehend die Partei programmatisch auf die Beseitigung der freiheitlichen demokratischen Grundordnung gerichtet sei. ${ }^{461}$ Allerdings setze das Merkmal des „Darauf-Ausgehens“ iSd. Art. 21 Abs. 2 GG eine gewisse Potentialität voraus, welche erst dann gegeben sei, wenn sich die Möglichkeit der Beeinträchtigung oder Beseitigung der freiheitlichen demokratischen Grundordnung durch die Partei hinreichend manifestie-

459 BGBl. 2017 I, S. 2346.

460 BVerfGE 144, 20 (202).

461 BVerfGE 144, 20 (246 ff.). 
re. ${ }^{462}$ So führte der Senat, entgegen der noch im KPD-Verbotsverfahren vertretenen Auffassung ${ }^{463}$, folgendes aus:

„Lässt das Handeln einer Partei dagegen noch nicht einmal auf die Möglichkeit eines Erreichens ihrer verfassungsfeindlichen Ziele schließen, bedarf es des präventiven Schutzes der Verfassung durch ein Parteiverbot als schärfste und überdies zweischneidige Waffe des demokratischen Rechtsstaats gegen seine organisierten Feinde nicht. Ein Parteiverbot kommt vielmehr nur in Betracht, wenn eine Partei über hinreichende Wirkungsmöglichkeiten verfügt, die ein Erreichen der von ibr verfolgten verfassungsfeindlichen Ziele nicht völlig aussichtslos erscheinen lassen und wenn sie von diesen Wirkungsmöglichkeiten auch Gebrauch macht. Ist dies nicht der Fall, fehlt es an einem „Darauf Ausgehen" iSv Art. 21 Abs. 2 GG. An der hiervon abweichenden Definition im KPD-Urteil, nach der es einem Parteiverbot nicht entgegenstehe, wenn für die Partei nach menschlichem Ermessen keine Aussicht darauf besteht, dass sie ihre verfassungswidrige Absicht in absehbarer Zukunft werde verwirklichen können, bält der Senat nicht fest." 464

Mit dem Verlangen der Realisierungspotentialität erhöhte das Bundesverfassungsgericht die verfassungsrechtlichen Anforderungen an ein Parteiverbot in einem beachtlichen Maße. Während es im KPD-Urteil noch die Auffassung vertrat, dass eine Partei auch dann verfassungswidrig i.S.d. Art. 21 Abs. 2 GG sein kann, „wenn nach menschlichem Ermessen keine Aussicht darauf besteht, daß sie ihre verfassungswidrige Absicht in absehbarer Zukunft verwirklichen könnte" ${ }^{\text {"465, }}$, müssen nun nicht mehr nur an subjektive Eigenschaften knüpfende Voraussetzungen erfüllt sein, sondern darüber hinaus ein der Verfügungsgewalt der Parteien teilweise entzogener objektiver Erfolgsmoment vorliegen. Der Grad der Potentialität wird an einem objektiven Maßstab bemessen, auf den die Parteien nur im begrenzten Ausmaß Einfluss ausüben können. Eine Partei kann sich demnach für noch so gefährlich halten und sich nach außen in diesem Sinne präsentieren; die realistische Chance der Verwirklichung ihrer verfassungsfeindlichen Ziele wird sie unterdessen nur geringfügig nach freiem Ermes-

462 BVerfGE 144, 20 (224ff.); siehe auch hierzu Klein, in: Maunz/Dürig (Hrsg.), Grundgesetz, 2018, Art.21, Rn. 527a; Streinz, in: Huber/Voßkuhle (Hrsg.), Grundgesetz, ${ }^{7} 2018$, Art. 21, Rn. 252b; Ipsen, in: Sachs (Hrsg.), Grundgesetz, ${ }^{8} 2018$, Art. 21, Rn. 213; ferner siehe Alter, Die Eingriffsschwelle beim Verbot extremistischer Parteien und Vereine in Deutschland und England, 2016, S. 248.

463 BVerfGE 5, 85 (143).

464 BVerfGE 144, 20 (225).

465 BVerfGE 5, 85 (143). 
sen beeinflussen können. Durch die verfassungsgerichtliche Erweiterung der Tatbestandsvoraussetzungen um das objektive Element der Realisierungspotentialität bleibt es dem Staat nun verwehrt, solche Parteien zu verbieten, die zwar eine verfassungsfeindliche Einstellung haben und ihre daraus entwachsenden Ziele für Staat und Gesellschaft auch öffentlichkeitswirksam kommunizieren, allerdings nach menschlichem Ermessen keine nennenswerte Aussicht haben, diese sich selbst gesetzten Ziele zu verwirklichen.

\section{EGMR-Rechtsprechung zu Parteiverboten}

Der Grund für die Abweichung von der früheren Ansicht des Senates waren wohl die an ein Parteiverbot zu stellenden Anforderungen durch den Europäischen Gerichtshof für Menschenrechte (EGMR), die das Bundesverfassungsgericht auch als Auslegungshilfe in dem Verbotsurteil deutlich hervorhob. ${ }^{466}$ Der Europäischen Menschenrechtskonvention kommt zwar nur der Rang eines formellen Bundesgesetzes $\mathrm{zu}^{467}$, diese besitzt allerdings aufgrund der „Völkerrechtsfreundlichkeit“ des Grundgesetzes bei der Auslegung von Verfassungsnormen eine besondere Relevanz. ${ }^{468}$ Der Konventionstext dient in diesem Sinne als „Auslegungshilfe für die Bestimmung von Inhalt und Reichweite von Grundrechten und rechtsstaatlichen Grundsätzen des Grundgesetzes“. ${ }^{469}$ Für die Beurteilung der konventionsrechtlichen Zulässigkeit von Parteiverboten zieht der EGMR den Art. 11 EMRK als Maßstab heran. ${ }^{470}$ Demnach wären Parteiverbote grundsätzlich mit der Konvention vereinbar, allerdings müssen bei der konkreten Ausgestaltung auf nationaler Ebene die Anforderungen des Art. 11

466 BVerfGE 144, 20 (234); siehe vertiefend über die Rechtsprechung des EGMR zu Parteiverboten Theuerkauf, Parteiverbote und die Europäische Menschenrechtskonvention, 2006.

467 BVerfGE 111, 307 (315 f.); BVerfGE 128, 326 (367); Wollenschläger, in: Dreier/ Bauer (Hrsg.), Grundgesetz, ${ }^{3} 2015$, Art. 25, Rn. 27.

468 BVerfGE 111, 307 (317); BVerfGE 128, 326 (367).

469 BVerfGE 111, 307 (328 f.); BVerfGE 128, 326 (367 f.).

470 EGMR, Urt. v. 30. 1. 1998, United Communist Party of Turkey and Others v. Turkey, Nr. 133/1996/752/951, Rz. 24 f.; EGMR, Urt. v. 25. 5. 1998, Socialist Party and Others v. Turkey, Nr. 20/1997/804/1007, Rz. 29; EGMR, Urt. v. 13. 2. 2003, Refah Partisi (The Welfare Party) and Others v. Turkey, Nr. 41 340/98 u. a. = NVwZ 2003, 1489 ff., Rz. 87. 
Abs. 2 S. 1 EMRK durch den nationalen Gesetzgeber berücksichtigt werden. ${ }^{471}$

Ein Parteiverbot muss, um den Voraussetzungen des Art. 11 Abs. 2 S. 1 EMRK gerecht zu werden, gesetzlich vorgesehen sein und sich in einer demokratischen Gesellschaft als notwendig für die nationale oder öffentliche Sicherheit, zur Aufrechterhaltung der Ordnung oder zur Verhütung von Straftaten, zum Schutz der Gesundheit oder der Moral oder zum Schutz der Rechte und Freiheiten anderer erweisen. Aus der Notwendigkeit eines solchen Parteiverbotes folgert der EGMR, dass für das Verbot einer Partei immer ein „dringendes soziales Bedürfnis“ vorliegen müsse, welches stets individuell festzustellen sei. ${ }^{472} \mathrm{Ob}$ ein „dringendes soziales Bedürfnis“ im Einzelfall gegeben sei, müsse jeweils anhand einer Gesamtwürdigung der Umstände beurteilt werden. In diesem Rahmen werde insbesondere berücksichtigt, ob sachliche Gründe vorlägen, die darauf hindeuten, dass die Gefahr der Beeinträchtigung der demokratischen Staatsform unmittelbar droht, die Handlungen der Parteiführung und der Parteimitglieder der Partei zugerechnet werden können und die Reden und Handlungen in ihrer Gesamtheit ein klares Bild des von der Partei propagierten, dem Leitbild der demokratischen Gesellschaft widersprechenden, Politikmodells darstellen. ${ }^{473}$ Bei der Gesamtwürdigung der Umstände sei des Weiteren zu prüfen, ob die Ziele der Partei den fundamentalen Grundsätzen der Demokratie und des Menschenrechtsschutzes widersprächen oder die Mittel zur Durchsetzung der parteilichen Ziele rechts- und demokratiewidrig seien. ${ }^{474}$ Der EGMR zieht als Maßstab zur Bestimmung der „Gefährlichkeit" den bei Parlamentswahlen erzielten Erfolg einer Partei und eine etwaige Verbundenheit zu terroristischen Vereinigungen her-

471 EGMR, Urt. v. 13. 2. 2003, Refah Partisi (The Welfare Party) and Others v. Turkey, Nr. 41 340/98 u. a. = NVwZ 2003, 1489 ff., Rz. 50 f.

472 EGMR, Urt. v. 25. 5. 1998, Socialist Party and Others v. Turkey, Nr. 20/1997/804/1007, Rz. 49; EGMR, Urt. v. 13. 2. 2003, Refah Partisi (The Welfare Party) and Others v. Turkey, Nr. 41 340/98 u. a. = NVwZ 2003, 1489 ff., Rz. 104, 132; EGMR, Urt. v. 30. 6. 2009, Herri Batasuna and Batasuna v. Spain, Nr. 25 803/04 und 25 817/04, Rz. 83 f.

473 Vgl. EGMR, Urt. v. 13. 2. 2003, Refah Partisi (The Welfare Party) and Others v. Turkey, Nr. 41 340/98 u. a. = NVwZ 2003, 1489 ff., Rz. 104; EGMR, Urt. v. 30.6. 2009, Herri Batasuna and Batasuna v. Spain, Nr. 25 803/04 und 25 817/04, Rz. 83; vgl. auch Shirvani, JZ 2014, 1074 (1077).

474 Insbesondere wenn sie zur Durchsetzung ihrer Ziele zu Gewalt aufruft oder die Anwendung dieser duldet, siehe Theuerkauf, Parteiverbote und die Europäische Menschenrechtskonvention, 2006, S. 260. 
an. ${ }^{475}$ Allein das Vorliegen eines "dringenden sozialen Bedürfnisses“ reiche nach Ansicht des EGMR allerdings nicht pauschal für das Verbot einer Partei aus. Auf der Rechtsfolgenseite müsse ferner eine Angemessenheitsprüfung ergeben, dass das Verhältnis zwischen den durch das Parteiverbot nach nationalem Recht eintretenden Folgen und der Intensität der Bedrohung für die Demokratie unter dem Gesichtspunkt des „dringenden sozialen Bedürfnisses" ausgewogen sei. ${ }^{476}$

Das Bundesverfassungsgericht verlangte in seiner früheren Rechtsprechung zum Parteiverbot nach Art. 21 Abs. 2 GG keine von der Partei unmittelbar ausgehende Gefahr für die demokratische Staatsordnung. ${ }^{477} \mathrm{Um}$ die Rechtsprechung des EGMR zu Parteiverboten, gerade hinsichtlich des Elementes des „dringenden sozialen Bedürfnisses“ und der Angemessenheitsprüfung bei dessen Anwendung hinreichend zu berücksichtigen, wäre es naheliegend, in den Tatbestand des Art. 21 Abs. 2 GG eine Verhältnismäßigkeitsprüfung zu integrieren. ${ }^{478}$ Das Bundesverfassungsgericht und die wohl noch h.M. lehnen allerdings eine Verhältnismäßigkeitsprüfung neben der Prüfung des Merkmals des „Darauf-Ausgehens“ als ungeschriebene Tatbestandsvoraussetzung des Parteiverbotes weiterhin ab. ${ }^{479}$ Der Verfassungsgeber habe mit Art. 21 Abs. 2 GG eine abschließende Regelung getroffen, bei dessen tatbestandlicher Einschlägigkeit bereits als zwingende Rechtsfolge die Verfassungswidrigkeit festzustellen und ein Verbot der Partei auszusprechen sei. ${ }^{480}$

475 Vgl. EGMR, Urt. v. 13. 2. 2003, Refah Partisi (The Welfare Party) and Others v. Turkey, Nr. 41 340/98 u. a. = NVwZ 2003, 1489 ff., Rz. 107 ff.; EGMR, Urt. v. 30. 6. 2009, Herri Batasuna and Batasuna v. Spain, Nr. 25 803/04 und 25 817/04, Rz. $85 \mathrm{ff} ., 89$.

476 EGMR, Urt. v. 13. 2. 2003, Refah Partisi (The Welfare Party) and Others v. Turkey, Nr. 41 340/98 u. a. = NVwZ 2003, 1489 ff., Rz. 133 f.; EGMR, Urt. v. 30. 6. 2009, Herri Batasuna and Batasuna v. Spain, Nr. 25 803/04 und 25 817/04, Rz. $92 \mathrm{f}$.

477 BVerfGE 5, 85 (143).

478 Zur Anwendung des Verhältnismäßigkeitsgrundsatzes Maurer, AöR 96 (1971), 203 (229); Sichert, DÖV 2001, 671 (679); Shirvani, JZ 2014, 1074 ff.; Kloepfer, NVwZ 2017, 913.

479 BVerfGE 144, 20 (227, 230 ff.); in der Literatur siehe Klein, in: Maunz/Dürig (Hrsg.), Grundgesetz, 2018, Art. 21, Rn. 527; Ipsen, in: Sachs (Hrsg.), Grundgesetz, ${ }^{8} 2018$, Art. 21, Rn. 171; Volkmann, DÖV 2007, 577 (580); vgl. auch Kumpf, DVBl 2012, 1344 (1348).

480 Vgl. BVerfGE 144, 20 (231 ff.); siehe auch Seifert, Die politischen Parteien im Recht der Bundesrepublik Deutschland, 1975, S. 470; Schmidt, Die Freiheit verfassungswidriger Parteien und Vereinigungen, 1983, S. 163; kritisch gerade aufgrund der Rechtsprechung des EGMR Shirvani, JZ 2014, $1074 \mathrm{ff}$. 
III. Einfluss auf die verfassungsgerichtliche Rechtsprechung

Je weiter man die beiden Anforderungen des EGMR an ein Parteiverbot in den Vordergrund stellt, umso weniger verwundert der Rechtsprechungswandel des Bundesverfassungsgerichtes hinsichtlich des Merkmals des „Darauf-Ausgehens“ iSd. Art. 21 Abs. 2 GG. Der EGMR fordert zur Rechtfertigung eines Parteiverbots im Einzelfall eine konkret vorliegende Gefahr für die demokratische Staatsordnung und ein angemessenes Verhältnis zwischen Verbotszweck und Verbotswirkung. Die bisherige Anwendung des Parteiverbotes durch das Bundesverfassungsgericht ließ das Gefahrenpotential einer Partei für die demokratische Staatsform sowohl auf der Tatbestands- als auch auf der Rechtsfolgenseite unberücksichtigt. ${ }^{481} \mathrm{Da}$ das Erfordernis einer Verhältnismäßigkeitsprüfung vom Bundesverfassungsgericht auf der Rechtsfolgenseite weiterhin abgelehnt wird ${ }^{482}$, bleibt lediglich eine anpassende Auslegung der geschriebenen Tatbestandsmerkmale, um den Anforderungen des EGMR gerecht zu werden. Die Gefahr, die von einer Partei ausgeht, bemisst sich maßgeblich an der objektiven Realisierungswahrscheinlichkeit ihrer verfassungswidrigen Zielsetzung. Durch die Neuinterpretation des Wortes „Darauf-Ausgehen“ und der Erweiterung des Verbotstatbestandes um ein Gefahrenelement legte das Bundesverfassungsgericht den Normtext des Art. 21 Abs. 2 GG konventionsgerecht aus und setzte dadurch die vom EGMR aufgestellten Anforderungen an Parteiverbote in das nationale Recht um. Ohne auf eine Abwägung im Rahmen einer Verhältnismäßigkeitsprüfung zurückgreifen zu müssen, hat das Bundesverfassungsgericht durch die „elastische“ Auslegung des Begriffes des „Darauf-Ausgehens“ die vom EGMR geforderte Folgen/Nutzen-Abwägung in den geschriebenen Tatbestand integriert, was hinsichtlich der im zweiten NPD-Verbotsverfahren durch das Bundesverfassungsgericht bestätigten Haltung zur Negierung ungeschriebener Tatbestandsmerkmale auch konsequent ist. ${ }^{483}$

IV. Einfluss auf die Gesetzgebung

Auf den verfassungsgerichtlichen Rechtsprechungswandel reagierte der verfassungsändernde Gesetzgeber durch die Novellierung des Art. 21

481 Shirvani, JZ 2014, 1074 (1078).

482 BVerfGE 144, 20 (227 ff.).

483 Vgl. BVerfGE 144, 20 (227). 
Abs. 3 GG mit dem Änderungsgesetz vom 19.07.2017 ${ }^{484}$. Art. 21 Abs. 3 GG unterscheidet sich im Tatbestand nach seinem Wortlaut kaum von Art. 21 Abs. 2 GG. Im Unterschied zu Art. 21 Abs. 2 GG wird von Art. 21 Abs. 3 GG lediglich kein „Darauf-Ausgehen“, sondern ein „AusgerichtetSein“ verlangt. Der entscheidende Unterschied zeigt sich auf der Rechtsfolgenseite.

Dem Staat war es bislang nur in sehr engen Grenzen möglich, an die politische Ausrichtung der Parteien bestimmte Rechtsfolgen anzuknüpfen. ${ }^{485}$ Vor der Änderung des Grundgesetzes zum Zwecke des Ausschlusses einer Partei aus der staatlichen Parteienfinanzierung war es dem Staat zur Prävention von Gefahren für die freiheitliche demokratische Grundordnung oder den Bestand der Bundesrepublik Deutschland nur möglich, eine Partei nach Art. 21 Abs. 2 GG zu verbieten. Durch die Schaffung des Finanzierungsausschlussverfahrens hat er sich eine Handlungsalternative eingeräumt, die es ihm ermöglicht, verfassungsfeindliche Bestrebungen einer Partei innerhalb eines vorgegebenen Tatbestandes festzustellen, ohne sie als zwingende Folge hiervon auflösen zu müssen. ${ }^{486}$ Durch die Rechtsprechung des EGMR und dem sich an ihr orientierenden Rechtsprechungswandel des Bundesverfassungsgerichtes ist es dem Staat nur dann möglich eine Partei zu verbieten, wenn ausreichende Anhaltspunkte vorhanden sind, die eine gewisse Realisierungswahrscheinlichkeit ihrer verfassungswidrigen Ziele belegen. Sollte der Staat allerdings „unterhalb der Schwelle des Parteiverbotsverfahrens" tätig werden, oder, anders formuliert, gegen Parteien vorgehen wollen, die nach menschlichem Ermessen über keine nennenswerte Möglichkeit der Verwirklichung ihrer Ziele verfügen, so müsse der verfassungsändernde Gesetzgeber im Wege der Verfassungsänderung eine Möglichkeit der staatlichen Bekämpfung solcher Parteien im Grundgesetz schaffen.

Während das Parteiverbotsverfahren als Rechtsfolge eine Auflösung der Partei nach $₫ 46$ Abs. 3 S. 1 BVerfGG vorsieht, stellt das Bundesverfassungsgericht bei einem erfolgreichen Antrag nach Art. 21 Abs.3 GG den Ausschluss aus der staatlichen Parteienfinanzierung nach $\$ 46 a$ Abs. 1 S. 1 BVerfGG fest. Die betroffene Partei wird damit nicht aus dem Wettbe-

484 BGBl. 2017 I, S. 2346.

485 BVerfGE 47, 130 (139); BVerfGE 107, 339 (362); Morlok, in: Dreier/Bauer (Hrsg.), Grundgesetz, ${ }^{3} 2015$, Art. 21, Rn. 157; Klein, in: Maunz/Dürig (Hrsg.), Grundgesetz, 2018, Art. 21, Rn. 571.

486 Vgl. Streinz, in: Huber/Voßkuhle (Hrsg.), Grundgesetz, ${ }^{7} 2018$, Art. 21, Rn. 252b. 
werb eliminiert, sondern weiterhin als aktiver Teilnehmer an der politischen Willensbildung geduldet.

\section{B. Verfassungsrechtliche Pflichtenkollision}

Die Leistungsgewährung stand vor der Verfassungsänderung nicht unter dem Vorbehalt einer verfassungskonformen politischen Haltung oder gar einer Staatstreue. Der Staat war aufgrund des strengen und formalen Gleichheitssatzes zur Finanzierung, auch vermeintlich verfassungsablehnender oder gar bekämpfender Parteien, verpflichtet. Er war somit von Verfassungs wegen dazu verpflichtet, sehenden Auges eine die freiheitliche demokratische Grundordnung gefährdende Partei bei Erfüllung der gesetzlichen Finanzierungsvoraussetzungen, insbesondere der Überwindung der Sperrklauseln, durch die fortwährende Gewährung der Parteienfinanzierung zu unterstützen. Jedenfalls seitdem das Bundesverfassungsgericht eine Zielrealisierungspotentialität als Voraussetzung für die Feststellung der mit einem Verbot zusammenhängenden Verfassungswidrigkeit anerkannt hat ${ }^{487}$, besteht keine andere rechtliche Möglichkeit, die steuerliche Privilegierung und unmittelbare Teilfinanzierung von verfassungsfeindlichen Parteien einzustellen. Dieser Umstand begründet einen in den Grundsätzen des staatlichen Handelns verankerten Konflikt, der in diesem Sinne den Staat auf der einen Seite verpflichtet, Garant der freiheitlichen demokratischen Grundordnung zu sein, und auf der anderen Seite, die Gefährdung der zu schützenden Staatsprinzipien durch Parteien fortwährend zu subventionieren. ${ }^{488}$

Die in Art. 20 Abs. 1 GG genannten Staatsstrukturprinzipien, insbesondere das der Demokratie, verpflichten den Staat nicht nur zur Einhaltung der verfassungsrechtlich vorgegebenen Staatsstruktur und deren Leitgedanken, sondern darüber hinaus auch zur dauerhaften Gewährleistung der sich daraus ergebenden konkreten Staatsordnung. ${ }^{489}$ Diese Verpflichtung des Staates, die ihn zum Garanten der demokratischen Herrschaftsform erhebt, weist eine enge Verbindung zu den grundrechtlichen Schutzpflichten auf und verpflichtet in diesem Sinne den Staat zur Aufrechterhaltung

487 BVerfGE 144, 20 (219 ff.).

488 Diesen Umstand als „inneren Widerspruch der Verfassung“ beschreibend Ipsen, in: Sachs (Hrsg.), Grundgesetz, ${ }^{8} 2018$, Art. 21, Rn. 179, 181.

489 Denninger, in: VVDStRL 37 (1979), S. 72. 
einer die Grundrechte achtenden Staatsstruktur. ${ }^{490}$ Dieser Verpflichtung läuft wiederum das dem Demokratieprinzip innewohnende Institut der Chancengleichheit entgegen. Da der Staat im politischen Wettbewerb zwingend eine neutrale Stellung einzunehmen hat ${ }^{491}$, sind bei einer staatlichen Leistungsgewährung auch alle Parteien, so auch insbesondere solche mit einer verfassungsfeindlichen Haltung, grundsätzlich gleich zu behandeln. ${ }^{492}$ So ergibt sich eine verfassungsrechtlich besonders aufgeladene Pflichtenkollision, in welcher der Garant der freiheitlichen demokratischen Grundordnung zur finanziellen Unterstützung derjenigen, die er bekämpfen sollte, verpflichtet ist. Dieser Konflikt ist über die allgemein anwendbaren Kollisionsregeln zu lösen, d.h. unter der Anwendung des Prinzips der praktischen Konkordanz. ${ }^{493}$ Die hier miteinander kollidierenden verfassungsrechtlichen Pflichten müssen durch eine staatliche Maßnahme in einer Art und Weise ausgeglichen werden, die beiden einen größtmöglichen Geltungsbereich einräumt.

Über Art. 21 Abs. 3 GG hat der Staat die Möglichkeit erhalten, verfassungsfeindliche Parteien aus dem System der staatlichen Parteienfinanzierung auzuschließen. In diesem Sinne wurde durch die Verfassungsänderung 494 eine Ausnahmeregelung zu dem sonst strengen und formalen Gleichheitssatz geschaffen. Bei Vorliegen der tatbestandlichen Voraussetzungen und der Einhaltung des hierfür vorgesehenen Verfahrens ${ }^{495}$ kann sich der Staat aufgrund einer unerwünschten politischen Ausrichtung der Partei von der weiteren Pflicht der Teilfinanzierung und der mittelbaren Parteienfinanzierung befreien. Insoweit wurde der Gleichheitssatz in Angelegenheiten der Parteienfinanzierung unter einen Vorbehalt der Verfassungskonformität gestellt, die im Rahmen des dafür vorgesehenen Verfahrens festzustellen ist. Der Widerspruch, als Garant der freiheitlichen demokratischen Grundordnung auch solche Parteien zu fördern, die sich gerade derer Beeinträchtigung oder Abschaffung verschrieben haben, wurde

490 Vgl. Klein, in: Maunz/Dürig (Hrsg.), Grundgesetz, 2018, Art. 21, Rn. 547; Häberle, in: VVDStRL 30 (1972), S. 103 ff.

491 Siehe $\$ 2$ B. II.

492 Siehe dazu Morlok/Jürgensen, JZ 2018, 695 (698).

493 Vgl. Hesse, Grundzüge des Verfassungsrechts der Bundesrepublik Deutschland, ${ }^{20} 1999$, Rn.72; auch von einer „Harmonisierung" sprechend Scheuner, in: VVDStRL 20 (1971), S. 134, 125.

494 BGBl. 2017 I, S. 2346.

495 Siehe für den konstitutiven Charakter des Verfahrens Ipsen, in: Sachs (Hrsg.), Grundgesetz, ${ }^{8} 2018$, Art. 21, Rn. 215. 
durch die Schaffung des Finanzierungsausschlussverfahrens insoweit gelöst.

\section{Inhalt des Finanzierungsausschlusses \\ I. Tatbestand}

Die Voraussetzungen, die bei ihrem Vorliegen den Ausschluss einer Partei aus der staatlichen Parteienfinanzierung rechtfertigen, müssen durch den verfassungsändernden Gesetzgeber so ausgestaltet worden sein, dass eine Gefährdung der demokratischen Staatsform durch das Werkzeug selbst nur eine geringe Realisierungswahrscheinlichkeit birgt. Die Rechtsfolge des Finanzierungsausschlussverfahrens ist im Vergleich zum Parteiverbot milder, was auch Einfluss auf die vom Gesetzgeber gewählte Eingriffsschwelle des Finanzierungsausschlussverfahrens hatte. ${ }^{496} \mathrm{Im}$ Folgenden werden die einzelnen Tatbestandsmerkmale des Art. 21 Abs. 3 GG untersucht.

\section{Auslegung der Tatbestandsmerkmale}

Der Wortlaut des Art. 21 Abs. 3 GG ähnelt dem des „älteren“ Verbotsverfahren nach Absatz 2. Der verfassungsändernde Gesetzgeber hat den Wortlaut des Art. 21 Abs. 2 GG mit Ausnahme des Begriffes des „Darauf-Ausgehens" und der Rechtsfolgenbeschreibung als Vorlage für das Finanzierungsausschlussverfahren nach Absatz 3 verwendet. Bei der Auslegung der einzelnen Tatbestandsmerkmale des Parteiverbotsverfahrens wurde sowohl in der Rechtsprechung ${ }^{497}$ als auch in der Literatur ${ }^{498}$ unter Hinweis auf die extreme Folge des Parteiverbotsverfahrens stets ein restriktiver Maßstab angewandt. So mag sich auf den ersten Blick die Frage aufdrängen, ob angesichts der "milderen“ Rechtsfolge des Art. 21 Abs. 3 GG ein weniger restriktiver Maßstab bei der Auslegung der einzelnen Tatbestandsmerkmale

496 Epping, Rechtsgutachten über die Frage, ob und unter welchen Voraussetzungen eine nicht nach Art. 21 II GG verbotene Partei von der staatlichen Parteifinanzierung ausgeschlossen werden kann, 14.11.2008, S. 46.

497 Vgl. BVerfGE 144, 20 (159 f.).

498 So z.B. Seifert, Die politischen Parteien im Recht der Bundesrepublik Deutschland, 1975, S. 461 im Bezug zur Auslegung der Begriffe des „Beeinträchtigen“ und „Gefährden“ iSd. Art. 21 Abs. 2 GG. 
angelegt werden könnte. ${ }^{499}$ Die Merkmale des Art. 21 Abs. 3 GG können nicht getrennt vom Parteiverbot bewertet werden, sondern richten sich vielmehr nach den Voraussetzungen des Art. 21 Abs. 2 GG. Der verfassungsändernde Gesetzgeber hatte sich bei der Schaffung des Finanzierungsausschlussverfahrens offensichtlich an den Voraussetzungen des Parteiverbots orientiert und die beiden Verfahren tatbestandlich in ein Stufenverhältnis zueinander gesetzt. ${ }^{500}$ Dafür spricht der ähnliche Wortlaut wie auch die gesetzgeberische Reaktion auf den Hinweis des Bundesverfassungsgerichtes hinsichtlich der Schaffung von Sanktionen unterhalb der Schwelle des Parteiverbotsverfahrens im Rahmen des zweiten NPD-Verbotsverfahrens. ${ }^{501}$ Durch die Wortlautangleichung des Art. 21 Abs. 3 GG an Absatz 2 kommt der Wille des verfassungsändernden Gesetzgebers zum Ausdruck, die Voraussetzungen des Finanzierungsausschlussverfahrens an die des Parteiverbots anzugleichen. ${ }^{502}$ Hierfür spricht nicht nur das gesetzgeberische Interesse an einer Vereinheitlichung der Rechtsordnung, sondern auch der historische Hintergrund des Art. 21 Abs. 3 GG. Das zweite NPD-Verbotsverfahren ${ }^{503}$ scheiterte aufgrund der mangelnden „Potentialität" der Realisierung der Parteiziele. ${ }^{504} \mathrm{Da}$ das Bundesverfassungsgericht die „Potentialität“ aus dem Merkmal des „Darauf-Ausgehens“ ableitet und der verfassungsändernde Gesetzgeber gerade diese Begrifflichkeit beim Finanzierungsausschlussverfahren durch ein "Ausgerichtet-Sein“ ersetzt hat, die anderen Tatbestandsmerkmale allerdings übertragen hat, ist von einer einheitlichen Auslegung der Tatbestandsmerkmale auszugehen, sofern die Begrifflichkeiten identisch sind. Somit hat allein der Formulierungsunterschied auf der Tatbestandsebene zur Folge, dass für einen Ausschluss aus der staatlichen Parteienfinanzierung eine niedrigere Eingriffsschwelle anzusetzen ist als beim Parteiverbot. Auch eine Änderung der bisherigen Auslegungspraxis ist aufgrund der Änderung des Art. 21 Abs. 3 GG nicht

499 In etwa in dieser Richtung Epping, Rechtsgutachten über die Frage, ob und unter welchen Voraussetzungen eine nicht nach Art. 21 II GG verbotene Partei von der staatlichen Parteifinanzierung ausgeschlossen werden kann, 14.11.2008, S. $51 \mathrm{ff}$. der aufgrund der milderen Rechtsfolge es für vertretbar hält, weniger strenge Anforderungen an den Ausschluss aus der staatlichen Parteienfinanzierung zu stellen.

500 Müller, DVBl 2018, 1035 (1038f.).

501 BVerfGE 144, 20 (202).

502 So im Ergebnis auch Streinz, in: Huber/Voßkuhle (Hrsg.), Grundgesetz, ${ }^{72018}$, Art. 21, Rn. 252b; Ipsen, in: Sachs (Hrsg.), Grundgesetz, ${ }^{8} 2018$, Art. 21, Rn. 213; ders., JZ 2017, 933 (934).

503 BVerfGE 144, $20 \mathrm{ff}$.

504 BVerfGE 144, 20 (325 ff.). 
zu erwarten, da das Parteiverbotsverfahren aufgrund seiner schwerwiegenderen Rechtsfolge immer noch eine restriktive Handhabung der Tatbestandsmerkmale verlangt. ${ }^{505}$ Was das Merkmal des „Ausgerichtet-Sein“ auf Tatbestandsebene voraussetzt, wird im Folgenden untersucht. ${ }^{506}$

2. Bestand der Bundesrepublik und die freiheitliche demokratische Grundordnung als Schutzgüter

Art. 21 Abs. 3 GG schützt die freiheitliche demokratische Grundordnung und den Bestand der Bundesrepublik Deutschland. Auch andere Verfassungsnormen (Art. 10 Abs. 2 S.2, 11 Abs. 2, 18 S. 1, 21 Abs. 2, 87a Abs. 4 S. 1 und 91 Abs. 1 GG) sehen in ihrem Wortlaut und Regelungsgehalt die freiheitliche demokratische Grundordnung und den Bestand der Bundesrepublik Deutschland als zu schützendes Rechtsgut vor. Insofern hat der verfassungsändernde Gesetzgeber für das Finanzierungsausschlussverfahren ein bereits vom Grundgesetz für andere Fälle statuiertes Schutzniveau gewählt. Unter dem Schutzgut des „Bestandes der Bundesrepublik Deutschland" sind die territoriale Integrität des Staates und seine außenpolitische Handlungsfähigkeit zu verstehen. ${ }^{507}$ Insbesondere ist darin die durch die territoriale Integrität vorausgesetzte äußere Souveränität im Schutzgut mit inbegriffen. ${ }^{508}$

Der Begriff der "freiheitlichen demokratischen Grundordnung" wurde vom ersten Senat des Bundesverfassungsgerichts seit dem SRP-Verbotsurteil nur anhand einer demonstrativen, aber nicht abschließenden Aufzählung von dazugehörigen Prinzipien eingegrenzt. ${ }^{509}$ Der erste Senat verstand unter dem Begriff der "freiheitlichen demokratischen Grundordnung" eine Ordnung,

"die unter Ausschluss jeglicher Gewalt- und Willkürherrschaft eine rechtsstaatliche Herrschaftsordnung auf der Grundlage der Selbstbestimmung des Volkes nach dem Willen der jeweiligen Mehrheit und der Freiheit und

505 So wohl Streinz, in: Huber/Voßkuhle (Hrsg.), Grundgesetz, ${ }^{7} 2018$, Art. 21, Rn. 252b; Ipsen, in: Sachs (Hrsg.), Grundgesetz, ${ }^{8} 2018$, Art. 21, Rn. 213; ders., JZ 2017, 933 (934).

506 Siehe $\$ 4$ C. I. 4.

507 Klein, in: Maunz/Dürig (Hrsg.), Grundgesetz, 2018, Art. 21, Rn. 520. m.w.N.

508 Vgl. Streinz, in: Huber/Voßkuhle (Hrsg.), Grundgesetz, ${ }^{7} 2018$, Art. 21, Rn. 230.

509 BVerfGE 2, 1 LS. 2; ähnliche Beschreibung der Rechtsprechung auch durch Thrun, DÖV 2019, 65 (68f.). 
Gleichheit darstellt. $\mathrm{Zu}$ den grundlegenden Prinzipien dieser Ordnung sind mindestens zu rechnen: die Achtung vor den im Grundgesetz konkretisierten Menschenrechten, vor allem vor dem Recht der Persönlichkeit auf Leben und freie Entfaltung, die Volkssouveränität, die Gewaltenteilung, die Verantwortlichkeit der Regierung, die Gesetzmäßigkeit der Verwaltung, die Unabhängigkeit der Gerichte, das Mehrparteienprinzip und die Chancengleichheit für alle politischen Parteien mit dem Recht auf verfassungsmäßige Bildung und Ausübung einer Opposition. "510

In der Literatur ist der Versuch der Begriffsinterpretation durch das Bundesverfassungsgericht sowohl auf Kritik ${ }^{511}$ als auch auf Zuspruch ${ }^{512}$ gestoßen. Kern der Kritik bildet die (wohl) willkürlich vorgenommene Enumeration der zur freiheitlichen demokratischen Grundordnung gehörenden Prinzipien, bzw. die nicht überzeugende dogmatische Herleitung dieser Interpretation durch das Bundesverfassungsgericht. Das Bundesverfassungsgericht selbst hat sich der Kritik aus dem Schrifttum angenommen und sie unter den Hauptaspekten der „Unvollständigkeit, Beliebigkeit, Unbestimmtheit, Missbrauchsanfälligkeit und fehlender Systematik“"513 zusammengefasst. Obwohl die juristische Methodik der Rechtsprechung des ersten Senates kritisiert wurde, besteht bezüglich des Inhaltes bzw. Ergebnisses ein weitestgehender Konsens.

Im zweiten NPD-Verbotsverfahren ${ }^{514}$ wurde die Kritik aus dem Schrifttum aufgegriffen. Der zweite Senat versuchte durch die Systematisierung anerkannter verfassungsrechtlicher Begrifflichkeiten der deutschen Staatslehre einen möglichst treffenden Inhalt des Begriffes der „freiheitlichen demokratischen Grundordnung" festzulegen ${ }^{515}$, was auch überzeugend gelang. Nach der jüngsten Auffassung des Gerichtes beschreibt die freiheitliche demokratische Grundordnung „nur jene zentralen Grundprinzipien, die

510 BVerfGE 2, 1 LS. 2.

511 Morlok, in: Dreier/Bauer (Hrsg.), Grundgesetz, ${ }^{3} 2015$, Art. 21, Rn. 148; Lameyer, Streitbare Demokratie, 1978, S. 37; Stollberg, Die verfassungsrechtlichen Grundlagen des Parteiverbots, 1976, S. 33; Gusy, AöR 105 (1980), 279 (291); siehe iÜ. BVerfGE 144, 20 (204f.) für weitere Nachweise.

512 Sattler, Die rechtliche Bedeutung der Entscheidung für die streitbare Demokratie, 1982, S. 56; Schmitt Glaeser, Missbrauch und Verwirkung von Grundrechten im politischen Meinungskampf, 1968, S. 43 ff.; Stern, Staatsrecht I, ${ }^{2} 1984$, S. 568 m.w.N.; im „Wesentlichen“ zustimmend wohl Dürig/Klein, in: Maunz/Dürig (Hrsg.), Grundgesetz, 2018, Art. 18, Rn. 62.

513 BVerfGE 144, 20 (204 f. Rn. 534) m.w.N.

514 BVerfGE 144, $20 \mathrm{ff}$.

515 Vgl. Thrun, DÖV 2019, 65 (69). 
für den freibeitlichen Verfassungsstaat schlechthin unentbebrlich sind" ".516 Ausgangspunkt dieser „zentralen Grundprinzipien“ bildet dabei die Menschenwürdegarantie aus Art. 1 Abs. 1 S. 1 GG $^{517}$, die ein normatives Leitbild vorgibt, nach welchem sich der konkrete Inhalt des Begriffes richtet. ${ }^{518}$ Aus der Menschenwürdegarantie folgt die Subjektsqualität des Menschen, aus der wiederum ein egalitärer, sozialer Wert- und Achtungsanspruch abgeleitet wird, der eine Degradierung des Menschen zu einem „bloßen Objekt" staatlichen Handelns strikt untersagt. ${ }^{519}$

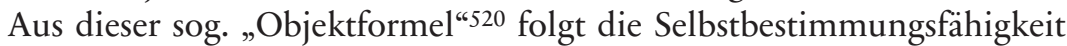
aller Bürger, die dazu führt, dass jeder Bürger befähigt sein muss, an den grundlegenden Entscheidungen im Staat mitzuwirken. Die Ausübung der Staatsgewalt muss, in Ansehnung des aus der Menschenwürde entspringenden normativen Leitbildes der Staatsordnung, stets vom Volk ausgehen. Aus diesem Grund wird auch das Demokratieprinzip als „konstitutiver Bestandteil“ des Begriffes der freiheitlichen demokratischen Grundordnung begriffen. ${ }^{521}$ Der zweite Senat konkretisierte den Demokratiegehalt der freiheitlichen demokratischen Grundordnung dahingehend, dass jedenfalls die gleichberechtigte Teilnahme aller Bürger am Prozess der politischen Willensbildung und die Rückbindung der Ausübung der Staatsgewalt an das Volk gewährleistet sein müssen. ${ }^{522}$

Aufgrund der leitbildlichen Funktion der Menschenwürdegarantie für den Begriff der freiheitlichen demokratischen Grundordnung ist auch das Rechtsstaatsprinzip, insbesondere die Bindung der öffentlichen Gewalt an Recht und Gesetz (Art. 20 Abs. 3 GG), die Kontrolle der Bindung durch unabhängige Gerichte, und das Gewaltmonopol des Staates umfasst. ${ }^{523}$ Durch die Miteinbeziehung der Gewährleistung einer unabhängigen richterlichen Kontrolle in den Begriff der freiheitlichen demokratischen Grundordnung wird, in Anknüpfung an die Rechtsprechung des zweiten

516 BVerfGE 144, 20 LS. 3.

517 BVerfGE 144, 20 (206).

518 Vgl. BVerfGE 144, 20 (206); siehe vertiefend auch Thrun, DÖV 2019, 65 (69 f.).

519 BVerfGE 57, 250 (274 f.); BVerfGE 122, 248 (271).

520 Siehe statt vieler zur Objektformel Herdegen, in: Maunz/Dürig (Hrsg.), Grundgesetz, 2018, Art. 1, Rn. 36; Höfling, in: Sachs (Hrsg.), Grundgesetz, ${ }^{8} 2018$, Art. 1, Rn. $15 \mathrm{ff}$.

521 BVerfGE 144, 20 (208 ff.); siehe auch Thrun, DÖV 2019, 65 (70).

522 BVerfGE 144, 20 (208f.).

523 BVerfGE 144, 20 (210). 
Senats, auch der Grundsatz der Gewaltenteilung dem Begriff der freiheitlichen demokratischen Grundordnung zugeordnet. ${ }^{524}$

Die Eingrenzung des Begriffes der freiheitlichen demokratischen Grundordnung auf die zentralsten Grundprinzipien, die von der Menschenwürdegarantie selbst umfasst sind, ist zu begrüßen und wurde vom Bundesverfassungsgericht dogmatisch überzeugend dargelegt. $\mathrm{Da}$ an die Tatbestandsmerkmale des Art. 21 Abs. 3 GG grundsätzlich dieselben Anforderungen zu stellen sind wie bei dem Parteiverbot, muss der Begriff der freiheitlichen demokratischen Grundordnung angesichts der erheblichen Eingriffswirkung dieser Instrumentarien in den offenen Prozess der politischen Willensbildung restriktiv ausgelegt werden. ${ }^{525}$ Das Prinzip der „wehrhaften Demokratie“ soll seinem Zwecke nach die demokratische Staatsordnung nicht über das notwendige $\mathrm{Ma}$ hinaus beeinträchtigen, sondern nur die fundamentalen Grundsätze der Verfassung zu schützen ermöglichen.

Das Schutzgut des Bestandes der Bundesrepublik Deutschland wird vor einer Gefährdung, die freiheitliche demokratische Grundordnung vor einer Beeinträchtigung oder Beseitigung geschützt. Die Begriffe des „Gefährdens“, „Beeinträchtigens“ und „Beseitigens“ legen insoweit das konkrete Ziel fest, auf dessen Realisierung die Partei hinwirken muss bzw. den konkreten Erfolg, den sie aufgrund ihrer Zielsetzung verfolgen. ${ }^{526}$ Die Voraussetzung des "Gefährdens" des Bestandes der Bundesrepublik Deutschland ist nach allgemeiner Auffassung nicht schon dann erfüllt, wenn eine konkrete Gefährdung eingetreten ist, sondern wenn eine Gefährdung durch die Partei bereits lediglich beabsichtigt wird. ${ }^{527}$ Anders verhält es sich mit den auf die freiheitliche demokratische Grundordnung bezogenen Zielsetzungen des „Beseitigens“ oder des „Beeinträchtigens“, die das Bundesverfassungsgericht erst in der Entscheidung über das zweite NPD-Verbotsverfahrens erstmalig voneinander abgegrenzt und näher definiert hat. ${ }^{528}$ Während der erste Senat in den vergangenen Verbotsverfah-

524 Überzeugend Thrun, DÖV 2019, 65 (70 f.).

525 So auch BVerfGE 144, 20 (205).

526 Vgl. Streinz, in: Huber/Voßkuhle (Hrsg.), Grundgesetz, ${ }^{7} 2018$, Art. 21, Rn. 228.

527 Ipsen, in: Sachs (Hrsg.), Grundgesetz, ${ }^{8} 2018$, Art. 21, Rn. 168; Streinz, in: Huber/ Voßkuhle (Hrsg.), Grundgesetz, ${ }^{7} 2018$, Art. 21, Rn. 230.; Klein, in: Maunz/Dürig (Hrsg.), Grundgesetz, 2018, Art. 21, Rn. 532; Morlok, in: Dreier/Bauer (Hrsg.), Grundgesetz, ${ }^{3} 2015$, Art. 21, Rn. 153; Stollberg, Die verfassungsrechtlichen Grundlagen des Parteiverbots, 1976, S. 51 f. m.w.N.

528 BVerfGE 144, 20 (211 ff.). 
ren der SRP 529 und $\mathrm{KPD}^{530}$ die Begriffe undifferenziert als "Schwächung, Untergrabung bzw. Zersetzung sowie die planmäßige Hetze, Verächtlichmachung und Verhöhnung der freiheitlichen demokratischen Grundordnung" verstanden hat ${ }^{531}$, trennte der zweite Senat die Begriffe inhaltlich voneinander und ordnete ihnen einen jeweils eigenständigen Regelungsgehalt zu. ${ }^{532}$ Unter dem Begriff des „Beseitigens“ sei demnach „die Abschaffung zumindest eines der Wesenselemente der freiheitlichen demokratischen Grundordnung oder deren Ersetzung durch eine andere Verfassungsordnung oder ein anderes Regierungssystem" zu verstehen. ${ }^{533}$ In Abgrenzung hierzu interpretiert das Bundesverfassungsgericht den Begriff des „Beeinträchtigens“ als eine „nach dem politischen Konzept der Partei mit hinreichender Intensität spürbare Gefährdung der freiheitlichen demokratischen Grundordnung“. 534 Nach diesem Verständnis des Begriffes liegt eine „Beeinträchtigung“ der freiheitlichen demokratischen Grundordnung somit bereits dann vor, „wenn eine Partei, ohne erkennen zu lassen, welche Verfassungsordnung an die Stelle der bestehenden treten soll, qualifiziert deren Außerkraftsetzung betreibt". .535

Das Ergebnis der „neuen“ verfassungsgerichtlichen Interpretation der Begriffe der „freiheitlichen demokratischen Grundordnung“ und des „Beeinträchtigens" und des „Beseitigens“ sind dogmatisch überzeugende Definitionen. Durch den eigenständigen Regelungsgehalt der Begriffe des „Beseitigens" und „Beeinträchtigens“ konnten klare Konturen des Tatbestandes des Art. 21 Abs. 2 und Abs. 3 GG geschaffen werden, anhand derer die Verfassungswidrigkeit und -feindlichkeit der Zielsetzung einer Partei nun

529 BVerfGE 2, 1.

530 BVerfGE 5, 85.

531 BVerfGE 2, 1 (21); BVerfGE 5, 85 (210 ff., 307 f.); besonders hingewiesen wird auf Seifert, Die politischen Parteien im Recht der Bundesrepublik Deutschland, 1975, S. 461, der eine Differenzierung zwischen den Begriffen des „Beeinträchtigens" und des „Beseitigens“ für nicht sinnvoll erachtet, da sie sich zu ähnlich und, seiner Auffassung nach, wohl inhaltlich identisch seien.

532 BVerfGE 144, 20 (211).

533 BVerfGE 144, 20 (211); kritisch hierzu Klein, in: Maunz/Dürig (Hrsg.), Grundgesetz, 2018, Art. 21, Rn.531, Fn. 631, der die Weite der Definition kritisiert und insbesondere darauf hinweist, dass die Forderung, das parlamentarische Regierungssystem durch ein Präsidialsystem zu ersetzen keine Partei in die Nähe der Verfassungswidrigkeit rückt.

534 BVerfGE 144, 20 (213) - Zitat wurde zwecks Stimmigkeit des Textes durch den Verfasser sprachlich verändert.

535 BVerfGE 144, 20 (213) - Zitat wurde zwecks Stimmigkeit des Textes durch den Verfasser sprachlich verändert. 
trennschärfer bestimmt werden kann. Der Begriff der freiheitlichen demokratischen Grundordnung wird dabei restriktiv ausgelegt, um der einschneidenen Wirkung des Parteiverbots- und Finanzierungsausschlussverfahrens in den offenen Prozess der politischen Willensbildung gerecht zu werden.

\section{Zielsetzung und Anhängerschaft der Partei}

Für die Feststellung der Verfassungsfeindlichkeit ist auf die Zielsetzung oder das Verhalten der Anhänger der Partei abzustellen. ${ }^{536}$ Dadurch schränkt Art. 21 Abs. 3 GG die Erkenntnisquellen zur Überprüfung der Verfassungsfeindlichkeit auf „die Ziele“ und das „Verhalten der Anhänger“ ein. ${ }^{537}$ Die abschließende Einschränkung der Erkenntnisquellen dient, wie auch beim Parteiverbot, einer Eingrenzung der staatlichen Bewertungsmöglichkeiten. Durch die inhaltliche, verfassungsrechtliche Vorgabe zum Erkenntnisprozess im Finanzierungsausschlussverfahren wurde ein transparenter Untersuchungsgegenstand vorgebegeben, der allein einen Aufschluss über die Eigenschaft der „Verfassungsfeindlichkeit“ zu geben vermag.

Nach der Auffassung des Bundesverfassungsgerichtes sind die Ziele einer Partei der „Inbegriff dessen, was eine Partei politisch anstrebt, unabhängig davon, ob es sich um Zwischen- oder Endziele, Nah- oder Fernziele, Haupt- oder Nebenziele handelt ${ }^{\text {“. }}{ }^{538}$ Die Erkenntnismittel zur genauen Bestimmung der „Ziele“ einer Partei hat das Bundesverfassungsgericht beispielhaft aufgezählt. Demnach ergäben sich die „Ziele“ regelmäßig aus dem Parteiprogramm, sonstigen parteiamtlichen Erklärungen, Schriften von für die politische Ideologie der Partei maßgeblichen Autoren, Reden von führenden Funktionären, von der Partei verwendetes Schulungs- und Propagandamaterial sowie herausgegebene und beeinflusste Zeitungen

536 Vgl. in Bezug zum Parteiverbotsverfahren statt aller Ipsen, in: Sachs (Hrsg.), Grundgesetz, ${ }^{8} 2018$, Art. 21, Rn. 155 ff.

537 Vgl. BVerfGE 144, 20 (214); Alter, Die Eingriffsschwelle beim Verbot extremistischer Parteien und Vereine in Deutschland und England, 2016, S. 231.

538 BVerfGE 144, 20 (214); BVerfGE 5, 85 (143 ff.); kritisch Meier, Parteiverbote und demokratische Republik, 1993, S. 275 ff., der kritisiert, dass das Bundesverfassungsgericht bei der Auslegung des Begriffes der "Zielsetzung" nicht die Realisierungswahrscheinlichkeit berücksichtigt. So genügt Meier kein bloßes Inaussichtstellen eines Fernzieles, da das Parteiverbotsverfahren dadurch revolutionäre Bekenntnisse sanktionieren würde (S. 276). 
und Zeitschriften. ${ }^{539}$ Nach der herrschenden Auffassung ist ferner nicht notwendig, dass sich eine Partei in einer öffentlichen Art und Weise zu ihren verfassungsfeindlichen Zielen bekennt, da auf ihre tatsächlichen, nicht lediglich nach Außen vorgegebenen Ziele abzustellen sei. ${ }^{540}$

Alternativ zu den „Zielen“ einer Partei dient auch das „Verhalten der Anhänger" als Erkenntnisquelle zur Feststellung der Verfassungsfeindlichkeit. Wie auch beim Parteiverbot kann sich im Verhalten der Anhänger die tatsächliche Absicht bzw. Zielsetzung der Partei widerspiegeln. ${ }^{541}$ Anhänger sind nach allgemeiner Ansicht Personen, die sich für eine Partei einsetzen und sich zu ihr bekennen, auch wenn sie nicht Mitglieder der Partei sind. ${ }^{542}$ Das relevante Verhalten muss sich der Partei zurechnen lassen können. ${ }^{543}$

\section{Ausgerichtet-sein}

Der tatbestandliche Unterschied zwischen Art. 21 Abs. 2 und Abs. 3 GG liegt in den Merkmalen des „Ausgerichtet-Seins“ und des „Darauf-Ausgehens“. Eine Partei muss, um aus der staatlichen Finanzierung ausgeschlossen zu werden, „darauf ausgerichtet sein“, den Bestand der Bundesrepublik Deutschland zu gefährden oder die freiheitliche demokratische Grundordnung zu beeinträchtigen oder zu beseitigen. Die Interpretation des Begriffes muss zwingend in Relation zu dem Begriff des „Darauf-Ausgehens“ erfolgen, da der verfassungsändernde Gesetzgeber bei der Festlegung des Tatbestandes des Art. 21 Abs. 3 GG das Parteiverbot als „Vorlage“ genutzt hat und damit die Intention verfolgte, den Tatbestand beider Sanktionsnormen weitestgehend anzugleichen. ${ }^{544}$ Art. 21 Abs. 2 GG und Art. 21 Abs. 3 GG stehen insoweit auf Tatbestandsebene in einem Stufenverhält-

539 BVerfGE 5, 85 (144); BVerfGE 144, 20 (214).

540 BVerfGE 144, 20 (215); BVerfGE 5, 85 (144); BVerfGe 2, 1 (20); Seifert, DÖV 1961, 81 (83); Shirvani, JZ 2014, 1074 (1075); Streinz, in: Huber/Voßkuhle (Hrsg.), Grundgesetz, ${ }^{7} 2018$, Art. 21, Rn. 234; Ipsen, in: Sachs (Hrsg.), Grundgesetz, ${ }^{8} 2018$, Art. 21, Rn. 156; kritisch Meier, Parteiverbote und demokratische Republik, 1993, S. 104 ff., 275 ff.

541 BVerfGE 144, 20 (215); BVerfGE 2, 1 (22).

542 BVerfGE 47, 130 (139); BVerfGE 2, 1 (22).

543 BVerfGE 144, 20 (215).

544 Vgl. Streinz, in: Huber/Voßkuhle (Hrsg.), Grundgesetz, ${ }^{7} 2018$, Art. 21, Rn. 252b; Ipsen, in: Sachs (Hrsg.), Grundgesetz, ${ }^{8} 2018$, Art. 21, Rn. 213; ders., JZ 2017, $933 \mathrm{f}$. 
nis, welches als maßgeblicher Anknüpfungspunkt zur Konkretisierung der Voraussetzung des „Ausgerichtet-Seins“ dient. ${ }^{545}$

Das Tatbestandsmerkmal des „Ausgerichtet-Seins“ gibt das Niveau der Störungshandlung vor, das durch das Verhalten der Partei erreicht werden muss, um einen Ausschluss aus der staatlichen Parteienfinanzierung zu rechtfertigen. ${ }^{546}$ Die Interpretation des Begriffs ist für die Frage der Zulässigkeit des Finanzierungsausschlussverfahrens von besonderer Bedeutung, da er die konkrete Störungs- bzw. Handlungsschwelle verfassungsfeindlicher Bestrebungen vorgibt. Welche Voraussetzungen erfüllt sein müssen, damit eine Partei „ausgerichtet ist“ den Bestand der Bundesrepublik Deutschland zu gefährden oder die freiheitliche demokratische Grundordnung zu beeinträchtigen oder zu beseitigen, kann allein anhand des Wortlautes nicht erschlossen werden. Anders als beim Parteiverbotsverfahren kann das Merkmal des „Ausgerichtet-Seins“ nicht eigenständig interpretiert werden, sondern bedarf einer relativierenden Auslegung unter der Maßgabe des Tatbestandes des Art. 21 Abs. 2 GG.

In den Gesetzgebungsmaterialien heißt es, dass beim Finanzierungsausschlussverfahren eine „gegen die freiheitliche demokratische Grundordnung oder den Bestand der Bundesrepublik Deutschland gerichtete Zielsetzung zukünftig die alleinige Tatbestandsvoraussetzung für einen Ausschluss politischer Parteien von der staatlichen Parteienfinanzierung sein soll, ohne dass es auf die Wahrscheinlichkeit eines Erfolges ankommen würde“. ${ }^{547}$ So kommt der gesetzgeberische Wille, die Realisierungspotentialität als Voraussetzung für den Ausschluss aus der staatlichen Finanzierung nicht übernehmen zu wollen, deutlich zum Ausdruck. Problematisch an der Formulierung der gesetzgeberischen Zielsetzung ist, dass eine „gegen die freiheitliche demokratische Grundordnung oder den Bestand der Bundesrepublik Deutschland gerichtete Zielsetzung zukünftig alleinige Tatbestandsvoraussetzung ${ }^{\text {"5 }} 48$ sein soll. Was genau laut dem gesetzgeberischen Willen unter den Begriff der "Zielsetzung" einer Partei verstanden wird, kann aus den Gesetzgebungsmaterialien nicht entnommen werden. So mag sich angesichts der unglücklichen Formulierung die Frage aufdrängen, ob bereits eine zu den Grundwerten der Verfassung kritisch stehende, rein inhaltliche Parteilinie nach der Auffassung des Gesetzgebers

545 Vgl. Müller, DVBl 2018, 1035 (1038f.).

546 Vgl. zu Art. 21 Abs. 2 GG Meier, Parteiverbote und demokratische Republik, 1993, S. 271.

547 BT-Drucksache 18/12357, S. 1.

548 BT-Drucksache 18/12357, S. 1. 
ausreichend sei, um den Ausschluss einer Partei aus der staatlichen Parteienfinanzierung zu rechtfertigen. Eine Partei nach diesen Grundsätzen somit dann auf die Gefährdung des Bestandes der Bundesrepublik Deutschland oder die Beeinträchtigung oder Beseitigung der freiheitlichen demokratischen Grundordnung ,ausgerichtet“ sei, wenn ihre innere Zielsetzung ohne das Vorliegen eines zusätzlichen Handlungselementes für das Erfüllen des Tatbestandes ausreiche. Anlass für diese Überlegung bietet insbesondere das von Volker Epping angefertigte Rechtsgutachten zu der Frage der Zulässigkeit des Ausschlusses verfassungsfeindlicher Parteien aus der staatlichen Parteienfinanzierung. Darin wird die Auffassung vertreten, dass für einen Ausschluss aus der staatlichen Parteienfinanzierung anders als beim Parteiverbotsverfahren keine aktiv aggressiv-kämpferische Grundhaltung erforderlich sei, sondern lediglich konkrete Bestrebungen zur Verfolgung verfassungsfeindlicher Ziele ausreichend seien. ${ }^{549}$ Die niedrigere Eingriffsintensität eines Ausschlusses aus der staatlichen Parteienfinanzierung gegenüber einem Parteiverbot würde „Abstriche hinsichtlich der Art und Weise der Verfolgung dieses Zieles" 550 rechtfertigen. Nach dieser Auffassung solle es in den Grenzen von Art. 79 Abs. 3 GG bereits dann zulässig sein, eine Partei aus der staatlichen Parteienfinanzierung auszuschließen, wenn sie konkreten Bestrebungen zur Verfolgung verfassungsfeindlicher Ziele aufzeige. ${ }^{551}$ Bestrebungen lägen immer dann vor, „wenn die politische Ausrichtung einer Partei gegen die freiheitliche demokratische Grundordnung im politischen Meinungskampf in einer Weise nach außen hin kenntlich gemacht wird, die auf die Beeinträchtigung oder Beseitigung dieser Ordnung abzielt. “552

In der Literatur wird das Tatbestandsmerkmal des "Ausgerichtet-Seins“ historisch ausgelegt und bis auf das Vorliegen der „Potentialität der Zielrealisierung" an den Begriff des "Darauf-Ausgehens" i.S.d. Art. 21

549 Epping, Rechtsgutachten über die Frage, ob und unter welchen Voraussetzungen eine nicht nach Art. 21 II GG verbotene Partei von der staatlichen Parteifinanzierung ausgeschlossen werden kann, 14.11.2008, S. $51 \mathrm{f}$.

550 Ders., Rechtsgutachten über die Frage, ob und unter welchen Voraussetzungen eine nicht nach Art. 21 II GG verbotene Partei von der staatlichen Parteifinanzierung ausgeschlossen werden kann, 14.11.2008, S. 51.

551 Ders., Rechtsgutachten über die Frage, ob und unter welchen Voraussetzungen eine nicht nach Art. 21 II GG verbotene Partei von der staatlichen Parteifinanzierung ausgeschlossen werden kann, 14.11.2008, S. 52.

552 Ders., Rechtsgutachten über die Frage, ob und unter welchen Voraussetzungen eine nicht nach Art. 21 II GG verbotene Partei von der staatlichen Parteifinanzierung ausgeschlossen werden kann, 14.11.2008, S. 53. 
Abs. 2 GG angelehnt. ${ }^{553}$ Demnach sollen bis auf das Vorliegen der „Potentialität" für den Ausschluss aus der staatlichen Parteienfinanzierung dieselben Voraussetzungen vorliegen müssen wie beim Parteiverbotsverfahren. Insoweit wird das Finanzierungsausschlussverfahren nach seinem Telos als Reaktion auf das zum wiederholten Male gescheiterte NPD-Verbotsverfahren verstanden und das tatbestandliche Stufenverhältnis zu Art. 21 Abs. 2 GG deutlich. ${ }^{554}$ Der Gesetzgeber sah angesichts der aufgrund des Parteiverbotsverständnisses des EGMR geänderten Rechtsprechung des Bundesverfassungsgerichtes das Parteiverbot als nicht mehr ausreichendes Mittel zur Bekämpfung systemfeindlicher Parteien an. Nach der neuesten Rechtsprechung des Bundesverfassungsgerichtes sei unter dem Begriff des Tatbestandsmerkmales des „Darauf-Ausgehens“ ein aktives und planvolles Handeln zu verstehen, das im Sinne einer qualifizierten Vorbereitungshandlung auf die Beeinträchtigung oder Beseitigung der freiheitlichen demokratischen Grundordnung oder auf die Gefährdung des Bestands der Bundesrepublik Deutschland gerichtet sei und daraus konkrete Anhaltspunkte erwüchsen, die einen Erfolg des gegen die freiheitliche demokratische Grundordnung oder den Bestand der Bundesrepublik Deutschland gerichteten Handelns zumindest möglich erscheinen lassen. ${ }^{555}$ Hinzukommen müsse nach der KPD-Rechtsprechung des Bundesverfassungsgerichtes noch eine „kämpferische, aggressive Haltung gegenüber der bestehenden Ordnung “. ${ }^{556}$ So setze nach dieser Auffassung das „Ausgerichtet-Sein“ ein aktives und planvolles Handeln voraus, das im Sinne einer qualifizierten Vorbereitungshandlung auf die Beeinträchtigung oder Beseitigung der freiheitlichen demokratischen Grundordnung oder auf die Gefährdung des Bestands der Bundesrepublik Deutschland gerichtet sei. Damit steht der Begriff des „Ausgerichtet-Seins“ in starker Ähnlichkeit zu der Auslegung des Begriffs des „Darauf-Ausgehens“ in der früheren Rechtsprechung des Bundesverfassungsgerichtes. 557

Das „Ausgerichtet-Sein“ unterscheidet sich bei nüchterner Betrachtung kaum vom Begriff des „Darauf-Ausgehens". ${ }^{558}$ Das Stufenverhältnis und die Normhistorie sind, so wie es in der Literatur bislang vertreten wird, ein

553 Ipsen, in: Sachs (Hrsg.), Grundgesetz, ${ }^{8} 2018$, Art. 21, Rn. 213; Streinz, in: Huber/ Voßkuhle (Hrsg.), Grundgesetz, ${ }^{7} 2018$, Art. 21, Rn. 252b.

554 Müller, DVBl 2018, 1035 (1038f.).

555 BVerfGE 144, 20 (219).

556 BVerfGE 5, 85 (141); BVerfGE 144, 20 (220).

$557 \mathrm{Vgl}$. insoweit BVerfGE 5, 85 (141 f.).

558 So auch Ipsen, in: Sachs (Hrsg.), Grundgesetz, ${ }^{8} 2018$, Art. 21, Rn. 213; ders., JZ 2017, 933 (934). 
überzeugender Anknüpfungspunkt für die Ermittlung des normativen Gehaltes des Begriffes. Die Schaffung des Finanzierungsausschlussverfahrens war von dem gesetzgeberischen Willen getragen, systemfeindliche Parteien unter geringeren Voraussetzungen als von Art. 21 Abs. 2 GG gefordert sanktionieren zu können. Das Bundesverfassungsgericht gab im zweiten NPD-Verbotsverfahren auch den deutlichen Hinweis an den Gesetzgeber, dass die Schaffung von Sanktionen unterhalb der Schwelle des Parteiverbots dem verfassungsändernden Gesetzgeber vorbehalten sei ${ }^{559}$, damit also die Möglichkeit einer anderweitigen, weniger einschneidenden Sanktionierung von Parteien unter dem Vorbehalt einer Verfassungsänderung bestehe. Durch das Scheitern des zweiten NPD-Verbotsverfahrens aufgrund einer fehlenden „Potentialität" der Zielrealisierung sollte ein Sanktionsmechanismus etabliert werden, der es dem Staat vorrangig ermöglicht, solche Parteien wie die NPD sanktionieren zu können. Parteien, die eine verfassungsfeindliche Zielsetzung verfolgen, allerdings keine objektiv bestimmbare Realisierungswahrscheinlichkeit dieser Zielsetzung vorweisen können, sollen auf anderem Wege durch die staatliche Gewalt an der weiteren Verfolgung ihrer Ziele gehindert werden. Deutlich wurde dies insbesondere in der Debatte des Bundestages zum Änderungsgesetz vom 18.07.2017560 und den Gesetzgebungsmaterialien ${ }^{561}$, worin die rechtspolitische Gebotenheit der Verfassungsänderung von den Abgeordneten aller Fraktionen explizit im Hinblick auf das gescheiterte NPD-Verbotsverfahren angeführt wurde..$^{562}$

Für die bereits aufgeführte historische Auslegung des Begriffes sprechen auch die Gesetzgebungsmaterialien. Der Gesetzesentwurf des Landes Niedersachsen ${ }^{563}$ sah den Begriff der „Bestrebungen“ für einen Ausschluss aus der Parteienfinanzierung vor. Dasselbe Land war auch Auftraggeberin des Rechtsgutachtens von Volker Epping ${ }^{564}$, sodass es nahe liegt, dass jenes Gutachten als Beratungs- und Arbeitsgrundlage für die Erstellung des Geset-

559 BVerfGE 144, 20 (202).

560 BGBl. 2017, I, S. 2346.

561 BT-Drucksache 18/12357, S. 1.

562 BT-Protokoll, 22.06.2017, S. $24551 \mathrm{ff}$.; siehe darüber hinaus BT-Drucksache $113 / 17$, S. 1, wo die Landesregierung von Niedersachsen die rechtspolitische Gebotenheit der Verfassungsänderung explizit auf das gescheiterte NPD-Verbotsverfahren bezieht.

563 BR-Drucksache 113/17.

564 Epping, Rechtsgutachten über die Frage, ob und unter welchen Voraussetzungen eine nicht nach Art. 21 II GG verbotene Partei von der staatlichen Parteifinanzierung ausgeschlossen werden kann, 14.11.2008. 
zesentwurfes verwendet wurde und der Begriff der „Bestrebungen“ im niedersächsischen Gesetzesentwurf inhaltsgleich mit der Vorstellung Volker Eppings war. ${ }^{565}$ Am 10. März 2017 beschloss der Bundesrat einen überarbeiteten Gesetzesentwurf ${ }^{566}$, worin nur die Entscheidungszuständigkeit im Unterschied zu dem niedersächsischen Gesetzesentwurf statt beim Bundesverwaltungsgericht beim Bundesverfassungsgericht angesiedelt werden sollte. Der Begriff der „Bestrebungen“ blieb erhalten. Erst im Gesetzesentwurf der Regierungsfraktionen CDU und SPD vom 16.05.2017 ${ }^{567}$, der später auch mit der erforderlichen Zwei-Drittel-Mehrheit beschlossen wurde, wurde der Begriff der „Bestrebungen“ durch den des „Ausgerichtet-Seins“ ersetzt. Dies deutet darauf hin, dass der Gesetzgeber bewusst Abstand von dem Begriff der „Bestrebungen“ genommen und ihn durch ein Wort ersetzt hat, das sich objektiv kaum von dem des „Darauf-Ausgehens“ iSd. Art. 21 Abs. 2 GG unterscheidet.

Auch eine teleologische Auslegung des Begriffes des „AusgerichtetSeins" führt zu dem Ergebnis, dass das einzige Unterscheidungsmerkmal zum Begriff des „Darauf-Ausgehens“ das Fehlen der Potentialität zur Realisierung ihrer verfassungsfeindlichen Ziele darstellt und das Finanzierungsausschlussverfahren keine reine gesinnungsbezogene Sanktionierung vorsieht. Insbesondere darf das Merkmal des „Ausgerichtet-Seins“, gleichlaufend zum Merkmal des „Daraus-Ausgehens“ in Art. 21 Abs. 2 GG $^{568}$, nicht im Sinne eines Weltanschauungs- oder Gesinnungsverbotes verstanden werden. Die Freiheit und Offenheit des politischen Wettbewerbes setzt einen freien Austausch der Interessen und Meinungen als konstitutives Element voraus ${ }^{569}$, was gerade dann demokratiebezogene Probleme aufwerfen sollte, wenn durch ein Gesinnungs- oder Weltanschauungsverbot ebendieser beeinträchtigt wird. Das Ziel der Sanktionierung darf nicht in der Repression von aus staatlicher Sicht missliebiger Meinungen und Interessen liegen, sondern muss sich stets auf das durch das Finanzierungsausschlussverfahren zu schützende Gut beziehen. Eine Partei darf nicht aufgrund des Vertretens einer bestimmten Meinung oder eines konkreten Interesses aus der staatlichen Parteienfinanzierung ausgeschlossen werden, sondern nur dann, wenn sie durch ein ihr zurechenbares Handeln in dem

565 Ders., Rechtsgutachten über die Frage, ob und unter welchen Voraussetzungen eine nicht nach Art. 21 II GG verbotene Partei von der staatlichen Parteifinanzierung ausgeschlossen werden kann, 14.11.2008, S. 53. BR-Drucksache 153/17.

567 BT-Drucksache 18/12357.

568 BVerfGE 144, 20 (219).

569 Klein, in: Maunz/Dürig (Hrsg.), Grundgesetz, 2018, Art. 21, Rn. 485. 
tatbestandlich vorgesehenen Umfang die Schutzgüter der Norm zu beeinträchtigen sucht.

Der dahinterstehende Gedanke, der Staat solle nur solche Parteien mit öffentlichen Geldern finanzieren müssen, deren Zielsetzung den Grundwerten den höchsten Verfassungswerten nicht zuwiderlaufen, rechtfertigt kein ausschließliches Abstellen auf das politische Programm, die sich daraus abstrahierende „Parteimeinung“ oder das von der Partei verfolgte Interesse. Um einen offenen Prozess der politisichen Willensbildung zu ermöglichen, muss der Fokus des Finanzierungsausschlussverfahren zwingend auf der Sanktionierung eines der Partei zurechenbaren Handelns und nicht des Bildens und Vertretens bestimmter Meinungen und Interessen liegen. Der Staat darf insoweit keine Gesinnungsprüfung im umfassenden Sinne vornehmen, um zu bestimmen, welche Parteien weiterhin in den Genuss staatlicher Leistungen kommen und welche nicht; die staatliche Parteienfinanzierung also nicht alleine davon abhängig gemacht werden, ob die Parteien eine „richtige“ oder "falsche“ Meinung vertreten. Staatlich auferlegte Weltanschauungs- und Gesinnungsverbote stellen einen schwerwiegenden Eingriff in die Meinungsfreiheit dar und grenzen die gesellschaftliche und für den demokratischen Willensbildungsprozess konstitutive Meinungs- und Interessenvielfalt in unzulässiger Weise ein. Ob das Vorgehen der Partei gegen den Bestand der Bundesrepublik Deutschland oder die freiheitliche demokratische Grundordnung aufgrund einer linken, rechten oder sonstigen politischen Ideologie erfolgt, muss bei der Feststellung der Verfassungsfeindlichkeit außer Betracht bleiben. ${ }^{570}$ Auch darf Systemkritik nicht unter dem Vorwand der „wehrhaften Demokratie“ als verfassungswidrig oder -feindlich gewertet werden ${ }^{571}$ und aufgrund dessen zu einem Ausschluss aus der staatlichen Parteienfinanzierung führen. Systemkritik, auch wenn sie sich in der Ablehnung ganzer verfassungsrechtlicher Institutionen oder der obersten Verfassungswerte zeigt, muss zulässig sein und darf grundsätzlich nicht durch den Staat untersagt werden. ${ }^{572}$ Demnach ist bei einer verfassungskonformen Auslegung des Begriffs des „Ausgerichtet-Seins“ nicht auf das Vorhandensein einer bestimmten Meinung abzustellen, sondern (wie auch beim Parteiverbot) auf eine konkrete, gegen den Staat und seine Grundwerte gerichtete Form der Organisation. ${ }^{573}$ Der Staat unterlässt eine fortwährende Gewährung der staat-

570 Siehe die Ausführungen zum Parteiverbotsverfahren BVerfGE 144, 20 (220).

571 Siehe die Ausführungen zum Parteiverbotsverfahren BVerfGE 5, 85 (140 f.).

572 Vgl. BVerfGE 5, 85 (140 f.); BVerfGE 144, 20 (205).

573 Klein, in: Maunz/Dürig (Hrsg.), Grundgesetz, 2018, Art. 21, Rn. 486. 
lichen Parteienfinanzierung und einen Verzicht auf die Erhebung von steuerlichen Abgaben nur dann, wenn die Partei aktiv auf die Beeinträchtigung oder Beseitigung der freiheitlichen demokratischen Grundordnung hinarbeitet. Zwar ist das Vorliegen einer Realisierungspotentialität keine Voraussetzung für das Feststellen des Ausschlusses aus der staatlichen Parteienfinanzierung ${ }^{574}$, an dem Abstellen auf ein planvolles Hinarbeiten zur Verwirklichung der eigenen Zielsetzung ändert dies, ähnlich wie beim Parteiverbot ${ }^{575}$, allerdings nichts. Ein planvolles Vorgehen liegt nach der ständigen Rechtsprechung des Bundesverfassungsgerichts dann vor, wenn die Partei kontinuierlich auf die Verwirklichung eines der freiheitlichen demokratischen Grundordnung widersprechenden politischen Konzepts hinarbeitet. ${ }^{576}$

Der mit dem Ausschluss aus der staatlichen Parteienfinanzierung erfolgende Eingriff in die dem Demokratieprinzip immanenten Verfassungsgüter (offener politischer Willensbildungsprozess und die Kommunikationsgrundrechte ${ }^{577}$ ) verlangt aus diesem Grund eine restriktive Auslegung des Art. 21 Abs. 3 GG. ${ }^{578}$ Besonders deutlich wird dies unter Beachtung der verfassungsgerichtlichen Rechtsprechung zum Parteiverbotsverfahren, in der die Missbrauchsgefahr eines solchen Instrumentes bei der Anwendung des Parteiverbotes angeführt wurde. Der Tatbestand müsse den „Missbrauch der Bestimmung im Dienste eifernder Verfolgung unbequemer Oppositionsparteien“ “579 ausschließen. Diesem Umstand ist auch bei der Auslegung des Tatbestandes des Art. 21 Abs. 3 GG Rechnung zu tragen. ${ }^{580}$ Ein Instrument zum Schutze der Staatsidentität und -ordnung darf nicht zu einem Werkzeug der Unterdrückung unliebsamer Meinungen verkommen. Das durch den Begriff des „Ausgerichtet-Seins“ konstruierte Störungsniveau ist deshalb nicht bereits dann erreicht, wenn eine Partei in ihrer Außenwirkung systemkritisch auftritt oder öffentlich vereinzelt

574 Streinz, in: Huber/Voßkuhle (Hrsg.), Grundgesetz, ${ }^{7} 2018$, Art. 21, Rn. 252b; Ipsen, in: Sachs (Hrsg.), Grundgesetz, ${ }^{8} 2018$, Art. 21, Rn. 213.

575 Vgl. zum Parteiverbot BVerfGE 144, 20 (221).

576 BVerfGE 144, 20 (221).

577 Siehe dazu Hesse, Grundzüge des Verfassungsrechts der Bundesrepublik Deutschland, ${ }^{20} 1999$, Rn. 161; Klein, in: Maunz/Dürig (Hrsg.), Grundgesetz, 2018, Art. 21, Rn. 485.

578 Vgl. die Ausführungen zum Parteiverbotsverfahren BVerfGE 144, 20 (200); siehe auch Hesse, Grundzüge des Verfassungsrechts der Bundesrepublik Deutschland, ${ }^{20} 1999$, S. 298, Rn. 715; Meier, Parteiverbote und demokratische Republik, 1993, S. 263.

579 BVerfGE 5, 85 (141).

580 So bereits auch bei der Entscheidungszuständigkeit, $\mathbb{} 4 \mathrm{D}$. II. 
grundgesetzliche Institutionen ablehnt. Vielmehr muss in einem Gesamtzusammenhang erkennbar sein, dass die Partei qualifizierte Vorbereitungshandlungen zur Beeinträchtigung der freiheitlichen demokratischen Grundordnung trifft und das subjektive Willenselement der Partei durch ein Handeln nach außen hin objektiv erkennbar in Erscheinung tritt. ${ }^{581}$

Angesichts der Historie und den verfassungsrechtlichen Anforderungen an ein gegen Parteien gerichtetes Sanktionsmittel ist im Ergebnis der in der Literatur vorherrschenden Auffassung zuzustimmen, dass das „Ausgerichtet-Sein" bis auf die Realisierungspotentialität dieselben Anforderungen an das Finanzierungsausschlussverfahren wie das Merkmal des „Darauf-Ausgehens" an das Parteiverbot stellt. Angesichts der niedrigeren Eingriffsintensität des Finanzierungsausschlussverfahrens im Vergleich zum Parteiverbotsverfahren entstehen auch keine Bedenken hinsichtlich der Senkung des erforderlichen Störungsniveaus durch die Streichung der „Realisierungspotentialität“. Insoweit ist Volker Epping Recht zu geben, dass in diesem Zusammenhang „Abstriche hinsichtlich der Art und Weise der Verfolgung des Ziels" gemacht werden können. ${ }^{582}$ Dass eine Partei „ausgerichtet ist“, den Bestand der Bundesrepublik Deutschland zu gefährden oder die freiheitliche demokratische Grundordnung zu beeinträchtigen oder zu beseitigen, verlangt das Äußern ihrer verfassungsfeindlichen Haltung in einem hinreichend qualifizierten planvollen Handeln. Allein das Vorliegen einer ablehnenden politischen Haltung vermag nicht zur Erfüllung des Tatbestandsmerkmals zu führen.

II. Rechtsfolgen

1. Ausschluss von staatlicher Finanzierung

a) Finanzielle Konsequenzen

Art. 21 Abs. 3 S. 1 GG sieht einen Ausschluss „von“ staatlicher Finanzierung vor. Der Begriff ist eng auszulegen und betrifft allein die staatliche

581 Ähnlich, eine systematische Stufenprüfung befürwortend Müller, DVBl 2018, 1035 (1039).

582 Epping, Rechtsgutachten über die Frage, ob und unter welchen Voraussetzungen eine nicht nach Art. 21 II GG verbotene Partei von der staatlichen Parteifinanzierung ausgeschlossen werden kann, 14.11.2008, S. 51. 
Parteienfinanzierung nach den $\mathbb{S} 18 \mathrm{ff}$. PartG. ${ }^{583}$ Es entfallen weder die Abgeordnetenentschädigung, Fraktionsfinanzierung oder die Zuwendungen an "parteinahe" Stiftungen, sofern die betroffene Partei nach Art. 21 Abs. 3 GG von staatlicher Finanzierung ausgeschlossen wird. ${ }^{584}$ Auch fällt die Finanzierung politischer Jugendorganisationen grundsätzlich nicht unter den Begriff der „staatlichen Finanzierung“, da sie - sofern sie rechtlich verselbstständigt und damit „Nebenorganisationen“ sind - keine „Parteien“ darstellen. 585 Der Wegfall der Mittel, die den Parteien im Rahmen der unmittelbaren Teilfinanzierung nach den $\mathbb{S} 18 \mathrm{ff}$. PartG zufließen, machen oft über ein Viertel bis fast die Hälfte ihrer Gesamteinnahmen aus. ${ }^{586}$ Das Fehlen dieser Mittel führt zu erheblichen Wettbewerbsnachteilen und kann eine reale Zermürbungsgefahr für die betroffene Partei darstellen. ${ }^{587}$

Erschwerend kommt hinzu, dass nach Art. 21 Abs. 3 S. 2 GG auch die steuerliche Begünstigung von Zuwendungen an die betroffene Partei entfällt. Der Staat unterlässt es damit nicht nur, selbst als unmittelbarer Finanzier der Partei aufzutreten, sondern sorgt zugleich dafür, dass Zuwendungen aus dem gesellschaftlichen Bereich nicht mehr steuerlich begünstigt und damit für spendenbereite Bürger unattraktiv werden. Spenden an und Mitgliedschaften in als verfassungsfeindlich geltende Parteien wird die steuerbezogene Rentabilität genommen und damit die ökonomische Attraktivität eingeschränkt. Der Gesetzgeber hat in den entsprechenden Steuergesetzen den Einfluss des Art. 21 Abs. 3 S. 2 GG normativ verankert $^{588}$ und damit eine Anpassung der steuerlichen Rechtslage vorgenom-

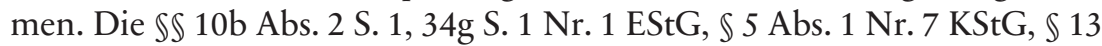
Abs. 1 Nr. 18 lit. a ErbStG und $\$ 4$ Nr. 18a UStG knüpfen an die Feststellung des Bundesverfassungsgerichtes an und haben in Bezug zu Art. 21 Abs. 3 S. 2 GG lediglich deklaratorischen Charakter, da das grundgesetzliche Finanzierungsausschlussverfahren unmittelbar anwendbares Recht darstellt. ${ }^{589}$

583 Ipsen, JZ 2017, 933 (934); Nikkho, DVBl. 2018, 337 (338); vgl. zudem Morlok, in: Dreier/Bauer (Hrsg.), Grundgesetz, ${ }^{3} 2015$, Art. 21, Rn. 44 f.

584 Siehe hierzu die Ausführungen unter $\$ 3$. A.

585 Siehe zu der Problematik eingehend $\$ 4$. C. II. 2. b).

586 Siehe bereits oben $\$ 3$. vor.A.; auch www.bundestag.de/resource/blob/694474/b1 2215 becf05c5eac13772a0377f10ce/finanz_19-data.pdf, zul. aufgerufen am 21.09.2020.

587 Nikkho, DVBl. 2018, 337 (340).

588 BGBl. 2017, I, S. $2730 \mathrm{ff}$.

589 Nikkho, DVBl 2018, 337 (341). 
Wie bereits angesprochen ${ }^{590}$ verhält sich der Wegfall jedweder steuerlichen Privilegierung akzessorisch zu dem Ausschluss aus der (unmittelbaren) staatlichen Parteienfinanzierung. Die Sätze 1 und 2 des Absatzes 3 sind im Sinne einer gesamtbildlichen Rechtsfolge zu verstehen. Der Staat unterlässt nicht nur die Leistungsgewährung iSd. $\$ \mathbb{S} 18 \mathrm{ff}$. PartG, sondern beendet gleichsam auch den "Verzicht" auf steuerliche Forderungen, die ihm ohne die parteispezifische Privilegierung nach den Vorschriften des Steuerrechts zustehen würden. ${ }^{591}$ Durch diese Rechtsfolge beeinflusst der Staat bei einem erfolgreichen Finanzierungsausschlussverfahren den politisch-ökonomischen Parteienwettbewerb in doppelter Hinsicht. Zum einen unterlässt er die fortwährende Gewährung der unmittelbaren Parteienfinanzierung nach den $\mathbb{S} 18 \mathrm{ff}$. PartG, während die konkurrierenden Parteien weiterhin in dessen Genuss kommen, und schafft zeitgleich eine zusätzliche finanzielle Mehrbelastung durch den Entzug jedweder steuerlichen Privilegierung. Die Rechtsfolge wirkt sich aus diesem Grund in ökonomischer Hinsicht doppelt belastend für die vom Ausschlussverfahren betroffene Partei aus und intensiviert damit auch die Verzerrung des politischen Wettbewerbs.

\section{b) Konsequenzen im gesellschaftlichen Ansehen}

Mit dem Finanzierungsausschluss ist ein staatliches Werturteil verbunden, dem neben der finanziellen Sanktionierung eine selbstständige Wirkung zukommt, die in der Regel für die Partei belastend sein dürfte. ${ }^{592}$ Durch ein Urteil des Bundesverfassungsgerichtes wird der betroffenen Partei ein Stigma auferlegt; sie erhält insoweit einen Status, der sie öffentlich als verfassungsfeindlich brandmarkt. Durch die Feststellung ihrer Verfassungsfeindlichkeit anhand des von Art. 21 Abs. 3 GG vorgegebenen Tatbestandes wird nicht nur der Ausschluss aus der staatlichen Parteienfinanzierung begründet, sondern damit auch eine staatliche Bewertung der Parteiziele und des Parteicharakters vorgenommen. Der Staat missbilligt durch das Feststellungsurteil in rechtserheblicher Weise das Verhalten und die innere politische Ausrichtung der betroffenen Parteien und straft sie aus diesem Grund durch die Verweigerung von Leistungen, die grundsätzlich allen

$590 \rrbracket 4$ C. III. 1.

591 Vgl. BVerfGE 8, 51 (62).

592 Vgl. zur Eingriffsqualität von staatlichen Werturteilen Murswiek, DVBl 1997, 1021 (1029 f.); Ferreau, NVwZ 2017, 1259 ff.; Voßkuble/Kaiser, JuS 2018, 343 ff. 
Parteien zustehen, ab. Sie wird anders gesagt aus dem Kreis der förderungswürdigen Parteien verbannt, weil sie durch ihre Haltung zur freiheitlichen-demokratischen ihr Recht an der Teilhabe der staatlichen Förderung verwirkt hat. Der Prozess der politischen Willensbildung wird insoweit beeinflusst, dass der Staat durch eines seiner Verfassungsorgane (namentlich dem Bundesverfassungsgericht) eine inhaltliche Kommentierung des Parteicharakters vornimmt, was faktisch auf eine negative staatliche Wahlempfehlung hinausläuft. Ein Finanzierungsausschlussverfahren kommt strategisch nur dann in Betracht, wenn die in Frage stehende Partei über ein für ein Verbot nicht ausreichendes Maß an Potentialität verfügt. ${ }^{593}$ Sollten als Gegenreaktion der Mitgliederbestand sowie die Wahlergebnisse oder die Unterstützerstrukturen eine positive Entwicklung aufweisen, steigt damit die für eine verfassungsgerichtlich festgestellte Verfassungswidrigkeit geforderte Gefahrenpotentialität an. Durch eine Zunahme der gesellschaftlichen Unterstützung mittels einer vermehrten Abgabe von Wählerstimmen, Eintritten in die Partei oder finanziellen Zuwendungen in Form von Spenden nimmt die Potentialität gleichlaufend zum Erfolg zu. Die Wahrscheinlichkeit, dass die für ein Verbot erforderliche Schwelle der Gefahrenpotentialität erreicht wird, steigt mit der Erfolgszunahme und könnte schließlich zu einer drohenden Gefahr für die dauerhafte oder langfristige Existenz der Partei werden. Der Wähler muss damit rechnen, dass seine Unterstützung für die Partei einen Beitrag zur Überschreitung der von den Verbotsvoraussetzungen aufgestellten Schwellen darstellen könnte. Seine Stimme könnte, zumindest mittelbar, seiner Wahlentscheidung zuwiderlaufen. Dies stellt einen erheblichen meinungsbildungsbezogenen Wettbewerbsnachteil für die betroffene Partei dar. Die Einstufung einer Partei als ,verfassungsfeindlich“ verdichtet sich zu einer unmittelbaren, neben der ökonomischen Beeinträchtigung bestehenden, Einschränkung der Chancengleichheit der Parteien.

Zweifel an dieser These können nur durch die Rechtsprechung des Bundesverfassungsgerichtes zu der Eingriffsqualität von mit Verfassungsschutzberichten verbundenen Werturteilen begründet werden, wonach von den Werturteilen im Verfassungsschutzbericht „keinerlei rechtliche Auswir-

593 Vgl. die neue verfassungsgerichtliche Rechtsprechung zu Parteiverboten BVerfGE 144, 20 (219 ff.); auch Ipsen, in: Sachs (Hrsg.), Grundgesetz, ${ }^{8} 2018$, Art.21, Rn.159; Streinz, in: Huber/Voßkuhle (Hrsg.), Grundgesetz, ${ }^{7} 2018$, Art. 21, Rn. 233a f. 
kungen" ausgingen ${ }^{594}$ und somit kein Eingriff in die Rechtsstellung der Parteien vorliege. Zwar war Gegenstand der verfassungsgerichtlichen Untersuchung die Eingriffswirkung von den Berichten der Verfassungsschutzbehörden und nicht von einem richterlichen Urteil, allerdings ließe sich die dahinterstehende Dogmatik auf solche ohne Abstriche übertragen. Seit der Anerkennung mittelbarer Eingriffsäquivalente in der Grundrechtsdogmatik ist diese Ansicht allerdings überholt und überzeugt in der Sache nicht mehr. ${ }^{595}$ Neben der unmittelbaren Ungleichbehandlung in Belangen der staatlichen Parteienfinanzierung wird die Partei zusätzlich durch das mit dem Feststellungsurteil untrennbar verbundene Werturteil belastet, das insoweit einen eigenständigen Wettbewerbsnachteil begründet.

\section{Erstreckungwirkung}

Die Feststellung, dass die betroffene Partei nach Art. 21 Abs. 3 GG von staatlicher Finanzierung ausgeschlossen ist, könnte sich auf andere Verbände oder Organisationen erstrecken. Vornehmlich drängt sich in diesem Zusammenhang die Regelung des $\$ 46 a$ Abs. 1 S. 2 BVerfGG auf, die insoweit eine Erstreckung der Feststellungswirkung auf „Ersatzparteien“ anordnet (a). Allerdings fällt auch die Förderung von politischen Jugendorganisationen nach der in dieser Arbeit vertretenen Auffassung 596 unter den Begriff der „staatlichen Parteienfinanzierung" im weiteren Sinne, was die Frage aufwirft, ob auch die ihnen gebührenden staatlichen Mittel von einem Ausschluss ihrer „Mutterpartei“ aus der staatlichen Parteienfinanzierung betroffen sind (b).

\section{a) Ersatzparteien}

Der Gesetzgeber hat die Rechtsfolgen der Feststellung des Bundesverfassungsgerichts nach Art. 21 Abs. 3, 4 GG einfachgesetzlich im Parteiengesetz, Bundesverfassungsgerichtsgesetz und den einschlägigen Steuerge-

594 BVerfGE 40, 287 (293); a.A. Murswiek, NVwZ 2004, 769 (773 f.); ders., DVBl 1997, 1021 (1029f.).

595 Vgl. Bethge/Weber-Dürler, in: VVDStRL 57 (1998), S. 7 ff.; siehe auch unten $₫ 5$ B. II. 1.

596 Siehe $\mathbb{3}$. A. IV. 
setzen näher geregelt. ${ }^{597}$ Relevant für die vorliegende Untersuchung ist insbesondere $\$ 46 \mathrm{a}$ BVerfGG, da die anderen Vorschriften lediglich der „Umsetzung" des Finanzierungsausschlusses dienen. Im Unterschied zu $\mathbb{1} 18$ Abs. 7 S. 2 PartG, $\mathbb{S} \$ 10$ b Abs. 2 S. 1,34g S. 1 Nr. 1 EStG, 5 Abs. 1 Nr. 7 KStG, 13 Abs. 1 Nr. 18 lit. a ErbStG und $\$ 4$ Nr. 18a UStG regelt $\$ 46$ a BVerfGG nicht die Rechtswirkung des abgeschlossenen Verfahrens, sondern konstruiert die zeitliche Dauer und die Erstreckungsmöglichkeit der Rechtswirkung auf Ersatzparteien. In diesem Sinne dient \$46a BVerfGG der Ausgestaltung des Ausschlussverfahrens, während die restlichen Vorschriften lediglich deren Umsetzung in den relevanten Rechtsgebieten sicherstellen.

\$46a BVerfGG konkretisiert die materielle Rechtswirkung des Ausschlusses aus der staatlichen Parteienfinanzierung in doppelter Hinsicht. So wird die Rechtswirkung einerseits nach $\$ 46 a$ Abs. 1 S. 1, Abs. 2 S. 1 BVerfGG einer Temporarität unterworfen und auf eine Dauer von 6 Jahren beschränkt, andererseits ordnet $\mathbb{4} 46 \mathrm{a}$ Abs. 1 S. 2 BVerfGG eine Erstreckung der Rechtswirkung auf Ersatzparteien an. Diese Rechtswirkungserstreckung auf Ersatzorganisationen ist nicht neu. So findet sich bereits in $\$ 33$ Abs. 1 PartG eine Legaldefinition, wonach Ersatzorganisationen solche sind, die „verfassungswidrige Bestrebungen einer nach Art. 21 Abs. 2 GG in Verbindung mit $\$ 46$ BVerfGG verbotene Partei an deren Stelle weiterverfolgen oder bestehende Organisationen als Ersatzorganisation fortführen“. Dass $\$ 33$ Abs. 1 PartG und $\$ 46$ BVerfGG von Ersatzorganisationen sprechen, während $\$ 46 a$ BVerfGG die Begrifflichkeit der „Ersatzparteien" verwendet, führt zu keinen nennenswerten materiellen Unterschieden. Die unterschiedliche Bezeichnung ist darauf zurückzuführen, dass bei einem erfolgreichen Antrag nach Art. 21 Abs. 2 GG die Partei verboten wird und damit ihre Eigenschaft als „Partei“ vollständig entfällt. ${ }^{598}$ Eine Organisation, welche die verfassungswidrige Zielsetzung ersatzweise anstelle der verbotenen Partei weiterverfolgt, kann damit von vornherein keinen Parteienstatus erlangen, womit die künftige Bezeichnung als „Organisation" die zutreffende ist. ${ }^{599}$ Beim Finanzierungsausschlussverfahren bleibt die Partei rechtlich weiterhin existent und verliert auch ihren Status als solchen nicht, womit eine weitere Bezeichnung als Partei nicht nur

597 Ipsen, in: Sachs (Hrsg.), Grundgesetz, ${ }^{8} 2018$, Art. 21, Rn. 216 ff.; Müller, DVBl 2018, 1035 (1041).

598 Ipsen, in: Sachs (Hrsg.), Grundgesetz, ${ }^{8} 2018$, Art. 21, Rn. 193.

599 Statt aller siehe Klein, in: Maunz/Dürig (Hrsg.), Grundgesetz, 2018, Art. 21, Rn. 559; vgl. auch Maurer, AöR 96 (1971), 203 (222). 
statthaft, sondern begrifflich auch geboten ist. Der Wortlaut der Norm trägt damit dem Umstand Rechnung, dass eine Vereinigung, die die Ziele einer aus der staatlichen Parteienfinanzierung ausgeschlossenen Partei weiterverfolgt, ebenfalls Träger des Parteienstatus sein kann. In diesem Sinne ist $\ 46 a$ Abs. 1 S. 1 BVerfGG klarstellend. Eine Partei muss, um als Ersatzpartei iSd. $\$ 46 a$ Abs. 1 BVerfGG zu gelten, nach Satz 3 „die Bestrebungen einer nach Satz 1 von der staatlichen Finanzierung ausgeschlossenen Partei als Ersatzpartei an deren Stelle weiterverfolgen oder fortführen." Ob es sich um eine „Ersatzpartei“ iSd. \46a Abs. 1 S. 2 BVerfGG handelt, stellt das Bundesverfassungsgericht gem. \46a Abs. 1 S. 3 BVerfGG fest.

\section{b) Politische Jugendorganisationen}

Eine weitaus komplexere und aus diesem Grund für die Arbeit besonders interessante Problematik bietet die Erstreckung des Ausschlussurteils auf politische Jugendorganisationen. Sinnvoll lässt sich der Problembereich der Finanzierung der politischen Jugendorganisationen in zwei Bereiche aufteilen. Zum einen stellt sich die Frage, inwieweit die personelle sowie organisatorische Verbundenheit der politischen Jugendorganisationen mit der Mutterpartei Auswirkungen auf die Qualifizierung der Jungendorganisation als „Bestandteil der Partei“ hat. Ein anderes Problemfeld bildet die Rechtsstellung der Jugendorganisation, nachdem ihre Mutterpartei aus der Parteienfinanzierung ausgeschlossen wurde. In diesem Rahmen wird zu untersuchen sein, ob bei der Feststellung der Verfassungsfeindlichkeit der „Mutterpartei“ auch zeitgleich eine weitere staatliche Förderung der Jugendorganisation entfällt und vor allem auf welchem Wege dies geschieht. Hierbei ist insbesondere die in $\$ 74$ Abs. 1 S. 1 Nr. 5 und $₫ 75$ Abs. 1 Nr. 5 SGB VIII aufgeführte Voraussetzung maßgeblich, demnach zur Anerkennung als Träger der freien Jugendhilfe und der damit zusammenhängenden Förderungen durch einen öffentlichen Träger erforderlich ist, dass der Träger eine Gewähr für eine den Zielen des Grundgesetzes förderliche Arbeit bieten kann. Zwangsläufig muss die Frage gestellt werden, ob politische Jugendorganisationen auch noch dann eine Gewähr für die Förderung der Ziele des Grundgesetzes bieten, wenn ihre Mutterpartei vom Bundesverfassungsgericht als verfassungsfeindlich eingestuft wurde. 
(1) Unmittelbare Erstreckung des Finanzierungsausschlussverfahrens

Eine unmittelbare Erstreckung der Ausschlusswirkung des Verfahrens nach Art. 21 Abs. 3 GG kann nur dann angenommen werden, wenn das Finanzierungsausschlussverfahren überhaupt auf Jugendorganisationen Anwendung findet. Ausschlaggebend ist, ob die Jugendorganisationen unter den Parteibegriff i.S.d. Art. 21 Abs. 1 S. 1 GG fallen bzw. ob die Rechtstellung der Partei auf die Jugendorganisationen als Nebenorganisationen der Partei übertragen werden kann.

Der Gesetzgeber hat bei der Einführung des Finanzierungsausschlussverfahrens das für die politischen Jugendorganisationen geltende Recht unberührt gelassen. Die Umsetzung erfolgte ausschließlich im staatlichen Parteienfinanzierungsrecht sowie im parteispezifischen Steuerrecht. Eine Erstreckung der Ausschlusswirkung ist damit bereits einfachgesetzlich nicht vorgesehen. Im Kontext des Parteiverbotsverfahrens nach Art. 21 Abs. 2 GG hat sich nach der herrschenden Meinung der Ansatz durchgesetzt, dass bei der Frage der Anwendbarkeit des Verbotsverfahrens zunächst auf die Abhängigkeit der in Frage stehenden Organisation von der Mutterpartei abzustellen sei. ${ }^{600} \mathrm{Je}$ nach Qualifikation der betroffenen Vereinigung solle das Verbotsverfahren der Art. 21 Abs. 2, Abs. 4 GG nur dann auch auf diese anwendbar sein, wenn sie eine satzungsgemäße Untergliederung der Partei darstelle. ${ }^{601}$ Im rechtlichen Sinne selbstständige, jedoch von der Partei in sonstiger Weise abhängige oder verbundene Organisationen (sog. Nebenorganisationen ${ }^{602}$ ) fallen nach der herrschenden Meinung nicht unter den Parteienbegriff und sind damit konsequenterweise auch nicht, zumindest rechtlich, von der Rechtswirkung eines erfolgreichen Parteiverbotsverfahrens betroffen. Die Nebenorganisationen können nach dieser Auffassung im Rahmen des Art. 9 Abs. 2 GG durch die Exekutive

600 BVerfGE 2, 1 (78); BVerfGE 5, 85 (392); Klein, in: Maunz/Dürig (Hrsg.), Grundgesetz, 2018, Art. 21, Rn. 518.

601 BVerfGE 2, 1 (78); BVerfGE 5, 85 (392); Klein, in: Maunz/Dürig (Hrsg.), Grundgesetz, 2018, Art. 21, Rn. 518.

602 BVerfGE 2, 1 (78); BVerfGE 5, 85 (392); Westerwelle, Das Parteienrecht und die politischen Jugendorganisationen, 1994, S. 95 ff.; Seifert, Die politischen Parteien im Recht der Bundesrepublik Deutschland, 1975, S. $331 \mathrm{ff}$.; Scholz, in: Maunz/Dürig (Hrsg.), Grundgesetz, 2018, Art. 9, Rn. 75; Klein, in: Maunz/Dürig (Hrsg.), Grundgesetz, 2018, Art. 21, Rn. 235. 
verboten werden und würden im Gegensatz zu Parteien keinen durch Art. 21 GG gewährleisteten besonderen Schutz genießen. ${ }^{603}$

In der Literatur wird eine deutliche Gegenposition vertreten und gemeinsam mit der Rechtstellung der Parteien (insbesondere in Form der Parteienfreiheit) das Parteienprivileg auch auf Jugendorganisationen als parteiliche Nebenorganisationen übertragen. ${ }^{604}$ Nach dieser Auffassung sei das Parteienprivileg auch auf die Jugendorganisationen zu erstrecken, da sie im Aufgaben- und Interessenkreis der Parteien tätig seien und die Parteien einen erheblichen Teil ihrer parteispezifischen Tätigkeit als jugendpolitische Aufgabe auf die ihnen nahestehenden Jugendorganisationen übertrügen. ${ }^{605}$ Nach dieser Auffassung stehe auch den Jugendorganisationen als Nebenorganisationen der verfassungsrechtliche Status der Parteienfreiheit zu. Durch das Zugestehen der parteispezifischen Rechtsstellung an die Nebenorganisationen könne ihr vollständiges Entfallen ausschließlich durch das Bundesverfassungsgericht im Rahmen eines Parteiverbotsverfahrens festgestellt werden. Dieses sei auch entsprechend gesondert zu beantragen.

Das Finanzierungsausschlussverfahren lässt allerdings keine unmittelbare Erstreckung der Rechtswirkung auf Nebenorganisationen der betroffenen Partei zu. Die in der Literatur vertretene Auffassung, wonach auch Nebenorganisationen in den Genuss der parteispezifischen Rechtstellung kämen, versucht die rechtliche Verselbstständigung durch eine Erweiterung des verfassungsrechtlichen Parteibegriffs zu überbrücken. Zuzugeben ist zwar, so wie das OVG Berlin-Brandenburg auch treffend verdeutlichte ${ }^{606}$, dass die Förderung von politischen Jugendorganisationen den verfassungsrechtlichen Bereich der politischen Willensbildung tangiert und in diesem Zusammenhang die Bedeutung der Jugendorganisationen für den demokratischen Wettkampf eine besondere Bedeutung gewinnt. Allerdings

603 BVerfGE 2, 1 (78); BVerfGE 5, 85 (392); Scholz, in: Maunz/Dürig (Hrsg.), Grundgesetz, 2018, Art. 9, Rn. 75; Klein, in: Maunz/Dürig (Hrsg.), Grundgesetz, 2018, Art. 21, Rn. 235.

604 So vor allem Westerwelle, Das Parteienrecht und die politischen Jugendorganisationen, 1994, S. 70, 96 ff.; Morlok, in: Dreier/Bauer (Hrsg.), Grundgesetz, ${ }^{3} 2015$, Art. 21 Rn. 42 f., 147; Streinz, in: Huber/Voßkuhle (Hrsg.), Grundgesetz, ${ }^{7} 2018$, Art. 21, Rn. $69 \mathrm{ff}$.

605 So insbesondere Westerwelle, Das Parteienrecht und die politischen Jugendorganisationen, 1994, S. $95 \mathrm{f}$.

606 OVG Berlin-Brandenburg, Urt. v. 14.03.2012, Rs. OVG 6 B 19.11., NVwZ 2012, 1265 ff. (1267 f.), welches allerdings ausdrücklich nicht näher auf die Anwendbarkeit des Art. 21 GG auf politische Jugendorganisationen einging; siehe hierzu Merten, NVwZ 2012, 1228 ff. 
kann aus dieser Bedeutung für die politische Willensbildung keine Egalisierung der Rechtsstellungen der Institutionen erfolgen. Die herrschende Meinung überzeugt mit dem Ansatz, die verfassungsrechtlichen Instrumente zum Schutze der freiheitlichen demokratischen Grundordnung sowie des Bestandes der Bundesrepublik Deutschlands auf die Parteien im verfassungsrechtlichen Sinne zu beschränken und die Nebenorganisationen nach dem allgemeinen Vereinsrecht zu behandeln. ${ }^{607}$

Die Parteien erfüllen im Unterschied zu den rechtlich verselbstständigten Nebenorganisationen für den verfassungsrechtlichen Parteienbegriff konstitutive Merkmale. So besitzen nur die Parteien den eigenen Willen, durch die Teilnahme an Wahlen an der politischen Willensbildung des Volkes mitzuwirken und eine Mitgliedschaft in den Volksvertretungen anzustreben. Ausschließlich aus diesem Grund gewährt ihnen Art.21 GG eine besondere Rechtsstellung und privilegiert Parteien gegenüber anderen Vereinigungen. Die Nebenorganisationen, insbesondere in der Ausprägung als politische Jugendorganisationen, wirken nicht eigenständig an der politischen Willensbildung mit, sondern werden gerade für die ihr nahestehende Partei tätig. ${ }^{608}$ Die Parteien können zwar durchaus, auch unter Berufung auf ihren Freiheitsstatus ${ }^{609}$, Aufgabenbereiche an ihre verselbstständigten Nebenorganisationen übertragen, soweit sie dadurch nicht die Erfüllung ihres verfassungsrechtlichen Mandats gefährden. Eine resultierende Notwendigkeit der Erstreckung der Rechtstellung auf diese Nebenorganisationen kann daraus aber nicht folgen. Auch gelten die parteispezifischen Verpflichtungen wie das Gebot der innerparteilichen Demokratie sowie die Rechenschaftspflicht nicht für Nebenorganisationen. ${ }^{610} \mathrm{Die}$ Er-

607 Im Zusammenhang des Finanzierungsausschlussverfahrens so wohl Ipsen, JZ 2017, 933 (934), der den Begriff der „staatlichen Finanzierung“ ausschließlich auf die in $\$ \mathbb{S} 18 \mathrm{ff}$. PartG geregelte Finanzierung bezieht. Siehe auch Seifert, DÖV 1961, 81 (87), der eine Erstreckung Verbotswirkung auf die Nebenorganisationen ablehnt.

608 In dieser Hinsicht nicht überzeugend Westerwelle, Das Parteienrecht und die politischen Jugendorganisationen, 1994, S. 96, der zwar von der Möglichkeit der „Auslagerung" parteipolitischer Tätigkeiten an die Jugendorganisationen spricht, dabei jedoch nicht den Umstand berücksichtigt, dass die Partei gerade nicht die Aufgabenfelder vollständig, d.h. bei gleichzeitigem Verlust der Kompetenz, auf die ihr nahestehende Jugendorganisation übertragen kann, die für ihre Parteieneigenschaft konstitutiv wirken.

609 Morlok, in: Dreier/Bauer (Hrsg.), Grundgesetz, ${ }^{3} 2015$, Art. 21, Rn. 55.

610 Besonders überzeugend in diesem Zusammenhang Klein, in: Maunz/Dürig (Hrsg.), Grundgesetz, 2018, Art. 21, Rn. 237. 
streckung des Parteibegriffs auf die Jugendorganisationen überschreitet die Grenzen einer zulässigen Auslegung des Wortlauts.

Das Argument, dass die Parteien bei einer solchen Handhabung des Rechts in ihrer Organisationsfreiheit eingeschränkt und deshalb eine funktionelle Betrachtungsweise zielführend sei ${ }^{611}$, überzeugt nicht. Die Parteien haben, auch wenn sie Aufgabenbereiche auf ihre Jugendorganisationen übertragen, nur begrenzte Einflussmöglichkeit auf ihre rechtlich verselbstständigten Nebenorganisationen. Die bestehenden Lenkungs- und Einflussmöglichkeiten sind faktischer Natur und keineswegs garantiert. ${ }^{612}$ Dieser Grad an Unabhängigkeit und organisatorischer Verselbstständigung lässt es nicht zu, solche Jugendorganisationen ebenfalls von der Rechtsstellung der Parteien profitieren zu lassen. Die Jugendorganisationen sind anders als die Parteien nicht notwendiger Bestandteil der demokratischen Ordnung. Sie unterstützen die Partei bei der Durchführung ihres verfassungsrechtlichen Mandats und gestalten auch die politischen Prozesse innerhalb der Partei mit, allerdings beläuft es sich hierbei ausschließlich auf eine Hilfsfunktion, die keinen unabdingbaren Aspekt darstellt. Den Jugendorganisationen eine ähnliche oder gar identische Rechtstellung wie den Parteien einzuräumen, ist deshalb weder notwendig noch zulässig. Der herrschenden Meinung bezüglich der Anwendbarkeit des Parteiverbotsverfahrens auf rechtlich selbstständige Nebenorganisationen ist somit im Ergebnis zuzustimmen und sie kann, gerade hinsichtlich der unterschiedlichen Zielsetzung der Finanzierungsarten und der nicht zu leugnenden Verselbstständigung der Nebenorganisationen, auch auf das Finanzierungsausschlussverfahren nach Art. 21 Abs. 3 GG übertragen werden. Eine unmittelbare Erstreckung der Wirkung des Finanzierungsausschlussverfahrens kommt nur dann in Betracht, wenn die Jugendorganisation nach Feststellung der Verfassungsfeindlichkeit zu einer Ersatzpartei der aus der staatlichen Finanzierung ausgeschlossenen Partei wird und das Bundesverfassungsgericht dies in einem eigenständigen Verfahren nach \46a Abs. 1 S. 2,3 BVerfGG feststellt. ${ }^{613}$

611 So insbesondere Morlok, in: Dreier/Bauer (Hrsg.), Grundgesetz, ${ }^{32015}$, Art. 21, Rn. 43; Streinz, in: Huber/Voßkuhle (Hrsg.), Grundgesetz, ${ }^{7} 2018$, Art. 21, Rn. 71.

612 So haben sich z.B. die Jungdemokraten 1982 aus eigenem Entschluss endgültig von der FDP getrennt. Die Jugendorganisationen haben somit das Recht, einseitig die Zusammenarbeit mit ihrer „Mutterpartei“ aufzukündigen.

613 Vgl. bezüglich des Verbotsverfahrens nach Art. 21 Abs. 2 GG Seifert, DÖV 1961, 81 (87), der ebenfalls die Möglichkeit einer Erstreckung der Verbotswirkung bei der Umwandlung in eine Ersatzorganisation annimmt. 
(2) Mittelbare Erstreckung des Finanzierungsausschlussverfahrens

Auch wenn eine unmittelbare Erstreckung der Ausschlusswirkung nicht möglich ist, so kann die Feststellung der Verfassungsfeindlichkeit einer Partei dennoch Auswirkungen auf die staatliche Förderung ihrer Jugendorganisation haben. Einen einfachgesetzlichen Anknüpfungspunkt bietet für die Bundesverbände jugendpolitischer Organisationen $\mathbb{} 83$ Abs. 1 S. 2 SGB VIII i.V.m. Punkt III. 1. (4) der Richtlinie über die Gewährung von Zuschüssen und Leistungen zur Förderung der Kinder- und Jugendhilfe durch den Kinder- und Jugendplan des Bundes (KJP) ${ }^{614}$ i.V.m. $\$ \mathbb{S} 74$ Abs. 1 Nr. 5, 75 Abs. 1 Nr. 4 SGB VIII. Demnach werden die Mittel nur dann gewährt, wenn die Jugendorganisation eine „Gewähr für eine den Zielen des Grundgesetzes förderliche Arbeit“ bieten kann. \$S 74 Abs. 1 Nr. 5, 75 Abs. 1 Nr. 4 SGB VIII setzen durch dieses Kriterium voraus, dass die Jugendorganisation positiv im Sinne der obersten Grundsätze der freiheitlichen Demokratie wirken muss. ${ }^{615}$ Konkreter wird verlangt, dass sich die geförderte politische Jugendorganisation zu den Grundprinzipien der Verfassung bekennt und sich in ihrem Handeln und ihrer Programmatik auf „dem Boden des Grundgesetzes bewegt“. 616

Aus den oben genannten Gründen stellt sich die Frage, inwieweit sich die Feststellung der Verfassungsfeindlichkeit einer Partei auf das Tatbestandsmerkmal der „Gewähr für eine den Zielen des Grundgesetzes förderliche Arbeit“ auswirkt. Relevant in diesem Zusammenhang ist, ob das Finanzierungsausschlussverfahren überhaupt einen Einfluss auf die staatliche Förderung politischer Jugendorganisationen begründen vermag und, sollte dies der Fall sein, in welcher Art und Intensität sich dieser Einfluss rechtlich äußert.

\section{(a) Statuszurechnung}

Um die staatliche Förderung einer Jugendorganisation, allein wegen des Ausschlusses der „Mutterpartei“ aus der staatlichen Parteienfinanzierung, einzustellen, bedarf es unter anderem einer Zurechnung des verfassungs-

614 Einsehbar unter https://www.bmfsfj.de/blob/111964/2f7ae557daa0d2d8fe78f8a3 f9569f21/richtlinien-kjp-2017-data.pdf, zul. aufgerufen am 18.02.2020.

615 BVerwGE 55, 232 (LS 1); Kern, in: Fischer/Mann/Schellhorn u.a. (Hrsg.), SGB VIII, ${ }^{5} 2017, \mathbb{1} 74, \mathrm{Rn} .10$.

616 Ders., in: Fischer/Mann/Schellhorn u.a. (Hrsg.), SGB VIII, ${ }^{5} 2017, \mathbb{\$} 74$, Rn. 10. 
feindlichen Status. Im Rahmen des Parteiverbotsverfahrens kann das Verhalten der Anhänger unter bestimmten Voraussetzungen der Partei zugerechnet werden. ${ }^{617}$ Nach allgemeiner Auffassung soll vor allem im Kontext des Parteiverbotsverfahrens eine Zurechnung des Verhaltens der Nebenorganisation unproblematisch sein. ${ }^{618}$ In diesem Fall ist die Situation spiegelbildlich. Es stellt sich nicht die Frage, ob sich eine Partei das Verhalten einer von ihr abhängigen Nebenorganisation zurechnen lassen muss, sondern umgekehrt, ob das Verhalten der Partei einer Nebenorganisation zugerechnet werden kann. Die Jugendorganisationen können eben nur dann durch die Verfassungsfeindlichkeit einer Partei betroffen sein, wenn dieser unliebsame Status ihnen in irgendeiner Art und Weise zuzurechnen ist. In diesem Zusammenhang ist die rechtliche und tatsächliche Verselbstständigung der Jugendorganisation ausschlaggebend.

Verselbstständigte Jugendorganisationen sind organisatorisch-personell mit ihrer „Mutterpartei“ verbunden. Aus diesem Grund kann eine Zurechnung bereits dann erfolgen, wenn die Jugendorganisation und ihre Mitglieder einen wesentlichen Einfluss auf die Partei ausüben und dadurch in nicht unerheblichem Maße an der Zielsetzung und der innerparteilichen Ausgestaltung mitwirken. ${ }^{619}$ In einem solchen Fall wäre die Jugendorganisation für die verfassungsfeindliche Haltung mitverantwortlich und würde diese durch Mitwirkung ihrer Funktionäre maßgeblich mitgestalten. Da die Jugendorganisation in einem solchen Falle eine Mitverantwortung für den später festgestellten verfassungsfeindlichen Status trägt, ist ihr dieser gleichsam zuzurechnen.

Je unselbstständiger und abhängiger eine Jugendorganisation ist, umso mehr muss sie sich die verfassungsfeindliche Einstellung der „Mutterpartei“ zurechnen lassen, da eine Trennung zwischen Partei und Jugendorganisation ab einem bestimmten Grad der Unselbstständigkeit nicht mehr möglich ist. Unproblematisch lässt sich die verfassungsfeindliche Einstellung den Jugendorganisationen zurechnen, die unselbstständige Organisa-

617 BVerfGE 144, 20 (215); BVerfGE 5, 85 (143); BVerfGE 2, 1 (22); Morlok, in: Dreier/Bauer (Hrsg.), Grundgesetz, ${ }^{3} 2015$, Art. 21, Rn. 152 m.w.N.

618 Ders., in: Dreier/Bauer (Hrsg.), Grundgesetz, ${ }^{3} 2015$, Art. 21, Rn. 152, Fn. 535.

619 BVerfGE 144, 20 (215), stellt insbesondere darauf ab, ob in dem Verhalten der Anhänger der politische Wille der Partei erkennbar ist. Dieser Gedanke lässt sich insoweit auf die Jugendorganisationen übertragen, als das Verhalten der Partei, das für die Feststellung als verfassungsfeindlich maßgeblich war, durch den Willen der Jugendorganisation weitestgehend mitgetragen oder gar gefördert wurde. 
tionen darstellen ${ }^{620}$, denn dann dürfte eine Exkulpation vom von der Partei begangenen Unrecht unmöglich sein, da diese im Rahmen des Finanzierungsausschlussverfahrens gleichsam unter den Begriff der „Partei“ fallen und kein eigenständiges Verfahren gegen die Jugendorganisation notwendig ist. Bei den verselbstständigten Jugendorganisationen stellt eine nach außen kommunizierte Zugehörigkeit zur „Mutterpartei“ ein taugliches Zurechnungselement dar und dürfte nur dann keine Rechtserheblichkeit mehr begründen, wenn sich die Jugendorganisation ebenfalls deutlich nach außen hin von der Partei distanziert und keine anderweitigen, auf eine ideologische Verbundenheit verweisenden Umstände vorliegen. Solche Umstände können in einer ähnlichen Programmatik, dem Verhalten der Anhänger und Mitglieder sowie der Öffentlichkeitsarbeit der Jugendorganisation oder ihrer Satzung liegen. Das gesamte tatsächliche Verhalten der Jugendorganisation kann dabei als Prüfungsmaßstab dienen.

\section{(b) Zurechnungsfolgen}

Eine Statuszurechnung von der Partei zur Jugendorganisation ist, wie oben dargestellt, rechtlich möglich. Die Folgen für die Jugendorganisation, wenn die „Mutterpartei“ aus der staatlichen Parteienfinanzierung ausgeschlossen wurde, dürften gravierend sein. Sollte durch das Bundesverfassungsgericht eine Partei für verfassungsfeindlich erklärt werden, so ist es am naheliegendsten, dass die zuständige Behörde die Jugendorganisation nach Art. 9 Abs. 2 GG $^{621}$ verbieten wird.

Im unwahrscheinlichen Fall der weiteren behördlichen Duldung einer Jugendorganisation trotz verfassungsfeindlicher Einstellung der Partei besteht nach den Vorschriften des SGB VIII die Möglichkeit, von einer weiteren staatlichen Förderung der Jugendorganisation abzusehen. Das in $\mathbb{S} 74$

620 So unterstehen die Jungsozialisten als Arbeitsgemeinschaft der Organisationsgewalt der SPD und lassen in diesem Sinne eine rechtliche Verselbstständigung missen. Dies geht sogar so weit, dass die SPD bei einem hinreichend sachlichen Grund Gliederungen der Jungsozialisten auflösen kann, vgl. $\$ 36$ Abs. 2 Organisationsstatuts der SPD, einsehbar unter https://www.spd.de/fileadmin/Dokume nte/Parteiorganisation/SPD_OrgaStatut_2020.pdf, zul. aufgerufen am 18.02.2020.

621 Zur Anwendbarkeit von Art. 9 Abs. 2 GG auf Nebenorganisationen siehe BVerfGE 2, 1 (78); BVerfGE 5, 85 (392); Scholz, in: Maunz/Dürig (Hrsg.), Grundgesetz, 2018, Art. 9, Rn. 75; Klein, in: Maunz/Dürig (Hrsg.), Grundgesetz, 2018, Art. 21, Rn. 235; Streitstand näher erläutert bei $\$ 3$ B. IV. 2. 
Abs. 1 Nr. 5, 75 Abs. 1 Nr. 4 SGB VIII festgelegte Tatbestandsmerkmal der „Gewähr für die Ziele des Grundgesetzes förderliche Arbeit“ bindet die Jugendorganisationen bei der Ausführung ihrer Tätigkeit an die Ziele der staatlichen Jugendförderung und Jugendarbeit, welche gerade im Bereich der politischen Bildung den grundlegenden Wertentscheidungen des Grundgesetzes eine maßgebliche Rolle zumessen. ${ }^{622}$ Im Falle des Ausschlusses aus der staatlichen Parteienfinanzierung durch das Bundesverfassungsgericht erfolgt, wenn dieser der Jugendorganisation gleichsam zugerechnet wird, eine ipso iure eingeleitete Sanktionskette, die zeitgleich die Voraussetzungen für eine weitere staatliche Förderung der Jugendorganisation entfallen lässt. Eine Jugendorganisation, die sich in ihrer Programmatik und ihren Zielen mit einer Partei verbunden fühlt, die vom Bundesverfassungsgericht als verfassungsfeindlich eingestuft wurde, kann keine „Gewähr für eine den Zielen des Grundgesetzes förderliche Arbeit“ bieten. Eine Akzessorietät in umgekehrter Richtung liegt hingegen nicht vor. Der Jugendverband kann auch dann keine „Gewähr für eine den Zielen des Grundgesetzes förderliche Arbeit" bieten, wenn sich die ihr nahestehende Partei in ihrem Verhalten und ihren Zielen im Rahmen der verfassungsmäßigen Ordnung bewegt.

\section{(3) Zusammenfassung}

Die staatliche Bezuschussung von politischen Jugendorganisationen fällt nicht unmittelbar unter den Begriff der „staatlichen Finanzierung“ iSd. Art. 21 Abs. 3 S. 1 GG. Die rechtlich selbstständigen Nebenorganisationen fallen nach der hier vertretenen Auffassung nicht unter den Parteienbegriff und haben dadurch weder parteispezifische Rechte noch Pflichten; eine unmittelbare Erstreckung der Ausschlusswirkung ist deshalb ausgeschlossen. Das im SGB VIII vorgesehene Förderungsverfahren, von dem auch politischen Jugendorganisationen profitieren, stellt allerdings als Förderungsbedingung eine grundlegende Vereinbarkeit der Ziele der Jugendorganisation mit den Werten des Grundgesetzes auf und schafft dadurch eine Art Automatismus, der bei einer Zurechnung der Verfassungsfeindlichkeit der Mutterpartei einen Einfluss auf den von der Jugendorganisation zu erfüllenden Tatbestand hat. Dass die Jugendorganisation unabhängig von dem Ausschluss der „Mutterpartei“ aus der Parteienfinanzierung keine Gewähr

622 Vgl. Kern, in: Fischer/Mann/Schellhorn u.a. (Hrsg.), SGB VIII, ${ }^{52017, ~} \mathbb{5} 74$, Rn. 6, 10. 
für eine den Zielen des Grundgesetzes förderliche Arbeit bietet, bleibt nach wie vor möglich. Bei behördlichen Entscheidungen gegen die Jugendorganisation sind die von der Partei zugerechneten Umstände gleichfalls im Rahmen einer Gesamtbetrachtung miteinzubeziehen.

\section{Dauer des Ausschlusses}

Ein Novum stellt die zeitliche Begrenzung der Ausschlusswirkung nach $\$ 46 a$ Abs. 1 S. 1 BVerfGG dar. Während das Verbot einer Partei nach $\$ 46$ Abs. 3 S. 1 BVerfGG zu einer dauerhaften Auflösung führt, so beschränkt sich die Wirkung des Finanzierungsausschlussverfahrens auf sechs Jahre ab dem Zeitpunkt der Feststellung des Ausschlusses durch das Bundesverfassungsgericht. Der Gesetzgeber hat mit der Wahl der Ausschlussdauer von sechs Jahren einen Zeitraum gewählt, der der Konsolidierungsspanne einer Partei nach $\$ 2$ Abs. 2 PartG entspricht. ${ }^{623}$ So wird einer aus der staatlichen Parteienfinanzierung ausgeschlossenen Partei die Möglichkeit der Rückkehr zum Boden der freiheitlichen demokratischen Ordnung ermöglicht und somit eine Art "goldene Brücke“624 zurück zu einer verfassungskonformen Zielsetzung eröffnet. Die Ausschlusswirkung endet mit Zeitablauf, es sei denn, eines der zur Antragstellung zum Ausschluss aus der staatlichen Parteienfinanzierung berechtigten Organe beantragt nach $\$ 46 \mathrm{a}$ Abs. 2 BVerfGG sechs Monate vor Ablauf der Ausschlussdauer die Wirkung des Art. 21 Abs. 3 GG zu verlängern.

Durch den sechsjährigen Ausschlusszeitraum wäre es möglich, eine Partei weiterhin aus der staatlichen Parteienfinanzierung auszuschließen, obwohl sich ihre Zielsetzung unter Umständen nicht mehr gegen die freiheitliche demokratische Grundordnung oder den Bestand der Bundesrepublik Deutschland richtet. Die absolute Zeitspanne des $\$ 46 a$ Abs. 1 S. 1 BVerfGG lässt keine frühzeitige Teilnahme an der staatlichen Parteienfinanzierung zu, was insbesondere hinsichtlicht der Parteiengleichheit erhebliche Bedenken, nicht nur rechtspolitischer Art, begründet. Zu beachten gilt hier insbesondere, dass die Zeitspanne nicht verfassungsrechtlich, sondern lediglich einfachgesetzlich normiert wurde und somit als einfachgesetzliches Bundesrecht nicht nur an Art. 79 Abs. 3 GG, sondern am gesamten Grundgesetz als höherrangigem Recht zu messen ist.

623 So schon Morlok, ZRP 2017, 66 (67).

624 So benannt von Ferreau, DÖV 2017, 494 (500). 
Die Sachlage zum Zeitpunkt der verfassungsgerichtlichen Entscheidung vermag allein zum Ausschluss aus der staatlichen Parteienfinanzierung für die Dauer von sechs Jahren führen, ohne dass eine Änderung der Sachlage im Zeitraum des Ausschlusses berücksichtigt werden kann. Der Ausschluss für die Dauer von sechs Jahren, unabhängig von der Möglichkeit einer früheren „Rückkehr“ zu der freiheitlichen demokratischen Grundordnung, verleiht dem Finanzierungsausschlussverfahren einen gewissen Sanktionscharakter. ${ }^{625}$ Denn unter Präventionsgesichtspunkten ließe sich die starre Zeitspanne von sechs Jahren nicht rechtfertigen, da eine Partei bereits vor Ablauf von sechs Jahren zur Verfassungskonformität "zurückkehren“ kann. Von einer zu den Werten der freiheitlichen demokratischen Grundordnung zurückkehrenden Partei geht keine Gefahr mehr für die bestehende Staatsordnung aus, wodurch eine Prävention insoweit auch nicht mehr erforderlich ist.

Vielmehr deutet die absolute Ausschlussdauer von sechs Jahren darauf hin, dass die Zeitspanne einen repressiven Charakter aufweist, der ein in der Vergangenheit liegendes Verhalten der betroffenen Partei durch den starren Ausschluss aus der Parteienfinanzierung ohne die Möglichkeit einer vorzeitigen Wiederbegünstigung zu bestrafen sucht. ${ }^{626}$ Der Sanktionscharakter, der dieser starren Zeitspanne innewohnt, verfolgt keinen „zwingenden Grund“627, der eine solche Ungleichbehandlung rechtfertigen mag. Dem einfachen Gesetzgeber steht im Rahmen seines Ausgestaltungsauftrags nach Art. 21 Abs. 5 GG $^{628}$ ein Beurteilungsspielraum zu, der nicht vollumfänglich der juristischen Kontrolle unterworfen ist und Raum für politische Entscheidungen lässt. So kann der Gesetzgeber durchaus einen starren Zeitraum des Ausschlusses festlegen, innerhalb dessen sich die Partei zunächst beweisen muss und insoweit das weitere Vorliegen der Verfassungsfeindlichkeit unwiderlegbar vermutet wird, da eine etwaige Neuausrichtung einer Partei in der Regel einen mehrjährigen Prozess darstellt. ${ }^{629}$ Die ihm durch Art. 21 GG gesetzten Grenzen darf der Gesetzgeber indessen dennoch nicht verletzen, indem er in unzulässiger Weise in den

625 Siehe die Gesetzesbegründung in BT-Drucksache 18/12357, S. 1, die Bezug zu dem verfassungsgerichtlichen Hinweis nimmt, Sanktionsmöglichkeiten unterhalb der Schwelle des Parteiverbots zu schaffen, BVerfGE 144, 20 (202).

626 Vgl. Müller, DVBl 2018, 1035 (1038).

627 BVerfGE 20, 56 (117); BVerfGE 24, 300 (339 ff.).

628 Morlok, in: Dreier/Bauer (Hrsg.), Grundgesetz, 32015, Art. 21, Rn. 161; Streinz, in: Huber/Voßkuhle (Hrsg.), Grundgesetz, ${ }^{72018}$, Art. 21, Rn. 253; Ipsen, in: Sachs (Hrsg.), Grundgesetz, ${ }^{8} 2018$, Art. 21, Rn. 225.

629 Vgl. Shirvani, DÖV 2018, 921 (926). 
für die Demokratie fundamentalen Rechtskreis der Parteien eingreift, sofern hierfür kein rechtfertigender, zwingender Grund vorliegt. Der Wesensgehalt des Art. 21 Abs. 3 GG beruht maßgeblich auf dem Gedanken der Gefahrenprävention ${ }^{630}$, sodass die Norm dem präventiven Staats- und Verfassungsschutz zuzuordnen ist. ${ }^{631}$ Dies muss der Gesetzgeber bei der einfachgesetzlichen Ausgestaltung der Norm berücksichtigen. Eine nicht mehr verfassungsfeindliche Partei für die Dauer von sechs Jahren von der staatlichen Parteienfinanzierung auszuschließen, ohne die aktuellen Gegebenheiten und eine etwaige Abkehr der Partei von ihrer verfassungsfeindlichen Ausrichtung berücksichtigen zu können, beeinträchtigt den politischen Wettbewerb für diesen Zeitraum grundlos, womit der „zwingende Grund“ zur Rechtfertigung eines solchen Eingriffs nicht mehr besteht. ${ }^{632}$

Die Ausschlussdauer von mindestens sechs Jahren lässt sich auch nicht durch die Typisierungsbefugnis des Gesetzgebers rechtfertigen. Über die Typisierungsbefugnis sollen zugunsten einer vereinfachten Rechtsanwendung und eines vereinfachten Gesetzesvollzuges umfangreiche Einzelfallprüfungen entfallen. ${ }^{633}$ Der gesetzliche „Normalfall“ wird dann insoweit gleichfalls zum Zwecke der Vereinfachung der Rechtsanwendung auf abweichende Sachverhalte angewendet ${ }^{634}$, was für sich genommen wiederum in Konflikt mit dem Gleichheitssatz gerät. ${ }^{635}$ Durch die sechsjährige Ausschlussdauer setzt der Gesetzgeber somit im Rahmen seines Ausgestaltungsermessens den „unwiderlegbaren Typus“636 der "sechsjährig verfassungsfeindlichen Partei“ fest. Nach der Rechtsprechung des Bundesverfassungsgerichts sei der Gesetzgeber zur Ordnung von Massenerscheinungen berechtigt, „generalisierende, typisierende und pauschalierende Regelungen zu verwenden, ohne allein wegen der damit verbundenen Härte gegen den allgemeinen Gleichheitssatz zu verstoßen. “637 Unabhängig davon, ob der Ausschluss aus der staatlichen Parteienfinanzierung eine „Massenerscheinung" darstellt, die mittels Typisierung zu ordnen ist, ist selbst bei einer Übertragung dieser Grundsätze auf das Finanzierungsausschlussver-

630 Ähnlich wie auch Art. 18 und Art. 21 Abs. 2 GG, siehe hierzu Bulla, AöR 98 (1973), 340 (348 f.) mwN.

631 Shirvani, DÖV 2018, 921 (922f.).

632 A.A. Shirvani, DÖV 2018, 921 (926).

633 Vgl. Wernsmann, DStR-Beiheft 2011, 72 (72).

634 Vgl. ders., DStR-Beiheft 2011, 72 (72).

635 Siehe hierzu ausführlich Isensee, Die typisierende Verwaltung, 1976, S. $133 \mathrm{ff}$.

636 Vgl. Kirchhof, in: Isensee/Kirchhof (Hrsg.), Handbuch des Staatsrechts der Bundesrepublik Deutschland V, ${ }^{3} 2007, \mathbb{} 118$, Rn. 103.

637 BVerfGE 111, 115 (137). 
fahren eine starre Ausschlussdauer von 6 Jahren unzulässig. Innerhalb dieser sechs Jahre werden Parteien, die weiterhin verfassungsfeindlich sind und solche, denen eine verfassungsfeindliche Ausrichtung nicht mehr nachgewiesen werden kann, gleichbehandelt. Eine Ungleichbehandlung von Parteien lässt sich nur durch „zwingende Gründe“ rechtfertigen. ${ }^{638}$ Eine Verzerrung des für die Demokratie konstitutiven Parteienwettbewerbs zum Zwecke der Vereinfachung des Finanzierungsausschlussverfahrens für die absolute Dauer von sechs Jahren ist mit dem strengen und formalen Gleichheitssatz ${ }^{639}$ nicht zu vereinbaren, da innerhalb dieses Zeitraums der Partei keine Möglichkeit geboten wird, durch das Nachweisen veränderter Umstände wieder durch die Parteienfinanzierung begünstigt $\mathrm{zu}$ werden. Insoweit ist eine Einzelfallprüfung, die durch die betroffene Partei selbst initiiert werden kann, im Rahmen des Art. 21 Abs. 3 GG unverzichtbar, da eine starre Orientierung an dem Konsolidierungszeitraum

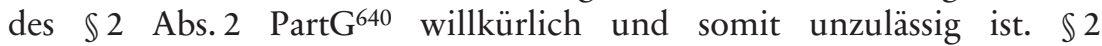
Abs. 2 PartG bezieht sich maßgeblich auf die Fähigkeit einer Partei, ihre aus Art. 21 Abs. 1 GG resultierenden Pflichten zu erfüllen. Sollten sie in einem Zeitraum von sechs Jahren weder an Bundestags- noch an Landtagswahlen teilnehmen oder ihre Pflicht zur Rechenschaftslegung aus Art. 21 Abs. 1 S. 4 GG nicht erfüllen, so verlieren sie ihre Rechtsstellung als Partei. Dies folgt aus der zutreffenden Überlegung, dass eine Partei, die über einen erheblichen Zeitraum ihren verfassungsrechtlichen Pflichten nicht nachkommt, mangels Erfüllung des verfassungsrechtlichen Auftrages auch keine Partei iSd. Art. 21 Abs. 1 GG mehr darstellt. Die Konsolidierungsspanne des $\$ 2$ Abs. 2 PartG knüpft an einen Struktur- und Organisationsmangel der Partei an, während Art. 21 Abs. 3 GG auf eine politisch-inhaltliche Eigenschaft der Partei Bezug nimmt. Hieraus zu schließen, dass eine Partei, deren Verfassungsfeindlichkeit einmalig festgestellt wurde, unwiderlegbar für die Dauer von sechs Jahren eine solche nicht abzulegen vermag, lässt sich auf keinen Erfahrungsgrundsatz und insbesondere nicht auf dieselben Erwägungen wie die Konsolidierungsspanne des $\$ 2$ Abs. 2 PartG stützen. Bei der Festlegung des starren Ausschlusszeitraums auf sechs Jahre

638 BVerfGE 20, 56 (117); BVerfGE 24, 300 (339 ff.); BVerfGE 111, 382 (398); siehe auch BVerfGE 6, 273 (280) - „verfassungsrechtliche Gründe“ oder BVerfGE 12, 10 (28) - „besondere Gründe“.

639 BVerfGE 8, 51 (68); BVerfGE 14, 121 (132); BVerfGE 20, 56 (116) - ständige Rechtsprechung; in der Literatur Arnim, DÖV 1984, 85 ff.; Lipphardt, Die Gleichheit der politischen Parteien vor der öffentlichen Gewalt, 1975, S. 694 f.; Kißlinger, Das Recht auf politische Chancengleichheit, 1998, S. $80 \mathrm{ff}$.

640 Vgl. Morlok, ZRP 2017, 66 (67). 
hat der Gesetzgeber die Grenzen seiner Einschätzungsprärogative, auch unter Berücksichtigung der Typisierungsbefugnis, überschritten. Die Norm ist insoweit unvereinbar mit Art. 3 Abs. 1 iVm. 21 Abs. 1 S. 1 GG.

Dies bedeutet nicht, dass dem Gesetzgeber im Rahmen seines Ausgestaltungsauftrages und seiner Typisierungsbefugnis die Festlegung starrer Ausschlusszeiträume verwehrt bleibt. Sollte er den Zweck verfolgen, durch den absoluten Ausschlusszeitraum die Ernsthaftigkeit der „Rückkehr“ zur freiheitlichen demokratischen Grundordnung sicherzustellen, kann dies unter Achtung des strengen und formalen Gleichheitssatzes zulässig sein. Indem sich die Partei, bevor ihr die Möglichkeit der Wiederbegünstigung durch die staatliche Parteienfinanzierung eingeräumt wird, über einen gewissen Zeitraum zu beweisen hat, würde dem präventiven Charakter des Finanzierungsausschlussverfahrens Rechnung getragen werden. Hierfür sollte eine einmalige, starre Ausschlussdauer von nicht mehr als vier Jahren zulässig sein, bis ein Antrag auf die Aufhebung des Ausschlusses aus der staatlichen Parteienfinanzierung durch die betroffene Partei gestellt werden kann; insoweit unwiderlegbar vermutet wird, dass die Partei in diesem Zeitraum ihre verfassungsfeindliche Haltung noch nicht abgelegt hat. Ein Ausschluss für die Dauer von sechs Jahren, dessen Verlängerung um weitere sechs Jahre durch die in $₫ 43$ Abs. 1 S. 1 BVerfGG genannten Organe beantragt werden kann, ohne der betroffenen Partei die Möglichkeit der Aufhebung des Ausschlusses durch einen eigenen Antrag einzuräumen, ist demnach unzulässig. Der betroffenen Partei muss insoweit die Möglichkeit eingeräumt werden, selbst eine vorzeitige Beendigung dieser Ungleichbehandlung prozessual herbeizuführen. Durch die aktuelle Fassung des $\$ 46 \mathrm{a}$ Abs. 1 S. 1 BVerfGG weicht der Gesetzgeber in unzulässiger Weise von dem präventiven Staatsschutzcharakter ${ }^{641}$ des Art. 21 Abs. 3 GG $a b$, indem er die betroffene Partei ohne Einräumung einer Antragsberechtigung zur Überprüfung des Finanzierungsausschlusses für die Dauer von sechs Jahren aus der staatlichen Parteienfinanzierung ausschließt und die Norm somit grundlos repressiv gestaltet.

Die Unvereinbarkeit mit den Vorschriften des Grundgesetzes könnte lediglich über die Möglichkeit einer analogen Anwendung des $\mathbb{4} 40$ S. 1 Alt. 2 BVerfGG vermieden werden. Die Vorschrift sieht bei der Verwirkung von Grundrechten vor, dass der Antragsgegner bei einer unbefristeten oder für einen längeren Zeitraum als ein Jahr ausgesprochenen Verwirkung von Grundrechten die Möglichkeit erhält, durch das Stellen eines Antrages die Verwirkung seiner Grundrechte ganz oder teilweise durch

641 Vgl. Shirvani, DÖV 2018, 921 (922 f.). 
das Bundesverfassungsgericht aufheben zu lassen. Dies würde der Partei die Möglichkeit einer vorzeitigen Teilnahme an der staatlichen Parteienfinanzierung ermöglichen und den politischen Wettbewerb damit nicht mehr als notwendig beeinträchtigen. Voraussetzung für die Bildung einer Analogie ist das Vorliegen einer planungswidrigen Regelungslücke und einer vergleichbaren Interessenlage. ${ }^{642}$ Eine vergleichbare Interessenlage wird durch den Umstand der Rechtskreisbegrenzung begründet, der in beiden Verfahren den eigentlichen Kern der Rechtsfolge ausmacht. In beiden Verfahren wird der grundrechtliche Rechtskreis der Antragsgegner für eine bestimmte oder unbestimmte Dauer eingeschränkt bzw. ganz aufgehoben. Sowohl im Rahmen der Verwirkung von Grundrechten als auch bei dem Ausschluss aus der staatlichen Parteienfinanzierung nimmt der Staat Einschränkungen von verfassungsrechtlichen Freiheits- und Gleichheitsgarantien vor, die über einen bestimmten Zeitraum Geltung beanspruchen. Dem Interesse des Antragsgegners, vor Ablauf der vorgesehenen Dauer die Eingrenzung seines Rechtskreises zu beenden, wird allerdings nur in $\$ 40$ BVerfGG Rechnung getragen. Eine vergleichbare Interessenlage ist somit anzunehmen. Problematischer ist das Vorliegen einer planwidrigen Regelungslücke. Eine solche setzt voraus, dass der Gesetzgeber bei der Regelung der Dauer des Finanzierungsausschlusses unbeabsichtigt das Treffen einer notwendigen Regelung versäumte. Die Gesetzgebungsmaterialien indizieren allerdings Gegenteiliges. Im ersten Gesetzesentwurf war für $\$ 46 a$ Abs. 2 BVerfGG folgende Fassung vorgesehen:

„Die Partei kann frühestens nach Ablauf von vier Jahren seit der Entscheidung beantragen, den Ausschluss wieder aufzuheben. In der Begründung des Antrags ist auszuführen, welche der Umstände, auf die das Bundesverfassungsgericht seine Entscheidung gestützt hatte, weggefallen sind oder sich geändert haben. Für das Verfahren der Überprüfung gelten die $\int \$ 38$ und 44 sowie Absatz 1 entsprechend. Das Bundesverfassungsgericht gibt den Antragsberechtigten nach $\mathbb{} 43$ Gelegenheit, sich binnen einer zu bestimmenden Frist zu äußern; sie können dem Verfahren beitreten. Das Bundesverfassungsgericht kann obne mündliche Verhandlung entscheiden. Der Antrag auf Aufhebung des Ausschlusses kann wiederholt werden, wenn seit der letzten Entscheidung des Bundesverfassungsgerichts vier Jahre verstrichen sind. "643

642 Vgl. Beaucamp/Beaucamp, Methoden und Technik der Rechtsanwendung, ${ }^{4} 2019$, S. 89 ff. mwN.

643 BT-Drucksache 18/12358, S. 3. 
Die Beschlussempfehlung des Innenausschusses des Deutschen Bundestages nahm diese Formulierung allerdings zum Anlass, dem Plenum eine Änderung des vorgesehenen Gesetzeswortlautes vorzuschlagen. In der Ausschussberatung brachte DIE LINKE einen Änderungsantrag ein, der explizit eine Streichung der Möglichkeit der Beantragung der vorzeitigen Überprüfung des Ausschlusses aus der staatlichen Parteienfinanzierung durch die betroffene Partei forderte. ${ }^{644}$ In der Begründung des Änderungsantrags wurde ausgeführt:

„Es sollte nicht der Partei die Möglichkeit eingeräumt werden, nach vier Jahren eine Überprüfung der Entscheidung zu beantragen. Vielmehr sollten die Antragsteller (Bundestag, Bundesrat, Bundesregierung) nach vier Jahren die Möglichkeit erhalten, eine Verlängerung des Ausschlusses zu beantragen."

Der Änderungsantrag wurde in der Ausschussberatung zwar abgelehnt, dennoch empfahl der Innenausschuss den $\$ 46$ a BVerfGG so auszugestalten, dass eine sechsjährige Frist einzuhalten sei, die lediglich auf Antrag der antragsberichtigten Organe verlängert werden kann. Die einzige Abweichung des von der LINKEN eingebrachten Änderungsvorschlages liegt damit ausschließlich in der Länge der Ausschlussfrist. Von der Möglichkeit einer vorzeitigen Überprüfung einer weiteren Notwendigkeit des Ausschlusses aus der staatlichen Parteienfinanzierung hat der Innenausschuss in seiner Beschlussempfehlung (die dann auch in der vorgeschlagenen Formulierung umgesetzt wurde ${ }^{646}$ ) allerdings gleichlaufend Abstand genommen. ${ }^{647}$ Aus den Gesetzgebungsmaterialien geht deutlich hervor, dass der Gesetzgeber bei der Beratung über die Ausgestaltung des Finanzierungsausschlussverfahrens Kenntnis von der Möglichkeit der vorzeitigen Überprüfung auf Antrag des Antragsgegners hatte, von dieser Möglichkeit allerdings bewusst Abstand nahm. Anstatt wie zu Beginn der Beratung vorgesehen eine Partei dauerhaft aus der staatlichen Parteienfinanzierung auszuschließen, bis auf ihren Antrag hin eine erneute Teilnahme an staatlichen Begünstigungen ermöglicht wird ${ }^{648}$, hat sich der Gesetzgeber bewusst für einen zeitlichen Ausschluss mit der ausschließlichen Möglichkeit der Verlängerung, nicht der Verkürzung der Zeitspanne entschieden. Eine Planwidrigkeit der Regelungslücke kann damit nicht angenommen werden,

644 Siehe BT-Drucksache 18/12846, S. 9 f.

645 BT-Drucksache 18/12846, S. 10.

646 BGBl. 2017, I, S. 2730.

647 BT-Drucksache 18/12846, S. 10.

648 BT-Drucksache 18/12358, S. 3. 
wodurch eine analoge Anwendung des $\$ 40$ BVerfGG nicht in Betracht kommt. Die in $\$ 46 a$ BVerfGG vorgesehene Regelung, dass eine Partei zwingend sechs Jahre aus der staatlichen Parteienfinanzierung ausgeschlossen ist, ist aus diesem Grund verfassungswidrig.

\section{Anwendbarkeit des Grundsatzes der Verhältnismäßigkeit}

Im Hinblick auf das Parteiverbotsverfahren nach Art. 21 Abs. 2 GG wurde vor der Änderung des Grundgesetztes zum Zwecke des Ausschlusses verfassungsfeindlicher Parteien aus der staatlichen Parteienfinanzierung die rechtsfolgenbezogene Anwendung des Grundsatzes der Verhältnismäßigkeit diskutiert. Die Anwendbarkeit des Verhältnismäßigkeitsgrundsatzes ist nicht schon deshalb kategorisch ausgeschlossen, weil das Finanzierungsausschlussverfahren einen staatsorganisationsrechtlichen Charakter aufweist. ${ }^{649}$ Parteien sind - wie bereits erwähnt - dem gesellschaftlichen Bereich und nicht der organisierten Staatlichkeit zuzuordnen, wodurch der Verhältnismäßigkeitsgrundsatz bereits dadurch zu achten ist, dass der Staat die Parteien seiner Sanktionsgewalt unterwirft, ihnen damit in einem Subordinationsverhältnis gegenübertritt ${ }^{650}$ und in ihren grundrechtlich garantierten Rechtskreis eingreift.

Anlass für die Diskussion war vor allem die Rechtsprechung des EGMR, wonach das Verbot einer Partei aufgrund der davon ausgehenden Wirkungen auf die Demokratie stets ,in einer demokratischen Gesellschaft notwendig" sein müsse, um mit der Vorschrift des Art. 11 Abs. 2 S. 1 EMRK im Einklang zu stehen. ${ }^{651}$ Sowohl das Bundesverfassungsgericht als auch die wohl herrschende Literatur lehnen die Anwendbarkeit des Verhältnismäßigkeitsgrundsatzes bei der Entscheidung über ein Parteiverbot ab, da eine solche Anwendung ein Ermessen des Entscheidungsträgers voraussetzt, was bei der zwingenden Rechtsfolge des Art. 21 Abs. 2 GG gerade ausgeschlossen sei. ${ }^{652}$ Mithin ist eine unter Verhältnismäßigkeitsgesichts-

649 Vgl. BVerfGE 144, 20 (231); zur Anwendbarkeit des Verhältnismäßigkeitsgrundsatzes im Staatsorganisationsrecht siehe Heusch, Der Grundsatz der Verhältnismäßigkeit im Staatsorganisationsrecht, 2003.

650 Siehe Müller, DVBl 2018, 1035 (1040); auch Shirvani, JZ 2014, 1074 (1080).

651 EGMR, Urt. v. 13. 2. 2003, Refah Partisi (The Welfare Party) and Others v. Turkey, Nr. 41 340/98 u. a. = NVwZ 2003, 1489 ff., Rz. 50 f.

652 BVerfGE 144, 20 (231); Schmidt, Die Freiheit verfassungswidriger Parteien und Vereinigungen, 1983, S. 163 ff.; Seifert, Die politischen Parteien im Recht der Bundesrepublik Deutschland, 1975, S. 470 f.; Koch DVBl 2002, 1388 (1389f.); 
punkten vorzunehmende Korrektur der zwingenden Rechtsfolge nicht möglich. Das Bundesverfassungsgericht hat der Rechtsprechung des EGMR durch das Hineinlesen der „Potentialität“ in das Merkmal des „Darauf-Ausgehens" Rechnung getragen ${ }^{653}$, sodass zumindest eine hinreichende Gefahr für die Schutzgüter des Art. 21 Abs. 2 GG vorliegen muss, um die Verfassungswidrigkeit und ein Verbot der Partei verfassungsgerichtlich feststellen zu lassen.

Bezugspunkt der Rechtsprechung des EGMR als auch der neueren Rechtsprechung des Bundesverfassungsgerichtes war die Bedeutung des Parteiverbotsverfahrens innerhalb einer demokratischen Herrschaftsordnung. Der EGMR betonte in seinen Entscheidungen, dass der Schutz von Parteien in einem engen Zusammenhang mit der durch Art. 10 EMRK garantierten Meinungsfreiheit stehe. ${ }^{654}$ Sowohl die Vereinigungs-, als auch die Meinungsfreiheit stellen demnach wichtige Komponenten einer pluralistischen Demokratie dar ${ }^{655}$, was zur Folge hat, dass ein Eingriff in die angeführten Konventionsrechte in einer „demokratischen Gesellschaft notwendig" sein muss. Auch im deutschen Verfassungsrecht wird allgemein die hohe Bedeutung der Chancengleichheit der Parteien für einen demokratisch verfassten Staat anerkannt. ${ }^{656}$ Gerade aus diesem Grund stellt sich die Frage, ob es in Ansehung des mit dem Ausschluss aus der staatlichen Parteienfinanzierung verfolgten Zwecks gerechtfertigt ist, die Feststellung der Erfüllung des Tatbestandes durch das Bundesverfassungsgericht einschränkend einer Verhältnismäßigkeitskontrolle zu unterwerfen. Die Diskussion der Anwendung des Grundsatzes der Verhältnismäßigkeit auf das Parteiverbotsverfahren lässt sich vor dem Hintergrund der einschneidenden Wirkung auf die Demokratie und der mit ihr zusammenhängenden Kommunikationsgrundrechte auch auf Art. 21 Abs. 3 GG übertragen. So dürfte sich auch im Hinblick auf die Rechtsprechung des EGMR die Frage

Klein, in: Maunz/Dürig (Hrsg.), Grundgesetz, 2018, Art. 21, Rn. 513; wohl auch Müller, DVBl 2018, 1035 (1040).

653 Vgl. oben $\mathbb{} 4$ A. II, III; dies ablehnend und die Anwendbarkeit des Verhältnismäßigkeitsgrundsatzes befürwortend Shirvani, JZ 2014, 1074 (1079f.); siehe auch Maurer, AöR 96 (1971), 203 (224 ff.).

654 EGMR, Urt. v. 30. 1. 1998, United Communist Party of Turkey and Others v. Turkey, Nr. 133/1996/752/951, Rz. 25, 42 f.; EGMR, Urt. v. 08.12.1999, ÖZDEP vs. Turkey, Nr. 23885/95, Rz. 37.

655 EGMR, Urt. v. 08.12.1999, ÖZDEP vs. Turkey, Nr. 23885/95, Rz. 37.

656 Statt vieler siehe Morlok, in: Dreier/Bauer (Hrsg.), Grundgesetz, ${ }^{3} 2015$, Art. 21, Rn. 77 ff.; Ipsen, in: Sachs (Hrsg.), Grundgesetz, ${ }^{8} 2018$, Art. 21, Rn. 33 ff.; Streinz, in: Huber/Voßkuhle (Hrsg.), Grundgesetz, ${ }^{7} 2018$, Art. 21, Rn. 119. 
stellen, ob eine systematische Ungleichbehandlung von Parteien auch dann gerechtfertigt ist, wenn der Ausschluss aus der staatlichen Parteienfinanzierung ähnlich wie die Rechtsprechung zum Parteiverbot in einer demokratischen Gesellschaft nicht notwendig ist.

Folgt man konsequent den überzeugenden Argumenten des Bundesverfassungsgerichts bei der Ablehnung der Anwendung des Verhältnismäßigkeitsgrundsatzes auf das Parteiverbotsverfahren, so muss man hinsichtlich des Ausschlusses aus der staatlichen Parteienfinanzierung zum selben Ergebnis kommen. Art. 21 Abs. 3 GG räumt gleichlaufend zum Parteiverbotsverfahren dem Bundesverfassungsgericht bei der Erfüllung der Tatbestandsvoraussetzungen kein Ermessen bei der Feststellung des Ausschlusses aus der staatlichen Parteienfinanzierung ein. ${ }^{657}$ Die Rechtsfolgen treten nicht ipso iure ein, da die verfassungsgerichtliche Feststellung konstitutiv für den Ausschluss aus der staatlichen Parteienfinanzierung ist und diese ferner eine vorläufige Antragstellung eines berechtigten Organs nach $₫ 43$ Abs. 1 S. 1 BVerfGG voraussetzt. ${ }^{658}$ Die Entscheidung über die Feststellung des Ausschlusses aus der staatlichen Parteienfinanzierung ist beim Vorliegen sämtlicher Tatbestandsvoraussetzungen für das Bundesverfassungsgericht bindend und deshalb nach der in der Rechtsprechung vertretenen Auffassung nicht unter der Beachtung des Verhältnismäßigkeitsgrundsatzes im Rahmen der Rechtsfolge zu fällen. ${ }^{69}$ Somit ist grundsätzlich anzunehmen, dass die bindende Entscheidung des Bundesverfassungsgerichts im Falle der Erfüllung sämtlicher Tatbestandsmerkmale einer zusätzlichen, gesonderten Anwendung des Verhältnismäßigkeitsgrundsatzes entgegensteht.

Auch die Möglichkeit, den Antrag auf den Ausschluss einer Partei aus der staatlichen Parteienfinanzierung nach $₫ 43$ Abs. 1 S. 2 BVerfGG hilfsweise zu einem Verbotsantrag zu stellen, eröffnet dem Bundesverfassungsgericht in der Sache keine Ermessensentscheidung. Eine ablehnende Entscheidung im Verbotsverfahren wird für die Entscheidungsmöglichkeit über den hilfsweise zu stellenden Antrag auf den Ausschluss aus der staatlichen Parteienfinanzierung vorausgesetzt; dem Bundesverfassungsgericht steht insoweit kein Auswahlermessen zu. ${ }^{660}$ Auch wenn das Finanzierungs-

657 Ipsen, in: Sachs (Hrsg.), Grundgesetz, ${ }^{8}$ 2018, Art. 21, Rn. 215; ders., JZ 2017, 933 (934); wohl auch Streinz, in: Huber/Voßkuhle (Hrsg.), Grundgesetz, ${ }^{7} 2018$, Art. 21, Rn. 252b.

658 Ipsen, in: Sachs/Battis (Hrsg.), Grundgesetz, ${ }^{7} 2014$, Art. 21, Rn. 215.

659 Im Ergebnis auch Müller, DVBl 2018, 1035 (1040).

660 So auch ders., DVBl 2018, 1035 (1040). 
ausschlussverfahren bis auf die „Realisierungspotentialität“ dieselben Voraussetzungen wie das Parteiverbot nach Art. 21 Abs. 2 GG aufweist, muss bei beiden Verfahren unabhängig voneinander das Vorliegen sämtlicher Tatbestandsmerkmale festgestellt werden. Welcher Antrag letztendlich gestellt wird, liegt im Ermessen der nach $\$ 43$ Abs. 1 BVerfGG antragberechtigten Staatsorgane.

Ein anderes Ergebnis lässt sich auch nicht damit rechtfertigen, dass das Finanzierungsausschlussverfahren keine Gefährdung der freiheitlichen demokratischen Grundordnung oder des Bestandes der Bundesrepublik Deutschland voraussetzt. Sein Zweck liegt nicht darin, eine konkrete Gefahr für die freiheitliche demokratische Grundordnung abzuwenden, sondern den Staat von der Pflicht zur Finanzierung solcher Bestrebungen zu entbinden und somit die Kollision zwischen der demokratisch aufgeladenen Gleichbehandlungspflicht und der Gewährleistung der durch Art. 20 Abs. 1 GG vorausgesetzten Staatsstruktur zu einem möglichst schonenden Ausgleich zu bringen. Der Staat soll nicht fortlaufend verfassungsfeindliche, wenn auch in ihrer konkreten Gestalt noch nicht realisierungsfähige Bestrebungen finanziell fördern müssen. Hierdurch ist auch hinsichtlich des Zweckes des Finanzierungsausschlussverfahrens eine Anwendbarkeit des Grundsatzes der Verhältnismäßigkeit abzulehnen. Der verfassungsändernde Gesetzgeber befand das Finanzierungsausschlussverfahren selbst schon für verhältnismäßig und ließ aus diesem Grund für eine gesonderte Anwendung des Übermaßverbotes keinen Raum. ${ }^{661}$

Auch wenn - wofür sich zumindest beachtliche Argumente anführen lassen - durch das „neue Verständnis“662 des Bundesverfassungsgerichtes vom Merkmal des „Darauf-Ausgehens“ nunmehr Verhältnismäßigkeitserwägungen im Rahmen der tatbestandlichen Prüfung zu berücksichtigen sind, führt dies nicht zu einer gesonderten Anwendung des Verhältnismäßigkeitsgrundsatzes beim Finanzierungsausschlussverfahren. Der Tatbestand des Art. 21 Abs. 3 GG enthält im Vergleich zu dem Parteiverbotsverfahren keine Möglichkeit zur Anwendung des Übermaßverbots. Das Überschreiten der „Potentialitätsschwelle“ ist keine Voraussetzung, sodass die Gefahr, die von der betroffenen Partei für die Staatsordnung ausgeht, nicht ins Verhältnis zum Zweck des Art. 21 Abs. 3 GG gesetzt wird. Dies schließt eine Beachtung der bei einem Ausschluss einer Partei aus der staatlichen Parteienfinanzierung betroffenen Verfassungsgüter, insbesondere

661 Vgl. hierzu auch Ipsen, in: Geis/Lorenz (Hrsg.), Staat, Kirche, Verwaltung, 2001, S. $172 \mathrm{f}$.

662 Siehe hierzu bereits ausführlich $₫ 4 \mathrm{~A}$. 
der Demokratie und der mit ihr zusammenhängenden Freiheitsgarantien und Wertentscheidungen, nicht aus. So muss bei der Auslegung der einzelnen Tatbestandsmerkmale den durch das Verfahren betroffenen Verfassungsgütern Rechnung getragen werden, um ihnen einen möglichst weiten Geltungsbereich zu verschaffen. ${ }^{663}$

\section{Verfahren}

\section{Anwendungsbereich}

In der Gesetzesbegründung der Verfassungsänderung zum Zwecke des Ausschlusses verfassungsfeindlicher Parteien aus der staatlichen Parteienfinanzierung wird Bezug auf Kleinstparteien genommen, deren Wahlerfolg so gering ist, dass sie nach $\$ 18$ Abs. 4 BVerfGG keine Mittel durch die staatliche Parteienfinanzierung erhalten. ${ }^{664}$ Der Gesetzgeber hat die Akzessorität des Wegfalls der steuerlichen Begünstigungen mit dem Ausschluss aus der Parteienfinanzierung betont und anhand der Kleinstparteien als Beispiel verdeutlicht, dass ein gesondertes, ausschließlich auf den Wegfall der steuerlichen Begünstigungen gerichtetes Verfahren nicht statthaft sein solle. Dies führte in der Literatur zur irrigen Annahme, dass das Finanzierungsausschlussverfahren auf solche Kleinstparteien nach der gesetzgeberischen Intention keine Anwendung finden solle. ${ }^{665}$ Die Gesetzesbegründung erklärt allerdings nicht deutlich, dass eine Anwendbarkeit dann ausscheidet, wenn die betroffene Partei aufgrund ihres zu geringen Stimmquorums keine Mittel aus der staatlichen Parteienfinanzierung erhält. Feststehend ist lediglich, dass der Gesetzgeber den Wegfall der steuerlichen Privilegien akzessorisch an den unmittelbaren Ausschluss aus der staatlichen Parteienfinanzierung iSd. $\$ \mathbb{S} 18 \mathrm{ff}$. PartG knüpfen wollte und nicht die Etablierung zweier separater Verfahren (das eine die unmittelbare Parteienfinanzierung nach den $\$ \mathbb{S} 18 \mathrm{ff}$. PartG, das andere ausschließlich den Wegfall der steuerlichen Begünstigungen betreffend) im Sinn hatte. ${ }^{666}$ Ob der Umstand, dass eine Partei zum Zeitpunkt der Antragstellung keine

663 BVerfGE 144, 20 (232); siehe dazu auch Alter, AöR 140 (2015), 571 (591ff.); Müller, DVBl 2018, 1035 (1040).

664 BT-Drucksache 18/12357, S. 7.

665 So Waldhoff, in: Walter/Grünewald (Hrsg.), BeckOK BVerfGG, 2018, \$46a, Rn. 8.

666 BT-Drucksache 18/12357, S. 7. 
nennenswerten Aussichten auf eine Begünstigung durch die unmittelbare Parteienfinanzierung hat, zu berücksichtigen ist, ist dennoch fraglich. So könnte, anders als in der bisherigen Praxis des Parteiverbots, ein objektives Feststellungsinteresse des Antragstellers im Rahmen der Zulässigkeit des Feststellungsantrags zu verlangen sein. An diesem könnte es fehlen, wenn die Antragsgegnerin bereits aufgrund ihres zu geringen Wahlerfolges keine staatlichen Mittel aufgrund der $\mathbb{1 8} \mathrm{ff}$. PartG erlangen kann und in erster Linie ein Ausschluss aus der staatlichen Parteienfinanzierung deshalb nicht in Betracht kommt. Aufschluss über die Frage, ob der Antrag auf Ausschluss einer Partei aus der staatlichen Parteienfinanzierung ein solches Feststellungsinteresse voraussetzt, ergibt eine Auslegung des Art. 21 Abs. 3 GG anhand der allgemein anerkannten juristischen Auslegungsmethoden. ${ }^{667}$

Der Wortlaut des Art. 21 Abs. 3 S. 1 GG könnte zumindest indizieren, dass eine Teilnahme an der staatlichen Parteienfinanzierung im Zeitpunkt der Antragstellung Voraussetzung für die Feststellung eines Ausschlusses ist, da ein Ausschluss von etwas die vorherige Teilnahme am Selbigen voraussetzt. Jemanden aus etwas ausschließen, woran er nicht teilnimmt, ist denklogisch nicht möglich. Eine Partei muss, so indiziert der Wortlaut, nicht nur den Tatbestand des Art. 21 Abs. 3 S. 1 GG erfüllen, damit ihr Ausschluss aus der staatlichen Parteienfinanzierung festgestellt werden kann, sondern muss zusätzlich bereits Begünstigte nach den $\$ \mathbb{S} 18 \mathrm{ff}$. PartG sein, damit der Ausschluss tatsächlich möglich ist. Demnach könnte eine Begünstigung durch die staatliche Parteienfinanzierung nicht nur ein objektives Feststellungsinteresse begründen, sondern als selbstständiges Tatbestandsmerkmal fungieren. Diese Auslegung ist allerdings nicht zwingend, da der Begriff des "Ausschlusses“ auch in Situationen verwendet wird, in denen bestimmte Personen oder Gruppierungen bereits im Vorfeld des Ausschlussgegenstandes an einer Teilnahme gehindert werden. Eine systematische Auslegung vermag keinen weiterführenden Erkenntnisgewinn zu begründen. So verwendet das Grundgesetz häufiger den Begriff des "Ausschließens" (Art. 42 Abs. 1 S. 2, 34 S. 3, 42 Abs. 1 S. 2, 44 Abs. 1 S. 2, 52 Abs. 3 S. 4 , 90 Abs. 2, 91c Abs. 2 S. 3, 115h Abs. 3, 143d Abs. 2 S. 6, Abs. 4 S. 4 GG), allerdings nur im Kontext des Öffentlichkeitsausschlusses und bestimmter Handlungsverbote, was keinen Rückschluss über die Notwendigkeit einer Begünstigung durch die staatliche Parteienfinanzierung im Zeitpunkt der Antragstellung zulässt. Die Gesetzgebungsmaterialien

667 Siehe zu den Auslegungsmethoden statt vieler Beaucamp/Beaucamp, Methoden und Technik der Rechtsanwendung, ${ }^{4} 2019$, S. 45 ff. mwN. 
führen nur zu der Erkenntnis, dass der Gesetzgeber den Wegfall der steuerlichen Begünstigungen in ein akzessorisches Verhältnis zum Ausschluss aus der staatlichen Parteienfinanzierung setzen wollte. ${ }^{668} \mathrm{Ob}$ das Verfahren in dessen Anwendbarkeit allerdings zwischen solchen Parteien differenziert, die eine Begünstigung durch die staatliche Parteienfinanzierung erfahren und solchen, die ausschließlich auf eine Eigenfinanzierung angewiesen sind, geht aus den Gesetzgebungsmaterialen nicht hervor. ${ }^{669}$ Gar wird ein gegenteiliges Ergebnis durch die Gesetzesbegründung indiziert. In der Gesetzesbegründung steht wörtlich:

„Die in Artikel 21 Absatz 3 Satz 2 GG verfassungsunmittelbar vorgegebene Rechtsfolge, dass die von staatlicher Finanzierung ausgeschlossenen Parteien und Zuwendungen an diese Parteien steuerlich nicht begünstigt sind, ist akzessorisch zu der Entscheidung des Bundesverfassungsgerichts über den Ausschluss der jeweiligen Partei von staatlicher Finanzierung. Dies gilt unabhängig davon, ob die betroffene Partei Mittel aus der staatlichen Finanzierung (gegenwärtig Teilfinanzierung) erhält. Gegen Parteien, deren Wablerfolge nicht ausreichen, um in den Genuss direkter Finanzierung zu gelangen, kann kein isoliertes Verfahren zum Entzug der nur mittelbaren steuerlichen Förderung geführt werden. Die nähere Ausgestaltung des Wegfalls der steuerlichen Begünstigung bleibt gesetzlicher Regelung nach Artikel 21 Absatz 5 - neu - GG vorbehalten. "670

Dass der Gesetzgeber ausdrücklich vorgibt, dass kein auf den Wegfall der steuerlichen Begünstigungen abzielendes Verfahren statthaft sein soll, könnte im Umkehrschluss bedeuten, dass gegen solche an der staatlichen Finanzierung nicht teilnehmenden Kleinstparteien dennoch ein „vollumfängliches" Finanzierungsausschlussverfahren durchgeführt werden muss und die Frage der Anwendbarkeit auf Kleinstparteien damit zu bejahen ist. Der Gesetzgeber ist auf die Kleinstparteien ausschließlich im Zusammenhang der beabsichtigten Akzessorität zwischen dem Ausschluss aus der staatlichen Parteienfinanzierung und dem Wegfall der steuerlichen Begünstigungen eingegangen und hat keine weiteren Ausführungen über die Anwendbarkeit des Art. 21 Abs. 3 GG vorgenommen. Auch diese Auslegung der Gesetzesbegründung vermag allerdings zu keinem zwingenden Ergebnis führen, sondern lediglich als Indiz für die gesetzgeberische Inten-

668 BT-Drucksache 18/12357, S. 7; auch Ipsen, JZ 2017, 933 (934).

669 Anders wohl Waldhoff, in: Walter/Grünewald (Hrsg.), BeckOK BVerfGG, 2018, $\$ 46 a$, Rn. 8.

670 BT-Drucksache 18/12357, S. 7. 
tion dienen. Die ausschlaggebende Erkenntnisquelle zur Klärung der Frage über die Anwendbarkeit des Finanzierungsausschlussverfahrens bildet die Auslegung der Norm am Maßstab ihres Sinns und Zwecks. Vordergründig dient die Einführung des Art. 21 Abs. 3 GG dem Ausbau des Systems der wehrhaften Demokratie ${ }^{671}$, indem der Staat von seiner Pflicht der finanziellen Begünstigung verfassungsfeindlicher, allerdings nicht verbotener Parteien befreit wird. Parteien sollen gerade aufgrund ihrer inhaltlichen, gegen die freiheitliche demokratische Grundordnung gerichteten Haltung keine staatliche Unterstützung mehr erhalten. Deshalb schreibt Art. 21 Abs. 3 S. 2 GG auch vor, dass untrennbar mit dem Ausschluss aus der staatlichen Parteienfinanzierung nach den $\mathbb{S} 18 \mathrm{ff}$. PartG auch eine weitere steuerliche Begünstigung in Form der „mittelbaren“ Parteienfinanzierung entfallen solle. Es geht damit nicht um einen formalen Ausschluss einer Partei aus der staatlichen Parteienfinanzierung, sondern um eine Einschränkung des gleichheitsbezogenen Rechtskreises der Partei. Der Staat soll nicht erst den Ausschluss einer bereits durch die staatliche Parteienfinanzierung begünstigten Partei anordnen können, sondern ihr generell aufgrund ihrer verfassungsfeindlichen Haltung die Möglichkeit einer Begünstigung durch die unmittelbare oder mittelbare Parteienfinanzierung verwehren. Auch wenn eine Partei aufgrund ihres zu geringen Stimmenquorums durch $\$ 18$ Abs. 4 PartG nicht an der staatlichen Teilfinanzierung teilnimmt, ist daneben dennoch der Anwendungsbereich des Art. 21 Abs. 3 GG i.V.m. $\$ 18$ Abs. 7 S. 2 PartG eröffnet. Der Ausschluss aus der staatlichen Parteienfinanzierung fungiert lediglich als rechtliche Objektivierung der verfassungsgerichtlich angeordneten Rechtskreiseingrenzung, die wiederum die streng-formale Gleichbehandlungspflicht des Staates bei Vorliegen einer verfassungsfeindlichen Grundhaltung partiell entfallen lässt. Es soll nicht nur die fortwährende Gewährung staatlicher Mittel unterbunden, sondern der Partei generell eine Beteiligung an dem System der staatlichen Parteienfinanzierung versagt werden. Damit kommt es nicht darauf an, ob die Partei zu einem vorherigen Zeitpunkt einmal durch die $\mathbb{S} \$ 18 \mathrm{ff}$. PartG staatliche Mittel erhalten hat. Eine Partei, die aufgrund des $₫ 18$ Abs. 4 PartG bereits nicht an der unmittelbaren staatlichen Parteienfinanzierung teilnimmt, kann dennoch nach Art. 21 Abs. 3 GG aus der staatlichen Parteienfinanzierung ausgeschlossen werden. Damit spielt es im Zeitpunkt der Antragstellung keine Rolle, ob die Antragsgegnerin

671 Siehe Ferreau, DÖV 2017, 494 (498); Nikkho, DVBl 2018, 337 ff.; Shirvani, DÖV 2018, $921 \mathrm{ff}$. 
bereits einmal eine Begünstigung durch die staatliche Parteienfinanzierung erfahren hat.

\section{Antragstellung}

Nach $₫ 43$ Abs. 1 S. 1 BVerfGG sind der Bundestag, der Bundesrat oder die Bundesregierung zur Stellung eines Antrags auf Feststellung des Ausschlusses aus der staatlichen Parteienfinanzierung berechtigt. Sofern sich die Organisation der betroffenen Partei nur auf das Gebiet eines Landes beschränkt, ist nach $\$ 43$ Abs. 2 BVerfGG zusätzlich noch die entsprechende Landesregierung antragsberechtigt. Der Kreis der Antragsberechtigten entspricht dem des Parteiverbotsverfahrens nach Art. 21 Abs. 2 GG.

Parteien sind selbt nicht berechtigt, im Rahmen des Art. 21 Abs. 2 und 3 GG das Verfahren einzuleiten. Parteien können damit nur Antragsgegner ${ }^{672}$ und keine Antragssteller sein. Die Möglichkeit, Parteien ein Antragsrecht einzuräumen, um ihre Verfassungskonformität positiv feststellen zu lassen, wurde auch bereits vor der Etablierung des Finanzierungsausschlussverfahrens diskutiert. ${ }^{673}$ Der Gesetzgeber hat allerdings bis heute diesen Gedanken nicht in geltendes Recht umgesetzt. Interessant könnte dieser Gedanke insbesondere angesichts der Tatsache sein, dass $\$ 46 a$ Abs. 1 S. 1 BVerfGG in verfassungswidriger Weise Parteien für einen Zeitraum von sechs Jahren, unabhängig von einer vermeintlichen Änderung der Sachlage, ausschließt. Dies könnte dadurch behoben werden, den Parteien einen gesetzlichen Anspruch auf die Feststellung ihrer Verfassungskonformität vor Ablauf der Sechsjahesfrist einzuräumen. ${ }^{674}$

\section{a) Legalitäts- oder Opportunitätsprinzip}

$\mathrm{Ob}$ den antragberechtigten Organen bei der Entscheidung über die Antragstellung ein Ermessen zusteht, ist hinsichtlich des Parteiverbotsverfahrens umstritten. ${ }^{675}$ Der Wortlaut des $₫ 43$ Abs. 1 BVerfGG indiziert durch

672 Waldhoff, in: Walter/Grünewald (Hrsg.), BeckOK BVerfGG, 2018, \$43, Rn. 23.

673 Siehe Hettich, Die Zulässigkeit verschiedener Handlungsalternativen des Staates im Vorgehen gegen extremistische Parteien unter Berücksichtigung des Parteienprivilegs, 2015, S. 83 ff., in Fn. 213, 214 m.w.N.

674 Siehe zu der Diskussion unten $₫ 4$ D. V.

675 Für die Anwendung des Legalitätsprinzips Seifert, Die politischen Parteien im Recht der Bundesrepublik Deutschland, 1975, S. 490 ff.; Doehring, Das Staats- 
das Wort „kann“ das Vorliegen eines Ermessens der Antragsteller bei der Entscheidung über die Einleitung eines solchen Verfahrens, während der Wortlaut des Art. 21 Abs. 3 GG, wonach die tatbestandserfüllenden Parteien aus der staatlichen Parteienfinanzierung ausgeschlossen sind, auf ein gegenteiliges Ergebnis hindeutet. Der Wortlaut vermag somit allein nicht ausreichende Klarheit über diese Frage zu schaffen.

Das Bundesverfassungsgericht spricht in Bezug zum Parteiverbot von einem „pflichtgemäßen Ermessen“676 oder einer „Frage des politischen Ermessens“ 677 und nimmt damit das Vorliegen eines Ermessens der antragsberechtigten Organe an. So führte es insbesondere im KPD-Verbotsverfahren folgendes aus:

"Ob die Bundesregierung diesen Antrag stellen will, steht in ibrem pflichtmäßigen Ermessen, für das sie und sie allein politisch verantwortlich ist. "678

Eine Pflicht zur Antragstellung kommt nur dann in Frage, wenn das Unterlassen rechtswidrig wäre; im konkreten Fall demnach eine Handlungspflicht besteht, die der Staat durch ein Unterlassen verletzen würde. Der Staat befindet sich hinsichtlich der fundamentalen Staatsstrukturen des Art. 20 Abs. 1 GG in einer Garantenstellung. ${ }^{679}$ Insoweit ließe sich eine Handlungspflicht nur daraus herleiten, dass es ihm aufgrund dieser Stellung untersagt ist, verfassungsfeindliche Bestrebungen durch die Gewährung finanzieller Mittel zu fördern. Als Anhaltspunkt wird gerade für die Bundesregierung als antragberechtigtem Organ der von ihren Mitgliedern

recht der Bundesrepublik Deutschland, ${ }^{2} 1980$, S. 140 f.; Streinz, in: Huber/ Voßkuhle (Hrsg.), Grundgesetz, ${ }^{7} 2018$, Art. 21, Rn. 245.; Ipsen, in: Sachs (Hrsg.), Grundgesetz, ${ }^{8} 2018$, Art. 21, Rn. 175 ff.; hingegen für die Opportunität der Antragstellung siehe die h.M. Pieroth, in: Jarass/Pieroth (Hrsg.), Grundgesetz für die Bundesrepublik Deutschland, ${ }^{14} 2016$, Art. 21, Rn.30; Kunig, in: Arnauld (Hrsg.), Grundgesetz-Kommentar, 2012, Art. 21, Rn. 89; Volkmann, in: Friauf/ Höfling (Hrsg.), Berliner Kommentar zum Grundgesetz, 2000, Art. 21, Rn.98; Stern, Staatsrecht I, ${ }^{2}$ 1984, S. 207; Maurer, AöR 96 (1971), 203 (225); Meier, Parteiverbote und demokratische Republik, 1993, S. 226 f.; nur für den Fall annehmend, dass keine politischen Lösungsmöglichkeiten mehr vorhanden sind Morlok, in: Dreier/Bauer (Hrsg.), Grundgesetz, ${ }^{3} 2015$, Art. 21, Rn. 160; kritisch, iE. aber wohl zustimmend Heckelmann, Das Ermessen staatlicher Organe bei der Stellung von Verbotsanträgen nach Art. 21 Abs. 2 GG ( $\$ 43$ BVerfGG), 1976, S. $62 \mathrm{ff}$.

676 BVerfGE 5, 85 (113).

677 Wohl BVerfGE 39, 334 (359f.).

678 BVerfGE 5, 85 (113).

679 Vgl. u.a. Denninger, in: VVDStRL 37 (1979), S. 72. 
zu leistende Amtseid aus Art. 64 Abs. 2 iVm. 56 GG angeführt. ${ }^{600}$ Weiter wird eine Ermessensreduzierung auf den Wortlaut des Art.21 Abs. 3 GG gestützt, der insoweit eine Antragspflicht indizieren würde. ${ }^{681} \mathrm{Da}$ bei einer Erfüllung des Tatbestandes Parteien aus der staatlichen Parteienfinanzierung ausgeschlossen sind und damit der Tatbestand den alleinigen Feststellungsmaßstab bildet, wäre es demnach auch konsequent, dasselbe für die antragberechtigten Organe anzunehmen.

Diese Auffassung vermag kaum zu überzeugen. Der Wortlaut des Art. 21 Abs. 3 GG gibt zwar den Tatbestand vor, der für den Ausschluss aus der staatlichen Parteienfianzierung erfüllt sein muss, lässt allerdings insoweit keinen unmittelbaren Rückschluss auf das hierfür notwendige Verfahren zu. Über Art. 21 Abs. 5 GG obliegt es dem einfachen Gesetzgeber, das für einen Ausschluss aus der staatlichen Parteienfinanzierung notwendige Verfahren tauglich auszugestalten. ${ }^{62} \mathrm{Ihm}$ steht in diesem Sinne ein Ausgestaltungsermessen zu, das seine Grenzen wiederum nur in den Vorschriften des höherrangigen Rechts findet. In $\mathbb{4} 43$ BVerfGG hat der Gesetzgeber nicht nur den Kreis der Antragsberechtigten bestimmt, sondern ihnen darüber hinaus auch durch das Wort „kann“ ein dahingehendes Ermessen eingeräumt. ${ }^{683}$ Das Spannungsverhältnis zwischen Art. 21 Abs. 3 GG, wonach Parteien bei einer Erfüllung des Tatbestandes von der staatlichen Parteienfinanzierung ausgeschlossen sind, und $₫ 43$ BVerfGG, wonach die Antragsberechtigten einen Antrag stellen können, ist über die Konzeption des Art. 21 Abs. 5 GG zu lösen. Deshalb ist für die Frage der Anwendung des Legalitäts- oder Opportunitätsprinzips als Anknüpfungspunkt die verfahrensrechtliche Ausgestaltung in $\$ 43$ BVerfGG maßgeblich. In diesem Sinne ist auf den Wortlaut des $₫ 43$ Abs. 1 BVerfGG abzustellen, da die Norm konkrete Vorgaben zum verfassungsgerichtlichen Verfahren trifft.

Auch das Argument, eine offensichtliche Verfassungsfeindlichkeit dürfe keinesfalls durch den Staat geduldet und im Falle der staatlichen Parteienfinanzierung gar gefördert werden, vermag die Anwendung des Legalitäts-

680 Oder auch, dass der Staat eine evidente Verfassungsfeindlichkeit nicht zu dulden hat, vgl. Seifert, Die politischen Parteien im Recht der Bundesrepublik Deutschland, 1975, S. 491.

681 Ders., Die politischen Parteien im Recht der Bundesrepublik Deutschland, 1975, S. 491; Ipsen, in: Sachs (Hrsg.), Grundgesetz, ${ }^{8} 2018$, Art. 21, Rn. 177.

682 Morlok, in: Dreier/Bauer (Hrsg.), Grundgesetz, ${ }^{3} 2015$, Art. 21, Rn. 161; Ipsen, in: Sachs (Hrsg.), Grundgesetz, ${ }^{8} 2018$, Art. 21, Rn. 225; Streinz, in: Huber/Voßkuhle (Hrsg.), Grundgesetz, ${ }^{7}$ 2018, Art. 21, Rn. 253.

$683 \mathrm{Zu}$ der gängigen Ermessenslehre siehe Maurer, Allgemeines Verwaltungsrecht, ${ }^{18}$ 2011, \ 7 Rn.9. 
prinzips auf die Antragstellung nicht hinreichend zu begründen. ${ }^{684}$ Jeder Eingriff in den Parteienwettbewerb ist aufgrund seiner einschneidenden Wirkung auf das Demokratieprinzip auf das Notwendigste zu beschränken und darf gerade im Bereich der parteibezogenen Chanchengleichheit nur aus besonders zwingenden Gründen erfolgen. ${ }^{685}$ Aus diesem Grund darf die Annahme, der Staat dürfe Verfassungswidriges oder -feindliches nicht dulden oder fördern, allein aus demokratischen Erwägungsgründen nicht zu einem Dogma verkommen. Der politische Wettbewerb darf grundsätzlich nur dann durch die staatliche Hand verzerrt werden, wenn ein solches Vorgehen verfassungsrechtlich zumindest geboten ist, denn erst dann ist ein staatliches Eingreifen zum Schutz oder zur Verhinderung von Gefahren für die bestehende Staatsordnung überhaupt erforderlich und somit „zwingend“. In diesem Zusammenhang hat das Bundesverfassungsgericht zurecht angeführt, dass vor der Stellung eines Antrags auf das Verbot einer Partei „zunächst“ die Möglichkeit besteht, die Partei durch die politische Auseinandersetzung zu bekämpfen. ${ }^{686}$ So ist die Abwehr verfassungsfeindlicher Bestrebungen im Wettbewerb selbst als vorrangig gegenüber einem staatlichen Eingriff zum Zwecke des Schutzes der freiheitlichen demokratischen Grundordnung anzusehen und das Verfahren an diese Prämisse anzupassen. ${ }^{687}$ Wann eine politische Bekämpfung einer verfassungsfeindlichen Partei gegenüber einem staatlichen Eingriff in den Parteienwettbewerb im konkreten Einzelfall als vorrangig gelten kann, muss der Einschätzung der nach $\$ 43$ BVerfGG antragsberechtigten Organe ${ }^{688}$ unterliegen. Nur diese können bei ihrer Entscheidung über die Einleitung des Verfahrens zum Ausschluss aus der staatlichen Parteienfinanzierung die Intensität der wettbewerbsverzerrenden Ungleichbehandlung, die Erfolgsaussichten des Verfahrens und die negativen Folgen eines erfolgreichen Finanzierungsausschlussverfahrens abwägen. ${ }^{689}$ Insoweit kann der Staat auch die Finanzierung einer materiell verfassungsfeindlichen Partei fortsetzen, um

684 In diese Richtung aber insbesondere Ipsen, in: Geis/Lorenz (Hrsg.), Staat, Kirche, Verwaltung, 2001, S. 163, 174; Ipsen, in: Sachs (Hrsg.), Grundgesetz, ${ }^{8} 2018$, Art. 21, Rn. 181; Seifert, Die politischen Parteien im Recht der Bundesrepublik Deutschland, 1975, S. 491.

685 BVerfGE 20, 56 (117); BVerfGE 24, 300 (339 ff.).

686 BVerfGE 40, 287 (291f.).

687 Ähnlich auch Maurer, AöR 96 (1971), 203 (225f.).

688 Denen ohnehin in anderen Bereichen ein weiter Einschätzungsspielraum zugestanden wird, siehe Klein, in: Maunz/Dürig (Hrsg.), Grundgesetz, 2018, Art. 21, Rn. 546.

689 Vgl. ders., in: Maunz/Dürig (Hrsg.), Grundgesetz, 2018, Art. 21, Rn. 546. 
dann im Rahmen der den antragsberechtigten Organen zustehenden Einschätzungsprärogative das generelle Einschreiten gegen die betroffene Partei und den hierfür maßgeblich günstigsten Zeitpunkt zu bestimmen.

Die paradoxe Rechtslage des Garanten, der die Bedrohung des durch ihn zu schützenden Gutes fördert, vermag deshalb keine generelle Handlungspflicht zu begründen. ${ }^{60}$ Zwar liegt der Zweck des Ausschlussverfahrens durchaus in der Befreiung des Staates von der Pflicht zur Finanzierung verfassungsfeindlicher Parteien, allerdings erwächst dem Staat daraus keine Befreiungspflicht, sondern allenfalls eine Befreiungsmöglichkeit, deren Gebrauch im politischen und pflichtgemäßen Ermessen der antragsberechtigten Organe steht. Eine Pflicht zur Stellung eines Antrages gerichtet auf den Ausschluss einer Partei aus der staatlichen Parteienfinanzierung kommt nur dann in Betracht, wenn andernfalls eine konkrete Gefahr für die freiheitliche demokratische Grundordnung begründet würde und diese nicht durch ein anderes Mittel beseitigt werden könnte. ${ }^{691}$ Dies folgt allerdings nicht aus der Konzeption des Art. 21 Abs. 3 GG und seinen Verfahrensregelungen, sondern im Ausnahmefall unmittelbar aus den die Garantenstellung begründenden Schutzpflichten des Staates. Insbesondere dann, wenn aufgrund einer Partei die ernsthafte Gefahr bestünde, ein menschenwürdiges und den Anforderungen des Art. 20 GG entsprechendes Herrschaftssystem nicht aufrechterhalten zu können. Dies dürfte für das Verfahren nach Art. 21 Abs. 3 GG allerdings kaum von Bedeutung sein, da bei einer von einer Partei ausgehenden konkreten Gefahr für die freiheitliche demokratische Grundordnung oder den Bestand der Bundesrepublik Deutschland bereits ein Verbotsverfahren nach Art. 21 Abs. 2 GG statthaft und auch zum Schutze der verfassungsmäßig vorgesehenen Staatsordnung wohl effizienter wäre.

\section{b) Umfang des Ermessens}

Das Bundesverfassungsgericht spricht den antragsberechtigten Organen ein Ermessen zu, welches „pflichtmäßig“ ausgeübt werden soll. ${ }^{692}$ So führte das Bundesverfassungsgericht im KPD-Verbotsverfahren aus:

690 Anders aber Ipsen, in: Sachs (Hrsg.), Grundgesetz, ${ }^{8} 2018$, Art. 21, Rn. 181.

691 Vgl. Morlok, in: Dreier/Bauer (Hrsg.), Grundgesetz, ${ }^{3} 2015$, Art. 21, Rn. 160.

692 Siehe BVerfGE 5, 85 (113). 
„Die KPD hat eingewendet, die Bundesregierung habe ibr Antragsrecht in diesem Verfahren mißbraucht, um eine ihr unbequeme Oppositionspartei aus dem politischen Leben auszuschalten. Dieser Einwand kann einem formell zulässigen Antrag nach $\mathbb{S} 43$ BVerfGG nicht entgegengehalten werden. $\mathrm{Ob}$ die Bundesregierung diesen Antrag stellen will, steht in ihrem pflichtmäßigen Ermessen, für das sie und sie allein politisch verantwortlich ist. Das Bundesverfassungsgericht hat nur die formale Zulässigkeit des Antrages zu prüfen. Läge ein Mißbrauch des Antragsrechts in dem von der KPD gemeinten Sinne vor, so könnte das nicht zur Abweisung des Antrages als unzulässig führen; die Sachprüfung würde ergeben, daß er unbegründet ist."693

Durch das Anerkennen eines „pflichtgemäßen Ermessens“ indiziert das Bundesverfassungsgericht das Vorliegen von Grenzen. ${ }^{64}$ Der Missbrauch des Antragsrechtes vermag zwar nach der verfassungsgerichtlichen Auffassung zunächst keine Auswirkungen auf die Zulässigkeit eines Verbotsantrags - und somit parallel ebenfalls auch auf einen Antrag nach Art. 21 Abs. 3 GG - zu haben, sondern würde allenfalls im Rahmen der Begründetheit ins Gewicht fallen und damit nur im Rahmen der Prüfung des Vorliegens der einzelnen Tatbestandsvoraussetzungen an Relevanz gewinnen. Ob auf einem anderen Wege, insbesondere durch ein Organstreitverfahren, die rechtmäßige Ausübung des Antragsermessens gerichtlich überprüft werden kann, ließ das Bundesverfassungsgericht allerdings offen. Die Annahme, das Ermessen der nach $\$ 43$ BVerfGG zur Antragstellung berechtigten Organe sei eine ausschließliche politische Frage und keiner richterlichen Kontrolle unterworfen, ruft erhebliche rechtsstaatsbezogene Bedenken hervor. ${ }^{65}$ So sollte zunächst bedacht werden, dass das Finanzierungsausschlussverfahren ein Mittel des Staates gegen Parteien darstellt ${ }^{696}$, weshalb die antragstellenden Organe bei ihrem Handeln insbesondere den Verhältnismäßigkeitsgrundsatz beachten müssen. ${ }^{697}$ Fraglich erscheint ohnehin, ob es in einem echten Rechtsstaat überhaupt ein solches Institut des „grenzenlosen Ermessens“ geben kann. ${ }^{698}$ Ein "grenzenloses“ Ermessen

693 BVerfGE 5, 85 (113).

694 Siehe hierzu Maurer, Allgemeines Verwaltungsrecht, ${ }^{18} 2011$, $\$ 7$, Rn. 17.

695 Ähnlich Klein, in: Maunz/Dürig (Hrsg.), Grundgesetz, 2018, Art. 21, Rn. 546.

$696 \mathrm{Zu}$ den Parteien als gesellschaftliche Gebilde, die den Rang einer verfassungsrechtlichen Insitution genießen siehe BVerfGE 4, 27 (30); auch Morlok, in: Dreier/Bauer (Hrsg.), Grundgesetz, ${ }^{32015}$, Art. 21, Rn. 22; Schröder, in: Merten/ Papier (Hrsg.), Handbuch der Grundrechte V, 2013, $\mathbb{1} 119$, Rn. 8.

697 Maurer, AöR 96 (1971), 203 (226).

698 Klar ablehnend ders., Allgemeines Verwaltungsrecht, ${ }^{18} 2011, \mathbb{~} 7$, Rn. 17. 
kann jedenfalls als solches nicht anzunehmen sein, wenn die Antragstellung selbst als Eingriff in eine subjektive Rechtsposition der betroffenen Partei zu klassifizieren ist.

Die Antragstellung eröffnet ein für die betroffene Partei negatives Verfahren, welches wiederum besondere verfahrensbezogene Nachteile mit sich führt. So kann bereits nach Eingang des Antrags auf Ausschluss aus der staatlichen Parteienfinanzierung gem. $\$ \$ \$ 47,38$ Abs. 1 BVerfGG durch das Bundesverfassungsgericht nach den Vorschriften der Strafprozessordnung eine Beschlagnahmung oder Durchsuchung gegen die betroffene Partei angeordnet werden ${ }^{699}$, wenn der Antrag nach $\ 43$ BVerfGG hinreichend zulässig und begründet ist. ${ }^{700}$ Zudem vermag bereits die Antragstellung eine ablehnende Haltung der Verfassungsorgane gegenüber einer bestimmten Partei zu kommunizieren, wodurch ebenfalls wettbewerbsrelevante Nachteile, insbesondere in der Wahrnehmung der Wählerschaft, entstehen können. Dies macht deutlich, dass bereits allein das Stellen des Antrags auf Ausschluss aus der Parteienfinanzierung eine belastende Wirkung gegenüber der betroffenen Partei entfaltet und dadurch in ihren grundgesetzlich garantierten Rechtskreis eingreift. Die in $₫ 43$ BVerfGG aufgeführten Organe treffen damit keine reine „Vorbereitungshandlung“, sondern eine echte Ermessensentscheidung und unterliegen gerade deshalb den allgemeinen rechtsstaatlichen Ermessensgrenzen..$^{701}$

Bei der Entscheidung über das Stellen des Antrages steht den in $\$ 43$ BVerfGG genannten Organen eine weite Einschätzungsprärogative $\mathrm{zu}^{702}$, die es erlaubt, im Rahmen eines politischen Entscheidungs- und Abwägungsprozesses das Vorliegen der tatbestandlichen Voraussetzungen und die Zweckmäßigkeit der Durchführung eines solchen Verfahrens zu beurteilen. Die vom einfachen Gesetzgeber vorgenommene starke Eingrenzung des Kreises der Antragsberechtigten auf Bundestag, Bundesrat und die Bundesregierung (ggf. nach $\ 43$ Abs. 2 BVerfGG auch eine Landesregierung) spricht zumindest dafür, dass ein weiter Entscheidungsspielraum vorgesehen ist. ${ }^{703}$

Sollte eines der Organe einen willkürlichen und damit missbräuchlichen Antrag auf Ausschluss einer Partei aus der staatlichen Parteienfinan-

699 Wie im Verbotsverfahren der SRP und KPD geschehen, siehe BVerfGE 2, 1 (7); BVerfGE 5, 85 (107).

700 Streinz, in: Huber/Voßkuhle (Hrsg.), Grundgesetz, ${ }^{7} 2018$, Art. 21, Rn. 246.

701 Maurer, AöR 96 (1971), 203 (226).

702 Ders., AöR 96 (1971), 203 (226).

703 So auch Klein, in: Maunz/Dürig (Hrsg.), Grundgesetz, 2018, Art. 21, Rn. 546. 
zierung stellen, so liegt bereits in diesem konkreten Handeln eine Rechtsverletzung vor. Diese kann dann auf Antrag der betroffenen Partei im Rahmen eines Organstreitverfahrens durch das Bundesverfassungsgericht nach der Maßgabe des $₫ 67$ S. 1 BVerfGG festgestellt werden.

\section{Art. 79 Abs. 3 GG als Maßstab der Verfassungsänderung}

Der Ausschluss einer Partei aus der staatlichen Parteienfinanzierung aufgrund einer verfassungsablehnenden inhaltlichen Ausrichtung im Wege der Verfassungsänderung ist an Art. 79 Abs. 3 GG zu messen. Bedenken bestehen mit Blick auf eine Berührung der in den Artikeln 1 und 20 GG niedergelegten Grundsätze, konkret vor allem des Demokratieprinzips, denn der Staat schafft innerhalb des grundsätzlich freien und gleichen Parteienwettbewerbes ein „Zwei-Klassen-System"704, welches zwischen staatlich gebilligten und missbilligten Parteien differenziert und die Verfassungskonformität zu einem unmittelbaren Wettbewerbsvorteil erhebt. ${ }^{705}$ Im Folgenden werden zunächst die Erforderlichkeit und im Anschluss die Zulässigkeit der Verfassungsänderung untersucht werden. Wenn der Ausschluss verfassungsfeindlicher Parteien aus der staatlichen Parteienfinanzierung bereits ohne eine Verfassungsänderung zulässig wäre, dann dürfte die rechtliche Durchsetzung des Finanzierungsausschlussverfahrens mittels Verfassungsänderung am Maßstab des Art. 79 Abs. 3 GG keine nennenswerten Bedenken aufweisen.

\section{Notwendigkeit der Verfassungsänderung}

Das Bundesverfassungsgericht wies im Urteil im Rahmen des zweiten NPD-Verbotsverfahrens darauf hin, dass "die Schaffung der Möglichkeit gesonderter Sanktionierung im Fall der Erfüllung einzelner Tatbestandsmerkmale des Art. 21 Abs. 2 GG unterhalb der Schwelle des Parteiverbots dem verfassungsändernden Gesetzgeber vorbehalten “ ist. $^{706}$ Indem das Gericht seinen Hinweis ausdrücklich an den verfassungsändernden Gesetzgeber richtete, ist anzunehmen, dass es selbst von der Notwendigkeit einer Verfassungsänderung zur Durchsetzung des angedachten Mittels ausgeht.

704 Vgl. Linke, DÖV 2017, 483 (492).

705 Vgl. Nikkho, DVBl 2018, 337 (340).

706 BVerfGE 144, 20 (202). 
Der dogmatische Ansatz zur Beantwortung der Frage, ob ein Ausschluss verfassungsfeindlicher Parteien ohne eine Verfassungsänderung zulässig gewesen wäre, richtet sich nach der Rechtfertigungsfähigkeit dieser parteienspezifischen Ungleichbehandlung. Wenn der Staat die staatliche Parteienfinanzierung von der inhaltlich-politischen Ausrichtung der Parteien abhängig macht und solche Parteien aus dem System ausschließt, die eine staatlich missbilligte (in diesem Fall verfassungsfeindliche) Ausrichtung vorweisen, beginnt der Staat zwischen den vorhandenen Parteien auf einem wettbewerbserheblichen Niveau zu differenzieren.

Nach der überzeugenden Rechtsprechung des Bundesverfassungsgerichts bedarf es zur Rechtfertigung einer staatlichen Differenzierung zwischen Parteien eines besonders „Zwingenden“ Grundes. ${ }^{707}$ Für eine einfachgesetzliche Gestaltung des Ausschlusses verfassungsfeindlicher Parteien aus der staatlichen Parteienfinanzierung muss ein solch „Zwingender“ Grund vorliegen. In Betracht kommt die Verpflichtung des Staates zur Wahrung der fundamentalen Verfassungsprinzipien. Sollte dies einen solchen zwingenden Grund darstellen, kann eine Rechtfertigung dennoch aufgrund des Parteienprivilegs ausgeschlossen sein.

\section{Staatliche Garantenstellung als Rechtfertigung einer Ungleichbehandlung}

Dem Staat obliegt hinsichtlich der Aufrechterhaltung der fundamentalen Staatsprinzipien eine Garantenstellung. ${ }^{708}$ Das Grundgesetz enthält selbst eine Mehrzahl an Bestimmungen, die dem Staat mächtige Werkzeuge zur Verteidigung der höchsten Verfassungswerte einräumen. Dahinter steht kein Selbstzweck, sondern vielmehr der Gedanke, den Staat nicht nur selbst über Art. 79 Abs. 3 GG an die fundamentalsten Staatsprinzipien zu binden, sondern ihm auch eine angemessene Wächter- und Garantenstellung hinsichtlich dieser Prinzipien aufzuerlegen. ${ }^{709}$ Dies bedeutet, dass der Staat nicht nur selbst zur strengsten Einhaltung dieser Prinzipien berufen ist, sondern auch jegliche aus der Gesellschaft hervortretenden Gefährdungen dieser Rechtsgüter aktiv zu bekämpfen hat. Diese Stellung vermag es auch zu rechtfertigen, wenn zum Zwecke der Bewahrung der fundamen-

707 BVerfGE 20, 56 (117); BVerfGE 24, 300 (339 ff.).

708 Denninger, in: VVDStRL 37 (1979), S. 72.

709 Vgl. BVerfGE 5, 85 (138), wonach dem Staat auch eine „Schutzpflicht“ bezüglich der fundamentalsten Verfassungsentscheidungen obliegt. 
talsten Staatsprinzipien Parteien durch den Staat ungleich behandelt werden; insoweit ein „zwingender Grund“710 vorliegt.

Wenn er solche Parteien mit Leistungen sachlicher oder finanzieller Art ausstattet, deren politische Ausrichtung sich gegen die fundamentalen Grundsätze der Verfassung richten, verschärft der Staat damit eine Gefahr für die Rechtsgüter, zu deren Erhalt und Schutz er verpflichtet ist. ${ }^{711}$ Die Parteienfinanzierung dient der Förderung des parteispezifischen verfassungsrechtlichen Mandates aus Art. 21 Abs. 1 S. 1 GG. ${ }^{712}$ Durch die Subventionierung des Mitwirkens verfassungsfeindlicher Parteien an der politischen Willensbildung fördert der Staat eine gegen sich selbst und die Güter, zu deren Schutz er berufen ist, gerichtete politische Entwicklung und damit eine solche, die er nach seiner durch das Grundgesetz vorgesehenen Stellung zu bekämpfen verpflichtet ist. Grundsätzlich läge, um seinem Schutz- und Garantenauftrag hinsichtlich der höchsten Staatswerte gerecht zu werden, ein zwingender Grund für den Ausschluss verfassungsfeindlicher Parteien aus der staatlichen Parteienfinanzierung vor.

\section{Parteienprivileg als verfassungsrechtliches Prinzip}

Auch wenn ein zwingender Grund für eine im Rahmen der staatlichen Parteienfinanzierung vorgenommenen Differenzierung vorliegen mag, so kann sie aufgrund bestimmter verfassungsrechtlicher Prinzipien dennoch unzulässig sein. In diesem Zusammenhang ist insbesondere das sogenannte „Parteienprivileg“ und dessen Auswirkungen auf die einfachgesetzliche Möglichkeit des Ausschlusses verfassungsfeindlicher Parteien aus der staatlichen Parteienfinanzierung zu untersuchen.

710 BVerfGE 20, 56 (117); BVerfGE 24, 300 (339 ff.); BVerfGE 111, 382 (398); siehe auch BVerfGE 6, 273 (280) - „verfassungsrechtliche Gründe“ oder BVerfGE 12, 10 (28) - „besondere Gründe“.

711 Vgl. Rumpf, Der ideologische Gehalt des Bonner Grundgesetzes, 1958, S. 35, der aus dem Regelungskonzept der Art. 79 Abs. 3 GG und Art. 9 Abs. 2, Art. 19 und Art. 21 Abs. 2 GG ein verfassungsrechtliches „Bekenntnis zur Verbindlichkeit und Unverbrüchlichkeit der höchsten Staatswerte“ zieht.

712 Koch, in: Ipsen (Hrsg.), Parteiengesetz, 2008, $\mathbb{\$} 18$, Rn. 5. 
a) Inhalt und Bedeutung des Parteienprivilegs

Das „Parteienprivileg“713 folgt aus Art. 21 Abs. 2, Abs. 3 und Abs. 4 GG. Es privilegiert Parteien gegenüber sonstigen Vereinigungen in zweifacher Hinsicht. Zum einen ordnet Art. 21 Abs. 4 GG dem Bundesverfassungsgericht das Monopol der Verbotsentscheidung von Parteien zu, was zu einer Entziehung der Verbotsmöglichkeit durch Stellen der Exekutive führt ${ }^{714}$, und zum anderen beinhaltet es ein Anknüpfungsverbot für sämtliche aus einer vermeintlichen Verfassungswidrigkeit $\mathrm{zu}$ erschließenden Rechtsfolgen. ${ }^{715}$ Das dem Parteienprivileg immanente Anknüpfungsverbot erstreckt seine Sperrwirkung auf die gesamte durch Art. 21 Abs. 1 GG (iVm. gegebenenfalls einschlägigen Grundrechten) gewährleistete Schutzwirkung der parteispezifischen Rechtsstellung. ${ }^{716}$ Eine Partei kann sich damit auf sämtliche aus der parteispezifischen Rechtsstellung ableitenden Rechtspositionen berufen, bis sie durch das Bundesverfassungsgericht verboten worden ist. Auch gelten alle Maßnahmen einer Partei vor Aussprache der Verbotsentscheidung durch das Bundesverfassungsgericht als rechtmäßig und verlieren nicht rückwirkend an Legalität. ${ }^{717}$ Der verfassungsgerichtlichen Feststellung der Verfassungswidrigkeit einer Partei kommt für die Verbotswirkung somit eine konstitutive Wirkung zu. ${ }^{718}$

Art. 21 Abs. 1 S. 1 GG weist den Parteien ein verfassungsrechtliches Mandat zu, welches sie zur Mitwirkung an der politischen Willensbildung des Volkes verpflichtet. Die Parteien nehmen insoweit eine für die Demokratie unverzichtbare meinungsgestaltende Funktion ein und müssen zwangsläufig weitestgehend staatsfrei innerhalb der Gesellschaft agieren

713 Der Begriff wird in Teilen der Literatur diskutiert, mangels Relevanz für die Untersuchung wird hier lediglich auf die einschlägige Literatur verwiesen. Siehe hierzu; Streinz, in: Huber/Voßkuhle (Hrsg.), Grundgesetz, ${ }^{72018, ~ A r t . ~ 21, ~}$ Rn. 215; Ipsen, in: Sachs (Hrsg.), Grundgesetz, ${ }^{8}$ 2018, Art. 21, Rn. 148.

714 Morlok, in: Dreier/Bauer (Hrsg.), Grundgesetz, ${ }^{3} 2015$, Art. 21, Rn. 157.

715 BVerfGE 5, 85 (140); BVerfGE 12, 296 (304); BVerfGE 13, 46 (52); BVerfGE 13, 123 (126) - ständige Rechtsprechung; statt vieler Morlok, in: Dreier/Bauer (Hrsg.), Grundgesetz, ${ }^{3} 2015$, Art. 21, Rn. 157.

716 Ansatz so insbesondere von Schmidt, Die Freiheit verfassungswidriger Parteien und Vereinigungen, 1983, S. 202 f.; auch Morlok, in: Dreier/Bauer (Hrsg.), Grundgesetz, ${ }^{3} 2015$, Art. 21, Rn. 158.

717 BVerfGE 12, 296 (305 ff.); vgl. auch Seifert, Die politischen Parteien im Recht der Bundesrepublik Deutschland, 1975, S. $477 \mathrm{ff}$.

718 Vgl. BVerfGE 12, 296 ff.; BVerfGE 13, 46 (52); BVerfGE 13, 123 (126); kritisch Stollberg, Die verfassungsrechtlichen Grundlagen des Parteiverbots, 1976, S. $610 \mathrm{f}$. 
können. Diese Funktion wäre allerdings gefährdet, wenn die von politischen Mehrheitsverhältnissen und Meinungskämpfen beeinflusste Exekutive oder Legislative ${ }^{719}$ die Möglichkeit eingeräumt bekäme, den Parteien aufgrund einer inhaltlichen Kontrolle ihrer politischen Einstellung rechtliche oder wirtschaftliche Nachteile zuzufügen. ${ }^{720}$ Die staatliche Bekämpfung einer Partei aufgrund einer vermeintlich verfassungswidrigen Einstellung ist somit allein dem Bundesverfassungsgericht als höchstem nationalen Organ der Judikative vorbehalten und eine vermeintliche Verfassungswidrigkeit darf nur im Rahmen der Verfahren nach Art. 21 Abs. 4 GG verfassungsgerichtlich festgestellt und mit negativen Rechtsfolgen versehen werden.

b) Parteienprivileg als Einschränkung staatlicher Handlungsmöglichkeiten

Die staatlichen Handlungsmöglichkeiten bei der Bekämpfung parteilichen Extremismus werden durch das Parteienprivileg eingeschränkt. ${ }^{721}$ Das dem Parteienprivileg immanente Anknüpfungsverbot hat zur Folge, dass es allein dem Bundesverfassungsgericht obliegt, über staatliche Maßnahmen aufgrund der Verfassungswidrigkeit einer Partei zu entscheiden. Dies untersagt konsequenterweise allen anderen staatlichen Institutionen ein aufgrund einer vermeintlichen Verfassungswidrigkeit erfolgendes Vorgehen gegen eine bestimmte Partei

Es obliegt dem Bundesverfassungsgericht demnach nicht nur allein, die vermeintlich verfassungswidrige Einstellung einer Partei festzustellen, sondern dies auch ausschließlich im Rahmen eines hierfür vorgesehenen Verfahrens zu unternehmen. Eine einfachgesetzliche Ausgestaltung eines Finanzierungsausschlussverfahrens wäre deshalb auch nicht mit einer $\mathrm{Zu}$ weisung der Entscheidungszuständigkeit an das Bundesverfassungsgericht möglich. Das Grundgesetz sah vor seiner Änderung ${ }^{722}$ vor, dass einer Partei solange das Parteienprivileg zukommt, bis das Bundesverfassungs-

719 So im Übrigen auf europäischer Ebene, in der das EU-Parlament die Entscheidungszuständigkeit über den Ausschluss von Europaparteien aus der europäischen Parteienfinanzierung zugeordnet bekommt, vgl. Kluth, in: Calliess/ Ruffert (Hrsg.), EUV/AEUV, ${ }^{5}$ 2016, Art. 224 AEUV, Rn. 10 ff.

720 Vgl. BVerfGE 12, 296 (305 ff).

721 Vgl. Alter, Die Eingriffsschwelle beim Verbot extremistischer Parteien und Vereine in Deutschland und England, 2016, S. 74.

722 BGBl. 2017 I, S. 2346. 
gericht rechtsverbindlich die Verfassungswidrigkeit der Partei festgestellt und als Folge davon ein Verbot ausgesprochen hat. Andere Mittel „unterhalb der Schwelle des Verbotsverfahrens" ${ }^{123}$ sah das Grundgesetz nicht vor und erklärte sie, sofern sie an die inhaltliche politische Ausrichtung anknüpften, für unzulässig. ${ }^{724}$

\section{Einfachgesetzliche Rechtsfolgenmodifikation des Art. 21 Abs. 2 GG}

Den Gedanken, den Ausschluss aus der staatlichen Parteienfinanzierung durch einen differenzierenden Rechtsfolgenkatalog des Verbotsverfahrens ohne eine Verfassungsänderung einzuführen, untersuchten Martin Morlok, Julian Krüper und Sebastian Roßner in einem Gutachten im Auftrag der Friedrich-Ebert-Stiftung über die Reformmöglichkeiten der staatlichen Parteienfinanzierung. ${ }^{725}$ Demnach könnte der Ausschluss aus der staatlichen Parteienfinanzierung durch eine einfachgesetzliche Erweiterung des $\$ 46$ Abs. 3 BVerfGG ermöglicht werden, indem dieser bei Erfüllung des Tatbestandes des Art. 21 Abs. 2 GG alternativ zu einem Verbot durch das Bundesverfassungsgericht angeordnet werden könnte. ${ }^{726}$ Durch eine Modi-

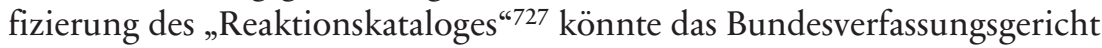
zwischen zwei von ihrer Intensität in einem Stufenverhältnis stehenden ${ }^{728}$ Rechtsfolgen wählen und bei der Ausübung seines Auswahlermessens Verhältnismäßigkeitserwägungen einfließen lassen. Ob dieser Vorschlag recht-

723 BVerfGE 144, 20 (202).

724 Anders Kloepfer, NVwZ 2017, 913 (917). Angesichts der Erkenntnis, dass das Parteienprivileg ein Anknüpfungsverbot enthält, welches verhindert, dass andere Maßnahmen als das Parteiverbot durch die Exekutive aufgrund einer vermeintlich vorliegenden Verfassungswidrigkeit angeordnet werden [(vgl. BVerfGE 5, 85 (140); BVerfGE 12, 296 (304); BVerfGE 13, 46 (52); BVerfGE 13, 123 (126) - ständige Rechtsprechung; statt vieler ders., in: Dreier/Bauer (Hrsg.), Grundgesetz, ${ }^{3} 2015$, Art. 21, Rn. 157)] ist diese Auffassung nicht überzeugend.

725 Morlok/Krüper/Roßner, Parteienfinanzierung im demokratischen Rechtsstaat, 2009, S. $68 \mathrm{ff}$.

726 Dies., Parteienfinanzierung im demokratischen Rechtsstaat, 2009, S. 68 ff.; ähnlich das Regelungskonzept der türkischen Verfassung, dass dem für das Verbot zuständige Verfassungsgericht ein Auswahlermessen dahingehend einräumt, angesichts der "Schwere der Verstöße" der Partei entweder das Parteiverbot oder einen vollständige oder teilweise erfolgen Finanzierungsausschluss anzuordnen, vgl. hierzu Art. 69 Abs. 7 TürkVerf.

727 Begriff so gewählt von dies., Parteienfinanzierung im demokratischen Rechtsstaat, 2009, S. 68.

728 Vgl. hierzu Müller, DVBl 2018, 1035 (1038f.). 
lich durchführbar wäre, hängt maßgeblich davon ab, ob der einfache Gesetzgeber durch eine Modifizierung des Rechtsfolgenkataloges des $\$ 46$ BVerfGG eine solche systemrelevante Umgestaltung vornehmen könnte. Von den Verfassern des Gutachtens wird angeführt, dass das einfache Recht einen Auslegungseinfluss auf verfassungsrechtliche Begrifflichkeiten ausübe und der einfache Gesetzgeber somit durch die Ausgestaltung des einfachen Rechts den Begriff der „Verfassungswidrigkeit“ modifizieren könne. ${ }^{729}$ Art. 21 Abs. 2 GG räume dem einfachen Gesetzgeber einen „Rechtsfolgenspielraum“ ein, den er „unter Beachtung der Direktionswirkung des Verhältnismäßigkeitsprinzips“ ausschöpfen könne. ${ }^{730} \mathrm{Da}$ die Struktur der staatlichen Parteienfinanzierung vergleichbar mit der der klassichen Leistungsverwaltung sei ${ }^{731}$, würde dem einfachen Gesetzgeber in dieser Hinsicht auch ein großzügigerer „Gestaltungsspielraum“ zustehen, der eine dahingehende Modifikation zuließe. ${ }^{732}$

Dieser Lösungsvorschlag zur Umgehung des Verfassungsänderungsvorbehalts erscheint elegant, da durch die einfachgesetzliche Modifizierung des $\mathbb{4} 46$ Abs. 3 BVerfGG die Anforderungen der EGMR-Rechtsprechung an Parteiverbote ${ }^{733}$ und das öffentliche Interesse am Ausschluss verfassungsfeindlicher Parteien aus der staatlichen Parteienfinanzierung gleichsam umgesetzt werden könnten, ohne den Anforderungen des Art. 79 GG gerecht werden zu müssen. Das eingeräumte Auswahlermessen auf der Rechtsfolgenseite würde dem Bundesverfassungsgericht die Anwendbarkeit des Verhältnismäßigkeitsgrundsatzes eröffnen, wodurch der konventionsrechtlichen Anforderung des „dringenden sozialen Bedürfnisses" ${ }^{\text {"734 }}$ Rechnung getragen werden könnte und eine dahingehende dogmatische Verortung auf der Rechtsfolgenseite keine Umdeutung des Begriffes des

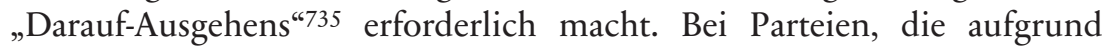
einer mangelnden Realisierungspotentialität nicht Ziel eines Verbotes sein

729 Vgl. Morlok/Krüper/Roßner, Parteienfinanzierung im demokratischen Rechtsstaat, 2009, S. 68, Rn. 209.

730 Dies., Parteienfinanzierung im demokratischen Rechtsstaat, 2009, S. 70, Rn. 211.

731 Dies., Parteienfinanzierung im demokratischen Rechtsstaat, 2009, S. 41, Rn. 107.

732 Dies., Parteienfinanzierung im demokratischen Rechtsstaat, 2009, S. 70, Rn. 212.

733 Siehe $\$ 4$ A. II.; auch zur Diskussion anlässlich der Rechtsprechung des EGMR Shirvani, JZ 2014, $1074 \mathrm{ff}$.

734 EGMR, Urt. v. 30. 1. 1998, United Communist Party of Turkey and Others v. Turkey, Nr. 133/1996/752/951, Rz. 49; EGMR, Urt. v. 13. 2. 2003, Refah Partisi (The Welfare Party) and Others v. Turkey, Nr. 41 340/98 u. a. = NVwZ 2003, 1489 ff., Rz. 104, 132; EGMR, Urt. v. 30. 6. 2009, Herri Batasuna and Batasuna v. Spain, Nr. 25 803/04 und 25 817/04, Rz. 79.

735 BVerfGE 144, 20 (219 ff.). 
können, könnte das Bundesverfassungsgericht im Rahmen desselben Verfahrens den Ausschluss aus der staatlichen Parteienfinanzierung anordnen.

Diese rechtspolitischen und -dogmatischen Vorteile vermögen allerdings nichts über die rechtliche Zulässigkeit auszusagen. Ob eine solche Modifizierung über eine Ausgestaltung des einfachen Rechts verfassungsrechtlich zulässig ist, hängt davon ab, ob der Begriff der „Verfassungswidrigkeit“ an seine Ausgestaltung durch den einfachen Gesetzgeber Mindestanforderungen stellt, die einer Gesetzesänderung in der vorgestellten Art und Weise entgegenstehen. Art. 21 Abs. 5 GG enthält einen dahingehenden Ausgestaltungsauftrag ${ }^{736}$, dem durch die Konzeption des Art. 21 GG allerdings verfassungsrechtliche Schranken auferlegt werden. Der einfache Gesetzgeber ist nicht frei bei der Regelung des „Näheren“ i.S.d. Art. 21 Abs. 5 GG, sondern muss die verfassungsrechtlich zwingenden Vorgaben der Norm bei der Ausgestaltung durch das einfache Recht wahren. Indem er den verfassungsrechtlichen Begriff der „Verfassungswidrigkeit“ im Wege der Änderung des einfachen Gesetzes dahingehend modifiziert, dass als dessen Folge ein Ausschluss aus der staatlichen Parteienfinanzierung festgestellt wird, könnten die verfassungsrechtlichen Grenzen des durch Art. 21 Abs. 5 GG eingeräumten Gestaltungspielraumes überschritten worden sein. Dies ist dann der Fall, wenn das Parteiverbot eine zwingende verfassungsrechtliche Folge der Feststellung der „Verfassungswidrigkeit“ darstellen würde. ${ }^{737}$ Für das Parteiverbot als zwingende verfassungsrechtliche Folge spricht, dass mit der Feststellung der Verfassungswidrigkeit der Verlust der parteilichen Rechtsstellung einhergeht und diese Rechtsfolge zum konkreten Inhalt mit Verfassungsrang erhoben wurde ${ }^{738}$ und auch ohne eine einfachgesetzliche Ausgestaltung das Verbotsverfahren „unmittelbar anwendbares

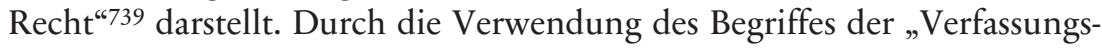

736 Zum Begriff siehe nur Streinz, in: Huber/Voßkuhle (Hrsg.), Grundgesetz, ${ }^{72018,}$ Art. 21, Rn. 253.

737 So BVerfGE 144, 20 (200 f. Rn. 525, 231 Rn. 600); Streinz, in: Huber/Voßkuhle (Hrsg.), Grundgesetz, ${ }^{72018}$, Art. 21, Rn. 239; Ipsen, in: Sachs (Hrsg.), Grundgesetz, ${ }^{8}$ 2018, Art. 21, Rn. 170; a.A. Maurer, AöR 96 (1971), 203 (222 ff.); Morlok, in: Dreier/Bauer (Hrsg.), Grundgesetz, ${ }^{3} 2015$, Art. 21, Rn. 155; dies., Parteienfinanzierung im demokratischen Rechtsstaat, 2009, S. $68 \mathrm{ff}$.

738 Vgl. insoweit BVerfGE 5, 85 (391 f.), siehe auch Klein, in: Maunz/Dürig (Hrsg.), Grundgesetz, 2018, Art. 21, Rn. 555 f.; Ipsen, in: Sachs (Hrsg.), Grundgesetz, ${ }^{8}$ 2018, Art. 21, Rn. 193; Streinz, in: Huber/Voßkuhle (Hrsg.), Grundgesetz, 72018, Art. 21, Rn. 247; Seifert, Die politischen Parteien im Recht der Bundesrepublik Deutschland, 1975, S. 495.

739 BVerfGE 2, 1 (13f.); BVerfGE 5, 85 (111); Klein, in: Maunz/Dürig (Hrsg.), Grundgesetz, 2018, Art. 21, Rn. 510. 
widrigkeit" wird deutlich, dass die alleinige Existenz der Partei einen verfassungswidrigen Zustand darstellt, der im Rahmen des Verfahrens nach Art. 21 Abs. 2 GG durch den Ausspruch eines Verbotes zu beheben ist ${ }^{740}$ und deshalb auch der Verlust der für die Mitwirkung an der politischen Willensbildung des Volkes eingeräumte Rechtsstellung den rechtsfolgenbezogenen Inhalt des Art. 21 Abs. 2 GG darstellt. Die mit der Feststellung der „Verfassungswidrigkeit“ verbundene Auflösung stellt eine „normale, typische und adäquate Folge“ ${ }^{\text {"741 }}$ des Verlustes der parteilichen Rechtstellung dar. Eine „verfassungswidrige“ Partei kann nicht unter erschwerten Wettbewerbsbedingungen am politischen Wettbewerb teilnehmen, da ihr mit der Qualifizierung als solche die Legitimation zur Teilnahme am politischen Verfassungsleben vollumfänglich versagt wird. Indem somit eine als „verfassungswidrig“ festgestellte Partei aus der staatlichen Parteienfinanzierung ausgeschlossen wird, sie allerdings weiterhin im vollen Umfang am politischen Wettbewerb teilnimmt, werden die Anforderungen des Art. 21 Abs. 2 GG unterschritten und die Verfassungsnorm würde durch das einfache Recht in unzulässiger Weise ausgestaltet werden. Der Vorschlag, den Ausschluss aus der staatlichen Parteienfinanzierung über eine einfachgesetzliche Neugestaltung des $\$ 46$ BVerfGG einzuführen, ist rechtspolitisch vorteilhaft, verfassungsrechtlich allerdings unzulässig. Eine Verfassungsänderung zur Etablierung des Finanzierungsausschlussverfahrens war alternativlos.

II. Legalität der Verfassungsänderung

1. Maßstab des Art. 79 Abs. 3 GG

Nach Art. 79 Abs. 1 GG bedarf es für eine Verfassungsänderung eines Gesetzes, das den Wortlaut des Grundgesetzes ausdrücklich ändert. Mithin ist Voraussetzung für eine wirksame Änderung der Verfassung ein formelles Gesetz, das den Formanforderungen des Art. 79 Abs. 1 GG gerecht werden muss. Das Änderungsgesetz vom 19.07.2017 742 änderte den Art. 21 Abs. 3 GG und verankerte an dieser Stelle des Grundgesetzes die Möglichkeit des Ausschlusses verfassungsfeindlicher Parteien aus der staatlichen

740 Vgl. Ipsen, in: Sachs (Hrsg.), Grundgesetz, ${ }^{8} 2018$, Art. 21, Rn. 178 f., der aus dem Begriff der „Verfassungswidrigkeit“ eine Pflicht zur Antragstellung herleitet.

741 BVerfGE 5, 85 (391).

742 BGBl. 2017 I, S. 2346. 
Parteienfinanzierung. Art. 21 Abs. 3 GG lautet seit Inkrafttreten des verfassungsändernden Gesetzes wie folgt:

„Parteien, die nach ibren Zielen oder dem Verhalten ibrer Anhänger darauf ausgerichtet sind, die freiheitliche demokratische Grundordnung zu beeinträchtigen oder zu beseitigen oder den Bestand der Bundesrepublik Deutschland zu gefährden, sind von staatlicher Finanzierung ausgeschlossen. Wird der Ausschluss festgestellt, so entfällt auch eine steuerliche Begünstigung dieser Parteien und von Zuwendungen an diese Parteien."

Für die Beantwortung der Frage, ob die Einführung des Finanzierungsausschlussverfahrens durch ein verfassungsänderndes Gesetz zulässig war, ist es zunächst notwendig, den Maßstab des Art. 79 Abs. 3 GG genau zu definieren.

\section{a) Verfassungsidentität als Schutzgut}

Nach Art. 79 Abs. 3 GG sind Verfassungsänderungen unzulässig, die die Gliederung des Bundes in Länder, die grundsätzliche Mitwirkung der Länder bei der Gesetzgebung oder die Grundsätze der Art. 1 und 20 GG berühren. Der verfassungsändernde Gesetzgeber hat im Falle einer Verfassungsänderung in materiell-rechtlicher Hinsicht die Anforderungen des Art. 79 Abs. 3 GG zu beachten, die allerdings unabhängig von einer etwaigen besonderen demokratischen Legitimation eines verfassungsändernden Gesetzes, wie beispielsweise durch einen einstimmig gefassten Beschluss, absolute Geltung beanspruchen. ${ }^{743}$ Art. 79 Abs. 3 GG entzieht die grundlegenden Verfassungsprinzipien der Dispositionsgewalt des verfassungsändernden Gesetzgebers und schafft somit Raum für sogenanntes „verfassungswidriges Verfassungsrecht" ${ }^{\text {"744 }}$. Verfassungsändernde Gesetze, die gegen Art. 79 Abs. 3 GG verstoßen, sind nichtig. ${ }^{75}$ Durch Art. 79 Abs. 3 GG sollen die fundamentalen Verfassungswerte, die durch die ihnen innewohnenden Grundsatzentscheidungen die Identität des Grundgesetzes in

743 BVerfGE 87, 181 (196); BVerfGE 84, 90 (120); BVerfGE 94, 12 (34); BVerfGE 94, 49 (85, 102 f.); vgl. zur Unbeachtlichkeit des Grades der demokratischen Legitimation Dreier, JZ 1994, 741 (748).

744 Ders., in: Dreier/Bauer (Hrsg.), Grundgesetz, ${ }^{3} 2015$, Art. 79 Abs. 3, Rn. 14.

745 Ders., in: Dreier/Bauer (Hrsg.), Grundgesetz, ${ }^{3} 2015$, Art. 79 Abs. 1, Rn. 14; BVerfGE 30, 1 (33); Unruh, Der Verfassungsbegriff des Grundgesetzes, 2002, S. 441; Möller, Die verfassungsgebende Gewalt des Volkes und die Schranken der Verfassungsrevision, 2004, S. 172 m.w.N. 
einem wesentlichen Maße geprägt und gestaltet haben, geschützt werden. ${ }^{746}$

Das Bundesverfassungsgericht führte im Rahmen der sogenannten Abhör-Entscheidung in Bezug zur Legitimation des Art. 79 Abs. 3 GG folgendes aus:

„Art. 79 Abs. 3 GG als Schranke für den verfassungsändernden Gesetzgeber hat den Sinn, zu verhindern, dass die geltende Verfassungsordnung in ihrer Substanz, in ibren Grundlagen auf dem formal-legalistischen Weg eines verfassungsändernden Gesetzes beseitigt und zur nachträglichen Legalisierung eines totalitären Regimes missbraucht werden kann. Die Vorschrift verbietet also eine prinzipielle Preisgabe der dort genannten Grundsätze. "747

Schutzgut des Art. 79 Abs. 3 GG ist damit die „Substanz“ oder die „Grundlage " der geltenden Verfassungsordnung. Mithin soll die Verfassungsidentität $^{748}$ der Revisionsgewalt des verfassungsändernden Gesetzgebers entzogen werden. Allerdings soll, wie die Beurteilung des Bundesverfassungsgerichtes zumindest indizieren mag, nicht nur eine „legale Revolution“ hin zu einem totalitären Umsturz verhindert, sondern ein darüberhinausgehender Gewährleistungsbereich der Verfassungsidentität geschaffen werden. In diesem Sinne beschränkt sich der Gewährleistungsbereich des Art. 79 Abs. 3 GG nicht nur auf den Schutz der höchsten Staatswerte vor einem totalitär ausgerichteten, sondern auch vor einem den Grundsatzentscheidungen des Grundgesetzes treu ergebenden, sich allerdings irrenden verfassungsändernden Gesetzgeber. ${ }^{749}$

b) Klassifikation der unberührbaren Grundsätze

Art. 79 Abs. 3 GG enthält, um seinem Zweck gerecht zu werden, das Verbot des gesetzgeberischen „Berührens“ der geschützten Grundsätze. $\mathrm{Ob}$ und wann ein durch Art. 79 Abs. 3 GG geschützter Grundsatz durch ein

746 Vgl. BVerfGE 30, 1 (24); vgl. auch Hain, Die Grundsätze des Grundgesetzes, 1999, S. $87 \mathrm{ff}$.

747 BVerfGE 30, 1 (24).

748 Häberle, in: Hangartner/Trechsel/Haug (Hrsg.), Völkerrecht im Dienste des Menschen, 1986, S. 81 ff.; Bryde, Verfassungsentwicklung, 1982, S. 236; Dreier, in: Dreier/Bauer (Hrsg.), Grundgesetz, ${ }^{32015}$, Art. 79 Abs. 1, Rn. 14; Maurer, Staatsrecht I, ${ }^{6} 2010, \$ 22, \mathrm{Rn} .17$.

749 Stern, JuS 1985, 329 (330); Dreier, in: Dreier/Bauer (Hrsg.), Grundgesetz, ${ }^{3} 2015$, Art. 79 Abs. 3, Rn. 16. 
verfassungsänderndes Gesetz „berührt“ wird bzw. wie der Terminus des „Berührens“ in Zusammenhang mit dem der „Grundsätze“ zu verstehen ist, ist umstritten.

Das Bundesverfassungsgericht legt den Begriff restriktiv aus und sieht die geschützten Staatswerte dann als nicht berührt an, „wenn ihnen im allgemeinen Rechnung getragen wird und sie nur für eine Sonderlage entsprechend deren Eigenart aus evident sachgerechten Gründen modifiziert werden“. ${ }^{750}$ Dabei hebt das Bundesverfassungsgericht auch noch hervor, dass der Begriff des „Berührens“ in Art. 79 Abs. 3 GG deutlich enger gefasst sei als der Begriff des „Antastens“ in Art. 19 Abs. 2 GG. ${ }^{751}$ Eine restriktive Auslegung sei nach der Ansicht des Bundesverfassungsgerichtes gerade deshalb geboten, da Art. 79 Abs. 3 GG entgegen des eigentlichen Prinzips der Volkssouveränität bzw. Volksherrschaft als eine Ausnahmevorschrift die umfassende Entscheidungsgewalt des Volkes einschränkt, indem er die höchsten Grundsatzentscheidungen des verfassungsgebenden Gesetzgebers der Disposition des verfassungsändernden Gesetzgebers entzieht. ${ }^{752}$ Es müsse bei der Auslegung des Art. 79 Abs. 3 GG berücksichtigt werden, dass es sich „um eine Ausnahmevorschrift handelt, die jedenfalls nicht dazu führen darf, daß der Gesetzgeber gehindert wird, durch verfassungsänderndes Gesetz auch elementare Verfassungsgrundsätze systemimmanent zu modifizieren“753. Das Bundesverfassungsgericht scheint damit den normativen Gehalt des Art. 79 Abs. 3 GG als ein „Verbot der revolutionären Verfassungsbeseitigung "754 zu verstehen und begrenzt das Merkmal des „Berührens“ damit auf den Kernbereich der geschützten Verfassungsgrundsätzen, das bereits dann nicht vorläge, wenn der verfassungsändernde Gesetzgeber den geschützten Verfassungsprinzipien allgemein Rechnung getragen hat und sie aus einem sachgerechten Grund lediglich modifiziert.

750 BVerfGE 30, 1 (24).

751 BVerfGE 30, 1 (24). Bei der Beratung über die Formulierung des Art. 79 Abs. 3 GG im Redaktionsausschuss des Parlamentarischen Rates wurde als Alternativvorschlag zum Merkmal des „Berührens“ das Wort „Antasten“ angeführt (Parl. Rat VII, S. 254). Die Auslegung hätte sich wohl nicht von der des „Berührens“ wesentlich unterschieden, siehe Dreier, in: Dreier/Bauer (Hrsg.), Grundgesetz, ${ }^{3} 2015$, Art. 79 Abs. 3, Rn. 19, Fn. 80; auch Stern, JuS 1985, 329 (333).

752 Vgl. BVerfGE 30, 1 (24 f.), die Art. 79 Abs. 3 GG aufgrund des Ausnahmecharakters der Norm restriktiv auslegen; siehe auch Roth, Verfassungsmäßigkeit der Einführung einer 3\%-Sperrklausel bei Kommunalwahlen durch Verfassungsänderung, insbesondere für das Land Nordrhein-Westfalen, 2015, S. 87.

753 BVerfGE 30, 1 (25).

754 Dreier, in: Dreier/Bauer (Hrsg.), Grundgesetz, ${ }^{3} 2015$, Art. 79 Abs. 3, Rn. 16. 
In der Literatur wird die Auslegung des Art. 79 Abs. 3 GG durch das Bundesverfassungsgericht im sogenannten Abhör-Urteil ${ }^{755}$ besonders scharf kritisiert. ${ }^{756}$ Die stark restriktive Auslegung des Art. 79 Abs. 3 GG durch das Bundesverfassungsgericht würde den normativen Gehalt der Ewigkeitsklausel auf ein „Revolutionsverbot“ reduzieren und dabei in Kauf nehmen, dass mit der bloßen „allgemeinen Rechnungstragung" ein allmählicher Zerfallsprozess der geschützten Grundwerte einherginge. ${ }^{757}$ So führt unter anderem auch Klaus Stern zum Gewährleistungsbereich aus, dass der normative Gehalt des Art. 79 Abs. 3 GG nicht nur ein „revolutionäres Verfassungsbeseitigungsverbot" umfasse, sondern eher den Schutz der konservierten Grundsätze vor einer „mosaik- oder scheibchenweise“ erfolgenden Aushöhlung durch Verfassungsänderungen in den teleologischen Vordergrund der Ewigkeitsklausel stelle. ${ }^{758}$ Weiter führen Stimmen in der Literatur an, dass durch das weitere Verständnis des Art. 79 Abs. 3 GG hin zu einem Schutz vor einem allmählichen Zerfall der obersten Verfassungswerte eine pauschalisierende, formelhafte Bestimmung den Grenzen und der Tragweite der Ewigkeitsklausel, so wie das Bundesverfassungsgericht sie handhabt, nicht mehr gerecht werde. ${ }^{759} \mathrm{Ob}$ ein durch Art.79 Abs.3 GG geschützter Grundsatz „berührt“ sei, entscheide sich demnach nicht nach pauschalen, auf alle Verfassungsänderungen anwendbaren formelhaft erstellten Voraussetzungen, sondern müsse anhand einer individuellen Auslegung des jeweils einschlägigen, durch Art.79 Abs. 3 GG geschützten Grundsatzes festgestellt werden. ${ }^{760}$ In diesem Rahmen sei einerseits zu beachten, dass bei der konkreten Auslegung des maßgeblichen Grundsatzes kein allzu restriktiver Maßstab angelegt werde, um dem eigentlichen Zweck der Ewigkeitsklausel Rechnung zu tragen. Auf der anderen Seite dürfe Art. 79 Abs. 3 GG auch nicht zu extensiv ausgelegt werden, da auf diese Art die Gefahr einer „Versteinerung“ der Verfassung drohen würde. ${ }^{761}$

755 BVerfGE 30, 1.

756 Rupp, NJW 1971, $275 \mathrm{ff}$.

757 BVerfGE 30, 1 (41 f.) - Sondervotum.

758 Stern, JuS 1985, 329 (331).

759 Hesse, Grundzüge des Verfassungsrechts der Bundesrepublik Deutschland, ${ }^{20} 1999$, Rn. 703; Badura, in: Isensee/Kirchhof/Bauer u.a. (Hrsg.), Handbuch des Staatsrechts der Bundesrepublik Deutschland XII, ${ }^{3} 2014$, $\$ 270$, Rn. 34.

760 Vgl. Stern, JuS 1985, 329 (333); Dreier, in: Dreier/Bauer (Hrsg.), Grundgesetz, ${ }^{3} 2015$, Art. 79 Abs. 3, Rn. 19; BVerfGE 30, 1 (41 f.) - Sondervotum.

761 Dreier, in: Dreier/Bauer (Hrsg.), Grundgesetz, ${ }^{3}$ 2015, Art. 79 Abs. 3, Rn. 19. 
Das divergierende Verständnis des Art. 79 Abs. 3 GG basiert auf einer unterschiedlichen Deutung der Ewigkeitsklausel. Während das Bundesverfassungsgericht die in Art. 79 Abs. 3 GG geschützten Grundsätze der Disposition des verfassungsändernden Gesetzgebers unterwirft, sofern „ihnen im allgemeinen Rechnung getragen wird und sie nur für eine Sonderlage entsprechend deren Eigenart aus evident sachgerechten Gründen modifiziert werden" ${ }^{6762}$, sieht die in der Literatur vertretene Gegenauffassung diese Grundsätze als „unberührbar“ an und will sie, sollte die Verfassungsänderung in einem durch einen solchen Grundsatz gewährleisteten Bereich eingreifen, vollständig der Disposition des verfassungsändernden Gesetzgebers entziehen. Feststehen sollte, dass die "Grundsätze“ i.S.d. Art.79 Abs. 3 GG einer etwaigen Veränderung gegenüber dauerhaft verschlossen sind. Die Grundsätze bilden einen festen Rahmen und legen insoweit Leitprinzipien fest, die zur dauerhaften Gewährleistung der Verfassungsidentität sowohl den einfachen als auch den verfassungsändernden Gesetzgeber indisponible Grenzen setzen. Diese Grenzen sind absolut, unveränderlich und auch nicht modifizierbar. Sie sind als formal-legalistische Grenzen der Volkssouveränität zu verstehen, die dem Staat in ihrem Rahmen einen Handlungs- und Beurteilungsspielraum überlassen. Insoweit sind die Auffassungen in der Literatur überzeugend. Das Merkmal des "Berührens“ wird streng formal verstanden und soll bereits dann erfüllt sein, wenn durch eine Verfassungsänderung einer der geschützten Grundsätze über dessen Abschaffung hinaus auch nur verändert wird. Das Merkmal des „Berührens“ ist deshalb vielmehr wie das des „Antastens“ i.S.d. Art. 1 Abs. 1 S. 1 GG oder Art. 19 Abs. 2 GG zu verstehen. ${ }^{763}$ Um der Revisionsgewalt des verfassungsändernden Gesetzgebers über Art. 79 Abs. 3 GG nicht zu enge Grenzen zu setzen, muss diesem Umstand bei der Auslegung des Begriffes der „Grundsätze“ Rechnung getragen werden.

Dem Bundesverfassungsgericht ist allerdings zumindest in dem Punkt zuzustimmen, dass eine Modifizierung von leitprinzipiellen Konkretisierungen jedenfalls aus „evident sachgerechten Gründen“ erfolgen muss. ${ }^{764}$ Eine willkürlich vorgenommene, eingrenzende Modifizierung von Kerninhalten der Verfassung kann unter der Maßgabe des Art. 79 Abs. 3 GG nicht zulässig sein. Durch eine Modifizierung staatsstruktureller Konkretisierungen wie der Parteiengleichheit greift der Staat mittelbar in die bürgerliche Freiheitssphäre ein und ändert dadurch im Einzelfall die Ausgestaltung ei-

762 BVerfGE 30, 1 (24).

763 Stern, JuS 1985, 329 (333).

764 BVerfGE 30, 1 (24); wohl auch Ferreau, DÖV 2017, 494 (498). 
nes Verfassungsprinzips. Die willkürliche Vornahme von Verfassungsänderungen räumt einem nicht verfassungsrechtlich anerkannten oder gar überhaupt existenten Grund einen Vorrang gegenüber dem im Rahmen dieser Änderung im Einzelfall betroffenen Prinzip ein. Eine Verfassungsänderung verstößt damit stets dann gegen Art. 79 Abs. 3 GG, wenn der verfassungsändernde Gesetzgeber ohne sachgerechte Erwägungen anzustellen einem willkürlich bestimmten Grund Vorrang gegenüber der geltenden Verfassungsstruktur einräumt.

c) Materielle Schranken des Art. 79 Abs. 3 GG bei leitprinzipiellen Konkretisierungen

Um im konkreten Einzelfall feststellen zu können, ob und wann ein Grundsatz „berührt“ wird, scheint die rechtstheoretische Differenzierung zwischen Prinzipien und Regeln einen brauchbaren dogmatischen Ansatzpunkt zu bilden. ${ }^{765}$ Prinzipien enthalten unbedingte Leitgedanken, die, um im Einzelfall angewendet werden zu können, konkreter Festsetzungen (namentlich Regeln) bedürfen. ${ }^{766}$ So enthalten beispielsweise die Gewährleistungen des Art. 20 Abs. 1, Abs. 2 GG keine Festsetzungen über den konkreten Inhalt der dort aufgeführten Staatsstrukturprinzipien, sondern werden durch eine Reihe anderer, nicht in Art. 79 Abs. 3 GG genannter, Vorschriften näher ausgestaltet. Die Prinzipien bilden in ihrer Gesamtheit eine „Rahmenordnung“ und legen somit Rahmenbedingungen fest, innerhalb derer konkretisierende Festsetzungen erfolgen können. ${ }^{767}$ Bei Prinzipien handelt es sich um Optimierungsgebote, deren Maß der Erfüllung von tatsächlichen wie auch rechtlichen Möglichkeiten abhängt. ${ }^{768}$ Der Gesetzgeber ist somit aufgrund des Optimierungsgebots grundsätzlich gehalten, jedes Prinzip in den Grenzen seiner tatsächlichen und rechtlichen Möglich-

765 Hain, in: Starck/Mangoldt/Klein (Hrsg.), Kommentar zum Grundgesetz, ${ }^{5} 2005$, Art. 79 Rn. 45; vertiefend Alexy, ARSP-Beiheft 1985, 13 ff.; siehe auch Epping, Rechtsgutachten über die Frage, ob und unter welchen Voraussetzungen eine nicht nach Art. 21 II GG verbotene Partei von der staatlichen Parteifinanzierung ausgeschlossen werden kann, 14.11.2008, S. 25.

766 Epping, Rechtsgutachten über die Frage, ob und unter welchen Voraussetzungen eine nicht nach Art. 21 II GG verbotene Partei von der staatlichen Parteifinanzierung ausgeschlossen werden kann, 14.11.2008, S. 25.

767 Vgl. Böckenförde, NJW 1976, 2089 (2091).

768 Vgl. Alexy, Theorie der Grundrechte, ${ }^{3} 1996$, S. 75 f.; Riedel, in: VVDStRL 58 (1999), S. 183. 
keiten in einem möglichst großen Umfang zu realisieren. ${ }^{769}$ Die gerichtliche Überprüfung der vorgenommenen Optimierung wird allerdings weitestgehend durch den Gestaltungsspielraum des Gesetzgebers eingeschränkt. ${ }^{770}$ So kann ein Verstoß gegen das Optimierungsgebot nicht schon darin gesehen werden, dass der Gesetzgeber die Summe der Einzelausprägungen des Prinzips reduziert. Vielmehr obliegt ihm im Rahmen seines Gestaltungsspielraumes, die Wahl der Mittel zur Erfüllung des Optimierungsgebotes eigenständig festzulegen.

Auf Art. 79 Abs. 3 GG übertragen hat dies zur Konsequenz, dass lediglich die grundlegenden Prinzipien vor einem „Berühren“ geschützt werden, eine Modifizierung der sie ausgestaltenden Konkretisierungen allerdings möglich ist. ${ }^{771}$ Die Leitprinzipien, die in diesem Sinne als Synonym für den Begriff der "Grundsätze“ verwendet werden, bedürfen der Umsetzung durch sogenannte „Konkretisierungen“, die anders als die „Grundsätze“ einer Veränderung zugänglich sind. Überzeugend verfolgt Volker Epping in seinem Rechtsgutachten zum Finanzierungsausschluss den Ansatz, dass bei der Frage der Zulässigkeit der Verfassungsänderung auf den Umstand einzugehen ist, ob der Änderungsgegenstand einer Verfassungsänderung lediglich eine „Konkretisierung“ eines durch Art. 79 Abs. 3 GG geschützten Verfassungsprinzips ist oder dessen Bestandteil darstellt. ${ }^{772}$ So soll die Ewigkeitsgarantie Leitprinzipien schützen, eine Modifizierung ihrer konkreten Festsetzungen allerdings zulassen.

Ein Verstoß gegen Art. 79 Abs. 3 GG liegt demnach dann vor, wenn die von Art. 21 Abs. 3 GG betroffenen Rechtsgüter verfassungsrechtliche Leitprinzipien und keine sie ausgestaltende Konkretisierung darstellen.

Bei der inhaltlichen Ausgestaltung verfügt der verfassungsändernde Gesetzgeber über ein Entscheidungs- und Beurteilungsermessen, das seine

769 Riedel, in: VVDStRL 58 (1999), S. 183.

770 Würtenberger, in: VVDStRL 58 (1999), S. 158.

771 So treffend Epping, Rechtsgutachten über die Frage, ob und unter welchen Voraussetzungen eine nicht nach Art. 21 II GG verbotene Partei von der staatlichen Parteifinanzierung ausgeschlossen werden kann, 14.11.2008, S. 25.

772 Ders., Rechtsgutachten über die Frage, ob und unter welchen Voraussetzungen eine nicht nach Art. 21 II GG verbotene Partei von der staatlichen Parteifinanzierung ausgeschlossen werden kann, 14.11.2008, S. 24 ff.; zustimmend Ferreau, DÖV 2017, 494 (497 ff.); vertieft auf die Prinzipientheorie eingehend Hain, Die Grundsätze des Grundgesetzes, 1999, S. 95 ff. 
Grenzen wiederum nur in den Leitprinzipien findet. ${ }^{773}$ Die Konkretisierung eines Leitprinzips darf dem ihm zugrundeliegenden Gedanken nicht zuwiderlaufen bzw. die Kerninhalte des Grundgesetzes nicht durch gegeläufige Grundsatzaussagen ersetzen. ${ }^{774}$ Eine Konkretisierung kann nur als eine solche verstanden werden, wenn sie den grundlegenden Inhalt des Leitprinzips bestätigend in einer spezifischeren Gestalt umsetzt. Da die Konkretisierung nur den Gehalt des Leitprinzips spezifizieren, allerdings nicht neu- oder umgestalten kann, bildet das Leitprinzip selbst den Maßstab für die Konkretisierung.

$\mathrm{Ob}$ eine Verfassungsänderung zum Zwecke des Ausschlusses verfassungsfeindlicher Parteien von der staatlichen Parteienfinanzierung zulässig ist, beurteilt sich folglich danach, ob die vorhandene Struktur des Verfassungsstaates durch die Konkretisierung bestätigt oder durch eine gegenläufige Grundsatzaussage ersetzt wird. ${ }^{775}$ Sollte Letzteres der Fall sein, ist einer der durch Art. 79 Abs. 3 GG geschützten Grundsätze als berührt und das Änderungsgesetz damit als materiell verfassungswidrig anzusehen.

\section{Chancengleichheit als unberührbarer Verfassungsgrundsatz}

Der Problemschwerpunkt der Verfassungsänderung liegt in der durch den Staat vorgenommenen Ungleichbehandlung. Indem der Staat solche Parteien aus der staatlichen Teilfinanzierung ausschließt, die verfassungsfeindliche Absichten verfolgen, greift er in den Bereich der parteienspezifischen Chancengleichheit ein. ${ }^{776} \mathrm{Um}$ die Verfassungsänderung auf ihre verfassungsrechtliche Zulässigkeit nach Art. 79 Abs. 3 GG untersuchen zu können, muss zunächst festgestellt werden, ob die parteienspezifische Chancengleichheit einem der durch die Ewigkeitsklausel geschützten Grundsätzen immanent ist. Ist dies der Fall, ist eine Verfassungsänderung aufgrund ihrer Unvereinbarkeit mit Art. 79 Abs. 3 GG unzulässig und eine Modifi-

773 Gerade hinsichtlich des Demokratieprinzips bleibt die konkrete Ausgestaltung und die Wahl eines demokratischen Systems dem Gesetzgeber überlassen Hain, in: Starck/Mangoldt/Klein (Hrsg.), Kommentar zum Grundgesetz, ${ }^{5} 2005$, Art. 79, Rn. 46.

774 Vgl. Kirchhof, in: Badura/Isensee/Kirchhof (Hrsg.), Handbuch des Staatsrechts der Bundesrepublik Deutschland II, ${ }^{3} 2004$, $\$ 21$, Rn. 99.

775 Vgl. Kirchhof, in: Badura/Isensee/Kirchhof (Hrsg.), Handbuch des Staatsrechts der Bundesrepublik Deutschland II, ${ }^{3} 2004$, \$21, Rn. 99.

776 Vgl. Ferreau, DÖV 2017, 494 (497); Gusy, NJW 2017, 601 (603); Linke, DÖV 2017, 483 (491). 
zierung der Parteiengleichheit durch den verfassungsändernden Gesetzgeber schlicht ausgeschlossen. Als einschlägige höchste Verfassungsgrundsätze, denen der parteienspezifische Gleichheitssatz immanent ist, kommen die Menschenwürde und das Demokratieprinzip in Betracht. ${ }^{777}$

a) Menschenwürde, Art. 1 Abs. 1 GG

Die in Art. 1 GG niedergelegten „Grundsätze“ sind nach Art. 79 Abs. 3 GG auch der Revisionsgewalt des verfassungsändernden Gesetzgebers entzogen. Die Grundrechte werden durch die Ewigkeitsklausel hingegen nicht umfassend vor einer Änderung durch den verfassungsändernden Gesetzgeber geschützt, da sich der Wortlaut des Art. 79 Abs. 3 GG explizit nur auf die „Grundsätze“ aus Art. 1 GG und 20 GG bezieht. Eine Änderung der Grundrechte ist nach Art. 79 Abs. 3 GG nur dann unzulässig, wenn durch das gesetzgeberische Tätigwerden der Menschenwürdegehalt oder -kern eines Grundrechtes verletzt werden würde. ${ }^{778}$ Das Bundesverfassungsgericht nimmt an, dass eine Änderung der Grundrechte dem verfassungsändernden Gesetzgeber insoweit entzogen ist, als sie für die Aufrechterhaltung einer den Art. 1 Abs. 1 und 2 GG entsprechenden Staats- und Gesellschaftsordnung notwendig sind. ${ }^{779}$ Der verfassungsändernde Gesetzgeber muss nach den Maßgaben des Art. 79 Abs. 3 GG „grundlegende Gerechtigkeitspostulate" beachten, worunter insbesondere das Willkürverbot und der Grundsatz der Rechtsgleichheit fallen. ${ }^{780}$

Angesichts der auch hier vertretenen Auffassung, dass der subjektive Status der Parteiengleichheit seinen dogmatischen Anknüpfungspunkt in dem grundrechtlichen Gleichheitssatz aus Art. 3 Abs. 1 GG findet ${ }^{781}$ und nach allgemeiner Auffassung der Kernbereich eines jeden Grundrechtes

777 In diesem Sinne auch Epping, Rechtsgutachten über die Frage, ob und unter welchen Voraussetzungen eine nicht nach Art. 21 II GG verbotene Partei von der staatlichen Parteifinanzierung ausgeschlossen werden kann, 14.11.2008, $26 \mathrm{ff}$., $30 \mathrm{ff}$.

778 Vgl. BVerfGE 102, 370 (392); BVerfGE 84, 90 (120f.); BVerfGE 94, 12 (34); Pieroth, in: Jarass/Pieroth (Hrsg.), Grundgesetz für die Bundesrepublik Deutschland, ${ }^{14}$ 2016, Art. 79, Rn. 15.

779 BVerfGE 84, 90(120 f.); BVerfGE 94, 49 (103); BVerfGE 109, 279 (310).

780 Vgl. BVerfGE 1, 208 (233); BVerfGE 23, 98 (106f.).

781 Siehe $\mathbb{2}$. B. II. 
einen Menschenwürdegehalt aufweist ${ }^{782}$, könnte die parteienspezifische Chancengleichheit als einer der Bestandteile der Menschenwürdegarantie des Art. 1 Abs. 1 S. 1 GG angesehen werden. ${ }^{783}$ Die Menschenwürde müsste insoweit einen gleichheitsrechtlichen Grundsatz vorsehen, der der Revisionsgewalt des verfassungsändernden Gesetzgebers über Art. 79 Abs. 3 GG entzogen ist. Die Parteiengleichheit müsste ein „grundlegendes Gerechtigkeitspostulat" darstellen, das per se keiner Änderung zugänglich ist, im engeren Sinne also einen Bestandteil einer der Menschenwürde entsprechenden Staats- und Gesellschaftsordnung darstellen.

Der hinter der Parteiengleichheit stehende Rechtsgedanke der gleichen Teilhabe aller Bürger am politischen Willensbildungsprozess folgt aus der der Menschenwürde inhärenten menschlichen Selbstbestimmungsfähigkeit. ${ }^{784}$ Weil alle Menschen ihre eigene Individualität entfalten können müssen, sind sie als gleich anzusehen. ${ }^{785}$ Die menschliche Selbstbestimmungsfähigkeit setzt das in der Rechtsprechung des Bundesverfassungsgerichtes angeführte „grundlegende Gerechtigkeitspostulat" voraus und verbietet in diesem Rahmen jegliche demütigende Ungleichbehandlung. ${ }^{786}$ Da sich das von der Menschenwürdegarantie umfasste Gerechtigkeitspostulat auf ein Willkürverbot und ein grundsätzliches Gebot der allgemeinen Rechtsgleichheit beschränkt, kann die Parteiengleichheit nicht per se der Menschenwürde zugeordnet werden. Die Parteiengleichheit soll die gleichen Teilhabemöglichkeiten aller Bürger bei der Bildung eines politischen Willens gewährleisten. Der Staat darf bei ihrer Einschränkung nicht die gleiche Teilhabe aller Bürger am politischen Willensbildungsprozess beseitigen oder übermäßig einschränken. Anknüpfungspunkt bildet damit nicht die Frage, ob eine Einschränkung der Parteiengleichheit automatisch zu einem „Antasten“ und damit einer Verletzung der Menschenwürde führt, sondern ob die Ungleichbehandlung von Parteien mittels eines

782 Vgl. BVerfGE 102, 370 (392); BVerfGE 84, 90 (120f.); BVerfGE 94, 12 (34); Pieroth, in: Jarass/Pieroth (Hrsg.), Grundgesetz für die Bundesrepublik Deutschland, ${ }^{14}$ 2016, Art. 79, Rn. 15.

783 So auch diskutiert von Epping, Rechtsgutachten über die Frage, ob und unter welchen Voraussetzungen eine nicht nach Art. 21 II GG verbotene Partei von der staatlichen Parteifinanzierung ausgeschlossen werden kann, 14.11.2008, S. $26 \mathrm{ff}$.

784 Häberle, in: Badura/Isensee/Kirchhof (Hrsg.), Handbuch des Staatsrechts der Bundesrepublik Deutschland II, ${ }^{3} 2004, \mathbb{} 22$, Rn. 68 f.

785 Vertiefend der Zusammenhang zwischen Freiheit und Gleichheit Kirchhof, in: Badura (Hrsg.), Wege und Verfahren des Verfassungslebens, 1993, S. 133, 137.

786 Höfling, in: Sachs (Hrsg.), Grundgesetz, ${ }^{8} 2018$, Art. 1, Rn. 35. 
„Durchgriffs“ auf das Prinzip der menschlichen Selbstbestimmungsfähigkeit der Menschenwürde widerspricht.

Da der Ausschluss aus der staatlichen Parteienfinanzierung auf der Grundlage der „wehrhaften Demokratie“ erfolgt, die selbst ein anerkanntes Verfassungsprinzip darstellt und somit bereits ein willkürliches staatliches Handeln ausschließt ${ }^{787}$, kann die Verletzung des Gerechtigkeitspostulates und des Prinzips der allgemeinen Rechtsgleichheit ausgeschlossen werden. Ein Verstoß gegen die Menschenwürdegarantie des Art. 1 Abs. 1 S. 1 GG liegt nicht vor. Aufgrund der zentralen Bedeutung der menschlichen Selbstbestimmung in Form des Prinzips der gleichen Teilhabe aller Bürger am politischen Willensbildungsprozess für die Demokratie ${ }^{788}$ wird nun weiter die Vereinbarkeit des Art. 21 Abs. 3 GG mit dem Demokratieprinzip zu untersuchen sein.

b) Demokratieprinzip, Art. 20 Abs. 1 GG

(1) Parteiengleichheit als Teil des offenen politischen Willensbildungsprozesses

Das Demokratieprinzip wird in Art. 20 Abs. 1 und Abs. 2 GG als Staatsstruktur garantiert und über Art. 79 Abs. 3 GG als eines der höchsten Verfassungsgüter konserviert. Es stellt damit eines der Leitprinzipien dar, die zum festen Kern der Verfassungsidentität zählen und der Revisionsgewalt des verfassungsändernden Gesetzgebers Grenzen setzen. Zum änderungsfesten Kern des Demokratieprinzips gehört insbesondere ein offener Prozess politischer Willensbildung, der die Möglichkeit eines Machtwechsels garantiert. ${ }^{789}$

Ein offener Prozess der politischen Willensbildung setzt voraus, dass das Kräftemessen der politischen Akteure innerhalb eines vom staatlichen Einfluss weitestgehend befreitem Wettbewerb die künftigen Machtverhältnisse im Staat bestimmt. ${ }^{790}$ Aus diesem Grund wird als objektiv-rechtliche In-

787 Siehe unten S. $\$ 4$ C. II. 2. b) (2).

788 Kirchhof, in: Badura (Hrsg.), Wege und Verfahren des Verfassungslebens, 1993, S. 133, 138.

789 Statt aller siehe BVerfGE 5, 85 (198 f.); BVerfGE 123, 267 (367).; Dreier, in: Dreier/Bauer (Hrsg.), Grundgesetz, ${ }^{32015}$, Art. 20 (Demokratie), Rn. 76 ff.

790 Vgl. statt aller ders., in: Dreier/Bauer (Hrsg.), Grundgesetz, ${ }^{3} 2015$, Art. 79 Abs. 3, Rn. 41; Herdegen, in: Maunz/Dürig (Hrsg.), Grundgesetz, 2018, Art. 79, Rn. 125; Zacharias, in: Thiel (Hrsg.), Wehrhafte Demokratie, 2003, S. 57, 87. 
stitutsgarantie nach Art. 21 Abs. 1 S. 1 und S. 2 GG i.V.m. Art. 20 Abs. 1, Abs. 2 und Art. 28 Abs. 1 S. 1 GG ein freier und gleicher Parteienwettbewerb vorausgesetzt. Die Akteure des politischen Lebens müssen in diesem Sinne dieselben Chancen für die Herbeiführung eines Machtwechsels erhalten. Die demokratische Staatsform ist eng mit dem Prinzip der Menschenwürde verwoben und verlangt insoweit, dass die Herrschaft über den Staat durch ein freies und vor allem gleiches Staatsvolk ausgeübt wird. ${ }^{791}$ Aufgrund dessen ist der Staat gehalten, die Chancengleichheit aller Teilnehmer am politischen Wettbewerb zu gewährleisten. Über die Kommunikationsgrundrechte, insbesondere Art. 5 Abs. 1, 8 Abs. 1 und 9 Abs. 1 GG, soll das objektiv-rechtliche Prinzip über subjektive Rechtsgarantien gewährleistet und tatsächlich umgesetzt werden.

Aufgrund der vorliegenden Tatsachen wird diskutiert, ob auch die sich aus Art. 21 Abs. 1 GG ableitende parteienspezifische Chancengleichheit dem änderungsfesten Kern des Demokratieprinzips immanent sei. ${ }^{792} \mathrm{Zu}-$ nächst bleibt nüchtern festzustellen, dass Art. 21 GG im Wortlaut des Art. 79 Abs. 3 GG keine ausdrückliche Erwähnung findet und somit an sich nicht ausdrücklich durch die Ewigkeitsklausel konserviert ist. Die parteienspezifische Chancengleichheit stellt einerseits ein aus Art. 21 Abs. 1 S. 1, 2 i.V.m. 3 Abs. 1 GG abzuleitendes subjektives Recht der Parteien dar ${ }^{793}$, dies jedoch nur zur Gewährleistung eines funktionierenden demokratischen Systems. Das den Parteien verliehene verfassungsrechtliche Mandat soll wiederum zweckgemäß der Umsetzung des durch den Verfassungsgeber gewählten Systems der Parteiendemokratie dienen. So führte das Bundesverfassungsgericht aus, dass sich die Chancengleichheit der Parteien als „Bestandteil der demokratischen Grundordnung von selbst“ verstehe. ${ }^{794}$

Unabhängig von der Diskussion, ob eine Parteiendemokratie die einzig denkbare Demokratieform darstellt und deshalb die Existenz und die damit einhergehende Gründungsfreiheit von Parteien zu den „Grundsätzen“

791 Vgl. Hain, Die Grundsätze des Grundgesetzes, 1999, S. 325; Ferreau, DÖV 2017, 494 (497).

792 Namentlich Epping, Rechtsgutachten über die Frage, ob und unter welchen Voraussetzungen eine nicht nach Art. 21 II GG verbotene Partei von der staatlichen Parteifinanzierung ausgeschlossen werden kann, 14.11.2008, S. 30.

793 Morlok, in: Dreier/Bauer (Hrsg.), Grundgesetz, ${ }^{3} 2015$, Art. 21, Rn. 78; wohl auch Klein, in: Maunz/Dürig (Hrsg.), Grundgesetz, 2018, Art. 21, Rn. 304.

794 BVerfGE 1, 208 (242). 
des Demokratieprinzips i.S.d. Art. 79 Abs. 3 GG zählen ${ }^{795}$, ist der Gleichheitsstatus nicht generell den Grundsätzen der demokratischen Staatsform zuzuordnen. ${ }^{796}$ Art. 21 GG ist modifizierbar, solange die dadurch für die Parteien eintretende Rechtsstellung keinen Widerspruch zum demokratischen Herrschaftssystem darstellt. ${ }^{797}$ Dieses Ergebnis ist vor dem Hintergrund der in dieser Arbeit vertretenen Auffassung und der Rechtsprechung des Bundesverfassungsgerichts auch nur konsequent. Denn wenn der Staat aus „Zwingenden Gründen“ eine Ungleichbehandlung von Parteien einfachgesetzlich vornehmen darf, kann die Parteiengleichheit nicht per se zum unveränderlichen Kern des Demokratieprinzips gehören und damit erst recht nicht umfassend der Disposition des verfassungsändernden Gesetzgebers entzogen sein. Bei Art. 21 GG handelt es sich um eine Konkretisierung des Demokratieprinzips hin zu einer Parteiendemokra$\mathrm{tie}^{798}$, die wiederum die Chancengleichheit der Parteien im freien Wettbewerb rückgekoppelt an das demokratische Herrschaftssystem gewährleistet. Als von einer Konkretisierung vorausgesetzten Rechtsstellung unterliegt damit der Bereich der parteienspezifischen Chancengleichheit grundsätzlich der Disposition des verfassungsändernden Gesetzgebers. Bei der Modifizierung des Gleichheitsstatus muss der verfassungsändernde Gesetzgeber allerdings die ihm durch das Leitprinzip der demokratischen Herrschaftsform auferlegten Grenzen achten und darf diese nicht verletzen. Ungleichbehandlungen bedürfen zwar einer besonderen Rechtfertigung, sind allerdings nicht generell unzulässig.

795 Epping, Rechtsgutachten über die Frage, ob und unter welchen Voraussetzungen eine nicht nach Art. 21 II GG verbotene Partei von der staatlichen Parteifinanzierung ausgeschlossen werden kann, 14.11.2008, S. 31 Fn. 90 m.w.N.

796 Vgl. ders., Rechtsgutachten über die Frage, ob und unter welchen Voraussetzungen eine nicht nach Art. 21 II GG verbotene Partei von der staatlichen Parteifinanzierung ausgeschlossen werden kann, 14.11.2008, S. 33; Ferreau, DÖV 2017, 494 (497).

797 Kirchhof, in: Badura/Isensee/Kirchhof (Hrsg.), Handbuch des Staatsrechts der Bundesrepublik Deutschland II, ${ }^{3} 2004, \mathbb{2} 2$, Rn. 99, der davon spricht, dass Verfassungsänderungen keine gegenläufigen Grundsatzaussagen treffen dürften. Insoweit gilt dies auch für Konkretisierungen, die dem Leitgedanken, den sie konkretisieren, nicht entgegenlaufen dürfen.

798 Kirchhof, in: Badura/Isensee/Kirchhof (Hrsg.), Handbuch des Staatsrechts der

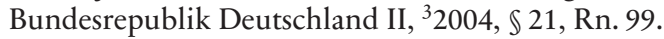


(2) Wehrhaftigkeit als Bestandteil und Schranke des Demokratieprinzips

Die Änderung des Art. 21 Abs. 3 GG $^{799}$ greift in den Bereich des durch das Demokratieprinzip vorausgesetzten offenen Prozesses der politischen Willensbildung und der Chancengleichheit der Parteien ein. Dies würde dann zu einer Unzulässigkeit anhand des Maßstabes von Art. 79 Abs. 3 GG führen, wenn der verfassungsändernde Gesetzgeber durch die Änderung des Grundgesetzes Kerninhalte des im Einzelfall betroffenen Leitprinzips durch gegenläufige Grundsatzaussagen ersetzen würde. ${ }^{800} \mathrm{Ob}$ dies vorliegend der Fall ist, hängt davon ab, ob ein in die Parteiengleichheit eingreifender Sanktionsmechanismus dem grundgesetzlichen Verständnis einer demokratischen Staatsform zuwiderläuft. Sofern sich der Gesetzgeber entscheidet, Konkretisierungen der durch Art. 79 Abs.3 GG geschützten Grundsätze zu modifizieren, so muss er dies aufgrund sachgerechter Erwägungen tun. ${ }^{801}$ Obwohl der pauschalisierenden Formel des Bundesverfassungsgerichtes zur Zulässigkeit von Verfassungsänderungen nicht gefolgt wird, so behält es dennoch Recht, wenn es die Notwendigkeit eines sachgerechten Grundes für die Verfassungsänderung zur Voraussetzung erklärt. ${ }^{802}$ Der Zweck des Finanzierungsausschlussverfahrens liegt im Ausbau des Systems der sogenannten „wehrhaften Demokratie“.

Das Prinzip der „wehrhaften Demokratie“ bedeutet, so wie Markus Thiel treffend formuliert, dass die Gegner der freiheitlichen demokratischen Grundordnung nicht mit allen, sogar den von der Verfassung selbst zur Verfügung gestellten Mitteln auf eine Beseitigung dieser Ordnung hinwirken dürfen, sondern sich bei Überschreiten bestimmter Grenzen staatlichen Schutzmechanismen und Abwehrmaßnahmen ausgesetzt sehen müssen. ${ }^{803}$ Die freiheitliche demokratische Grundordnung und alle ihr immanenten Grundprinzipien des Grundgesetzes stellen somit den Bezugszweck der „wehrhaften Demokratie“ dar und sollen durch die Abwehrinstrumente des Prinzips verteidigt werden (können). ${ }^{804}$ Das Bundesverfassungsgericht erkennt das Institut der „wehrhaften Demokratie“ als eine

799 BGBl. 2017, I, S. 2346.

800 Vgl. Kirchhof, in: Badura/Isensee/Kirchhof (Hrsg.), Handbuch des Staatsrechts der Bundesrepublik Deutschland II, ${ }^{3} 2004, \mathbb{2} 21$, Rn. 99.

801 BVerfGE 30, 1 (24).

802 BVerfGE 30, 1 (24); daran anknüpfend und den Ausbau der „wehrhaften Demokratie" als sachgerechten Grund i.S.d. Rechtsprechung anerkennend Shirvani, DÖV 2018, 921 (924).

803 Thiel, in: ders. (Hrsg.), Wehrhafte Demokratie, 2003, S. 1.

804 Vgl. Thrun, DÖV 2019, 65 ff. 
verfassungsrechtliche Grundentscheidung an. ${ }^{805}$ Aus einer Gesamtschau der Bestimmungen des Grundgesetzes, insbesondere Art. 9 Abs. 2, 20 Abs. 4, 18, 21 Abs. 2, 98 Abs. 2 und $5 \mathrm{GG}^{806}$, ergebe sich die verfassungspolitische Grundentscheidung, die wehrhafte Demokratie zu einem verfassungsrechtlichen Leitprinzip zu erheben. Das Bundesverfassungsgericht hebt in seiner Rechtsprechung insbesondere die „Normentrias“ der Art. 9 Abs. 2, Art. 18 und Art. 21 Abs. 2 GG hervor, die insoweit den Kernbestandteil des präventiven Verfassungsschutzes ausmachen würden. ${ }^{807} \mathrm{Da}$ raus folgt die Überlegung, ob bestimmte Einschränkungen demokratischer Prinzipien gerade dann zulässig sind, wenn sie für die dauerhafte Erhaltung der demokratischen Staatsform vorgenommen werden.

In Bezug auf das Parteiverbotsverfahren des Art. 21 Abs. 2 GG hat das Bundesverfassungsgericht einen Widerspruch zum offenen politischen Willensbildungsprozess verneint. ${ }^{808}$ Dieses Prinzip sei vor allem darauf ausgelegt, eine dauerhafte demokratische Ordnung zu gewährleisten und zu diesem Zwecke verfassungsrechtliche Freiheiten gerade dann einzuschränken, wenn diese missbraucht werden, um die vom Grundgesetz vorausgesetzte Staatsordnung zu beseitigen. ${ }^{809}$ Ein weiterer Ansatzpunkt historischen Charakters bildet Art. 47 Abs. 4 des Herrenchiemsee-Entwurfes, wonach schon dort der Wille des verfassungsgebenden Gesetzgebers, ein Parteiverbotsverfahren und damit ein Mittel der „wehrhaften Demokratie“ zu schaffen, zum Ausdruck kam. .10

Das Prinzip der „wehrhaften Demokratie“ wird auch größtenteils in der Literatur als verfassungsrechtliche Grundentscheidung anerkannt. ${ }^{811}$ Insoweit stelle sich das Wehrhaftigkeitsprinzip als ein allgemein anerkannter verfassungsrechtlicher Grundsatz dar. Dabei werden unterschiedlichste, allerdings inhaltlich identische Begrifflichkeiten für die "Wehrhaftigkeit“

805 Vgl. BVerfGE 28, 36 (48); BVerfGE 30, 1 (19f.); siehe hierzu auch Lameyer, Streitbare Demokratie, 1978, S. 94 ff.; Thiel, in: ders. (Hrsg.), Wehrhafte Demokratie, 2003, S. $1 \mathrm{ff}$.

806 Vgl. BVerfGE 28, 36 (48); auch Alter, Die Eingriffsschwelle beim Verbot extremistischer Parteien und Vereine in Deutschland und England, 2016, S. $212 \mathrm{ff}$.

807 BVerfGE 144, 20 (166); BVerfGE 107, 339 (387) - Sondervotum.

808 BVerfGE 5, 85 (137 ff.); BVerfGE 144, 20 (195 ff.).

809 BVerfGE 144, 20 (194f.).

810 So z.B. BVerfGE 5, 85 (137).

811 Siehe hierzu Klein, in: Maunz/Dürig (Hrsg.), Grundgesetz, 2018, Art.21, Rn. 490; Lameyer, Streitbare Demokratie, 1978; Boventer, Grenzen politischer Freiheit im demokratischen Staat, 1985; Thiel, in: ders. (Hrsg.), Wehrhafte Demokratie, 2003, S. 1 ff. m.w.N. 
der Demokratie verwendet. So ist von einer „wertgebundenen“812, „streit-

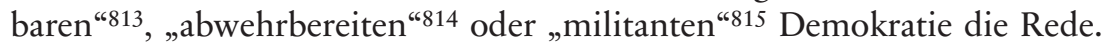
Das Grundgesetz bekennt sich durch Art. 79 Abs. 3 GG i.V.m. Art. 1 und 20 Abs. 1 GG zu einer die Menschenwürde achtenden demokratischen Staatsordnung und schränkt als extreme Folge daraus die Revisionsgewalt des verfassungsändernden (und demokratisch legitimierten) Gesetzgebers dementsprechend ein. Wenn das Grundgesetz durch Art. 79 Abs. 3 GG eine Unberührbarkeit der Grundsätze der Art. 1 und 20 GG vor dem formell legal handelnden verfassungsändernden Gesetzgeber statuiert, so muss es erst recht staatliche Abwehrmaßnahmen gegen in sonstiger Weise die verfassungsrechtlichen Grundprinzipien gefährdenden Subjekte zulassen.

Das Prinzip der „wehrhaften Demokratie“ begründet an sich die Möglichkeit einer tauglichen Einschränkung der das Demokratieprinzip ausgestaltenden Festsetzungen. ${ }^{816}$ Die Frage, „ob“ die von einem offenen politischen Willensbildungsprozess vorausgesetzte Parteiengleichheit generell unter dem Aspekt der wehrhaften Demokratie eingeschränkt werden kann, ist damit zu bejahen. ${ }^{817}$ Das Prinzip der wehrhaften Demokratie hat in der Rechtsordnung eine Doppelfunktion inne, die Eingriffe in die Freiheiten der Bürger sowohl legitimiert als auch limitiert. ${ }^{818}$ So kann in der Verschärfung des Wehrhaftigkeitsprinzips ein legitimer Grund liegen, um die politischen Gleichheitsrechte der Parteien einzuschränken. ${ }^{819}$ Einschränkungen der sich aus dem Demokratieprinzip ergebenden parteienspezifischen Gleichheitsrechte sind damit grundsätzlich möglich. Den of-

812 Thiel, in: ders. (Hrsg.), Wehrhafte Demokratie, 2003, S. 1, 5.

813 BVerfGE 5, 85 (139); siehe auch Bulla, AöR 98 (1973), 340 ff.; Loewenstein, Am Polit Sci Rev 1937, 417 ff.

814 Schmitt Glaeser, Missbrauch und Verwirkung von Grundrechten im politischen Meinungskampf, 1968, S. 31, 38.

815 Dreier, JZ 1994, 741 (751).

816 Kritisch insbesondere Ridder, in: Bethge/Bünemann/Enderlein (Hrsg.), Die Zerstörung der Demokratie in der BRD durch Berufsverbote, ${ }^{2}$ 1976, S. 57, 62, der das „Prinzip der wehrhaften Demokratie“ als rechtlich zulässige Ausnahme qualifiziert.

817 Siehe gerade im Zusammenhang mit der Verfassungsänderung zum Zwecke des Ausschlusses verfassungsfeindlicher Parteien aus der staatlichen Parteienfinanzierung Ferreau, DÖV 2017, 494 (498).

818 Denninger, in: VVDStRL 37 (1979), S. 15; Thiel, in: ders. (Hrsg.), Wehrhafte Demokratie, 2003, S. 1, 22.

819 Zum Verhältnis von Freiheit und Gleichheit siehe Kirchhof, in: Badura (Hrsg.), Wege und Verfahren des Verfassungslebens, 1993, S. 133, 137. 
fenen politischen Willensbildungsprozess zum Zwecke einer dauerhaften Gewährleistung der demokratischen Staatsform einzuschränken wird damit auch durch Art. 79 Abs. 3 GG nicht generell untersagt, solange das hierfür eingesetzte Mittel nicht selbst im Widerspruch zur demokratischen Staatsform steht.

\section{Vereinbarkeit mit Art. 79 Abs. 3 GG}

Das Verfahren zum Zwecke des Ausschlusses verfassungsfeindlicher Parteien aus der staatlichen Parteienfinanzierung stellt einen Eingriff in den Status der Parteiengleichheit dar. Der verfassungsändernde Gesetzgeber bewegt sich in einem rechtlichen Bereich, der aufgrund seines ausgeprägten Bezuges zum Demokratieprinzip gegenüber Einschränkungen besonders empfindlich ist. So sind bei der Ausgestaltung des Verfahrens die Grundsätze einer demokratischen Herrschaftsordnung in angemessener Weise zu berücksichtigen. Das Prinzip der Wehrhaftigkeit der Demokratie vermag Einschränkungen demokratischer Leitgedanken zu rechtfertigen, darf diese allerdings nicht in ihr Gegenteil verkehren. Verfahrenstechnische und tatbestandliche Ausgestaltungen des Art. 21 Abs. 3 GG sowie ihre konkrete Rechtsfolge könnten individuell als auch im Rahmen einer Gesamtbetrachtung die Grundsätze des Demokratieprinzips berühren und dadurch nach Art. 79 Abs. 3 GG unzulässig sein. Nachdem das Verfahren bereits an vorheriger Stelle dargestellt wurde, wird nun im Einzelnen untersucht, ob Art. 21 Abs. 3 GG mit den Maßgaben des Art. 79 Abs. 3 GG vereinbar ist.

Die verfassungsrechtliche Relevanz in Bezug auf Art. 79 Abs. 3 GG liegt sowohl in der Institutionalisierung des Finanzierungsausschlussverfahrens („Ob“), als auch in der konkreten Ausgestaltung der eingreifenden staatlichen Maßnahme selbst („Wie“). Der verfassungsrechtliche Grundgedanke, zur dauerhaften Gewährleistung der demokratischen Staatsform Eingriffe in die Freiheits- und in diesem Falle Gleichheitssphäre zuzulassen, kann nicht uneingeschränkt gelten. Je umfassender der Staat die „Wehrhaftigkeit" seines Systems ausgestaltet, umso höher fällt die Eingriffsintensität in anderen Bereichen, insbesondere der sich aus dem Demokratieprinzip ergebenden Freiheits- und Gleichheitssphäre der Bürger aus. ${ }^{820}$ Nicht zu Un-

820 Vgl. Thiel, in: ders. (Hrsg.), Wehrhafte Demokratie, 2003, S. 1, 14; siehe auch Scheuner, in: Um Recht und Gerechtigkeit, 1950, S. 313, 323, der auf eine aus dem Prinzip des Verfassungsschutzes erwachsene staatliche institutionelle Verbürgung zu den Freiheitsrechten spricht. 
recht wurde auf die Gefahr hingewiesen, dass durch eine konsequente und radikale Anwendung des Wehrhaftigkeitsprinzips die „Lehre der streitbaren Demokratie“ in ein autoritäres oder totalitäres Staatsverständnis münden kann. ${ }^{821}$

\section{a) Gestörtes Konkurrenzverhältnis}

Für die Frage nach der Vereinbarkeit der Grundgesetzänderung mit Art. 79 Abs. 3 GG ist der Grad der wettbewerblichen Verzerrung, der durch die staatliche Kategorisierung von Parteien ausgeht, maßgeblich. Durch die Feststellung des Ausschlusses aus der staatlichen Parteienfinanzierung institutionalisiert der Staat einen politischen Wettbewerb, der durch ein staatlich kategorisiertes und dadurch gestörtes Konkurrenzverhältnis geprägt ist. ${ }^{822}$ Art. 21 Abs. 3 GG gibt dem Staat nicht nur ein Werkzeug zur Hand, verfassungsfeindliche Parteien aus der staatlichen Parteienfinanzierung auszuschließen, sondern schafft eine verfassungsrechtlich etablierte Kategorie der „Parteien zweiter Klasse“ 823 , die vorsieht, dass die Parteien ohne jedwede staatliche Begünstigung in Form der unmittelbaren oder mittelbaren Parteienfinanzierung mit an der staatlichen Parteienfinanzierung teilnehmenden und in steuerlichen Belangen privilegierten Parteien konkurrieren müssen. ${ }^{824}$ Ausgehend von dem Standpunkt, dass die Demokratie eine egalitäre Ordnung ist, die die Chancengleichheit aller Wettbewerber voraussetzt, scheint es problematisch, wenn durch eine Verfassungsänderung ein politischer Wettbewerb mit zwei unterschiedlich zu behandelnden Gruppen etabliert wird ${ }^{825}$; der Staat durch die Vornahme einer Kategorisierung der Wettbewerber selbst lenkend in den politischen Willensbildungsprozess eingreift und die streng formale Chancengleichheit der Parteien unter den Vorbehalt der Verfassungskonformität stellt. Der Ausschluss aus der staatlichen Parteienfinanzierung wirft die Frage auf, ob in einer demokratisch-egalitären Verfassungsordnung eine Kategorisierung mit rechts- und wettbewerbserheblichem Charakter von Parteien generell zulässig ist.

821 Bulla, AöR 98 (1973), 340 (360).

822 Als „Zweiklassensystem“ bezeichnend Morlok, ZRP 2017, 66 (68).

823 Linke, DÖV 2017, 483 (492).

824 Vgl. Janson, NVwZ 2018, 288 (289).

825 Morlok, ZRP 2017, 66 (68). 
Das Änderungsgesetz zum Zwecke des Ausschlusses von Parteien aus der staatlichen Parteienfinanzierung war noch nicht Gegenstand einer verfassungsgerichtlichen Normenkontrolle, hat allerdings bereits zahlreiche Reaktionen im Schrifttum hervorgerufen. ${ }^{826}$ Die weit überwiegende Mehrheit im Schrifttum nimmt die Verfassungskonformität des Art. 21 Abs. 3 GG an. ${ }^{827}$ Dennoch gibt es Auffassungen, die zumindest erhebliche Zweifel an der Zulässigkeit der Verfassungsänderung äußern. ${ }^{828}$ Insbesondere sei für Tobias Linke zweifelhaft, ob die Novelle des Art. 21 GG $^{829}$ aufgrund des durch sie auftretenden „Zwei-Klassen-Wettbewerbs“ tatsächlich am Maßstab des Art. 79 Abs. 3 GG zulässig sein könne, denn so würde durch den Ausschluss aus der staatlichen Parteienfinanzierung ein Paradoxon im „repräsentativ-parteienstaatlichen Gefüge des Grundgesetzes“ hervorgerufen werden. ${ }^{830}$ Durch die partielle Einschränkung der Chancengleichheit der Partei würde der Staat gleichzeitig das Recht oder die Fähigkeit der Partei, an der politischen Willensbildung mitzuwirken, bestreiten und damit im Kern ihre „Parteieneigenschaft“ infrage stellen, was das demokratische Herrschaftssystem gerade aufgrund der wesensmäßig vorausgesetzten Chancengleichheit im politischen Wettbewerb grundsätzlich nicht zulasse.

Dieser Einwand vermag allerdings insoweit nicht zu überzeugen, als die (vermeintliche) Unzulässigkeit der Verfassungsänderung damit begründet wird, dass der Staat durch die Einschränkung der Chancengleichheit den Parteien ihr Recht oder ihre Fähigkeit der Mitwirkung an der politischen Willensbildung in Abrede stelle. Richtig ist, dass die betroffene Partei in

826 Siehe zur Diskussion u.A. Shirvani, DÖV 2018, 921 (924); Linke, DÖV 2017, 483 (492); Ferreau, DÖV 2017, 494 (497 f.); Morlok, ZRP 2017, 66 ff.; Barczak, in: ders. (Hrsg.), BVerfGG Mitarbeiterkommentar zum Bundesverfassungsgerichtsgesetz, 2018, \$46a, Rn. 5 .

827 Epping, Rechtsgutachten über die Frage, ob und unter welchen Voraussetzungen eine nicht nach Art. 21 II GG verbotene Partei von der staatlichen Parteifinanzierung ausgeschlossen werden kann, 14.11.2008, S. 22 ff.; Morlok/Krüper/ Roßner, Parteienfinanzierung im demokratischen Rechtsstaat, 2009, S. 74 ff.; Schwarz, NVwZ-Beilagenheft 2017, 39 (40 f.); Ferreau, DÖV 2017, 494 (497 ff.); Kloepfer, NVwZ 2017, 913 (917); Shirvani, DÖV 2018, 921 (924); Barczak, in: ders. (Hrsg.), BVerfGG Mitarbeiterkommentar zum Bundesverfassungsgerichtsgesetz, 2018, \46a, Rn. 5; Klein, in: Maunz/Dürig (Hrsg.), Grundgesetz, 2018, Art. 21, Rn. 540d; Grzeszick/Rauber, in: Schmidt-Bleibtreu/Hofmann/Henneke (Hrsg.), GG, ${ }^{14} 2018$, Art. 21, Rn. 164.

828 Deutlich Linke, DÖV 2017, 483 (492); Gusy, NJW 2017, 601 (603).

829 BGBl. 2017, I, S. 2346.

830 Im Folgenden Linke, DÖV 2017, 483 (492). 
einem gestörten Konkurrenzverhältnis zu ihren anderen Wettbewerbern steht und insoweit eine erhebliche Beeinträchtigung ihrer Wettbewerbsfähigkeit durch einen Ausschluss aus der staatlichen Parteienfinanzierung zu befürchten hat, wodurch nicht nur ihre subjektive Rechtsstellung beschränkt, sondern auch die objektiv-rechtliche Institution des offenen Parteienwettbewerbs verzerrt ist. Maßgeblich ist allerdings, dass der Eingriff in die Chancengleichheit die Parteien zumindest nicht unmittelbar an einer weiteren Teilnahme am politischen Wettbewerb hindert. Ihr Status als „Partei“ wird nicht infrage gestellt, sondern ihr Rechtskreis, der ihr kraft ihrer Parteieneigenschaft zusteht, eingegrenzt und nicht aberkannt. ${ }^{831}$ Der Rechtskreis oder der Status der Parteien weist zwar eine unabdingbare Verbindung zur demokratischen Staatsordnung auf, ist allerdings nicht uneinschränkbar. Die parteispezifischen Rechte können keine absolute Geltung beanspruchen, soweit diese nicht im konkreten Einzelfall für die Demokratie von zentraler Bedeutung sind. Das Bundesverfassungsgericht hat auch betont, dass es keine staatliche Neutralität gegenüber den Feinden der Verfassung geben kann und der Staat deshalb zum Schutze seiner verfassungsmäßig festgelegten höchsten Rechtsgüter Ungleichbehandlungen vornehmen darf. ${ }^{832}$

Der Staat befand sich in einer Pflichtenkollision, die der verfassungsändernde Gesetzgeber über eine Erweiterung des Prinzips der wehrhaften Demokratie versucht hat, angemessen aufzulösen. Der Einwand, es handele sich bei der Befreiung von der Pflicht zur staatlichen Finanzierung nicht um ein verfassungsrechtliches, sondern bestenfalls um ein allgemeinpolitisches Motiv ${ }^{833}$ ist auch nicht überzeugend, da wie bereits ausgeführt ${ }^{834}$, dem Staat eine verfassungsrechtliche Pflicht zur Aufrechterhaltung der fundamentalen Verfassungsprinzipien obliegt und er dieser Pflicht gerade zuwiderhandelt, wenn er verfassungsablehnende oder -gefährdende Organisationen staatlich fördert. Die mit der Novelle des Art. 21 GG einhergehende staatliche Störung der parteilichen Konkurrenzverhältnisse führt allein nicht zu einem Verstoß gegen Art. 79 Abs. 3 GG. Der Parteienwettbewerb wird zwar verzerrt und der Staat nimmt eine erhebliche, auch für die bestehende demokratische Staatsordnung bedeutende Ungleichbehandlung vor, die vorgenommene Ungleichbehandlung lässt sich angesichts des Prinzips der „wehrhaften Demokratie“ jedoch rechtfertigen. Der verfas-

831 Vgl. Müller, DVBl 2018, 1035 (1039).

832 BVerfGE 5, 85 (139); BVerfGE 39, 334 (349).

833 So Linke, DÖV 2017, 483 (492).

834 Siehe $₫ 4 \mathrm{~B}$. 
sungsändernde Gesetzgeber verfolgt ein sachgerechtes und verfassungsrechtlich gebotenes Ziel, indem er für sich selbst die Möglichkeit schafft, verfassungsablehnende Parteien von einer fortwährenden staatlichen Förderung auszuschließen. Eine erhebliche wettbewerbsverzerrende Wirkung ist zwar nachweislich vorhanden, aufgrund der gebotenen Zielsetzung verfassungsrechtlich allerdings nicht zu beanstanden.

\section{b) Bewertung der Intensität der Ungleichbehandlung}

Bei der Novellierung des Art. 21 GG musste der Staat die Anwendung des Prinzips der wehrhaften Demokratie mit der damit einhergehenden demokratiebezogenen Intensität der Wettbewerbsverzerrung angemessen ausgleichen, sodass ein Widerspruch zu dem Demokratieprinzip vermieden wird. Ob die Grundsätze des Demokratieprinzips „berührt“ sind, kann nicht nur formelhaft danach bemessen werden, ob die Parteiengleichheit dem übergeordneten demokratischen Leitprinzip immanent und damit einer Modifikation unzugänglich ist oder lediglich eine in zulässiger Weise veränderbare Konkretisierung dessen darstellt. Zwar stellt, wie auch die h.M. annimmt, die Parteiengleichheit lediglich eine Konkretisierung des Demokratieprinzips dar und ist deshalb einer Modifizierung durch den verfassungsändernden Gesetzgeber zugänglich ${ }^{835}$, allerdings muss weiter im Einzelfall beurteilt werden, ob die vorliegende Veränderung der Chancengleichheit so weit reicht, dass ein Durchgriff auf das übergeordnete Demokratieprinzip angenommen werden kann. Dies kann effektiv über eine auf einer Gesamtbetrachtung basierenden Wertung des Art. 21 Abs. 3 GG ermittelt werden. Der politische Willensbildungsprozess müsste, um einen Verstoß gegen Art. 79 Abs. 3 GG zu begründen, durch die „Kategorisierung" in einem solchen Maße beeinflusst werden, dass ein offener politischer Willensbildungsprozess mit den gleichen Teilhabemöglichkeiten aller Bürger nicht mehr gewährleistet werden kann. Der „Grundsatz“ der Demokratie müsste somit durch das Finanzierungsausschlussverfahren berührt werden.

835 Epping, Rechtsgutachten über die Frage, ob und unter welchen Voraussetzungen eine nicht nach Art. 21 II GG verbotene Partei von der staatlichen Parteifinanzierung ausgeschlossen werden kann, 14.11.2008, S. 37 ff.; Schwarz, NVwZBeilagenheft 2017, 39 (40 f.); Shirvani, DÖV 2018, 921 (924); Barczak, in: ders. (Hrsg.), BVerfGG Mitarbeiterkommentar zum Bundesverfassungsgerichtsgesetz, 2018, $\mathbb{4} 46 \mathrm{a}, \mathrm{Rn} .5$. 
Die egalitäre Ordnung und die damit einhergehende Chancengleichheit der Parteien stehen im Zusammenhang mit der Möglichkeit des Machtwechsels. Durch diese Art der Sanktionierung von Parteien und der damit verbundenen Einschränkung der Parteiengleichheit versucht der Staat seine grundlegenden Verfassungswerte unter Inkaufnahme ihrer gleichzeitigen Einschränkung zu schützen.

Durch den Ausschluss aus der staatlichen Parteienfinanzierung wird die betroffene Partei weiterhin als vollwertiger politischer Akteur geduldet und ihre Teilnahme am politischen Willensbildungsprozess lediglich finanziell erschwert, rechtlich allerdings weiterhin gewährleistet. ${ }^{836}$ Anders als das Parteiverbot, das nach $₫ 1 \mathrm{AbgG}$ iVm. $\$ 46$ Abs. 1 S. 1 Nr. 5 BWG zu dem Verlust sämtlicher Abgeordnetenmandate der zur betroffenen Partei zugehörigen Bundestagsabgeordneten führt und damit der Partei als solcher die Legitimität zur Teilnahme am politischen Wettbewerb vollständig abspricht ${ }^{837}$, beeinflusst Art. 21 Abs. 3 GG zwar die Wettbewerbsfähigkeit der Partei negativ, ermöglicht ihr allerdings weiterhin als Partei an der politischen Willensbildung teilzunehmen. ${ }^{838}$ Die Sorge, eine Partei könnte durch den Ausschluss aus der staatlichen Parteienfinanzierung in eine ihre Existenz bedrohende Lage geraten ${ }^{839}$, ist zwar begründet, doch dem kann entgegengehalten werden, dass durch den Ausschluss der Partei eigene Bemühungen um ihre Finanzierung nicht versagt werden. ${ }^{840}$ Die Wirkung des Art. 21 Abs. 3 GG begrenzt sich ausschließlich auf die Parteiengleichheit und erstreckt sich weder auf das konkrete Wahlrecht noch auf die Stellung der Abgeordneten im Deutschen Bundestag. Der politische Wettbewerb wird zwar verzerrt, allerdings verhält sich dies in einem Rahmen, in dem zweifelslos noch ein offener politischer Willensbildungsprozess gewährleistet werden kann. Die Fähigkeit des politischen Wettbewerbs, Minderheiten zu Mehrheiten erstarken zu lassen und die Staatsgewalt maßgeblich nach dem freien Willen des Volkes auszugestalten, bleibt gewahrt.

836 A.A. Linke, DÖV 2017, 483 (492).

837 Shirvani, Das Parteienrecht und der Strukturwandel im Parteiensystem, 2012, S. 291 f.; ders., DÖV 2018, 921 (923 f.); Klein, in: Maunz/Dürig (Hrsg.), Grundgesetz, 2018, Art. 21, Rn. 495.

838 Shirvani, DÖV 2018, 921 (924).

839 Kloepfer, NVwZ 2017, 913 (919); Nikkho, DVBl 2018, 337 (340).

840 So auch Shirvani, DÖV 2018, 921 (923). 
c) Argumentum a maiore ad minus

Ein weiterer Ansatzpunkt zur Begründung der Verfassungskonformität des Art. 21 Abs. 3 GG stellt ein argumentum a maiore ad minus ${ }^{841}$ dar. Demnach sei die Einführung des Finanzierungsausschlussverfahrens nicht zu beanstanden, da nach der Konzeption des Grundgesetzes das Parteiverbot zulässig ist und dies erst recht für mildere Maßnahmen gelten müsse, die dieselbe Zielrichtung aufwiesen. ${ }^{842}$ Wenn also das Parteiverbot die „Grundsätze“ i.S.v. Art. 79 Abs. 3 GG i.V.m. Art. 20 Abs. 1 GG nicht berührt, dann muss dies erst recht für das Finanzierungsausschlussverfahren gelten, sofern es tatsächlich eine mildere Maßnahme darstellt.

Dieser Ansatzpunkt stützt sich auf ein relativierendes Verständnis des Art. 79 Abs. 3 GG, was zunächst voraussetzt, dass die Verfassungsänderung und das Parteiverbot eine Wesensverwandschaft aufweisen, damit die Instrumente im Rahmen dieser Methodik überhaupt miteinander ins Verhältnis gesetzt werden können. Demnach wird zunächst die Verfassungsmäßigkeit des Parteiverbotes ${ }^{843}$ unterstellt und dieses sodann als qualitative "Schwelle“844 des im Rahmen des Demokratieprinzips zulässigen Sanktionsmittel gegen Parteien definiert. Anschließend wird das in der Verfassungsänderung vorgesehene Mittel mit der gebildeten „Schwelle“ ins Verhältnis gesetzt, wobei darauf zu achten ist, ob die Folgen der Verfassungsänderung leichter, gleich schwer oder schwerer wiegen als das zur „Schwellenbildung“ herangezogene Instrument. Sollte dieses Vorgehen zu dem Ergebnis führen, dass die Verfassungsänderung hinsichtlich der Schwere ihrer Folgen hinter der gesetzten Schwelle zurückbleibt (und somit ein „Minus“ darstellt), kann dies im Rahmen der bei Art. 79 Abs. 3 GG vorzunehmenden Einzelfallbetrachtung ${ }^{845}$ als Umstand herangezogen wer-

841 Barczak, in: ders. (Hrsg.), BVerfGG Mitarbeiterkommentar zum Bundesverfassungsgerichtsgesetz, 2018, 46a, Rn. 5; Linke, DÖV 2017, 483 (490); Müller, DVBl 2018, 1035 (1038f.).

842 Barczak, in: ders. (Hrsg.), BVerfGG Mitarbeiterkommentar zum Bundesverfassungsgerichtsgesetz, 2018, \46a, Rn. 5; Kloepfer, NVwZ 2017, 913 (919); Shirvani, DÖV 2018, 921 (923 f.); Müller, DVBl 2018, 1035 (1038f.).

843 Hierzu siehe BVerfGE 144, 20 (195 ff.); auch statt vieler Morlok, in: Dreier/Bauer (Hrsg.), Grundgesetz, ${ }^{3} 2015$, Art. 21, Rn. 143 ff.

844 Vgl. hierzu BVerfGE 144, 20 (202), das im Hinblick zum Parteiverbot auch ein „Schwellenverständnis“ zugrunde legt.

845 Siehe hierzu bereits oben\$ 4. D.II.1.; vgl. Stern, JuS 1985, 329 (333); Dreier, in: Dreier/Bauer (Hrsg.), Grundgesetz, ${ }^{3}$ 2015, Art. 79 Abs. 3, Rn. 19; BVerfGE 30, 1 (41 f.) - Sondervotum. 
den, um eine Vereinbarkeit der Verfassungsänderung mit dem im Einzelfall maßgeblichen Prinzip zu begründen.

\section{(1) Streitstand zur Qualifizierung als „Minus“ oder „Aliud“}

Die maßgebliche Problematik hinter dem argumentum a maiore ad minus stellt die Qualifizierung des Art.21 Abs.3 GG als „Minus“ oder echtes „Aliud“ im Verhältnis zum Parteiverbot dar. Ausgangspunkt zur Lösung der umstrittenen Frage ist, ob Art. 21 Abs. 3 GG insoweit eine „mildere Rechtsfolge" aufweist bzw., um die Auffassung des Bundesverfassungsgerichtes aufzugreifen, eine Maßnahme „unterhalb der Schwelle des Parteiverbotes" ${ }^{846}$ darstellt. Tobias Linke führt, ohne sich abschließend auf eine Lösung festzulegen, zwei Punkte an, die nach seiner Auffassung gegen eine Einordnung des Finanzierungsausschlusses als „Minusmaßnahme“ sprächen. ${ }^{847}$ Zum einen gäbe es eine teleologische Konvergenz zum Verbot, die aus der Prämisse hervorginge, dass beide Verfahren auf das Entfernen der Partei aus dem politischen Wettbewerb abzielten, indem mit dem Finanzierungsausschlussverfahren erreicht werden solle, dass sich kleine und mittellose Parteien in letzter Konsequenz aus ökonomischen Gründen auflösen müssten. ${ }^{848}$ Selbiges Argument entkräftet er teilweise im Anschluss mit dem Hinweis, dass das Finanzierungsausschlussverfahren im Unterschied zum Parteiverbot die Existenz der betroffenen Partei nicht unmittelbar bedrohe. Als zweite Überlegung wird von ihm angeführt, dass durch den Ausschluss aus der staatlichen Parteienfinanzierung das Wesen der Parteienfinanzierung dergestalt verändert werde, dass durch die partielle Einschränkung der Chancengleichheit der Parteien in Belangen der staatlichen Parteienfinanzierung, deren Gewährungs- und Verteilungsgrundsätze bislang wertneutral ausgestaltet waren ${ }^{849}$, der Staat der Partei das Recht und die Fähigkeit absprechen würde, in chancengleicher Weise an der politischen Willensbildung des Volkes mitzuwirken und damit im Ergebnis ihre Parteieneigenschaft als solche bestreite. ${ }^{850}$

846 BVerfGE 144, 20 (202).

847 Im Folgenden Linke, DÖV 2017, 483 (491); Barczak, in: ders. (Hrsg.), BVerfGG Mitarbeiterkommentar zum Bundesverfassungsgerichtsgesetz, 2018, \46a, Rn. 6.

848 Linke, DÖV 2017, 483 (491); Nikkho, DVBl 2018, 337 (340).

849 Siehe $\$ 3$ A. II.

850 Linke, DÖV 2017, 483 (491f.). 
Bedenken hinsichtlich Art. 21 Abs. 3 GG als mildere Maßnahme äußert auch Tristan Barczak, der sich zwar letztendlich gegen die Qualifizierung als „Aliud“ ausspricht ${ }^{851}$, allerdings gleichzeitig darauf hinweist, dass das Finanzierungsausschlussverfahren nah an ein „Verbotsäquivalent unter Ausschluss des Potentialitätskriteriums“ herankäme. ${ }^{852}$ Die Befristung der Ausschlusswirkung in $\$ 46$ a Abs. 1 S. 1 BVerfGG würde einer Einordnung als Aliud entgegenstehen und somit verhindern, dass es sich bei Art. 21 Abs. 3 GG um „verfassungswidriges Verfassungsrecht“ handele. ${ }^{853}$

Eine weitere Ansicht vergleicht das Parteiverbot und den Finanzierungsausschluss auf normativer Ebene und zieht aus der tatbestandlichen und rechtsfolgenbezogenen Divergenz sowie den tatsächlichen Auswirkungen der beiden Verfahren den Schluss, dass es sich bei Art. 21 Abs. 3 GG um eine „Minusmaßnahme“ handele. ${ }^{854}$ So zweifelt insbesondere Foroud Shirvani an der existenzbedrohenden Wirkung des Art. 21 Abs. 3 GG und weist darauf hin, dass die Fähigkeit, eine eigenständige Finanzierung sicherzustellen, weiterhin uneingeschränkt gegeben und der staatliche Anteil an der Parteienfinanzierung aufgrund der relativen und absoluten Obergrenze ohnehin limitiert sei. ${ }^{855}$ Zudem würde sich die Wirkung des Parteiverbotes auf das Wahlrecht als solches erstrecken, indem die Bundestagsabgeordneten der Partei bei der Feststellung der Verfassungswidrigkeit durch das Bundesverfassungsgericht ihr Mandat verlierten und die rechtliche Existenz der Partei als solche unmittelbar durch einen Hoheitsakt beendet werde. ${ }^{856}$

Auch der EGMR hat sich, bezogen auf die türkische Verfassung, für die Qualifizierung eines Finanzierungsausschlusses als Minusmaßnahme zum Parteiverbot ausgesprochen. ${ }^{857}$ Im Rahmen einer Verhältnismäßigkeitsprüfung sah der EGMR einen Ausschluss aus der staatlichen Finanzierung als mildere Handlungsalternative des Staates an. Hintergrund ist vor allem,

851 Barczak, in: ders. (Hrsg.), BVerfGG Mitarbeiterkommentar zum Bundesverfassungsgerichtsgesetz, 2018, \46a, Rn. 5 .

852 Ders., in: ders. (Hrsg.), BVerfGG Mitarbeiterkommentar zum Bundesverfassungsgerichtsgesetz, 2018, $\$ 46 a$, Rn. 6.

853 Ders., in: ders. (Hrsg.), BVerfGG Mitarbeiterkommentar zum Bundesverfassungsgerichtsgesetz, 2018, $\$ 46 a$, Rn. 6.

854 Shirvani, DÖV 2018, 921 (923 f.); ähnlich, und deshalb im Zusammenhang erwähnt auch Müller, DVBl 2018, 1035 (1039).

855 Shirvani, DÖV 2018, 921 (923).

856 Vgl. ders., DÖV 2018, 921 (923).

857 EGMR, Urt. v. 12.01.2016, DTP ua v. Turkey, Nr. 3840/10, 3870/10, 3878/10, 15616/10, 21919/10, 39118/10, 37272/10 = NVwZ-RR 2017, 473 ff., Rz. 104. 
dass Art. 69 Abs. 7 der türkischen Verfassung vorsieht, dass „anstelle der Schließung ${ }^{858}$ einer Partei“, je nach Schwere der Verstöße, auch eine „teilweise oder vollständige Versagung staatlicher Unterstützung“ angeordnet werden kann. Mithin hat der Verfassungswortlaut selbst eine Qualifizierung als rechtliches Minus indiziert, wodurch der EGMR nur die Systematik der Eingriffsgrundlage selbst bei der Abwägung berücksichtigt hat. Das türkische Parteiverbotsverfahren räumt dem anordnenden Verfassungsgericht ein Auswahlermessen ein, in dessen Rahmen es anhand der „Schwere der Verstöße“ als Auswahlkriterium bei Erfüllung des Tatbestandes entscheiden kann, entweder ein Verbot der Partei auszusprechen oder ihr ganz oder teilweise die staatliche Finanzierung zu versagen.

\section{(2) Stellungnahme}

Das Finanzierungsausschlussverfahren stellt dann eine mildere Maßnahme als das Parteiverbot dar, wenn es verbotsähnlich und dadurch vergleichbar ist und wenn die Rechtsfolge eine geringere Ingerenzwirkung aufweist. Durch die tatbestandliche Ähnlichkeit zum Parteiverbot und der Einschränkung des Rechtskreises der Parteien als identische Zielwirkung kann geschlossen werden, dass das Finanzierungsausschlussverfahren qualitativ eine Wesensverwandtschaft zum Parteiverbot aufweist. ${ }^{859}$ Eine Vergleichbarkeit liegt jedenfalls vor.

Weiter müsste die Ingerenzwirkung des Finanzierungsausschlussverfahrens qualitativ geringer sein als die des Parteiverbotes. Insoweit dient als methodisch richtiger Ansatzpunkt der Rechtsfolgenvergleich auf normativer Ebene, der als allgemeine Grundlage bei der Beantwortung der vorliegenden Problemstellung Verwendung fand. ${ }^{860}$ Tristan Barczak stellt auf die befristete Wirkung des Finanzierungsausschlussverfahrens ab, um zwischen einem Aliud und einer Minusmaßnahme zu unterscheiden. So führt er aus, dass „die Befristung die Qualifikation als rechtliches Aliud und damit das Verdikt des verfassungswidrigen Verfassungsrechtes" verhinde-

858 Gleichbedeutend mit dem Begriff des „Verbots“.

859 Als „Stufenverhältnis“ beschreibend vgl. Müller, DVBl 2018, 1035 (1038f.).

860 Methodisch haben alle Auffassungen diese Vorgehensweise gemein, siehe Linke, DÖV 2017, 483 (491); Barczak, in: ders. (Hrsg.), BVerfGG Mitarbeiterkommentar zum Bundesverfassungsgerichtsgesetz, 2018, $\$ 46 a$, Rn. 5, 6; Shirvani, DÖV 2018, 921 (923 f.); Müller, DVBl 2018, 1035 (1039). 
re. ${ }^{861}$ Die Befristungswirkung des Finanzierungsausschlusses geht allerdings nicht unmittelbar aus Art. 21 Abs. 3 GG hervor, sondern wurde einfachgesetzlich in $₫ 46 \mathrm{a}$ Abs. 1 S. 1 BVerfGG geregelt. So scheint es, als habe die einfachgesetzliche Ausgestaltung des Finanzierungsausschlussverfahrens eine unmittelbare Wirkung auf die Verfassungsmäßigkeit des Art. 21 Abs. 3 GG selbst. Hierdurch hänge die Vereinbarkeit mit Art. 79 Abs. 3 GG auch von durch den einfachen Gesetzgeber getroffenen Ausgestaltungsregelungen $a b$.

Diese Argumentationsweise ist abzulehnen, da einfachrechtlich bedingte Verfassungsnormen in der Systematik des Grundgesetzes nicht vorgesehen sind. ${ }^{862}$ Bei der Wahrnehmung des Ausgestaltungsauftrages aus Art. 21 Abs. $5 \mathrm{GG}^{863}$ hat der einfache Gesetzgeber die Vorgaben des Grundgesetzes $\mathrm{zu}$ achten, sodass er das Finanzierungsausschlussverfahren anhand des Maßstabes des gesamten Grundgesetzes tauglich ausgestalten muss. Insbesondere hat er die Vorgaben des Art. 21 Abs. 1 bis Abs. 4 GG zu wahren und sie im Sinne der Norm, und nicht über die von ihr gesetzen Grenzen hinaus, auszugestalten. Damit stellt die grundgesetzliche Norm stets den Maßstab der einfachgesetzlichen Ausgestaltung dar, was dazu führt, dass eine untaugliche einfachgesetzliche Ausgestaltungsnorm normhierarchisch nicht zu „verfassungswidrigem Verfassungsrecht" 864 führen kann, sondern eine normative Grenzüberschreitung lediglich in der Verfassungswidrigkeit der einfachgesetzlichen Ausgestaltungsregelung resultiert. Nachdem die Befristungswirkung sowie andere einfachgesetzliche Ausgestaltungsregelungen bei der Frage, ob Art. 21 Abs. 3 GG aufgrund der Qualifikation als „Minusmaßnahme“ zum Parteiverbot mit Art. 79 Abs. 3 GG vereinbar ist, nicht miteinbezogen werden können, muss das Finanzierungsausschlussverfahren allein nach der grundgesetzlichen Konzeption ein rechtliches Minus darstellen. Insoweit muss ein Vergleich der Eingriffsintensität beider Rechtsfolgen auf der Ebene des Grundgesetzes Aufschluss über die Qualifikation des Normcharakters als rechtliches Minus oder Aliud ergeben.

Für eine Qualifizierung des Art. 21 Abs. 3 GG als rechtliches Minus ist die Rechtsfolgenwirkung sowohl hinsichtlich ihrer Intensität in subjektive

861 Barczak, in: ders. (Hrsg.), BVerfGG Mitarbeiterkommentar zum Bundesverfassungsgerichtsgesetz, 2018, \$46a, Rn. 6; Shirvani, DÖV 2018, 921 (923).

862 Vgl. Nikkho, DVBl 2018, 337 (341).

863 Zum Begriff siehe nur Streinz, in: Huber/Voßkuhle (Hrsg.), Grundgesetz, ${ }^{72018,}$ Art. 21, Rn. 253.

864 Barczak, in: ders. (Hrsg.), BVerfGG Mitarbeiterkommentar zum Bundesverfassungsgerichtsgesetz, 2018, $\$ 46 a$, Rn. 5 . 
wie auch objektive Rechtsgüter maßgeblich. Das Parteiverbot bewirkt auch ohne die einfachgesetzliche Ausgestaltung der Rechtsfolge in $\$ 46$ BVerfGG, dass eine Partei ihre Rechtsstellung als solche verliert und damit sämtliche zusammenhängenden Rechte und Pflichten entfallen. ${ }^{865}$ Der Vereinigung als solcher wird das verfassungsrechtliche Mandat aus Art. 21 Abs. 1 S. 1 GG entzogen und sie fiele, hätte der einfache Gesetzgeber nicht die zwingende Auflösung der Vereinigung in $\$ 46$ Abs. 3 S. 1 BVerfGG vorgesehen, in den Status einer unqualifizierten Vereinigung i.S.d. Art. 9 Abs. 1 GG. ${ }^{866}$ Subjektiv-rechtlich beseitigt das Parteiverbot somit die Rechtsstellung einer Partei und entzieht ihr sämtliche hiermit zusammenhängenden Privilegien. Hierdurch wird insbesondere in den Kernbereich der Bestands- und Betätigungsgarantie ${ }^{867}$ eingegriffen. Objektivrechtlich wird eine Partei aus dem politischen Wettbewerb entfernt und damit ein Akteur des politischen Lebens sowie die ihm zuzuordnende politische Strömung vollständig beseitigt.

Vergleicht man die Rechtsfolgenwirkung von Art. 21 Abs. 2 GG mit dem Finanzierungausschlussverfahren, so drängt sich ein qualitativer Unterschied nahezu auf. Die subjektiv-rechtlichen Auswirkungen konzentrieren sich ausschließlich auf die Chancengleichheit der Partei, die auch nicht vollständig beseitigt, sondern ausschließlich in Belangen der staatlichen Parteienfinanzierung eingeschränkt wird. Im Übrigen bleibt die Rechtsstellung der Partei ohne Abstriche erhalten und sie verliert insbesondere nicht ihr Recht zur Teilnahme an Wahlen, wodurch ihr weiterhin das verfassungsrechtliche Mandat, an der politischen Willensbildung des Volkes mitzuwirken, zuerkannt wird. Während das Parteiverbot die ganze Rechtsstellung der betroffenen Partei restlos beseitigt, wird durch den Finanzierungsausschluss lediglich in eine konkrete Rechtsposition (die Chancengleichheit der Partei) eingegriffen. ${ }^{868}$ Der Einwand, durch das Finanzierungsausschlussverfahren werde konkludent die Parteieneigenschaft als solche bestritten ${ }^{869}$, vermag angesichts des weiterhin vorhandenen par-

865 Klein, in: Maunz/Dürig (Hrsg.), Grundgesetz, 2018, Art. 21, Rn. 555 f.; Ipsen, in: Sachs (Hrsg.), Grundgesetz, ${ }^{8} 2018$, Art. 21, Rn. 193; Streinz, in: Huber/Voßkuhle (Hrsg.), Grundgesetz, ${ }^{7} 2018$, Art. 21, Rn. 247; Seifert, Die politischen Parteien im Recht der Bundesrepublik Deutschland, 1975, S. 495.

866 Klein, in: Maunz/Dürig (Hrsg.), Grundgesetz, 2018, Art. 21, Rn. 555 f..

867 Vgl. nur Streinz, in: Huber/Voßkuhle (Hrsg.), Grundgesetz, ${ }^{72018, ~ A r t . ~ 21, ~}$ Rn. 103 ff. m.w.N.

868 Vgl. insoweit auch Grzeszick/Rauber, in: Schmidt-Bleibtreu/Hofmann/Henneke (Hrsg.), GG, ${ }^{14} 2018$, Art. 21, Rn. 162.

869 So Linke, DÖV 2017, 483 (491 f.). 
teilichen Rechtskreises nicht zu überzeugen. Allein dies stellt eine zur Qualifizierung des Art. 21 Abs. 3 GG als rechtliches Minus ausreichende qualitative Divergenz dar. In objektiv-rechtlicher Sicht wird der Parteienwettbewerb, ähnlich wie beim Parteiverbot, verzerrt. Allerdings verbleibt die politische Partei als Akteur des politischen Wettbewerbs, auch wenn dessen Gleichwertigkeit gegenüber den anderen Teilnehmern gemindert ist. Die Beeinträchtigung einer Partei stellt im Verhältnis zu ihrer vollständigen Beseitigung eine qualitativ mildere Verzerrung des politischen Wettbewerbs dar. Auch der Einwand, durch den Ausschluss aus der staatlichen Parteienfinanzierung werde ein faktisches Verbotsäquivalent geschaffen ${ }^{870}$, vermag nicht zu überzeugen. Es kann zwar nicht ausgeschlossen werden, dass eine Partei angesichts der entzogenen Mittel der staatlichen Parteienfinanzierung zur Auflösung aus wirtschaftlichen Gründen gedrängt wird, im Unterschied zum Parteiverbot, wo die Auflösung der Partei durch einen Rechtsakt angeordnet wird, liegt die „Auflösung“ an sich dabei allerdings teilweise im Machtbereich der Partei. Sie kann den ausgefallenen Posten im Haushalt durch das selbstständige Bemühen um ihre Finanzierung versuchen auszugleichen oder zumindest zu minimalisieren. ${ }^{871}$

Eine hinsichtlich Art. 79 Abs. 3 GG bedenkliche Einschränkung des offenen politischen Willensbildungsprozesses kann somit nicht angenommen werden. Der politische Wettbewerb bleibt trotz vereinzelten Ausschlüssen weiterhin staatsfrei und gewährleistet die Willensbildung vom Volk zu den Staatsorganen und kehrt den Prozess nicht um. Die vom Finanzierungsausschluss betroffenen Parteien bleiben weiterhin dem Wettbewerb erhalten und werden ihrer staatsbildenden Funktion nicht beraubt. Da der Staat nicht gezwungen ist, sich auf eine Sanktionsmöglichkeit zu beschränken und sich insgesamt auch auf tatbestandlicher Ebene bei einer verfassungskonformen Auslegung keine Bedenken hinsichtlich der Vereinbarkeit mit den Grundsätzen der Demokratie und insbesondere dem offenen Prozess der politischen Willensbildung aufzeigen, ist der Ausschluss aus der staatlichen Parteienfinanzierung und die damit zusammenhängende staatliche Kategorisierung des Parteienwettbewerbs verfassungsrechtlich nicht zu beanstanden.

870 Vgl. Barczak, in: ders. (Hrsg.), BVerfGG Mitarbeiterkommentar zum Bundesverfassungsgerichtsgesetz, 2018, $\$ 46 a$, Rn. 6.

871 Vgl. Shirvani, DÖV 2018, 921 (923 f.). 
4. Annex: Finanzierungsausschluss unter der Geltung der EMRK

Maßgeblichen Einfluss auf die verfassungsgerichtliche Rechtsprechung zu Parteiverboten und insbesondere dem neuen Merkmal der „Potentialität“ hatte die Rechtsprechung des EGMR. ${ }^{872}$ Wenn staatliches Handeln in Konflikt mit demokratischen Grundprinzipien gerät, liegt nicht nur eine rechtliche Kontrolle am Maßstab des Grundgesetzes nahe, sondern auch eine Überprüfung anhand der einschlägigen Konventionsrechte der EMRK. So wird zunächst herausgearbeitet, welche Konventionsrechte gerade bei Parteiverboten und einer Ungleichbehandlung im Zusammenhang mit der Gewährung einer staatlichen Parteienfinanzierung zusammenhängen und ob Art. 21 Abs. 3 GG den in diesem Rahmen gestellten Anforderungen gerecht wird.

\section{a) Anzuwendende Konventionsrechte}

Nach der Rechtsprechung des EGMR müsse sich das Parteiverbot an Art. 11 Abs. 2 S. 1 EMRK messen lassen und dürfe deshalb nur dann ausgesprochen werden, wenn es in einer demokratischen Gesellschaft zur Aufrechterhaltung der nationalen oder öffentlichen Sicherheit, zur Aufrechterhaltung der Ordnung oder zur Verhütung von Straftaten, zum Schutz der Gesundheit, der Moral oder der Rechte und Freiheiten Dritter notwendig sei. ${ }^{873}$ Die Notwendigkeit setze nach der Auffassung des Gerichtshofs ein „dringendes soziales Bedürfnis" 874 voraus, welches wiederum in angemessener (oder verhältnismäßiger) Art und Weise die Vereinigungsfreiheit aus Art. 11 EMRK einzuschränken vermöge. ${ }^{875}$

872 Siehe ausführlich hierzu bereits oben $₫ 4$.A.

873 EGMR, Urt. v. 13. 2. 2003, Refah Partisi (The Welfare Party) and Others v. Turkey, Nr. 41 340/98 u. a. = NVwZ 2003, 1489 ff., Rz. 51.

874 EGMR, Urt. v. 13. 2. 2003, Refah Partisi (The Welfare Party) and Others v. Turkey, Nr. 41 340/98 u. a. = NVwZ 2003, 1489 ff., Rz. 104, 132; EGMR, Urt. v. 30. 6. 2009, Herri Batasuna and Batasuna v. Spain, Nr. 25 803/04 und 25 817/04, Rz. 79.

875 EGMR, Urt. v. 25. 5. 1998, Socialist Party and Others v. Turkey, Nr. 20/1997/804/1007, Rz. 49; EGMR, Urt. v. 13. 2. 2003, Refah Partisi (The Welfare Party) and Others v. Turkey, Nr. 41 340/98 u. a. = NVwZ 2003, 1489 ff., Rz. 104, 132; EGMR, Urt. v. 30. 6. 2009, Herri Batasuna and Batasuna v. Spain, Nr. 25 803/04 und 25 817/04, Rz. 83 f. 
Die Dogmatik des EGMR zu der Zulässigkeit von Parteiverboten lässt sich allerdings nicht auf den Ausschluss aus der staatlichen Parteienfinanzierung übertragen, da es nicht um eine Auflösung, sondern um eine Ungleichbehandlung gegenüber anderen Parteien geht. ${ }^{876}$ Der Ausschluss aus der staatlichen Parteienfinanzierung knüpft nicht an die Freiheits- sondern an die Gleichheitssphäre der Parteien an. Auch der Einwand, dass das Unterlassen einer weiteren Begünstigung zu der Auflösung der Partei aus wirtschaftlichen Gründen führen könne ${ }^{877}$, vermag die Verwendbarkeit des Art. 11 EMRK als Maßstab für Art. 21 Abs. 3 GG nicht zu begründen. Die betroffene Partei wird nicht unmittelbar in ihrem Bestand bedroht, sondern sieht sich lediglich einer durch den Staat veränderten Wettbewerbslage ausgesetzt. Die Ungleichbehandlung durch den Staat steht im Vordergrund, weshalb der Ausschluss aus der Parteienfinanzierung auch auf der Konventionsebene nicht an Freiheits- sondern an Gleichheitsgarantien gemessen werden muss. Die Gleichheit der Wahl ist als subjektives, auch Parteien zustehendes Recht ${ }^{878}$ auf der Ebene der EMRK anerkannt und leitet sich aus dem in Art. 3 19/1-EMRKZusProt verankerten Recht auf freie Wahlen ab. ${ }^{879}$ Zudem ist im Zusammenhang der staatlichen Parteienfinanzierung auch Art. 14 EMRK zu beachten, wonach eine Diskriminierung aufgrund der politischen Anschauung grundsätzlich verboten ist. ${ }^{880}$ Die Dogmatik gleicht der im deutschen Verfassungsrecht und setzt auch die Gleichheit aller am politischen Wettbewerb teilnehmenden Parteien voraus. ${ }^{881}$ Die Wahlgleichheit gilt nicht als absolut und unterliegt nach der Auffassung des EGMR sog. „ungeschriebenen Einschränkungen “. ${ }^{882}$ Anders als Art. 11 EMRK wird durch die Konvention insoweit kein Zweck vorgegeben, der durch die Einschränkung des Rechts verfolgt werden muss. Der EGMR prüft die Vereinbarkeit einer Einschränkung des Art. 14 EMRK sowie des Art. 3 19/1-EMRKZusProt deshalb anhand von

876 Anders wohl Grzeszick/Rauber, in: Schmidt-Bleibtreu/Hofmann/Henneke (Hrsg.), GG, ${ }^{14} 2018$, Art. 21, Rn. 165.

877 Vgl. hierzu Kloepfer, NVwZ 2017, 913 (919); Nikkho, DVBl 2018, 337 (340).

878 Vgl. EGMR, Urt. v. 8.7. 2008, Georgian Labour Party v. Georgia, Nr. 9103/04, Rz. 72; EGMR, Urt. v. 10.7. 2012, Staatkundig Gereformeerde Partij v. Niederlande, Nr. 58369/10, Rz. 75 ff.; Meyer-Ladewig/Nettesheim, in: Meyer-Ladewig/ Nettesheim/Raumer u.a. (Hrsg.), EMRK, ${ }^{4} 2017$, Art. 3 19/1-EMRKZusProt, Rn. 12.

879 Dies., in: Meyer-Ladewig/Nettesheim/Raumer u.a. (Hrsg.), EMRK, ${ }^{4}$ 2017, Art. 3 19/1-EMRKZusProt, Rn. 17.

880 Vgl. EGMR, Urt. v. 10.5.2012, ÖDP v. Turkey, Nr. 7819/03, Rz. 26 ff.

881 Vgl. EGMR, Urt. v. 8.7. 2008, Yumak u. Sadak v. Turkey, Nr. 10226/03, Rz. 108.

882 EGMR, Urt. v. 8.7.2008, Yumak u. Sadak v. Turkey, Nr. 10226/03, Rz. 109. 
zwei Kriterien: Die Ungleichbehandlung muss verhältnismäßig sein (insbesondere ein legitimes Ziel verfolgen ${ }^{883}$ ) und darf nicht in „die freie Äußerung der Meinung des Volkes“ eingreifen. ${ }^{884}$ In die „freie Äußerung der Meinung des Volkes“ wird nach der Rechtsprechung des Gerichtshofes dann unzulässig eingegriffen, wenn durch die Einschränkung die Integrität und Wirksamkeit des Wahlverfahrens nicht gewahrt wird und sie dadurch den Wahlen die Fähigkeit nimmt, in legitimer Weise den Willen des Volkes festzustellen. ${ }^{85}$ Im Ergebnis führt der EGMR eine klassische Verhältnismäßigkeitsprüfung durch, wobei insbesondere darauf geachtet wird, dass der "Wesensgehalt" der Art. 14 EMRK und Art. 3 19/1-EMRKZusProt gewahrt bleibt. Ob eine Einschränkung überhaupt verhältnismäßig sein kann, wenn der Wesensgehalt des Konventionsrechts angetastet wird, lässt der EGMR allerdings offen. Dogmatisch überzeugender, allerdings vorliegend nicht von wirklicher Relevanz, erscheint es, das Antasten des Wesensgehaltes in die Verhältnismäßigkeitsprüfung zu integrieren. ${ }^{886}$

Hinsichtlich der Legitimität des Finanzierungsausschlusses unter der Geltung der EMRK bedeutet es, dass das Finanzierungsausschlussverfahren ein legitimes Ziel verfolgen und Art. 3 19/1-EMRKZusProt in verhältnismäßiger Weise einschränken muss, insbesondere den „Wesensgehalt“ der Wahlrechtsgleichheit nicht antasten darf. Da Art. 3 19/1-EMRKZusProt keine Zielbestimmung wie die Art. 8 bis Art. 11 EMRK enthält, genügt jede mit dem Grundsatz der Rechtsstaatlichkeit und den allgemeinen Zielen der EMRK übereinstimmende Zielverfolgung. ${ }^{887}$ Insbesondere bedürfe es keines „dringenden sozialen Bedürfnisses“, wie im Falle des Art.11 EMRK. ${ }^{888}$

In der Vergangenheit hat sich der EGMR in der Sache ÖDP./. Türkei vom 10. Mai 2012 mit Ungleichbehandlungen im Zusammenhang mit einer staatlichen Parteienfinanzierung auseinandergesetzt. ${ }^{89}$ Anlass war eine im türkischen Recht vorgesehene Sperrklausel, wonach Parteien bei Wahlen ein Mindestquorum von 7\% der Wählerstimmen auf sich vereinen mussten, um durch die staatliche Parteienfinanzierung begünstigt zu wer-

883 Vgl. EGMR, Urt. v. 10.5.2012, ÖDP v. Turkey, Nr. 7819/03, Rz. 26.

884 Vgl. EGMR, Urt. v. 10.5.2012, ÖDP v. Turkey, Nr. 7819/03, Rz. 29; EGMR, Urt. v. 8.7.2008, Yumak u. Sadak v. Turkey, Nr. 10226/03, Rz. 109.

885 EGMR, Urt. v. 8.7.2008, Yumak u. Sadak v. Turkey, Nr. 10226/03, Rz. 109, 118.

$886 \mathrm{Zu}$ diesem auch hier anwendbaren dogmatischen Grundsatz siehe statt aller Sachs, in: ders. (Hrsg.), Grundgesetz, ${ }^{8} 2018$, Art. 19, Rn. 40 m.w.N.

887 EGMR, Urt. v. 8.7.2008, Yumak u. Sadak v. Turkey, Nr. 10226/03, Rz. 109.

888 EGMR, Urt. v. 8.7.2008, Yumak u. Sadak v. Turkey, Nr. 10226/03, Rz. 109.

889 EGMR, Urt. v. 10.5.2012, ÖDP v. Turkey, Nr. 7819/03. 
den. ${ }^{890}$ Nach der Auffassung des EGMR sei das Erfordernis eines Minimums an Unterstützung durch die Wählerschaft zur Verhinderung einer „Zersplitterung“ des Parlamentes und der damit einhergehenden Beeiträchtigung der Funktionalität des Parlamentswesens ein solch „legitimes Ziel“, dessen Verfolgung derartige Ungleichbehandlungen rechtfertige. ${ }^{891}$ Anders als das Bundesverfassungsgericht, dass am Maßstab des Grundgesetzes wohl allein einen Wählerstimmenanteil von höchstens $0,5 \%$ für zulässig erachtet ${ }^{892}$, beanstandet der EGMR eine Hürde von $7 \%$ nicht. ${ }^{893}$ Dass als Hürde ein Wählerstimmenanteil von 7\% gewählt worden sei, beruhe insoweit auf objektiven und verständlichen Gründen, die den Wesensgehalt der „freien Äußerung der Meinung des Volkes“ nicht berührten und deshalb nicht im Widerspruch zu Art. 14 EMRK sowie Art. 3 19/1-EMRKZusProt stünden.

b) Vereinbarkeit von Art. 21 Abs. 3 GG mit der EMRK

Der EGMR hat bereits die Kürzung staatlicher Mittel an Parteien als ein „milderes Mittel“ im Vergleich zum Parteiverbot eingestuft. Bei der Entscheidung über das in der Türkei ausgesprochene Parteiverbot gegen die Demokratik Toplum Partisi (DTP) führte das Gericht aus:

„Das türkische Verfassungsgericht hat die härteste in der Verfassung vorgesehene Maßnabme angeordnet, nämlich die Auflösung der DTP, und nicht eine weniger schwere, nämlich der Partei ganz oder teilweise die finanzielle Unterstützung des Staates zu entziehen" 894.

890 Zur deutschen Rechtslage siehe bereits die Ausführungen oben $\$ 3 . C . I I I$.

891 EGMR, Urt. v. 10.5.2012, ÖDP v. Turkey, Nr. 7819/03, Rz. 37 ff.

892 BVerfGE 24, 300 (342 f.).

893 EGMR, Urt. v. 10.5.2012, ÖDP v. Turkey, Nr. 7819/03, Rz. 48 f.

894 EGMR, Urt. v. 12.01.2016, DTP ua v. Turkey, Nr. 3840/10, 3870/10, 3878/10, 15616/10, 21919/10, 39118/10, 37272/10 = NVwZ-RR 2017, 473 ff., Rz. 104. Der Ausschluss aus der staatlichen Parteienfinanzierung ist in Art. 69 Abs. 7 türkVerf verankert, dessen Wortlaut wie folgt lautet: „Das Verfassungsgericht kann anstelle der Schließung nach vorstehenden Vorschriften je nach Schwere der Verstöße auch die teilweise oder vollständige Versagung staatlicher Unterstützung anordnen." Mit Schließung ist die Auflösung einer Partei aufgrund eines Verbotes gemeint. Interessant ist, dass die Verfassung dem türkischen Verfassungsgericht bei Vorliegen der Verbotsvoraussetzungen ein Auswahlermessen dahingehend einräumt, eine „Schließung“ anzuordnen oder eine weitere Begünstigung durch die staatliche Parteienfinanzierung teilweise oder vollständig zu Versagen. 
Der EGMR hat damit nicht nur anerkannt, dass ein Entzug staatlicher Unterstützung finanzieller Art ein milderes Mittel in Relation zum Parteiverbot darstellt, sondern darüber hinaus die Aussprache eines Parteiverbots unter expliziter Inbezugnahme der Möglichkeit eines Finanzierungsausschlusses unter eine Angemessenheitsprüfung gestellt. Folgt man dieser Rechtsprechung, führt dies über ein argumentum a fortiori zu dem Schluss, dass ein Ausschluss aus der staatlichen Parteienfinanzierung zumindest nicht eine generelle Unvereinbarkeit mit der EMRK begründet, sondern vielmehr gar als echte Alternative vor der Anordnung eines Parteiverbots in Betracht kommt. ${ }^{895}$ Denn wenn die EMRK in ihrem Geltungsbereich die Aussprache von Parteiverboten zulässt, so muss dies erst recht für mildere Sanktionsalternativen gelten. Der Ausschluss aus der staatlichen Parteienfinanizierung bei gleichzeitiger fortlaufender Begünstigung anderer Parteien als Mittel zur Abwehr staatsgefährdender politischer Kräfte ist damit nicht per se mit den Vorgaben der EMRK unvereinbar.

Nach den oben genannten Maßstäben gilt zudem folgendes: Da Art. 21 Abs. 3 GG nach seinem Normzweck die Befreiung des Staates von der Finanzierungspflicht verfassungsfeindlicher Parteien verfolgt und somit die Möglichkeit einräumt, die staatliche Förderung demokratiefeindlicher Strömungen einzustellen, liegt jedenfalls aufgrund des demokratischen Wahrungscharakters der Norm ein konventionsrechtlich „legitimes Ziel“" vor. Der Gerichtshof hat bereits mehrfach die hohe Bedeutung einer demokratischen Staatsordnung im Geltungsbereich der EMRK hervorgehoben, sodass der Schutz dieser Herrschaftsordnung jedenfalls als legitimes Ziel anerkannt werden muss. ${ }^{896}$ So führte er insbesondere aus: „..., the Court points out that it has previously held that some compromise between the requirements of defending democratic society und individual rights is inherent in the system oft the Convention"897. Die EMRK lässt somit eine Einschränkung individueller Rechte zur Verteidigung einer demokratischen Gesellschaft zu. Unter Verhältnismäßigkeitsgesichtspunkten ist Art. 21 Abs. 3 GG auch konventionsrechtlich nicht zu beanstanden. Die zum Schutze der freiheitlichen demokratischen Grundordnung und des Bestandes der Bundesrepublik Deutschland etablierte Regelung stellt für ihren Einsatz sehr hohe An-

895 Wohl auch in diese Richtung argumentierend Müller, DVBl 2018, 1035 (1041).

896 Zur besonderen Rolle der Demokratie im Geltungsbereich der EMRK siehe EGMR, Urt. v. 30. 1. 1998, United Communist Party of Turkey and Others v. Turkey, Nr. 133/1996/752/951, Rz. 45.

897 EGMR, Urt. v. 30. 1. 1998, United Communist Party of Turkey and Others v. Turkey, Nr. 133/1996/752/951, Rz. 32. 
forderungen auf und konzentriert die Zuständigkeit der für die Rechtswirkung konstitutiven Feststellung des Rechtsfolgeneintritts beim höchsten nationalen Organ der Judikative.

Aufgrund der Einschränkung der Parteiengleichheit ist zwar auch eine staatliche Beeinflussung der Meinungsbildung des Volkes anzunehmen, diese tastet allerdings nicht den Wesensgehalt freier Wahlen an. Die Konzeption des Art. 21 Abs. 3 GG ist nicht der dauerhafte Erhalt etablierter Mehrheiten, sondern die Sanktionierung verfassungsfeindlicher Parteien (deren Programm im Übrigen auch nicht mit den Vorgaben der EMRK übereinstimmen wird) und die Prävention drohender Gefahren für die freiheitliche demokratische Grundordnung. Das Mittel ist damit nicht unmittelbar auf die Einschränkung der freien Meinungsbildung des Volkes gerichtet, sondern auf ihre Gewährleistung. Die Wählbarkeit und das Wahlrecht an sich werden nur mittelbar angetastet, indem die wirtschaftliche Leistungsfähigkeit eingeschränkt wird. Art. 21 Abs. 3 GG ist somit auch im Hinblick auf die EMRK und die Völkerrechtsfreundlichkeit des Grundgesetzes nicht $\mathrm{zu}$ beanstanden und im Vergleich zu Art. 21 Abs. 2 GG nicht an Art. 11 EMRK, sondern an den unter geringeren Voraussetzungen einschränkbaren Art. 14 EMRK und Art. 3 19/1-EMRKZusProt zu messen.

Einzig die einfachgesetzliche Ausgestaltung des Verfahrens in $\$ 46 a$ BVerfGG ist auch unter der Berücksichtigung der EMRK als unzulässig einzustufen. Durch die formelle sechsjährige Ausschlussdauer nach $\$ 46 a$ Abs. 1 S. 1 BVerfGG besteht die Möglichkeit, eine materiell (erneut) verfassungskonforme Partei weiterhin aus der staatlichen Parteienfinanzierung auszuschließen, ohne dass dies für die Wahrung der Demokratie erforderlich wäre. Eine Abschreckungswirkung ${ }^{898}$ vermag die Verzerrung des politischen Wettbewerbs durch den Eingriff in die Chancengleichheit der Parteien nicht zu rechtfertigen.

\section{E. Rechtspolitische Bewertung}

Durch die Eröffnung einer zweiten Handlungsalternative hat der verfassungsändernde Gesetzgeber das im zweiten NPD-Verbotsverfahren ${ }^{899}$ auftretende Problem der fehlenden „Realisierungspotentialität“ erkannt und

898 Wohl anders Shirvani, DÖV 2018, 921 (922f.), der einen repressiven Charakter des Art. 21 Abs. 3 GG ablehnt.

899 BVerfGE 144, $20 \mathrm{ff}$. 
versucht, diesem durch die entsprechende Grundgesetznovelle abzuhelfen. ${ }^{900}$ Das Finanzierungsausschlussverfahren nach Art. 21 Abs. 3 GG modifiziert die Chancengleichheit der Parteien, ohne dabei die „Grundsätze“ der Demokratie iSd. Art. 79 Abs. 3 GG zu „berühren“. Insoweit ist die verfassungsrechtliche Zulässigkeit der Verfassungsänderung zumindest nach dem Maßstab des Art. 79 Abs. 3 GG nicht zu beanstanden. Ob aus der Legalität der Verfassungsänderung deren politische Legitimität folgt, ist allerdings zweifelhaft.

\section{Modifizierte Wettbewerbslage}

Der Staat hat sich eine Befreiungsmöglichkeit von der Pflicht zur Finanzierung verfassungsfeindlicher Parteien geschaffen, deren bedenkliche Wirkung auf die Demokratie durch sehr hohe Einsatzvoraussetzungen und eine taugliche Ausgestaltung des Verfahrens auf ein erträgliches Maß reduziert wurde. Betrachtet man allerdings die Historie der Parteienfinanzierung und setzt diese in Relation zu der Novelle des Art.21 GG, so fällt auf, dass der Staat durch die Etablierung der Parteienfinanzierung das Niveau des politischen Wettbewerbs zunächst angehoben hat und nun verfassungsfeindlichen Parteien eine Begünstigung durch die staatliche Parteienfinanzierung verwehren kann. Der ursprüngliche Parteienwettbewerb, in welchem die Parteien maßgeblich durch eine Eigenfinanzierung die durch sie gesetzten Ziele verfolgen mussten, wurde insoweit umgestaltet, dass inzwischen eine staatliche Teilfinanzierung in den Haushalten der durch sie regelmäßig begünstigten Parteien fest verankert ist. ${ }^{901}$ Der politische Wettbewerb hat sich verändert und durch die Novellierung des Art. 21 GG eine eigenartige Doppelfunktion erhalten. So hat der verfassungsändernde Gesetzgeber die staatliche Parteienfinanzierung durch die Verfassungsänderung von einem Mittel zur Gewährleistung der Funktionalität des Parteienwesens $s^{902}$ auch zu einem Werkzeug der „wehrhaften Demokratie“ umgestaltet. ${ }^{903}$ Treffend schrieb Konrad Zweigert bereits 1959 im Bezug zum

900 Ipsen, in: Sachs (Hrsg.), Grundgesetz, ${ }^{8} 2018$, Art. 21, Rn. 221.

901 Siehe hierzu die Tabelle bei $\$ 3$. vor.A., wonach teilweise fast die Hälfte der Parteifinanzen aus der staatlichen Parteienfinanzierung stammen.

902 Vgl. Klein, in: Maunz/Dürig (Hrsg.), Grundgesetz, 2018, Art. 21, Rn. 434; Morlok, in: Dreier/Bauer (Hrsg.), Grundgesetz, ${ }^{3} 2015$, Art. 21, Rn. 45; Pieroth, in: Grundgesetz für die Bundesrepublik Deutschland, ${ }^{15} 2018$, Art. 21, Rn. 19.

903 Hierzu Nikkho, DVBl 2018, 337 ff. 
KPD-Verbotsverfahren ${ }^{904}$, dass es „politisch weiser gewesen wäre, diese (nicht verfassungskonformen) Parteien den leisen Tod der Erfolglosen sterben zu lassen, statt sie mit der blanken Waffe des Art. 21 (Abs.2) GG zu erschlagen". .905 Diese Wertung kann ohne Abstriche auch auf Art. 21 Abs. 3 GG übertragen werden. Da jeder Eingriff in den offenen Willensbildungsprozess stets demokratiebezogene Bedenken hervorrufen mag, ist einer möglichst politischen, den Wettbewerb unangetasteten Konfrontation der Vorrang einzuräumen. Radikale, allerdings erfolglose und für die Staatsordnung aus diesem Grund ungefährliche Parteien sollten daher vorrangig gesellschaftlich und nicht staatlich bekämpft werden. Betrachtet man unter dieser Prämisse die Novelle des Art.21 GG, so bleibt festzuhalten, dass der Staat durch das Ausschlussverfahren nun ein Mittel hat, das zwar durch die Bezeichnung der betroffenen Partei als „verfassungsfeindlich" die gesellschaftliche Bekämpfung in den Vordergrund stellt, die Bedingungen des Wettbewerbs allerdings zum wesentlichen Nachteil der betroffenen Partei verändert. Die dadurch geschaffene relativ-ungleiche Wettbewerbslage kann eine echte Existenzgefahr für die betroffene Partei begründen. Durch den Ausschluss aus der staatlichen Parteienfinanzierung wird die Erfolglosigkeit einer Partei verdichtet, die Wahrscheinlichkeit der Auflösung aus wirtschaftlichen Gründen erhöht. ${ }^{906}$ Dieser beeinflussten Wettbewerbslage bemächtigt sich nun der Staat, um verfassungsfeindliche Parteien in einen (in Ansätzen meist ohnehin vorhandenen) ökonomischen Notstand zu bringen, aufgrund dessen die Wirkungsmöglichkeiten und die damit zusammenhängende Wettbewerbsfähigkeit im Vergleich zur Konkurrenz erhebliche Einbußen hinnehmen müssen. Durch die Parteienfinanzierung, die zu Beginn der Bundesrepublik als etwas Außergewöhnliches galt und einer mehrfachen verfassungsgerichtlichen Korrektur unterlag, und die Novelle des Art. 21 Abs. 3 GG hat der Staat mehr als zuvor dem politischen Wettbewerb eine Abwehrfunktion verfassungsfeindlicher Bestrebungen verliehen. Einzigartig daran ist, dass das Zusammenwirken einer staatlichen Maßnahme und des grundsätzlich staatsfreien Parteienwettbewerbs den Schutz der freiheitlichen demokratischen Grundordnung tauglich gewährleisten kann.

904 BVerfGE 5, $85 \mathrm{ff}$.

905 Zweigert, JZ 1959, 677 (677).

906 Nikkho, DVBl 2018, 337 (341). 


\section{Entscheidungszuständigkeit}

Die Entscheidungszuständigkeit kann bei der Gestaltung eines gegen Parteien gerichteten Sanktionsverfahrens demokratiebezogene Bedenken hervorrufen und ist jedenfalls deshalb in verfassungsrechtlicher und rechtspolitischer Hinsicht diskussionswürdig. ${ }^{907}$ Ein offener politischer Willensbildungsprozess setzt die Möglichkeit eines Machtwechsels voraus, der generell der Minderheit ermöglichen muss, zu einem späteren Zeitpunkt zur Mehrheit zu erwachsen. ${ }^{908}$ Das Werkzeug einer wehrhaften Demokratie darf nicht zu einer Waffe des Machterhalts politischer Mehrheiten verkommen. Allein die Missbrauchsgefahr kann, unabhängig von einer hinreichend konkretisierten Missbrauchsabsicht, eine bedenkliche Einschränkung des offenen politischen Willensbildungsprozesses darstellen. ${ }^{909}$ So führte das Bundesverfassungsgericht in Bezug auf Art.21 Abs. 2 GG aus, dass bereits der Tatbestand einen „Missbrauch der Bestimmung im Dienste eifernder Verfolgung unbequemer Oppositionsparteien" "910 ausschließen müsse, woraus sich schließen lässt, dass die Missbrauchsanfälligkeit sowohl bei der Ausgestaltung des Tatbestandes als auch des Verfahrens einen zu berücksichtigenden Faktor darstellt. Auch wenn sich das Bundesverfassungsgericht in seiner Ausführung nur auf den Tatbestand bezog, ist der zugrundeliegende Gedanke dieser Rechtsprechung auch auf die Ausgestaltung der Entscheidungszuständigkeit übertragbar. Um die Missbrauchsgefahr auf ein erträgliches Maß zu reduzieren, muss der Entscheidungsträger eine vom politischen Wettbewerb weitestgehend unbeeinflusste staatliche Institution sein. So ist insbesondere darauf zu achten, dass die Entscheidungsgewalt über den Einsatz eines solchen Mittels keiner politisch gebildeten Mehrheit obliegt. Organe der Legislative sind deshalb aufgrund ihrer starken Verbundenheit, auch hinsichtlich ihrer konkreten Zusam-

907 Vgl. Morlok, ZRP 2017, 66 (67); auch ders., in: Dreier/Bauer (Hrsg.), Grundgesetz, ${ }^{3}$ 2015, Art. 21, Rn. 146, der beim Parteiverbotsverfahren bereits auf die Missbrauchsmöglichkeiten von staatlichen Sanktionen gegen Parteien hinweist; vgl. ferner Klein, in: Maunz/Dürig (Hrsg.), Grundgesetz, 2018, Art. 21, Rn. 492.

908 BVerfGE 5, 85 (198f.); BVerfGE 123, 267 (367); BVerfGE 132, 195 (247); Sommermann, in: Huber/Voßkuhle (Hrsg.), Grundgesetz, ${ }^{7} 2018$, Art. 20, Rn. 86.

909 Vgl. insoweit Morlok, in: Dreier/Bauer (Hrsg.), Grundgesetz, ${ }^{32015}$, Art. 21, Rn. 146, der in Bezug zum Parteiverbotsverfahren auf die Missbrauchsmöglichkeit hinweist und daraus die Gebotenheit einer Konzentration der Entscheidungszuständigkeit beim Bundesverfassungsgericht ableitet.

910 BVerfGE 5, 85 (141). 
mensetzung, zum politischen Wettbewerb grundsätzlich ungeeignet, über die Sanktionierung von Parteien zu befinden. ${ }^{911}$

Nach Art. 21 Abs. 4 Alt. 2 GG entscheidet über die Frage des Ausschlusses von staatlicher Finanzierung nach Absatz 3 das Bundesverfassungsgericht. Der verfassungsändernde Gesetzgeber hat damit die Entscheidungsgewalt über die Frage des Ausschlusses verfassungsfeindlicher Parteien aus der staatlichen Parteienfinanzierung dem Bundesverfassungsgericht übertragen. Im Schrifttum kommen gegen diese gesetzgeberische Entscheidung kaum Bedenken auf. ${ }^{912}$ So wird insbesondere von Martin Morlok vertreten, dass die Ansiedelung der Entscheidungszuständigkeit beim Bundesverfassungsgericht für das Finanzierungsausschlussverfahren zwingend sei. ${ }^{913}$ Andere Stimmen halten dies für nicht unabdingbar, allerdings wünschenswert ${ }^{914}$ oder bezweifeln die Zweckmäßigkeit der Entscheidungszuständigkeit des Bundesverfassungsgerichtes für das Finanzierungsausschlussverfahren ${ }^{915}$.

Ähnlich, mit wiederum eigenen Besonderheiten, verhält es sich mit der Anfälligkeit der Exekutive für eine missbräuchliche Verwendung von Sanktionsmitteln gegen Parteien. Volker Epping sprach sich zwar dafür aus, die Entscheidungszuständigkeit für den Ausschluss aus der staatlichen Parteienfinanzierung dem Bundestagspräsidenten $\mathrm{zu}$ übertragen, da dieser nach den $\int \mathbb{S} 18$ ff. PartG ohnehin die Anträge der Parteien entgegen nähme und ihm in diesem Rahmen auch eine inhaltliche Entscheidungs- und Prüfungskompetenz zustünde. ${ }^{916}$ Diese Auffassung stieß allerdings zu

911 Vgl. Maurer, AöR 96 (1971), 203 (227); so allerdings auf europäischer Ebene, wo die Frage nach dem Ausschluss aus der EU-Parteienfinanzierung dem Parlament obliegt, siehe Kluth, in: Calliess/Ruffert (Hrsg.), EUV/AEUV, ${ }^{5} 2016$, Art. 224 AEUV, Rn. $10 \mathrm{ff}$.

912 Lediglich Epping, Rechtsgutachten über die Frage, ob und unter welchen Voraussetzungen eine nicht nach Art. 21 II GG verbotene Partei von der staatlichen Parteifinanzierung ausgeschlossen werden kann, 14.11.2008, S. 57, der die Entscheidungszuständigkeit des Bundesverfassungsgerichtes aus Kapazitäts- und Praktikabilitätserwägungen für schwerfällig befindet.

913 Morlok, ZRP 2017, 66 (67).

914 Wohl auch Ipsen, JZ 2017, 933 (934).

915 Epping, Rechtsgutachten über die Frage, ob und unter welchen Voraussetzungen eine nicht nach Art. 21 II GG verbotene Partei von der staatlichen Parteifinanzierung ausgeschlossen werden kann, 14.11.2008, S. 57.

916 Epping, Rechtsgutachten über die Frage, ob und unter welchen Voraussetzungen eine nicht nach Art. 21 II GG verbotene Partei von der staatlichen Parteifinanzierung ausgeschlossen werden kann, 14.11.2008, S. 58; Laubinger, ZRP 2017, 55 ff. 
Recht auf Kritik. ${ }^{917}$ Der Bundestagspräsident als Organ der Exekutive wird durch die traditionell von politischen Meinungs- und Machtkämpfen beherrschte Legislative bestimmt. Die Verbundenheit zum politischen Wettbewerb ist in einem solch hohen Maße vorhanden, dass eine Einflussnahme von Partei- und Partikularinteressen auf den Bundestagspräsidenten evident ist. ${ }^{918}$ Ähnlich würde es sich auch bei einer Konzentration der Maßnahmenzuständigkeit auf das Bundesinnenministerium, was angesichts der Zuständigkeit für Vereinsverbote nach $\$ 3$ Abs. 2 S. 1 Nr. 2 VereinsG am naheliegendsten wäre, verhalten. Die Ernennung des Bundeskanzlers erfolgt durch den Willen einer politischen Mehrheit. Durch die politische Mehrheit im Bundestag wird somit auch maßgeblich die Wahl der Minister bestimmt. Die Gefahr des Missbrauchs staatlicher, gar verfassungsrechtlicher Werkzeuge des Verfassungsschutzes zum Zwecke des dauerhaften Machterhalts liegt bei einem durch politische Mehrheiten erwachsenen und bestimmten staatlichen Organ vergleichsweise höher als bei Organen mit keinem bis geringen politischen Einfluss. Auch ein nachträglich zu gewährender Rechtsschutz über das Bundesverwaltungsgericht bis hin zu außerordentlichen Rechtsbehelfen wie der Verfassungsbeschwerde nach Art. 93 Abs. 1 Nr. 4a GG vermögen die aus einem Ausschluss der staatlichen Finanzierung resultierenden Nachteile, insbesondere der öffentlichen Stigmatisierung, nicht zu kompensieren. ${ }^{919}$ Nach erfolgtem Ausspruch des Ausschlusses aus der staatlichen Parteienfinanzierung wäre eine durch ein Gericht erfolgende Rehabilitation im öffentlichen Meinungsbild nur eingeschränkt möglich. Die Tatsache, dass bereits einmal aufgrund einer vermeintlich vorliegenden Verfassungsfeindlichkeit von Staats wegen gegen eine bestimmte Partei vorgegangen wurde, wird sich durch ein abhelfendes Gerichtsurteil im öffentlichen Meinungsbild nicht vollständig verdrängen lassen. Insoweit kann selbst eine judikative Kontrolle die mit der erhöhten Missbrauchsgefahr einhergehenden Probleme nicht in tauglicher Weise einschränken.

Versucht man eine generelle Eingriffskompetenz in den Parteienwettbewerb bei einer der drei Gewalten zu verorten, ist die Judikative die hierfür am besten geeignete. Die durch Art. 97 Abs. 2 GG garantierte persönliche

917 Ferreau, DÖV 2017, 494 (498).

918 Vgl. ders., DÖV 2017, 494 (499).

919 Zumal Ipsen, JZ 2017, 933 (934) darauf hinweist, dass der Weg über das Bundesverwaltungsgericht ohnehin beim Bundesverfassungsgericht enden würde und deshalb allein aus diesem Grund naheliegend ist, die Entscheidungszuständigkeit gleich beim Bundesverfassungsgericht anzusiedeln. 
richterliche Unabhängigkeit gewährleistet eine weitestgehend von staatlichen wie gesellschaftlichen Einflüssen befreite Entscheidungsfindung. ${ }^{920}$ Die Sicherheit, dass eine Entscheidung allein aufgrund der Bindung der Gerichte und Richter an Recht und Gesetz erfolgt ist, ist somit deutlich höher als bei den Organen der anderen beiden Gewalten. Die Parteiengleichheit nimmt eine besondere Stellung im bundesdeutschen Staatswesen ein. Ungleichbehandlungen können aufgrund der herausragenden staatsstrukturtragenden Bedeutung nur unter Einhaltung besonders hoher Hürden erfolgen. ${ }^{921}$ Aufgrund der hervorgehobenen Bedeutung eines freien Parteienwettbewerbes für die demokratische Staatsform ist es deshalb zusätzlich sachdienlich, die Entscheidungszuständigkeit nicht nur der dritten Gewalt, sondern darüber hinaus einem innerhalb dieser Gewalt mit einer besonderen Position versehenen Organ, wie z.B. den obersten Gerichtshöfen i.S.d. Art. 95 GG, zu übertragen. So erscheint es im ersten Moment nicht völlig fernliegend anhand des Kompetenztitels von $₫ 50$ VwGO dem Bundesverwaltungsgericht die Entscheidungszuständigkeit über den Ausschluss verfassungsfeindlicher Parteien aus der staatlichen Parteienfinanzierung einzuräumen. Nach $\$ 50$ Abs. 1 Nr. 2 VwGO entscheidet das Bundesverwaltungsgericht als erste und letzte Instanz des ordentlichen Rechtszugs über die Rechtmäßigkeit von Vereinsverboten. ${ }^{922}$ Aufgrund der bisherigen Konzeption des Parteienprivilegs ist es jedoch naheliegender die Entscheidungszuständigkeit dem Bundesverfassungsgericht zuzuordnen. Im Unterschied zu den obersten Gerichtshöfen ist das Bundesverfassungsgericht nach allgemeiner Auffassung nicht nur Gericht, sondern auch ein Verfassungsorgan ${ }^{923}$, welches durch die Verfassung selbst weitreichende formelle und materielle Prüfungskompetenzen zugesprochen bekommt. ${ }^{924}$ Als unabhängige verfassungsrechtliche Institution mit dem Auftrag, über die Anwendung und Auslegung des Grundgesetzes zu entscheiden ${ }^{925}$, nimmt das Verfassungsgericht die Stellung des „Verfassungshüters" ein. So sieht das Grundgesetz bereits in vielen Vorschriften des

920 Vgl. BVerfGE 14, 56 (69); BVerfGE 14, 156 (162); BVerfGE 30, 149 (160); Hillgruber, in: Maunz/Dürig (Hrsg.), Grundgesetz, 2018, Art. 97, Rn. 98.

921 BVerfGE 20, 56 (117); BVerfGE 24, 300 (339ff.); statt aller Morlok, in: Dreier/ Bauer (Hrsg.), Grundgesetz, ${ }^{3} 2015$, Art. 21, Rn. 82.

922 Vgl. Ipsen, JZ 2017, 933 (934), der bei einer Entscheidungszuständigkeit der Exekutive zwangsläufig den Weg über das Bundesverwaltungsgericht vorhersagt.

923 BVerfGE 7, 1 (14).

924 Papier/Krönke, Grundlagen, Staatsstrukturprinzipien, Staatsorgane und -funktionen, ${ }^{2} 2015$, Rn. 442.

925 Maurer, Staatsrecht I, ${ }^{7} 2014$, S. 627, Rn. 9. 
Verfassungsschutzes, die zumindest auch neben ihrer Schutzwirkung in die Freiheitsrechte der Bürger eingreifen, wie Art. 18, 21 Abs. 2, Abs. 4, 61 und 98 Abs. 2 GG, eine Zuständigkeit des Bundesverfassungsgerichtes vor. Die Entscheidungsgewalt im Finanzierungsausschlussverfahren ist aufgrund der einschneidenden Wirkung in die Gleichheitssphäre der Parteien und dem grundsätzlich von staatlicher Einflussnahme befreiten Parteienwettbewerb richtigerweise dem Bundesverfassungsgericht $\mathrm{zu}$ übertragen. Insoweit ist die Entscheidung des verfassungsändernden Gesetzgebers, die Entscheidungszuständigkeit beim Bundesverfassungsgericht anzusiedeln konsequent und damit zu begrüßen.

\section{Geringeres Einsatzhemmnis}

Durch die geringeren Anforderungen könnte zu befürchten sein, dass die politische Hemmschwelle zum Einsatz dieses Mittels im Vergleich zu dem eher unpopulären Parteiverbot absinkt und dadurch eine erhöhte Bereitschaft zur Anwendung dieser einschneidenden Maßnahme besteht. ${ }^{926} \mathrm{Je}-$ denfalls muss der Antragssteller bei der Entscheidung über die Einleitung des Verfahrens nach Art. 21 Abs. 3 GG sorgfältig zwischen dem Nutzen und den Folgen des Ausschlusses aus der staatlichen Parteienfinanzierung abwägen. Ein Scheitern des Finanzierungsausschlussverfahrens kann die betroffene Partei als politischen Triumph feiern ${ }^{927}$, einen Ausschluss aus der staatlichen Parteienfinanzierung auf der anderen Seite als ein durch begangenes Unrecht erzeugtes Martyrium propagieren. Das Vertrauen der Bürger in einen gerechten, die fundamentalen Grundsätze einer demokratischen Herrschaftsordnung nicht antastenden Staat kann insbesondere durch den Vorwurf erschüttert werden, dass dessen Gewalt zur Repression unliebsamer Meinungen und Interessen missbraucht werde. Bereits die historische Erfahrung mit dem Sozialistengesetz von 1878 hat gezeigt, dass staatliche Unterdrückung politischer Strömungen einen gegenteiligen Effekt zumindest nicht ausschließt, wenn nicht gar in manchen Fällen fördert. ${ }^{928}$ Bei der Entscheidung über die Nutzung des Mittels ist deshalb nicht nur eine auf den konkreten Einzelfall bezogene Abwägung vorzunehmen, sondern auch die generelle Häufigkeit des Einsatzes zu berück-

926 Ähnlich auch Linke, DÖV 2017, 483 (492).

927 Ähnlich im Bezug zum Parteiverbot Klein, in: Maunz/Dürig (Hrsg.), Grundgesetz, 2018, Art. 21, Rn. 546.

928 Siehe hierzu bereits die historische Einleitung $\mathbb{\$} 1 \mathrm{~A}$. II. 
sichtigen. Der Eindruck, Art. 21 Abs. 3 GG werde als Mittel des Machterhalts etablierter politischer Mehrheiten missbraucht, muss zwingend zum Wohle der Stabilität des bestehenden politischen Systems und der Staatsordnung vermieden werden. ${ }^{929}$ Gerade weil die Antragstellung nach der auch hier vertretenen Auffassung im "plichtgemäßen Ermessen“ der Antragssteller liegt und nur in offensichtlichen Missbrauchsfällen eine Pflichtverletzung im Rahmen eines Organstreitverfahrens festgestellt werden könnte ${ }^{930}$, wäre es zu begrüßen, dass für die Zulässigkeit eines solchen Antrages zumindest eine Überzeugung des Antragstellers von der Verfassungsfeindlichkeit der Antragsgegnerin vorzuweisen wäre. Das Vorweisen einer solchen „Antragsbefugnis“, die gesondert zur Antragsberechtigung zu prüfen wäre, ist nach der aktuellen Rechtslage allerdings nicht notwendig.

Ob diese Befürchtung tatsächlich berechtigt ist, wird sich noch zeigen. Der erste Antrag, der auf die Feststellung des Ausschlusses aus der staatlichen Parteienfinanzierung gerichtet ist, wurde am 02.02.2018 durch den Bundesrat vor dem Bundesverfassungsgericht gestellt. ${ }^{931}$ Demnach soll die NPD, nachdem das zweite Verbotsverfahren gegen die Partei gescheitert ist $^{932}$, nun durch das mildere Sanktionsmittel bekämpft werden. Angesichts des politischen Hintergrunds der Schaffung des Finanzierungsausschlussverfahrens ist es allerdings wenig verwunderlich, dass sich die Initiative des Bundesrates gerade gegen diese Partei richtet. Denn es war die NPD, die bis auf die Realisierungspotentialität sämtliche Voraussetzungen für ein Verbot nach Art. 21 Abs. 2 GG erfüllte und aufgrund dessen überhaupt erst über die Möglichkeit der Einführung des Finanzierungsausschlussverfahrens beraten wurde. ${ }^{933}$ Wenig verwunderlich wird auch sein, wenn das Finanzierungsausschlussverfahren, welches auch als „Lex NPD“934 bezeichnet wird, tatsächlich zum erfolgreichen Ausschluss der

929 Dies hat auch die Bundesregierung erkannt und in die Gesetzesbegründung aufgenommen, siehe BT-Drucksache 18/12357, S. 5.

930 Siehe $\$ 4$ C. III. 2.

931 https://www.bundesrat.de/SharedDocs/texte/18/20180202-parteienfinanzierung. html, zul. aufgerufen am 18.02.2020.

932 BVerfGE 144, $20 \mathrm{ff}$.

933 Wobei bereits vor dem Urteil die Konformität der verfassungsgerichtlichen Rechtsprechung zu den Parteiverboten mit der EMRK angezweifelt wurde, siehe Koch, DVBl 2002, 1388 ff.; Theuerkauf, Parteiverbote und die Europäische Menschenrechtskonvention, 2006; Shirvani, JZ 2014, $1074 \mathrm{ff}$.

934 Siehe u.A. Hasselmann/Künast, FAZ 22.06.2017 - http://www.faz.net/aktuell/poli tik/inland/parteiverbote-eine-lex-npd-schadet-der-demokratie-15071039.html, zul. aufgerufen am 18.02.2020; Steffen, Die Zeit 22.06.2017; Barczak, in: ders. 
NPD aus der staatlichen Parteienfinanzierung führen wird. Spannend werden nicht nur das Urteil des Bundesverfassungsgerichts und seine Gründe sein, sondern auch der Verlauf der künftigen Anwendungspraxis durch die antragsberechtigten Organe.

\section{Ende der Parteiverbote?}

Da die Voraussetzungen des Parteiverbots und des Finanzierungsausschlusses lediglich in dem Punkt divergieren, dass für ein Verbot eine „Realisierungspotentialität" vorliegen muss, während dies beim Finanzierungsausschluss nicht der Fall ist ${ }^{935}$, wird das letztere ohnehin nur im Falle einer „erfolglosen“ Partei zweckmäßig Anwendung finden. Dies führt zu der Annahme, dass aufgrund der geringeren Anforderungen in Zukunft der Ausschluss aus der staatlichen Parteienfinanzierung nach Art. 21 Abs. 3 GG zur gängigen Praxis wird und das Stellen eines auf ein Parteiverbot gerichteten Antrags dadurch an praktischer Relevanz verliert. ${ }^{936} \mathrm{Ob}$ diese Prognose zutreffend ist, wird sich zum aktuellen Zeitpunkt nur schwer sagen lassen. Anhand allgemeiner Praktikabilitätserwägungen lässt sich allerdings erahnen, dass zukünftig sowohl Art. 21 Abs. 2 GG als auch Absatz 3 in einem einheitlichen Verfahren zur Anwendung kommen. Da nach $₫ 43$ Abs. 1 S. 2 BVerfGG ein Antrag auf Ausschluss einer Partei aus der staatlichen Parteienfinanzierung hilfsweise zu einem Verbotsantrag gestellt werden kann, liegt es nahe, beide Verfahren zu einer Erhöhung der Erfolgswahrscheinlichkeit gemeinsam einzuleiten. Sollte nicht ganz deutlich sein, ob eine Partei über eine ausreichende „Realisierungspotentialität“ ihrer als verfassungsfeindlich eingeschätzten Zielsetzung verfügt, käme ein Antrag auf Feststellung der Verfassungswidrigkeit mit einem hilfsweise gestellten Antrag auf die Feststellung des Ausschlusses aus der staatlichen Parteienfinanzierung am ehesten in Frage. Das Stufenverhältnis ${ }^{937}$ der beiden Sanktionsmittel und ihre verfahrenstechnische Ausgestaltung lassen es zu, dass der Antragsteller mit dem ihm schärfsten zur Verfügung stehenden Mittel gegen Parteien vorgeht und im Falle, dass dessen strenge

(Hrsg.), BVerfGG Mitarbeiterkommentar zum Bundesverfassungsgerichtsgesetz, 2018, \$ 46a, Rn. 6.

935 Linke, DÖV 2017, 483 (492).

936 Kloepfer, NVwZ 2017, 913 (919); Müller, DVBl 2018, 1035 (1041); Ipsen, in: Sachs (Hrsg.), Grundgesetz, ${ }^{8} 2018$, Art. 21 Rn. 221; Kluth, in: Epping/Hillgruber (Hrsg.), BeckOK GG, ${ }^{32} 2017$, Art. 21, Rn. 212d.

937 Siehe dazu Müller, DVBl 2018, 1035 (1038). 
Voraussetzungen nicht erfüllt sind, auf das mildere, aber dennoch mit einem erheblichen Sanktionscharakter versehene Werkzeug des Art. 21 Abs. 3 GG ausweichen kann. Es wird weiter im staatlichen Interesse liegen, vermeintlich verfassungswidrige Parteien verbieten zu lassen und ihre Wirkungsmöglichkeit dadurch auf Null zu reduzieren. Da ein solches Vorgehen für den Antragsteller keine nachteiligen Folgen hat, wird keines der beiden Verfahren das andere verdrängen. Vielmehr ist es wahrscheinlicher, dass beide Verfahren als einheitliches Mittel gegen verfassungsfeindliche oder verfassungswidrige Parteien eingesetzt werden. Nur im Fall, dass die Voraussetzungen für ein Parteiverbot offensichtlich nicht vorliegen, also die betroffene Partei offenkundig nicht über eine ausreichende „Realisierungspotentialität" verfügt, ist die singuläre Anwendung des Finanzierungsausschlussverfahrens naheliegend. So wurde Art. 21 Abs. 3 GG bei dessem ersten Einsatz als selbstständiger Antrag gestellt, da das dem vorangegangen Parteiverbotsverfahren ${ }^{938}$ (was auch zur Entstehung des Finanzierungsausschlussverfahrens beigetragen hat) gegen die NPD gerade aufgrund der fehlenden Realisierungspotentialität der Partei gescheitert war und somit das Stellen eines erneuten Verbotsantrags mangels neuer Tatsachen oder Beweismittel nicht in Betracht kam.

\section{Anspruch auf Feststellung der Verfassungskonformität de lege ferenda}

Die geltende verfahrenstechnische Ausgestaltung des Art. 21 Abs. 3 GG lässt es nicht zu, dass eine aus der staatlichen Finanzierung ausgeschlossene Partei vor Ablauf der sechsjährigen Ausschlussfrist wieder durch die staatliche Parteienfinanzierung begünstigt werden kann. Abgesehen von der Verfassungswidrigkeit ${ }^{939}$ dieser einfachgesetzlichen Ausgestaltung des Finanzierungsausschlussverfahrens in $\$ 46 \mathrm{a}$ Abs. 1 S. 1 BVerfGG wird angesichts der Ausschlussdauer vorgeschlagen, den von dem Ausschlussverfahren betroffenen Parteien einen Anspruch auf Feststellung der Verfassungskonformität einzuräumen, sofern die Voraussetzungen des Art. 21 Abs. 3 GG nicht mehr vorliegen. ${ }^{940}$ Vor der Etablierung des Art. 21 Abs. 3 GG wurde die verfassungsgerichtliche Feststellung der Verfassungskonformität von der NPD erfolglos angestrebt, da ein solches Verfahren nach den Vorschriften des Grundgesetzes und des Bundesverfassungsge-

938 BVerfGE 144, 20.

939 Siehe hierzu die Ausführungen bei $\$ 4$ C. II. 3.

940 Ferreau, DÖV 2017, 494 (500); Müller, DVBl 2018, 1035 (1042). 
richtsgesetzes nicht vorgesehen ist. ${ }^{941}$ Eine dahingehende verfahrenstechnische Ausgestaltung ist nunmehr, im Unterschied zur früheren Rechtslage, insbesondere im Bezug auf Art. 21 Abs. 3 GG verfassungsrechtlich geboten. ${ }^{942}$ Dies ist allerdings keinesfalls so wie von der NPD beabsichtigt als ein Vorschlag zur Etablierung eines jederzeit einzuleitenden Verfahrens zu verstehen, das als Rechtsfolge die verfassungsgerichtliche Feststellung der „Verfassungskonformität“ vorsieht. ${ }^{943}$ Vielmehr muss ein Ausschluss aus der staatlichen Parteienfinanzierung vorangegangen sein, damit ein dahingehender Antrag gestellt werden kann. Dieser sollte somit nicht selbstständig neben den $\$ \$ 43 \mathrm{ff}$. BVerfGG stehen, sondern in das Verfahren selbst integriert werden, um die Möglichkeit einer vorzeitigen Begünstigung vor Ablauf der sechsjährigen Ausschlussfrist zu ermöglichen (sofern weiter an diesem zeitlichen Rahmen festgehalten wird).

Wie bereits oben geschildert, scheitert zwar eine analoge Anwendung des $\$ 40$ BVerfGG auf das Finanzierungsausschlussverfahren am deutlich entgegenstehenden Willen des Gesetzgebers. ${ }^{944}$ Für eine zukünftige, verfassungsmäßig gebotene Anpassung des $\$ 46$ a BVerfGG, sollte weiterhin eine sechsjährige Frist vorgesehen sein, bietet sich die Aufnahme des $\$ 40$ BVerfGG in seiner entsprechenden Anwendung in die Verweisung des $₫ 47$ BVerfGG an. Die betroffene Partei würde dann nach einem Jahr ab dem Zeitpunkt des Ausschlusses aus der staatlichen Parteienfinanzierung die Möglichkeit erhalten, beim Bundesverfassungsgericht eine vorzeitige (Wieder-)Begünstigung durch die staatliche Parteienfinanzierung zu beantragen. Verlangt werden kann in solchen Fällen allerdings, dass die Partei substantiiert vorbringen muss, inwieweit sich die Sachlage geändert hat, um nicht weiter von der Verfassungsfeindlichkeit der Partei auszugehen. 945

941 BVerfGE 133, 100 (106).

942 So auch Müller, DVBl 2018, 1035 (1042).

943 So wie die NPD in BVerfGE 133, $100 \mathrm{ff}$. beabsichtigte.

944 BT-Drucksache 18/12846, S. 10.

945 In diese Richtung auch Müller, DVBl 2018, 1035 (1042). 


\section{\5 Der Status der Verfassungsfeindlichkeit}

Neben den mit Art. 79 Abs. 3 GG zusammenhängenden Problemen des Finanzierungsausschlussverfahrens stellt sich weiter die Frage, welche Auswirkungen über den bloßen Finanzierungsausschluss hinaus faktisch mit dem Feststellungsurteil des Bundesverfassungsgerichtes einhergehen. So soll hierauf bezogen zunächst näher der Begriff der „Verfassungsfeindlichkeit" untersucht werden, der im Zusammenhang mit dem Ausschluss aus der staatlichen Parteienfinanzierung aufgeworfen wird. Im Weiteren wird sodann auf die Frage eingegangen werden, wie sich das Feststellungsurteil sodann zum Parteienprivileg verhält und ob die betroffene Partei gerade im Bereich der sog. „faktischen Nachteile“ Veränderungen zu ihren Lasten befürchten muss.

\section{A. Begriff der Verfassungsfeindlichkeit}

Die Bezeichnung von Parteien als „verfassungsfeindlich“ vor der Änderung des Grundgesetzes war vordergründig im Kontext der Grundsätze des Berufsbeamtentums ${ }^{946}$ und amtlicher parteibezogener Äußerungen ${ }^{947}$ relevant. Die Entscheidung darüber, ob eine Partei als „verfassungsfeindlich“ eingestuft wird, war insoweit nur eine Vorfrage, um die Loyalität eines Beamten gegenüber dem Staat feststellen zu können. Nunmehr wurde der Begriff der „Verfassungsfeindlichkeit“ in den Gesetzgebungsmaterialen zum Finanzierungsausschluss allerdings konkret auf solche Parteien bezogen, die die Voraussetzungen des Art. 21 Abs. 3 GG erfüllen.9 ${ }^{948}$ Das „Gesetz zum Ausschluss verfassungsfeindlicher Parteien von der Parteienfinanzierung“949 enthält bereits in seinem Titel den Begriff der „Verfassungs-

946 Siehe hierzu u.A. Streinz, in: Huber/Voßkuhle (Hrsg.), Grundgesetz, ${ }^{7} 2018$, Art. 21, Rn. 219; Ipsen, in: Sachs (Hrsg.), Grundgesetz, ${ }^{8}$ 2018, Art. 21, Rn. 206 f.; Isensee, JuS 1973, 265 ff.; Plümer, NJW 1973, 4 ff.

947 Siehe hierzu u.A. Streinz, in: Huber/Voßkuhle (Hrsg.), Grundgesetz, ${ }^{72} 2018$, Art. 21, Rn. 218; Ipsen, in: Sachs (Hrsg.), Grundgesetz, ${ }^{8}$ 2018, Art. 21, Rn. 202; Eder, »Rote Karte« gegen »Spinner«?, 2017.

948 Siehe hierzu Streinz, in: Huber/Voßkuhle (Hrsg.), Grundgesetz, ${ }^{72018}$, Art. 21, Rn. 252b.

949 BGBl. 2017, I, $2730 \mathrm{f}$. 
feindlichkeit" und bezieht diesen ausdrücklich auf Parteien, deren Ausschluss aus der staatlichen Parteienfinanzierung vom Bundesverfassungsgericht festgestellt wurde. Auffällig ist auch der Unterschied zu der Parallelvorschrift des Art. 21 Abs. 2 GG, wonach die Bezeichnung als „verfassungswidrig“ unmittelbare Rechtsfolge ist. Die „verfassungswidrige“ Partei wird dabei durch den Tatbestand legaldefiniert, während eine Erfüllung des Tatbestandes des Art. 21 Abs. 3 GG nach dem Wortlaut lediglich zu einem Ausschluss aus der staatlichen Parteienfinanzierung und dem Wegfall jedweder steuerlichen Begünstigungen führt.

Bereits vor der Novellierung des Art. 21 Abs. 3 GG wurde der Begriff der „Verfassungsfeindlichkeit“ für Parteien gebraucht, die nicht verboten, allerdings staatlich unerwünscht waren. ${ }^{950}$ Die Problematik der „verfassungsfeindlichen" Parteien trat insbesondere im öffentlichen Dienst auf, wo die Mitgliedschaft in einer als „verfassungsfeindlich“ eingestuften Partei zu einer Nichtberücksichtigung im Bewerbungsverfahren oder gar der Entlassung führen konnte. ${ }^{951}$ So ging das VG Stuttgart in einem im Rahmen eines Eilverfahrens getroffenen Beschlusses näher auf die rechtliche Einordnung einer Partei als „verfassungsfeindlich“ ein, um die RechtmäBigkeit der Entlassung eines Lehrers aus dem Beamtenverhältnis auf Probe zu überprüfen. ${ }^{952}$ Das Gericht nahm Abstand von einer abschließenden Festlegung des Begriffes und führte, unter Bezugnahme der Rechtsprechung des Bundesverwaltungsgerichtes ${ }^{953}$, zwei unterschiedliche Deutungen an. ${ }^{954}$ So schien es für das VG Stuttgart „naheliegend“, den Begriff der „Verfassungsfeindlichkeit“ als Synonym der "Verfassungswidrigkeit" iSd. Art. 21 Abs. 2 GG zu verstehen. Eine Partei sei demnach dann als „verfassungsfeindlich“" zu qualifizieren, wenn diese die Tatbestandsvoraussetzungen des Art. 21 Abs. 2 GG erfülle, vom Bundesverfassungsgericht allerdings bislang noch nicht verboten wurde. Nach diesem Verständnis beschreibt der Begriff der „Verfassungsfeindlichkeit“ solche Parteien, die materiell die Verbotsvoraussetzungen erfüllen, die Feststellung der „Verfassungswidrigkeit" durch das Bundesverfassungsgericht als formeller Akt allerdings noch ausgeblieben ist.

950 Siehe VG Stuttgart, Urt. v. 29.08.1975, Rs. VII 168/75, JZ1976, $209 \mathrm{ff}$; auch Wiese, DVBl 1976, 317 ff.; Kriele, ZRP 1975, 201 ff.; Kloepfer, NJW 2016, 3003 ff.

951 Vgl. BVerwGE 47, 330 (344 ff,); siehe auch BVerfGE 39, 334 (360).

952 VG Stuttgart, Urt. v. 29.08.1975, Rs. VII 168/75, JZ 1976, 209 ff.

953 Siehe BVerwGE 47, $330 \mathrm{ff}$.

954 VG Stuttgart, Urt. v. 29.08.1975, Rs. VII 168/75 = JZ 1976, 209 (210). 
Das Bundesverwaltungsgericht hat die „Verfassungsfeindlichkeit“ einer Partei in Bezug auf die Treuepflichten von Beamten bereits unter deutlich geringeren Voraussetzungen angenommen. ${ }^{95}$ Nach dieser Rechtsprechung genüge bereits eine Zielsetzung, die nicht mit der freiheitlichen demokratischen Grundordnung zu vereinbaren sei, das von Art. 21 Abs. 2 GG vorausgesetzte Störungsniveau also nicht zwingend erreicht werden müsse, um eine Partei aufgrund ihrer inhaltlichen Ausrichtung als „verfassungsfeindlich“ zu bezeichnen und ggf. Mitglieder daraufhin aus dem Berufsbeamtentum auszuschließen. Die Divergenz äußerte sich deshalb vor allem in dem Streit, ob eine „kämpferische, aggressive Grundhaltung $^{\text {“956 }}$ gegenüber der bestehenden Ordnung vorliegen müsse, um die Partei als „verfassungsfeindlich“ in rechtserheblicher Weise für deren Mitglieder einordnen zu können.

Obwohl der Wortlaut des Art. 21 Abs. 3 GG allein keine inhaltliche Unterscheidung zwischen dem Begriff der „Verfassungswidrigkeit“ und dem der "Verfassungsfeindlichkeit“" zulässt, kann die frühere Rechtsprechung der Verwaltungsgerichte sowie der teleologische Hintergrund der Verfassungsänderung zur Begriffsbestimmung herangezogen werden. Die Bedeutung des Begriffes leitet sich aus der der Verfassungsänderung zugrundeliegenden Vorstellung ab, Parteien, die aufgrund mangelnder Gefährlichkeit die Voraussetzungen für ein Verbot nicht erfüllen, sich allerdings gegen die höchsten Staatswerte richten, von einer weiteren Begünstigung durch die staatliche Parteienfinanzierung auszuschließen. ${ }^{957}$ Der Begriff definiert sich insoweit über seine Abgrenzung zu Art. 21 Abs. 2 GG und verdeutlicht das Stufenverhältnis ${ }^{958}$ der beiden Vorschriften. Verfassungsfeindlich ist demnach eine Partei dann, wenn sich ihre Willensbetätigung gegen die freiheitliche-demokratische Grundordnung richtet, sie dies durch das Verhalten ihrer Mitglieder oder ihrer Anhänger nach außen hin kenntlich macht und nach einer umfassenden Betrachtung ihrer objektiven Möglichkeiten von ihr keine nennenswerten Gefahren für die höchsten Staatswerte ausgehen. Ob dieser Begriff ausschließlich auf solche Parteien bezogen werden kann, die durch ein entsprechendes Urteil des Bundesverfassungs-

955 Vgl. BVerwGE 47, 330 (345 ff.).

956 Zum Begriff siehe BVerfGE 5, 85 (141); vgl auch BVerwGE 47, 330 (345).

957 Vgl. Barczak, in: ders. (Hrsg.), BVerfGG Mitarbeiterkommentar zum Bundesverfassungsgerichtsgesetz, 2018, $\mathbb{S} 46$ a, Rn. 14., der den Begriff in Relation zu dem Parteiverbotsverfahren und dem damit verbundenen historischen Hintergrund setzt.

958 Siehe Müller, DVBl 2018, 1035 (1038f.). 
gerichtes von der staatlichen Finanzierung ausgeschlossen sind, wird an anderer Stelle untersucht. ${ }^{959}$

\section{B. Auswirkung des Finanzierungsausschlusses auf die Rechtsstellung der Parteien}

Durch die Einführung des Art. 21 Abs. 3 GG sieht sich der Staat mit einer neuen Rechtslage konfrontiert, die das bisherige Verständnis der Beziehungen zwischen Staat und Parteien komplexer gestaltet. ${ }^{960}$ So konnte der Staat bislang nur zwischen Parteien und verbotenen Parteien unterscheiden, wobei letztere durch die Feststellung ihrer Verfassungswidrigkeit durch das Bundesverfassungsgericht ihren Parteienstatus verloren und sich somit ab dem Zeitpunkt der Auflösung nicht mehr auf Art. 21 GG berufen konnten. ${ }^{961}$ Durch das Finanzierungsausschlussverfahren wird die bislang binäre Entscheidungsstruktur ${ }^{962}$ des Staates erweitert, indem eine Partei, deren verfassungsfeindliche Einstellung durch das Bundesverfassungsgericht festgestellt wurde, weiterhin rechtlich existent bleibt. Indem die Partei im politischen Wettbewerb verbleibt, wird sich insbesondere die Verwaltung der neuartigen Herausforderung stellen müssen, den richtigen Umgang mit einer solchen Partei zu finden. Ob und wie sich die Rechtsstellung der Partei durch ein Feststellungsurteil des Bundesverfassungsgerichtes ändert, wird Gegenstand der nachfolgenden Untersuchung sein.

I. Ausschluss aus der staatlichen Parteienfinanzierung als Anknüpfungsgrundlage weiterer staatlicher Maßnahmen

Einer aus der staatlichen Parteienfinanzierung ausgeschlossenen Partei wird durch die Entscheidung des Bundesverfassungsgerichts eine inhaltlich verfassungsfeindliche Ausrichtung, zumindest zum Zeitpunkt der Feststellung, formell nachgewiesen. Bereits nach dem Urteil des Bundesverfassungsgerichtes im zweiten NPD-Verbotsverfahren ${ }^{963}$ wurde von staatlicher Seite aus versucht, die in der Urteilsbegründung angeführte ver-

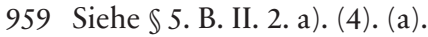

960 Kritisch Linke, DÖV 2017, 483 (492).

961 Ipsen, in: Sachs (Hrsg.), Grundgesetz, ${ }^{8} 2018$, Art. 21, Rn. 193.

962 Begriff angelehnt an Linke, DÖV 2017, 483 (492).

963 BVerfGE 144, 20. 
fassungsfeindliche Haltung der NPD zum Anlass zu nehmen, gegen die Partei vorzugehen. Im zweiten NPD-Verbotsverfahren wurde die NPD zwar nicht verboten, allerdings hat das Bundesverfassungsgericht unter anderem festgestellt, dass die Ziele der Partei gegen die Menschenwürde und das Demokratieprinzip verstößen und eine Wesensverwandtschaft zum historischen Nationalsozialismus aufwiesen. ${ }^{964}$ Dies führte bereits kurz nach Abschluss des Verbotsverfahrens zu einer Satzungsänderung des Gemeinderats der Stadt Büdingen, die einen Ausschluss aus der Fraktionsfinanzierung für die NPD-Gemeinderatsfraktion vorsah. ${ }^{965}$ Auch wurde unter Berufung auf das verfassungsgerichtliche Urteil der NPD der Zugang zu öffentlichen Einrichtungen verwehrt. ${ }^{966}$ Dies indiziert eine in Teilen vorhandene Bereitschaft der Behörden, die inhaltliche verfassungsfeindliche Ausrichtung einer Partei im Rahmen des ihnen zustehenden Ermessens zu berücksichtigen, sofern die Verfassungsfeindlichkeit in irgendeiner fundierten Art und Weise festgestellt wurde (wie z.B. in der Urteilsbegründung der zweiten Verbotsentscheidung durch das Bundesverfassungsgericht). Die Urteilsbegründung des Bundesverfassungsgerichts im zweiten NPDVerbotsverfahren wurde bereits (vergeblich) zur Rechtfertigung staatlicher Eingriffe und Ungleichbehandlungen angeführt. ${ }^{967}$

Eine aus der staatlichen Parteienfinanzierung ausgeschlossene Partei darf aufgrund des Feststellungsurteils des Bundesverfassungsgerichts allerdings grundsätzlich kein weitergehender rechtlicher Nachteil erwachsen, da unter der Geltung des Parteienprivileges der Staat weiterhin auf die ihm durch Art. 21 Abs. 2 und Abs. 3 GG vorgegebenen Sanktionsmittel beschränkt ist. ${ }^{968}$ Das Feststellungsurteil darf insoweit nicht als Anknüpfungsgrundlage weiteren staatlichen Handelns herangezogen werden und eine Partei im rechtlichen Sinne über den Ausschluss aus der staatlichen Parteienfinanzierung hinaus noch weiteren belastenden Maßnahmen aussetzen (was beispielsweise insbesondere im Bereich des Gefahrenabwehr-

964 BVerfGE 144, 20 (246).

965 VG Gießen, Beschl. v. 20.12.2017 - Az. 8 L 9187/17.GI, juris.

966 VGH Kassel, Urt. v. 5.4.2017 - Az. 8 C 459/17.N, juris; siehe auch Hecker, NVwZ 2018, 787 ff.; BVerwG, Urt. v. 28.11.2018 - Az. 6 C 2/17 = NJW 2019, $1317 \mathrm{ff}$.

967 Siehe beispielsweise VG Gießen, Beschl. v. 20.12.2017 - Az. 8 L 9187/17.GI, juris; VGH Kassel, Urt. v. 5.4.2017 - Az. 8 C 459/17.N, juris.

968 So die allg. Ansicht, siehe u.A. Müller, DVBl 2018, 1035 (1038ff.); Streinz, in: Huber/Voßkuhle (Hrsg.), Grundgesetz, ${ }^{7} 2018$, Art. 21, Rn. 252d; allgemein zu Inhalt und Reichweite des Parteienprivilegs siehe die Ausführungen oben unter \$4. D. I. 2. 
rechts denkbar wäre). ${ }^{969}$ Der Partei erwächst aus dem Ausschluss aus der staatlichen Parteienfinanzierung keine Stellung, die sie gegenüber dem Staat „schutzlos" lässt und sie insoweit für „vogelfrei“ erklärt. Der Rechtskreis der Partei wird nur in den konkreten Belangen der unmittelbaren und mittelbaren Parteienfinanzierung eingegrenzt, im Übrigen stehen der Partei die gleichen Rechte zu wie ihrer Konkurrenz. Die Anordnung der Rechtsfolge des Art. 21 Abs. 3 GG setzt allerdings voraus, dass eine verfassungsfeindliche Haltung festgestellt werden konnte, womit die Begründung des Ausschlussurteils zwar nach wie vor nicht in Rechtskraft erwächst, allerdings durch die Anordnung der Rechtsfolge das Erfüllen des Tatbestandes bestätigt. Ob die Partei dadurch auf tatsächlicher Ebene weitergehende Nachteile zu erwarten hat, wird an späterer Stelle ausgeführt. ${ }^{970}$

\section{Verfassungsfeindlichkeit im politischen Wettbewerb}

Durch das Feststellungsurteil wird die Bewertung der Partei als „verfassungsfeindlich" in besonderer Weise legitimiert. So erfolgt die staatliche Bewertung einer Partei als „verfassungsfeindlich“ nicht mehr, wie bislang, im Bereich des Berufsbeamtentums oder der politischen Auseinandersetzung, sondern wird nunmehr in einem gesonderten Verfahren explizit unter der verfassungsgerichtlichen Verwertung von Tatsachen festgestellt. Durch den Ausschluss aus der staatlichen Parteienfinanzierung erfolgt eine unvermeidbare Bewertung der Parteiziele durch das Bundesverfassungsgericht. Dies wirkt sich vor allem im Bereich der sog. „faktischen Nachteile“971 aus.

Die Feststellung der Verfassungsfeindlichkeit stellt somit einen selbstständigen Nachteil dar, der nicht nur den Ausschluss aus der staatlichen Parteienfinanzierung vorsieht, sondern darüber hinaus auch eine etwaige materielle verfassungsfeindliche Ausrichtung der Partei zum Zeitpunkt der Urteilsverkündung in tatsächlicher Hinsicht bestätigt. Die aus der Bestätigung der materiellen Verfassungsfeindlichkeit entstehenden Folgen könnten die Rechtstellung der betroffenen Partei insoweit verändern, dass

969 Statt aller siehe Streinz, in: Huber/Voßkuhle (Hrsg.), Grundgesetz, ${ }^{7} 2018$, Art. 21, Rn. 252d; siehe zur „Verfassungsfeindlichkeit als Gefahr“ auch unten \$5.B.II.2.e).

970 Siehe unten $₫ 5$ B. II. 2.

971 Siehe dazu die Ausführungen unten $\$ 5$ B. II. 1. 
ab dem Zeitpunkt ihres Ausschlusses aus der staatlichen Parteienfinanzierung weitere faktische Wettbewerbsnachteile erwachsen. Zwar kann ein Feststellungsurteil nach Art. 21 Abs. 3 GG formell nicht dazu führen, dass sich die betroffene Partei bis auf die Ungleichbehandlung in Angelegenheiten der staatlichen Parteienfinanzierung einem erhöhten Sanktionsregime des Staates gegenübergestellt sieht, die durch das Feststellungsurteil bescheinigte verfassungsfeindliche Haltung könnte allerdings in anderer Hinsicht weitere nachteilige Folgen für die betroffene Partei beinhalten. Dies bedeutet, dass auf der Rechtsebene das Feststellungsurteil des Bundesverfassungsgerichtes keine weitergehenden Nachteile als den Ausschluss aus der Parteienfinanzierung bewirken darf, allerdings bei der Beurteilung, ob die Voraussetzungen zur Ergreifung bestimmter anderer Maßnahmen erfüllt sind, die Erfüllung des Tatbestandes des Art. 21 Abs. 3 GG durch die Partei als Indiz besonderen Gewichts für ihr Verfassungsfeindlichkeit berücksichtigt werden kann. Insbesondere steht das Parteienprivileg sog. „faktischen Nachteilen" nicht entgegen.

\section{Die Figur der faktischen Nachteile}

Die Wertung des Feststellungsurteils nach Art. 21 Abs. 3 GG hängt der Partei für die Dauer des Ausschlusses an. Sie kann sich dem, auch durch eine inhaltliche Neuausrichtung, zumindest für die Dauer von sechs Jahren nicht entziehen. Dies kann für die Partei gerade dort zu einem erheblichen Nachteil erwachsen, wo sie im politischen Wettkampf mit staatlichen Institutionen und ihren Amts- und Mandatsträgern in Kontakt gerät.

\section{a) Problemstellung}

Der Staat kann Parteien aufgrund ihrer verfassungsfeindlichen inhaltlichen Ausrichtung nicht nur die Nachteile zufügen, die in Art. 21 GG normiert sind. Das Parteienprivileg schützt zwar immer noch vor der Anknüpfung weiterer staatlicher Maßnahmen an die Feststellung des Ausschlusses aus der staatlichen Parteienfinanzierung, allerdings führt dies nicht zu einem absoluten Schutz der Parteien vor jeglicher Entäußerung staatlichen Handelns. So wird insbesondere von der Rechtsprechung anerkannt, dass Parteien durch das Parteienprivileg nicht vor staatlichen Maß- 
nahmen geschützt sind, deren Folge lediglich „faktische Nachteile“972 darstellen. Insbesondere im Bereich des politischen Meinungskampfes und -wettbewerbs engagieren sich Amts- und Mandatsträger und veröffentlichen nicht selten negative Werturteile über konkrete Parteien. ${ }^{973}$ Benachteiligungen einer Partei aufgrund ihrer politischen Haltung außerhalb des Parteiverbotes sind somit im Rahmen der sog. „faktischen Nachteile“ anerkannt. ${ }^{974}$ Insbesondere werden die Folgen staatlicher Maßnahmen, wie die nachrichtendienstliche Überwachung von Parteien, die Bewertung durch staatliche Organe als „verfassungswidrig oder -feindlich“ und die Erwähnung in den Berichten der Verfassungsschutzbehörden unter die Kategorie der "faktischen Nachteile“ gefasst. ${ }^{975}$ Durch die Figur der faktischen Nachteile ist es dem Staat möglich, ohne gegen die ihm durch das Parteienprivileg gezogenen Grenzen zu verstoßen, zumindest mittelbar in die politische Wettbewerbslage zulasten einer Partei einzugreifen. Diese Praxis blieb jedoch nicht frei von Widerspruch, gerade weil das Parteienprivileg die Parteien solange vor einer staatlichen Behandlung als "verfassungsfeindlich“ schützt, solange die Verfassungswidrigkeit oder -feindlichkeit nicht durch das Bundesverfassungsgericht in einem hierfür vorgesehenen Verfahren festgestellt wurde. ${ }^{976}$

Eine Partei, die aus der staatlichen Finanzierung ausgeschlossen wurde, könnte somit zu befürchten haben, dass die rechtlichen Hürden für als zulässig erachtete, allerdings dennoch wettbewerbsverzerrende staatliche Maßnahmen ihr gegenüber gesenkt werden. ${ }^{977}$ Die Etablierung des Art. 21 Abs. 3 GG könnte insoweit zu einem Paradigmenwechsel innerhalb der Fallgruppe der sog. „faktischen Nachteile“ führen und den Anwendungsbereich von der Rechtsprechung anerkannter Handlungsalternativen ${ }^{978}$ im Umgang mit Parteien erweitern bzw. modifizieren.

972 Zu der Figur der „faktischen Nachteile“ siehe BVerfGE 39, 334 (360); BVerfGE 40, 287 ( $292 \mathrm{f}$.).

973 Eingehend Eder, »Rote Karte« gegen »Spinner«?, 2017.

974 So die h.M. BVerfGE 39, 334 (360); BVerfGE 40, 287 (292 f.); Ipsen, in: Sachs (Hrsg.), Grundgesetz, ${ }^{8} 2018$, Art. 21, Rn. 202 ff.

975 Statt aller siehe Ipsen, in: Sachs (Hrsg.), Grundgesetz, ${ }^{8} 2018$, Art. 21, Rn. 202 ff.

976 Kritisch insbesondere Streinz, in: Huber/Voßkuhle (Hrsg.), Grundgesetz, ${ }^{7} 2018$, Art. 21, Rn. 218 ff.

977 Dies wohl befürwortend Streinz, in: Huber/Voßkuhle (Hrsg.), Grundgesetz, 72018, Art. 21, Rn. 252d.

978 Wie bereits erwähnt zählen hierzu insbesondere die staatliche Bekämpfung im politischen Diskurs, die Überwachung durch die Verfassungsschutzbehörden sowie der Ausschluss von Parteimitgliedern aus dem öffentlichen Dienst, siehe vertiefend hierzu Hettich, Die Zulässigkeit verschiedener Handlungsalternativen 
b) Faktische Beeinträchtigung der Wettbewerbslage

Die Figur der faktischen Nachteile tritt insbesondere dort auf, wo eine staatliche Institution im Rahmen ihrer originären Aufgabenwahrnehmung die inhaltliche-politische Ausrichtung einer Partei bewertet. Typische Fälle bilden dabei Äußerungen von Amtswaltern und Staatsorganen zur „extremistischen" oder „verfassungsfeindlichen" Haltung einer Partei und die Berücksichtigung von Parteimitgliedschaften in Anstellungsverhältnissen im öffentlichen Dienst. Die Figur der „faktischen Nachteile“ ist nicht unumstritten ${ }^{979}$, sie wird allerdings vom Bundesverfassungsgericht bislang in ständiger Rechtsprechung anerkannt ${ }^{980}$ und eröffnet somit dem Staat im Bereich der politischen Bekämpfung mehrere Handlungsalternativen, die nicht in den Anwendungsbereich der zum Parteienprivileg zugehörigen Sperrwirkung fallen. Der Umstand, dass die inhaltliche Ausrichtung von Parteien aufgrund des Parteienprivilegs kein Anknüpfungspunkt beschwerenden staatlichen Handelns sein darf, gilt angesichts der Figur der faktischen Nachteile nicht absolut.

Die folgende Untersuchung widmet sich im ersten Schritt der Figur der „faktischen Nachteile“ und ihrem Verhältnis zum Parteienprivileg. In einem zweiten Schritt wird dann der Einfluss der Rechtsstellung einer aus der staatlichen Parteienfinanzierung ausgeschlossenen Partei auf die anerkannten Paradigmen solchen staatlichen Handelns (insbesondere den parteipolitischen Äußerungen von Amtsträgern sowie dem Anstellungsverhältnis im öffentlichen Dienst) untersucht werden.

\section{c) Dogmatik}

(1) Ansatz des Bundesverfassungsgerichtes

Das Bundesverfassungsgericht hält das Zufügen „faktischer Nachteile“ entgegen vorhandener Kritik ${ }^{981}$ trotz der Sperrwirkung des Parteienprivilegs

des Staates im Vorgehen gegen extremistische Parteien unter Berücksichtigung des Parteienprivilegs, 2015.

979 So zweifelnd insbesondere Streinz, in: Huber/Voßkuhle (Hrsg.), Grundgesetz, 72018, Art. 21, Rn. 115, 218; im weiteren Sinne lediglich auf die Bezeichnung einer Partei als „verfassungsfeindlich“ abstellend Morlok, in: Dreier/Bauer (Hrsg.), Grundgesetz, ${ }^{3} 2015$, Art. 21, Rn. 158.

980 BVerfGE 39, 334 (360); BVerfGE 40, 287 (292 f.).

981 Streinz, in: Huber/Voßkuhle (Hrsg.), Grundgesetz, ${ }^{7}$ 2018, Art. 21, Rn. 115, 218. 
für zulässig und stellt dabei, so wie die überwiegend h.M. auch, auf die Eingriffsqualität der Maßnahme in Art. 21 GG ab. ${ }^{982}$ Die faktischen Nachteile beschreiben das Produkt staatlichen Handelns, das aus der ordentlichen Aufgabenwahrnehmung staatlicher Organe heraus entsteht und Parteien als Nebenfolge ihrer Tätigkeit in irgendeiner Art und Weise beschwert, allerdings nicht als Eingriff in den von Art. 21 GG vorausgesetzten Rechtskreis von Parteien zu qualifizieren ist. ${ }^{983}$ Bereits vor der Novellierung des Art. 21 Abs. 3 GG wurde vom Bundesverfassungsgericht anerkannt, dass bestimmte Parteien gerade beim Vorliegen des Verdachts der Verfassungsfeindlichkeit staatliche Maßnahmen besonders politischer Art dulden müssen, ohne dass sie sich auf den Schutz des Parteienprivilegs berufen könnten. So führte das Bundesverfassungsgericht aus:

„Deshalb ist es verfassungsrechtlich unbedenklich und von der politischen Verantwortung der Regierung gefordert, daß sie ibren jährlichen Bericht über die Entwicklung verfassungsfeindlicher Kräfte, Gruppen und Parteien dem Parlament und der Öffentlichkeit vorlegt. Soweit daraus für eine Partei faktische Nachteile (bei der Gewinnung von Mitgliedern oder Anhängern) entstehen, ist sie dagegen nicht durch Art. 21 GG geschützt. "984

Das Bundesverfassungsgericht spricht damit bestimmten staatlichen Maßnahmen die Eingriffsqualität in Art. 21 GG ab, sofern sich die Maßnahme im Rahmen der Aufgabenwahrnehmung eines staatlichen Organes bewegt und die daraus entstehende (faktische) Belastung für die Partei nur eine Nebenfolge darstellt. Dies gilt gleichfalls für Auswirkungen einer solchen Bewertung für berufliche Laufbahnen im öffentlichen Dienst, wo die Ablehnung eines Bewerbers aufgrund der Parteimitgliedschaft auch lediglich unter die Fallgruppe der „faktischen Nachteile“ fällt und somit keinen Eingriff in den Rechtskreis des Art. 21 GG darstellt, obwohl mittelbar die Attraktivität einer Mitgliedschaft erhebliche Einbußen erleidet. ${ }^{985}$

982 BVerwGE 110, 126 (131); Klein, in: Maunz/Dürig (Hrsg.), Grundgesetz, 2018, Art. 21, Rn. 575.

983 Siehe BVerfGE 39, 334 (360).

984 BVerfGE 39, 334 (360); siehe auch BVerfGE 40, 287 (292 f.).

985 BVerfGE 39, 334 (360). 


\section{(2) Ansätze in der Literatur}

In der Literatur existiert keine einheitliche Auffassung zu der rechtlichen Figur der faktischen Nachteile. So wird teilweise nur die hinter der verfassungsgerichtlichen Rechtsprechung stehende Dogmatik kritisiert, das Ergebnis allerdings befürwortet. ${ }^{986}$ Teilweise wird aber auch die Kategorisierung staatlicher Eingriffe in „echte“ und „faktische“ Nachteile gänzlich abgelehnt. ${ }^{987}$ Eine Gemeinsamkeit besteht, trotz unterschiedlicher Auffassungen zu der Figur der „faktischen Nachteile“ im Allgemeinen, in der Ablehnung der verfassungsgerichtlichen Dogmatik. Kern der Kritik bildet die verfassungsgerichtliche Begründung, dass die unter den Begriff der „faktischen Nachteile“ fallenden Maßnahmen deshalb vom Bundesverfassungsgericht nicht als rechtserheblicher Eingriff zu qualifizieren seien, weil ihnen eine gewisse Unmittelbarkeit fehle. Da die verfassungsgerichtliche Rechtsprechung auch sog. faktischen Grundrechtseingriffe ${ }^{988}$ anerkenne, sei es nicht überzeugend, einen Eingriff in den Rechtskreis der Parteien danach zu bestimmen, ob die Folgen des staatlichen Handelns eine unmittelbare Rechtswirkung gegen die Partei entfalten oder lediglich faktisch die vorgefundene Wettbewerbslage zu verzerren vermögen. ${ }^{989}$ Hans Klein teilt die dogmatischen Bedenken, hält allerdings dennoch eine Rechtsverletzung der Parteien durch solche amtlichen Äußerungen für ausgeschlossen, die sich im Rahmen der „Toleranzgrenze“ bewegen und wohl deshalb keinen Eingriff darstellten. ${ }^{990}$ Kritik müsse eine Partei nach dieser Auffassung grundsätzlich hinnehmen, auch wenn diese durch ein Staatsorgan unter der Nutzung seiner Amtsautorität geäußert werde.

Ähnlich, allerdings einen neuen Ansatzpunkt in die Diskussion einbringend, äußert sich Dietrich Murswiek. Demnach stellten staatliche Bewertungen und die daran anknüpfenden „faktischen Nachteile“ durchaus einen Eingriff in die Rechtsposition des Art. 21 GG dar, da eine Partei erhebliche Wettbewerbsnachteile durch ein negatives Werturteil eines Amtswalters oder der Verfassungsschutzbehörden erleide. ${ }^{991}$ Dieser Eingriff basiere auch aufgrund einer staatlichen Bewertung der vermeintlich verfassungsfeindlichen Haltung der Partei. Allerdings entstehe dennoch kein Konflikt

986 So Klein, in: Maunz/Dürig (Hrsg.), Grundgesetz, 2018, Art. 21, Rn. 575.

987 Streinz, in: Huber/Voßkuhle (Hrsg.), Grundgesetz, ${ }^{7} 2018$, Art. 21, Rn. 115.

988 Vgl. Bethge/Weber-Dürler, in: VVDStRL 57 (1998), S. 7 ff.

989 Klein, in: Maunz/Dürig (Hrsg.), Grundgesetz, 2018, Art. 21, Rn. 575; Murswiek, DVBl 1997, 1021 (1029).

990 Klein, in: Maunz/Dürig (Hrsg.), Grundgesetz, 2018, Art. 21, Rn. 575.

991 Murswiek, DVBl 1997, 1021 (1029). 
mit dem Anknüpfungsverbot des Parteienprivileges, da Art. 21 Abs. 2, Abs. 3 und Abs. 4 GG die Parteien lediglich vor staatlichen Maßnahmen mit rechtsverbindlichem Charakter schütze. ${ }^{992}$ Die Grenzen der Sperrwirkungen würden somit nicht durch solche Maßnahmen überschritten, die zwar mittelbar eine wettbewerbsverzerrende Wirkung entfalten, allerdings keine rechtsverbindliche Regelung beinhalten. Sollte der Staat die Wettbewerbschancen einer Partei durch negative Werturteile verschlechtern, denen keine Regelungswirkung zukommt, sei dies zwar als Eingriff in die Rechtsposition der Parteien aus Art. 21 GG zu verstehen, allerdings im Unterschied zu Maßnahmen mit rechtsverbindlicher Regelungswirkung im Rahmen der Rechtfertigung nicht auf die Vereinbarkeit mit dem Parteienprivileg zu prüfen.

\section{(3) Faktische Nachteile als Eingriffsäquivalent}

Auch wenn die Kritik an der Dogmatik des Bundesverfassungsgerichts überzeugen mag, ist der verfassungsgerichtlichen Rechtsprechung zu der Figur der „faktischen Nachteile“ im Ergebnis zu folgen. Durch staatliches Handeln hervorgerufene mittelbar-faktische Grundrechtsbeeinträchtigungen (worunter die Kategorie der „faktischen Nachteile“ fällt) werden inzwischen von der h.M. - zutreffend - als rechtfertigungsbedürftig erachtet. ${ }^{993}$ Dies führt allerdings keineswegs auch zu der Wertung, dass die „faktischen Nachteile“ die Rechtsposition der Parteien in einer Art und Weise beeinträchtigen, die das Anknüpfungsverbot des Art. 21 Abs. 4 GG zur Anwendung bringt, denn das eigentliche Problem hinter der Figur der faktischen Nachteile stellt deren Verhältnis zum Parteienprivileg dar. Bei einer weiten Auslegung des Parteienprivilegs wäre jedes staatliche Handeln, das den Parteien aufgrund ihrer inhaltlichen Ausrichtung einen auch nur theoretischen Nachteil zufügen kann, verfassungsrechtlich weitestgehend unmöglich.

Die Rechtsprechung des Bundesverfassungsgerichtes ist insbesondere vor dem Hintergrund zu verstehen, dass Ermittlungen von Verfassungsschutzbehörden gegen Parteien mit der anschließenden Veröffentlichung der Ermittlungsergebnisse sowie andere durch Amtswalter gefällte Werturteile aufgrund der politischen Ausrichtung der Partei allgemein verfas-

992 Ders., DVBl 1997, 1021 (1029f.).

993 Siehe ausführlich Starke, DVBl 2018, 1469 ff.; vgl. dazu noch Murswiek, DVBl 1997, 1021 ff.; Lege, DVBl 1999, 569 ff.; Gusy, NJW 2000, 977 (982 ff.). 
sungswidrig und unzulässig wären, wenn man sie als einen Eingriff in die Rechtsposition des Art. 21 GG ansehen würde. ${ }^{994}$ Aus diesem Grund negierte das Bundesverfassungsgericht wohl die Eingriffsqualität solcher negativen Werturteile wie den Verfassungsschutzberichten und amtlichen Äußerungen von Staatsorganen. Denn wenn solchen staatlichen Werturteilen keine Eingriffsqualität innewohnt, dann seien sie auch unter der Geltung des Parteienprivileges zulässig. ${ }^{995}$

Die Dogmatik der mittelbar-faktischen Grundrechtseingriffe kann nicht uneingeschränkt mit dem Ergebnis auf Art. 21 GG übertragen werden, dass jedweder aus der politischen Haltung erwachsende Nachteil in Konflikt mit dem Parteienprivileg gerät. Insoweit ist die Ablehnung des gesamten Instituts der "faktischen Nachteile“ nicht überzeugend, sofern sie allein aufgrund der Qualifizierung der amtlichen Äußerungen als ein mit dem Parteienprivileg unvereinbarer Eingriff erfolgt. ${ }^{996}$ Zwar ist zuzugeben, dass es widersprüchlich ist, einerseits auf grundrechtlicher Ebene bei mittelbar-faktischen Beeinträchtigungen die Notwendigkeit einer Rechtfertigung $\mathrm{zu}$ fordern, andererseits bei der Beeinträchtigung durch Art. 21 GG geschützter Rechtspositionen eine gewisse Unmittelbarkeit vorauszusetzen. Es ist richtig, auch solche staatlich begründeten Nachteile als Eingriff in die Rechtsposition, insbesondere der Betätigungsfreiheit und der Chancengleichheit der Parteien, zu verstehen und als Folge dessen deren Verfassungsmäßigkeit von der Rechtfertigungsfähigkeit abhängig zu machen. Nicht überzeugend ist allerdings der Schluss, dass auf allen Ebenen staatlichen Handelns eine Berücksichtigung von verfassungsfeindlichen Positionen verfassungsrechtlich ausgeschlossen ist, sofern die Partei nicht durch das Bundesverfassungsgericht verboten wurde. Dies würde angesichts der Anerkennung mittelbar-faktischer Grundrechtseingriffe ${ }^{997} \mathrm{zu}$ einem ungünstigen Verhältnis vom Staat zu Parteien führen, indem jedwedes als Werturteil oder gar reine Tatsachenbehauptung zu qualifizierende staatliche Handeln, auch wenn es im Rahmen einer originären Aufgabenwahrnehmung erfolgt, im umfassenden Sinne verfassungsrechtlich unzulässig wäre, sofern es die Wettbewerbslage einer Partei zu ihren Lasten oder Gunsten ändern mag. Auch würde dies entgegen der Grundsätze des Berufsbeamtentums dazu führen, dass der Staat Mitglieder offen verfas-

994 Murswiek, DVBl 1997, 1021 (1029).

995 So BVerfGE 39, 334 (360).

996 So allerdings Streinz, in: Huber/Voßkuhle (Hrsg.), Grundgesetz, ${ }^{7} 2018$, Art. 21, Rn. 115.

997 Vertiefend Starke, DVB1 2018, 1469 ff. 
sungsfeindlicher Parteien im öffentlichen Dienst dulden müsste. Ein solches Ergebnis und ein so umfassender Schutz von Parteien vor jeglichen staatlichen Handeln kann verfassungsrechtlich nicht gewollt sein.998

Die „faktischen Nachteile“ sind danach nicht an der Prämisse zu messen, ob sie einen Eingriff in den von Art. 21 GG vorausgesetzten Rechtskreis darstellen, sondern vielmehr daran, ob das Parteienprivileg bei der Annahme des Vorliegens eines Eingriffsäquivalentes ihrer Zulässigkeit entgegensteht.

Überzeugend ist daher der von Dietrich Murswiek vertretene Ansatz, der besagt, dass die Handlungen, deren Folge die sog. faktischen Nachteile darstellen, zwar als Eingriff in Art. 21 GG zu verstehen, allerdings nicht aufgrund des Anknüpfungsverbotes des Parteienprivilegs als unzulässig anzusehen seien. ${ }^{999}$ Statt den "faktischen Nachteilen“ trotz ihrer wettbewerbsverzerrenden Wirkung die Eingriffsqualität gänzlich abzusprechen ${ }^{1000}$ oder sie unter eine nur schwer bestimmbare „Toleranzgrenze“ $\mathrm{zu}$ fassen ${ }^{1001}$, wird der dogmatische Ansatzpunkt zur Lösung des Problems an den Inhalt des Parteienprivilegs geknüpft. So soll das Parteienprivileg nur vor solchen Nachteilen schützen, die unmittelbar in der Anordnung einer Rechtsfolge liegen und somit einen rechtsverbindlichen Charakter aufweisen. ${ }^{1002}$ Die Berücksichtigung einer verfassungsfeindlichen Position im Rahmen originärer Staatsaufgaben, deren Wahrnehmung als Nebenfolge wettbewerbserhebliche Nachteile für Parteien nach sich zieht, stellt insoweit keinen Verstoß gegen das Parteienprivileg dar. Insbesondere Werturteile, z.B. in der Form von amtlichen Äußerungen der Bundesregierung oder den Verfassungsschutzberichten, bedürfen aufgrund ihrer wettbewerbsverzerrenden Wirkung einer Rechtfertigung, die der Äußerungsbefugnis staatlicher Stellen materielle Grenzen setzt, diese allerdings nicht generell für unzulässig erklärt. So ist eine „politische Bekämpfung“ durch Staatsorgane, wie sie das Bundesverfassungsgericht auch als echte Handlungsalternative zur Einleitung eines Parteiverbotsverfahrens anerkennt ${ }^{1003}$, nach wie vor möglich. Dies bedeutet, dass staatliche Maßnahmen zwar auch dann als eingriffsgleiche Beeinträchtigung des von Art. 21 GG vorausgesetzten Rechtskreises zu werten sind, wenn sie ledig-

998 Vgl. auch BVerwGE 47, 330 (349) in Bezug auf die Eignung eines Bewerbers für die Beamtenlaufbahn.

999 Murswiek, DVB1 1997, 1021 (1029f.).

1000 BVerfGE 39, 334 (360); BVerfGE 40, 287 (292 f.).

1001 So Klein, in: Maunz/Dürig (Hrsg.), Grundgesetz, 2018, Art. 21, Rn. 575.

1002 Murswiek, DVBl 1997, 1021 (1029).

1003 BVerfGE 40, 287 (292). 
lich „faktische Nachteile“ für die betroffene Partei begründen, dafür das Anknüpfungsverbot des Parteienprivilegs bei der Beurteilung von deren Zulässigkeit allerdings keine Rolle spielt. Das Parteienprivileg setzt voraus, dass bis zu einer entsprechenden Entscheidung des Bundesverfassungsgerichts die Verfassungswidrigkeit oder Verfassungsfeindlichkeit einer Partei nicht rechtsverbindlich festgestellt werden kann. Der staatlichen Bewertung einer Partei, insbesondere bei der Erwähnung in den Berichten der Verfassungsschutzbehörden und bei Äußerungen der Bundesregierung, fehlt es allerdings an einer solchen Rechtswirkung. Dafür spricht, dass das Parteienprivileg nicht dazu dienen sollte, den Parteien im politischen Meinungskampf gegen Amts- und Mandatsträger einen Vorteil zu verschaffen, indem das Parteienprivileg jeglichen aus einem Werturteil oder einem Tatsachenvortrag entstehenden Nachteil verbietet. ${ }^{1004}$ Solange der Staat nur eine Bewertung vornimmt und sich als Akteur an dem politischen Meinungskampf beteiligt, ohne das Ergebnis des Bewertungsprozesses als Anknüpfungsgrundlage zielgerichteten Vorgehens zu nutzen, ist dieses Handeln nicht am Parteienprivileg zu messen. Solange also der Staat bis zum Verbot einer Partei oder deren Ausschluss aus der staatlichen Parteienfinanzierung aufgrund einer vermeintlich vorliegenden Verfassungsfeindlichkeit keine Maßnahme mit rechtsgestaltender Wirkung anordnet, sondern in seinem eigenen staatlichen Handeln (insbesondere im Bereich der Informations- und Öffentlichkeitsarbeit oder dem Umgang mit Staatsdienern) auf einer tatsächlichen Ebene die inhaltliche Positionierung berücksichtigt, liegt kein Konflikt mit dem Parteienprivileg vor.

2. Paradigmatische Darstellung der Rechtsstellung verfassungsfeindlicher Parteien

Das Hervorrufen der "faktischen Nachteile“ stellt nach der hier vertretenen Auffassung einen Eingriff in den durch Art. 21 GG vorausgesetzten Rechtskreis dar und bedarf deshalb einer Rechtfertigung. Gerade im Falle der staatlichen Teilnahme am politischen Diskurs sind die Grenzen der Neutralität und der damit zusammenhängenden Chancengleichheit der Parteien zu wahren. ${ }^{1005}$ Im Folgenden werden die Auswirkungen des Aus-

1004 Ähnlich Klein, in: Maunz/Dürig (Hrsg.), Grundgesetz, 2018, Art. 21, Rn. 575.

1005 Vgl. BVerfGE 40, 102 (109 ff.).; Möstl, in: Uhle (Hrsg.), Information und Einflussnahme, 2018, S. 49, 63 ff.; Barczak, NVwZ 2015, 1014 ff. f.; Ferreau, NVwZ 2017, 1259 (1260). 
schlusses aus der staatlichen Finanzierung auf die rechtliche Bewertung typischer Konfliktlagen untersucht werden. Hierzu zählen die staatliche Teilnahme am politischen Diskurs (a), die Beachtung von Parteimitgliedschaften bei Beschäftigungsverhältnissen im öffentlichen Dienst (b), die nachrichtendienstliche Überwachung (c) und die Berücksichtigung einer verfassungsfeindlichen Grundhaltung im Rahmen der kommunalen Leistungsverwaltung (d). Zudem wird der Einfluss des Ausschlussurteils auf den öffentlich-rechtlichen Gefahrenbegriff (e) untersucht.

a) Staatliche Teilnahme am politischen Meinungskampf

Ein Problemfeld im Bereich der „faktischen Nachteile“ ist die staatliche Beteiligung am politischen Meinungskampf. Aus der Chancengleichheit der Parteien folgt ein Gebot der staatlichen Neutralität im politischen Wettbewerb, da sich die Willensbildung vom Volk zu den Staatsorganen vollziehen muss. ${ }^{1006}$ Diese Äußerungen werden üblicherweise im Rahmen des Aufgabenbereiches des jeweiligen Staatsorganes getätigt und sorgten bereits in der Vergangenheit für Konflikte zwischen dem sich äußernden Staatsorgan und der von der Äußerung betroffenen Partei. Die Aktualität der Problematik ist (erneut) angestiegen, seitdem in jüngerer Vergangenheit Parteimitglieder vom Bundespräsidenten als „Spinner"1007 bezeichnet und Teilorganisationen von Parteien vom Bundesamt für Verfassungsschutz als „Prüffall“1008 eingestuft wurden sowie Parteien von Ministerien die „rote Kartei“1009 gezeigt bekommen haben. ${ }^{1010}$ Doch nicht nur politische Äußerungen im engeren Sinne standen im Fokus der Öffentlichkeit, sondern auch andere Verhaltensweisen, die als Werturteil qualifiziert werden können. ${ }^{1011}$

1006 Ferreau, NVwZ 2017, 1259 (1260); BVerfGE 20, 56 (99); BVerfGE 44, 125 (140 ff.); BVerfGE 138, 102 (109 ff).

1007 Siehe hierzu BVerfGE 136, $323 \mathrm{ff}$.

1008 Vgl. hierzu VG Köln, Beschl. v. 26.02.2019 - 13 L 202/19 -, juris; siehe hierzu auch Nikkho, jurisPR-ITR 8/2019.

1009 Siehe hierzu BVerfGE 140, $225 \mathrm{ff}$.

1010 Zur Vertiefung der Problematik siehe Eder, »Rote Karte« gegen »Spinner«?, 2017.

1011 So ordnete ein Oberbürgermeister an, die Lichter am Rathaus auszuschalten siehe das Urteil BVerwGE 159, $327 \mathrm{ff}$. 


\section{(1) Neutralitätsgebot}

Da es zu den demokratischen Grundsätzen gehört, dass sich die politische Willensbildung von „unten nach oben“ vollzieht ${ }^{1012}$, darf der Staat nicht lenkend in den politischen Wettbewerb eingreifen. Dies setzt voraus, dass grundsätzlich jeder Akteur des politischen Wettkampfes die gleichen Chancen eingeräumt bekommt und die Kräfteverhältnisse im Wesentlichen allein im gesellschaftlichen Wettbewerb ermittelt werden. Eine staatliche Einflussnahme ist grundsätzlich untersagt und nur in besonders engen Grenzen zulässig.

Die staatliche Informations- und Öffentlichkeitsarbeit wird durch den Grundsatz der staatlichen Neutralität eingegrenzt. Dieser Grundsatz ist insbesondere dann von besonderer Relevanz, wenn sich der Staat durch ein Organ oder einen Amtswalter zu einer bestimmten politischen Frage äußert und sich dabei insbesondere gegen eine bestimmte politische Partei positioniert. ${ }^{1013}$ Die sich äußernde Person muss dabei im Rahmen ihrer Amtsfunktion handeln. Voraussetzung für die Beachtung des staatlichen Neutralitätsgebotes ist nämlich, dass die Äußerung der staatlichen Sphäre zugerechnet werden kann, die sich äußernde Person im Zeitpunkt der Äußerung damit „im Amt“ handelt. Denn erst dann kann die Äußerung als staatlicher Eingriff in den politischen Wettbewerb und der Chancengleichheit der Parteien qualifiziert werden. Ob die betreffende Person bei der Beteiligung am politischen Diskurs einen ausreichenden Staatsbezug aufweist, muss anhand einer objektiven Betrachtung aller tatsächlichen Umstände des Einzelfalls ermittelt werden. ${ }^{1014}$ Von Relevanz sind bei der Beurteilung insbesondere der Inhalt, die Form und der äußere Zusammenhang der Aussage. ${ }^{1015}$ Sofern ermittelt werden kann, dass die Äußerung mit der dem öffentlichen Amt immanenten Amtsautorität getätigt wurde, ist ein hinreichender Staatsbezug vorhanden, der die Achtung der politischen Chancengleichheit zwingend vorschreibt.

Dem Grundgesetz liegt die Vorstellung zugrunde, dass Regierungsämter durch Parteimitglieder besetzt werden, denen wiederum selbst - auch wenn sie ein Regierungsamt innehaben - die Teilnahme am politischen

1012 Siehe statt aller Sachs, in: ders. (Hrsg.), Grundgesetz, ${ }^{8} 2018$, Art. 20, Rn. 18.

1013 Vgl. Spitzlei, JuS 2018, 856 (857 ff.); Ferreau, NVwZ 2017, 1259 (1260).

1014 RhPfVerfGH, Beschl. v. 21.5.2014 - VGH A 39/14 = NVwZ-RR 2014, 665 (667).

1015 Barczak, NVwZ 2015, 1014 (1016). 


\section{\5 Der Status der Verfassungsfeindlichkeit}

Wettbewerb nicht vollumfänglich versagt werden darf. ${ }^{1016}$ Die Abgrenzung zwischen den Positionen, in der sich die äußernde Person im Zeitpunkt der Tätigung der Aussage befand, ist für die Ermittlung der rechtlichen Voraussetzungen notwendig. Denn wenn kein Staatsbezug gegeben und die Äußerung damit „privater“ Natur ist, liegt auch keine Bindung des Äußernden an das politische Neutralitätsgebot vor.

Dass staatliche Organe durch Öffentlichkeits- und Informationsarbeit am politischen Diskurs teilnehmen, wird verfassungsrechtlich als notwendig erachtet. ${ }^{1017}$ Staatlichen Organen, insbesondere solchen, deren Bildung und Zusammensetzung maßgeblich durch den politischen Wettbewerb bestimmt wird (wie z.B. der Regierung), muss es erlaubt sein, ihre Entscheidungen auch im öffentlichen Diskurs zu verteidigen und zu bewerben. Da auch die Parteiendemokratie vorsieht, dass Parteimitglieder in öffentliche Positionen gewählt werden, darf die Übernahme staatlicher Verantwortung dem parteipolitischen Engagement nicht umfassend entgegenstehen. ${ }^{1018}$

Wenn Amtswalter ihrer (zumindest im Falle der Bundesregierung)1019 verfassungsrechtlich gebotenen Öffentlichkeitsarbeit nachgehen, kann es zu Kollisionen mit dem objektiv-rechtlichen Neutralitätsgebot im politischen Wettbewerb kommen. Äußerungen, auch die Verteidigung eigener politischer Positionen, kann die Wettbewerbslage zulasten oder zugunsten einer Partei verändern.

\section{(2) Herleitung von Äußerungsbefugnissen}

Anerkannt bei Äußerungen staatlicher Organe ist deren Eingriffsqualität in Art. 21 GG, sofern sie für eine bestimmte Partei oder einen bestimmbaren Kreis an Parteien einen Wettbewerbsnachteil (auch lediglich faktischer Art) darstellen. ${ }^{1020}$ Versucht man anhand dessen die staatliche Beteiligung am politischen Diskurs rechtlich einzuordnen, so kommt man zu dem Ergebnis, dass sie Bestandteil der Eingriffsverwaltung ist und es somit grundsätzlich einer gesetzlichen Befugnis bedarf, um in dieser Art und Weise

1016 BVerfGE 138, 102 (117); kritisch zu dieser Differenzierung Tannenberger/ Nemeczek, NVwZ 2015, 209 (215 f.) - Urteilsanmerkung zu BVerfGE 138, 102.

1017 BVerfGE 44, 125 (147).

1018 Vgl. BVerfGE 138, 102 (117); siehe auch RhPfVerfGH, Beschl. v. 21.5.2014 VGH A 39/14 = NVwZ-RR 2014, 665 (667).

1019 Vgl. BVerfGE 105, 252 (270 ff.).

1020 Vgl. Murswiek, DVBl 1997, 1021 (1029f.). 
überhaupt handeln zu dürfen. Nach der wohl h.M. wird die Befugnis, sich wettbewerbserheblich zu äußern, aus der Zuständigkeit der betreffenden Organe bzw. aus deren Amtsfunktion abgeleitet. ${ }^{1021}$ Rechtsdogmatisch wird insoweit von der Aufgabe auf die Befugnis geschlossen ${ }^{1022}$ und die Reichweite der Äußerungsbefugnis wird durch die Kompetenzgrenzen des betreffenen Organes oder Amtswalters beschränkt. ${ }^{1023}$ Eine Äußerung muss sich, dies gilt allgemein, innerhalb der Grenzen des Aufgabenbereichs des jeweiligen Organes bewegen. Im Folgenden wird die Befugnis zur amtlichen Äußerung durch den Bundespräsidenten, die Bundesregierung und die (Ober-)Bürgermeister untersucht werden.

\section{(a) Bundespräsident}

Das Bundesverfassungsgericht schließt aus der Aufgabe des Bundespräsidenten die Befugnis, sich innerhalb bestimmter Grenzen zu politischen Sachverhalten zu äußern. ${ }^{1024}$ Die Aufgabe der Staatsrepräsentation und -integration als Staatsoberhaupt ${ }^{1025}$ sowie die Stellung als „Staatsnotar"1026 mit eigenständiger Entscheidungsbefugnis soll, so die verfassungsgerichtliche Auffassung, den Bundespräsidenten anleiten, Gefahren für das Gemeinwohl und Missstände, sowie deren Verursacher nach eigenem Ermessen auch öffentlich zu benennen. ${ }^{1027}$ Aufgrund dieses Auftrages sei es ihm gestattet, das Gebot der staatlichen Neutralität nicht immer strikt befolgen zu müssen. Vergleiche man auch die gegebene Machtstellung des Bundespräsidenten mit der des Reichspräsidenten in der Weimarer Republik, fällt auf, dass die erhebliche Eingrenzung der Befugnisse dazu führe, dass der Bundespräsident „weiche Mittel“ (Reden, mediale Äußerungen, Führung inoffizieller Gespräche mit Parteifunktionären ${ }^{1028}$, etc.) nutzen müsse, um

1021 Vgl. BVerfGE 136, 323 (332); kritisch Barczak, NVwZ 2015, 1014 (1018).

$1022 \mathrm{Zu}$ Recht kritisch gesehen von Barczak, NVwZ 2015, 1014 (1018); Lege, DVBl 1999, 569 ( 574 f.).

1023 Vgl. BVerfGE 44, 125 (149).

1024 BVerfGE 136, 323 (332).

1025 BVerfGE 136, 323 (335).

1026 Zum Begriff vgl. Eder, »Rote Karte« gegen »Spinner«?, 2017, S. 93.

1027 BVerfGE 136, 323 (335); auch Barczak, NVwZ 2015, 1014 (1017); a.A. Eder, »Rote Karte« gegen »Spinner«?, 2017, S. 64 ff., 143 ff., 188 ff.

1028 Wie Bundespräsident Frank-Walter Steinmeier zur Bildung einer „großen Koalition" aus CDU/CSU und SPD im Jahr 2017, nachdem die SPD eine Regierungsbeteiligung ausgeschlossen hatte und die einzig alternativ denkbare "Jamaika-Koalition“ aus CDU/CSU, FDP und Bündnis 90/Grüne gescheitert war, 
seiner verfassungsrechtlichen Aufgabe gerecht zu werden. ${ }^{1029}$ Aus der Stellung des Bundespräsidenten und der ihm zur Verfügung stehenden Steuerungsmittel sei er befugt, sich innerhalb bestimmter Grenzen auch zulasten einer konkreten Partei politisch zu äußern. So hat das Bundesverfassungsgericht bezüglich der Äußerungsbefugnis des Bundespräsidenten vertreten, dass diese „seinem Amte immanent“ sei. ${ }^{1030}$

\section{(b) Bundesregierung}

Eine Äußerungsbefugnis zu politischen Angelegenheiten ist auch für die Bundesregierung vom Bundesverfassungsgericht anerkannt. Insbesondere leite sich eine dahingehende Äußerungsbefugnis aus der "Staatsleitungskompetenz" der Bundesregierung ab. ${ }^{1031}$ Nach der Rechtsprechung folge aus der „Staatsleitungsfunktion“ die Aufgabe, durch die rechtzeitige Veröffentlichung von Informationen gesellschaftliche Konflikte zu bewältigen und kurzfristig auftretende Krisen schnell und sachgerecht zu entschärfen sowie dem Bürger zur „Orientierung“ zu verhelfen. ${ }^{1032}$ Dies beziehe sich nicht nur auf den ökonomischen, sondern auch auf den politischen Wettbewerb. Innerhalb der Bundesregierung sei grundsätzlich jedes Mitglied für den eigenen Ressortbereich zuständig ${ }^{1033}$, aufgrund der Richtlinienkompetenz des Bundeskanzlers nach Art. 65 S.1 GG erstrecke sich dessen Äußerungsbefugnis allerdings auf den gesamten Geschäftsbereich. ${ }^{1034}$

\section{(c) (Ober-)Bürgermeister}

Eine bundeseinheitliche Regelung zu der Rechtstellung des Oberbürgermeisters existiert nicht, da dieser Regelungskomplex in der Kompetenz der Bundesländer liegt. Doch auch wenn die länderrechtlichen Gemeindeord-

siehe http://www.faz.net/aktuell/politik/inland/schulz-trifft-zum-gespraech-mit -bundespraesident-steinmeier-ein-15306567.html, zul. aufgerufen am 18.02.2020.

1029 Treffend Barczak, NVwZ 2015, 1014 (1017); Arnauld, in: ders. (Hrsg.), Grundgesetz-Kommentar, 2012, Art. 54, Rn. 9.

1030 BVerfGE 136, 323 (332).

1031 Vgl. BVerfGE 105, 252 (270); BVerfGE 138, 102 (114).

1032 BVerfGE 105, 252 (269).

1033 Barczak, NVwZ 2015, 1014 (1017).

1034 Ders., NVwZ 2015, 1014 (1017). 
nungen keine explizite Ermächtigung des Oberbürgermeisters, sich zu politischen Themen zu äußern, enthalten sollten, so ergibt sich eine Äußerungsbefugnis zumindest aus der Selbstverwaltungsgarantie der Kommune. ${ }^{1035}$ Nach allgemeiner Ansicht leitet sich ein Äußerungsrecht der Kommunalvertreter aus dem Recht der Gemeinden aus Art. 28 Abs. 2 S. 1 GG, im Rahmen der Gesetze alle örtlichen Angelegenheiten selbst zu regeln ${ }^{1036}$, ab. Aus der allgemeinen Verbandszuständigkeit der Gemeinden für die örtlichen Angelegenheiten erwächst das Organrecht des (Ober-)Bürgermeisters, sich zu in der örtlichen Gemeinschaft wurzelnden Interessen und Bedürfnissen zu äußern. ${ }^{1037} \mathrm{Da}$ der Oberbürgermeister nicht nur „Teil der Verwaltung“, sondern im Rahmen der Wahlen zu seinem Amt unmittelbarer Teilnehmer am politischen Wettbewerb ist, ist seiner Amtsstellung auch eine politische Funktion immanent, die ihn berechtigt, auch am politischen Diskurs in seinem Amt als (Ober-) Bürgermeister teilzunehmen.

\section{(3) Grenzen amtlicher Beteiligung am politischen Diskurs}

Eine Beteiligung staatlicher Organe oder Amtswalter am politischen Meinungskampf ist grundsätzlich gestattet. Allerdings unterliegt sie Grenzen, die insbesondere durch das Gebot der staatlichen Neutralität und auch durch den Aufgabenbereich der „Öffentlichkeitsarbeit" selbst statuiert werden. ${ }^{1038}$ So versteht man unter der „regierungsamtlichen Öffentlichkeitsarbeit" schon begrifflich eine "gezielte, sachliche, direkte und grundsätzlich dialogorientierte Information der Öffentlichkeit über die Politik der Regierung, die sich eines aggressiv herabsetzenden Urteils gegenüber politisch anders Denkenden enthält". ${ }^{1039}$ Sowohl aus der Eigenart der Öffentlichkeitsarbeit als auch aus dem Grundsatz der staatlichen Neutralität im politischen Wettbewerb haben sich allgemein anerkannte Voraussetzungen entwickelt, deren Einhaltung für die rechtliche Zulässigkeit einer staatlichen Beteiligung am politischen Diskurs zwingend ist. Die allgemeinen Voraussetzungen sind, dass sich die amtliche Äußerung im Einzelfall

1035 Siehe insbesondere zum kommunalen Informationshandeln als Angelegenheit der örtlichen Gemeinschaft Papier/Schröder, DVBl 2017, 1 f.

1036 Vgl. nur BVerfGE 79, 127 (151).

1037 Barczak, NVwZ 2015, 1014 (1017).

1038 Spitzlei, JuS 2018, 856 (857); siehe ferner in Bezug zum politischen Einsatz von sog. Social-Bots Schröder, DVBl 2018, $465 \mathrm{ff}$.

1039 Siehe Mandelartz, LKRZ 2010, 371 (372); Barczak, NVwZ 2015, 1014 (1015). 
innerhalb der Grenzen des Aufgaben- und Zuständigkeitsbereiches bewegt und sich somit im Rahmen der Äußerungsbefugnis hält (a) und dass die Äußerung im Hinblick auf die durch sie eintretende Verzerrung des politischen Wettbewerbs verhältnismäßig ist (b). ${ }^{1040}$

(a) Aufgaben- und Zuständigkeitszuweisung

Die Äußerung muss sich im Rahmen des Zuständigkeitsbereiches des jeweiligen Organes bewegen, da andernfalls eine Beeinträchtigung der Chancengleichheit der Parteien mangels einer hinreichenden Befugnis nicht zu rechtfertigen wäre. ${ }^{1041}$ Die Äußerung müsste damit ihrer Natur nach staatlich sein. Da sich die Äußerungsbefugnis der oben genannten ${ }^{1042}$ Amtsträger aus ihrer amtlichen Stellung bzw. ihrer amtlichen Aufgabe herleitet, werden die Grenzen der Äußerungsbefungis durch den Aufgabenund Zuständigkeitsbereich bestimmt. Die formellen Grenzen der Zuständigkeit sind damit identisch mit den materiellen Grenzen der Äußerungsbefugnis.

Sollte ein ausreichender Amtsbezug vorhanden sein, ist ein mittelbarfaktischer Eingriff in die Chancengleichheit der Parteien anzunehmen und muss dementsprechend gerechtfertigt werden. Dies setzt zunächst voraus, dass die Äußerung ihrer inhaltlichen Art nach zu dem Aufgaben- und Zuständigkeitsbereich des betreffenden Amtswalters gehört.

\section{(b) Verhältnismäßigkeit}

Äußerungen von Amtsträgern sind (wie Maßnahmen der Eingriffsverwaltung im Allgemeinen) am Übermaßverbot zu messen. ${ }^{1043}$ Die Äußerung muss sich nicht nur innerhalb des staatlichen Aufgabenbereiches des jeweiligen Amtswalters oder Organes bewegen, sondern auch in einem angemessenen Verhältnis zu der hierdurch hervorgerufenen Wettbewerbsverzerrung und der damit einhergehenden Einschränkung der Chancengleichheit stehen.

1040 Ausführlich Eder, "Rote Karte« gegen "Spinner«?, 2017, S. 152 ff.; vgl. noch Barczak, NVwZ 2015, 1014 (1015 ff.); Spitzlei, JuS 2018, 856 (858ff.).

1041 Eder, »Rote Karte« gegen »Spinner«?, 2017, S. 152.

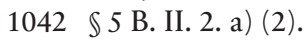

1043 Eder, »Rote Karte« gegen »Spinner«?, 2017, S. 158 ff. 
Rechtsprechung und Literatur haben durch die Festlegung von Paradigmen innerhalb der Verhältnismäßigkeitsprüfung zusätzliche Anforderungen geschaffen, die als Beurteilungsmaßstab für die Zulässigkeit solcher Äußerungen dienen. So führt beispielsweise eine unsachliche staatliche Beteiligung am politischen Diskurs stets zu einer Verletzung der verfassungsrechtlich garantierten Chancengleichheit der Parteien. ${ }^{1044}$ Ämter mit regierender oder regierungsähnlicher Funktion (Bundesregierung, Landesregierungen oder auch Bürgermeister) müssen bei der Teilnahme am politischen Diskurs ihre Aussagen sachlich tätigen, was insbesondere ein Verbot diffamierender Äußerungen beinhaltet. ${ }^{1045}$ Der Eingriff in den politischen Wettbewerb darf nicht durch eine Äußerung erfolgen, die keinen Beitrag zu einer sachlichen Auseinandersetzung mit der betreffenden Thematik erbringen kann. Die Rechtsprechung nimmt insoweit Bezug zur Dogmatik der Reichweite der grundrechtlichen Meinungsfreiheit. Aussagen, deren Inhalt auch unter den grundrechtlichen Maßstäben der Meinungsfreiheit als „Formalbeleidigungen“ oder „Schmähkritik“1046 verstanden werden, sind nicht rechtfertigungsfähig und deshalb generell unzulässig. ${ }^{1047} \mathrm{Ob}$ bei „Formalbeleidigungen“ oder „Schmähkritik“ der betreffende Amtswalter dann überhaupt noch in dem ihm zugewiesenen Aufgabenbereich agiert, kann dahinstehen. ${ }^{1048}$ Eine staatliche Beteiligung am politischen Diskurs kann nur auf einer sachlichen Ebene erfolgen, andernfalls wird in unzulässiger Weise in den Rechtskreis der Parteien eingegriffen.

Bei der Bewertung solcher Äußerungen vor dem Hintergrund des Übermaßverbotes ist insbesondere auch auf die „Wahlwerbequalität“ zu achten. ${ }^{1049} \mathrm{Je}$ mehr eine staatliche politische Äußerung einen Individualvorteil zugunsten einer bestimmten Partei begründen kann, umso strengere An-

1044 BVerfGE 57, 1 (8); BVerfGE 136, 323 (335 f.); BVerfGE 138, 102 (112f.); vgl. auch SaarlVerfGH, Urt. v. 8.7.2014 - Lv 5/14 = NVwZ-RR 2014, 905.; Eder, »Rote Karte« gegen »Spinner«?, 2017, S. 157 f.

1045 Vgl. BVerfGE 136, 323 (335 f.); BVerfGE 138, 102 (112f.); Barczak, NVwZ 2015, 1014 (1017 f.).

1046 Vgl. BVerfGE 93, $266(294,313)$.

1047 Vgl. BVerfGE 136, 323 (335 f.); BVerfGE 138, 102 (112f.); Barczak, NVwZ 2015, 1014 (1017 f.).

1048 So wohl BVerfGE 138, 102 (113), das eine unsachliche Auseinandersetzung mit der „Repräsentations- und Integrationsaufgabe“ des Bundespräsidenten für unvereinbar hält.

1049 Vgl. BVerfGE 44, 125 (151 ff.); RhPfVerfGH, Urt. v. 23.10.2006 - VGH O 17/05 = NVwZ 2007, 200 (201 f.); RhPfVerfGH, Beschl. v. 21.5.2014 - VGH A 39/14 = NVwZ-RR 2014, 665 (666 f.); Gusy, NVwZ 2015, 700 (703 f.); Barczak, NVwZ 2015, 1014 (1019). 
forderungen sind an den Grundsatz der Verhältnismäßigkeit zu stellen. Die Anforderungen werden insbesondere durch ein wahlbezogenes Momentum determiniert. So wird vertreten, solche wettbewerbsverzerrenden Äußerungen, die grundsätzlich zulässig seien, dann als unzulässig zu werten, wenn diese in zeitlicher Nähe zu einer bestimmten Wahl getätigt würden oder wenn sich gerade in Wahlkampfzeiten Äußerungen von Amtsträgern quantitativ mehren. ${ }^{1050}$ Das zeitliche Kriterium der „Vorwahlkampfphase" ist nicht als eigenständige Schranke amtlicher Äußerungen zu verstehen. ${ }^{1051}$ Vielmehr ist die „Vorwahlkampfphase“ im Rahmen der Verhältnismäßigkeitsprüfung zu berücksichtigen, da einer amtlichen Äußerung gerade dann eine erhöhte wettbewerbsverzerrende Wirkung zukommt, wenn sie in zeitlicher Hinsicht unmittelbar vor einer Wahl erfolgt oder sich gar inhaltlich darauf bezieht. So ist abzusehen, dass eine den Parteienwettbewerb verzerrende Amtsäußerung gerade dann an Intensität gewinnt, wenn sie innerhalb der „Vorwahlkampfphase“ in einer hohen Quantität erfolgt oder die Grenze zur offensiven Wahlwerbung überschreitet. Sowohl das Gebot der Sachlichkeit als auch die Berücksichtigung der „Vorwahlkampfphase“ als zeitlich modifizierbare Schranke stellen lediglich spezifizierte Erwägungen der Verhältnismäßigkeitsprüfung dar und sind aus diesem Grund nicht als selbstständige Grenzen zu verstehen.

\section{(4) Modifizierung durch Art. 21 Abs. 3 GG}

Die vorangegangenen Grundsätze sind auf alle Parteien gleichermaßen anzuwenden. Sollten demnach Äußerungen von Amtswaltern faktische Nachteile für eine bestimmte Partei begründen, sind diese grundsätzlich hinzunehmen, wenn sich die äußernde Stelle innerhalb ihres Aufgabenbereiches bewegt und die Äußerung mit dem Grad der durch sie hervorgerufenen Wettbewerbsverzerrung in einem angemessenen Verhältnis steht. Diese Grundsätze könnten bei einer aus der staatlichen Parteienfinanzierung ausgeschlossenen Partei modifiziert worden sein. So stellt sich einerseits die Frage, ob der Begriff der „verfassungsfeindlichen Partei“ durch

1050 So BVerfGE 44, 125 (151); siehe auch RhPfVerfGH, Beschl. v. 21.5.2014 VGH A 39/14 = NVwZ-RR 2014, 665 (666f.); Gusy, NVwZ 2015, 700 (704f.); Barczak, NVwZ 2015, 1014 (1019); Eder, »Rote Karte« gegen »Spinner«?, 2017, S. $160 \mathrm{f}$.

1051 Dahingehend wohl, allerdings keinesfalls zwingend, Eder, »Rote Karte« gegen »Spinner«?, 2017, S. 160 f. 
Art. 21 Abs. 3 GG an Ausschließlichkeit gewonnen hat mit der Folge, dass diese Bezeichnung in Äußerungen von Hoheitsträgern nur auf solche Parteien bezogen werden darf, die aus der staatlichen Parteienfinanzierung ausgeschlossen wurden. ${ }^{1052}$ Auch ist fraglich, ob die Anforderungen an die Zulässigkeit der Bezeichnung einer Partei als „verfassungsfeindlich“ im Falle des Ausschlusses aus der staatlichen Parteienfinanzierung geringer ausfallen.

\section{(a) Ausschließlichkeit}

Durch die Verwendung des Begriffes der „Verfassungsfeindlichkeit“ im Gesetzestitel des „Gesetzes zum Ausschluss verfassungsfeindlicher Parteien aus der staatlichen Parteienfinanzierung" stellt sich die Frage, ob der Begriff nur auf solche Parteien bezogen werden darf, deren Ausschluss aus der staatlichen Parteienfinanzierung vom Bundesverfassungsgericht festgestellt wurde. ${ }^{1053}$ Der Begriff der Verfassungsfeindlichkeit spiegelt das Stufenverhältnis ${ }^{1054}$ zwischen Art. 21 Abs. 2 und Abs. 3 GG wieder und hat dadurch die Qualität eines selbstständigen Rechtsbegriffes erworben. ${ }^{1055}$ Der Tatbestand des Art. 21 Abs. 3 GG beschreibt, welche Vorstellung der Gesetzgeber von den von der Regelung betroffenen Parteien hat. Eine Ausrichtung gegen die freiheitliche demokratische Grundordnung oder den Bestand der Bundesrepublik Deutschland stellt damit das spezifische Verhalten dar, das die Verfassungsfeindlichkeit einer Partei begründet.

Von einer Ausschließlichkeit des Begriffes kann man nur dann ausgehen, wenn der Begriff als solcher die Feststellung der Erfüllung des Tatbestandes des Art. 21 Abs. 3 GG durch das Bundesverfassungsgericht voraussetzen würde oder wenn die Bezeichnung einer Partei als „verfassungsfeindlich" durch eine staatliche Institution ohne das Vorliegen eines dahingehenden Feststellungsurteils des Bundesverfassungsgerichtes allgemein rechtsverletzend wäre. Da der Begriff lediglich einen Tatbestand umschreibt, ist kein dahingehendes Feststellungsurteil des Bundesverfassungsgerichtes notwendig. Eine rechtsverletzende Qualität des Begriffes könnte

1052 Streinz, in: Huber/Voßkuhle (Hrsg.), Grundgesetz, ${ }^{7} 2018$, Art. 21, Rn. 252d.

1053 Die Frage einbringend ders., in: Huber/Voßkuhle (Hrsg.), Grundgesetz, ${ }^{72018}$, Art. 21, Rn. 252e.

1054 Müller, DVBl 2018, 1035 (1038f.).

1055 Vgl. Streinz, in: Huber/Voßkuhle (Hrsg.), Grundgesetz, ${ }^{72018, ~ A r t .21, ~}$ Rn. 252e. 


\section{\5 Der Status der Verfassungsfeindlichkeit}

indessen nur dann angenommen werden, wenn die Geltendmachung dieser Eigenschaft durch eine andere staatliche Institution als dem Bundesverfassungsgericht hinsichtlich des Parteienprivileges unzulässig wäre. Wie allerdings bereits erläutert, liegt gerade dann keine Kollision mit dem Parteienprivileg vor, wenn keine rechtsverbindliche Folge an die staatliche Bewertung geknüpft wird und die Äußerung lediglich ein Werturteil darstellt. ${ }^{1056}$ Deshalb sind an eine Bewertung einer Partei als „verfassungsfeindlich" die bereits aufgeführten allgemeinen Grundsätze anzuwenden, die lediglich eine Kompetenz der äußernden Stelle und die Wahrung des Verhältnismäßigkeitsgrundsatzes verlangen. Eine Ausschließlichkeit des Begriffes der „Verfassungsfeindlichkeit" wurde somit nicht durch die Etablierung des Art. 21 Abs. 3 GG geschaffen.

\section{(b) Schrankenmodifizierung}

Durch die gesetzgeberische Verwendung des Begriffes der „Verfassungsfeindlichkeit" im Kontext des Finanzierungsausschlussverfahrens könnten die verfassungsrechtlichen Anforderungen für die Bezeichnung einer Partei als „verfassungsfeindlich“von anderen staatlichen Institutionen als dem Bundesverfassungsgericht für solche Parteien, deren Ausschluss aus der staatlichen Parteienfinanzierung festgestellt wurde, geringer ausfallen. Hans Klein stellt bereits fest, dass die staatlich geführte politische Bekämpfung einer aus der staatlichen Parteienfinanzierung ausgeschlossenen Partei nach wie vor möglich sei. ${ }^{1057}$

Die Feststellung, dass eine Partei von der staatlichen Parteienfinanzierung ausgeschlossen ist, erwächst insoweit zu einem gewichtigen Indiz, welches einer Partei zumindest für die Dauer des Ausschlusses formell im Abwägungsprozess vorgehalten werden kann. Da zumindest im Zeitpunkt des Ausschlusses über eine verfassungsgerichtliche Tatsachenverwertung eine verfassungsfeindliche Ausrichtung nachgewiesen werden konnte, muss sich die betroffene Partei diesen Umstand auch im politischen Diskurs vorhalten lassen. Eine staatliche Pflicht, vorliegende Tatsachen zu ignorieren oder zu verschweigen, besteht insbesondere dann nicht, wenn diese Tatsachen im Rahmen einer zum staatlichen Aufgabenbereich gehörenden sachlichen Auseinandersetzung angeführt werden. Zur staatlichen Informations- und Öffentlichkeitsarbeit gehört, dass die staatlichen Institu-

$1056 \rrbracket 5$ B. II. 1.; auch Murswiek, DVBl 1997, 1021 (1029f.).

1057 Klein, in: Maunz/Dürig (Hrsg.), Grundgesetz, 2018, Art. 21, Rn. 540d. 
tionen die Öffentlichkeit über ihre Politik, Maßnahmen und Vorhaben informieren und aufklären. ${ }^{1058}$ Eine inhaltliche Bewertung der Parteiziele wird sich damit weitestgehend erübrigen, da staatliche Äußerungen durch das Feststellungsurteil insoweit einen formellen Anhaltspunkt erhalten, der die verfassungsrechtliche Legitimität des Vorwurfes der „Verfassungsfeindlichkeit" insoweit indiziert. Hier verdeutlicht sich der gesellschaftliche Nachteil, der einer Partei neben dem Ausschluss aus der staatlichen Parteienfinanzierung droht. Durch die verfassungsgerichtliche Feststellung der Erfüllung des Tatbestandes wird über die ökonomische Belastung hinaus noch die Legitimität der Teilnahme an der politischen Willensbildung angezweifelt und der Partei dadurch im politischen Wettbewerb ein weiterer Nachteil zugefügt. Nach der aktuellen Rechtslage erstreckt sich dieser Nachteil durch $\$ 46 a$ Abs. 1 S. 1 BVerfGG zwingend über sechs Jahre, sodass es möglich ist, dass eine Partei, die ihre verfassungsfeindliche Ausrichtung aufgegeben hat, weiterhin im politischen Diskurs mit der Tatsache, aufgrund ihrer verfassungsfeindlichen Ausrichtung aus der staatlichen Parteienfinanzierung ausgeschlossen zu sein, konfrontiert wird, solange ein hinreichender Sachbezug vorhanden ist. ${ }^{1059}$

\section{b) Öffentlicher Dienst}

Eine weitere unter den Begriff der „faktischen Nachteile“ fallende Maßnahmenfolge stellt der Ausschluss von Mitgliedern einschlägiger Parteien aus dem öffentlichen Dienst dar. So führte beispielsweise der Radikalenerlass vom 18. Februar $1972^{1060}$ dazu, dass (vor allem) links- und rechtsextremistischen Personen weitestgehend der berufliche Zugang zum öffentlichen Dienst verwehrt werden konnte. Unmittelbarer Adressat war nicht die Partei, sondern das einzelne Mitglied, wodurch auch hier wie bei einer durch ein Staatsorgan vorgenommenen Beurteilung der Partei nur ein mittelbarer oder eben "faktischer" Nachteil entstand. ${ }^{1061}$ Die nachteilige Berücksichtigung der politischen Zugehörigkeit im Bewerbungsverfahren beeinträchtigt die Attraktivität der Parteimitgliedschaft und übt somit auch Einfluss auf den Standpunkt der betroffenen Partei im politischen Wettbe-

1058 Vgl. BVerfGE 20, 56 (100); BVerfGE 44, 125 (147).

1059 Siehe die Kritik an der 6-jährigen-Ausschlussdauer bei $\$ 4$ C. II. 3.

1060 Ministerialblatt für das Land Nordrhein-Westfalen vom 29.02.1972, S. 342.

1061 Vgl. BVerfGE 39, 334 (360). 
werb aus. ${ }^{1062}$ Nach einer kurzen Darstellung der bisherigen Praxis im Öffentlichen Dienst werden die Rechtsprechung des Bundesverfassungsgerichts sowie Ansichten der Literatur zur Zulässigkeit dieses Vorgehens nun im Folgenden dargestellt und untersucht.

\section{(1) Bisherige Praxis}

Die Vollzugspraxis des Radikalenerlasses, insbesondere die der sog. „Regelanfragen" an die Verfassungsschutzbehörden, führte zu heftiger Kritik ${ }^{1063}$, sodass diese im Jahr 1979 von der damaligen Bundesregierung aufgegeben wurde. Dies darf allerdings nicht darüber hinwegtäuschen, dass die Mitgliedschaft in einer als „extremistisch“ oder als „verfassungsfeindlich“ eingestuften Partei auch heute noch negative Auswirkungen auf ein Beschäftigungsverhältnis im öffentlichen Dienst hat. So ist es insbesondere im Freistaat Bayern noch üblich, vor der Einstellung in den öffentlichen Dienst eine Liste mit extremistischen, auch politische Parteien berücksichtigenden, Listen vorgelegt zu bekommen und eine Erklärung über eine Mitgliedschaft in einer der dort aufgeführten Vereinigungen abzugeben. Die Rechtsprechung befand ein solches Vorgehen bislang für zulässig. ${ }^{1064}$

Eine Berücksichtigung der Mitgliedschaft in einer als verfassungsfeindlich klassifizierten Partei bei der Einstellung im öffentlichen Dienst wird zutreffend - als weitestgehend zulässig erachtet. ${ }^{1065}$ Insoweit ist allerdings die Reichweite der Berücksichtigung und deren Grenzen genauer zu bestimmen. So ist insbesondere umstritten, ob ein Bewerber bereits allein aufgrund seiner Mitgliedschaft in einer für verfassungsfeindlich befundenen Partei abgelehnt werden darf oder ob weitergehende Indizien für die individuelle ablehnende Einstellung zur freiheitlichen demokratischen Grundordnung vorliegen müssen.

1062 Vgl. Maurer, NJW 1972, 601 (603).

1063 Insbesondere wurde der Radikalenerlass als „Berufsverbot“ bezeichnet und dementsprechend scharf kritisiert, siehe allgemein hierzu Bethge, Die Zerstörung der Demokratie in der BRD durch Berufsverbote, 1976.

1064 Vgl. BVerfGE 39, 334 (357 ff.); BVerwGE 47, 330 (344 ff.).

1065 BVerfGE 39, 334 (360); a.A. Streinz, in: Huber/Voßkuhle (Hrsg.), Grundgesetz, 72018, Art. 21, Rn. 105; Ipsen, in: Sachs (Hrsg.), Grundgesetz, ${ }^{8} 2018$, Art. 21, Rn. $206 \mathrm{f}$. 
(2) Parteizugehörigkeit als Ablehnungsgrund

Das Bundesverfassungsgericht erachtet die Berücksichtigung der Mitgliedschaft in einer verfassungsfeindlichen Partei innerhalb des öffentlichen Dienstes für zulässig. ${ }^{1066}$ So gehöre es zu den Grundsätzen des Berufsbeamtentums nach Art. 33 Abs. 5 GG, dass die Beamten aufgrund ihrer aus diesen Grundsätzen erwachsenden Treuepflicht die Gewähr bieten, jederzeit für die freiheitliche demokratische Grundordnung einzutreten. ${ }^{1067}$ Diese Pflicht wurde in der Vergangenheit bereits einfachgesetzlich in $\$ S 4$ Abs. 1 Nr. 2, 35 Abs. 1 S. 3 BRRG bzw. nach der aktuellen Rechtslage in $\$ 7$ Abs. 1 Nr. 2 BBG und $₫ 7$ Abs. 1 Nr. 2 BeamtStG konkretisiert. Demnach ist es gesetzlich vorgesehen, dass für eine Berufung in das Beamtenverhältnis nur derjenige in Betracht kommt, der die Gewähr bietet, jederzeit für die freiheitliche demokratische Grundordnung im Sinne des Grundgesetzes einzutreten und jederzeit dieser Verpflichtung für die Dauer des Beamtenverhältnisses auch fortwährend nachzukommen. Ob ein Beamter eine ausreichende Gewähr hierfür bietet, beurteilt sich nach dessen Verhalten. Die Zugehörigkeit zu einer als verfassungsfeindlich geltenden Partei oder Organisation würde allerdings solch erhebliche Zweifel an der Gewähr des Eintritts durch den Beamten für die freiheitliche demokratische Grundordnung begründen, dass eine Ablehnung oder ein Entlassen in der Regel allein auf diesen Umstand gestützt werden kann. ${ }^{1068}$ Die Parteizugehörigkeit stellt damit zwar nicht unter Beweis, dass eine verfassungsfeindliche Haltung vorliegt, begründet allerdings solche Zweifel an der Person des Beamten, dass von einer Einstellung oder Weiterbeschäftigung abgesehen werden kann.

In Teilen der Literatur wird das Abstellen auf die Parteizugehörigkeit bei der Einstellung in den öffentlichen Dienst aufgrund eines Verstoßes gegen das Parteienprivileg für verfassungswidrig erachtet. ${ }^{1069}$ Sofern die Parteizugehörigkeit als ausschlaggebendes Kriterium im Einstellungsverfahren des öffentlichen Dienstes berücksichtigt wird, stelle dies einen Verstoß gegen Art. 21 Abs. 4 GG dar und sei deshalb unzulässig. Vielmehr müsse auf das konkrete Verhalten des einzelnen Bewerbers, auch inner-

1066 BVerfGE 39, 334 (358 ff.); aA. Rupp, in: BVerfGE 39, 334 (378 ff) - Sondervotum.

1067 BVerfGE 39, 334 (359).

1068 Vgl. Plümer, NJW 1973, 4 (8 f.).

1069 Streinz, in: Huber/Voßkuhle (Hrsg.), Grundgesetz, ${ }^{7} 2018$, Art. 21, Rn. 219; Ipsen, in: Sachs (Hrsg.), Grundgesetz, ${ }^{8} 2018$, Art. 21, Rn. 206. 
halb der Partei, abgestellt werden, um die Eignung zu beurteilen. ${ }^{1070}$ Gerade bei inaktiven Mitgliedschaften ließe sich ein klares Bekenntnis zu den verfassungsfeindlichen Zielen der Partei nicht ableiten, sodass eine Prüfung über das Kriterium der Parteizugehörigkeit hinaus zur Feststellung der Eignung für eine Anstellung im öffentlichen Dienst notwendig sei. ${ }^{1071}$

Der Dissenz zwischen Teilen der Literatur und der Rechtsprechung des Bundesverfassungsgerichtes rührt aus einer unterschiedlichen Interpretation des mit einer Parteimitgliedschaft verbundenen politisch-inhaltlichen Bekenntnisses zu einer bestimmten politischen Auffassung. Während das Bundesverfassungsgericht es für zulässig erachtet, allein aus der Parteimitgliedschaft zu schließen, dass die Person keine Gewähr für ein jederzeitiges Eintreten für die freiheitliche demokratische Grundordnung bietet ${ }^{1072}$, erachtet die Literatur dies für nicht ausreichend und fordert weitergehende Anhaltspunkte im Verhalten des Bewerbers, um einen Rückschluss auf die Gewähr zum jederzeitigen Eintreten für die freiheitliche demokratische Grundordnung zuzulassen. ${ }^{1073}$ Die kritischen Stimmen der Literatur übersehen allerdings, dass mit der Mitgliedschaft - auch der inaktiven - zumindest konkludent eine Duldung und Identifizierung mit den Parteizielen einhergeht, die bei der Beurteilung des individuellen Verhaltens berücksichtigt werden müssen. ${ }^{1074}$ Ferner muss bei Mitgliedschaften bedacht werden, dass eine Förderung der Partei und ihrer verfassungsfeindlichen Ziele nicht nur durch das konkludente ideologische Bekenntnis zu den Parteizielen erfolgt, sondern die Mitglieder in der Regel auch durch das Entrichten von Mitgliedsbeiträge die verfassungsfeindlichen Bestrebungen der Partei auf finanzielle Art fördern. Wer nicht nur ein konkludentes Bekenntnis zu den verfassungsfeindlichen Parteizielen einer Partei durch seine Mitgliedschaft abgibt, sondern darüber hinaus durch das Entrichten von Mitgliedsbeiträgen die Bestrebungen auch finanziell fördert, erweckt erhebliche Zweifel an der Bereitschaft, jederzeit für die freiheitliche demokratische Grundordnung einzutreten. Es wird nicht formell auf die Mitgliedschaft in einer als verfassungsfeindlich geltenden Partei abgestellt, sondern auf das damit einhergehende Verhalten. Ein Eintreten für die frei-

1070 Vgl. Streinz, in: Huber/Voßkuhle (Hrsg.), Grundgesetz, ${ }^{7} 2018$, Art. 21, Rn. 219; Ipsen, in: Sachs (Hrsg.), Grundgesetz, ${ }^{8} 2018$, Art. 21, Rn. 206; Maurer, NJW 1972, 601 (603 f.).

1071 Vgl. Isensee, JuS 1973, 265 (270).

1072 BVerfGE 39, 334 (359).

1073 Maurer, NJW 1972, 601 (604 f.); Isensee, JuS 1973, 265 (269 ff.); vgl. ferner Ipsen, in: Sachs (Hrsg.), Grundgesetz, ${ }^{8} 2018$, Art. 21, Rn. 206 f.

1074 Vgl. insoweit Plümer, NJW 1973, 4 (7). 
heitliche demokratische Grundordnung ist mit der finanziellen Förderung einer verfassungsfeindlichen Partei oder Organisation nicht vereinbar. Dem Bewerber muss im Einzelfall zwar die Möglichkeit gewährt werden, die Indizkraft seiner Mitgliedschaft in einer verfassungsfeindlichen Partei $\mathrm{zu}$ widerlegen. Im Ergebnis ist es verfassungsrechtlich allerdings unbedenklich, die Parteizugehörigkeit als Verweigerungsgrund für die Beschäftigung im öffentlichen Dienst anzuerkennen, sofern kein alternativer Umstand die Verfassungstreue des Bewerbers zweifelsfrei beweisen kann. Insofern darf dies nicht als formeller Ausschlussgrund verstanden werden, allerdings als Indiz besonderen Gewichtes bei der Beurteilung der Einstellungsvoraussetzungen des einzelnen Bewerbers.

(3) Mitgliedschaft in verfassungsfeindlichen Parteien iSd. Art. 21

Abs. 3 GG und das Beamtenverhältnis

Eine Mitgliedschaft in einer nach Art. 21 Abs. 3 GG aus der staatlichen Parteienfinanzierung ausgeschlossenen Partei hat zur Folge, dass durch das Feststellungsurteil ein Indiz besonderen Gewichtes vorliegt, welches auf ein Vorliegen einer verfassungsfeindlichen Einstellung hindeutet. Die Rechtsfolge bezieht sich zwar nur auf den Ausschluss aus der staatlichen Parteienfinanzierung, allerdings wird die Verfassungsfeindlichkeit durch das Ausschlussurteil rechtsverbindlich festgestellt. ${ }^{1075}$ Das Problemfeld bezieht sich damit nicht auf die Verhaltensweise des Bewerbers, sondern auf die Frage, ob die Mitgliedschaft in der infrage stehenden Partei ausreichende Zweifel an der Gewähr, jederzeit für die freiheitliche demokratische Grundordnung einzutreten, zu begründen vermag.

Da das Bundesverfassungsgericht über die Erfüllung des Tatbestandes des Art. 21 Abs. 3 GG anhand der bis zum Zeitpunkt der Urteilsverkündung vorliegenden Tatsachen entscheidet ${ }^{1076}$ und eine weitergehende Rechtswirkung als der Ausschluss aus der staatlichen Parteienfinanzierung ausgeschlossen ist, kann bei der Beurteilung der verfassungsfeindlichen

1075 Vgl. Maurer, NJW 1972, 601 (602), der die rechtsverbindliche Feststellung der Verfassungswidrigkeit einer Partei als ausreichendes Kriterium für den Ausschluss von dessen Mitgliedern aus dem öffentlichen Dienst erachtet.

1076 Kliegel, in: Barczak (Hrsg.), BVerfGG Mitarbeiterkommentar zum Bundesverfassungsgerichtsgesetz, 2018, $₫ 41$, Rn. 6; a.A. Storost, in: Umbach/Clemens/ Dollinger (Hrsg.), Bundesverfassungsgerichtsgesetz, 22005, $\$ 41$, Rn. 6; Lenz/ Hansel, in: dies. (Hrsg.), Bundesverfassungsgerichtsgesetz, ${ }^{2} 2015$, $\mathbb{4} 41$, Rn. 4; Benda/Klein/Klein, Verfassungsprozessrecht, ${ }^{3}$ 2011, S. 486, Rn. 1200. 
Haltung der Partei nur auf den Zeitpunkt der Urteilsverkündung abgestellt werden. Die Annahme, dass die Partei für die in $\$ 46 a$ Abs. 1 S. 1 BVerfGG vorgesehene Dauer unwiderlegbar als „verfassungsfeindlich“ gelten könne, ist deshalb ausgeschlossen. Die Verfassungsfeindlichkeit wurde im Zeitpunkt der Urteilsverkündung festgestellt und bildet deshalb nur ein Indiz für in der Vergangenheit liegendes Verhalten. Sollte die Partei innerhalb der Konsoldierungsspanne von sechs Jahren einen inhaltlichen Wandel vollziehen und die Abkehr von ihren verfassungsfeindlichen Zielen nachweisen können, so ist dies bei der Beurteilung der Verfassungsfeindlichkeit und der Mitgliedschaft in dieser Partei gleichwohl zu berücksichtigen. Insoweit kommt dem Feststellungsurteil des Bundesverfassungsgerichtes in dieser Angelegenheit kein Rechts- sondern lediglich ein Tatsachenwert zu, dessen Inhalt gegenüber jeder weiteren Tatsacheninstanz widerlegbar ist.

\section{c) Nachrichtendienstliche Überwachung}

Die Überwachung von Parteien durch die Verfassungsschutzbehörden ist seit langem umstritten. Rechtswidrige und damit fehlerhafte Einsätze haben zu medienträchtigen Skandalen geführt. So scheiterte ein Verbotsverfahren gegen die NPD, da der Einsatz von V-Personen durch die Verfassungsschutzbehörden so intensiv geführt wurde, dass selbst Positionen in der Führungsebene der Partei von Mitarbeitern des Verfassungsschutzes besetzt wurden. ${ }^{1077}$ Auch wird die Frage breit diskutiert, ob bestimmte bislang unauffällige Parteien - durch die Verfassungsschutzbehörden beobachtet werden sollten. ${ }^{1078}$

Ausgangspunkt der folgenden Untersuchung bildet die Frage, wie die Verfassungsschutzbehörden mit Parteien verfahren können bzw. müssen, deren Ausschluss aus der staatlichen Parteienfinanzierung durch das Bundesverfassungsgericht festgestellt wurde. Die Anforderungen an ein Einschreiten des Verfassungsschutzes sind aufgrund der besonderen verfassungsrechtlichen Stellung der Parteien hoch und müssen grundsätzlich auch hinreichend dargelegt werden. Ob und wie sich ein Ausschluss einer Partei aus der staatlichen Parteienfinanzierung im Hinblick auf die nach-

1077 Siehe BVerfGE 107, 339 (360 ff.).

1078 So beispielsweise bei der AfD; siehe http://www.faz.net/aktuell/politik/inland/a fd-koennte-beobachtung-durch-verfassungsschutz-drohen-15871698.html (zul. aufgerufen am 18.02.2020). 
richtendienstliche Überwachung auswirkt, soll deshalb in der folgenden Untersuchung den Schwerpunkt bilden. Zunächst ist zwischen der Aufgabeneröffnung und dem Befugniseinsatz der Verfassungsschutzbehörden zu differenzieren. Zur Vereinfachung wird die Problematik allein am Beispiel des Bundesverfassungsschutzgesetzes (BVerfSchG) untersucht, da die Gesetze der Landesverfassungsschutzbehörden keine für diese Untersuchung relevanten Unterschiede aufweisen.

\section{(1) Aufgabeneröffnung}

Den Verfassungsschutzbehörden des Bundes und der Länder wird nach den $\$ \$ 3$ Nr. 1 und 4 BVerfSchG die Aufgabe übertragen, Informationen über gegen die freiheitliche Grundordnung gerichtete Bestrebungen zu sammeln. Da solche Bestrebungen auch von politischen Parteien ausgehen können, erstreckt sich die gesetzliche Aufgabe der Verfassungsschutzbehörden auch auf deren Beobachtung. Sollte der Aufgabenbereich des Verfassungsschutzes nach den $\mathbb{S} \mathbb{S}$ und 4 BVerfSchG eröffnet sein, kommt der Einsatz der in den $\$ \mathbb{S} 8 \mathrm{ff}$. BVerfSchG vorgesehenen nachrichtendienstlichen Befugnisse in Betracht. Die Aufgabeneröffnung geht mit einem Beobachtungsauftrag einher, sodass eine Eröffnung des gesetzlichen Aufgabenbereiches im Einzelfall zu einer Handlungspflicht der Verfassungsschutzbehörden führen kann. ${ }^{1079}$

Voraussetzung für die Aufgabeneröffnung der Verfassungsschutzbehörden ist das Vorliegen tatsächlicher Anhaltspunkte für verfassungsfeindliche Bestrebungen oder Tätigkeiten einer Partei, vgl. $\$ 4$ Abs. 1 S. 3 BVerfSchG. ${ }^{1080}$ Nach allgemeiner Auffassung liegen solche tatsächlichen Anhaltspunkte dann vor, wenn konkrete und in gewissem Umfang verdichtete Umstände als Tatsachenbasis vorliegen, die bei vernünftiger Betrachtung auf das Vorliegen verfassungsfeindlicher Bestrebungen hindeuten. ${ }^{1081}$ Bei einer aus der staatlichen Parteienfinanzierung ausgeschlossenen Partei wurde bereits vom Bundesverfassungsgericht als Tatsacheninstanz eine Ausrichtung gegen die freiheitliche demokratische Grundord-

1079 Vgl. Roth, in: Schenke/Graulich/Ruthig (Hrsg.), Sicherheitsrecht des Bundes, 22018, S\$ 3, 4 BVerfSchG, Rn. 86 ff.

1080 Vgl. ders., in: Schenke/Graulich/Ruthig (Hrsg.), Sicherheitsrecht des Bundes, ${ }^{2} 2018$, S\$ 3, 4 BVerfSchG, Rn. 100 ff.- oder auch als hinreichender Verdacht bezeichnet.

1081 ders., in: Schenke/Graulich/Ruthig (Hrsg.), Sicherheitsrecht des Bundes, ${ }^{2} 2018$, $\mathbb{S} \$ 3,4$ BVerfSchG, Rn. $101 \mathrm{mwN}$. 


\section{\5 Der Status der Verfassungsfeindlichkeit}

nung festgestellt. Dass die Partei somit nicht nur eine inhaltliche Ausrichtung gegen die freiheitliche demokratische Grundordnung pflegt, sondern darüber hinaus auch in einer aggressiv-kämpferischen Weise gegen diese vorgeht, ist somit zumindest im Zeitpunkt der Urteilsverkündung auf einer Tatsachenbasis rechtsverbindlich festgestellt worden. Das Feststellungsurteil wirkt somit nicht auf der Rechts-, sondern der Tatsachenebene und bildet einen tatsächlichen Anhaltspunkt, der den Verdacht verfassungsfeindliche Bestrebungen zu verfolgen im besonderen Maße indiziert. Die Feststellung der Rechtsfolge des Art. 21 Abs. 3 GG setzt zwingend eine Ausrichtung gegen die freiheitliche demokratische Grundordnung voraus $^{1082}$, womit dem verfassungsgerichtlichen Feststellungsurteil als „tatsächlichem Anhaltspunkt" für verfassungsfeindliche Bestrebungen insoweit eine erhebliche Indizwirkung zukommt. Diese Indizwirkung kann auch während des Ausschlusszeitraumes des $\ 46 a$ Abs. 1 S. 1 BVerfGG widerlegt werden, da eine Rechtswirkung aufgrund des Parteienprivileges ausgeschlossen ist.

\section{(2) Befugnisse}

(a) Auswertung öffentlich zugänglicher Informationen

Sollten die Behörden des Verfassungsschutzes ihre Beobachtung einer Partei nur auf die Auswertung ohnehin öffentlich zugänglicher Informationen begrenzen, liegt in der Regel kein Eingriff in den Rechtskreis der Partei vor. ${ }^{1083}$ Unter öffentlich zugängliche Informationen fallen vor allem die politischen Bekundungen in Broschüren und Wahlprogrammen, die Äußerungen von Parteifunktionären und das Auftreten der Partei auf öffentlichen Versammlungen. ${ }^{1084}$ Zwar gehört es zum Kernbereich des parteilichen Rechtes auf eine selbstbestimme Parteiführung, selbst und ohne staatliche Einflussnahme oder Überwachung über ihre Ziele, Organisation und Tätigkeiten zu entscheiden. ${ }^{1085}$ Eine Auswertung öffentlich zugänglicher Materialien stellt allerdings in der Regel keine „Überwachung“ der Partei dar, auch wenn das Ansammeln und Auswerten gezielt erfolgt. So-

1082 Ipsen, in: Sachs (Hrsg.), Grundgesetz, ${ }^{8} 2018$, Art. 21, Rn. 213.

1083 Gusy, DVBl 1991, 1288 (1288), wohl auch Klein, in: Maunz/Dürig (Hrsg.), Grundgesetz, 2018, Art. 21, Rn. 577.

1084 Ders., in: Maunz/Dürig (Hrsg.), Grundgesetz, 2018, Art. 21, Rn. 577.

1085 BVerwGE 110, 126 (131 f.). 
lange der Staat das öffentliche Auftreten einer Partei zur Kenntnis nimmt und die erworbenen Informationen als Informationsgrundlage weiteren Vorgehens verwendet, wird die Partei in keiner Weise in ihrer aus Art. 21 Abs. 1 GG abgeleiteten Parteienfreiheit, auch in Verbindung mit dem Recht auf informationelle Selbstbestimmung ${ }^{1086}$, berührt. Insbesondere veröffentlicht sie ihre Informationen freiwillig und eröffnet damit wissentlich und willentlich den Zugang, sodass die Verfassungsschutzbehörden nicht entgegen dem Willen der Parteiführung diese Informationen sammeln und somit auch kein Eingriff, der einer Rechtfertigung bedarf, vorliegt. ${ }^{1087}$ Für die Aufgabeneröffnung der Verfassungsschutzbehörden ist zwingend ein hinreichender Anfangsverdacht notwendig ${ }^{1088}$, der erst durch eine Aus- und Bewertung öffentlich zugänglicher Materialien begründet werden kann. Die Auswertung erfolgt damit zur Ausübung des Entschließungsermessens der Verfassungsschutzbehörden und berührt nicht den Rechtskreis der betroffenen Partei, sodass in dieser Hinsicht auch nicht die Notwendigkeit einer Rechtfertigung besteht.

(b) Öffentliche Berichterstattung durch den Verfassungsschutz

Das Bundesamt für Verfassungsschutz ist nach $₫ 16$ Abs. 1 BVerfSchG befugt, die Öffentlichkeit über Bestrebungen gegen die freiheitliche demokratische Grundordnung zu informieren. Diese Art der öffentlichen Berichterstattung stellt nach allgemeiner Auffassung ${ }^{1089}$ einen Eingriff in die Rechte der Parteien dar und bedarf einer hinreichend Rechtfertigung, da die Berichterstattung des Bundesamtes für Verfassungsschutz die Wirkmöglichkeiten der betroffenen Partei nachteilig beeinflusst und potenziel-

1086 Nach wohl herrschender Auffassung können sich auch juristische Personen auf das allgemeine Persönlichkeitsrecht, das auch das Recht auf informationelle Selbstbestimmung erfasst, berufen, vgl. nur Di Fabio, in: Maunz/Dürig (Hrsg.), Grundgesetz, 2018, Art. 2 Abs. 1 GG, Rn. 224 mwN.

1087 Vgl. Gusy, DVBl 1991, 1288 (1288).

1088 Roth, in: Schenke/Graulich/Ruthig (Hrsg.), Sicherheitsrecht des Bundes, ${ }^{2} 2018$, SS 3, 4 BVerfSchG, Rn. 100.

1089 VGH München, Urt. v. 06.07.2017 - 10 BV 16.1237 - Rn. 18, juris; ThürVerfGH, Urt. v. 03.12.2014 - 2/14 - ThürVBl 2015, 295; Mallmann, in: Schenke/Graulich/Ruthig (Hrsg.), Sicherheitsrecht des Bundes, 22018, $\mathbb{1 6}$ BVerfSchG, Rn. 2a; Barczak, NVwZ 2015, 1014 (1018); Murswiek, NVwZ 2003, 1 (5); vgl. auch zum staatlichen Informationshandeln und Art. 12 GG, BVerfGE 148, 40 (51 ff.). 
le Wähler abhalten könnte, diese zu wählen. ${ }^{1090} \mathrm{Um}$ eine Berichterstattung nach $\$ 16$ Abs. 1 BVerfSchG zu ermögliche, bedarf es „hinreichend gewichtiger tatsächlicher Anhaltspunkte" für das Vorliegen von Bestrebungen gegen die freiheitliche demokratische Grundordnung. Der Wortlaut der Norm orientiert sich an der verfassungsgerichtliche Rechtsprechung, die insoweit das Vorliegen „hinreichend gewichtiger tatsächlicher Anhaltspunkte" für die Berichterstattung über verfassungsfeindliche Bestrebungen durch die Verfassungsschutzbehörden verlangt. ${ }^{1091}$ Sollten durch das Verhalten einer Partei „hinreichend gewichtige tatsächliche Anhaltspunkte“ für das Vorliegen einer verfassungsfeindlichen Bestrebung festgestellt werden können, so wird von „Verdachtsfällen“1092 gesprochen. Eine Berichterstattung über Parteien, die die Schwelle zum „Verdachtsfall“ (noch) nicht überschritten haben, ist demnach unzulässig. ${ }^{1093}$

\section{(c) Observation durch den Einsatz nachrichtendienstlicher Befugnisse}

Während das Sammeln, Aus- und Bewerten von öffentlich zugänglichem Material zumindest in der Regel keinen Eingriff in den Rechtskreis der Parteien darstellt ${ }^{1094}$, unterliegt die Observation unter Verwendung nachrichtendienstlicher Mittel aufgrund ihrer hohen Eingriffsqualität strengeren Grenzen. Das Bundesverwaltungsgericht zählt zum „Kernbereich der Parteienfreiheit", dass die Parteien eigenständig und ohne Überwachung über ihre Ziele, Organisation und Tätigkeiten entscheiden können. ${ }^{1095}$ So wird deutlich, dass gerade beim Einsatz nachrichtendienstlicher Befugnisse und der geheimen Überwachung einer Partei in einen deutlich empfindlicheren verfassungsrechtlichen Rechtskreis eingegriffen wird, als es bei der Auswertung öffentlich zugänglicher Materialien der Fall ist. Dieser Umstand ist bei der Beurteilung der verfassungsrechtlichen Zulässigkeit solcher Maßnahmen im besonderen Maße zu berücksichtigen.

1090 Vgl. hierzu VG Köln, Beschl. v. 26.02.2019 - 13 L 202/19 - Rn. 57, juris; siehe hierzu auch Nikkho, jurisPR-ITR 8/2019.

1091 BVerfGE 113, 63 (81).

1092 Vgl. VG Köln, Beschl. v. 26.02.2019 - 13 L 202/19 -, juris.

1093 So beispielsweise die Bezeichnung als „Prüffall“, siehe VG Köln, Beschl. v. 26.02.2019 - 13 L 202/19 -, juris.

1094 Wohl Klein, in: Maunz/Dürig (Hrsg.), Grundgesetz, 2018, Art. 21, Rn. 577.

1095 Klein, in: Maunz/Dürig (Hrsg.), Grundgesetz, 2018, Art. 21, Rn. 577; BVerwGE 110,126 (131 f.). 
Sowohl in der Rechtsprechung als auch der Literatur wird der Einsatz nachrichtendienstlicher Befugnisse gegen nicht-verbotene, aber als verfassungsfeindlich erachtete Parteien für zulässig befunden, sofern die Grenzen des Verhältnismäßigkeitsgrundsatzes gewahrt bleiben. ${ }^{1096}$ Nach einer in der Literatur vertretenen Auffassung solle das legitime Ziel der Beobachtung durch das Parteienprivileg ausschließlich auf die Vorbereitung eines Verbotsantrages begrenzt sein. ${ }^{1097}$ Ziel der Observation müsse nach dieser Auffassung sein, dass durch die nachrichtendienstliche Überwachung nicht öffentlich zugängliche Beweise erhoben werden können, die im Rahmen eines Verbotsverfahrens für die Verfassungswidrigkeit der Partei sprechen. Eine andere Zielverfolgung führe demnach generell zur Unverhältnismäßigkeit der Überwachung, womit von Verfassungs wegen nur diese bestimmte Zielrichtung vorgegeben werde.

Das Bundesverwaltungsgericht hält es ebenfalls für zulässig, zur Vorbereitung eines Verbotsantrages eine nachrichtendienstliche Observation durchzuführen. Allerdings begrenzt es die zulässige Zielsetzung nicht auf die Vorbereitung eines Verbotsantrages, sondern hält auch eine Überwachung zum Zwecke der amtlichen und öffentlichen Informationsgewinnung und einer darauf aufbauenden politischen Bekämpfung für zulässig, sofern die Grenzen der Verhältnismäßigkeit gewahrt blieben. ${ }^{1098}$

Die Ansicht des Bundesverwaltungsgerichtes ist rechtsdogmatisch konsequent. Das Bundesverwaltungsgericht fasst die nachrichtendienstliche Überwachung unter den Begriff der „faktischen Nachteile“ mit der Folge, dass kein Verstoß gegen Art. 21 Abs. 4 GG vorliegt und somit auf allgemeine rechtsstaatliche Grundsätze bei der Beurteilung der Rechtmäßigkeit einer solchen Überwachung zurückzugreifen ist. Dass der Sinngehalt des Art. 21 Abs. 4 GG in die Verhältnismäßigkeitsprüfung Eingang finde und dadurch das Übermaßverbot in Angelegenheiten der nachrichtendienstlichen Überwachung zu einer Art Parteienprivileg mit einer normativen Ausnahmeregelung für die Vorbereitung eines Verbotsantrages modifiziert werde, überzeugt indessen dogmatisch nicht. ${ }^{1099}$ Eine staatliche Aufklä-

1096 Vgl. BVerwGE 110, 126 (134f.); Klein, in: Maunz/Dürig (Hrsg.), Grundgesetz, 2018, Art. 21, Rn. 579; Ipsen, in: Sachs (Hrsg.), Grundgesetz, ${ }^{8} 2018$, Art. 21, Rn. 205; Streinz, in: Huber/Voßkuhle (Hrsg.), Grundgesetz, ${ }^{72018, ~ A r t . ~ 21, ~}$ Rn. 218.

1097 Streinz, in: Huber/Voßkuhle (Hrsg.), Grundgesetz, ${ }^{72018}$, Art. 21, Rn. 218; Ipsen, in: Sachs (Hrsg.), Grundgesetz, ${ }^{8} 2018$, Art. 21, Rn. 205.

1098 BVerwGE 110, 126 (134f.).

1099 So allerdings Streinz, in: Huber/Voßkuhle (Hrsg.), Grundgesetz, ${ }^{72018}$, Art. 21, Rn. 218; Ipsen, in: Sachs (Hrsg.), Grundgesetz, ${ }^{8} 2018$, Art. 21, Rn. 205. 
rung auch unter Einsatz nachrichtendienstlicher Befugnisse dient gerade der Vorbereitung staatlichen Handelns auf das Auftreten einer Gefahr für die freiheitliche demokratische Grundordnung und soll darüber hinaus auch die politische Bekämpfung einer Partei ermöglichen. ${ }^{1100}$ Nach Ansicht des Bundesverfassungsgerichtes stellt eine politische Bekämpfung eine echte Handlungsalternative zum Parteiverbot dar und solle - als milderes Mittel - einem dahingehenden Antrag auch vorgehen. ${ }^{1101}$ Das Parteienprivileg bewahrt Parteien nicht davor, dass ihre Ziele und Inhalte ermittelt werden, um ihnen diese dann im politischen Diskurs vorzuhalten und damit eine politische Bekämpfung zu ermöglichen. Die Intensität von Überwachungsmaßnahmen ist unstreitig hoch, was auf der Rechtfertigungsebene auch Berücksichtigung finden muss. Ob eine konkrete Überwachungsmaßnahme allerdings zulässig ist, muss anhand der Umstände des Einzelfalls ermittelt und kann nicht formelhaft durch das Aufstellen von Grenzen innerhalb der Verhältnismäßigkeitsprüfung beurteilt werden.

(d) Auswirkungen des Finanzierungsausschlussverfahrens auf nachrichtendienstliches Handeln

Eine Partei muss sich die Tatsache, aufgrund ihrer verfassungsfeindlichen Einstellung aus der staatlichen Parteienfinanzierung ausgeschlossen $\mathrm{zu}$ sein, vorhalten lassen. Insoweit wird der Umstand, dass das Bundesverfassungsgericht eine verfassungsfeindliche Haltung im Zeitpunkt der Urteilsverkündung rechtsverbindlich feststellt, auch im Rahmen des Einsatzes von nachrichtendienstlichen Befugnissen berücksichtigt. Da eine verfassungsfeindliche Grundhaltung im Zeitpunkt der Urteilsverkündung rechtsverbindlich festgestellt wurde, sind bei einer fortwährenden Observation geringere Anforderungen zu erfüllen als bei anderen Parteien. Dass eine verfassungsfeindliche Grundhaltung der Partei im Zeitpunkt der Urteilsverkündung vorlag, wird insoweit durch das Feststellungsurteil des Bundesverfassungsgerichtes indiziert. Sollten keine entlastenden Tatsachen bekannt sein, die eine Abkehr der Partei von ihrer verfassungsfeindlichen Zielsetzung belegen, so genügt zur Begründung eines für die heimliche Überwachung erforderlichen hinreichenden Verdachtes auf die im Urteil des Bundesverfassungsgerichtes festgestellten Tatsachen abzustellen. Insbe-

1100 BVerwGE 110, 126 (134).

1101 BVerfGE 40, 287 (292). 
sondere wirkt sich an dieser Stelle das Stufenverhältnis ${ }^{1102}$ des Art. 21 Abs. 3 GG zu Art. 21 Abs. 2 GG aus. Da ein Ausschluss aus der staatlichen Parteienfinanzierung annähernd identische Tatbestandsmerkmale wie ein Parteiverbot aufweist und lediglich keine konkrete Gefährdung der freiheitlichen demokratischen Grundordnung verlangt wird ${ }^{1103}$, kann die fortwährende Observation der Partei zur Beobachtung ihrer Wirkmöglichkeiten dienen und die daraus ermittelten Tatsachen zur Vorbereitung eines Verbotsverfahrens verwendet werden. Da die „Vorstufe“ zum Parteiverbot bereits erreicht wurde und lediglich die Realisierungspotentialität für die Feststellung der Verfassungswidrigkeit iSd. Art. 21 Abs. 2 GG fehlte, kann das Ziel einer an den Finanzierungsausschluss anschließenden Observation die Überwachung der streitigen Realisierungspotentialität sein.

Obwohl Art. 21 Abs. 3 GG lediglich vorsieht, dass das Bundesverfassungsgericht den Ausschluss aus der staatlichen Parteienfinanzierung feststellt, indiziert es daneben im besonderen Maße das Vorliegen einer verfassungsfeindlichen Haltung, die auf Tatsachenebene beim administrativen Umgang mit Parteien Berücksichtigung findet. Insbesondere im Rahmen der Verhältnismäßigkeitsprüfung wird sowohl in der Zielrichtung als auch in der Interessenabwägung im engeren Sinne der Ausschluss einer Partei aus der staatlichen Parteienfinanzierung als Indiz besonderen Gewichts für eine verfassungsfeindliche Haltung der Partei zu berücksichtigen sein.

\section{d) Nutzung öffentlicher Einrichtungen}

Konflikte zwischen radikalen Parteien und dem Staat finden oft auf der kommunalen Ebene statt. In der Vergangenheit wurde seitens der Kommunen wiederholt versucht, Mittel und Wege zu finden, um verfassungsfeindlichen Parteien in rechtmäßiger Weise einen Nachteil zuzufügen. $\mathrm{Zu}$ solchen Mitteln zählten beispielsweise insbesondere die Verweigerung der Gebrauchsüberlassung von kommunalen Einrichtungen ${ }^{1104}$ oder über Satzungsänderungen die Fraktionen im Gemeinde- oder Stadtrat von der dort vorgesehenen Fraktionsfinanzierung auszuschließen. ${ }^{1105} \mathrm{Im}$ Landesrecht

1102 Müller, DVBl 2018, 1035 (1038 ff.).

1103 Streinz, in: Huber/Voßkuhle (Hrsg.), Grundgesetz, ${ }^{7} 2018$, Art. 21, Rn. 252b; Ipsen, in: Sachs (Hrsg.), Grundgesetz, ${ }^{8} 2018$, Art. 21, Rn. 213.

1104 Siehe zur Problematik Hecker, NVwZ 2018, 787 ff.

1105 Auch ders., NVwZ 2018, 1613 ff.; siehe auch BVerfG, Beschl. v. 24.03.2018 - 1 BvQ 18/18 = NVwZ 2018, 819. 
der Bundesländer sind regelmäßig Ansprüche auf die Nutzung kommunaler Einrichtungen vorgesehen ${ }^{1106}$, die sowohl Einwohnern als auch ortsfremden Personenvereinigungen zustehen und oft in Verbindung mit der Gebrauchspraxis der einzelnen Gemeinden konkrete Nutzungsrechte für politische Parteien begründen. ${ }^{1107}$

Wie bereits festgestellt ist es ausgeschlossen, dass der Ausschluss aus der staatlichen Parteienfinanzierung eine unmittelbare Rechtswirkung auf die Leistungsgewährung in anderen Bereichen entfaltet und auf diese Weise weitergehende Benachteiligungen ermöglicht. ${ }^{1108}$ Dies gilt erst Recht auch für Parteien, die im Rahmen eines Verbotsverfahrens in den Urteilgründen vom Bundesverfassungsgericht zwar als „verfassungsfeindlich“ bezeichnet, allerdings nicht verboten wurden. ${ }^{1109}$ Dies mag auf den ersten Blick zu dem eindeutigen Ergebnis führen, dass eine Änderung der aktuellen Rechtslage auch nicht auf der kommunalen Ebene, insbesondere der Leistungsverwaltung, zu befürchten ist (dazu 1.). Die Kommunen haben allerdings kreative Lösungsansätze gefunden, wie sie unliebsame Parteien auch bei der Gewährung von Leistungen mittelbar benachteiligen können, ohne in Konflikt mit der Chancengleichheit und dem Parteienprivileg zu geraten. Über privatrechtliche Ausgestaltungen von Nutzungsverhältnissen kommunaler Einrichtungen wird die Durchführung des Nutzungsanspruchs ${ }^{1110}$ entweder unmöglich gemacht, was zu einer faktischen Nutzungsversagung führt oder die Nutzung erheblich erschwert. ${ }^{1111}$ Für die Gemeinden besteht in engen Grenzen die Möglichkeit, bei der Nutzungsgewährung kommunaler Einrichtungen durch eine bestimmte Ausgestaltung des Nutzungsvertrages verfassungsfeindliche Parteien erheblich zu benachteiligen (dazu 2. und 3.).

1106 Beispielsweise in Bayern Art. 21 BayGO, Hessen $\mathbb{2 0} \mathrm{HGO}$, Brandenburg $\mathbb{} 12$ BbgKVerf.

1107 Vgl. Wachsmuth, in: Kommunalverfassungsrecht Bayern, 2005, Art. 21, Rn. 6.

1108 Siehe $\$ 4$ C. II. 1.

1109 Vgl. VGH Kassel, Beschl. v. 23.02.2018 - 8 B 23/18 - Rn. 4, juris in Bezug zur NPD und das sie betreffende Parteiausschlussverfahren BVerfGE 144, 20.

1110 Ein solcher ergibt sich aus dem Landesrecht, wie beispielsweise Art. 21 BayGO.

1111 Vgl. Brand, BayVBl 2001, 104 (107 f.), der richtigerweise darauf hinweist, dass dies grundsätzlich unzulässig ist; vgl. hierzu auch Ossenbühl, DVBl 1973, 289 (298). 


\section{(1) Grundsätze}

Neben der staatlichen Parteienfinanzierung erhalten Parteien auch den Zugang zu anderen öffentlichen Leistungen. So zählen zu den „klassischen" Fällen die Gebrauchsüberlassung von kommunalen Einrichtungen $^{1112}$ und die Gewährung von Sendezeit durch die öffentlich-rechtlichen Rundfunksender ${ }^{1113}$. Der Ausschluss aus der staatlichen Parteienfinanzierung kann keinen rechtlichen Einfluss auf die Gewährung anderer staatlicher Leistungen ausüben und somit insbesondere nicht zu einer Verweigerung des Zuganges zu öffentlichen Einrichtungen oder der Verteilung von Sendezeiten aufgrund der im Finanzierungsausschlussverfahren festgestellten Verfassungsfeindlichkeit führen. ${ }^{1114}$ Der betroffenen Partei wird nur in Belangen der staatlichen Parteienfinanzierung im engeren Sinne ein Recht auf Gleichbehandlung abgesprochen, ihre darüberhinausgehende Freiheits- und Gleichheitssphäre unterliegt Einschränkungen nach den allgemeinen, für alle Parteien gleichermaßen geltenden Regelungen unabhängig von der konkreten inhaltlich-politischen Ausrichtung. Da die Gleichheit der Parteien durch Art. 21 Abs. 3 GG nach dessen unmissverständlichem Wortlaut nur in Belangen der staatlichen Parteienfinanzierung eingeschränkt wird, kann die im Rahmen des Finanzierungsausschlussverfahrens festgestellte verfassungsfeindliche Haltung der Antragsgegnerin nicht als ungeschriebener Ausschlussgrund für ihr zustehende Leistungsrechte fungieren. ${ }^{1115}$ Im Bereich der Parteien begünstigenden Leistungsverwaltung darf deshalb, außer in Belangen der staatlichen Parteienfinanzierung nach den $\int \mathbb{S} 18 \mathrm{ff}$. PartG und den entsprechenden steuerrechtlichen Begünstigungen, keine Mittelgewährung von einer staatlich erwünschten inhaltlichen Ausrichtung abhängig gemacht werden, da dies nach wie vor unter der Geltung des Parteienprivileges ausgeschlossen ist. ${ }^{1116}$ Zudem gilt darüber hinaus zu beachten, dass Art. 21 Abs. 3 GG ausschließlich Parteien adressiert und darüber hinaus keine weitergehenden Sanktionen gegen mit Parteien verbundene Institutionen oder Personen (Parlamentsfraktio-

1112 Im Allgemeinen siehe BVerwGE 31, $368 \mathrm{ff}$.

1113 Siehe dazu BVerfGE 7, 99 (107); BVerfGE 47, $198 \mathrm{ff}$.

1114 Streinz, in: Huber/Voßkuhle (Hrsg.), Grundgesetz, ${ }^{7} 2018$, Art. 21, Rn. 252d; Hecker, NVwZ 2018, 787 (789).

1115 Vgl. dazu Hecker, NVwZ 2018, 787 (788ff.); auch Shirvani, DÖV 2018, 921 (925).

1116 So auch schon die bislang geltende Rechtslage, siehe Klein, in: Maunz/Dürig (Hrsg.), Grundgesetz, 2018, Art. 21, Rn. 540d. 
nen, Abgeordnete, Stiftungen, Mitglieder etc. ${ }^{1117}$ ) vorsieht, so wie es beim Parteiverbot nach Art. 21 Abs. 2 GG der Fall ist. ${ }^{1118}$ Bei der Verteilung von staatlichen Mitteln ist außerhalb des Geltungsbereichs der staatlichen Parteienfinanzierung weiterhin der streng formale Gleichheitssatz zu beachten und die aus der staatlichen Parteienfinanzierung ausgeschlossene Partei von Staats wegen genau so zu behandeln wie ihre politische Konkurrenz. Dies bedeutet, dass ein Antrag der Partei auf eine konkrete Begünstigung (mit Ausnahme von der staatlichen Parteienfinanzierung) nicht aufgrund des Ausschlusses aus der staatlichen Parteienfinanzierung abgelehnt werden darf. Die Chancengleichheit der Parteien wird durch Art. 21 Abs. 3 GG nur hinsichtlich der staatlichen Parteienfinanzierung nach den $\int \mathbb{S} 18 \mathrm{ff}$. PartG und der steuerlichen Begünstigungen eingeschränkt. Andere Maßnahmen im Rahmen der Leistungsverwaltung dürfen nach wie vor nicht an die verfassungsgerichtliche Feststellung nach Art. 21 Abs.3 GG angeknüpft werden, da dies nicht nur aufgrund des Parteienprivilegs unzulässig wäre, sondern generell nach dem Regelungskonzept des Finanzierungsausschlussverfahrens schlicht nicht vorgesehen ist. ${ }^{1119}$

(2) Privatrechtliche Ausgestaltung kommunaler Nutzungsverhältnisse

Den Gemeinden steht nach herrschender Meinung bei der Ausgestaltung von Rechtsverhältnissen im Rahmen der Leistungsverwaltung, sofern gesetzlich ein hoheitliches Handeln nicht vorgeschrieben ist, eine Rechtsformwahl zu. ${ }^{1120}$ So können sie Rechtsverhältnisse sowohl öffentlich-rechtlich als auch privatrechtlich ausgestalten. Bei der Ausgestaltung von kommunalen Nutzungsverhältnissen stellen die Kommunen vermehrt auf das sog. "Verwaltungsprivatrecht" ${ }^{\text {"1121 }} \mathrm{ab}$. Während die Frage zur generellen

1117 Siehe dazu bereits $₫ 3$ B.

1118 Abgeordnete einer verbotenen Partei verlieren nach $₫ 46$ Abs. 1 S. 1 Nr. 5 BWG ihr Mandat und die Fortführung einer für verfassungswidrig erklärten Partei steht auch nach $\$ 84$ StGB unter Strafe. Solche anknüpfenden Sanktionsmechanismen sieht Art. 21 Abs. 3 GG nicht vor. Siehe allgemein Saliger, Parteiengesetz und Strafrecht, 2005.

1119 Statt aller siehe Klein, in: Maunz/Dürig (Hrsg.), Grundgesetz, 2018, Art. 21, Rn. 540d.

1120 Vgl. BVerwGE 92, 56 (64 f); BVerwGE 129, 9 (14f.); siehe auch Brand, BayVB1 2001, 104 (106); Maurer/Waldhoff, Allgemeines Verwaltungsrecht, ${ }^{19} 2017, \mathbb{} 3$, Rn. $25 \mathrm{ff}$.

1121 Siehe hierzu Maurer/Waldhoff, Allgemeines Verwaltungsrecht, ${ }^{19} 2017, \mathbb{1}$ 17, Rn. $1 \mathrm{ff}$. 
Zulassung der Nutzung einer gemeindlichen öffentlichen Einrichtung stets Bestandteil des öffentlichen Rechts ist, wird im „Verwaltungsprivatrecht" die konkrete Ausgestaltung des Nutzungsverhältnisses auf privatrechtlicher Ebene vorgenommen.

Die privatrechtliche Ausgestaltung von öffentlich-rechtlichen Rechtsverhältnissen eröffnet den kommunalen Trägern eine weitere Handlungsebene, in deren Rahmen sie die Durchführbarkeit und die konkrete Durchführung der geplanten Veranstaltung in gewissen Grenzen beeinflussen können. Indem der Staat als (grundsätzlich gleichrangiger) Vertragspartner auftritt und die Ausübung hoheitlicher Befugnisse unterlässt, entfernt sich die Sachmaterie von dem mit grundrechtlichen Garantien aufgeladenen Gebiet des öffentlichen Rechts und nimmt eine von der Privatautonomie und der unternehmerischen Entscheidungsfreiheit getragenen privatrechtliche Natur an.

Dies führt allerdings nicht dazu, dass die Gemeinden beim verwaltungsprivatrechtlichen Handeln die vollumfänglichen Freiheiten eines Privaten besitzen. Die Gemeinden werden durch die privatrechtliche Ausgestaltung ihrer Nutzungsverhältnisse nicht von ihren öffentlich-rechtlichen Pflichten befreit. Insbesondere bleiben die Hoheitsträger weiterhin an Grundrechte gebunden. ${ }^{1122}$ Dies zeichnet sich insbesondere darin aus, dass durch eine (miet-)vertragliche Ausgestaltung das Recht der Partei auf Nutzung einer öffentlichen Einrichtung nicht ausgehöhlt oder faktisch vernichtet werden darf. ${ }^{1123}$ Aufgrund der Grundrechtsbindung der hoheitlichen Träger der öffentlichen Einrichtungen ist auch bei der individuellen Ausgestaltung des grundsätzlich privatrechtlichen Mietverhältnisses die Rechtsstellung der Parteien zu achten und darf nicht in unzulässiger Weise beeinträchtigt werden. Willkürliche Vertragsregelungen, deren Zweck die Diskriminierung einer bestimmten Partei ist, sind weiterhin rechtsverletzend und damit - trotz der privatrechtlichen Natur - unzulässig. ${ }^{1124}$ Den Gemeinden ist es allerdings in bestimmten Fällen erlaubt, Parteien bei der Nutzungsüberlassung von kommunalen Einrichtungen ungleich zu behandeln. ${ }^{1125}$

1122 Vgl. nur BVerfGE 128, 226 (244 ff.).

1123 Ossenbühl, DVBl 1973, 289 (298); Brand, BayVBl 2001, 104 (107).

1124 Vgl. VG Augsburg, Beschl. v. 16.11.2012 - Au 7 E 12.1447 - Rn.71, juris; Brand, BayVBl 2001, 104 (107); Zundel, JuS 1991, 472 (475).

1125 Ossenbühl, DVBl 1973, 289 (298); Brand, BayVBl 2001, 104 (107 f.). 


\section{(3) Ausgestaltungsregelungen}

In Betracht kommen nur Maßnahmen, die zwar an alle Parteien gleichsam gerichtet sind, faktisch allerdings gerade solche Parteien treffen, die in der öffentlichen Wahrnehmung als radikal oder verfassungsfeindlich gelten. Die vertragliche Ausgestaltung von Nutzungsüberlassungen öffentlicher Einrichtungen eröffnet den kommunalen Trägern einen Handlungsspielraum, in dessen Rahmen verfassungsfeindliche Parteien faktisch benachteiligt werden können. Ansatzpunkt kann sowohl die generelle Frage der Gebrauchsüberlassung als auch die konkrete vertragliche Ausgestaltung des Nutzungsverhältnisses sein. Beispielsweise hat sich etabliert, den Zugang zu den öffentlichen Einrichtungen für alle Parteien gleichermaßen von der Mitwirkung privater Dritter abhängig zu machen ${ }^{1126}$ oder der Partei vertraglich eine verschuldensunabhängige Haftung für Schäden an der Einrichtung aufzuerlegen. ${ }^{1127}$ Durch eine Ausgestaltung auf vertraglicher Ebene werden private Dritte in einem solchen Ausmaß in das Vertragsverhältnis eingebunden, dass dessen konkrete Durchführung von dem Willen privater Dritter abhängig gemacht wird. Ein Beispiel bildet die vertragliche Bedingung, dass vor der Gebrauchsüberlassung der öffentlichen Einrichtung von der Partei der Nachweis des Abschlusses einer Haftpflichtversicherung erbracht werden muss (dazu a). Ferner und noch unmittelbarer verfassungsfeindliche Parteien benachteiligend ist die vertragliche Übertragung einer verschuldensunabhängigen Haftung für (auch) von veranstaltungsfremden Dritten verursachte Schäden, weil die Partei durch ihre politisch extreme Haltung eine höhere „Gefahr- und Schadensgeneigtheit“ der Veranstaltung hervorruft (dazu b). Letzterer Fall betrifft verfassungsfeindliche Parteien unmittelbarer, da der Staat an eine ihr nachgesagten politischen Haltung einen weitergehenden Individualnachteil anknüpft und als „gemäßigt“ geltende Parteien eine solche Forderung des Einrichtungsträgers nicht zu befürchten haben. Insofern berücksichtigt der Staat die Verfassungsfeindlichkeit einer Partei nicht im Rahmen der Ausübung hoheitlicher Gewalt, sondern auf zivilrechtlicher Vertragsebene unter Ausnutzung seiner Monopolstellung.

1126 Wie z.B. im Fall des VG Augsburg, Beschl. v. 16.11.2012 - Au 7 E 12.1447 -, juris.

1127 Vgl. VGH Mannheim, Beschl. v. 9.4.1987 - 1 S 851/87 = DÖV 1987, 650 ff. 


\section{(a) Untersuchungsbeispiel 1: Nachweis einer Haftpflichtversicherung}

Durch das Erfordernis des Nachweises einer Veranstaltungshaftpflichtversicherung wird die Durchführung des Nutzungsverhältnisses von der Mitwirkung privater Dritter abhängig gemacht. Ein geeigneter Versicherer muss sich demnach bereit erklären, für eventuell anfallende veranstaltungsbezogene Schäden gegen eine Versicherungsgebühr für die veranstaltende Partei aufzukommen. Die Kommunen haben ein berechtigtes Interesse an der finanziellen Abdeckung von Sach- und Personenschäden und an der Verringerung des mit solchen Schäden zusammenhängenden Insolvenzrisikos durch eine Haftpflichtversicherung. ${ }^{1128}$ In der öffentlichen Wahrnehmung als „verfassungsfeindlich“ geltende Parteien werden es allerdings oft schwer haben, einen Versicherer $\mathrm{zu}$ finden, der eine Bereitschaft zum Eingehen eines dahingehenden Vertrages aufzeigt. So konnte beispielsweise der NPD die Nutzung einer öffentlichen Einrichtung versagt werden, da sie keinen Nachweis über den Abschluss einer Haftpflichtversicherung erbringen konnte, obwohl dies vertraglich vorausgesetzt war. ${ }^{1129}$

Die Rechtsprechung hat das Verlangen nach dem Nachweis einer Haftplichtversicherung des hoheitlichen Trägers der kommunalen Einrichtungen regelmäßig für zulässig erachtet ${ }^{1130}$, was gerade dann überzeugt, wenn alle Nutzer einer Stadthalle eine Haftpflichtversicherung nachweisen müssen. Insbesondere wurde ein Anspruch der Parteien nach Art. 3 Abs. 1 iVm. 21 Abs. 1 GG bzw. $\$ 5$ Abs. 1 PartG auf Befreiung von der Pflicht des Nachweises einer Haftpflichtversicherung verneint. Der Staat ist lediglich zur Gleichbehandlung aller politischer Parteien verpflichtet, muss diese allerdings nicht vor jeglicher negativen Entäußerung ihrer gesellschaftlichen Stellung schützen und sie darüberhinaus gerade wegen ihres negativen Gesellschaftsbildes nicht gegenüber den anderen Parteien privilegieren, indem bei radikalen Parteien auf die für alle geltende zwingende Mitwir-

1128 VG Augsburg, Beschl. v. 16.11.2012 - Au 7 E 12.1447 - Rn. 60, juris.

1129 VG Augsburg, Beschl. v. 16.11.2012 - Au 7 E 12.1447, juris.

1130 VGH Mannheim, Beschl. v. 9.4.1987 - 1 S 851/87 = DÖV 1987, 650 ff.; VGH München, Beschl. Beschl. v. 21.1.1988 - Nr. 4 CE 87.03883 = BayVBl 1988, 497, 498; VG Augsburg, Beschl. v. 16.11.2012 - Au 7 E 12.1447 - Rn. 65 ff., juris, VGH München, Beschl. v. 22.11.2012 - 4 CE 12.2511 = BayVBl 2013, 346; unter dem Grundsatz der Verhältnismäßigkeit kritisch betrachtend Hettich, Die Zulässigkeit verschiedener Handlungsalternativen des Staates im Vorgehen gegen extremistische Parteien unter Berücksichtigung des Parteienprivilegs, 2015, S. 185 ff. 
kung von privaten Dritten verzichtet wird. Nicht nur würde dies zu der absurden Rechtslage führen, dass aufgrund der Verfassungsfeindlichkeit der Staat gezwungen wäre, einer Partei gegenüber ihrer Konkurrenz einen unmittelbaren Vorteil einzuräumen. Auch würde der Staat durch einen Verzicht auf den Nachweis einer Haftpflichtversicherung einen Nachteil ausgleichen, der der Partei aufgrund ihrer negativen gesellschaftlichen Stellung entstanden ist und dadurch wiederum eine Wettbewerbsverzerrung zulasten der anderen Parteien hervorrufen. Die Chancengleichheit bezieht sich nur auf das Handeln des Staates, eine Diskriminierung von gesellschaftlicher Seite haben Parteien grundsätzlich hinzunehmen, da dies gerade ein Bestandteil des politischen Wettbewerbs und des offenen Willensbildungsprozesses ist. ${ }^{1131}$ Auch kann der Umstand, dass kein privater Versicherer mit einer bestimmten Partei einen Vertrag abschließen möchte, nicht zu einer Unzulässigkeit solcher Klauseln führen. Sollte einer Partei aufgrund eines negativen gesellschaftlichen Ansehens ein Nachteil erwachsen, so ist der Staat aufgrund des Gleichheitssatzes nicht verpflichtet, diesen zu kompensieren. Die Forderung nach einer Haftpflichtversicherung könnte nur dann rechtsverletzend sein, wenn sie willkürlich erfolgt oder offensichtlich darauf abzielt, eine bestimmte Partei durch eine Änderung der Vergabepraxis zu benachteiligen. ${ }^{1132}$ Um die Nutzung von öffentlichen Einrichtungen von der Mitwirkung privater Dritter abhängig zu machen, bedarf es seitens des Hoheitsträgers lediglich eines hinreichend sachlichen Grundes, der ein willkürliches Vorgehen ausschließt. Das Verlangen nach dem Vorweisen einer Haftpflichtversicherung wird sich in der Regel durch das haushaltswirtschaftliche Interesse der Gemeinde, ihre Einrichtungen gegen Schäden abzusichern, sachlich begründen lassen. ${ }^{1133}$ Nur in Fällen, in denen offensichtlich ist, dass durch eine solche Vergabepraxis eine bestimmte Partei von der Nutzung kommunaler Einrichtungen abgehalten werden soll, ist dieses Vorgehen unzulässig. Sollten einer Partei aufgrund ihres negativen gesellschaftlichen Ansehens faktische Nachteile erwachsen, so wird sie hiervor nicht durch ihr Gleichheitsrecht geschützt.

1131 Wohl ähnlich ders., Die Zulässigkeit verschiedener Handlungsalternativen des Staates im Vorgehen gegen extremistische Parteien unter Berücksichtigung des Parteienprivilegs, 2015, S. $188 \mathrm{f}$.

1132 Vgl. etwa Glaser/Hermann/Marcic-Schaller/Scharpf, in: Bayerische Gemeindeordnung, 2018, Art. 21 BayGO, Rn. 19a, 20; VG Augsburg, Beschl. v. 16.11.2012 Au 7 E 12.1447 - Rn. 71, juris.

1133 Vgl. hierzu im Zusammenhang mit der Übertragung verschuldensunabhängiger Haftungsregime VGH Mannheim, Beschl. v. 9.4.1987 - 1 S 851/87 = DÖV 1987, 650 (651). 
Zwar kann bereits, ohne aus der staatlichen Parteienfinanzierung ausgeschlossen zu sein, ein negatives öffentliches Ansehen zu solchen Folgen führen. Die zusätzliche Legitimation durch das Feststellungsurteil, dürfte allerdings auf eine hohe Resonanz stoßen, da insoweit der Partei durch das Bundesverfassungsgericht eine verfassungsfeindliche Ausrichtung rechtsverbindlich attestiert wurde. ${ }^{1134}$ Ein dauerhafter Ausschluss verfassungsfeindlicher Parteien aus öffentlichen Einrichtungen dürfte durch diese Vorgehensweise nicht gewährleistet werden können. Sofern auf staatlicher Seite ein legitimes Interesse besteht, die Nutzung von öffentlichen Einrichtungen von der Mitwirkung privater Dritter abhängig zu machen, kann das negative Verdikt des Finanzierungausschlussurteils genutzt werden, um den betroffenen Parteien einen weitergehenden faktischen Nachteil zuzufügen. Dieses Vorgehen ist aufgrund der oben genannten Erwägungen auch zulässig.

(b) Untersuchungsbeispiel 2: Übertragung verschuldensunabhängiger Haftungsregime

Ein subtileres Mittel, um verfassungsfeindlichen Parteien den Zugang zu öffentlichen Einrichtungen zu erschweren, ist die vertragliche Übertragung einer verschuldensunabhängigen Haftung. Zwar erhält die Partei den Zugang zu der von ihr begehrten Einrichtung, allerdings werden die Nutzungskonditionen so ausgestaltet, dass die tatsächliche Durchführung des Vertrages für die betroffene Partei aus wirtschaftlichen oder tatsächlichen Gründen unzumutbar sein könnte. Indem der Partei als Veranstalter eine verschuldensunabhängige Haftung für die von Dritten verursachten Schäden übertragen wird, muss die Partei zur Nutzung der öffentlichen Einrichtung ein hohes wirtschaftliches Risiko eingehen, was von anderen (als gemäßigt geltenden) Parteien im Rahmen des Nutzungsvertrages nicht verlangt wird. Die Gemeinden versuchen durch diese Differenzierung insoweit das Schadensrisiko von sich auf die veranstaltende Partei zu verlagern. ${ }^{1135}$

1134 Siehe oben $\$ 4$ C. II. 1. b).

1135 Gassner, VerwArch 85 (1994), 533 (561). 
Nach der Auffassung der h.M. sei ein solches Vorgehen zulässig, sofern die rechtlichen Grenzen gewahrt blieben. ${ }^{1136}$ Die rechtlichen Grenzen eines solchen Vorgehens leiteten sich aus dem allgemeinen Gleichheitssatz $\mathrm{ab}^{1137}$, wodurch eine Differenzierung in der kommunalen Vertragspraxis dann zulässig sei, wenn ein sachlicher Grund vorliege und die Grenzen der Verhältnismäßigkeit gewahrt werden. ${ }^{1138}$

Anknüpfungspunkt für die Rechtfertigung eines solchen Vorgehens sei die kommunale haushaltswirtschaftliche Verpflichtung zur Wahrung eines gesamtwirtschaftlichen Gleichgewichtes. ${ }^{1139}$ Dies umfasse, in Bayern beispielsweise in Art. 61 Abs. 3 BayGO explizit vorgesehen, auch eine Verpflichtung zur finanziellen Risikominimierung. Dieser gesetzlichen Verpflichtung würden die Gemeinden demnach nicht nachkommen, wenn sie ihr Vermögen (inklusive der öffentlichen Einrichtungen) für besonders riskante Veranstaltungen bereitstellen würden und damit die Gefahr eines hohen Vermögensschadens begründeten. Auch wenn nicht absehbar sei, wie wahrscheinlich der Schadenseintritt sein wird, wenn polizeilichen Sicherheitsvorkehrungen getroffen werden, habe die Gemeinde weiterhin ein Interesse, ihr eigenes Schadensrisiko auf die veranstaltende Partei zu übertragen, um somit ihr Restrisiko weiter so gering wie möglich zu halten.

Die Verpflichtung der Gemeinde zur Risikominimierung kann nur dann als Rechtfertigung für die Übertragung einer verschuldensunabhängigen Haftung angeführt werden, wenn eine Gefahr für kommunale Vermögenswerte von der Partei und der Art ihrer geplanten Veranstaltung ausgeht. Die Gefahr der Verursachung von Personen- und Sachschäden durch veranstaltungsfremde Dritte (Schadensrisiko) muss der Partei zugerechnet werden können. ${ }^{1140}$ Eine verfassungsfeindliche oder extremistische Haltung der Partei werde, so ein Beschluss des VGH Mannheim ${ }^{1141}$, zu

1136 Vgl. BVerwGE 32, 333 (337); VGH Mannheim, Beschl. v. 9.4.1987 - 1 S 851/87 = DÖV 1987, 650 ff.; Glaser/Hermann/Marcic-Schaller, Scherpf, in: Bayerische Gemeindeordnung, 2018, Art. 21 BayGO, Rn. 20; Ossenbühl, DVBl 1973, 289 (297 f.); Zundel, JuS 1991, 472 (475); a.A. Meyer, Kommunales Parteien- und Fraktionenrecht, 1990, S. 89; Brand, BayVBl 2001, 104 (108); Gassner, VerwArch 85 (1994), 533 (563).

1137 Ossenbühl, DVBl 1973, 289 (298).

1138 Vgl. statt vieler Jarass, in: Grundgesetz für die Bundesrepublik Deutschland, ${ }^{15} 2018$, Art. 3, Rn. 18 ff. m.w.N.

1139 Vgl. VGH Mannheim, Beschl. v. 9.4.1987 - 1 S 851/87 = DÖV 1987, 650, 651.

1140 Vgl. VGH Mannheim, Beschl. v. 9.4.1987 - 1 S 851/87 = DÖV 1987, 650 (651); Meyer, Kommunales Parteien- und Fraktionenrecht, 1990, S. $87 \mathrm{ff}$.

1141 VGH Mannheim, Beschl. v. 9.4.1987 - 1 S 851/87 = DÖV 1987, 650 (651). 
einer besonderen „Gefahrengeneigtheit" der geplanten Veranstaltung führen. Indem die extremistische Haltung der Partei eine Polarisierung der Gesellschaft vorantreibe und Gegendemonstrationen provoziere, liege in dem Wesen von Veranstaltungen verfassungsfeindlicher Parteien bereits eine für die Übertragung des Schadensrisikos ausreichende "Sachnähe“. ${ }^{1142}$ Die in der Person des Veranstalters liegenden Eigenschaften werden insoweit zum Beurteilungskriterium der "Gefahrengeneigtheit“ einer Veranstaltung erhoben. Bei der Zurechnung der Gefahr differenziert die h.M. auch zwischen dem polizeirechtlichen Störerbegriff und der vertraglichen Risikoübertragung. Während im Gefahrenabwehrrecht aus Gegendemonstrationen erwachsende Gefahren nicht der veranstaltenden Partei im Rahmen der Störerauswahl zugerechnet werden dürfen ${ }^{1143}$, sei dies bei der vertraglichen Risikoübertragung aufgrund der "Sachnähe“ der Partei als zulässig zu werten. ${ }^{1144}$ Die Differenzierung zwischen den Systemen der polizeirechtlichen Störerauswahl und der zivilrechtlichen Vertragsausgestaltung zum Zwecke der finanziellen Risikominimierung sei zulässig, da die Maßstäbe und Voraussetzungen für die Gefahrenverantwortlichkeit im Polizeirecht und der schadensersatzrechtlichen Risikoverteilung nicht zwingend deckungsgleich seien. ${ }^{1145}$

Daraus ergibt sich folgendes Problem, das gerade hinsichtlich der aus Art. 21 Abs. 3 GG folgenden Verfassungsfeindlichkeit einer Partei für diese Untersuchung von besonderer Relevanz ist: Die Verfassungsfeindlichkeit einer Partei wird vom Staat mit einer Gefahrensituation verknüpft, was ein gefahrenabwehrrechtliches Vorgehen auf privatrechtlicher Ebene rechtfertigen soll. Dies ist unzulässig, da die „Gefahrengeneigtheit“ einer Veranstaltung nicht zwingend aus dem politischen Standort, sondern aus dem gesellschaftlichen Ansehen der Partei resultiert. ${ }^{1146}$ Erfährt eine Partei eine große gesellschaftliche Ablehnung, unabhängig von ihrer auf die freiheitliche demokratische Grundordnung bezogenen Zielsetzung, so liegt darin die „Sachnähe“ zu potenziell durch Dritte verursachte Schäden. Ob die gesellschaftliche Ablehnung aus einer verfassungsfeindlichen Haltung oder einem anderen Grund herrührt, ist daher für die Beurteilung der Gefahrengeneigtheit von Veranstaltungen irrelevant. Aufgrund des Parteienpri-

1142 VGH Mannheim, Beschl. v. 9.4.1987 - 1 S 851/87 = DÖV 1987, 650 (651).

1143 Vgl. VGH Mannheim, Urt. v. 10.11.1967 - II 756/67 = DÖV 1968, 179 (180 f.); OVG Münster, Urt. v. 26.6.1968 - III A 47/68 = DVBl 1968, 842 (845 f.).

1144 VGH Mannheim, Beschl. v. 9.4.1987 - 1 S 851/87 = DÖV 1987, 650 (651).

1145 VGH Mannheim, Beschl. v. 9.4.1987 - 1 S 851/87 = DÖV 1987, 650 (651); Ossenbühl, DVBl 1973, 289 (298).

1146 Ähnlich wohl Brand, BayVBl 2001, 104 (107). 
vilegs und des Neutralitätsgebotes ist es den kommunalen Trägern der Einrichtungen untersagt, eine Bewertung der parteilichen Ziele vorzunehmen und daran Rechtsfolgen anzuknüpfen. ${ }^{1147}$ Die Entscheidung über die haftungsrechtliche Risikoverlagerung beruht allerdings nicht auf einer politischen Einschätzung der Partei, sondern vielmehr auf einer generellen Gefahrenprognose unter Inbezugnahme aller entscheidungserheblichen Faktoren. Zwar wird eine verfassungsfeindliche Ausrichtung typischerweise Gegendemonstrationen mit einem gewissen Gewaltpotential provozieren, dies muss allerdings für jeden Fall gesondert unter Berücksichtigung aller konkret vorliegenden Umstände festgestellt werden. Damit ist im Einzelfall festzustellen, ob der bestehende Ablehnungsgrad zu Gefährdungen von Sachwerten und Personen führen kann. ${ }^{1148}$ Eine Bewertung der politischen Ziele einer Partei ist unzulässig und im Übrigen auch entbehrlich, solange eine erhöhte gesellschaftliche Gewaltbereitschaft - unabhängig von ihrer konkreten Ursache - behördlich festgestellt werden kann.

Einer aus der staatlichen Parteienfinanzierung ausgeschlossene Partei darf somit nicht allein aufgrund ihrer verfassungsgerichtlich festgestellten Verfassungsfeindlichkeit eine verschuldensunabhängige Haftung für Dritte übertragen werden, sofern keine weiteren Indizien vorhanden sind, die den Verdacht einer übermäßigen Gefährdung der kommunalen Sachwerte begründen. Sollte aus den Umständen des Einzelfalls allerdings erkennbar sein, dass die Gefahr der Beschädigung der kommunalen Einrichtung in einem ungewöhnlich hohen Maße vorhanden ist, ist eine Übertragung des Schadensrisikos auf die veranstaltende Partei verhältnismäßig und deshalb zulässig. ${ }^{1149}$ Die gesetzliche Verpflichtung zur haushaltswirtschaftlichen Risikominimierung stellt dorthingehend einen tauglichen sachlichen Grund dar. ${ }^{1150}$ Das Parteienprivileg steht dem nicht entgegen, da lediglich eine abstrakte Gefahrenprognose erfolgt und nicht auf die inhaltliche Ausrichtung abgestellt wird. Es besteht keine Verpflichtung der Kommune, ihre öffentlichen Einrichtungen für gefahrengeneigte Veranstaltungen bereitzustellen und in diesem Zusammenhang politische Parteien gegenüber sonstigen Nutzungswilligen besonders zu privilegieren.

1147 Unmittelbar auf Stadthallenfälle bezogen Ossenbühl, DVBl 1973, 289 (298).

1148 Insofern richtig VGH Mannheim, Beschl. v. 9.4.1987 - 1 S 851/87 = DÖV 1987, $650 \mathrm{ff}$., das bei der Gefahrenprognose für die Veranstaltung den Umstand berücksichtigt hat, dass sich bereits im Vorfeld Dritte, unter Hervorrufen eines hohen Sachschadens, gewaltsam Zutritt zur Versammlungshalle verschafft haben und dort politische Parolen an die Wände sprühten.

1149 Vgl. VGH Mannheim, Beschl. v. 9.4.1987 - 1 S 851/87 = DÖV 1987, 650 (651).

1150 Vgl. VGH Mannheim, Beschl. v. 9.4.1987 - 1 S 851/87 = DÖV 1987, 650 (651). 
e) Verfassungsfeindlichkeit als Gefahr

Die "Gefahr" im rechtlichen Sinne eröffnet den Aufgabenbereich der Sicherheitsbehörden und ermächtigt sie zur Verwendung gefahrenabwehrrechtlicher Befugnisse. Einer aus der staatlichen Parteienfinanzierung ausgeschlossenen Partei haftet der "Status der Verfassungsfeindlichkeit“ an, was die gefahrenabwehrrechtlichen Handlungsalternativen ihr gegenüber im Vergleich zu anderen Parteien modifizieren könnte. Zwar schließt das Parteienprivileg das Anknüpfen weiterer Maßnahmen an das Feststellungsurteil aus ${ }^{1151}$, allerdings weisen Beispiele in der Verwaltungs- und Rechtsprechungspraxis darauf hin, dass die Eigenschaft der „Verfassungsfeindlichkeit" mit dem Begriff der "Gefahr" in einen rechtlichen Zusammenhang gebracht wird. ${ }^{1152}$ Auch erheben Sicherheitsgesetze, wie beispielsweise das bayerische Landesstraf- und Verordnungsgesetz in Art. 7 Abs. 2 Nr. 1 Alt. 2, Abs. 5, den Begriff der „verfassungsfeindlichen Handlung“ zu einem Tatbestandsmerkmal, das ein sicherheitsrechtliches Einschreiten legitimiert. $\mathrm{Zu}$ Recht wird ein gefahrenabwehrrechtliches Einschreiten allerdings abgelehnt, wenn eine Partei gemeinhin als „verfassungsfeindlich“ gilt. ${ }^{1153}$ Die bloße Eigenschaft der „Verfassungsfeindlichkeit“, die im Rahmen des Art. 21 Abs. 3 GG festgestellt wird, begründet für sich keine Gefahr, die ein sicherheitsbehördliches Einschreiten rechtfertigen vermag. Vielmehr sind die Behörden weiterhin angewiesen, eine konkrete Gefahrenprognose für bestimmte Veranstaltungen oder Sachverhalte zu erstellen ${ }^{1154}$ und dabei den Ausschluss der Partei aus der staatlichen Parteienfinanzierung unbeachtet zu lassen. Ein Abstellen auf das Parteienprivileg ist insoweit auch nicht notwendig, da der Ausschluss aus der staatlichen Parteienfinanzierung keine "Gefahr" iSd. Gefahrenabwehrrechts begründet. Auch auf eine „drohende Gefahr“, die beispielsweise für zahlreiche Maßnahmen nach dem Bayrischen Polizeiaufgabengesetz vorausgesetzt wird, kann nicht durch den Ausschluss aus der staatlichen Parteienfinanzierung geschlossen werden, da hier das Parteienprivileg verbietet, aufgrund der inhaltlichen Ausrichtung einer Partei andere Maßnahmen als die in Art. 21 Abs. 2 und Abs. 3 GG genannten zu ergreifen.

1151 \4 C. I. 2.

1152 So beispielsweise VGH Mannheim, Beschl. v. 9.4.1987 - 1 S 851/87 = DÖV 1987, 650 (651).

1153 Vgl. hierzu Siegel/Hartwig, NVwZ 2017, 590 (595).

1154 Vgl. dies., NVwZ 2017, 590 (595). 


\section{Rehabilitierung durch Zeitablauf}

Der Ausschluss aus der staatlichen Parteienfinanzierung ist nach $\int 46 \mathrm{a}$ Abs. 1 S. 1 BVerfGG auf sechs Jahre befristet. Angesichts der vorangegangenen Untersuchungsergebnisse stellt sich dadurch die Frage, ob der Zeitablauf des Ausschlusses zu einer Rehabilitierung der Partei führt und sie hierdurch wie jede andere Partei unter denselben Bedingungen am politischen Wettbewerb teilnehmen kann. Der Ausschluss aus der staatlichen Parteienfinanzierung belegt zumindest im Zeitpunkt der Urteilsverkündung eine verfassungsfeindliche Haltung der Partei, die ihr im politischen Diskurs auch von Amtsträgern vorgehalten werden kann und die für die Verfassungsschutzbehörden zumindest ein für eine Beobachtung ausreichendes Indiz darstellt. Die durch Zeitablauf der Sechs-Jahres-Frist erfolgende Rehabilitierung könnte Auswirkungen auf die Indizwirkung des Feststellungsurteiles haben, indem diese Indizwirkung insoweit entfallen könnte.

Die Antragsberechtigten (Bundestag, Bundesrat, Bundesregierung und Landesregierung ${ }^{1155}$ ) haben nach $\$ 46 a$ Abs. 2 BVerfGG die Möglichkeit, einen Antrag auf Verlängerung des Ausschlusses zu stellen. Bei der „Verlängerung“ des Finanzierungsausschlusses handelt es sich um einen „besonderen Fall des Ausschlusses“1156, in dessen Rahmen die fortbestehende verfassungsfeindliche Zielsetzung der Partei durch das Bundesverfassungsgericht festgestellt werden muss. ${ }^{1157}$ Die Rehabilitierungswirkung entsteht nicht durch die erneute Teilnahme an der staatlichen Parteienfinanzierung, sondern entweder durch eine bewusste Entscheidung der antragsberechtigten Organe, keinen Verlängerungsantrag zu stellen, oder im Falle des Vorliegens eines entsprechenden Antrags durch die Ablehnung der Ausschlussverlängerung durch das Bundesverfassungsgericht. Im letzteren Falle wird das Fehlen einer verfassungsfeindlichen Ausrichtung, sofern der Verlängerungsantrag zulässig ist, durch ein rechtskräftiges Urteil festgestellt und die Rückkehr der Partei zum „Boden des Grundgesetzes“ durch das Bundesverfassungsgericht bestätigt. Ob entweder kein erneuter Antrag auf den Ausschluss aus der staatlichen Parteienfinanzierung gestellt wird oder das Bundesverfassungsgericht den Tatbestand des Art. 21 Abs. 3 S. 1 GG nicht mehr als erfüllt ansieht, muss im Rahmen der sachgemäßen

1155 Siehe $\mathbb{} 4$ C. III. 2.; auch Barczak, in: ders. (Hrsg.), BVerfGG Mitarbeiterkommentar zum Bundesverfassungsgerichtsgesetz, 2018, $\$ 46 a$, Rn. 8.

1156 Vgl. BT-Drucksache 18/12846, S. 10.

1157 Barczak, in: ders. (Hrsg.), BVerfGG Mitarbeiterkommentar zum Bundesverfassungsgerichtsgesetz, 2018, $\$ 46 a$, Rn. 21. 
Aufgabenwahrnehmung von jedwedem Teil staatlicher Gewalt berücksichtigt werden.

\section{Rechtsstellung der verfassungsfeindlichen Partei}

Eine aus der staatlichen Parteienfinanzierung ausgeschlossene Partei verliert nicht die ihr zuvor zustehenden Rechte und Pflichten. ${ }^{1158}$ Sie wird vielmehr als aktiver Teilnehmer am politischen Wettbewerb geduldet, was auch bedeutet, dass der Staat im Umgang mit der Partei sämtliche verfassungsrechtlichen Garantien zu beachten hat. Nur in Belangen der staatlichen Parteienfinanzierung wird sich die Partei nicht auf den parteilichen Gleichheitsstatus und die daraus ableitenden subjektiven Rechtspositionen berufen können. Das Anknüpfen weitergehender unmittelbarer Nachteile bleibt dem Staat aufgrund des Parteienprivileges, worauf sich auch aus der staatlichen Parteienfinanzierung ausgeschlossene Parteien berufen können, verwehrt. ${ }^{1159}$

Dennoch sorgt die Feststellung der Erfüllung des Tatbestandes des Art. 21 Abs. 3 GG für eine Indizwirkung, welche der betroffenen Partei auch von staatlicher Seite vorgehalten werden kann. Im Unterschied zu dem Ausschluss aus der staatlichen Parteienfinanzierung, dem eine unmittelbare Rechtswirkung zukommt, kommt dem mit dem Feststellungsurteil zusammenhängenden Stigma lediglich ein Tatsachenwert zu, der im Rahmen von Abwägungsprozessen berücksichtigt werden kann. Während es vor der Novellierung des Art. 21 Abs. 3 GG in engen Grenzen möglich war, die verfassungsfeindliche Haltung einer Partei zum Anlass staatlichen Handelns zu nehmen, bildet das Feststellungsurteil nun einen formellen Ansatzpunkt, der das Bestehen einer verfassungsfeindlichen Grundhaltung zumindest im Zeitpunkt der Urteilsverkündung indiziert. Die handelnden Behörden müssen in solchen Fällen keine materiellen Erwägungen über die Verfassungsfeindlichkeit treffen, sondern können ihre Entscheidung vielmehr auf das Feststellungsurteil als formelles Indiz stützen. Eine unmittelbare Auswirkung hat das Feststellungsurteil vor allem in Belangen der nachrichtendienstlichen Überwachung, wo mit dem Ausschlussurteil

1158 Siehe dazu bereits $\ 4$ C. II.; vgl. auch Shirvani, DÖV 2018, 921 (923 f.); Ipsen, in: Sachs (Hrsg.), Grundgesetz, ${ }^{8} 2018$, Art. 21, Rn. 214; Streinz, in: Huber/ Voßkuhle (Hrsg.), Grundgesetz, ${ }^{7} 2018$, Art. 21, Rn. 252d.

1159 Vgl. Streinz, in: Huber/Voßkuhle (Hrsg.), Grundgesetz, ${ }^{72018, ~ A r t .21, ~}$ Rn. 252d. 
eine Feststellung einhergeht, die sowohl für die Aufgabeneröffnung als auch Befugnisverwendung der Verfassungsschutzbehörden von hervorgehobener Wichtigkeit ist. ${ }^{1160}$

Die rechtskräftig als „verfassungsfeindlich“ geltende Partei nimmt somit im politischen Wettbewerb eine besondere Stellung ein. Während ihrer Teilnahme am politischen Willensbildungsprozess formell nicht die Legitimität abgesprochen wird, sieht sich die Partei dennoch über den Ausschluss aus der staatlichen Parteienfinanzierung hinausgehenden Nachteilen ausgesetzt, die durch das verfassungsgerichtliche Feststellungsurteil begründet, aufrechterhalten oder verstärkt werden. Ihnen haftet ein Verdacht an, dem bereits eine so hohe Indizwirkung zukommt, dass behördliche Prognosen über den Grad der vorliegenden Verfassungsfeindlichkeit maßgeblich gesteuert werden. Auch wird der gesellschaftliche Rückhalt der Partei durch den Ausschluss aus der staatlichen Parteienfinanzierung negativ beeinflusst. Die Möglichkeit einer Beschäftigung im öffentlichen Dienst wird für Parteimitglieder erheblich eingeschränkt, da die Gewähr für das jederzeitige Eintreten für die freiheitliche demokratische Grundordnung unvereinbar mit der Anhängerschaft einer als rechtskräftig verfassungsfeindlich geltenden Partei ist.

Während die Parteiengleichheit gezielt durch Art. 21 Abs. 3 GG eingeschänkt wird, beeinträchtigt das mit dem Feststellungsurteil einhergehende Stigma die Partei weitergehend in ihrer Freiheit. Die exekutive Eingriffsschwelle wird durch das verfassungsgerichtliche Feststellungsurteil herabgesetzt, sodass im Vergleich zu sonstigen Parteien geringere Anforderungen zum staatlichen Vorgehen erfüllt sein müssen.

1160 Siehe $\$ 5$ B. II. 2. c). 


\section{$\$ 6$ Resümee}

\section{A. Parteiengleichheit und der Parteienwettbewerb}

Rechtlicher Ausgangspunkt der vorliegenden Arbeit ist der durch die Parteiengleichheit statuierte freie Parteienwettbewerb. ${ }^{1161}$ Die Demokratie lebt von einem offenen politischen Willensbildungsprozess, der es der Minderheit ermöglicht, zur Mehrheit zu erstarken, und somit einen unbeeinflussten Machtwechselprozess voraussetzt. Dieser kann nur gewährleistet werden, wenn allen Teilnehmern am politischen Wettbewerb die gleichen Chancen eingeräumt werden, durch Zuwachs ihres Stimmanteils einen erhöhten Einfluss auf die Entscheidungen der Staatsgewalt zu nehmen. Konkretisierungen des Prinzips sind sowohl im Grundgesetz als auch in den Verfassungen der Bundesländer zu finden. Beispielsweise schreibt Art. 38 Abs. 1 S. 1 GG in Bezug zu den Abgeordnetenwahlen zum Deutschen Bundestag vor, dass diese in gleicher Wahl zu erfolgen haben.

Die Chancengleichheit der Parteien bezieht sich allerdings nicht nur auf Wahlen, sondern auch auf die Zeiträume dazwischen. Durch die Offenheit des politischen Willensbildungsprozesses wird ein andauernder und ununterbrochender politischer Wettbewerb konstituiert, der von Verfassungs wegen vor staatlicher Einflussnahme geschützt ist. Die sog. Parteiengleichheit beinhaltet sowohl eine objektiv-rechtliche als auch subjektiv-rechtliche Dimension. Um objektiv-rechtlich die demokratische Staatsform gewährleisten zu können, wird den Parteien als unmittelbare Teilnehmer des politischen Wettbewerbs eine subjektive Rechtsposition eingeräumt, die diese auch gerichtlich geltend machen können. Die Parteiengleichheit gewährleistet insoweit einen freien Parteienwettbewerb, der rückgekoppelt an demokratische Prinzipien eine ständige Veränderung der geltenden Machtverhältnisse ermöglicht.

Die Parteiengleichheit nimmt insofern für die Demokratie eine herausragende Stellung ein. Da jede staatliche Ungleichbehandlung von Parteien eine Verzerrung des politischen Wettbewerbs zur Folge hat und dadurch das Demokratieprinzip eingeschränkt wird, sind erhöhte Anforderungen an die Rechtfertigung einer eingreifenden Maßnahme zu stellen. Sofern im Handeln des Staates eine rechtserhebliche Ungleichbehandlung vor-

1161 Siehe $\$ 2$ B. II. 
liegt, kann diese nur durch „zwingende Gründe“ gerechtfertigt werden. ${ }^{1162}$ Die Ungleichbehandlung muss somit schon bezüglich ihrer Zweckrichtung höheren Anforderungen gerecht werden als dies bei anderweitigen, nicht parteibezogenen Ungleichbehandlungen der Fall ist.

\section{B. Parteienfinanzierung als Wettbewerbsmodifikator}

Da Parteien dem gesellschaftlichen Bereich zugeordnet werden und eine Integration in die organisierte Staatlichkeit verfassungswidrig ist ${ }^{1163}$, sind die Parteien auf die eigenständige Finanzierung ihrer politischen Tätigkeit angewiesen. Es ist dem Staat somit grundsätzlich untersagt, durch die Subventionierung von Parteien eine dahingehende finanzielle Abhängigkeit zu schaffen. Dennoch hat sich bereits in den Anfangsjahren eine Tendenz zur staatlichen Politikfinanzierung entwickelt, die verfassungsrechtlich dauerhaft umstritten war und einer mehrfachen Korrektur durch die Legislative wie auch der Judikative unterlag.

Die staatliche Parteienfinanzierung umfasst die unmittelbare Teilfinanzierung nach den $\mathbb{\$} 18 \mathrm{ff}$. PartG und die mittelbare Parteienfinanzierung, die maßgeblich von steuerrechtlichen Privilegierungen ausgeht. Im letzteren Fall werden Parteien, beispielsweise durch $₫ 5$ Abs. 1 Nr. 7 KStG, von der Entrichtung von Steuern befreit oder Zuwendungen an Parteien nach $\mathbb{S} 10 \mathrm{~b}$ Abs. 2, 34g EStG unter Ausschluss des Abzugs als Betriebsausgaben nach $₫ 4$ Abs. 6 EStG einkommenssteuerrechtlich privilegiert, um für die Zuwendenden einen besonderen Anreiz zu schaffen. Durch die staatliche Parteienfinanzierung wurde die Finanzkraft der Parteien insgesamt erhöht. Während die mittelbare Parteienfinanzierung allen Parteien im gleichen Ausmaß zugute kommt, wird bei der Gewährung von Mitteln aus der unmittelbaren Teilfinanzierung differenziert. Die Differenzierung erfolgt aufgrund des „Erfolges“ einer Partei, der anhand der erhaltenen Stimmen bei (Landtags-, Bundestags-, oder Europa-) Wahlen wie auch der Höhe an Zuwendungen durch Mitgliedsbeiträge oder Spenden ermittelt wird. Auch unterscheidet sich die unmittelbare Teilfinanzierung durch eine verfassungsrechtlich höchst bedenkliche, dennoch durch das Bundesverfas-

1162 BVerfGE 20, 56 (117); BVerfGE 24, 300 (339 ff.); siehe auch BVerfGE 6, 273 (280); BVerfGE 12, 10 (28); BVerfGE 111, 382 (398).

1163 Insbesondere BVerfGE 20, 56 (101f.); siehe auch Hesse, in: VVDStRL 17 (1967), S. 1, 33. 
sungsgericht gebilligte ${ }^{1164}$ Sperrklausel von der mittelbaren Parteienfinanzierung. Bei der Vergabe von Mitteln aus der unmittelbaren Teilfinanzierung bleiben solche Parteien unberücksichtigt, die das in $\mathbb{1} 18$ Abs. 4 S. 1 PartG festgesetzte Stimmquorum bei Landtags- oder Bundestagswahlen nicht erreicht haben.

Durch die Etablierung der staatlichen Parteien- und Politikfinanzierung hat sich der politische Wettbewerb verändert. Die Differenzierung anhand der Erfolgsrate wird durch die Chancengleichheit zwingend vorgeschrieben, da eine Nivellierung der wettbewerbsbedingten Unterschiede wiederum einen Verstoß gegen den Grundsatz der parteilichen Chancengleichheit darstellen würde. ${ }^{1165}$ Die durch den Wettbewerb selbst hervorgerufenen Unterschiede stellen das Ergebnis des politischen Meinungskampfes dar und dürfen durch den Staat grundsätzlich nicht ausgeglichen werden. Die in dieser Arbeit untersuchte Verfassungsänderung birgt das Problem, dass aufgrund der inhaltlichen Ausrichtung bestimmte Parteien aus der staatlichen Parteienfinanzierung ausgeschlossen werden und dadurch in Konkurrenz zu den Parteien stehen, die durch die staatliche Parteienfinanzierung begünstigt werden. Indem Art. 21 Abs. 3 GG an das bestehende Finanzierungssystem anknüpft, wurde das Instrument zur Förderung des politischen Lebens gleichzeitig zu einer Waffe gegen verfassungsfeindliche Parteien ausgestaltet. Anstatt mittels der schärftsten Waffe der wehrhaften Demokratie, dem Parteiverbot, eine Partei vollständig aus dem Parteienwettbewerb zu entfernen, kann der Staat nun darauf hoffen, dass die zermürbende Kraft des Wettbewerbs dafür sorgt, dass eine aus der Parteienfinanzierung ausgeschlossene Partei sich entweder aus wirtschaftlichen Gründen auflöst oder für unbestimmte Zeit in der politischen Bedeutungslosigkeit verschwindet. Mit dem Ausschluss aus der staatlichen Parteienfinanzierung kann der Staat auf eine mildere Art und Weise die Wettbewerbsbedingungen einer Partei zu deren Nachteil verändern und dadurch den Wettbewerb selbst hin zu einem Schutzinstrument der freiheitlichen demokratischen Grundordnung modifizieren.

1164 Vgl. BVerfGE 20, 56 (117); siehe hierzu bereits $\$ 3$ A. II. c).

1165 Siehe hierzu bereits $\$ 2$ B. II. 


\section{Verfassungsmäßigkeit des Finanzierungsausschlussverfahrens}

Die Verfassungsmäßigkeit der Verfassungsänderung vom 18.07.2017 1166 muss an Art. 79 GG gemessen werden, der insoweit die Dispositionsgewalt des verfassungsändernden Gesetzgebers einschränkt. Aufgrund von Art. 79 Abs. 3 GG darf die Verfassungsänderung die „Grundsätze des Art. 1

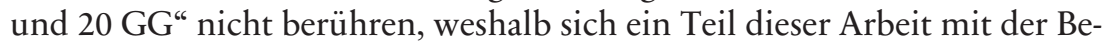
antwortung der Frage nach der Vereinbarkeit des Finanzierungsausschlussverfahrens mit dem Demokratieprinzip und der Menschenwürde auseinandersetzt. ${ }^{1167}$

Zu den Grundsätzen des in Art. 20 Abs. 1, Abs. 2 GG verankerten Demokratieprinzips gehört die Offenheit des politischen Willensbildungsprozesses und die Selbstbestimmungsfähigkeit des Volkes. Die parteibezogene Chancengleichheit stellt eine Konkretisierung des durch Art. 79 Abs. 3 GG i.V.m. Art. 20 Abs. 1, Abs. 2 GG geschützten Demokratieprinzips dar. Durch die Anwendung des Finanzierungsausschlussverfahrens wird der parteipolitische Wettbewerb verzerrt, weshalb der politische Willensbildungsprozess spiegelbildlich an Offenheit verliert. Relevant für die vorgenommene Untersuchung ist somit die Frage, ob durch das Finanzierungsausschlussverfahren der offene Prozess der politischen Willensbildung in einem solchen Maße eingeschränkt wird, dass durch die Verfassungsänderung die Grundsätze der Demokratie tangiert werden. Für die Frage der Vereinbarkeit eines solchen Verfahrens mit demokratischen Grundsätzen nimmt das verfassungsrechtliche Prinzip der „wehrhaften Demokratie“ einen besonderen Stellenwert ein. ${ }^{1168}$ Das Prinzip der wehrhaften Demokratie ist nach allgemeiner Ansicht als verfassungsrechtliches Prinzip anerkannt und sieht Einschränkungsmöglichkeiten demokratischer Prozesse vor, solange sie ihrem Schutz dienen; die Staatsordnung dadurch also demokratische Entscheidungsprozesse einschränkt, um eine demokratische Herrschaftsordnung dauerhaft gewährleisten zu können.

Der dogmatische Ansatzpunkt zur Lösung der Frage der Vereinbarkeit der Verfassungsänderung mit Art. 79 Abs. 3 GG ist die rechtstheoretische Differenzierung zwischen Prinzipien und Regeln. ${ }^{1169}$ Prinzipien sind inso-

1166 BGBl. 2017, I, S. 2346.

1167 \4 C. II.

1168 Siehe $\$ 4$ C. II. 2. b) (2).

1169 Vgl. Hain, in: Starck/Mangoldt/Klein (Hrsg.), Kommentar zum Grundgesetz, ${ }^{5}$ 2005, Art. 79, Rn. 45; Epping, Rechtsgutachten über die Frage, ob und unter welchen Voraussetzungen eine nicht nach Art. 21 II GG verbotene Partei von 
weit Optimierungsgebote ${ }^{1170}$ und entsprechen den „Grundsätzen“ iSd. Art. 79 Abs. 3 GG; sie bedürfen aufgrund ihrer Generalität zu ihrer Umsetzung ausgestaltender Konkretisierungen. Der Gesetzgeber ist durch Optimierungsgebote grundsätzlich gehalten, jedes Prinzip in den Grenzen seiner tatsächlichen und rechtlichen Möglichkeiten in einem möglichst großen Umfang zu realisieren. ${ }^{1171}$ Die gerichtliche Überprüfung der vorgenommenen Optimierung wird allerdings weitestgehend durch den Gestaltungsspielraum des Gesetzgebers eingeschränkt. ${ }^{1172}$ So kann ein Verstoß gegen das Optimierungsgebot nicht schon darin gesehen werden, dass der Gesetzgeber die Summe der Einzelausprägungen des Prinzips reduziert. Vielmehr obliegt ihm im Rahmen seines Gestaltungsspielraumes, die Wahl der Mittel zur Erfüllung des Optimierungsgebotes eigenständig festzulegen.

Während die Prinzipien einer Veränderung unzugänglich und der Dispositionsgewalt des verfassungsändernden Gesetzgebers entzogen sind, können die sie ausgestaltenden Konkretisierungen modifiziert werden. ${ }^{1173}$ Die parteibezogene Chancengleichheit stellt nach den Ergebnissen dieser Untersuchung eine Konkretisierung des Demokratieprinzips, eines der Leitprinzipien des Grundgesetzes, dar, und ist einer Modifizierung durch den verfassungsändernden Gesetzgeber somit zugänglich. Eine Modifizierung der parteibezogenen Chancengleichheit wäre unter dem Regelungsregime des Art. 79 Abs. 3 GG nur dann unzulässig, wenn deren Veränderung zu einem verfassungsimmanenten Widerspruch führen würde, die Regelung somit im Widerspruch zu dem ihr übergeordneten Prinzip stünde.

Durch die Verzerrung des parteipolitischen Wettbewerbs greift der Staat zwar in die Offenheit des politischen Willensbildungsprozesses ein, indem er die Wettbewerbsbedingungen zulasten bestimmter Parteien verändert, allerdings liegt dieser gesetzgeberischen Entscheidung der Gedanke zugrunde, keine Parteien weiterhin staatlich fördern zu müssen, deren Zielsetzung sich gegen die freiheitliche demokratische Grundordnung richtet.

der staatlichen Parteifinanzierung ausgeschlossen werden kann, 14.11.2008, S. 37 ff.; vertiefend Alexy, ARSP-Beiheft 1985, $13 \mathrm{ff}$.

1170 Alexy, Theorie der Grundrechte, ${ }^{3} 1996$, S. 75 f.; Riedel, in: VVDStRL 58 (1999), S. 183.

1171 Riedel, in: VVDStRL 58 (1999), S. 183.

1172 Würtenberger, in: VVDStRL 58 (1999), S. 158.

1173 Epping, Rechtsgutachten über die Frage, ob und unter welchen Voraussetzungen eine nicht nach Art. 21 II GG verbotene Partei von der staatlichen Parteifinanzierung ausgeschlossen werden kann, 14.11.2008, S. $37 \mathrm{ff}$. 
Der Staat vermag sich durch Art. 21 Abs. 3 GG von seiner Verpflichtung zu befreien, Parteien finanziell zu unterstützen, die sich den Umsturz der bestehenden Gesellschafts- und Verfassungsordnung verschrieben haben. Durch die sachgerechte Modifizierung der Chancengleichheit wurde auch lediglich eine mildere Maßnahme zum Parteiverbot geschaffen, die einen angemessenen Ausgleich zwischen der Chancengleichheit der Parteien und dem verfassungsrechtlichen Auftrag des Staates zur dauerhaften Gewährleistung der bedeutensten Prinzipien seiner Verfassungsordnung herstellt. Der Staat hat somit die Pflichtenkollision in Belangen der Finanzierung verfassungsfeindlicher Parteien durch das Einführen von Art. 21 Abs. 3 GG in zulässiger Weise gelöst, sodass das Änderungsgesetz vom 18.07.2017 $7^{1174}$ verfassungsrechtlich nicht zu beanstanden ist.

Die einfachgesetzliche Ausgestaltung des Art.21 Abs.3 GG durch \$46a BVerfGG ist im Unterschied zur Verfassungsänderung missglückt. Während Art. 21 Abs. 3 GG durch den verfassungsändernden Gesetzgeber geschaffen worden und somit an Art. 79 Abs. 3 GG zu messen ist, muss sich die einfachgesetzliche Ausgestaltung am Regelungsgehalt des gesamten Grundgesetzes messen lassen. Die vorgesehene Ausschlussfrist von sechs Jahren, ohne der Partei eine frühere Teilnahme an der staatlichen Parteienfinanzierung zu ermöglichen, ist nach diesem Maßstab verfassungswidrig. Aufgrund des intensiven Bezuges der Chancengleichheit zum Demokratieprinzip darf eine Einschränkung nur aus „zwingenden Gründen " vorgenommen werden. ${ }^{1175}$ Der Gewährleistungsbereich der parteibezogenen Chancengleichheit wird nicht nur im Zeitpunkt des Ausschlusses durch die Verkündung des Feststellungsurteils des Bundesverfassungsgerichts eingeschränkt, sondern unterliegt während der gesamten Ausschlussdauer einer Beeinträchtigung, deren rechtfertigende Umstände bis zum Ende des Ausschlusses vorliegen müssen. Sofern es einer Partei allerdings vor Ablauf der Sechs-Jahres-Frist gelingt, inhaltlich zu den grundlegenden Verfassungswerten zurückzukehren, ist ein weiterer Ausschluss nicht erforderlich und der politische Wettbewerb wird anlasslos verzerrt. Der Ausschluss aus der staatlichen Parteienfinanzierung muss somit durch die betroffene Partei selbst aufgehoben werden können. Aufgrund des Fehlens einer planwidrigen Regelungslücke scheidet eine analoge Anwendung des $₫ 40$ BVerfGG aus, wodurch die Parteien nach Feststellung ihrer verfassungsfeindlichen Ausrichtung durch das Bundesverfassungsgericht keine Möglichkeit einer vorzeitigen Begünstigung durch die Parteienfinan-

1174 BGBl. 2017, I, S. 2346.

1175 Siehe $\$ 2$ B. II. 
zierung erhalten. ${ }^{1176}$ Die Einräumung einer entsprechenden Antragsberechtigung der betroffenen Partei zur Feststellung des Wegfalls der Ausrichtung gegen die freiheitliche demokratische Grundordnung und einer damit verbundenen Teilnahme an der staatlichen Parteienfinanzierung wäre nicht nur rechtspolitisch wünschenwert, sondern auch verfassungsrechtlich geboten.

\section{Rechtsstellung der verfassungsfeindlichen Partei}

Sollte eine Partei aus der staatlichen Parteienfinanzierung ausgeschlossen sein, stellt sich die Frage, ob sie weitergehende rechtliche sowie tatsächliche Nachteile zu befürchten hat. Grundsätzlich bleibt festzuhalten, dass ein erfolgreiches Verfahren nach Art. 21 Abs. 3 GG ausschließlich zu einem Ausschluss aus der staatlichen Parteienfinanzierung führt und keine Grundlage für die Anordnung anderweitiger belastender Maßnahmen gegen die betroffene Partei bietet. ${ }^{1177}$ Die in diesem Rahmen festgestellte verfassungsfeindliche Haltung darf nicht zu einer weitergehenden rechtsverbindlichen Benachteiligung der Partei führen und lässt die Rechtsstellung im Übrigen unangetastet. Das Parteienprivileg gilt, mit einer Ausnahme für die staatliche Parteienfinanzierung, unverändert weiter. Ob die Partei allerdings weitere Nachteile durch einen Ausschluss aus der staatlichen Parteienfinanzierung dulden muss, hängt davon ab, ob das Parteienprivileg in allen Fällen einer Berücksichtigung der verfassungsfeindlichen Haltung im Verwaltungshandeln entgegensteht.

Das Parteienprivileg schützt Parteien nicht vor solchen Maßnahmen, die sie nicht in rechtsverbindlicher Weise treffen. Insoweit wurde sich im Rahmen dieser Arbeit der Auffassung von Murswiek zur Problematik angeschlossen ${ }^{1178}$, inwieweit die verfassungsfeindliche Ausrichtung einer Partei berücksichtigt werden darf, ohne einen Verstoß gegen das Parteienprivileg zu begründen. Relevant wird dieses Ergebnis im Bereich der sog. „faktischen Nachteile“. Das Bundesverfassungsgericht vertritt die Auffassung, dass solche staatlichen Maßnahmen, die lediglich faktische Nachteile für eine Partei begründen, keinen Eingriff in den Rechtskreis der Parteien darstellen würden und somit nicht am Inhalt des Parteienprivilegs zu messen

1176 Siehe $\$ 4$ C. II. 3.

1177 Siehe $\$ 5$ B. II.

1178 Murswiek, DVBl 1997, 1021 (1029f.); siehe $\$ 5$ B. II. 1. 
seien. ${ }^{1179}$ Die faktischen Nachteile sind durch die Rechtsprechung des Bundesverfassungsgerichts anerkannt und beschreiben wettbewerbsrelevante Nachteile, die als Nebenprodukt der Wahrnehmung originärer Staatsaufgaben entstehen und deren Zweckrichtung sich nicht unmittelbar gegen eine Partei richtet. Durch die Figur der faktischen Nachteile kann eine verfassungsfeindliche Ausrichtung einer Partei im Rahmen staatlichen Handelns berücksichtigt werden, ohne dass das Anknüpfungsverbot des Parteienprivilegs Anwendung findet. Das Bundesverfassungsgericht hält dies für zulässig, da es den faktischen Nachteilen die Eingriffsqualität in den Rechtskreis der Parteien abspricht. Diese Rechtsprechung ist angesichts der Anerkennung faktischer Grundrechtseingriffe allerdings nicht haltbar.

Das Feststellungsurteil des Bundesverfassungsgerichts enthält bereits selbst eine staatliche Wertung, die im Rahmen der Tatsachenverwertung durch jedwede Art staatlicher Gewalt berücksichtigt werden kann. Bei der Entscheidung über die Beobachtung einer Partei durch die Verfassungsschutzbehörden des Bundes und der Länder und deren Erwähnung in öffentlich einsehbaren Berichten, sowie in politischen Äußerungen von Amtswaltern oder im Rahmen des Einstellungsverfahrens im öffentlichen Dienst kann die Tatsache, dass die Partei aus der staatlichen Parteienfinanzierung ausgeschlossen wurde, Berücksichtigung finden. Insoweit wird die Rechtsstellung der „verfassungsfeindlichen Partei“ nicht im besonderen Maße verändert, allerdings erfolgt ein Paradigmenwandel bei der Bestimmung, ob eine Partei verfassungsfeindlich ist oder ihre Werte eine grundsätzliche Vereinbarkeit mit der freiheitlichen demokratischen Grundordnung aufweisen. Die Tatsache, dass eine Beteiligung an der unmittelbaren Teilfinanzierung und den steuerlichen Privilegierungen vorenthalten wird, weil die Partei gegen die freiheitliche demokratische Grundordnung oder den Bestand der Bundesrepublik ausgerichtet ist, muss sich die Partei vorhalten lassen. Dem Feststellungsurteil kommt insoweit eine bestätigende Wirkung zu, die ohne die Verwertung weiterer relevanter Umstände das Vorliegen einer verfassungsfeindlichen Haltung in besonderer Weise indiziert. Während die Anknüpfung rechtsverbindlicher Maßnahmen an die Feststellung der verfassungsfeindlichen Ausrichtung durch das Bundesverfassungsgericht aufgrund des Parteienprivilegs untersagt ist, ist die Beurteilung einer Partei als „verfassungsfeindlich“ mit allen hiermit zusammenhängenden Nachteilen möglich. Durch die erneute Beteiligung an der staatlichen Parteienfinanzierung, sei es durch Zeitablauf oder dem Schei-

1179 Vgl. BVerfGE 39, 334 (360). 
tern eines wiederholten Finanzierungsausschlussantrages oder eines hiermit vergleichbaren Verlängerungsantrages nach $\$ 46 a$ Abs. 2 BVerfGG, wird die Partei rehabilitiert und die Indizwirkung des vorangegangenen Feststellungsurteils beendet. 


\section{Literaturverzeichnis}

Alexy, Robert, Rechtsregeln und Rechtsprinzipien, ARSP-Beiheft 1985, 13 ff.

—, Theorie der Grundrechte, 3. Aufl., Frankfurt am Main 1996.

Alter, Maximilian J., Das Parteiverbot: Weltanschauungsvorsorge oder Gefahrenabwehr?, AöR 140 (2015), S. 571-597.

-, Die Eingriffsschwelle beim Verbot extremistischer Parteien und Vereine in Deutschland und England, Dissertation 2016.

Anschütz, Gerhard (Hrsg.), Die Verfassung des Deutschen Reiches vom 11. August 1919, 14. Aufl., Berlin 1933.

Arnauld, Andreas von (Hrsg.), Grundgesetz-Kommentar, München 2012.

Arnim, Hans Herbert von, Der strenge und der formale Gleichheitssatz, DÖV 1984, S. 85-92.

—, Finanzierung der Politik - Abgeordnetenentschädigung, Parteien-, Fraktionsund Stiftungsfinanzierung, ZRP 1989, S. 257-265.

- Verfassungsfragen der Fraktionsfinanzierung im Bundestag und in den Landesparlamenten, in: Wewer, Göttrik (Hrsg.), Parteienfinanzierung und politischer Wettbewerb - Rechtsnormen - Realanalysen - Reformvorschläge, Wiesbaden 1990, S. 134-162.

—, Beruf und Mandat-Einflüsse der Diätenregelung, in: Bitburger Gespräche Jahrbuch 1993/2; [Parteien und Parteienfinanzierung], München 1993, S. 169186.

—, Die Partei, der Abgeordnete und das Geld - Parteienfinanzierung in Deutschland, München 1996.

—, Parteienfinanzierung: Zwischen Notwendigkeit und Missbrauch - Alte Probleme und neue Entwicklung, NVwZ 2003, S. 1076-1080.

Bäcker, Alexandra, Der Ausschluss aus der Bundestagsfraktion, Berlin 2011.

Badura, Peter, $\mathbb{} 270$ Verfassungsänderung, Verfassungswandel, Verfassungsgewohnheitsrecht, in: Isensee, Josef/Kirchhof, Paul u.a. (Hrsg.), Handbuch des Staatsrechts der Bundesrepublik Deutschland XII, 3. Aufl., 2014, S. 591-612.

Barczak, Tristan, Die parteipolitische Äußerungsbefugnis von Amtsträgern - Eine Gratwanderung zwischen Neutralitätsgebot und politischem Wettbewerb, NVwZ 34 (2015), S. 1014-1020.

- (Hrsg.), BVerfGG Mitarbeiterkommentar zum Bundesverfassungsgerichtsgesetz - Kommentar, Berlin/Boston 2018.

Beaucamp/Beaucamp, Methoden und Technik der Rechtsanwendung, 4. Aufl., Heidelberg 2019.

Benda, Ernst/Klein, Eckart/Klein, Oliver, Verfassungsprozessrecht - Ein Lehr- und Handbuch, 3. Aufl., Heidelberg 2011. 
Bethge, Herbert, Das Duell der Kanzlerkandidaten im Spannungsfeld zwischen Rundfunkfreiheit und Parteiengleichheit, ZUM 2003, S. 253-261.

Bethge, Herbert/Weber-Dürler, Beatrice, Der Grundrechtseingriff - Berichte und Diskussionen auf der Tagung der Vereinigung der Deutschen Staatsrechtslehrer in Osnabrück vom 1. bis 4. Oktober 1997, VVDStRL 57 (1998), S.7ff., Berlin 1998.

Bethge, Horst/Bünemann, Richard/Enderlein, Hinrich/Kurz, Ingrid/Roßmann, Erich/ Schiller, Theo/Stein, Helmut/Stuby, Gerhard, Die Zerstörung der Demokratie in der BRD durch Berufsverbote, Köln 1976.

Schmidt-Bleibtreu, Bruno/Hofmann, Hans/Henneke, Hans-Günter (Hrsg.), GG - Kommentar zum Grundgesetz, 14. Aufl., Köln 2018.

Böckenförde, Ernst-Wolfgang, Die Methoden der Verfassungsinterpretation - Bestandsaufnahme und Kritik, NJW 1976, S. 2089-2099.

Boventer, Gregor Paul, Grenzen politischer Freiheit im demokratischen Staat - Das Konzept der streitbaren Demokratie in einem internationalen Vergleich, Berlin 1985.

Brand, Torsten, Zur Gleichbehandlung von Parteien bei der Überlassung kommunaler Einrichtungen auf der vertraglichen Ausgestaltungsstufe, BayVBl 2001, 104-109.

Bryde, Brun-Otto, Verfassungsentwicklung - Stabilität und Dynamik im Verfassungsrecht der Bundesrepublik Deutschland, Baden-Baden 1982.

Bulla, Eckart, Die Lehre von der streitbaren Demokratie - Versuch einer kritischen Analyse unter besonderer Berücksichtigung der Rechtsprechung des Bundesverfassungsgerichtes, AöR 98 (1973), S. 340-360.

Bundesministerium des Innern - Kommission, Rechtliche Ordnung des Parteiwesens Problem eines Parteiengesetzes: Bericht, Frankfurt am Main 1958.

Calliess, Christian/Ruffert, Matthias (Hrsg.), EUV/AEUV - Das Verfassungsrecht der Europäischen Union mit Europäischer Grundrechtecharta: Kommentar, 5. Aufl., München 2016.

Delius, Hans, Das preußische Vereins- und Versammlungsrecht - unter besonderer Berücksichtigung des Gesetzes vom 11. März 1850, Berlin 1891.

Denninger, Erhard, Verfassungstreue und Schutz der Verfassung, VVDStRL 37 (1979).

Denninger, Erhard/Klein, Hans H./Rudolf, Walter, Verfassungstreue und Schutz der Verfassung - Der öffentliche Dienst im Staat der Gegenwart, de Gruyter 1979.

Doehring, Karl, Das Staatsrecht der Bundesrepublik Deutschland - Unter bes. Berücks. d. Rechtsvergleichung u. d. Völkerrechts, 2. Aufl., Frankfurt am Main 1980.

Doehring, Karl/Isensee, Josef/Kisker, Gunter/Püttner, Günter, Die staatsrechtliche Stellung der Ausländer in der Bundesrepublik Deutschland, VVDStRL 32 (1974).

Dolde, Klaus-Peter, Die politischen Rechte der Ausländer in der Bundesrepublik, Berlin 1972. 
Dreier, Horst, Grenzen demokratischer Freiheit im Verfassungsstaat, JZ 1994, S. 741-752.

Dreier, Horst/Bauer, Hartmut (Hrsg.), Grundgesetz - Kommentar, 3. Aufl., Tübingen 2015.

Dübber, Ulrich, Parteifinanzierung in Deutschland - Eine Untersuchung über das Problem der Rechenschaftslegung in einem künftigen Parteiengesetz, Wiesbaden 1962.

Eder, Christian, »Rote Karte« gegen »Spinner«?, Berlin 2017.

Epping, Volker, Rechtsgutachten über die Frage, ob und unter welchen Voraussetzungen eine nicht nach Art. 21 II GG verbotene Partei von der staatlichen Parteifinanzierung ausgeschlossen werden kann, Leibniz Universität Hannover 14.11.2008.

Epping, Volker/Hillgruber, Christian (Hrsg.), BeckOK GG, 32. Aufl., München 2017.

Eschenburg, Theodor, Staat und Gesellschaft in Deutschland, Stuttgart 1956.

—, Probleme der modernen Parteifinanzierung, Tübingen 1961.

Fenske, Hans, Deutsche Parteiengeschichte - Von den Anfängen bis zur Gegenwart, Paderborn 1994.

Ferreau, Frederik, Die Sanktionierung von Parteien und das Recht auf Chancengleichheit im politischen Wettbewerb - Eine verfassungsdogmatische und -theoretische Betrachtung angesichts der beabsichtigten Änderung des Artikels 21 GG, DÖV 2017, S. 494-500.

—, Grenzen staatlicher Beteiligung am politischen Diskurs, NVwZ 2017, S. 12591263.

Frau, Robert, Rechtsschutz für Kleinstparteien - Nichtanerkennungsbeschwerden, DÖV 2018, S. 152-157.

Friauf, Karl Heinrich/Höfling, Wolfram (Hrsg.), Berliner Kommentar zum Grundgesetz, Berlin 2000.

Gassner, Ulrich, Grenzen des Zulassungsanspruchs politischer Parteien zu kommunalen öffentlichen Einrichtungen, VerwArch 85 (1994), S. 533-566.

Grabitz, Eberhard/Hilf, Meinhard/Nettesheim, Martin/Athen, Marco (Hrsg.), Das Recht der Europäischen Union, 2015. Aufl., München 2015.

Graf zu Dohna, Alexander, $\mathbb{S} 17$. Die staatlichen Symbole und der Schutz der Republik, in: Anschütz, Gerhard/Thoma, Richard (Hrsg.), Handbuch des deutschen Staatsrechts, Bd. 1, Tübingen 1930, S. 200-208.

Grau, Richard, $\mathbb{\$} 80$. Die Diktaturgewalt des Reichspräsidenten, in: Anschütz, Gerhard/Thoma, Richard (Hrsg.), Handbuch des deutschen Staatsrechts, Bd. 2, Tübingen 1930, S. 274-295.

Günther, Uwe/Vesper, Michael, Wie weiter mit dem Stiftungsgeld?, ZRP 1994, S. 289-292.

Gusy, Christoph, Die „freiheitliche demokratische Grundordnung“ in der Rechtsprechung des Bundesverfassungsgerichts, AöR 105 (1980), S. 279.

—, Befugnisse des Verfassungsschutzes zur Informationserhebung, DVBl 1991, S. 1288-1295. 
-, Verwaltung durch Information - Empfehlungen und Warnungen als Mittel des Verwaltungshandelns, NJW 2000, S. 977-986.

- Neutralität staatlicher Öffentlichkeitsarbeit - Voraussetzungen und Grenzen, NVwZ 2015, S. 700-704.

—, Verfassungswidrig, aber nicht verboten!, NJW 2017, S. 601-604.

Häberle, Peter, Verfassungsrechtliche Ewigkeitsklausel als verfassungsrechtliche Identitätsgarantie, in: Hangartner, Yvo/Trechsel, Stefan/Haug, Hans (Hrsg.), Völkerrecht im Dienste des Menschen - Festschrift für Hans Haug, Bern, Stuttgart 1986, S. 81-108.

—, Die Menschenwürde als Grundlage der staatlichen Gemeinschaft, in: Badura, Peter/Isensee, Josef/Kirchhof, Paul (Hrsg.), Handbuch des Staatsrechts der Bundesrepublik Deutschland II, 3. Aufl., Heidelberg 2004, S. 317-367.

Hain, Karl-Eberhard, Die Grundsätze des Grundgesetzes - Eine Untersuchung zu Art. 79 Abs. 3 GG, Baden-Baden 1999.

Häntzschel, Kurt/Schönner, Kurt (Hrsg.), Gesetz zum Schutze der Republik - mit den Ausführungsbestimmungen des Reichs und der Länder. Unter besonderer Berücksichtigung der Rechtsprechung, Berlin 1930.

Hasselmann, Britta/Künast, Renate, Parteiverbote - Eine Lex NPD schadet der Demokratie, FAZ 22.06.2017.

Heckelmann, Harald, Das Ermessen staatlicher Organe bei der Stellung von Verbotsanträgen nach Art. 21 Abs. 2 GG (\$ 43 BVerfGG), München 1976.

Hecker, Wolfgang, Verweigerung der Stadthallennutzung gegenüber der NPD, NVwZ 2018, S. 787-791.

- Verweigerung von Fraktionszuschüssen an kommunale Fraktion im Gemeinderat wegen Verfassungsfeindlichkeit, NVwZ 2018, S. 1613-1615.

Henke, Wilhelm, Das Recht der politischen Parteien, Göttingen 1964.

Henrichs, Wilhelm, Parteibegriff, und Parteienregistrierung, DVBl 1958, S. 227-232.

Hesse, Konrad, Die verfassungsrechtliche Stellung der politischen Parteien im modernen Staat, VVDStRL 17 (1958).

—, Grundzüge des Verfassungsrechts der Bundesrepublik Deutschland, 20. Aufl., Heidelberg 1999.

Hettich, Jens, Die Zulässigkeit verschiedener Handlungsalternativen des Staates im Vorgehen gegen extremistische Parteien unter Berücksichtigung des Parteienprivilegs, Hamburg 2015.

Heusch, Andreas, Der Grundsatz der Verhältnismäßigkeit im Staatsorganisationsrecht, Berlin 2003.

Hoffmann, Hans, Die Neuregelung der staatlichen Parteienfinanzierung, DÖV 1994, S. 504-515.

Höfling, Wolfram, Steuermindernde Parteienfinanzierung auf „direktem Umweg“?, NJW 1985, S. 1943-1945.

Hölscheidt, Sven, Das Recht der Parlamentsfraktionen, Rheinbreitbach 2001.

Huber, Ernst Rudolf, Band 7 - Deutsche Verfassungsgeschichte seit 1789 - Ausbau, Schutz und Untergang der Weimarer Republik, 1. Aufl., Stuttgart 1984. 
-, Band 3 - Deutsche Verfassungsgeschichte seit 1789 - Bismarck und das Reich, 3. Aufl., Stuttgart 1988.

—, Band 6 - Deutsche Verfassungsgeschichte seit 1789 - Die Weimarer Reichsverfassung, 1. Aufl., Stuttgart 1993.

—, Band 4 - Deutsche Verfassungsgeschichte seit 1789 - Struktur und Krisen des Kaiserreichs, 2. Aufl., Stuttgart 1994.

Huber, Peter/Voßkuble, Andreas (Hrsg.), Grundgesetz - Kommentar, 7. Aufl., München 2018.

Huber, Peter, Das parteienrechtliche Transparenzgebot und seine Sanktionierung, DÖV 2000, S. 745-753.

Ipsen, Jörn, Globalzuschüsse statt Wahlkampfkostenerstattung, JZ 1992, S. 753-761.

—, Parteiverbot und „politisches“ Ermessen, in: Geis, Max-Emanuel/Lorenz, Dieter (Hrsg.), Staat, Kirche, Verwaltung - Festschrift für Hartmut Maurer zum 70. Geburtstag, München 2001.

—, Parteiverbot und „politisches“ Ermessen - Festschrift für Helmut Maurer, in: Geis, Max-Emanuel/Lorenz, Dieter (Hrsg.), Staat, Kirche, Verwaltung - Festschrift für Hartmut Maurer zum 70. Geburtstag, München 2001, S. 163-175.

- (Hrsg.), Parteiengesetz - [Gesetz über die politischen Parteien]; Kommentar, München 2008.

-, Das Ausschlussverfahren nach Art. 21 Abs. 3 GG - ein mittelbares Parteienverbot?, JZ 2017, S. 933-936.

Isensee, Josef, Der Beamte zwischen Parteifreiheit und Verfassungstreue. Zur Vereinbarkeit der Mitgliedschaft in einer verfassungsfeindlichen Partei., JuS 1973, S. 265-272.

-, Die typisierende Verwaltung - Gesetzesvollzug im Massenverfahren am Beispiel der typisierenden Betrachtungsweise des Steuerrechts, Berlin 1976.

Janson, Nils, Staatliche Politikfinanzierung in Bewegung - Keine Fraktionszuwendungen für „Verfassungsfeinde“?, NVwZ 2018, S. 288-293.

Jarass, Hans D./Pieroth, Bodo (Hrsg.), Grundgesetz für die Bundesrepublik Deutschland - Kommentar, 15. Aufl., München 2018.

Jasmut, Gunter, Die politischen Parteien und die europäische Integration - Der Beitrag der Parteien zur demokratischen Willensbildung in europäischen Angelegenheiten, Frankfurt am Main 1995.

Jasper, Gotthard, Der Schutz der Republik - Studien zur staatlichen Sicherung der Demokratie in der Weimarer Republik, Tübingen 1963.

Jellinek, Walter, $\$ 73$. Das verfassungsändernde Reichsgesetz, in: Anschütz, Gerhard/ Thoma, Richard (Hrsg.), Handbuch des deutschen Staatsrechts, Bd. 2, Tübingen 1930, S. 182-189.

Ipsen, Jörn (Hrsg.), Parteiengesetz - Kommentar, 2. Aufl., München 2018.

Jülich, Heinz-Christian, Chancengleichheit der Parteien, Dissertation, Westfälische Wilhelms-Universität 1966 (zit. Jülich).

Kersten, Jens/Rixen, Stephan/Augsberg, Steffen (Hrsg.), Parteiengesetz (PartG) und europäisches Parteienrecht - Kommentar, Stuttgart 2009. 


\section{Literaturverzeichnis}

Kiesow, Wilhelm/Zweigert, Erich (Hrsg.), Gesetz zum Schutze der Republik - nebst den Ausführungsverordnungen des Reichs, Berlin 1923.

Kilz, Hans Werner, Flick: Die gekaufte Republik, 81. Aufl., Reinbek b. Hamburg 1984.

Kimminich, Otto, Deutsche Verfassungsgeschichte, 2. Aufl., Baden-Baden 1987.

Kirchhof, Paul, Gleichmaß und Übermaß, in: Badura, Peter (Hrsg.), Wege und Verfahren des Verfassungslebens - Festschrift für Peter Lerche zum 65. Geburtstag, München 1993, S. 133-149.

— $\$ 21$ Die Identität der Verfassung, in: Badura, Peter/Isensee, Josef/Kirchhof, Paul (Hrsg.), Handbuch des Staatsrechts der Bundesrepublik Deutschland II, 3. Aufl., Heidelberg 2004.

—, Die Steuern, in: Isensee, Josef/Kirchhof, Paul (Hrsg.), Handbuch des Staatsrechts der Bundesrepublik Deutschland V, 3. Aufl., Heidelberg 2007, S. 9591099.

Kißlinger, Andreas, Das Recht auf politische Chancengleichheit, Baden-Baden 1998.

Klein, Hans H., Die Rechenschaftspflicht der Parteien und ihre Kontrolle, NJW 2000, S. 1441-1450.

Kloepfer, Michael, $\mathbb{} 42$ Öffentliche Meinung, Massenmedien, in: Isensee, Josef/ Badura, Peter u.a. (Hrsg.), Handbuch des Staatsrechts der Bundesrepublik Deutschland III, 3. Aufl. 2005, Heidelberg, S. 389-424.

—, Über erlaubte, unerwünschte und verbotene Parteien, NJW 2016, S. 3003-3008.

-, Parteienfinanzierung und NPD-Urteil - Zum Ausschluss der staatlichen Teilfinanzierung für verfassungsfeindliche Parteien, NVwZ 2017, S. 913-920.

Koch, Thomas, Neutralitätspflicht und Chancengleichheit der Leistung an politische Parteien, ZParl 2002, S. 694-716.

Koch, Thorsten, Parteiverbote, Verhältnismäßigkeitsprinzip und EMRK, DVB1 2002, S. 1388-1393.

Kommission unabhängiger Sachverständiger, Empfehlung der Kommission unabhängiger Sachverständiger zur Parteienfinanzierung 19.02.1993.

Kretschmer, Gerald, Fraktionen, Heidelberg 1984.

Kriele, Martin, Feststellung der Verfassungsfeindlichkeit von Parteien ohne Verbot, ZRP 1975, S. 201-204.

Kühr, Hana, Legalität und Legitimität von Mandatsträgerbeiträgen, Baden-Baden 2014.

Kulitz, Peter, Unternehmerspenden an politische Parteien, Berlin 1983.

Kumpf, Tobias, Verbot politischer Parteien und Europäische Menschenrechtskonvention, DVBl 2012, S. 1344-1348.

Kunig, Philip, $₫ 40$ Parteien, in: Böckenförde, Ernst-Wolfgang/Isensee, Josef/Kirchhof, Paul (Hrsg.), Handbuch des Staatsrechts der Bundesrepublik Deutschland III, 3. Aufl., Heidelberg 2005, S. 297-356.

Küstermann, Burkhard, Das Transparenzgebot des Art. 21 Abs. 1 Satz 4 GG und seine Ausgestaltung durch das Parteiengesetz, Göttingen 2003. 
Lameyer, Johannes, Streitbare Demokratie - Eine verfassungshermeneutische Untersuchung, Berlin 1978.

Landfried, Christine, Parteifinanzen und politische Macht - Eine vergleichende Studie zur Bundesrepublik Deutschland, zu Italien und den USA, Baden-Baden 1990.

Laubinger, Hans-Werner, Verfassungswidrigkeit politischer Parteien - Entscheidung durch den Bundestagspräsidenten?, ZRP 2017, S. 55-57.

Lege, Joachim, Nochmals: Staatliche Warnungen - Zugleich zum Paradigmenwechsel in der Grundrechtsdogmatik und zur Abgrenzung von Regierung und Verwaltung, DVBl 1999, S. 569-578.

Lenz, Christofer/Hansel, Ronald (Hrsg.), Bundesverfassungsgerichtsgesetz - Handkommentar, 2. Aufl., Baden-Baden 2015.

Leyendecker, Hans/Stiller, Michael/Prantl, Heribert, Helmut Kohl, die Macht und das Geld, 2. Aufl., Göttingen 2000.

Linck, Joachim, Staatliche Leistungen an Verfassungsfeinde - Eine Pervertierung der wehrhaften Demokratie, DÖV 2006, S. 939-947.

Linke, Tobias, Verbotsunwürdige Verfassungsfeinde, streitbare, aber wertarme Demokratie und problematische Sanktionsalternativen - Anmerkung zum Urteil des Zweiten Senats des Bundesverfassungsgerichts vom 17. Januar 2017, DÖV 2017, S. 483-493.

Lipphardt, Hanns-Rudolf, Die Gleichheit der politischen Parteien vor der öffentlichen Gewalt - Kritische Studie zur Wahl- und Parteienrechtsjudikatur des Bundesverfassungsgerichts, Berlin 1975.

Loewenstein, Karl, Militant Democracy and Fundamental Rights, I, Am Polit Sci Rev 31 (1937), S. 417-432.

Lontzek, Christoph, Die Sonderbeiträge von Abgeordneten an Partei und Fraktion, Berlin 2012.

Lösche, Peter, Kleine Geschichte der deutschen Parteien, Stuttgart 1993.

Mandelartz, Herbert, Grenzen regierungsamtlicher Öffentlichkeitsarbeit, LKRZ 2010, S. 371-374.

Mardini, Martina, Die Finanzierung der Parlamentsfraktionen durch staatliche Mittel und Beiträge der Abgeordneten, Frankfurt am Main 1990.

Martens, Wolfgang/Häberle, Peter/Bachof, Otto/Brohm, Winfried, Grundrechte im Leistungsstaat, VVDStRL 30 (1972).

Maunz, Theodor/Dürig, Günter (Hrsg.), Grundgesetz - Kommentar, München 2018.

Mauersberger, Axel, Die Freiheit der Parteien - Der Rechtscharakter des Art. 21 GG, Baden-Baden 1994.

Maurer, Hartmut, Das Verbot politischer Parteien, AöR 96 (1971), S. 203-236.

-, Die Mitgliedschaft von Beamten in verfassungsfeindlichen Parteien und Organisationen, NJW 1972, S. 601-607.

-, Staatsrecht I - Grundlagen, Verfassungsorgane, Staatsfunktionen, 6. Aufl., München 2010.

—, Allgemeines Verwaltungsrecht, 18. Aufl., München 2011. 
—, Staatsrecht I - Grundlagen, Verfassungsorgane, Staatsfunktionen, 7. Aufl., München 2014.

Maurer, Hartmut/Waldhoff, Christian, Allgemeines Verwaltungsrecht, 19. Aufl., München 2017.

Meier, Horst, Parteiverbote und demokratische Republik - Zur Interpretation und Kritik von Art. 21 Abs. 2 des Grundgesetzes, Baden-Baden 1993.

Merten, Heike, Die Finanzierung politischer Jugendorganisationen gerät unter Gesetzgebungsdruck, NVwZ 2012, S. 1228-1231.

Meyer, Hubert, Kommunales Parteien- und Fraktionenrecht - Verfassungsrechtliche Determinanten und ausgewählte Probleme unter besonderer Berücksichtigung der Chancengleichheit sowie Fragen der Finanzierung, Baden-Baden 1990.

-, Teilhabe von Fraktionen verfassungsfeindlicher Parteien (hier: NPD) an kommunalen Fraktionszuschüssen, NVwZ 2017, S. 886-889.

Meyer-Ladewig, Jens/Nettesheim, Martin/Raumer, Stefan von/Albrecht, Frauke (Hrsg.), EMRK - Europäische Menschenrechtskonvention: Handkommentar, 4. Aufl., Baden-Baden u.a. 2017.

Möller, Hauke, Die verfassungsgebende Gewalt des Volkes und die Schranken der Verfassungsrevision - Eine Untersuchung zu Art. 79 Abs. 3 GG und zur verfassungsgebenden Gewalt nach dem Grundgesetz, Berlin 2004.

Morlok, Martin, Sicherung der Rechtsstellung als politische Partei durch Teilnahme an den Wahlen zum Europäischen Parlament?, DVBl 1989, S. 393-399.

-, Thesen zu Einzelaspekten der Politikfinanzierung, in: Tsatsos, Dimitris Th./ Fromont, Michel (Hrsg.), Politikfinanzierung in Deutschland und in Europa Aspekte aus Wissenschaft und Politik ; Erträge des Internationalen Symposions des Instituts für Deutsches und Europäisches Parteienrecht an der FernUniversität - Gesamthochschule in Hagen, 23. und 24. Februar 1996, Baden-Baden 1997.

—, Das BVerfG als Hüter des Parteienwettbewerbs, NVwZ 2005, S. 157-160.

—, Kein Geld für verfassungsfeindliche Parteien?, ZRP 2017, S. 66-69.

—, Notwendigkeit und Schwierigkeit eines Rechtes der Politik, DVBl 2017, S. $995-$ 1002.

Morlok, Martin/Bäcker, Alexandra, Zugang verweigert: Fehler und fehlender Rechtsschutz im Wahlzulassungsverfahren, NVwZ 2011, S. 1153-1159.

Morlok, Martin/Jürgensen, Sven, Faktische Chancengleichheit - insbesondere im Recht der politischen Parteien, JZ 2018, S. 695-702.

Morlok, Martin/Krüper, Julian/Roßner, Sebastian, Parteienfinanzierung im demokratischen Rechtsstaat - Reformmöglichkeiten der Gewährung staatlicher Leistungen an politische Parteien, Berlin 2009.

Möstl, Markus, Demokratische Willensbildung und Hoheitsträger. Grund und Grenzen öffentlicher Äußerungsbefugnisse von Repräsentanten des Staates, in: Uhle, Arnd (Hrsg.), Information und Einflussnahme - Gefährdungen der Offenheit des demokratischen Willensbildungsprozesses, Berlin 2018, S. 49-80. 
Müller, Michael, Der Ausschluss von der staatlichen Finanzierung als milderes Mittel zum Parteiverbot - Zur Systematik von Art. 21 n.F. GG, DVBl 2018, S. 10351042.

Murswiek, Dietrich, Staatliche Warnungen, Wertungen, Kritik als Grundrechtseingriff - Zur Wirtschafts- und Meinungslenkung durch staatliches Informationshandeln, DVBl 1997, S. 1021-1030.

- Das Bundesverfassungsgericht und die Dogmatik mittelbarer Grundrechtseingriffe - Zu der Glykol- und der Osho-Entscheidung vom 26.6.2002, NVwZ 2003, S. 1-8.

- Der Verfassungsschutzbericht - das scharfe Schwert der streitbaren Demokratie - Zur Problematik der Verdachtsberichterstattung, NVwZ 2004, S. 769-778.

Nikkho, Ramin, Staatliche Parteienfinanzierung als verfassungsrechtliches Institut der freie Wettbewerb als Schutz der freiheitlichen demokratischen Grundordnung, DVBl 2018, S. 337-342.

-, Rechtliche Grenzen der Öffentlichkeitsarbeit des Bundesamtes für Verfassungsschutz, jurisPR-ITR 8/2019.

Nipperdey, Thomas, Die Organisation der deutschen Parteien vor 1918, Düsseldorf 1961.

Oerter, Volker, Rechtsfragen des Verhältnisses zwischen politischen Parteien und ihren Sonder- und Nebenorganisationen, Bochum 1971.

Ossenbübl, Fritz, Rechtliche Probleme der Zulassung zu öffentlichen Stadthallen zur Dogmatik der Gewährung öffentlicher Leistungen, DVBl 1973, 289-300.

Plümer, Egon, Mitgliedschaft von Beamten und Beamtenanwärtern in verfassungsfeindlichen Parteien, NJW 1973, S. 4-10.

Poetzsch-Heffter, Fritz, Handkommentar der Reichsverfassung vom 11. August 1919, 3. Aufl., Berlin 1928.

Pohl, Heinrich, $\mathbb{\$} 42$. Die Zuständigkeiten des Reichspräsidenten, in: Anschütz, Gerhard/Thoma, Richard (Hrsg.), Handbuch des deutschen Staatsrechts, Bd. 1, Tübingen 1930, S. 482-502.

Preuss, Susanne, Daimler öffnet die Geldbörse für Parteien, FAZ 21.04.2017.

Rabus, Günther, Die innere Ordnung der politischen Parteien im gegenwärtigen deutschen Staatsrecht, AöR 78 (1952), S. 163-193.

Radbruch, Gustav, $\mathbb{\$} 25$. Die politischen Parteien im System des deutschen Verfassungsrechts, in: Anschütz, Gerhard/Thoma, Richard (Hrsg.), Handbuch des deutschen Staatsrechts, Bd. 1, Tübingen 1930, S. 285-294.

Ridder, Helmut, Berufsverbot? Nein, Demokratieverbot, in: Bethge, Horst/Bünemann, Richard/Enderlein, Hinrich (Hrsg.), Die Zerstörung der Demokratie in der BRD durch Berufsverbote, 2. Aufl., Köln 1976, S. 57-66.

Riedel, Eibe H., Rechtliche Optimierungsgebote oder Rahmensetzungen für das Verwaltungshandeln? VVDStRL 58 (1999).

Roth, Wolfgang, Die Abgeordnetenentschädigung als Verdienstausfallentschädigung, AöR 129 (2004), S. 219-262. 
—, Verfassungsmäßigkeit der Einführung einer 3\%-Sperrklausel bei Kommunalwahlen durch Verfassungsänderung, insbesondere für das Land NordrheinWestfalen, Berlin 2015.

Rumpf, Helmut, Der ideologische Gehalt des Bonner Grundgesetzes 1958.

Rupp, Hans Heinrich, BVerfG, 15.12.1970 - 2 BvF 1/69, 2 BvR 629/68, 308/69: Verfassungsmäßigkeit der Beschränkung des Brief-, Post u. Fernmeldegeheimnisses durch Notstandsgesetzgebung - mit Anmerkung Rupp, NJW 1971, S. 275-284.

Sachs, Michael (Hrsg.), Grundgesetz - Kommentar, 8. Aufl., München 2018.

Saliger, Frank, Parteiengesetz und Strafrecht - Zur Strafbarkeit von Verstößen gegen das Parteiengesetz, insbesondere wegen Untreue gemäß $\$ 266$ StGB, Tübingen 2005.

Sattler, Andreas, Die rechtliche Bedeutung der Entscheidung für die streitbare Demokratie - Untersucht unter besonderer Berücksichtigung der Rechtsprechung des Bundesverfassungsgerichts, Baden-Baden 1982.

Fischer, Lothar/Mann, Horst/Schellhorn, Helmut/Kern, Christoph (Hrsg.), SGB VIII Kinder- und Jugendhilfe: Kommentar, 5. Aufl., Köln 2017.

Papier, Hans-Jürgen/Krönke, Christoph, Grundlagen, Staatsstrukturprinzipien, Staatsorgane und -funktionen, 2. Aufl., Heidelberg 2015.

Papier, Hans-Jürgen/Schröder, Meinhard, Verfassungsrechtliche Grenzen kommunaler Publikationen, DVB1 2017, S. 1-10.

Sachs, Michael/Battis, Ulrich (Hrsg.), Grundgesetz - Kommentar, 7. Aufl., München 2014.

Schenke, Wolf-Rüdiger/Graulich, Kurt/Ruthig, Josef (Hrsg.), Sicherheitsrecht des Bundes, 2. Aufl., München 2018.

Schneider, Peter/Ehmke, Horst/Jaenicke, Günther/Leisner, Walter, Prinzipien der Verfassungsinterpretation. Gefährdungshaftung im öffentlichen Recht, VVDStRL 20 (1971).

- , Der Verfassungsschutz im Bonner Grundgesetz, in: Um Recht und Gerechtigkeit - Festgabe für Erich Kaufmann, 1950, S. 313-330.

Schmidt, Thomas, Die Freiheit verfassungswidriger Parteien und Vereinigungen Zur Schrankenlehre im Rahmen von Art. 21 Abs. 2 und 9 Abs. 2 GG, Berlin 1983.

Schmidt-Jortzig, Edzard/Hansen, Frank, Neue Rechtsgrundlage für die Bundestagsfraktionen, NVwZ 1994, S. 1145-1150.

Schmitt, Carl, Verfassungslehre, 10. Aufl., Berlin 2010.

Schmitt Glaeser, Walter, Missbrauch und Verwirkung von Grundrechten im politischen Meinungskampf, Bad Homburg 1968.

Schneider, Georg Christoph, Die Finanzierung der Parlamentsfraktionen als staatliche Aufgabe - Eine verfassungsrechtliche Untersuchung unter besonderer Berücksichtigung der aktuellen Fraktionsgesetzgebung, Berlin 1997.

Schneider, Hans, Die Reichsverfassung vom 11. August 1919, in: Isensee, Josef/ Badura, Peter u.a. (Hrsg.), Handbuch des Staatsrechts der Bundesrepublik Deutschland I, 3. Aufl., Heidelberg 2003, S. 177-234. 
Schoch, Friedrich, Der Gleichheitssatz, DVBl 1988, S. 863-882.

Schröder, Meinhard, $\mathbb{S} 119$ - Stellung der Parteien, in: Merten, Detlef/Papier, HansJürgen (Hrsg.), Handbuch der Grundrechte V, Heidelberg 2013, S. 519-553.

Schröder, Meinhard, Rahmenbedingungen der staatlichen Regulierung von Social Bots, DVBl 2018, S. 465-472.

Schulz, Norbert/Wachsmuth, Hans/Zweick, Wolfram/Bauer, Thomas/ Mühlbauer, Peter/ Oehler, Gerhard/ Stanglmayr, Helmut/Winkler, Carmen/ Stadtlöder, Anton/ Hauth, Rudolf/ Bloeck, Oliver, Kommunalverfassungsrecht Bayern - Kommentare, München 2005.

Schwartmann, Rolf, Verfassungsfragen der Allgemeinfinanzierung politischer Parteien, Berlin 1995.

Schwarz, Kyrill, Der Ausschluss verfassungsfeindlicher Parteien von der staatlichen Parteienfinanzierung, NVwZ-Beilagenheft 2017, S. 39-41.

Schwerdtner, Eberhard, Chancengleichheit und Minderheitenschutz in der Kommunalpolitik. Gemeinderat und Verwaltung im kommunalen Spannungsfeld: Anmerkung zur Rechtsprechung, DÖV 1990, S. 14-16.

Seifert, Karl-Heinz, Zur Rechtsstellung der politischen Parteien, DÖV 1956, S. 1-7.

—, Zum Verbot politischer Parteien, DÖV 1961, S. 81-91.

—, Die politischen Parteien im Recht der Bundesrepublik Deutschland, Köln 1975.

Shirvani, Foroud, Die politischen Parteien im Staatsrecht des Deutschen Kaiserreichs, MIP 2006, S. 77-87.

—, Parteienfreiheit, Parteienöffentlichkeit und die Instrumente des Verfassungsschutzes, AöR 134 (2009), S. 572.

-, Das Parteienrecht und der Strukturwandel im Parteiensystem - Staats- und europarechtliche Untersuchungen zu den strukturellen Veränderungen im bundesdeutschen und europäischen Parteiensystem, Tübingen 2012.

—, Parteienverbot und Verhältnismäßigkeitsgrundsatz, JZ 2014, S. 1074-1083.

—, Das „scharfe Schwert“ des parteienrechtlichen Transparenzgebots, NVwZ 2017, S. 1321-1325.

-, Parteienfinanzierung als verfassungsrechtliche Ausprägung streitbarer Demokratie, DÖV 2018, S. 921-927.

Sichert, Markus, Das Parteiverbot in der wehrhaften Demokratie, DÖV 2001, S. 671-681.

Siegel, Thorsten/Hartwig, Sebastian, Die zweite Stufe des Parteiverbotsverfahrens Zur Reichweite des so genannten Anknüpfungsverbots in den Materien des Besonderen Verwaltungsrechts, NVwZ 2017, S. 590-597.

Spitzlei, Thomas, Die politische Äußerungsbefugnis staatlicher Organe, JuS 2018, S. 856-860.

Starck, Christian/Mangoldt, Hermann von/Klein, Friedrich (Hrsg.), Kommentar zum Grundgesetz - [in drei Bänden], 5. Aufl., München 2005.

Starke, Christian Paul, Die Lehre vom mittelbar-faktischen Grundrechtseingriff im Spiegel der aktuellen Rechtsprechung des Bundesverfassungsgerichts, DVBl 2018, S. 1469-1473. 
Steffen, Tilman, Bundestag verabschiedet „Lex NPD“ - Verfassungsfeindlichen Parteien soll künfitg die Staatsfinanzierung entzogen werden. Für eine solche Entscheidung gibt es aber hohe Hürden, Die Zeit 22.06.2017.

Steinberger, Helmut, Rechtsprechung des BVerfG zur staatlichen Parteienfinanzierung, in: Bitburger Gespräche - Jahrbuch 1993/2; [Parteien und Parteienfinanzierung], Bd. 2, München 1993, S. 25-59.

Stern, Klaus, Staatsrecht I - Grundbegriffe und Grundlagen des Staatsrechts, Strukturprinzipien der Verfassung, 2. Aufl., München 1984.

—, Die Bedeutung der Unantastbarkeitsgarantie des Art. 79 III GG für die Grundrechte, JuS 1985, S. 329-338.

Stollberg, Frank, Die verfassungsrechtlichen Grundlagen des Parteiverbots, Berlin 1976.

Stolleis, Michael/ Heinz, Schäffer / Rhinow, René A./ Lange, Klaus/ Breuer, Rüdiger, Parteienstaatlichkeit - Krisensymptome des demokratischen Verfassungsstaats?, VVDStRL 44 (1986).

Stricker, Gregor, Der Parteienfinanzierungsstaat, Baden-Baden 1998.

Tannenberger, Steffen/Nemeczek, Heinrich, Neutralitätsgebot für Mitglieder der Bundesregierung - Fall Schwesig, NVwZ 2015, S. 209-216.

Theuerkauf, Sarah, Parteiverbote und die Europäische Menschenrechtskonvention Analyse der Rechtsprechung des Europäischen Gerichtshofes für Menschenrechte unter Berücksichtigung der Rolle politischer Parteien in Europa, Zürich 2006.

Thiel, Markus, Zur Einführung: Die „wehrhafte Demokratie“ als verfassungsrechtliche Grundentscheidung, in: Thiel, Markus (Hrsg.), Wehrhafte Demokratie Beiträge über die Regelungen zum Schutze der freiheitlichen demokratischen Grundordnung, Tübingen 2003, S. 1-24.

Thoma, Richard, $\mathbb{1}$ 16. Das Reich als Demokratie, in: Anschütz, Gerhard/Thoma, Richard (Hrsg.), Handbuch des deutschen Staatsrechts, Bd. 1, Tübingen 1930, S. 186-200.

—, $\$ 71$. Grundbegriffe und Grundsätze, in: Anschütz, Gerhard/Thoma, Richard (Hrsg.), Handbuch des deutschen Staatsrechts, Bd. 2, Tübingen 1930, S.137159.

Thrun, Felix, Worum kämpft die wehrhafte Verfassung? - Die Rekonzeption der freiheitliche-demokratische Grundordnung, DÖV 2019, S. 65-73.

Tsatsos, Dimitris Th./Morlok, Martin, Parteienrecht - Eine verfassungsrechtliche Einführung, Heidelberg 1982.

Ule, Carl Hermann, Die Entwicklung des Beamtenrechts durch die Rechtssprechung der Verwaltungsgerichte, in: Külz, Helmut/Naumann, Richard (Hrsg.), Staatsbürger und Staatsgewalt - Verwaltungsrecht und Verwaltungsgerichtsbarkeit in Geschichte und Gegenwart, Karlsruhe 1963, S. 113-147.

Umbach, Dieter C./Clemens, Thomas/Dollinger, Franz-Wilhelm (Hrsg.), Bundesverfassungsgerichtsgesetz - Mitarbeiterkommentar und Handbuch, 2. Aufl., Heidelberg 2005.

Umbach, Dieter C./Clemens, Thomas (Hrsg.), GG, Heidelberg 2002. 
Unruh, Peter, Der Verfassungsbegriff des Grundgesetzes - Eine verfassungstheoretische Rekonstruktion, Tübingen 2002.

Vieregge, Henning von, Die Partei-Stiftungen: Ihre Rolle im politischen System, in: Wewer, Göttrik (Hrsg.), Parteienfinanzierung und politischer Wettbewerb Rechtsnormen - Realanalysen - Reformvorschläge, Wiesbaden 1990, S. 164-194.

Volkmann, Uwe, Politische Parteien und öffentliche Leistungen, Berlin 1993.

—, Wettbewerbsneutrale Parteienfinanzierung - ein Unding?, KJ 1995, S. 203-209.

—, Dilemmata des Parteiverbots, DÖV 2007, S. 577-585.

Voßkuble, Andreas/Kaiser, Anna-Bettina, Grundwissen - Öffentliches Recht: Informationshandeln des Staates, JuS 2018, S. 343-346.

Waldecker, Ludwig, $\mathbb{\$} 104$. Vereins- und Versammlungsfreiheit, in: Anschütz, Gerhard/Thoma, Richard (Hrsg.), Handbuch des deutschen Staatsrechts, Bd. 2, Tübingen 1930, S. 637-651.

Walter, Christian/Grünewald, Benedikt (Hrsg.), BeckOK BVerfGG, München 2018.

Wernsmann, Rainer, Verhaltenslenkung in einem rationalen Steuersystem, Tübingen 2005.

—, Typisierung und Typusbegriff, DStR-Beiheft 2011, S. 72-76.

Westerwelle, Guido, Das Parteienrecht und die politischen Jugendorganisationen, Baden-Baden 1994.

Bayerische Gemeindeordnung - Mit Verwaltungsgemeinschaftsordnung, Landkreisordnung und Gesetz über die kommunale Zusammenarbeit ; Kommentar, München 2018.

Wiese, Walter, Rechtsschutz gegenüber der „Abstempelung“ als verfassungsfeindlich?, DVBl 1976, S. 317-323.

Wietschel, Wiebke, Der Parteibegriff - Zur verfassungsrechtlichen und verfassungspolitischen Funktion des Parteibegriffs unter besonderer Berücksichtigung der Verbotsproblematik, Baden-Baden 1996.

—, Unzulässige Parteiverbotsanträge wegen Nichtvorliegens der Parteieneigenschaft, ZRP 1996, S. 208.

Würtenberger, Thomas,- Das parlamentarische Regierungssystem und der Bundesrat - Entwicklungsstand und Reformbedarf. Rechtliche Optimierungsgebote oder Rahmensetzungen für das Verwaltungshandeln? VVDStRL 58 (1999).

Zacharias, Diana, Die sog. Ewigkeitsgarantie des Art. 79 Abs. 3 GG, in: Thiel, Markus (Hrsg.), Wehrhafte Demokratie - Beiträge über die Regelungen zum Schutze der freiheitlichen demokratischen Grundordnung, Tübingen 2003, S. 57-97.

Zirn, Armin, Das Parteiverbot nach Art. 21 Abs. 2 GG im Rahmen der streitbaren Demokratie des Grundgesetzes, Dissertation 1988.

Zuleeg, Manfred, Zur staatsrechtlichen Stellung der Ausländer in der Bundesrepublik Deutschland, DÖV 1973, S. 361-370.

Zundel, Frank, Die Zulassung politischer Parteien zu kommunalen öffentlichen Einrichtungen, JuS 1991, S. 472-475.

Zweigert, Konrad, Drei Jahre KP-Verbot, JZ 1959, S. 677. 
